\title{
EVALUATION OF THE GEOLOGIC RELATIONS AND \\ SEISMOTECTONIC STABILITY OF THE YUCCA MOUNTAIN AREA, NEVADA NUCLEAR WASTE SITE INVESTIGATION (NNWSI)
}

\author{
FINAL REPORT \\ July 26, 1988
}

revised October 1988

\author{
DISCLAIMER
}

\begin{abstract}
This report was prepared as an account of work sponsored by an agency of the United States Govermment. Neither the United States Government nor any agency thereof, nor any of their employees, makes any wartanty, express or implied, or assumes any legal liability or responsibility for the accuracy, completeness, or usefulness of any information, apparatus, product, or process disclosed, or represents that its use would not infringe privately owned rights. Reference herein to any specific commercial product, process, or service by trade name, trademark, manufacturer, or otherwise does not necessarily constitute or imply its endorsement, recorn. mendation, or favoring by the United States Government or any agency thercof. The views and opinions of authors expressed herein do not necessarily state or reflect those of the United States Government or any agency thereof.
\end{abstract}

\section{CENTER FOR NEOTECTONIC STUDIES}


FINAL REPORT JANUARY 1, 1987 - JUNE 30,1988

\section{INTRODUCTION}

This repzot provides a summal of progress for the project "Evaluation of the Geologie Reiations and seismotectonic stability

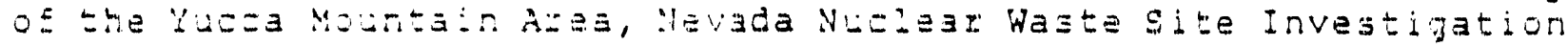
(NWWSI)" for the eighteen month period of January 1, lag to Jurie 10, 1938. This final report was preceded by the final report for the intial aix month period, July 1, 1986 to December 31, 2936 (submitted on January 25, 1937 , and revised in June 1987).

The General Task continued to coordinate project activities to meet gentral deadilnes and responsibilities. The cantral oftize provided general secretarial suppozt. The activitias that wex started din:ng the tirst project perioj included expanison of the central cagying facilities, growth of the central reprint, map, aerial and photograph coliet: tons, and some expansion of personal computer capabilities. The research and review accomplishments are mainy unier the following taskis:

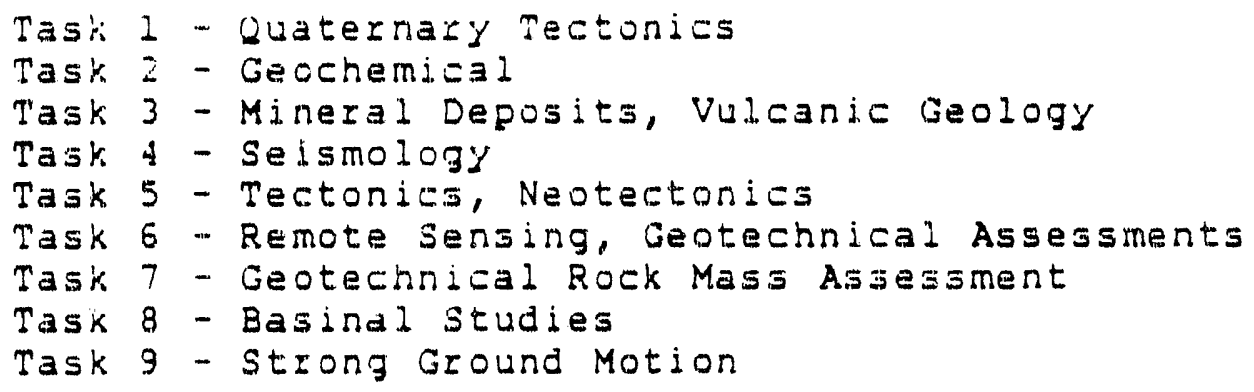

STAFF

David B. Slemmons (Project Director), Michael Eliis and Peizhen zhang (Postdoctoral Fellows), Ingrid Ramos (Secretary), Paul Bodin and Xiayi Zhang (Research Assistants).

\section{MAJOR ACCOMPLISHMENTS}

In November 1987 the Center organized and presented the workshop, "Late Cenozole Evolution of the Southern Great Basin." The workshop was convened by slemmons, schweickert, and Bell, and was organized by Ellis. The proceedings of the workshop will be published as an open-file report by the Nevada Bureau of Mines and Geology.

An important accomplishment for this period, was preparation and submission in May 1388, of the draft copy "Technical procedures for the Quality Assurance program." The document provides both a general and specific framework for our operation. It is antici- 
pated that the final imi lementation of this program will take place in the next few months.

in adition, after January 2388 , we prepared our review of the "Consultation Draft of the site characterization plan" from the Department of Energy. This extensive document of almost six thousand pages length was the focus of review by all tasks, and our final review was submitted to the Nevada Nuclear Waste Project OEfice on June $17,1983$.

Michael Ellis organized a seminar series (Ceology 900) that focussed on the geology (and specificaliy neotectonics) os the southern Graat Basin.

Another activity during the spring of 1988 concerned the release of the report by Jerry szymanski, "Conceptual Considerations of the Death Valley Groundwater system with special Emphasis on the Adequacy of this system to Accommodate the HighLevei Nuclear Waste Repository." Several staff members were asked by the Nevada Nuclear Waste Eroject office to provide a technical review of this document. This review was submitted to the state in May ig3a.

\section{TECHNICAL ACTIVITIES}

Most of the research contributions are discussed under the individual task descriptions. However, the general task lists some manuscripts, papers, or abstracts prepared by general stafe personmel, to investigate seismotectonic problems of the Yucca Mountain region, or general interrelationships of surface fault rupture parameters with earthquake size or magnitude.

The data for relations for contractional tectonic settings were refined and expanded for extensional environments by the study of Slemmons, Bodin, and zhang (preprint in press, and appended to this report). This investigation reports on the interrelationships of earthquake magnitude with surface rupture length or maximum displacement. If either of the surface rupture parameters is determined, then the magnitude of the associated event can be estimated. Also Bodin, Brune, slemmons and Zhang (1987) discussed the scaling relations among the source parameters of shallow earthquakes. The important result of these studies is that the fault type is less significant than was previously thought, so that there is probably littie difference for earthquake magnitude stuaies of the Yucca Mountain area whether the fault is normal-silp or strike-slip. Worldwide data are currently being compiled to permit regressions for average displacement, rather than maximum displacements as has been traditional done. The advantage of this will be to permit more precise use of exploratory trenching data, and to permit better use of moment magnitude scales. 
Another topic of investigation was the interrelationships between historical Basin and Range surface ruptures and their host faults by dePolo, Clark and slemons (in press). This study reviews the historical character of rupture reiative to the

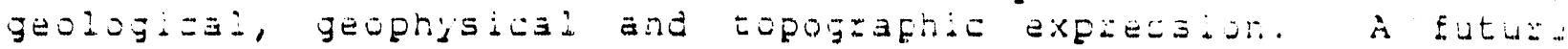
follow w study to evaluate the Yucca Mountain setting to determine

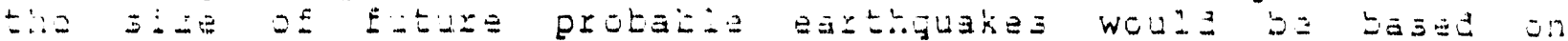
paiesseismic and geologic, seismologic and geophyzicai evidence from the region. Another related topic, the evaluation of earth

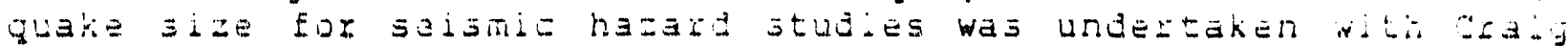
depolo of rask 1. Their abstract, depolo and slemmons, and related

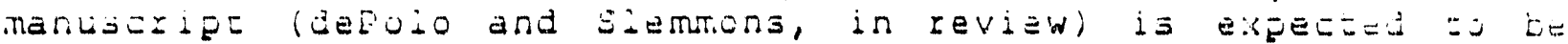
=omedest

Feizhen zhang spearheaded a study with Michae: Ellid and David

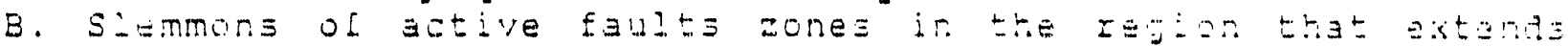

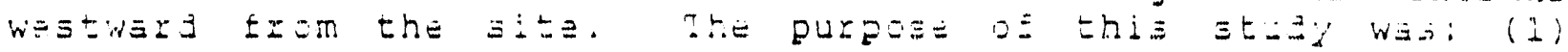

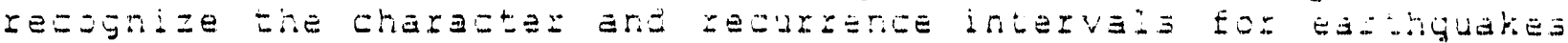

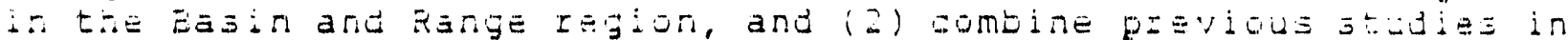

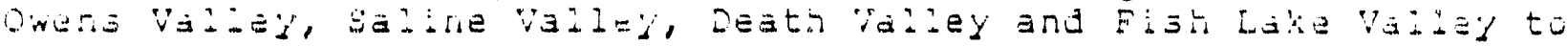
bettez understand the late cenozoil sectonia evolution of the Death Valiey Extensional kegion. This will assist in determining whether the activity of the southern Walker Lane and the Las Vegas Shear zone has migrated westward. The current work indicates that there is a westward migration of activity. Three upcoming papers are planned to summarize this data and to investigate the temporal or spatial ciustering of activity on faulting in this region. In order to study a paleoseismic example from the Basin and Range Province near the site, and to investigate the neotectonic activity along the western edge of the province trom the southern Walker Lane to the Sierra Nevada, work was concentrated on the southern Panamint Valley fault zone. A fresh zone of scarps from the last prehistoric earthquake showed that average right laterai displacement: was $3.1+0.4 \mathrm{~m}$, with a $2.5+0.24 \mathrm{~mm} / \mathrm{yr}$ and recurzence interval of 1200 to lEoc jears. Eeveral upooming gager. are being grepared.

\section{REFERENCES}

Bodin, P., Brune, J., slemmons, D.B., and zhang, X., 1387, sca:ing Relations among the Source Parameters of Shallow Earthquakes: EOS, v. 68 .

depolo, C.M., and Slemmons, D.B., 1987, Methods for estimating earthquak size Eor seismic hazard anaijsis: Geologidal society of America, Abstracts with Erggrams, v. 13, p.óii.

depolo, C.M., Clark, D.C., and slemmons, D.B., Historbal Basin and Range province surface fallting and fault segmentation: U.S. Geological survey, Open-File Report xxx, 29 . 
Slemmons, D.B., Bodin, $P$. , and zhang, $X$, in press, Determination of earthquake size from surface faulting eventa: Proceedinga of the International Seminar on Seizmic zonation, cuangzhou, Chiria, $1 \geq p$.

Yucea Mountain Project, June 1987, Evaluation of the Gedogic Relationa and Seismotectonic btability of the Yuca Mcuntain AIea, Nevada Nuclear Waste site Investigation. NNWSI; Center

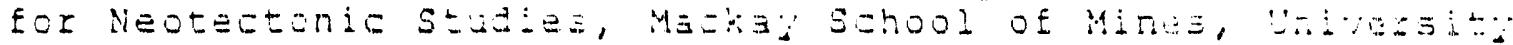
of Nevada-Reno, Final Report to the Nevada Nuclear Waste Project iffice, January 25,2987 , revisela: June 1337,405 pagez.

Yucea Mountain Project, Decemter 1987 , Evaluation of the Gologid Relations and Seismotectonie stability of the Yucua Mountain. area, Nevada Nuclear Waste Site Investigation (WWWai: Center for Nedtectonia Studies, Malkgy school of hires, University of Nevada-keno, Research Eroposal to the Nevada Nuclear Waste Projecta of 249 Pages.

Yucca Mountain Project, May 1938, Review by Yucca Mountain personne? in the center for Neotectonic studies and the Seismological Laboratory, University of Nevada-Reno of Conceptual considerations of the Death Valley groundwater system with special emphasis on the adequacy of this system to accommodate the high-level nuclear waste repository: Center for Neotectonic Studies, Mackay achool of Mines, Univeraity of Nevada-Reno, letter report to the Nevada Nuclear Waste Project office, 20 pages.

Yucca Mountain Project, May 20, 1983, Technical Procedures for the Quality Assurance Program: Center for Neotectonic Studies, Mackay School of Mines, University of Nevada-Reno, draft report to the Nevada Nuclear Waste Project Office, 392 pages.

Yucaa Mountain Eroject, June 1988, Critical Review of the Department of Energy's consultation Draft of the aite Characterization Pian: Center Eor Neotectonic Studies, Mackay School of Mines, University of Nevada-Reno, 163 pages. 
This paper was submitted in April 1988:

Slemmons, D.B., Bodin, P., and Zhang, X., in press, Determination of earthquake size from surface faulting events: Proceedings of the international seminar on Seismic zonation, Guangzhou, China, $18 \mathrm{p}$.

DETERMINATION OF EARTHQUAKE SIZE FROM SURFACE FAULTING EVENTS Slemmons, D. Burton 1' Bodin, Paul, and zhang, Xiaoyi 1

\section{SUMMARY}

To prepare complese seismic zoning maps and seismic risk assessments it is necessary to use both paleoseismic and seismologic data. Paleoseismic evaluations of surface fauts commonly utilize linear regressions of fault rupture parameters with earthguake magnitude. This procedure has been recently markea by an almost exponential growth in development of methodologies and applications.

We present a new, simpie, and easily applied method for assigning earthquake magnitudes from surface rupture parameters that uses only two tectonic settings -- extensional and contractional (compressional) -- rather than five fault types. The method is generaliy applicable, has a good statistical basis, and can supplement conventional methods.

\section{INTRODUCTION}

Paleoseismic analysis (i.e.: estimation of earthruake magnitude and source parameters from surface deformation effects of earthquakes) is increasingly being applied as a tool by geoscientists and engineers. These analyses may be integrated with scientific, engineering, or land use studies to enhance earthquake hazard and risk assessment. When combined with historical and instrumental seismologic data, paleoseismic information may substantialiy extrapolate the historical record, leading to a more complete understanding and realistic appraisal of the earthquake hazard.

Paleoseismic methods are mainly used for interplate settings where seismicity commenly occurs on well delineated faults. Paleoseismic analysis may also be appropriate in certain intraplate settings with well defined capable faults. Examples include the Meers fault in Oklahoma (USA), the New Madrid fault in the central USA, and zeveral faults in southwestern Australia, all generally regarded as being in stable intraplate areas.

ICenter for Neotectonic studies, Mackay school of Mines, University of Nievada-keno, Reno, Nevada 33557 
Several recent studies of about fifty well-documented historical earthquakes, show that a good correlation exists between earthquake size or magnitude and fault rupture parameters. The rupture dimensions used here include discrete faults and complex zones of faults in both extensional and contractional tectonie settings.

Despite some uncertainties in results, paleoseismic evaluations help characterize earthquake hazards by providing

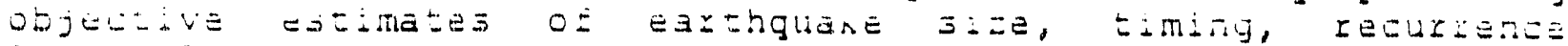
intervali, dud constraints on surface deformation or rupture

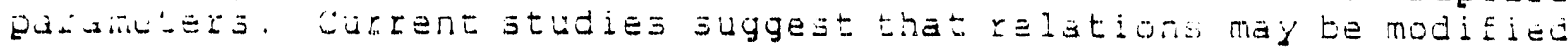
by such factors as source region, thichness of selimogenie zune, recurrerae intervala, seismie attenustion, segmertation, and ztres dLOF.

\section{HISTORICAL UEVELORMENT OF PALEOSEISMIC ANALYSIS}

Palecseismic methods evolied graduaily with sketchy axtirulaticn of the gareial zelations and no use of the term

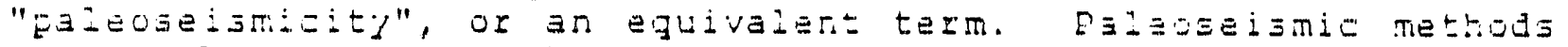
were implicit in several early studies, inciuding several impurtant basic contzibutions made almost a century ago by Gilbert (i390) and Lawson and others (1908), and almost forty years ago by Louderback $(1950)$. The study of paleoseismicity during the past twenty to thicty years has been marked by rapid development, with increased emphasis on refinement and quantification of methods.

The initial regression analyses of Tocher (1958) showed a relation between earthquake size (magnitude), and the fault rupcure parameters of total rupture length and maximum fault displacement. The repetition or recurrence of earthquakes and surface deformation along active faults was recognized and studied by many workers -Waliace (1970), Allen (1975), Matsuda (1975), Siemmons (1977), Cluft and others (1980), Sieh and Jahns (1984), and several contributions in both wallace (1386) and Crone and Omdahl (1987).

The use of scarp morphology for determining the timing and recurrence of earthquakes along faults was developed by Wallace (1377), modified by Busknam and Andezson ( 2373 ), and refined during the 1980s by many workers, inclucing Nasi (2986) and Hanks and others (1934). Larger scale geomorphic expression is also expressive of activity, as shown by Matsuda (1975), and slemmons (1377 and 1981 ).

The possible predictability of renewed earthquake activity has been noted by many workers including shimazaki and Nakata (1930) and Cluff and others (1980). Although quantitative data is only now being collected and analyzed for different tectonic settings, the advances in this area may represent a major new application of 
paleoseismicity. More recently, these ideas have been used by Schwartz and Coppersmith (1984, and 1987) Eor repetition of similar or "characteristic" events.

Fault segmentation was vaguely recognized at least as early as 1965 (Albee and Sinith) through the use of a sractional fault length method. Segmentation is more clearly demonstrated in the historical ruptures along the North Anatolian fault (Ambraseys, 1973:, and was described by schwartz and Coppersmith (1984 and 1936) for 3tzike-slip Ealling along the San Andreas Fallt and normal-slip faulting along the Wasatah Fault zone. This methou has been deveioped during the past six or eight years for assessing the earthquake potential at vital engineering structures (e.g. San Onofre Nuziear Power glant; and is currently receiving more sophisticased analyses, as it appezrs to be the most usef:l method of rnaking a quantitative, or zemi-guantilative evaluation at mary sites.

The camined use of paleoseismic and seismologie data for providing estimares of potential earthguake size is reviewed by Slemmon:s (-932), Gahwartz anz other $(1934)$ and slemmons and depolo (1986). Currentiy these combined methods are widely used in many parts of the world for preparation of earthquake zoning maps.

Paleoselsmic methods use several relatively new techniques, including remote sensing, geomorphic, exploratory trenching and geophysical methods. They are needed for:

- Determining earthquake potential in aseismic, or weakly seismic regions.

- Extzapolating the brief historical. and seismological record to hundreds, thousands, or longer time intervals.

- providing a measure of expected earthquake magnitude values that are based on real, rather than assumed values.

- Representing a methodology that will eventually be testable, although the uncertainty is not well-known at present.

\section{APPLICATION TO INTERPLATE, INTRAPLATE, AND MICROPLATE SETTING}

paleoseismi $=$ methods have been applied to interplate areas in many tectonically active regions. More recently, applications have been extended to intraplate areas as noted by Slemmons and depolo (1936b) and Ramelli and others (1937). The analyses of Bonilla and others (1984) permit refinements for regions with different $Q$ values (for example California, intraplate earthguakes, Turkey. ete.). For some settings it may be necessary to derive special regression relations, particularly for regions with high stress 
drops, long recurrence intervals, or thick zones of brittie failure, or other special characteristies (Bonilla and othezs $(1984)$.

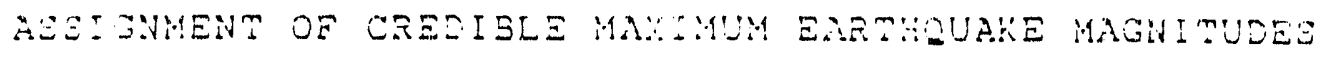

The assignment of maximum earthqual: magnitudes from paleoseismic and seismologic data an be made daing methods described by slemmons (1982), slemmons and chung (1932), Schwartz (1935), and slemons and dePolo (2joba and 1932b). The methods yideld result.s that tend to be equal to, or are somewhat less, than actual maximum

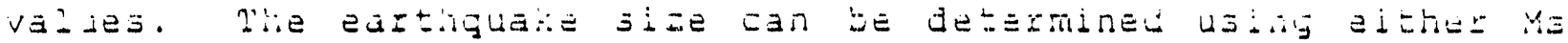
Magnitude or moment magn:tuce. Although the use of the two methoda for the same event may lead to somewhat different values, tha results generaliy agree within a fration of a magnitude unit.

\section{USE OF DELERMINISTIC AND PKOBAEILISTIC METHODS}

Although deterministic methods are much more commonly used, or are rajuirad by raguiation, probabilistic and logic trae ana:yje $a s \geq$ often lised as supplemental methods. By including timitg or recurrence data, : is posibibe to use tield data for both deterministic and probabilistic analyses to provide semiindependent checks.

\section{NEW REGRESSION ANALYSES OF SURFACE FAUL" RUPTURE PARAMETER AND EARTHQUARE SIZE}

The regression analyses of Slemmons (1982), slemmons and Chung (1982), and Bonilla and other (1934) permit the determination of surface magnitude ( $M$ ) from surface rupture length or maximum displacement for different fault types. Also, as noted in Bonilia and others (1984), we regard ordinary least squares regressions are appropriate for our analysis. As noted in discussions by Bolt (1978), and Mark (1979), two regressions are given for each relationship shown in Figures 2 and 3 . Note that only the regressions of length or maximum displacement on Ms majnitude should be used for determination of magnitude. The other regression line for each chart should be used for determining the probable length or maximum displacement for a given magnitude.

In this paper we present a new regression analysis. The analysis does not require evaluation of fault type, but simply creates a two-fold division of the data by tectonic setting: extensional and contractional. An extensional region may be thought of as one in which the dominant mode of deformation results in crustal extension and increase of surface area, while a contractional regime is one characterized by crustal shortening and reduction of surface area. This two-fold division is suggested by 
our observation that within a given province, for example in the extensional Basin and Range brovince, the surface magnitude to maximum displacement or rupture length is not greatly injluenced by the type of fault inormal-slip, normal-oblique-slip, or strikesitp) and ail tyees may occur together in a conjugate reiationship.

Thij sivijion not onil appears to be genetically valid, but it is aiso straightforward to categorize events into the appropriate category based on earthguake focal mechanism and geologic setting. Extensiona? and contiactionai regimes äe thus distinguished by models of lithospheric plate-scaied behayior, by JurE:cial avidence of eitinex rifting or zontzaction, by in jitl stress measurements, and by focal mechanism studies. Use of the indicators usuaily coincides with our intuition about which regime is representad. Use of this two-fold division is simpler than Eive fault types: nozmal, noxmal-obliqua, reverse, reverse-oblique, and strine-siti.

There are two motivations for such a division. The first goal is to improve the statisticai sigrificance and extend the zange os applicability of the regressions. In previous regression aralyses utilizing many categories, some of the fault type categories contained of very few eventz. By combining observations from several categories, we are able to increase the number of events and extend the magnitude range for each regression category. For the current preliminary analysis we use 22 earthquakes in the extensional category and 26 in the contractional category. The second goal is to simplify the application of the regression to hazard assessment problems. If there is little or no degradation in the accuracy of the regression, it is simpler for the user to refer to one of two possible regressions rather than to several.

The data we used were all from earthquakes that occurred during this century with Ms magnitude greater than 6 . We have reexamined and included many events from the earlier studies of Slemmons (2982), Slemmons and Chung (1932), and Bonilla and others (1984). We excluded any event for which there were not weil documented observations of both the total rupture length and the maximum slip. Events were excluded as well if there was evidence that the data were inextricably contaminated by inclusion of, or failure to recognize soil fallure, landslides, or sub-aqueous faulting. Severzl recent earthquakes were ircluded and earlier events were updated with new information from recent literature.

Regression analyses for preliminary determinations for 48 contracticial and extensional jurface Eaulting events are shown in Eijure - The greliminary regressions with one standard deviation for 26 eventz Eor reverse-slip and strike-silp fauling in contractional regimes is shown in Figure 2. Preliminary regressions with one standard deviation for 22 events for normal- 
slip and strike-slip faulting in extensional regimes are shown in Figure 3 .

Figure 1 shows that there is little difference in the regreasions Eor rupture lengths vs. magnitude between the extensional and the contractional data sets. However, there is a sutstantial difference in the regression between the magnitude and maximum displacement values in the higher magnitude range for the two regimes. This observation may point to an underlying similarity in the physics of the rupture process that lengthens the rupture as a rupture grows larger, in either the extensional or contractional regime. The reducad similarity in the regressions between the magnitude and the maximum displacement values for the two regimes ( $F i g .1$ ), and the greater scatter in the maximum displacement data (see error bunds in Figs. 2 and 3 ), imply that the physics that controls the slip function may be influenced by tectonic regimes. This pattern of variation may represent the superimposed effects of:

A. systematic difference in average stress drop between the two tectonic regines we have used, and

B. random effects of variable stress-drops (i.e. the presence of high atress-Jrop asperities on the eault plane).

In addition, Figures 2 and 3 show that inclusion of strikeslip with dip-slip events in the data has, at most, minor effects on regressions of magnitude and length. In the regressions of maximum displacement and magnitude, particularly for extensional settings (Figure 3 , bottom of page), dip-silip events in the magnitude range around magnitude 6.5 show somewhat greater displacement than strike-slip events. This observation is contrary to our initial intuition. However, we conjecture that it might result from different average stress among various tectonic regimes (Kanamor: and Allen, 1986).

CONCLUSIONS

- New regressions are presented for a simple two-fold classification into extensional and contractional tectonic settings. This is simpler than for regression analyses using five fault types.

- Regressions may apply within intraplate regions (e.g. Meers fault in oklahoma, several faults in Australia, and possibly ir. China for the stable interiors of such blocks as the ordus Pᄂaニミau). 


\section{ACKNOWLEDGEMENTS}

We greatiy benefited from discussions with, and editorial assistance from, Michael Ellis and Duug Cla:k of the Center for Neotectonic studies. We also wish to express our gratitude to the U.S. Nuclear Regulatory Commission for their support of the University of Nevada-Reno's Diablo Canyon project which investigates fault rupture parameters in compressional tectonic settings. We also wish to thank the state of vevada for their support of the Yucca Mountain Nuclear Waste Site Investigation project that investigates extensional settings.

\section{REFERENCES}

(1) Albee, A.L. and Smith, J.L., 1966, Earthquake characteristics and fault activity in southern California: in Engineering Geology in Southern California, Lung, L. and Proctor, R., eds., Associated Engineering Geologista, Giendale, Galiforria, p. 9-33.

(2) Alien, C.R., 1975, Bonilla, M.G., Mark, R.K., and Lienkaemper, J.J., 2984, Statistical relations among earthquake magnitude, surface rupture length, and surface faul displacement, Seismological Society America Bulletin, v. 74, p. 2397-2411.

(3) Ambraseys, N.N., 1978, studies in historical seismicity and tectonics: in The Environmental History of the Near and Middle East, Brice, W.C., ed., Academic Press, New York, p. 135-210.

(4) Bolt, B.A., 1978, Incomplete formulations of the regiessions of earthquake magnitude with surface fault rupture length: Geology, v. 6, D. $233-235$.

(5) Bonilla, M.G., Mark, R.K., and Lienkaemper, J.J., 1984, Statistical relations among earthquake magnitude, surface rupture length, and surface fault displacement: Seismological society America Bulletin, V.4, P. 2379-2422.

(6.) Bucknam, R.C. and Anderson, R.E., 1979, Estimation of faultscarp ages from scarp-height-slope-angle relationsinip: Geology, V.7, P. $11-14$.

(7) ClufE, L.S., Patwardhan, A.S., and Coppersmith, K.J., 1980, Estimating the probability of occurrences of surface faulting earthquakes on the Wasatch Fault Zone, Utah: Seismological society America, v.70, p. 463-478.

(8) Crone, A.J. and ohmdahl, E.M., 1927, Directions ir. paleoseismicity: U.S. Geological survey open-file Report 37-673, p. 456 . 
(9) Gllbert, G.K., 1890, Lake Bonnevllle: y.s. Geologlcal Survey Monograph 1 .

(10) Hanks, T.E., Bucknam, K. C., Eajole, Y.R., and Wallace, R.E., 1984, Modtication of wave-cut and fault-contzolied landforms: Journal Geophysical Research, $\because$. 89, p. 5771-5790.

(11) Kanamori, H. and Alien, C.R., 1985, Earthquake repeat time and average stress-drop: ir Earthquake Source Mechanics, Das, $s .$, Boatwright, J., and Scholz, C., eds., American Geophysical Union, Washington D.C.

(:2) Lawscn, A.C., et a 1., 1908, The Californda earthguake of April 28, 1906 - Report ol the State Earthquake Investigation Commission: v.1, Part 1, p. 1-254; Rart a: Carnegie Institution of Washington, publication 87 p. $255-45$.

(13) Loudertack, G.0., 1950, Faults and engineering geology, in Application of Geologi to Englieering peactice, paige, s.. ed., Geological society of America, Boulder, Colo., p. 125-150.

(14) Mark, R.K., 1979, Comment on 'incomplete formulations of the regresion of earthquake magnitude with surtace fault length': Geology, v. 7, p, 1-6.

(15) Matsuda, Tn., 2975, Magnitude and recurrence interval of earthquakes from a cult (in Japanes ), Earthquake, ser. 2, v. 28, p. $269-283$.

(16) Nash, D.B., 1986, Morphologic dating and modeling degradation of fault scarps: in Active Tectonics, Wallace, R.E., ed. National Academy Press, Washington, D.C., D. 181-194.

(17) RameII1, A.R. and Sleminons, D.B., 1986, Neotectonic activity of the Meers fault: Oklahoma Geological Survey Guidebook 24, The Slick Hilis of Southwestern Oklahoma - Eragmentes of $3 n$ Aulacogen?, R. $45-54$.

(18) Schwartz, D.P. and Coppermith, K.J., 1984, Fault behavior and characteristic earthquakes: Examples from the Wasatch and san Ardreas Faults: Journal Geophysical Research, v. 89, p. 5681-5698.

(19) Schwartz, D.P., Coppersmith, K.J., and Swan, F.H., III, 1984, Methods for estimating maximum earthquake magnitudes, in proceedings of the ejihth wozld conference on earthouaks

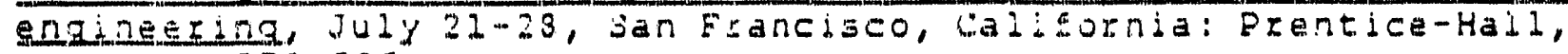
v. : . 279-285.

(20; Schwartz, D.P. and Coppersmith, K.J., 1986, Seismic Hazards: New trends in analysis using geologic data: In Active Tectonics, Waliace, R.ż., ed., Nathond Academy press, Wastington, D.C., 2 . $215-220$. 
(21) Sieh, K.E. and Jahns, R.H.: 1984, Holocene activity of the San Andreas fault at Wallace Creek, California: Geological society Anerice Bulletin, v. 95, p. 883-896.

(22) Shimazaki, K. and Nakata, T., 1980, Time-predictable recurrence model for large earthquakes: Geophysical Research Letter, v. 7, p. 279-282.

(23) Slemons, D.B., 1977, Faults and earthquake magnitude: U.S. Army Engineers Waterways Experiment station, Vickaburg, Miss., Miscellaneous Paper $s-73-1$, keport 6, p. 166 .

(24) Slemmons, D.B., 1981, A procedure for analyzing faultcontrolied lineaments and the activity of faults: in proceedings 3rd International Conference on Basement Tectonics, o'Lear\%, D.W. and Earle, J.L., eds., International Basement Tectorics Association, v. 3, p. 33-49.

(25) Slemmors, D.B., 1982, Determination of design earthquake magnitudes for microzonation: in 3rd Intermational Earthquake Microzonation Conference proceedings, p. 119-130.

(26) Siemmons, D.B. and Chung, D., 1982, Maximum credibie earthquake magnitudes for the Calaveras and Hayward fault zones, California: California Division of Mines and Geology special Paper 62 , P. 215-124.

(27) Slemmons, D.B. and dePolo, C.M., 1986a, Determination of earthquake size: Proceedings, of Conference XXXIV: U.S. Geological Survey Open-File Report, p. 181-196.

(20) Slemmons, D.B. and dePolo, C.M., 1986b, Evaluation of active faulting and associated hazards in dctive Tectonics, Wallace, R.E., ed.: Geophysics study Committee, National Academy Press, washington, D.C., p. 45-62.

(29) Tocher, D., 1958, Earthquake energy and ground breakage: seismological soclety America Bulletin, v. 48, p. 147-153.

(30) Wallace, R.E., 1970. Earthquake recurrence intervals on the San Andreas Faudt, California: Beological Society America Bulletin, v. 81, P. 2875-2890.

(31) Wallace, R.E', 1977, Profiles and ages of young fault scarps, noxtr-centad Nevada: Geological Society America Bulletin, v. 88 , p. $2267-1231$.

(32) Wallace, R.E., ed., 1986, Active Tectonics: National Academy Press, Washington, D.C., 206 p. 
ALL DATA

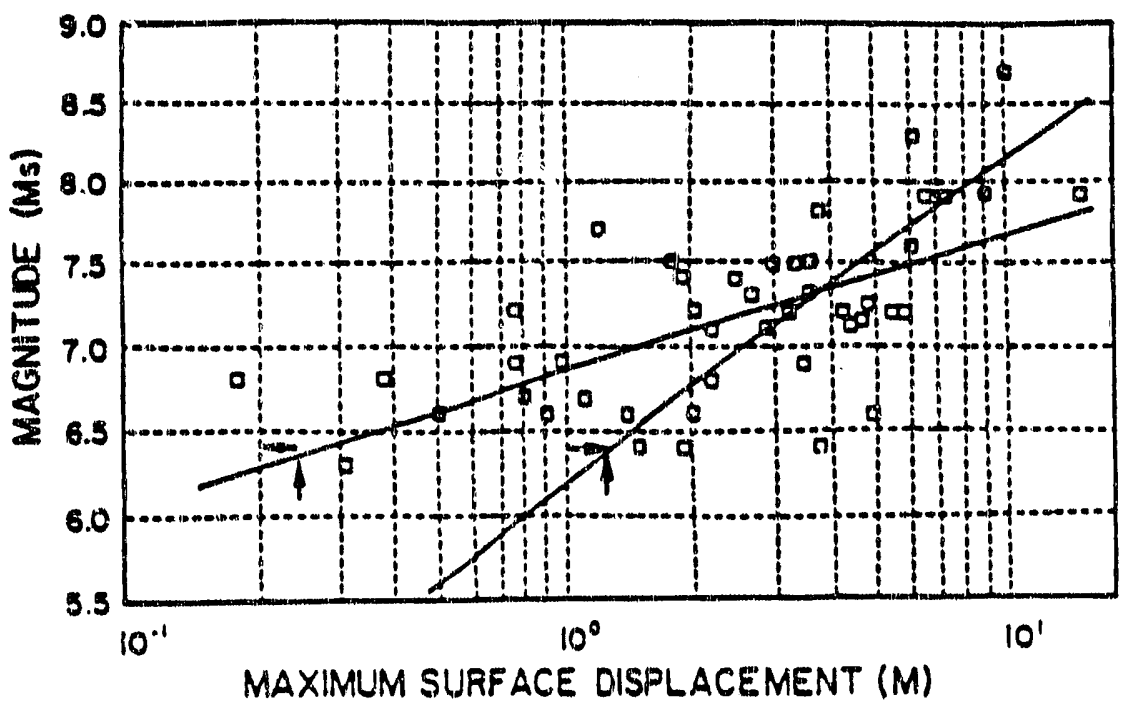

ALL DATA

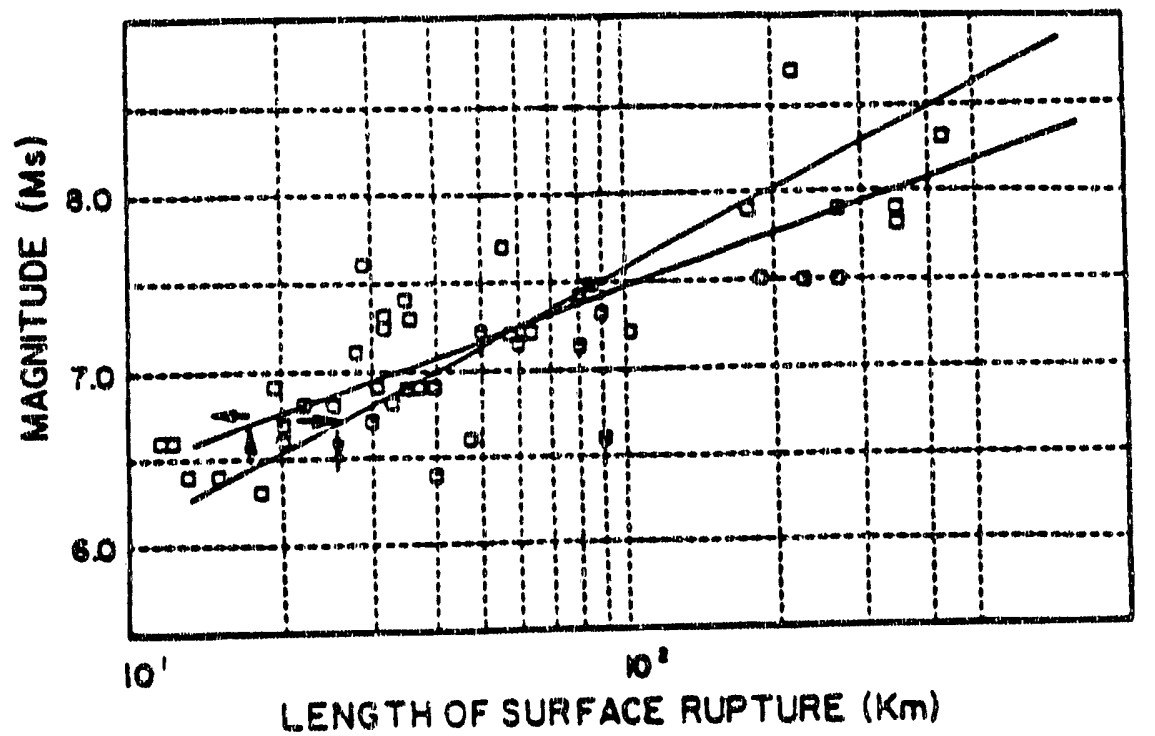

Foure 1: Surface faulting parameters of maximum displacement in ueters (top diagram) and rupture length in Kllometers (bottom diagram) for 48 earthquake events in both extensional and contractional settings. Regression lines are shown for surface magnitude (Ms) on maximum displacement and surface rupture or defortation length for all events. There are two regressions shown each graph, with arrows leading toward the dependent parameter to be determined. The model parameters are given in Table 1 and 2 , and in captions of figures 2 and 3. 

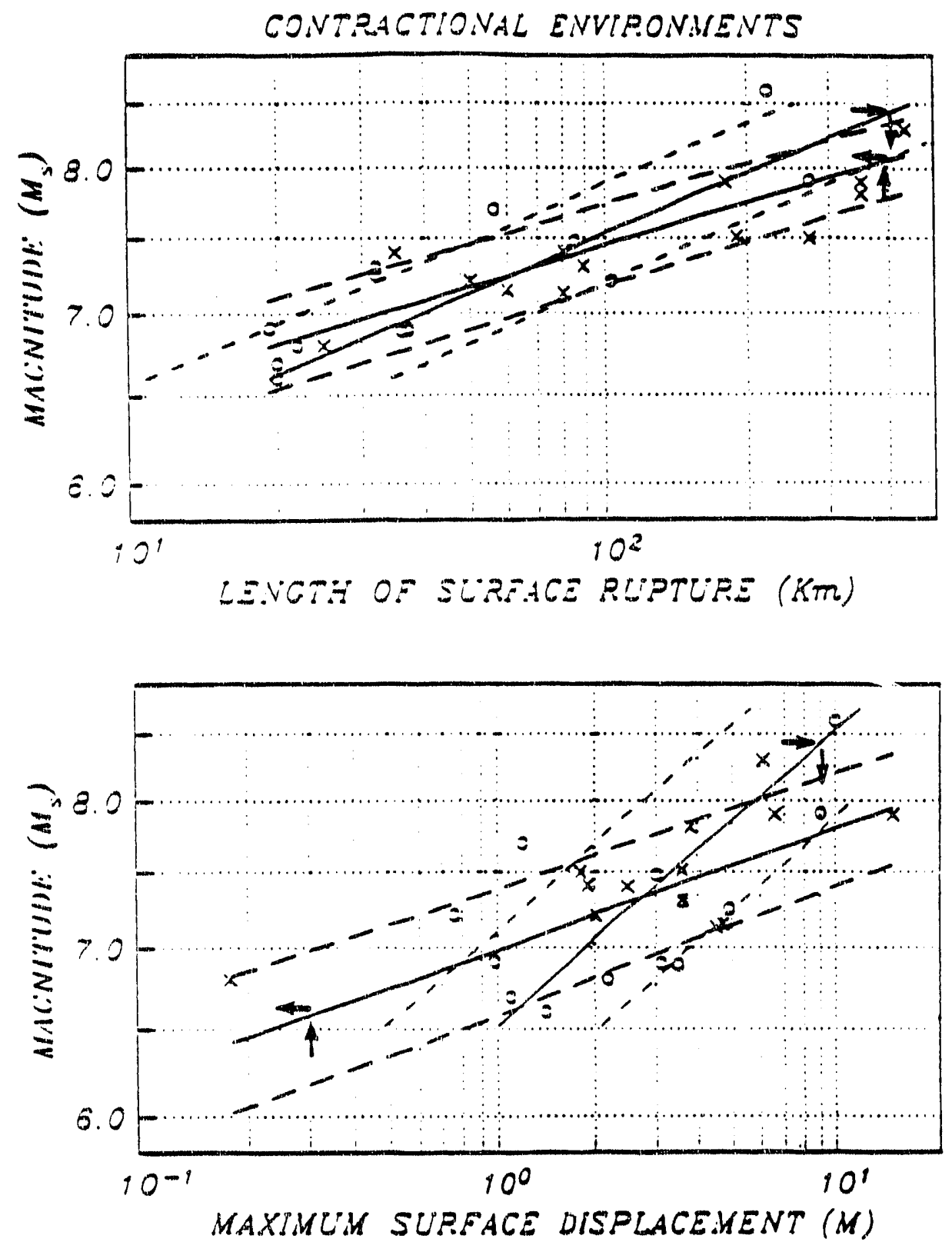

Figure 2: Ljnear regression (solid lines) and plus or minus one standard deviation (long dashes for magnitude on fault parameter, short dashes for fault paraneter on magnitude), for 26 compressional setting earthquake events with associated surface faulting. Data points shown as " $x$ " are dominantly strike-silp events; data points shown as "o" are dominantly dip-silp events. Regressions are for magnitude $\left(\mathrm{K}_{s}\right)$ on length in kilometers (top diagram), or maximum displacement in meters (bottom diagram), and for length and maximum displacement on magnitude. The arrows lead to the assumed dependent parameter. The coefficiants for the regression lines are given in rables 1 and 2. 

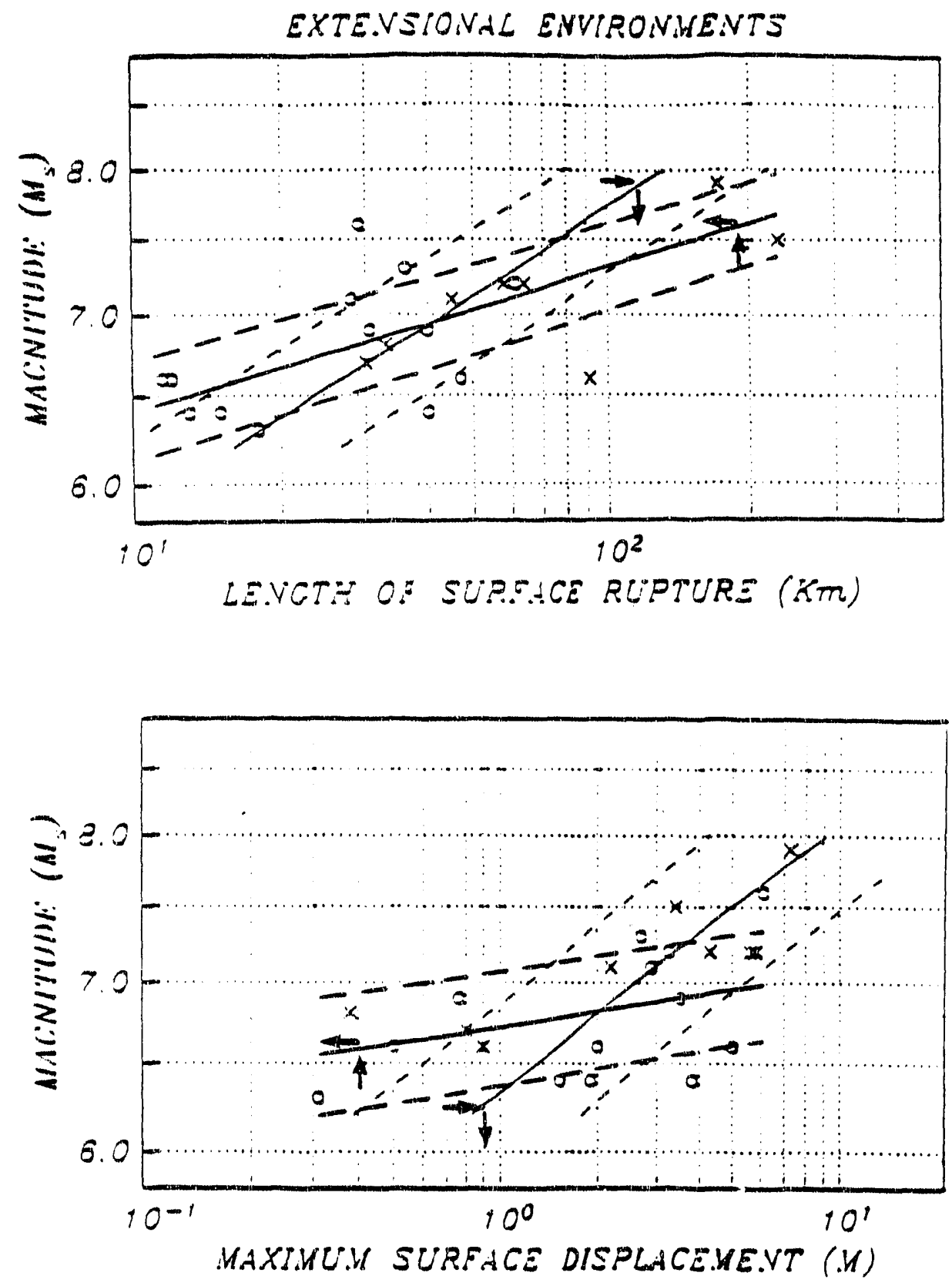

Figure 3: Linear regrassion (solid line) and plus or minus one standard deviation (long dashed for magnitude on lault parameter, short dashes for fault parameter on magnitude), for 22 extensional setting earthquake events with associated surface faulting. data points shown as " $x$ " are dominantly strike-slip events; data points shown as "o" are dominantly dip-silp evants. Regressions are for surface magnitude $\left(M_{H}\right)$ on langth in kiloweters (top diagram) and maximum displacement in metors (botto diagram), and for inagth and maximum displacemant on magnitude. The arrows lead to the assumed dependent parameter. The coefficients for the regression lines are given in Table 1 and 2. 
Table 1: Relations of earthquake magnitude(Ms) regressed on Log(L) or (Dmax): Ms $=A+B * I$ og (I) or (Dmax)

\begin{tabular}{|c|c|c|c|c|c|c|c|}
\hline Regime & Type & $x$ & $A$ & B & $\mathbf{R}$ & $S *$ & $\mathbb{N}$ \\
\hline ALL EVENTS & $\begin{array}{l}\text { ALL } \\
\text { ALI } \\
\text { SS } \\
\text { SS } \\
\text { DIP } \\
\text { DIP }\end{array}$ & $\begin{array}{l}D \\
L \\
D \\
L \\
D \\
L\end{array}$ & $\begin{array}{l}6.86 \\
5.39 \\
7.04 \\
5.50 \\
6.74 \\
5.10\end{array}$ & $\begin{array}{l}0.79 \\
1.03 \\
0.70 \\
0.95 \\
0.83 \\
1.25\end{array}$ & $\begin{array}{l}0.62 \\
0.83 \\
0.72 \\
0.87 \\
0.56 \\
0.79\end{array}$ & $\begin{array}{l}0.41 \\
0.30 \\
0.31 \\
0.22 \\
0.46 \\
0.34\end{array}$ & $\begin{array}{l}48 \\
48 \\
22 \\
22 \\
26 \\
26\end{array}$ \\
\hline $\begin{array}{c}\text { CONTRACTIONAL } \\
\text { EVENTS }\end{array}$ & $\begin{array}{l}\text { ALL } \\
\text { ALL } \\
\text { SS } \\
\text { SS } \\
\text { DIP } \\
\text { DIP }\end{array}$ & $\begin{array}{l}D \\
L \\
D \\
L \\
D \\
L\end{array}$ & $\begin{array}{l}7.02 \\
5.57 \\
7.19 \\
5.73 \\
6.85 \\
5.10\end{array}$ & $\begin{array}{l}0.80 \\
0.96 \\
0.62 \\
0.85 \\
1.02 \\
1.29\end{array}$ & $\begin{array}{l}0.63 \\
0.84 \\
0.68 \\
0.86 \\
0.63 \\
0.86\end{array}$ & $\begin{array}{l}0.40 \\
0.28 \\
0.31 \\
0.21 \\
0.47 \\
0.31\end{array}$ & $\begin{array}{l}26 \\
26 \\
13 \\
13 \\
13 \\
13\end{array}$ \\
\hline $\begin{array}{c}\text { EXTENSIONAL } \\
\text { EVENTS }\end{array}$ & $\begin{array}{l}\text { ALL } \\
\text { ALL } \\
\text { SS } \\
\text { SS } \\
\text { DIP } \\
\text { DIP }\end{array}$ & $\begin{array}{l}D \\
L \\
D \\
I \\
D \\
L\end{array}$ & $\begin{array}{l}6.72 \\
5.48 \\
6.87 \\
5.17 \\
6.63 \\
5.57\end{array}$ & $\begin{array}{l}0.34 \\
0.93 \\
0.72 \\
1.12 \\
0.39 \\
0.87\end{array}$ & $\begin{array}{l}0.84 \\
0.71 \\
0.81 \\
0.82 \\
0.50 \\
0.55\end{array}$ & $\begin{array}{l}0.35 \\
0.29 \\
0.26 \\
0.25 \\
0.35 \\
0.35\end{array}$ & $\begin{array}{r}22 \\
22 \\
9 \\
9 \\
13 \\
13\end{array}$ \\
\hline
\end{tabular}

Table 2: Relations of Log (I) or (Dmax) regressed on earthquake magnitude (Ms): $\log (L)$ or $(D)=A+B$ (Ms)

\begin{tabular}{|c|c|c|c|c|c|c|c|}
\hline Regime & rype & $x$ & $A$ & B & $\mathbf{R}$ & $S *$ & $\mathbf{N}$ \\
\hline ALL EVENTS & $\begin{array}{l}\text { ALL } \\
\text { ALL } \\
\text { SS } \\
\text { SS } \\
\text { DIP } \\
\text { DIP }\end{array}$ & $\begin{array}{l}D \\
L \\
D \\
L \\
D \\
L\end{array}$ & $\begin{array}{l}-3.00 \\
-3.00 \\
-4.95 \\
-4.29 \\
-2.31 \\
-2.17\end{array}$ & $\begin{array}{l}0.49 \\
0.66 \\
0.73 \\
0.85 \\
0.38 \\
0.53\end{array}$ & $\begin{array}{l}0.62 \\
0.83 \\
0.72 \\
0.87 \\
0.56 \\
0.81\end{array}$ & $\begin{array}{l}0.32 \\
0.24 \\
0.32 \\
0.21 \\
0.32 \\
0.22\end{array}$ & $\begin{array}{l}48 \\
48 \\
22 \\
22 \\
26 \\
26\end{array}$ \\
\hline $\begin{array}{c}\text { CONTRACTIONAL } \\
\text { EVENTS }\end{array}$ & $\begin{array}{l}\text { ALL } \\
\text { ALI } \\
\text { SS } \\
\text { SS } \\
\text { DIP } \\
\text { DIP }\end{array}$ & $\begin{array}{l}D \\
I \\
D \\
L \\
D \\
L\end{array}$ & $\begin{array}{l}-3.19 \\
-3.47 \\
-5.20 \\
-4.49 \\
-2.35 \\
-2.48\end{array}$ & $\begin{array}{l}0.49 \\
0.72 \\
0.76 \\
0.88 \\
0.38 \\
0.57\end{array}$ & $\begin{array}{l}0.62 \\
0.84 \\
0.68 \\
0.86 \\
0.61 \\
0.86\end{array}$ & $\begin{array}{l}0.32 \\
0.25 \\
0.34 \\
0.22 \\
0.30 \\
0.21\end{array}$ & $\begin{array}{l}26 \\
26 \\
13 \\
13 \\
13 \\
13\end{array}$ \\
\hline $\begin{array}{l}\text { EXTENS IONAL } \\
\text { EVENTS }\end{array}$ & $\begin{array}{l}\text { ALI } \\
\text { ALL } \\
\text { SS } \\
\text { SS } \\
\text { DIP } \\
\text { DIP }\end{array}$ & $\begin{array}{l}D \\
L \\
D \\
L \\
D \\
D\end{array}$ & $\begin{array}{l}-3.68 \\
-1.96 \\
-6.10 \\
-3.42 \\
-2.95 \\
-5.20\end{array}$ & $\begin{array}{l}0.58 \\
0.51 \\
0.90 \\
0.72 \\
0.48 \\
0.20\end{array}$ & $\begin{array}{l}0.61 \\
0.71 \\
0.81 \\
0.83 \\
0.50 \\
0.50\end{array}$ & $\begin{array}{l}0.33 \\
0.22 \\
0.29 \\
0.21 \\
0.35 \\
0.22\end{array}$ & $\begin{array}{r}22 \\
22 \\
9 \\
9 \\
13 \\
13\end{array}$ \\
\hline
\end{tabular}


SCALTNG REIATIONS AMOAKG THE SOURCE PARAMETERS OF SHAIION EARIHQUAKES

Bodin, $P_{.}$, Brume, J., Sleumons, D.B!, and thang, X., Center for Neorectonic studies, and Seismological Iaboratory; Mackay School of Mines, University of Nevada Reno, Reno NV 89557)

Elastic models of the fault slip for hich aspect-ratio (long) earthquake ruptares predict that maximum and average co-seismic slip will be related to the width (narrow dinension) of nuture. For shallow earthquakes, if the width of co-seiswic rupture is limited by the overall depth of the seismogenic zane, then we expect that observed displacements should be virtuaily independent of rupture length above some threshold length. We use the expected fault slip as a function of rupture length for elliptical cracks, assuming uniform stress drop and uniform material rigidity, and assuming a maximu depth of faulting (a W-model), and we compare several data sets of observed surface rupture parameters to this model.

Although there is oonsiderable scatter in the data, it is apparent that the data are not inconsistent with the predicted model. In fact, the data presented are more supportive of this model than they are of earlier results by other workers that indicated a linear relation between the magnitude of comseismic slip and the rupture length (I-models). We discuss the differences between our data base and that of previous investigators.

Ihis result has several consequences, both for rupture physics and for earthquake hazard assessment. It implies that the majority of slip curing a shallow earthquake takes place within the seismogenic zane and that the base of the seismogenic zane is effectively "locked" to coseismic nupure. Ihis may comrelate with the general lack of flat-lying (detactment) focal mechanisms suggesting faulting at the base of the seismogenic zone. There is no suggestion that stress drop is dependent on rupture length for high aspect-ratio shallow earthquakes. It implies that, at least for large shallow earthquakes, there is a linear relation between rupture length and mament. The scatter in the data probably results from non-uniform stress drop and terial properties.
1. 1987 Fall Meeting

2. 003673701

3. (a) Paul Bodin Mackay School of Mine: University of Reno Reno, NV 89557

$$
\text { (b) (702) } 784-1688
$$

4. S

5. (a) Fault Mechanics and Earthquake Rupture Processes

(b) 7213 Earthquake Parameters

6. N/A ???

7. 08

8. \$15 enclosed check

9. C

10. None 
Depolo, C. M., and Slemmons, D. B., 1987, Methods for Estimating earthquake size for seismic hazard analysis: Geological Society of Anerica, Abstracts with Programs, v. 19, p. 641.

METHODS EOR ESTIMATING EARTHQUAKE SIZE

FOR SEISMIC HAZARD ASSESSMENT

№ 142955

DEPOLO, Craig M. and SLEMMONS, D. Burton, Center for Neotectonic Studies, Mackay School of Mines,

University of Nevada - Reno, Reno, NV 89557

Several methods have been developed in the last couple of decades for estimating potential earthquake intensities, magnitudes, and seismic moments. These methods utilize historical seismicity, paleoseismicity, fault-length, fault-displacement, Eault-area, seismic moment, and relative comparisons. The need for many different methods has xisen from a wide variability in seismic sources and the type and amount of information available. Different approaches to earthquake size estimation are often used in detexministic versus probabilistic analyses. Different approaches are also used in interplate versus "stable cratonic interior" regions (e.g. California versus eastern U.S.). A common difference between these approaches is the analysis of a specific reature (e.g. fault) versus estimating the hazard of a source zone or seismicity zone which lacks an identified causative feature. Recent emphasis has been placed on the uncertainties of the techniques and estimations, refining techniques and the data used, and incorporation of new information and ideas into the estimation process. Segmentation is a promising method being aggressively pursued by geologists and geophysists which involves the identification of discrete rupture segments. However, variability of faults and historical evento creates a difficult task for those applying the method. The use of multiple estimation techniques usually leads to more confident and defendable final values. 


\section{FINAL REPORT JANUARY 1,1987 - JUNE 30,1988}

TASK 1 Quaternary Geology and Active Faulting at and near yucca Mountain

Principal Investigator: John W. Bell, Engineering Geolngist

Co-Investigators: Alan R. Ramelli, Research Associate Craig M. dePolo, Research Associate Harold F. Bonham, Jr., Geologist

Assistants: Keryl Fleming, Computer specialist

Nick Varnum, Graduate Assistant

Consultants: Ronald I. Dorn, Texas Tech University Frederick F. Peterson, University of Nevada-Reno Steven Forman, University of Colorado Teh-Lung Ku, University of Southern California 
Major Activities.......................... 1-1

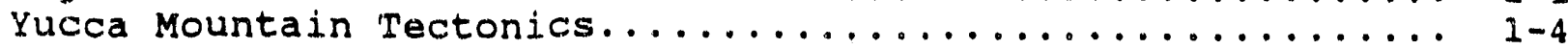

Low-sun-angle Photography.................... 1-4

Solitario Canyon Fault...................... 1-5

Fatigue Wash Fault....................... 1-7

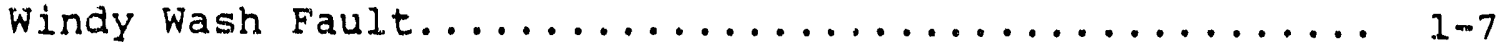

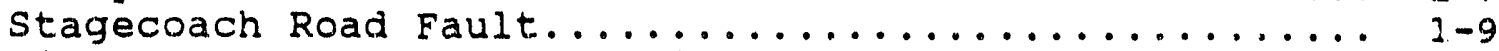

Midway Valley (Surface Facilities Area)............. 1-9

Bow Ridge Fault.......................... 1-10

Paintbrush Canyon Fault......................10

Complex, Distributed Faulting Events.............. 1-11

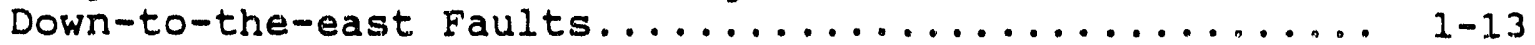

Structural Control of Lathrop Wells Cone............ 1-13

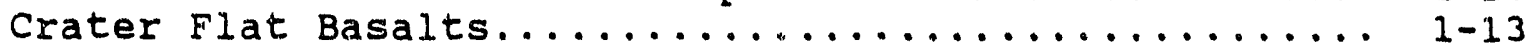

Quaternary stratigraphic studies in Yucca Mt. Area........ 1-15

Rock Varnish Dating......................... 1-15

Iimitations of the Cation-Ratio Dating Method.... 1-16

Evaluation of Cation-Ratio Dating for Use on

the Yucca Mountain Site..................1-17

Cation-leaching Curve Calibration............ 1-17

Soil-Geomorphic studies...................... 1-19

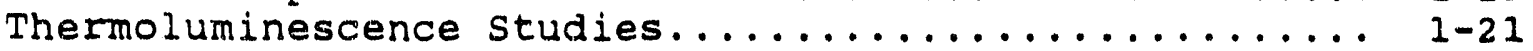

U-Series stidies.......................... 1-22

studies of the 1932 Cedar Mountain Earthquake........... 1-25

The Use of the Relative Comparison Approach

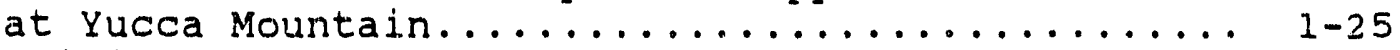

Similarities Between Yucca Mountain and the 1932

Cedar Mountain Earthquake Area............... 1-26

Quaternary stratigraphy of the Cedar Mountain Area... 1-27

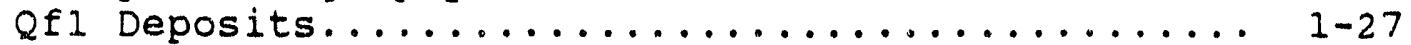

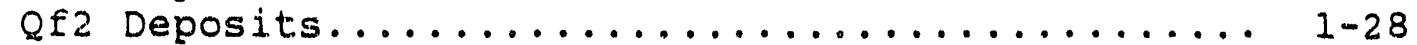

Qf3 Deposits.......................... 1-28

Trench studies in Monte cristo valley............. 1-29

Three Dimensional study at Trench $3 \ldots \ldots \ldots \ldots$ 1-29

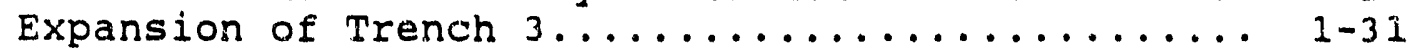

Interpretations of Trench $3 \ldots \ldots \ldots \ldots$ 1-31

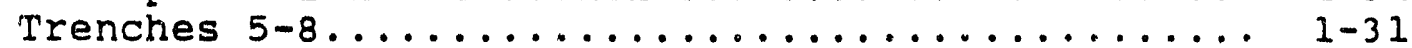

stewart and Gabbs Valleys studies................ 1-32

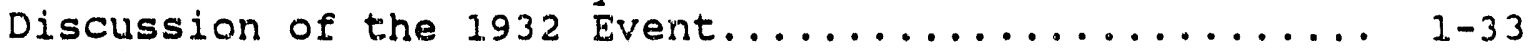

Preliminary Results of Quaternary Tectonic studies

in the 1932 Cedar Mountain Fault zone......... 1-34

overview of SEISRISK II....................... 1-37

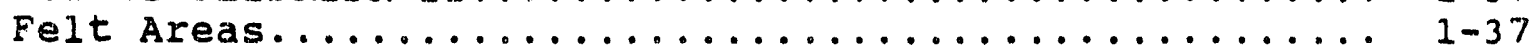

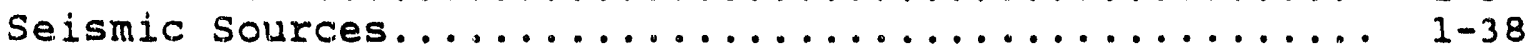

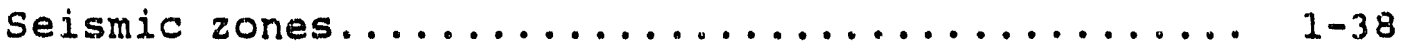

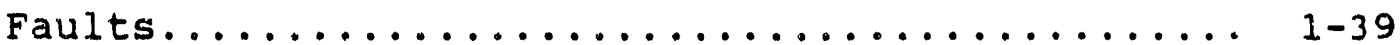

SEISRISK III............................... 1-39

Future Use of SEISRISK II and III............... 1-40

Summary for the Period 1 January 1987 - 31 July $1988 \ldots \ldots \ldots$ 1-41

References cited................................ 1-43

Appendices..................................... 1-46 


\section{Appendices}

Appendix A - Consultant's report: A critical evaluation of cationratio dating of rock varnish, and an evaluation of its application to the Yucca Mountain repository by the Department of Energy and its subcontractors; R. I. Dorn

Appendix B - Consultant's report: Soil-geomorphology studies in the crater Flat, Nevada, area; F. F. Peterson

Appendix $c$ - Consultant's report: Assessment of the applicability of the thermoluminescence (TL) dating technique to natural hazard evaluations at the high-level nuclear waste repository site, Yucca Mountain, Nevada; S. L. Forman

Appendix D - Consultant's report: Radiometic dating with $U$ - and Th-series isotopes in the Nevada Test site region - a review; T. I. Ku

Appendix E - Cedar Mountain field guide: Visit to trenches along the southern part of the 1932 Cedar Mountain earthquake ruptures, Monte Cristo Valley, Nevada; C. M. defolo, A. R. Ramelli, and J. W. Bell

Appendix F - Abstracts presented and/or submitted 


\section{List of Figures}

Figure 1: Late Quaternary fault scarps identified from low-sunangle photography

Figure 2: Generalized surficial map along the central part of the solitario Canyon fault zone

Figure 3: Cation-leaching curves

Figure 4: Sample locations for rock varnish (CFP, JWB) and uraniumseries dating (U).

Figure 5: Surface faulting associated with the 1932, 1934, and 1954 earthquakes

Figure 6: Surficial geology of Monte Cristo Valley

Figure 7: Isometric fence diagram of cedar Mountain trenches 3A, $3 B$, and $3 C$

Figure 8: Partial log of Cedar Mountain trench $3 \mathrm{~A}$, cut back $80 \mathrm{~cm}$ from original face on south wall

Figure 9: Partial log of Cedar Mountain trench $3 \mathrm{~A}$ on original face on south wall

Figure 10: Trench 3B log of south wall

Figure 11: Trench 3C $\log$ of east wall

Figure 12: Trench 7 log of south wall

Figure 13: Trench $7 \mathrm{log}$ of north wall

Figure 14: Quaternary and 1932 faulting in Monte cristo Valley 


\section{MAJOR ACTIVITIES}

During the contract period, the following activities were conducted as part of the Task 1 review, monitoring, and independent research program:

* Flew 750 line-miles (1239 frames) of $1: 12,000-$ and $1: 6,000-$ scale low-sun-angle aerial photography over the yucca Mountain and Crater Flat areas.

* Flew 1:12,000-scale low-sun-angle aerial photography over a 1200 square mile area in the Beatty and Amargosa Valley areas.

* Flew 710 line-miles (1076 frames) of 1:12,000-scale low-sunangle aerial photography over the stewart and Gabbs valley areas.

* Analyzed aerial photography covering the major faults in the Yucca Mountain area to evaluate the existence of unmapped Quaternary faults.

* Conducted Quaternary soils, stratigraphic and geomorphic studies in crater Flat to evaluate the adequacy of the existing stratigraphic data.

* Conducted reconnaissance-level review of DOE trenches at Yucca Mountain to evaluate the adequacy of existing fault data.

* Evaluated the rock varnish dating technique and existing data through AMS radiocarbon and cation ratio dating of deposits in crater flat.

* Evaluated the thermoluminescence dating technique and existing data.

* Evaluated the uranium-trend and uranium-series dating techniques and existing data.

* Conducted a reconnaissance-level review of Quaternary volcanotectonic relationships along the windy wash fault in crater Flat.

* Excavated 6 additional trenches across portions of the 1932 Cedar Mountain faults.

* Conducted detailed Quaternary stratigraphic studies in the Monte Cristo Valley portion of the 1932 Cedar Mountain fault zone.

* Developed further documentation of the extent and effects of faulting related to the 1932 cedar Mountain earthquake, and established a structural-tectonic association between this

$$
1-1
$$


zone and the Yucca Mountain area.

* Assisted in logging trenches across faults in the Fish Lake Valley portion of the Northern Death Valley-Furnace Creek fault zone.

* Acquired and placed on line SEISRISK II AND SEISRISK III computer programs designed by the U.S. Geological survey to assess seismic hazard.

* Acquired and reviewed U.S.G.S. unpublished aerial photography of Yucca Mountain ranging in scale from 1:3,800 to 1:30,000.

* Acquired and reviewed high-altitude $U-2$ aerial photography covering the walker lane region from Yucca Mountain to Cedar Mountain.

* Acquired and reviewed 1:20,000-scale color BLM aerial photography of the Yucca Mountain and Crater Flat areas.

* Acquired 1:24,000-scale orthophoto coverage for $71 / 2$ minute quadrangles in the Yucca Mountain area.

* Reviewed the Department of Energy's Consultation Draft of the Site Characterization plan and submitted a 30 page report to NNWPO.

* Reviewed The NRC's Draft Generic Technical position on Guidance for Determination of Anticipated Processes and Events and Unanticipated Processes and Events, and submitted a six page report to NNWPO.

* Reviewed the Szymanski report on Conceptual Considerations of the Death Valley Groundwater system with Special Emphasis on the Adequacy of this system to Accommodate the High-Level Nuclear Waste Repository.

* Conducted a 3-day field trip at the request of the NRC to field sites at Yucca Mountain, crater Flat, Bullfrog Hills, Goldfield, Tonopah, and Monte cristo Valley, February, 1987; attended by the NRC, DOE, SAIC, and LINL.

* Attended the Department of Energy's Meeting with the Nuclear Regulatory Commission to summarize the Seismic/Tectonic Strategies presented in the Consultation Draft of site Characterization Plan in Las Vegas, september 22-23, 1987.

* Attended the Department of Energy's Workshop on Alternative Conceptual Models in Las Vegas, April 11-15, 1988.

* Co-convened a Yucca Mountain related workshop on "Late Cenozoic Evolution of the Southern Great Basin"; presented a

$$
1-2
$$


paper on "The 1932 Cedar Mountain Earthquake and its Relationship to Yusca Mountain" (Appendix F).

- Conducted a two-day post-workshop field trip for the DOE, USGS, SAIC, and others to the Cedar Mountain and Hawthorne areas to view historic faulting, detachment faulting, and vein mineralization. Prepared a 28 page guidebook (Appendix E) for the $50+$ participants of the trip.

* Co-convened a symposium on "Applications of Quaternary Geology to Heotectonic Problems in the Great Basin" at the 1988 cordilleran section Meeting of the Geological society of America, and presented a paper "Quaternary Geology Studies in the 1954 Dixie Valley and 1932 cedar Mountain Farthquake Areas, Central Nevada" (Appendix F).

* Presented a paper titled "Geometry of strike-slip faulting related to the 1932 Cedar Mountain earthquake, central Nevada" at the 1987 cordilleran section Meeting of the Geological Society of America (Appendix F).

* Submitted an abstract titled "Evidence for Distributive Faulting at Yucea Mountain, Nevada" to the 1988 Anrual Meeting of the Geological Society of America (Appendix F).

* Submitted an abstract titled "Implications of Rock Varnish Dating at Crater Flat, Near Yucca Mountain, Nevadal to the 1988 Annual Meeting of the Geological Society of America (Appendix F).

* Obtained permission from the Bureau of Iuand Management to excavate nine soil pits in crater Flat.

* Submitted and obtained provisional approv 1 of an operations and Safety Plan from DOE for conducting field investigrations at NTS.

* Submitted a seven page $\$ 161,000$ proposal to NNWPO for a sixmonth extension of the 1987 contract program.

* Submitted a 51 page $\$ 1.8$ million proposal to NNWPO for a three-year program in Quaternary Tectonics.

* Submitted Technical Procedures for the Quality Assurance Program to NNWPO.

- Conducted a national search and received 18 applications for the position of soil scientist/Geomorphologist. 


\section{Low-sun-angle Aerial Photography}

Low-sun-angle aerial photography of the Yucca Mountain/Crater Flat area was flown in mid-1987. This project included block coverage, with both morning and evening solar illumination, flown at approximate scales of $1: 12,000$ and flight lines covering specific faults at approximate scales of 1:6,000. These photos are of good to excellent quality; however, since many of the principal faults lie at the bases of steep, west-facing ridges (slopes $>20^{\circ}$ ), it was necessary for some lines to be flown with sun angles greater than ideal conditions. It is recommended that additional photos of specific areas be flown under more optimum conditions at some time in the future.

A number of previously unrecoanized fault scarps were identified on the newly acouired low-sun-angle photography. The more significant and/or definite of these are shown in Figure 2 , with discussions on some of these given below. A number of the faults represented in Figure 14 of Bell and others (1987) could not be definitively confirmed and some are probably not real, but many others show up quite well on the new photography.

The newly recognized scarps do not add any obvious new major faults, but they do indicate younger ages, greater rupture lengths, and much more complexity than previous work indicates. Most scarps are located along faults with previously recognized quaternary activity. For example, scarps are present along the west sides of Busted Butte and Exile Hill. Although these faults (Paintbrush Canyon and Bow Ridge, respectively) were known from field study to have late Quaternary activity, scarps along them are not obvious on standard photography or on the ground.

For a number of faults, swadley and others (1984, Table 4) inferred ages of greater than $1.2 \mathrm{~m} . \mathrm{y}$, based on the lack of fault scarps. A number of the faults so identified do in fact exhibit scarps, but even for those that do not, this is not a valid basis for age estimations. Scarp preservation is dependent on a number of factors, only one of which is age. other factors include climate, competence of materials, vegetative cover, scarp aspect, and scarp height. The first three of these factors should be relatively similar to areas throughout most of the Basin and Range province, the region for which most of the relationships of scarp degradation have been developed. Aspect (predominately westfacing) is also similar to many other faults in the Basin and Range. The remaining factor, scarp height plays a significant role in scarp degradation (Bucknam and Anderson, 1979; pierce and Coleman, 1986), especially for small scarps. Small scarps produced during historical earthquakes have been observed to degrade very quj.ckly. For example, the 1954 Rainbow Mountain scarps (up to about $30 \mathrm{~cm}$ ) are now difficult to recognize in the field without

$$
1-4
$$


knowing exactly where they are located. Since recent vertical displacements at Yucca Mountain appear to have been small (ten's of centimeters), it can be expected that they likewise would not be preserved for long. The fact that they can be seen at all is strongly suggestive of recent activity (i.e. Holocene or latestmost Pleistocene).

The low-sun-angle photography permits better delineation of the ends of fault traces, allowing for better interpretations of extensions and connections with other faults. In general, this indicates the faults to be highly interconnected, as was previously believed.

\section{Solitario canyor Fault}

The solitario canyon fault bounds the west side of the proposed subsurface facilities, so it is one of the most significant faults with respect to the postclosure period. A displacement event along this fault could cause a number of potentially undesirable effects on the waste packages, including: shearing of waste packages along secondary fault traces; vibratory motion causing spalling in boreholes and/or damage to waste packages; changes in local stress conditions, possibly leading to changes in water table elevation; and creation of new pathways for groundwater movement.

Scarps along the solitario canyon fault can be traced nearly continuously for about $12.5 \mathrm{~km}$, from Solitario Canyon to the south end of a low, rounded ridge $5 \mathrm{~km}$ NNE of Lathrop wells cone (fig. 1). Just north of this low ridge, a small, subdued scarp can be discerned crossing a surface mapped as QTa by Swadley and others (1984). If this were truly a QTa surface, only a minor amount (a few tens of centimeters) of vertical Quaternary displacement would be indicated. However, as noted by Bell (1986), this surface is veneered by younger deposits, some of which have obliterated parts of this scarp. A cation-ratio age of $190 \mathrm{ka}$ was obtained on rock varnish from these deposits by Dorn (see Appendix A). Although small enough to not be obvious on the ground, this scarp coincides with fault exposures in streamcuts observed by Bell (1986). Although this surface is apparently younger than the underlying deposits, the lack of large displacements of soils (thick calcretes) formed in these deposits indicate that large vertical offsets (soveral meters) have not occurred along this fault during the late Quaternary.

The identifiable scarp length of $12.5 \mathrm{~km}$ is a minimum. The scarp can not be traced ali the way to the north end of solitario Canyon, presumably because displacement dies out in that direction and small scarps at the end of the rupture are not well preserved. Ruptures at this end of the fault probably die out near the head of the canyon. To the south of the low ridge, the scarp is covered

$$
1-5
$$


by younger deposits ( $Q 1$ as mapped by Swadley and others, 1984). It will probably not be possible to determine the exact southern end of this fault. It likely terminates either at its intersection with the stagecoach Road fault or at Lathrop Wells cone. This suggests a maximum length of about $24 \mathrm{~km}$ (taken from xucca wash to Lathrop Wells cone), but it is conceivable that this or other connected faults extend beyond Lathrop Wells cone.

Swadley and others (1984) interpreted the solitario canyon fault to have last moved 1.2 million years ago, based on tentative correlation of basaltic ash within the fault zone with the midQuaternary basalts of crater Flat. This interpretation is incorrect, because; 1) as is shown and descrited in swadley and others' (1984) $\log$ of Trench 8, "minor" displacements offset materials younger than $1.2 \mathrm{~m} . \mathrm{y}_{i}{ }^{2}$ ) the basaltic ash is within fractures crosscutting deposits less than $1.2 \mathrm{~m} . \mathrm{y}$. old and thus more likely originated from the Lathrop Wells Cone, with an age of possibly less than 20,000 years; and 3) displacement post-dating the emplacement of the ash in fault fractures has not been ruled out.

The low-sun-angle photography shows that surfaces cut by the Solitario canyon fault are offset by varying amounts, indicating multiple events. A small scarp present in the youngest displaced surface (surface \#1; fig. 2) indicates about $20 \mathrm{~cm}$ of vertical displacement, as determined by scarp profiling. This presumably occurred during a single, Holocene event; a scarp this small could not be preserved for great periods of time, especially on a steep (about $10^{\circ}$ ) alluvial fan surface, thus suggesting an age no older than latest-most pleistocene. This amount of displacement is compatible with the "minor" recent offsets obsexved in trench 8 , $2 \mathrm{~km}$ to the north (Bell, 1986). A somewhat older surface, or group of similar aged surfaces (surface \#2; fig. 2), is located about $1 / 2$ $\mathrm{km}$ to north of surface \#1. It is displaced by about one meter, which was also determined by scarp profiling. Between these two surfaces, a larger, compound scarp is present, with bedrock exposed on the upthrown side of the fault.

These surfaces have not been examined and their ages are not precisely known. It is estimated that the ages of these surfaces in the scheme of Swadiey and others (1984) are surface $1=Q 1$ and surface $2=22$ or QTa.

Three DOE trenches have been excavated across or near the Solitario canyon fault. The only one actually located across the fault is trench 8 . The other two, trenches $10 \mathrm{~A}$ and $10 \mathrm{~B}$ are not lucated on the main fault trace, although one of these (IOB) did cross a secondary trace. 


\section{Eatigue Wash Fault}

The Fatigue wash fault lies between and parallel to the Solitario Canyon and Windy Wash faults (Scott and Bonk, 1984). This fault bounds a ridge (Jet Ridge) with a morphology similar to Yucca Crest and West Ridge, suggesting an approximately similar displacement history. These ridges all have steep $\left(>20^{\circ}\right)$ westfacing slopes, with fault scarps running along their bases. The scarp along the Fatigue wash fault appears to be somewhat smaller (i.e. less vertical displacement) than either of those along the solitario Canyon or windy wash faults, but a quantitative determination has not yet been made.

Due to the anastomosing nature of the faults at Yucca Mountain, it may not be all that significant to infer continuations of individual faults for great distances. Nonetheless, the fault across which trench $C F-1$ is located appears to have more straightforward connections with the Fatigue wash fault than it does with the Windy Wash fault.

Adequate understanding of the Fatigue wash fault is important for characterization of faulting in general at Yucca Mountain, particularly with regard to complex, distributive rupture events, and also because this fault bounds one of the primary repository expansion areas. As yet, this fault has received relatively little attention. Swadley and others (1984) did not recognize the scarp, nor has it been trenched. No specific plans are described in the CDSCP (consultation draft of the site characterization plan) for study of this fault, although statements in the CDSCP imply that studies, including trenching, will be applied to faults such as this. Specific studies may be included in the study plans, which have not yet been made available.

\section{Windy Wash Fault}

One of the most studied faults in the Yucca Mountain area is the windy Wash fault. This name was originally applied by scott and Bonk (1984) to the fault bounding West Ridge, about $2.5 \mathrm{~km}$ to the NW of the subsurface operations area. This fault has subsequently been interpreted to extend southward and connect with the fault trace across which trenches $C F-2$ and $C F-3$ are located (Whitney and others, 1986), and more informally has been inferred to include the trace across which trench CF-1 is located (scott and Whitney, 1987; scott, oral communication). This usage may lead to some confusion about fault names. For example, in Table 1-7 of the CDSCP, the fault trace at trenches $C F-2$ and $C F-3$ is referred to as the Windy Wash fault, whereas the fault trace originally named the Windy Wash fault by scott and Bonk (1984) is referred to as fault "N", after Swadley and others" (1984) terminology. These fault traces almost surely do connect in some manner, but extrapolating names for great distances is somewhat misleading. These faults

$$
1-7
$$


have a quite complex, anastomosing pattern, and lack the continuity implied by delineating discrete zones. However, since the name "Windy Wash" has been established for the favit at trenches CF-2 and $C F-3$, and this is familiar to most readers, its usage is not strongly discouraged. As long as it is recognized that these faults are highly interconnected, and that individual fault traces are unlikely to act independently, it is probably not all that significant as to what they are called. For clarity, discussions in this section will refer to the "Windy wash trace," the "CF-1 trace," and the "CF-2/3 trace."

Windy Wash trace: As mentioned above, the windy wash trace bounds the west side of West Ridge, forming one of the most prominent escarpments in the area. The fault forms a prominent scarp along the base of this ridge. At the southern end of the ridge, the scarp becomes diffuse and is hard to trace; exactly how this trace connects with the CF-1 trace or the down-to-the-east trace is difficult to tell without further detailed studies.

CF-1 fault trace: The CF-1 trace does not have obvious connections with the Windy Wash trace, but it is believed that a splay, perhaps not recently active, does connect the two. The CF1 trace does, however, appear to have relatively more straightforward connection with the Fatigue Wash fault (fig. 1). South of the end of the CF-1 trace mapped by swadley and others (1984), a scarp with a NNW-trend cross-cuts the main scarp. South from here, scarps along this trace are exposed intermittently to where it merges with the $C F-2 / 3$ trace, about $1 \mathrm{~km}$ south of the $C F-$ $2 / 3$ trench site.

$C F-2 / 3$ fault trace: The $C F-2 / 3$ trace, for which whitney and others (1986) obtained age-estimates suggesting Holocene faulting, has a number of interesting aspects. While it and the windy Wash trace are indirectly connected by the $C F-1$ trace, they are more directly connected by a down-to-the-east trace located north of the trench $\mathrm{CF}-2 / 3$ site (fig. 1). Whitney and others (1986) speculated that the $C F-2 / 3$ trace might have a component of strike-slip displacement, based on fault patterns exposed at the surface and in trenches. The fact that the vertical displacement flops from down-to-the-west to down-to-the-east along this fault also suggests strike-slip displacement, since such faults (i.e. "hinged" or "scissors" faults) are commonly indicative of strike-slip displacement. However, definitive evidence of strike-slip displacement has as yet been neither described nor observed.

Morphology of the $C F-2 / 3$ scarp, as defined on the large-scale low-sun-angle photographs, supports the interpretation of a small Holocene displacement superimposed on a compound late quaternary scarp (Whitney and others, 1986), contradicting the earlier work of swadley and others (1984). The recent break forms a continuous oversteepened mid-section on the scarp. For such small displacements (a few tens of centimeters), such oversteepening 
should be smoothed into the scarp profile over a period of no more than several thousands of years. The fact that this oversteepening is so pronounced lends credibility to the thermoluminescence ageestimates and interpretation of Holocene faulting.

At the trench $\mathrm{CF}-2 / 3$ site, the Iow-sun-angle photography shows there is more complexity than previously recognized. There is a probable east-facing scarp, parallel to and approximately $100 \mathrm{~m}$ to the west of the main trace and a down-to-the-west splay from the inain trace about $100 \mathrm{~m}$ north of trench $C F-2$.

To the south of the trench site, the $C F-2 / 3$ trace displaces Pliocene basalt flows of crater Flat. A discussion of this is given elsewhere in this report.

\section{Stagecoach Road Fault}

The stagecoach Road fault has been ascribed considerable significance, with extensive study proposed in the CDSCP. This fault was named and originally studied by Bob scott and John Whitney of the U.S.G.S. They observed probable indications of left-lateral deflections of drainages and interpreted the fault to be the southern part of a "break-away zone" that included the Paintbrush Canyon and Yucca Wash faults (see Bell and others, 1987). Another possibility is that an extension of this fault trends along the southeast side of Busted Butte, and that it is part of the Mine Mountain fault system (Maldonado, 1985).

The stagecoach Road fault was interpreted to have last moved between 2 and 0.7 million years aqo by Swadley and others (1984; fault I in text, fault $J$ on map). Similar to several other faults, the age of the most recent displacement was overestimated by a considerable amount in that report. This fault has one of the younger geomorphic expressions, and has almost surely been active during the Holocene.

\section{Midway Valley (Surface Facilities Area)}

The most critical area with respect to surface faulting is the surface facilities area located in Midway Valley. The CDSCP states that it is felt that the FITS (facilities important to safety) can be designed to withstand up to $5 \mathrm{~cm}$ of vertical surface displacement.

No late Quaternary surface faulting has been recognized in the FITS area proper, but the area ia bounded by the Bow Ridge,

${ }^{1}$ Among other drafting problems, the fault lettering in swadley and others (1984) is in error, with the lettering for most faults described in the text off by one from plate 1.

$$
1-9
$$


Midway Valley, and Paintbrush Canyon faults. The absence of recent faulting will be difficult to substantiate, since much of Midway Valley is covered by young surficial deposits. The CDSCP states that it is expected that trenching will expose Quaternary materials at least 100,000 years old. It is not stated what thickness of younger deposits are expected to be encountered, so it is not known how deep trenches will need to be to intersect 100,000 year old deposits, nor even if such deposits can be recognized.

Bow Ridge fault: The Bow Ridge fault, site of the trench 14 controversy, is interpreted by Swadley and others (1984) to have last moved between about 270,000 and 38,000 years ago. At this point, it appears that the younger end of this range is probably a reasonable approximation. The low-sun-angle photography does show a scarp associated with the fault at Exile Hill (site of trench 14), but it is quite subdued and not as youthful looking as others in the area (e.g. Windy Wash and Solitario Canyon faults). An interesting aspect of the Exile Hill scarp is that it trends NNE-SSW, rather than north-south parallel to the hill. It trends down the side of the hill and projects out into the alluvium. The reason and significance of this is not known, but it can be speculated that recent displacements have responded to a somewhat different stress orientation than was present when the fault was first formed.

North of Exile Hill, the fault has deflected drainages cut into QTa and Q2 deposits. South of the hill, the fault is covered by $Q 1$ deposits that show no obvious indications of surface faulting.

\section{Paintbrush Canyon Fault}

In the CDSCP, the Paintbrush Canyon fault is assumed to be the controlling seismic source for design purposes (i.e. the source capable of most likely producing ground rupture and the strongest ground motion at the site). This is a significant departure from earlier DOE considerations that inferred the Bare Mt. fault to be the controlling seismic source. If a realistic magnitude value is assigned to the Paintbrush Canyon fault, the repository facilities will probably be adequately designed, since such a near-field event would far overshadow any event more than a few kilometers away.

A potential problem with the way the CDSCP treats seismic sources is the assumption that faults behave independently. A magnitude value based solely on parameters assigned to the Paintbrush Canyon fault (such as fault length) could greatly underestimate the size of a complex event involving several faults.

The Paintbrush Canyon fault can be traced on photography, north to the southern edge of Timber Mountain caldera. Assuming a likely connection with the fault along the west side of Busted Butte and the stagecoach Road fault to the south, it can be

$$
1-10
$$


inferred to have a length of slightly over $30 \mathrm{~km}$.

U.S. Geological Survey seismicity plots for 1986 show a clustering of small earthquakes at the northern end of the Paintbrush canyon fault. Active seismicity associated with a specific fault is typically assumed to indicate a significantly higher probability of large magnitude events along those faults. Thus, the presence of active seismicity along this fault requires additional conservatism when estimating its seismic potential.

Aside from the west flank of Busted Butte, there are no obvious scarps located along the paintbrush canyon fault. However, suggestions of small displacements $(10-20 \mathrm{~cm})$ of the surficial materials have been observed in trench 16B. Although the sides of this trench are fairly well degraded, especially near the fault, the surficial material (Q2s; Swadley and others, 1984) appears to be draped over the fault, with an angle-of-repose fabric to it, suggesting it was involved in a faulting event.

\section{Complex, Distributed Faulting Events}

In general, the CDSCP calls for analysis of the effects of displacement along only a single local fault; this applies to both estimations of ground motion and rupture of waste packages. However, existing data strongly suggest the possibility of complex. faulting events at Yucca Mountain, with distributive rupture along several faults at the surface. The most compelling evidence for this likelihood is the presence of basaltic ash in fault fractures of at least four faults exposed in DOE trenches. Supportive, although more circumstantial, evidence includes the close spacing of Quaternary faults, similarities in scarp morphology, ages of offset deposits, and comparisons to historical events (in particular the 1932 Cedar Mountain earthquake, which is discussed elsewhere in this report). Failure to consider complex. distributive events could lead to significant underestimations of earthquake sizes and/or numbers of waste packages ruptured.

A possible scenario for faulting at Yucca Mountain is an extensional event, or sequence of events, accommodated by rifting and dike intrusion in the lower- to mid-crust, and by distributive rupture along several faults in the upper-crust and at the surface. The occurrence of rifting and dike intrusion is evidenced by the Pliocene and Quaternary basalts in and around crater Flat. The three discrete episodes of basaltic volcanism indicate temporal variation, with sequences of extrusive eruptions separated by substantial periods of time with no such events. Whether similar temporal gaps in suriace faulting have likewise occurred is unknown. If they have, this would strongly support a link between volcanism and surface faulting, but even if they have not, the possibility could not be excluded, since 1) extension in the lowerto mid-crust could be accommodated by means other than intrusion 
and 2) it is unlikely that every intrusive body would reach the surface, so there should be more surface faulting events than volcanic eruptions. It would be useful to evaluate the surface faulting/basaltic volcanism relationships throughout the Death Valley/Pancake Range basalt belt.

Basaltic ash has been found in fractures formed in faultfilling $\mathrm{CaCO}_{3}$ deposits. So far, this ash has been found in four fault traces (the windy wash fault at trenches CF-2/3; fault "M" at trench $C F-1$; the Solitario Canyon fault at trench 8 ; and the Bow Ridge fault at trench 14). The ash extends down these fractures to depths of at least four meters, even though the fractures are only a centimeter or less in width. It is highly unlikely that these fractures could remain open for long periods of time (i.e. more than a few years), so this indicates that ash was present on the surface, or was deposited contemporaneously, the time of faulting.

The close spacing of Quaternary faults $(<2 \mathrm{~km}$; in some cases only ten's of meters) is supportive of a complex event scenario, because this is such a short distance relative to seismogenic depths (about 10-15 km). It is improbable that parallel faults with spacing this close would extend to great depths (i.e. more than a few $\mathrm{km}^{\prime} \mathrm{s}$ ) without interconnecting. Additionally, the surface traces of most of these faults are arcuate in detail, suggesting that they do not extend to depth as perfectly planar faults, although this does not necessarily require listric fault structure. The spacing and patterns of surface faulting suggest interconnection of faults, but do not explicitly indicate linkage with the volcanism.

As a first approximation, the principal nortr-south faults have similar morphologies and offet similar age materials, indicating they have been active through the same time periods. These faults form ridges of approximately similar height, with similar surface slopes $\left(20^{\circ}-25^{\circ}\right)$ and with late Quaternary fault scarps at their bases. This strongly suggests similar fault histories. This is not to say that the same deposits are offset by different faults nor that scarp morphology is similar enough in detail to indicate synchroneity of rupture, but rather that most of these faults have been active contemporaneously with each other.

Faulting at Yucca Mountain has many similarities with the rupture area of the 1932 Cedar Mountain earthquake, which has been studied as an analogue. Discussion on the cedar Mountain studies and comparisons to Yucca $M t$. are given elsewhere in this report.

Encountering positive evidence for such distributive faulting is considered quite fortuitous. In most cases, it is unlikely that definitive indications of such events would be found. For example, no evidence has yet been found to indicate that it would be possible predict the distributive pattern of ruptures that occurred

$$
1-12
$$


during the 1932 Cedar Mountain earthquake. Conclusively establishing this relationship at Yucca Mountain, however, will require precise age-estimations of volcanism and faulting events.

Down-to-the-East Faults

Nearly all of the north-south faults in the yucca Mountain/ crater Flat area are down-to-the-west. However, a few have downto-the-east displacement. These include fault "S" (Swadley and others, 1984; text'), the windy wash fault north of trenches $C F-2$ and $C F-3$, and a fault bounding the east side of the hill in the southwest corner of the Topopah springs NW 15 ' quadrangle. These faults are roughly confined to a northwest-trending belt in the east-central part of Crater flat and have limited extents (less than $5 \mathrm{~km}$ length). This "telt" may coincide with an increase in deformation of the soutriern part of Yucca $\mathrm{Mt}$. , relative to the northern part. The exact reason for the apparent localization of these faults in a belt is unknown, but this may be a reflection of a deep-seated northwest-trending structure.

\section{structural control of Lathrop Wells cone}

Lathrop Wells cone, the late Quaternary basaltic cinder cone located just south of the repository site, has taken on added importance since data has been developed suggesting it is much younger than previous age-estimates indicated (Wells and others, 1988; Dorn, written communication). Adequate understanding of structural controls of this feature is essential, because this will have direct bearing on where future eruptions might occur. It is assumed that basalts such as this are emplaced along structures oriented perpendicular to the local extension direction. The midQuaternary basalts in crater flat are oriented in a northeasttrending alignment, presumably reflecting the trend of the dike structure along which they are located. The pliocene basalts in Crater flat were apparently emplaced along a north-south dike system, suggesting a stress rotation between 3 and 1 million years ago. Measurements of the state of sibess at Yucca Mt. have shown that the current extension direction is oriented about $\mathrm{N} 60^{\circ} \mathrm{W}$. This is similar to the orientation that would be inferred for the $1 \mathrm{~m} \cdot \mathrm{y}$. basalts. If the Lathrop Wells cone were located along a structure running parallel to the $1 \mathrm{~m} \cdot \mathrm{y}$. basalts, it would trend toward the surface facilities area in Midway valley.

\section{Crater Flat Basalts}

The older crater Flat basalts (est. $3.7 \mathrm{~m} \cdot \mathrm{y}_{.}$) are faulted by the Windy wash fault south of trenches $C F-2$ and $C F-3$ and appear to be slightly tilted toward the east. If the deformation history of

$$
1-13
$$


these basalts can ke reasonably determined, a long-term history of timing and amounts of faulting in the area can be constructed.

In the 1986 final report (Bell and others, 1987), it was stated that these Pliocene basalts intruded along, and were subsequently faulted by, the windy wash fault. The possibility that they did intrude along the fault can not yet be ruled out, but no strong evidence could be found to substantiate this. However, it was observed that the basalts along this fault are largely composed of flows up to several meters thick. These were likely derived from a dike system exposed to the west. This dike system was not looked at in detail.

Most work to date (e.g. Carr, 1984; scott and Bonk, 1984) has interpreted most of the displacement along the faults at yucca Mountain to have occurred prior to $11.5 \mathrm{~m} . \mathrm{y}$. , based primarily on the distribution of the Timber Mountain Tuff. The basalts are displaced several to tens of meters by the windy wash fault. If the distribution and exact amount of displacement of these basalts could be determined, it would be possible to infer how much of the post-11.5 m.Y. displacement occurred during late pliocene and Quaternary time. This would indicate whether 1) displacements have occurred at low, even rates over the late cenozoic, 2) renewed activity has occurred more recently, with much or all of the post$11.5 \mathrm{~m} . \mathrm{y}$. displacement occurring over the last $3.7 \mathrm{~m} \cdot \mathrm{y}$. , or 3 ) the interpretation that most displacement occurred prior to $11.5 \mathrm{~m} . \mathrm{y}$. may in part be in error. 
The basis for constraining the Quaternary tectonic history of the Yucca Mountain area revolves around the Quaternary stratigraphic scheme developed by swadley and others (1984). This scheme was developed for the purpose of mapping at $1: 62,500$ and $1: 24,000$ scale, and is therefore too generalized for site-specific purposes, but has nevertheless continued to be used for estimating faulting parameters (Department of Energy, 1988). A thorough assessment of the definitions and assigned absolute ages of these units is therefore critical to the evaluation of the Yucca Mountain site. If the estimated ages of these units is in error, the values derived for recurrence intervals, slip rates, elapsed times, and, ultimately, seismic hazard will also be in error.

The estimated ages for the most important units defined by Swadley and others (1984) (Q1a, b, c; and Q2a, b, and c) are presently determined primarily on the basis of soils (Hoover and others, 1981; Taylor, 1986), uranium-trend dating of pedogenic carbonate (Rosholt and others, 1985), and cation ratio dating of rock varnish (Harrington and Whitney, 1987). Additional age constraints were developed by whitney and others (1986) on the basis of dating faulted Av horizons by the thermoluminescence technique. Because of the critical nature of these age constraints, this study has involved a preliminary assessment of each of the following areas: soils/geomorphic relationships; cation ratio dating of rock varnish; thermoluminescence dating of Av horizons; and uranium-trend dating of pedogenic carbonate. Each of these areas was evaluated by a consultant regarded as an expert in their respective field. Their complete individual reports are attached as Appendices, and the significant results are summarized here.

\section{Rock Varnish Dating}

Cation ratio dating of rock varnish has been used by the Department of Energy to estimate ages of Quaternary surfaces for the purposes of establishing numerical age control on faulting and erosion (Harrington and Whitney, 1987). Because of numerous uncertainties and assumptions in this dating technique, Dr. Ronald I. Dorn was contracted as a consultant to evaluate the existing rock varnish data base at Yucca Mountain. Dr. Dorn, who is widely regarded as one of the foremost authorities on the origin and applicability of dating rock varnish, has assessed the DOE data base from several aspects:

* The theoretical limitations of the cation ratio dating method

* An evaluation of the rock varnish work of the DOE and its subcontractors, Los Alamos National Laboratories and U.S. Geological survey 
* The independent determination of rock varnish ages of alluvial surfaces in crater flat based on cation ratio dating and AMS radiocarbon dating

Dr. Dorn's detailed discussion of these three separate aspects is presented in Appendix A, and the following is a summary of the most significant elements of his study.

\section{Limitations of the Cation Ratio Dating Method}

Rock varnish is a thin coating of mostly clay minerals and manganese and iron oxides that forms on rocks most commonly in arid and semi-arid environments (Dorn and oberlander, 1982). Cation ratio (CR) dating of rock varnish is based on observations of the progressive lowering of the ratio of $(\mathrm{K}+\mathrm{Ca}) / \mathrm{Ti}$ in the varnishes over time, where the rock varnish has formed on geomorphic surfaces of established relative or numerical age. The usefulness of the CR dating technique is predicated on the ability to calibrate the varnish CR's with established radiometric ages in a cation-leaching curve (CLC) (Dorn, 1983; Dorn and others, 1987a, b). General assumptions of the $C R$ dating method include:

* The initial ratio (airborne fallout that is incorpcrated into varnish) is assumed to have been similar for the period of time under examination at all compared sites.

* Rock varnish is assumed to serve as a cation-exchange complex where rates of $(\mathrm{K}+\mathrm{Ca}) / \mathrm{T} i$ change have been similar for compared samples.

* Environmental factors are assumed to affect varnish CR's at comparable sites in a similar fashion.

In addition to these basic assumptions, the inherent limitations of the $C R$ dating technique include:

* Any CR age-estimate is based on a CLC and is therefore tied to the calibration points

* The statistics of CLC curve construction are not well worked out

* A CR calibrated-age on rock varnish can only be considered a minimum-limiting age-estimate for the stabilization of the underlying rock surface

* The semi-log nature of a varnish CLC means that there is a low-level of dating precision for older samples 
Evaluation of Cation Ratio Dating for Use on the Yucca Mountain Site

The $C R$ dating method employed by DOE is the SEM-EDAX technique of Harrington and Whitney (1987). This method was initially tested by Dorn (1983), but was found to be inferior to other approaches. The following are concerns unique to the SEM method of CR dating:

* SEM-EDAX is biased towards the surface layer of varnish

* SEM-EDAX cannot be reproduced by other analytical methods

* Barium overlaps with titanium in the EDAX analysis, making discrimination of titanium uncertain

* SEM-EDAX is not an independently testable method of varnish CR determination

As the $C R$ dating pertains directly to Yucca Mountain, Dr. Dorn has critically reviewed the methods and results of Harrington and Whitrey (1987) and makes the following observations:

* No attempt appears to have been made to identify an initial ratio for the yucca Mountain CLC

* No attempt appears to have been made to evaluate most of the environmental concerns that can affect a varnish CR

* Welded tuff in crater Flat may suffer from problems of abundant microcolonial fungi

* No mention is made of analysis of varnish cross sections to evaluate paleo-erosional episodes

* No mention is made of evaluating the regularity of the varnish-rock boundary

* No mention is made of a procedure to collect observations about surface biological phenomena such as microcolonial fungi or filamentous fungi

* Discarding the highest $C R$ appears to be an arbitrary procedure

* Of significance is the fact that it is possible that the chemical criteria used by Harrington and Whitney (1987) to distinguish rock from varnish may be in part flawed

\section{cation-leaching curve calibration}

The cation-leaching curve (CLC) constructed by Harrington and Whitney (fig. 3A) is of major importance because it is this curve from which numerical age estimates are made for samples collected 
Irom undated surfaces. Calibration of this curve is called into question by Dr. Dorn for several different reasons:

* The number of calibration points is limited

* Uranium-trend analysis is very important to the Xucca Mountain curve of Harrington and whitney (1987)

* The Yucca Mountain CLC is anomalous in its high initial ratio and its steep slope, when compared to other CLC's from other arid areas

* The Yucca Mountain curve constructed by the SEM-EDAX method differs substantially from the one constructed by scrapingPIXE (Dorn's method)

The scraping-PIXE method of CR dating was employed by Dr. Dorn as part of this study to assess the accuracy of the DOE data. Dr. Dorn believes that the scraping-PIXE method is a far superior method for dating rock varnish primarily because it addresses most of the inadequacies described above. The PIXE method does provide a testable means of assessing contamination, is more precise than SEM-EDAX, and is less destructive. The scraping procedure is also tied closely to the sample preparation necessary for the AMS radiocarbon analysis.

The independent rock varnish dating conducted by Dr. Dorn was composed of two separate elements: AMS radiocarbon dating of the varnish; and cation ratio dating of the varnish. Seven sample locations were selected for radiocarbon analysis and $C R$ calibration, and six additional sites were selected for CR dating alone. Sample locations are shown on Figure 4 , and results are tabulated in Tables 1 and 2 . Almost all sites are keyed to pedon sites described by Dr. Peterson in separately attached report on the soil-geomorphology relationships (Appendix $B$ ).

Organic matter is incorporated in rock varnish in very small quantities. These minute amounts are sufficient for radiocarbon analysis on an accelerator mass spectrometer (AMS), the purpose being to approximate the time of exposure of the rock underlying the varnish, as was originally demonstrated by Dorn and DeNiro (1985). The scraping-PIXE method is well-suited for this method because the varnish is scraped off the individual clasts and processed concurrently for both an AMS radiocarbon age and a CR ratio. Given both values, a calibrated cation-leaching curve can be constructed from which other ages may be interpolated using cation ratios alone.

The AMS-calibrated cation-leaching curve determined by the scraping-PIXE method of analysis for the crater Flat samples is shown in figure $3 \mathrm{~B}$, along with the curve of Harrington and Whitney (1987). Both curves use K-Ar dated calibration points around $1 \mathrm{~m} . Y$, 
so the older end-points are the same. At the younger ends of the curves, however, there is a significant divergence. Although both curves show a 2 sigma error curve, the SEM-EDAX curve of Harrington and Whitney (1987) has a much higher $C R$ ratio for a given age in the <l m.y. range. This is particularly important to the Quaternary stratigraphic controls at yucca Mountain because the SEM-EDAX curve is calibrated at the younger end by the use of the uranium-trend ages (Rosholt and others, 1985). As Dr. Dorn observes, the uraniumtrend ages may be skewing the DOE curve to the older end; this direction of bias would result in the overorediction of ages of stratigraphy and faulting events and the underestimation of the seismic hazard at the Yucca Mountain site.

Additional work needs to be done to more completely evaluate these significant differences in $C R$ ages determined by the two different methods. A CR ratio of 6.0 taken of the DOE curve for a 40,000 year old sample, for example, yields an age of about 10,000 years on the scraping-PIXE curve. Such age conflicts are significant, and can lead to substantially different stratigraphic and hazard interpretations.

\section{Soil-Geomorphic studies}

A reconnaissance study of the geomorphic surfaces and soils in Crater Flat was conducted by Dr. Frederick F. Peterson; his complete report is attached in Appendix B, and the following is a sumnary of the substantive findings. This study was initiated for several reasons: first, there were earlier findings (Bell, 1986) suggesting that some Quaternary soil and stratigraphic relationships described in Crater Flat by Swadley and others (1984) appeared anomalous: second, some key numerical dating methods developed by DOE (uranium-trend, rock varnish, and thermoluminescence dating) were highly dependent upon soil and geomorphic relationships; and third, the independent chronostratigraphic studies being conducted by this trask required that key stratigraphic locations be tied to pedon descriptions and geomorphic surfaces.

Dr. Peterson describes 18 representative pedons from seiected geomorphic surfaces in Crater Flat. Based on the relative degree of soil development in each of these profiles, on an analysis of the aerial photography, and on the results of AMS radiocarbon and cation ratio dating of rock varnish by Ronald Dorn (Appendix A), five distinctive geomorphic surfaces are defined here:

* Crater flat surface (modern to mid-Holocene)

* Iittle Cones surface (early Holocene to late Pleistocene)

* Black cone surface (late to mid-pleistocene) 
* Yucca surface (mid-Pleistocene)

* Solitario surface (mid-to early pleistocene)

The crater Flat surface is characterized by active and recently active washes, inset fans, and far skirts that show no significant formation of genetic soil horizons; the soils are Typic Torriorthents. The surface can be differentiated into several subunits based on degree of preservation and "muting" of the barand-swale microtopography; this subdivision is generally consistent with that of Swadley and others (1984). The crater Flat surface is less than $7.3 \mathrm{Ka}$ old based on an age derived from the next older unit.

The Little cones surface comprises one large fan-skirt remnant surrounding Little cones in the southwestern crater flat area mapped both as $Q 1$ and $Q 2$ by Swadley and others (1984). The surface can be distinguished from the older Black Cone surtace on the basis of inset topographic relationships and soils; the soil of the Little cone surface is a Typic camborthid and is morphologically distinct from both the Black cone surface and the younger crater Flat surface. Rock varnish ages of 7,310 and 11,200 years were obtained by AMS radiocarbon analysis of two sites in this unit. Much of the Little cone surface is therefore substantially younger than the $Q 2$ age assigned to most of the surface by swadley and others (1984).

The Black Cone surface comprises small to large fan-piedmont remnants in crater flat that in aggregate are about as extensive as the crater Flat surface. Much of what Swadley and others (1984) mapped as $Q 2$ deposits is part of this geomorphic unit. The unit can be subdivided into early and late Black cone surfaces based on soils and AMS radiocarbon and $C R$ ages derived from the rock varnish. The subdivisions are difficult to distinguish surficially because there are no inset or overplaced relationships. Pedons on the early Black Cone surfaces have Typic and Haplic Durargids while those on the late Black cone surfaces generally have Typic Calciorthids and locally Haplic Durargids. AMS radiocarbon ages of $28,300,33,400,29,700,19,000$, and 31,800 years were obtained from the younger Black Cone surfaces. CR ages of 128,000 and 137,000 years were obtained from the older Black Cone surfaces. Depending on the location within crater Flat, the Black Cone surface was mapped as Q2 and QTa by Swadley and others (1984).

The Yucca surface comprises three areas of fairly extensive, deeply dissected fan-piedmont remnants, and is characterized on the aerial photography by transverse bands of darkly varnished desert pavement alternating with light-colored biocoppice areas. Soils on the Yucca surface typically have relatively thick $(40-60 \mathrm{~cm}) \mathrm{Bt}$ horizons and $30-60 \mathrm{~cm}$ of underlying opalized duripan. Cation ratio ages of 380,000 and 360,000 years were obtained from two different pedon localities on this surface.

$$
1-20
$$


The solitario surface is a singular remnant-- a ballena-located just to the southwest of the mouth of solitario canyon. spur remnants up Solitario Canton and elsewhere in valleys of yucca Mountain suggest that the surface was once more extensive. Since the surface is a ballena, the remnant is deeply dissected and there is no actual, solitario-age soil found. The soils present are a complex of more extensive Typic Durorthids with small spots of Typic Durargids. A CR age of 660,000 years was obtained from a pedon site on this surface.

Based on the detailed soils and geomorphic assessment and an incorporation of the rock varnish age dates, Dr. Peterson reaches the following preliminary conclusions:

* There are five major geomorphic surfaces in the crater Flat area: the crater Flat, Little cones, Black cone, Yucca and Solitario surfaces. Each has distinctive differences in soils.

* Swadley and Hoover's (1983) and Swadley and others (1984) mapping of "surficial deposits" in crater Flat failed to distinguish three clearly separate geomorphic surfaces in their QTa unit (the Black Cone, Yucca and Solitario surfaces). Their $Q 2$ unit contains two separable surfaces, the Little Cones and Black Cone surfaces.

* Swadley and others' (1984) "surficial deposits" concept and mapping are fatally flawed and should be abandoned. Geomorphic surfaces defined in terms of soils and stratigraphic relations should instead be used.

Thermoluminescence studies

Preliminary thermoluminescence (TL) studies were conducted on a subcontract basis by Dr. Steven L. Forman of the center for Geochronological Research at the University of Colorado, Boulder, and his consultant's report is appended as Appendix C.The aim of Dr. Forman's evaluation was two-fold: 1) to critically review past applications of the TL technique to paleoearthquakes near yucca Mountain, and 2) to recommend future directions in TL dating research with respect assessing natural hazards relevant to Yucca Mountain.

Approximately sixteen TL dates have been produced as part of the DOE work on eolian AV horizon material from Trenches $C F-2$ and CF-3 excavated across the windy Wash fault in crater Flat. These deposits are cut by the most recent faulting, and these TI dates, which have not as yet been individually published, provide maximum estimates on the latest faulting at about $3-6.5 \mathrm{ka}$ ago (Whitney and others, 1986). Dr. Forman's assessment is based on a review of the unpublished data, provided as a courtesy by John whitney of the U.S. Geological survey, and on a review of the field sample sites.

$$
1-21 \text {. }
$$


His preliminary conclusions are:

* The tectonic significance of the TL age estimates relies on the (Whitney and others') assumptions that an Av horizon is cumulative and has not been homogenized by pedoturbation or bioturbation. Although the sample sites appear to have avoided such irregular locations, it is difficult to unequivocally ascertain whether the sampled Av horizons are homogenized or actually record a vertical stratigraphy.

* Equivalent doses determined by the regeneration, total bleach, and partial bleach methods are in agreement at one standard deviation. This indicates that these sediments were well bleached prio: to deposition and are amenable to TL dating.

* Dose rate determinations were made on the basis of radiation from the AV horizon alone, and the gamma component may thus not be correctly represented, with an unknown resultant effect. In addition, the dose rate may be over-estimated by 5-15\% because all samples were shallow, resulting in a corresponding over-estimate in age.

* The cumulative total additional error in determining equivalent doses and dose rates is probably between 10 and 40\%. A more realistic age span for the sampled Av horizons may be 2 to $8 \mathrm{ka}$.

* Future application of the TL technique to deposits in the Yucca Mountain area should include detailed pedologic and sedimentologic studies of the Av horizons; field measurement of the dose rate; and applying multiple dating and geochronologic studies in combination with the TL method.

\section{Uranium-series studies}

constraints on ages of Quaternary stratigraphic units and faulting events at Yucca Mountain have in large part been derived by DOE from dating of secondary (pedogenic) carbonate using the uranium-trend and uranium-series methods (Rosholt and others, 1985; Swadley and others, 1984). The uranium-trend dates have also been used to calibrate the cation-ratio leaching curve for rock varnish ages developed by Harrington and Whitney (1987). To date, these uranium dates constitute the bulk of the Quaternary radiometric controls critical to assessing the fault-related earthquake potential at Yucca Mountain. As part of this review, Dr. Teh-Lung Ku of the University of Southern California was contracted as an independent consultant to review and critique the existing data base related to the use of uranium and thorium series isotopes in radiometric dating in the Yucca Mountain area: his report is appended as Appendix $D$. 
Dr. Ku's review consists of several parts: a summary of the uranium-series and uranium-trend methods; the merits and demerits of the two approaches; the current data base in the Yucca Mountain area; and recommendations for future work. Dr. Ku's significant findings include the following:

* The conventional U-series method is based on the geochemical fact that uranium is much more soluble than thorium in natural solutions and thus readily precipitates out with carbonate and silica in descending soil waters. This relationship can be successfully used to date the age of carbonate and silica deposits as long as the system has remained geochemically closed for the duration of the depositional history; this closed system requirement is a critical assumption in the technique and must be carefully verified.

* An "unconventional" method known as the uranium-trend method has been devised to date deposits by modelling the behavior and distribution of isotopes in a sample which is assumed to act as an open system, thereby eliminating the need to verify closed system conditions. The essence of this method is a model that describes the migration of uranium in a solid-fluid matrix through time.

* The primary advantage in using the uranium-series method is that derived data are much more straightforward and easier to be substantiated, if the closed system conditions are fulfilled. The main disadvantage is that there is no wellestablished criteria for sample screening to ensure closed system conditions.

* The main advantages of the uranium-trend method are that it is potentially applicable to a wide variety of materials, including soil, alluvial, lacustrine, eolian, and glacial deposits, and it has a relatively large age range (10-800 ka). The technique is experimental, however, and some of the possible problems include: unknown variables influencing the uranium flux, a key component of the empirical model; the calibration of the uranium flux relationships is not well constrained; and there is a sensitivity problem in how well one is able to resolve or determine ages from the analytical data.

* Uranium-trend ages have been reported for 40 suites of samples from the Nevada Test site area, with each suite consisting of 4-12 samples from a stratigraphic unit or section. The derived age data can be split into three categories based on the goodness of the data and the relative errors possible. Category A dates (including several from the Yucca Mountain and Crater flat areas) probably have errors in the range of 10-20\%; Category $B$ dates have age uncertainties in the range of about 508; and category $C$ dates have age estimations with

$$
1 \cdot 23
$$


large uncertainties of $>100 \%$.

* Future work with the U-series isotopes in the Yucca Mountain area should include multiple geochronological assessments to establish internal and external consistency. Internal checks would include reproducibility of results obtained on a single sample and dating a group of samples from the same stratigraphic position. External checks would include dating deposits by alternative dating techniques, such as rock varnish dating. Because the U-trend method can only be presently regarded as experimental emphas is should be placed on the conventional U-series dating technique for future work in the Yucca Mountain area.

* Six samples of pedogenic carbonate and opal were collected from Crater Flat trenches $C F-1$ and $C F-3$ across the windy wash fault (fig. 4). These samples will be analyzed by the conventional $U$-series method as a means of independently verifying the previously derived U-trend ages obtained from these same trench locations. 
The 1932 Cedar Mountain earthquake was a large earthquake $\left(M_{s}=7.2\right)$ which had a highly distributed surface rupture pattern (fig. 5). Numerous surface faults ruptured during this event, making it difficult or impossible to have specifically forecast the earthquake before it occurred on the basis of paleoseismic rupture patterns, Doser (in review, 1987) suggests the 1932 earthquake was a multiple event consisting of a few moderate earthquakes occurring in sequence, based on modeling regional and teleseismic body waves. This could in large part explain why surface faulting was so widespread and diffuse.

The longest fault in the area of surface ruptures is the Stewart - Monte cristo Valleys fault zone (SMCFZ). This zone appears to be between 25 and $45 \mathrm{~km}$ long. The wide range in this estimate is due to the question of whether an 8-10 km section having no identified fault zone, but significant tectonic folding, interrupts the stewart - Monte cristo valleys fault zone or whether it is in fact a continuous fault at depth.

Studies of the Cedar Mountain earthquake and its similarities and implications to the Yucca Mountain site consisted of: 1) establishing the similarities between the character of the 1932 event and the character of the faults in the Yucca Mountain area; 2) defining the Quaternary stratigraphy in Monte Cristo Valley; 3 ) expanding the trenching program in Monte cristo Valley, and 4) flying low-sun-angle photography of stewart and Gabbs valleys.

The Use of the Relative Comparison Approach at Yucca Mountain

One of the many approaches or techniques used in assessing the seismic hazard of a critical facility is the "relative comparison approach" (depolo and slemmons, in review). This approach involves the comparison of an area or a potential source with other sources or areas which have either experienced historical earthquakes or have been studies in enough detail to definitively establish a seismotectonic history.

The Basin and Range province is very complicated seismotectonically, and is in general poorly understood. A small number of faults have been studied in detail in comparison to the number of potential "surface faults" and other sources. Further, several historical earthquakes occurring within the Basin and Range province have behaved in manners which are generally not predictable or typically considered in a standard seismotectonic analysis. These include events which have ruptured beyond their mapped fault or speculated segment lengths, events (e.g. 1932) which have had widely distributed surface rupture patterns, and so called "floating" or "random" earthquakes. Many other observations, such as grouping and clustering of earthquake events

$$
1-25
$$


in the Basin and Range province (Wallace, 1987) are not presently incorporated into seismotectonic analyses.

The relative comparison approach is particularly instructive for seismotectonic analyses in the Basin and Range province, especially for critical structures, such as the high-level waste facilities. A number of historical earthquakes can be considered which would have similarities with the Yucca Mountain site. One of the largest regional historical earthquakes which has many reasonable similarities, however, is the 1932 Cedar Mountain earthquake.

Similarities Between Yucca Mountain and the 1932 Cedar Mountain Earthquake Area

When using a relative comparison approach it is important to document the similarities between the facility site and the comparative event or source. In the case of comparing the Yucca Mountain site with the 1932 earthquake area, the similarities are significant and substantiate the use of the 1932 earthquake in the Yucca Mountain seismotectonic analysis.

Some of the principle similarities which are important in this analysis are similarities in tectonic setting, distributed fault patterns, and fault structures exposed in trenches. similarities between both sites in tectonic setting include:

* existence within the Basin and Range Province and the Walker Lane belt,

* northwest-oriented least principle stress directions,

* activity of both north-south and northeast-trending faults,

* detachment structures have been proposed locally,

* conjugate structures exist locally,

* focal mechanisms are dominated by strike-slip displacement and include north-south nodal planes,

* adjacent or local caldera structures exist or have been proposed.

Distributed fault patterns and ruptures extending beyond mapped fault lengths are aspects of the 1932 earthquake which are not accounted for in standard seismotectonic analyses, but need to be considered in the seismotectonic input for the Yucca Mountain facilities. Short faults which are not easily attributed to a seismogenic fault system or do not appear kinematically inked have the potential to fail in sequence or be expressions of deeper, 
larger systems, which have larger earthquake potentials.

The similarities between fault structures exposed in trenches at both the Yucca Mountain and Cedar Mountain areas are important for both substantiating active strike-slip displacement for both region and documenting the need of a strike-slip component to be considered for displacements of the Yucca Mountain faults. Similarities in these trenches which have been noted include vertical faults and flower structures.

\section{Quaternary stratigraphy of the Cedar Mountain Area}

Quaternary stratigraphic studies were conducted in the Monte cristo Valley portion of the 1932 Cedar Mountain fault zone (fig. $6)$ in order to establish constraints on the recency and frequency of large-magnitude earthquakes. The timing of events on this fault zone is important for defining the spatial and temporal relationships of active faulting within the Walker Lane.

Several aspects of the faulting within this segment of the Walker Lane can reasonably be extended to the segment within which Yucca Mountain lies (see previous discussion). Comparisons of recurrence intervals, slips rates, elapsed time, etc., allow best estimates to be established for likely faulting scenarios and probabilities at Yucca Mountain.

As discussed in Bell and others (1987), the stratigraphic scheme used in the early stages of this study was that developed by Molinari (1984). The stratigraphy discussed here is a modified version of that used by Molinari (1984) based on observed differences in soils, geomorphic character, and absolute age. These differences result from the development of detailed chronostratigraphic controls derived from trenching and large-scale surficial mapping. Further refinements of this scheme are possible as the study continues.

\section{QfI Deposits}

The oldest of the differentiated Quaternary units, QfI deposits, lie unconformably above the Tertiary Esmeralda Formation. The deposits are characterized by well dissected alluvial-fan surfaces flanking the volcanic bedrock of the Pilot Mountains and occurring as uplifted remnants on the east (upthrown) side of the Monte cristo valley fault zone (fig. 6). A soil pit excavated on the top of one uplifted remnant exposed a $45 \mathrm{~cm}$ thick Bkm horizon containing stage III carbonate. To the southwest near Trench 1 (fig. 6), wash cuts expose Qf1 deposits beneath Qf 2 deposits, and suggest that $Q f l$ deposits are also characterized by stage IV carbonate horizons $1 \mathrm{~m}$ or more in thickness.

In Trenches $3 a$ and $3 b$ (fig. 7), the oldest deposits are

$$
1-27
$$


inferred to be $Q f 1$ based on stratigraphic position. The deposits in both trenches contain a cearse volcanic ash layer interbedded within the gravelly alluvial-fan material. An electron microprobe analysis of the ash was done by Andrei Sarna-Wojcicki of the U. $S$. Geological survey who concluded (1987, written communication) that the ash could be one of three possible Long Valley-Mono Crater tephras. The closest geochemical match is with the Glass Mountain "G" bed, but nearly identical matches are also possible with the Bishop ash and the Glass Mountain "D" ash bed; further paleomagnetic work would be necessary to determine the exact identity. The age of the ash, however, can be bracketed between $0.73 \mathrm{Ma}$ (the age of the Bishop ash) and $1.0 \mathrm{Ma}$ (the age of the Glass Mountain "G" ash).

\section{Qf2 Deposits}

Alluvial-fan deposits of late Pleistocene age ( $Q f 2$ ) occur as scattered remnants near the bedrock hills and as extensive uplifted remnarits on the east side of the main fault zone (fig. 6). They unconformably overlie $Q f 1$ deposits and typically have broad interfluvial surfaces with well developed desert pavement and varnish. Multiple fan levels are present, particularly east of the fault zone, but are not differentiated here. Exposures of these deposits in four soil pits and in Trenches 1,3 , and 4 indicate that Qf2 deposits are characterized by Bt horizons about $10 \mathrm{~cm}$ thick underlain by Bk horizons about $45 \mathrm{~cm}$ thick containing stage II-III carbonate. On nearly all of the uplifted remnants, the surface of the Qf2 deposits has been eroded and younger BW horizons about $10 \mathrm{~cm}$ thick are developed.

About $1 \mathrm{~km}$ west of Trench 3, a $1-2 \mathrm{~cm}$ thick tephra is exposed in $Q f 2$ deposits in a wash bank (fig. 6). This ash was chemically analyzed by Andrei Sarna-Wojcicki who believes that it is an unnamed tephra also encountered in a drillhole at walker Lake (written communication, 1988). The age of this ash is estimated by Sarna-Wojcicki to be about 135-145 $\mathrm{ka}$ based on the depth of burial at walker Lake and extrapolation of sedimentation rates.

\section{Qf3 Deposits}

Extensive areas of the piedmont west of the main fault zone in Monte cristo Valley are underlain by the youngest alluvial-fan deposits, Qf3 (fig. 6). The unit is characterized by broad, slightly dissected surfaces exhibiting incipient desert pavement and varnish. Soils have Bw horizons about 10-15 cm thick underlain by Bk horizons about $45-50 \mathrm{~cm}$ thick containing stage I carbonate.

No absolute stratigraphic controls have been established on these deposits yet, but the weak relative degree of soil development suggests that the unit is latest pleistocere to Holocene in age. Deposits with similar soils to the north in Dixie 
Valley contain Mazama and Turupah Flat tephras, 6900 and 1600 yrs, respectively (Bell and Katzer, 1987).

These deposits are important for understanding and constraining the Quaternary tectonics of the Monte cristo valley fault zone because this study indicates that $Q f 3$ deposits are offset only by 1932 faulting; no substantive evidence of pre-1932 displacement of this unit has been observed.

\section{Trenching studies in Monte cristo valley}

Several trenching activities were conducted during the contract period along the southern end of the 1932 surface ruptures in Monte cristo Valley (fig. 6). These include a three dimensional trenching study at trench 3 and the excavation of four additional trenches.

Three Dimensional study at Trench 3

The three dimensional trenching study was conducted to establish the nature of the fault zone exposed in trench $3 a$ and to explore the use of small scale, hand-excavated 3-D trenching to document strike-slip displacement along a fault zone. Original exposures of the fault zone in tranch 3 showed a warped surface offset formed by the 1932 earthquak, several suspicious fractures with an indeterminant amount of offset in a zone for a couple meters to the west of the main fault, and flower structures (Bell and others, 1987; depolo and others, 1987). Since the sense of displacement was dominantly strike-silp at this site, it was anticipated that a three dimensional view of the flower structures might document Riedel and conjugate Riedel fractures, and the rotation of the fractures as they splay away from the main fault, from which a lateral component of displacement could be inferred. This type of study is viewed as potentially useful for some of the faults in the Yucca Mountain area whose overall geomorphic characteristics suggest normal faulting, even though the present stress regime and flower structures present in trench exposures suggest a significant component of strike-slip displacement is presently operative.

The warped surface formed in 1932 (warped over a small apparent reverse fault) died out and gave way as the face was cut back to a more discrete, apparent normal, brittle offset. Warped offsets typically occur along the 1932 surface ruptures at small en echelon steps in the scarp and where mole tracks occur. There is a small change in the strike (about $5^{\circ}$ ) of the scarp on either side of the trench $3 \mathrm{a}$, and the initial exposure may have been close to the bend or a small (on the order of centimeters) step in the fault. Subsequent cut-back exposures showed small, abrupt offsets in the surficial materials from the 1932 event (fig. 8). 
There are basically two stratigraphic sequences exposed in trench 3a, separated by the main fault. The eastern stratigraphy consists of mid- to late pleistocene alluvial fan gravels and cobbles overlying highly disturbed Miocene lacustrine sediments. The stratigraphic sequence to the west of the fault consists of younger ponded mud units, with minor gravel and cobbles, vich interfinger westward with gravels. In the vicinity of the fault zone are tectonically mixed zones which are often bounded by faults and are pervasively sheared.

The mass of carbonate which was discovered in the original exposure of trench 3 was examined further during the 3D trenching project. It is believed that this carbonate mass formed within the fault zone and has experienced at least a few displacement events, similar to the Yucca Mountain faults. Portions of the carbonate mass were deposited in northeast-trending fractures within the mass. This suggests that at least in part, this mass is forming through fracturing during fault events and subsequent deposition. Slickensides observed along the side of the carbonate mass are considered particularly valuable for neotectonic studies. Many exposures of slickensides are difficult to use for confidently deducing slip directions of the most recent events (e.g. bedrock slickensides). The fault zone carbonate, however, is in a state of dynamic equilibrium and slickensides tend to be degraded, or deposited on, relatively rapidly.

The slickensides measured in trench $3 a$ on carbonate are $6-10^{\circ}$ to the north. These values are consistent with lateral:vertical offset ratios determined from trench and surface exposures.

Secondary fractures and faults were seen to extend to the surface only in a few cases. With successive cutbacks these features would transgress upwards and downwards through different stratigraphic units. This underscores the importance of getting a three dimensional view of a fault zone, with significant spatial dimensions, to properly characterize structures seen in trenches. Fractures mapped in this study were consistent with a wrench fault system, with most fractures being northeast-trending (potential Riedel fractures). Northwest-trending fractures are the secondmost common, and fractures parallel to the fault zone were generally not observed.

At Yucca Mountain, bulldozer trenches have been dug across faults, wiping out wide swaths of the fault zone. For faults which are critical to facilities or where the sense of displacement is in question, valuable information may have bee lost. In the future, for important faults, these swaths may want to be removed more carefully, and mapped to better characterize the faults, and the nature of their present seismotectonic senses of displacement. The floor of the presently existing trenches across these faults could be mapped in this same endeavor. 


\section{Expansion of Trench 3}

Trench 3 was additionally expanded by backhoe into an "H" shape with two arms crossing the fault zone (figs. 7, 9, 10, and deposits. The two new get a three dimensional view of the original trench 3 was renamed thes were named $3 b$ and $3 c$ and the 3 revealed greater continuity trench 3 a. The expansion of trench than was expected, as well of the ponded units west of the fault gravels.

\section{Interpretations of Trench 3}

In trenches $3 a$ and $3 b$ (figs. 9 and 10), older alluvial deposits ( $Q f 1$ and $Q f 2$ ) are exposed on the east side of the fault mentioned previously. the east. Within II - III carbonate soil her part of these deposits occurs a stage

QfI deposits are not exposed in the west (downthrown) side of these trenches, and thus must be vertically downfaulted at least $3 \mathrm{~m}$, the bottom of the exposure on the west side of the fault in trench 3. Since ofl deposits are thought to be $0.73 \mathrm{~m}$. Ma old (the estimated age of the ash), minimum vertical slip-rates of 0.003 to $0.004 \mathrm{~mm} / \mathrm{yr}$ can be calculated. Considering a vertical to horizontal ratio of $1: 7$ suggested by slickensides and offset features, minimum horizontal slip-rates of 0.02 to $0.03 \mathrm{~mm} / \mathrm{yr}$ are estimated over the last 0.73 to I Ma time period.

Based on stratigraphic position and pedogenic similarities, Qf 2 deposits can be correlated across the fault zone to the west side in trench $3 b$, and correlated to $Q f 2$ deposits exposed elsewhere which contain an unnamed tephra (estimated age $135 \mathrm{ka}$, see discussion of Qf2 deposits). In trenches $3 \mathrm{~b}$ and in soil pits on opposite sides of the fault to the soldth, it appears that this carbonate horizon is displaced downward to the west on the order this horizon 1 meter. Considering the correlated age and offset of considering therticad slip-rate of $0.007 \mathrm{~mm} / \mathrm{yr}$ is estimated and slip rate of $0.05 \mathrm{~mm} / \mathrm{yr}^{\mathrm{s}}$ is estimated ratio, a minimum horizontal

Trenches 5 through 8

Four additional trenches were dug along the 1932 fault trace to gain information on recurrence intervals. Trench 5 (fig. 6) was placed across young alluvium (Qf3) which only showed surficial evidence of the 1932 event. The trench exposed a well developed fault zone with mismatched alluvial deposits on either side of the 
fault. Deposits on the western side of the main fault were relatively finer grained than the east side reflecting some ponding of sediments. An antithetic fault forming a graben structure also exists at this site to the west of the main fault. Trench 5 has not yet been logged.

Trench 6 ( $f i g .6$ ) was dug across the fault scarp where vertical displacement of $1 / 2 \mathrm{~m}$ occurred in 1932 , and a colluvial wedge is actively forming. Trench 6 was dug in anticipation of finding buried colluvial wedges from past events. Unfortunately, no obvious colluvial wedges were found in reconnaissance of the trench. Again, the deposits across a well developed fault zone were mismatched. Trench 6 has not been logged yet.

Trench 7 (fig. 6) was located across a ponded area behind the 1932 fault scarp in very young $Q f 3$ deposits. It was hoped to break through these young deposits, and potentially see the last ponding event. On the east side of the trench, the Qf3 deposits were found to be overlying Miocene sediments at a depth of about $1.5 \mathrm{~m}$. On the west side of the trench, the deposits were not indurated enough to support a deep trench, and the trench was only dug $1.5 \mathrm{~m}$ deep. The Qf3 deposits were the lowest unit encountered. A radiocarbon sample from the north wall, $1 \mathrm{~m}$ below the surface, had a $c^{14}$ age of $235+-65$ yrs. Trench logs for the north and south walls of Trench 7 are presented in Figures 12 and 13 .

Trench 8 (fig. 6) is located across the southwestern side of the large pressure ridge in Monte cristo Valley. This trench crosses a fault zone, with a reverse sense of displacement, which ruptured discontinuously in 1932. The trench is located in mostly Miocene sandstones and siltstones which are dipping vertically or steeply northward. Small faults cross-cut these beds, as well as occurxing parallel to or along bedding planes. Trench 8 has not yet been logged. The reverse fault characteristics confirm speculations made earlier (Bell and others, 1987) that this small ridge is a compressional feature (pressure ridge) representing compression between a left-step in the main strike-slip trace of the SMCFZ.

\section{Stewart and Gabbs Valleys studies}

Studies of the 1932 Cedar Mountain earthquake were expanded into stewart Valley to examine the northern rupture zones and epicentral area. Stewart Valley is bounded on the west and partly of the east sides by faults; The SMCFZ on the west side and a range front fault along the west side of Cedar Mountain (Molirari, 1984a and $b)$. Within stewart Valley are Miocene, lacustrine and fluvial sediments which range in age from 11-15 Ma (Molinari, 1984a). Several episodes of downcutting and planation have occurred during the Quaternary forming pediment remnants (Molinari, 1984b). 
Within stewart slley are many northwest trending folds which trend subparallel to the large right-lateral faults in the Gabbs Valley Range (Molinari, $1984 a$ and $b$ ). Studies by Ekren and Byers (1984) and Keller and others (1987) have documented detachment faulting, related to strike-slip faulting, in the Gabbs Valley Range, to northwest of stewart valley. Some of the folds mapped by Molinari and the faults in hills between stewart and Gabbs Valleys may also be related to detachment faulting, accompanying strike-slip faulting.

In Gabbs Valley and the Monte cristo Mountains, ash-flow fissures and a possible caldera complex have been identified by Ekren and Byers (1976). A inferred caldera boundary is shown by Ekren and Byers (1978), just to the north of the northernmost 1932 surface rupture.

Future studies of stewart and Gabbs Valleys are important to determine if detachment processes may have been involved in the parts of the 1932 earthquake sequence and to determine if the prior event in the paleoseismic record was similar in extent to the 1932 rupture. The northern part of the 1932 ruptures, in Gabbs Valley, is where the epicenter is placed (Doser, in review). Low-sun-angle aerial photography has been obtained for Gabbs and stewart Valleys as well as high-altitude U-2 photography. These photographs will be used to put together a tectonic map of these valieys and identify potential sites for determining the event prior to 1932 through trenching studies. Paleoseismic histories developed from these studies will be compared to the history of the stewart and Monte Cristo Valley Fault zone.

\section{Discussion of the 1932 Event}

The distributed rupture pattern which occurred in 1932 may be explained by: 1) wrench tectonics, 2) multiple faults rupturing, and/or 3) shallow detachment faulting. Wrench tectonics have been previously discussed and are believed to be a good model for the Monte cristo Valley ruptures (Bell and others, 1987; fig. 14). Multiple faults rupturing or failing in sequence is suggested from seismograms (Doser, in review) and by the different orientations and spacing of faults which ruptured the surface in the 1932 earthquike in stewart and Gabbs Valleys. Shallow detachment faulting may have occurred in parts of stewart valley as discussed above.

Al] three of the above potential explanations for distributed faulting could be operative at yucca Mountain. Conceptual models of the seismotectonics for input into hazard studies should incorporate wrench tectonics, multiple faults failing, and detachment faulting.

Conjugate fault structures were important during the 1932 earthquake sequence, both locally and regionally. Iocaliy, several

$$
1-33
$$


northeast-trending, commonly left-lateral faults occur in the cedar Mountain area and some of these ruptured in 1932. These include the fault zone along the northwest side of Cobble Cuesta in Gabbs Valley and faults on the northern flank of Cedar Mountain. Regionally, the area was seismically very active for 2 to 3 years. In 1934, the Excelsior Mountains earthquake occurred along a northeast-trending fault, within an east-west trending belt. The northwest-trending faults of the Gabbs Valley Range and 1932 earthquake do not extend south of this east-west belt and may be broadly truncated by it.

A close relationship between conjugate structures, both locally and regionally is suggested by the close temporal relationships of these structures during the 1932 earthquake. similar conjugate structures exist at Yucca Mountain, and their influence on the seismotectonic analysis must also be evaluated.

preliminary Results of Quaternary Tectonic studies in the 1932 Cedar Mountain Fault zone.

* Surficial geology relationships suggest long recurrence intervals

Analysis of low-sun-angle aerial photography coupled with surficial mapping and exploratory trenching suggest that recurrence intervals on this portion of the fault zone are relatively long, possibly tens of thousands of years in length. There is a distinct lack of pre-1932 faulting in the Qf 3 deposits, suggesting that previous displacements were preHolocene in age. Existing pre-1932 fault scarps are subdued and there is a general lack of fresh strike-slip geomorphic features, such as pressure ridges or sag depressions, which would be indicative of relativeiy frequent repeated movements.

* Trenching studies indicate recurrent strike-stip movements in the last $730 \mathrm{ka}$

Data obtained from stratigraphic and structural relationships in Trenches $3 A$ and $3 B$ indicate that multiple strike-slip displacements have occurred since the deposition of the Bishop ash (or the slightly older possible ash correlations). Since Qfl deposits are not encountered on the downthrown side of the fault, a minimum of $3 \mathrm{~m}$ of vertical separation occurred on this segment of the fault in the last 7? $\mathrm{u} \mathrm{ka}$. Based on a correlation of $Q f 2$ deposits across the fault in Trench $3 B$, about $1 \mathrm{~m}$ of vertical separation has occurred in the last approximately $135 \mathrm{ka}$ (the estimated age of the unnamed ash in Qf 2). 


\section{Total late Quaternary right slip is Rresently unknown}

Measured offsets associated with the 1932 faulting indicate that about $15-30 \mathrm{~cm}$ of vertical offset was accompanied by about 1-2 $m$ of right slip in the vicinity of Trench 3 . This ratio of vertical to horizontal slip is in agreement with that determined from the rake of sickensides (6-10 degrees) exposed in Trench 3A. A total right slip in excess of $21 \mathrm{~m}$ is suggested on the basis of a vertical to horizontal slip ratio of 1:7. The total vertical and horizontal slip, however, is unknown. Additional stratigraphic and geomorphic (offset fan surfaces) data is necessary to constrain the cumulative late Quaternary displacement.

Minimum horizontal slip rates are estimated as follows:

$$
\begin{aligned}
& >21 \mathrm{~m} / 730 \mathrm{ka}=>0.03 \mathrm{~mm} / \mathrm{yr} \\
& 7 \mathrm{~m} / 135 \mathrm{ka}=0.05 \mathrm{~mm} / \mathrm{yr} \\
& 1 \mathrm{~m} / 10 \mathrm{ka}=0.1 \mathrm{~mm} / \mathrm{yr}
\end{aligned}
$$

* Thickness of ponded deposits in Trench 3 suggest nonuniform long-term slip events

The fine-grained ponded deposits exposed on the downthrown side of the fault in trench 3 vary in thickness. The thicknesses of the youngest deposits (platy silt and Av) are similar to the vertical displacement that occurred during the 1932 earthquake (about $15-30 \mathrm{~cm}$ ). The underlying massive muds are much thicker (about $1 \mathrm{~m}$ ), suggesting that earlier events involved greater vertical displacements. If specific units could be correlated to discrete slip events, as may be the case, two events between about 100-200 ka, with vertical offsets of about $1 \mathrm{~m}$, could be inferred. However, the possibility that multiple events caused ponding of the massive muds can not yet be ruled out.

* Adaitional work is necessary to define the temporal history of the Cedar Mountain fault zone

Although average recurrence intervals are believed to be on the order of tens of thousands of years, there is presently insufficient data to precisely constrain these intervals or to determine slip rates, interseismic intervals (actual time between events), and elapsed times. Additional data needs to be collected on absolute amounts of vertical and horizontal slip, and additional age data needs to be developed for $Q f 3$ deposits.

The structural-tectonic similarities that can be established between Yucca Mountain and the cedar Mountain areas indicate 
that the 1932 earthquake should be regarded as a design basis earthquake. If other similarities, such as comparable recurrence intervals and slip rates, are demonstrated to exist, these similarities can contribute significantly to completing the comparison. If long recurrence intervals and low slip rates characterize the Cedar Mountain fault zone, the significance of this large-magnitude historic earthquake is all that more critical to the estimation of the seismic hazard at Yucca Mountain. 
SEISRISK II (Bender and Perkins, 1982) calculates the level of ground motion at a site (or sites) that has a specified probability of being exceeded during a given time period. It assumes that earthquake occurrence has a Poisson distribution (no memory of preceding events), and that occurrence rates remain constant during the time period considered. Ground motions (acceleration, velocity, or some other measure) are assumed to be a function of magnitude and distance. The program inputs consist of two major categories: definition of the affected or 'felt' areas, and definition of the seismic sources.

\section{Felt Areas}

Felt points or sites can be expressed as either sites on a rectangular grid or as sites on a line. In either case, the sites must lie within a specified rectangular coordinate system, which I will call. the area of interest (seismic sources, discussed below, may or may not lie within the area of interest). The program transforms the area of interest to a new 'local' coordinate system, thereby enabling area and distance calculations to be done linearly, rather than using equations needed for a spherical earth. The authors indicate that less than $0.6 \%$ error is introduced in distance and area calculations on a transformed area that is 12 degrees square. The inputs for the area of interest require the end points of a new 'equator' and the coordinates of two opposite corners (upper left, lower right) of the rectangular area. The equator does not have to be in the center of the rectangle, but it does have to be parallel to the 'east-west' lines of the new coordinate system. The area of interest does not have to lie parallel to 'real' longitude or latitude lines. The area of interest is gridded by inputting evenly divisible increments of degrees (or fractions of degrees) for $x$ and $y$. All coordinates for this program are input as either degrees, minutes, or decimal degrees.

once the area of interest is established, felt sites are input. Felt sites can be established by a grid and/or as points on a line. A gridded set of felt site locations is established by inputting starting and ending rows and columns of the grid established in the area of interest. Sites located on a line are established by inputting the end points of the line and the number of sites on the line. These sites are spaced at even intervals along the line with sites at each end of the line.

Example of line method:

Number of sites on the line $=5$

End points of line 120.039 .0

120.038 .0 
Site locations will be on longitude 120.0

at latitudes $38.0,38.25,38.5,38.75,39.0$

A single site can be established by indicating one site and inputting the coordinates of that site twice.

Determining where sites will be located using the gridded approach is difficult. The algorithm used to establish the grid is complicated, taking into account divergence of parallel latitudes and converting decimal degrees to kilometers (in other words, I don't understand it). The output files will list the coordinates of gridded sites, but I haven't found a way to calculate them before hand. If it is desired to have felt sites placed at specific locations, it is easily done with the line method. By inputting a series of parallel lines with the same number of sites per line, a grid can be established. The program is set up such that the number of sites per line is input and then the end points of the lines. Once the number of sites per line is set, it can not be changed for individual lines.

In addition to establishing the locations of felt sites, an attenuation table is constructed. This consists of inputting magnitudes and distance and the attenuation that is a function of magnitude and distance. Attenuation values can represent acceleration, velocity, or whatever. The table will look something like this:

\begin{tabular}{clll} 
& \multicolumn{3}{c}{ Magnitudes } \\
Dist $(\mathrm{km})$ & 7.0 & 6.0 & 5.0 \\
10 & & & \\
100 & .52 & .33 & .22 \\
& .015 & .005 & .001
\end{tabular}

Seismic sources

Seismic sources are modeled as seismic zones and/or as rupture lengths along faults.

\section{Seismic zones}

A seismic zone is defined as a seismically homogeneous area an area or areas that have the same recurrence interval for a specified range of earthquake magnitudes. A seismic zone may consist of subareas which can be connected or separated. An example of a zone might be two volcanic fields with similar seismic characteristics (recurrence and magnitude) separated by some distance. Each of the volcanic fields or 'subareas' are input as a quadlateral or series of quadlaterals. A quadlateral is defined as the endpoints of two line segments. 
The ground motion given to a 'felt' site from a source guadlateral is a fairly complicated process. Briefly, each quadlateral is divided into seven areas, with each area bounded by evenly spaced arcs. The radius of the arcs originate at the felt site. The ground motion at the felt site is evaluated for each of the arc bounded subareas (as a function of distance, magnitude, and area of the arc bounded subarea). The important point is that the ground motion given to the site is 'integrated' over the area of the source quadlateral and is not simply a function of the distance between the felt site and the center of the quadiateral.

Faults

Modeling seismicity with faults is similar to that of source zones. Fault zones are identified on the basis of similar recurrence and magnitude ranges as are source zones. Each fault zone is subdivided into individual faults and input as points on the fault.

In addition, the values for als, bls, and sigls are input for the equation:

$$
\text { rupture length }=10 * *(a l s+b l s * m+f r * s i g l s)
$$

where: $\mathrm{m}=$ magnitude

als and bls are constants

$$
\begin{aligned}
& \text { sigls = stand. dev. (in log length) } \\
& \text { fr }=5 \text { if sigls >0 } \\
& =1 \text { if sigls }=0
\end{aligned}
$$

0.52

The program defaults to als $=-1.085$, bls $=0.389$, sigls $=$

SEISRISK II allows either one or five rupture lengths per magnitude to be used depending on the value of sigls. If sigls= 0 , a median rupture length is used. If sigls $=1$, five rupture lengths are used, each wholely contained in the fault length.

\section{SEISRISK III}

SEISRISK II was revised and released as SEISRISK III (Bender and Perkins, 1987). There are several important differences between the two programs. SEISRISK II assumes that seismicity within a seismic source zone is uniform, that each point within the source zone has the same probability of being the epicenter of a future earthquake. SEISRISK III assumes a normal distribution of earthquakes within the zone. The earlier version resulted in the projected rate of earthquakes changing abruptly at the source zone boundaries. The assumption of normal distribution permits 
seismicity to vary smoothly across the zone boundaries.

In the fault-rupture model, SEISRISK II and SEISRISK III allow earthquakes to be modeled as finite-length ruptures along fault segments. Ground-motion at a site resulting from a fault rupture is regarded as a function of closest site-to-rupture distance. Because the computations are performed for a discrete set of magnitudes, the ground-motion produced by the rupture at the closest distance will be calculated as occurring more frequently than other ground-motion levels, and the calculated probability of exceeding a specified ground-motion level at a site does not vary smoothly as a function of ground-motion level. SEISRISK III smooths this irregularity by treating the closest distance ruptures for each magnitude as if they occurred over a range of magnitudes.

SEISRISK II and SEISRISK III allow "artificial" parallel faults to be modeled when the presence of faulting is inferred from geologic considerations, and the orientations of the faults is assumed to be known. If a series of equidistant parallel faults are input into the program, SEISRISK III can do a partial smoothing (not available in SEISRISK II) to simulate a finer spacing between faults to better approximate a uniform distribution.

Both program versions calculate the probability of ground motion at all sites resulting from earthquakes in a single source before proceeding to the next source. This requires retaining intermediate calculations for each site to accumulate groundmotions from successive sources. SEISRISK II wrote these intermediate results to disk, SEISRISK III saves the results in memory. Storing this data in memory requires the use of a PC with at least one megabyte of memory and a Fortran compiler capable of addressing the additional memory above the standard 640 kilobyte limit of disk operating systems.

\section{Future Use of Seisrisk II and II}

Future plans call for implementation of seisrisk II and III in assessing the fault-related earthquake risk at Yucca Mountain. Faults will be digitized and faulting parameters will be assigned to define seismic source characteristics. These computer programs will allow preliminary base-line risk estimates to be established. 
In assessing the Quaternary tectonics of the Yucca Mountain area, principal activities during the contract period (1 January 1987 to 30 June 1988) have focussed on three main topics: Quaternary tectonics at the Yucca Mountain site; Quaternary stratigraphy at the Yucca Mountain site; and analogue studies in the 1932 Cedar Mountain fault zone.

The Quaternary tectonics of the Yucca Mountain area was evaluated primarily through the use of newly flown low-sun-angle aerial photography. More than 750 line-miles of $1: 12,000-$ and 1:6,000-scale black and white photography was flown over the site and immediately adjacent areas. The photography was analyzed in detail and a number of previously unrecognized Quaternary fault scarps have been identified. These newly recognized fault scarps do not add any obvious new major faults, but they do indicate that the recognized faults have younger ages, greater rupture lengths, and much more complexity than previous work suggests. These observations are critical to future earthquake hazard and risk assessments.

Quaternary stratigraphic studies were initiated in order to evaluate the adequacy of the previously defined DOE stratigraphic scheme as it relates to constraining the recency and frequency of Quaternary faulting at Yucca Mountain. These studies centered on four key areas: soils/geomorphic relationships; rock varnish dating; thermoluminescence dating; and uranium-isotope dating. These areas were assessed with the assistance of Dr. Frederick F. Peterson, Dr. Ronald I. Dorn, Dr. Steven L. Forman, and Dr. TehLung $\mathrm{Ku}$, who each have prepared separate reports on these respective subjects.

An evaluation of the relative merits of both the SEM-EDAX and the scraping-PIXE methods for cation-ratio ages of rock varnish suggests that the SEM-EDAX method may be deficient in a number of areas. In particular, an independentiy derived cation-leaching curve for the Crater Flat area suggests that the previous curve developed by Harrington and Whitney (1987) may overpredict the age of Quaternary deposits and faulting events thereby resulting in an underestimation of the seismic hazard at the Yucca Mountain site. Seven rock varnish samples were dated by the AMS radiocarbon method to provide independent soils/geomorphic age control and to calibrate the cation-leaching curve. Six additional samples were collected and dated using the newly derived curve.

The soils and geomorphic study consisted of a detailed evaluation of the relationships in crater flat and an assessment of the adequacy of the previous work of Swadley and others (1984). Five major geomorphic surfaces were identified based on an analysis of aexial photography, nineteen representative pedons, and thirteen 
cation ratio and AMS radiocarbon dates on rock varnish. principal conclusions reached include observations that swadley and others (1984) failed to recognize three clearly separate geoinorphic surfaces in their QTa map unit and two separate surfaces in their Q2 map unit. In addition, the "surficial deposits" concept of Swadley and others (1984) is fatally flawed and should be abandoned in favor of a scheme that is defined in terms of soils and stratigraphic relations.

An evaluation of the thermoluminescence (TL) dating of whitney and others (1986) was made and preliminary conclusions can be drawn regarding the adequacy of this technique in dating eolian Av horizons in the Windy Wash fault area of Crater Flat. Although the previous sample sites appear to have avoided disturbed Av material, it can not be unequivocally ascertained whether the sampies have been homogenized, resulting in anomalously young ages. Based on an analysis of the equivalent doses and dose rates, the cumulative total additional error is probably between 10-40\%, resulting in a corresponding over-estimate in the numerical age determined by Whitney and others (1986). A more realistic age span for the samples AV horizons may be 2 to $8 \mathrm{ka}$.

A review of the uranium-trend method of dating Quaternary deposits in the Yucca Mountain area suggests that this method is "unconventional" and is only in the experimental stage of development. Although the technique has a large age range (10-800 ka) and can be used on a wide variety of deposits, there are a number of unknown variables influencing a key uranium flux parameter and this parameter is presently not well constrained. Forty suites of samples have been previously dated by the uraniumtrend method in the Nevada Test site area, and these data can be divided into three categories based on goodness of data and relative errors. A number of samples from the Yucca Mountain and Crater Flat areas fall within the first category having probable errors of only 10-20\%. Other samples may have errors of $100 \%$ or more.

Stratigraphic and trenching studies were conducted in the Monte Cristo Valley portion of the 1932 Cedar Mountain earthquake $(M s=7.2)$ area in order to determine if analogous seismotectonic conditions exist at Yucca Mountain. Similarities found to exist in both areas include tectonic setting, distributive fault pattern, and fault structures exposed in trenches. Quaternary stratigraphic studies were conducted to establish constraints on the recency and frequency of large-magnitude earthquakes since this timing may also be important in comparing the seismotectonic settings of both areas. Preliminary results from surficial geologic and trenching studies suggest that a 1932 Cedar Mountain type earthquake should probably be considered a design basis earthquake for yucca Mountain, but additional work should be conducted to more definitely establish this. 


\section{References cited}

Bell, J.W., 1986, Report on field review of surficial geology and trenches in Crater Flat: Report to the Nevada Nuclear Waste Project office, $8 \mathrm{p}$.

Bell, J.W., and Katzer, T., 1987, surficial geology, hydrology, and and late Quaternary tectonics of the IXL Canyon area, Nevada: Nevada Bureau of Mines and Geology Bulletin 102, 51 p.

Bell, J.W., depolo, C.M., and Ramelli, A.R., 1987, Final Report, Task 1, Review of Quaternary geology and evaluation of potential for undetected Quaternary faults at and near yucca Mountain: Report to the Nevada Nuclear Waste Project office, $214 \mathrm{p}$.

Bender, B., and Perkins, D.M., 1982, SEISRISK II: a computer program for seismic risk hazard estimation: U.S. Geological Survey Open-file Report 82-293, 103 p.

1987, SEISRISK III-- a computer program for seismic hazard estimation: U.S. Geological Survey Bulletin 1772,48 p.

Bucknam, R. C. and Anderson, R. E., 1979, Estimation of fault-scarp ages from a scarp-height-slope-angle relationship: Geology, v. 7, no. 1, p. 11-14.

Department of Energy, 1988, Consultation draft, site characterization plan, Yucca Mountain site, Nevada Research and Development area, Nevada.

depolo, C.M., Bell, J.W., and Ramelli, A.R., 1987, Geometry of strike-slip faulting related to the 1932 Cedar Mountain earthquake, central Nevada: Geological Society of America Abstracts with Program, v. 19, no.6, p. 371.

depolo, C.M., and slemmons, D.B., in review, Estimation of earthquake size for seismic hazards: Geological society of America Centennial Volume on Engineering Geology.

Dorn, R.I., 1983, Cation ratio dating: a new rock varnish agedetermination technique: Quaternary Research, v. 20, p. 4973.

Dorn, R.I., and DeNiro, M.J., 1985, stable carbon isotope ratios of rock varnish organic matter: a new paleoenvironmental indicator: Science, v. 227, p. 1472-1474.

Dorn, R.I., and oberlander, T.M., 1982, Rock varnish: Progress in physical geography, v. 6, p. 317-367. 
Dorn, R.I., Tanner, D., Turrin, B.D., and Dohrenwend, J.C., 1987a, Cation-ratio dating of Quaternary materials in the eastcentral Mojave Desert, California: Physical Geography, v. 8, p. 72-81.

Dorn, R.I., Turrin, B.D., Jull, A.J.T, Limick, T.W., and Donahue, D.H., 1987b, Radiocarbon and cation ratio ages for rock varnish on Tioga and Tahoe morainal boulders of Pine creek, eastern Sierra Nevada in California, and paleoclimatic implications: Quaternary Research, v. 28, p. 38-49.

Doser, D.I., in review, Source mechanisms of earthquakes in the Nevada Seismic Belt (1915-1943) and implications for deformation in the western Great Basin: Journal of Geophysical Research.

Ekren, E.B., and Byers, F.M., Jr., 1976, Ash-flow fissure vent in west-central Nevada: Geology, v. 4, p. 247-251.

1978a, Preliminary geologic map of the Luning SE quadrangle, Mineral and Nye Counties, Nevada: U.S. Geological Survey Open-File Report 78-918.

1978b, Preliminary geologic map of the Luning NE quadrangle, Mineral and Nye Counties, Nevada: U.S. Geological Survey Open-file Report 78-915.

, 1984, The Gabbs Valley Rangem- a well exposed segment of the Walker Lane in west-central Nevada, in Lintz, J., ed., Western Geological Excursions: Geological society of America Annual Meeting Guidebook, v. 4, p. 203-215.

Harrington, C.D., and Whitney, J.W., 1987, scanning electron microscope method for rock varnish dating: Geology, v. 15, p. $967-970$.

Hoover, D.I., Swadley, W.C., and Gordon, A.J., 1981, correlation characteristics of surficial deposits with a description of surficial stratigraphy in the Nevada Test site region: U.S. Geological Survey Open-file Report 81-512, 27 p.

Keller, R.P., Oldow, J.S., Hardyman, R.F., and Geissman, J.W., 1987, Transtensional development of low-angle detachment faults, Walker Lane, western Great Basin: American Geophysical Union, EOS, v. 68 , p. 1475.

Maldonado, F., 1985, Geologic map of the Jackass Flats area, Nye County, Nevada: U.S.G.S., Miscellaneous Inves. Series Map I1519.

Molinari, M.P., 1984a, Late Cenozoic geology and tectonics of the Stewart and Monte Cristo Valleys, west-central Nevada: 
Unpublished M.S. thesis, University of Nevada-Reno, $124 \mathrm{p}$.

1984b, Late Cenozolc structural geology of stewart and Monte Cristo Valleys. Walker Lane of west central Nevada, in Lintz, J., ed., Western Geological Excursions: Geological Society of America Annual Meeting Guidebook, v. 4, p. $219-231$.

Pierce, K. L. and Colman, S. M., 1986, Effect of height and orientation (microclimate) on geomorphic degradation rates and processes, late-glacial terrace scarps in central Idaho: GSA, Bull. v. 97 , p. 869-885.

Rosholt, J.N., Bush, C.A., Carr, W.J., Hoover, D.L., Swadley, W.C., and Dooley, J.R., Jr., 1985, Uranium-trend dating of Quaternary deposits in the Nevada Test Site area, Nevada and California: U.S. Geological Survey Open-file Report: 85-540, $72 \mathrm{p}$.

Scott, R. B. and Whitney, J. W., 1987, The upper crustal detachment system at Yucca Mountain, SW Nevada: Geological Society of America, Abstracts with Programs, v. 19, no. 5, p. 332-333.

Scott, R. B. and Bonk, J., 1984, Preliminary geologic map of Yucca Mountain, Nye County, Nevada, with geologic sections: U.S.G.S., Open-file report $84-494$.

Swadley, W.C., Hoover, D.L., and Rosholt, J.N., 1984, Preliminary report on late cenozoic faulting and stratigraphy in the vicinity of Yucca Mountain, Nye County, Nevada: U.S. Geological survey Open-file Report 84-788, $42 \mathrm{p}$.

Taylor, E., 1986, Impact of time and climate on Quaternary soils in the Yucca Mountain area of the Nevada Test Site: unpublished M.S. thesis, University of Colorado, Boulder, 217 p.

Wallace, R.E., 1987, Grouping and migration of surface faulting and variations in sljp rates on faults in the Great Basin Province: Seismological. Society of America Bulletin, v. 77 , p. $868-876$.

Wells, S.A., MCFadden, L.D., Renault, C., 1988, A geomorphic assessment of Quaternary volcanism in the Yucca Mountain area, Nevada Test site, Southern Nevada: Geological society of America Abstracts with Program, v. 20, no. 3, p. 242.

Whitney, J.W., Shroba, R.R., simmonds, F.W., and Harding, S.T., 1986, Recurrent Quaternary movement on the Windy Wash fault, Nye County. Nevada: Geological Society of America Abstracts with Program, v. 18 , no. 6, p. 787 . 


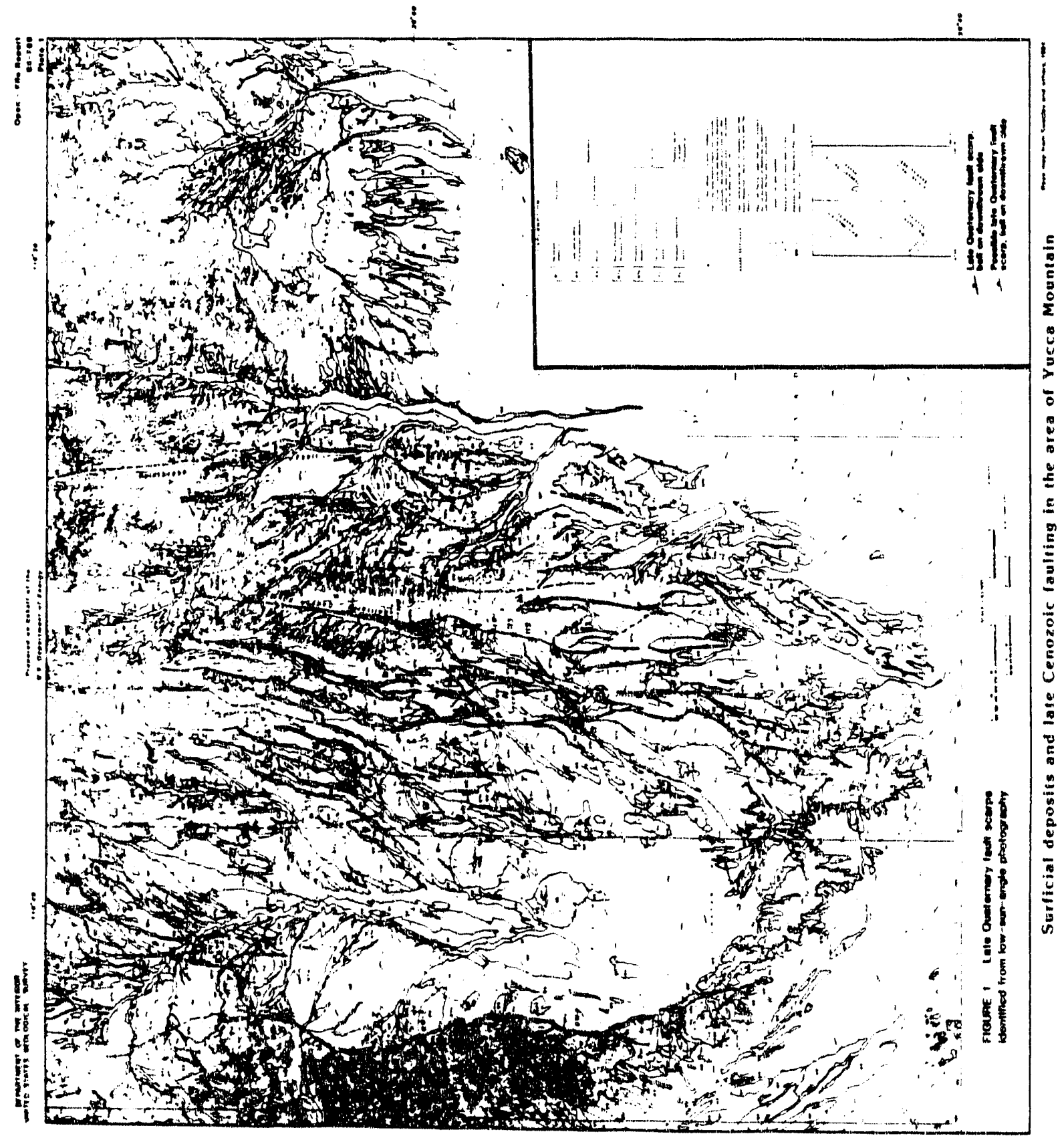




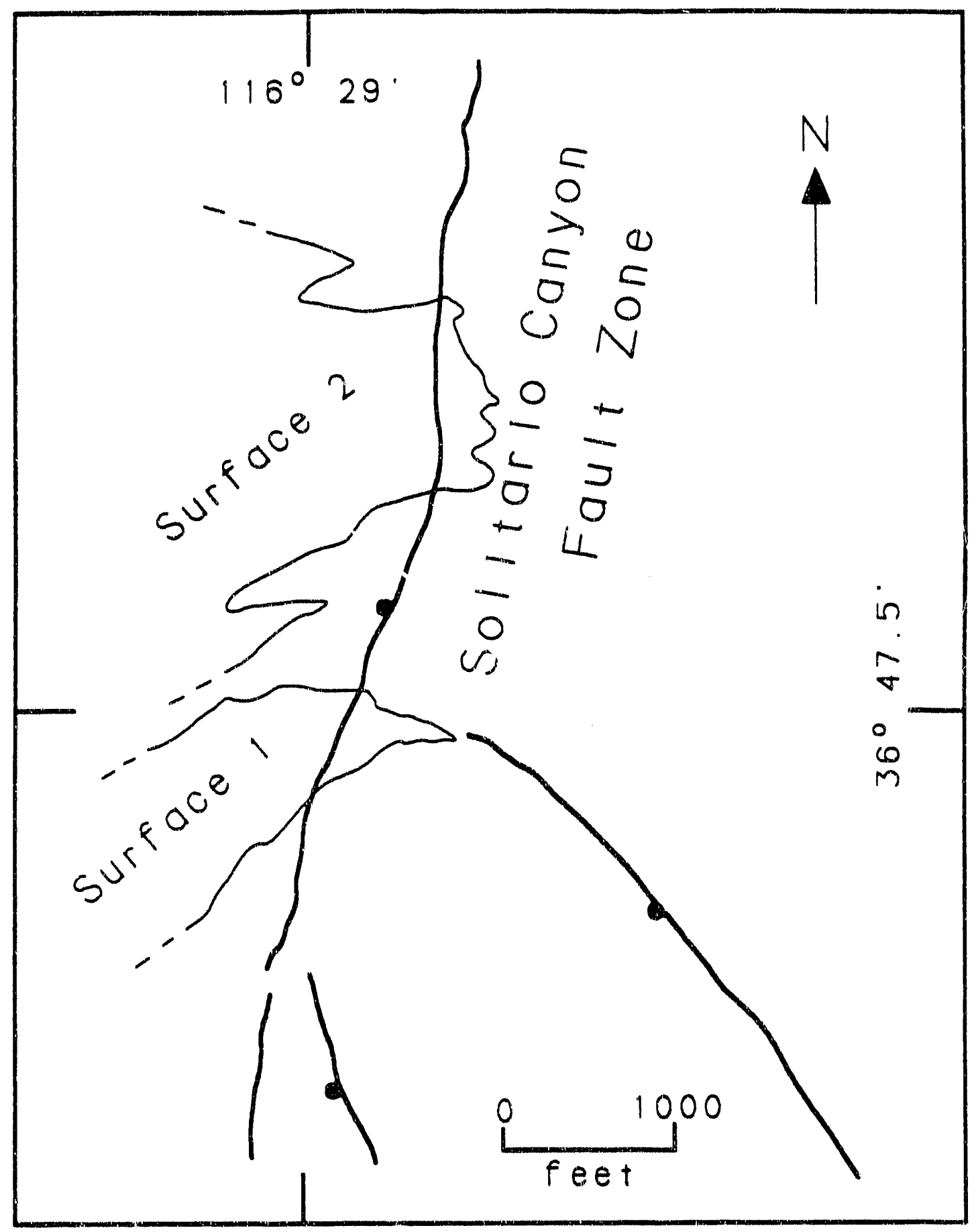

Figure 2: Generalized surficial geologic map along the central. part of the solitario canyon fault. surface 1 is offset vertically by about $20 \mathrm{~cm}$; surface 2 by about $1 \mathrm{~m}$. 
Figure 3 (following page). Comparison of cation-leaching curves for the Yucca Mountain area. 3A: Curve based on SEM-EDAX as presented in Harrington and Whitney (1987); 3B: Scraping-PIXE curve, based on data from this study; $3 C$ : Overlay of the SEMEDAX and srcaping-PIXE curves. 


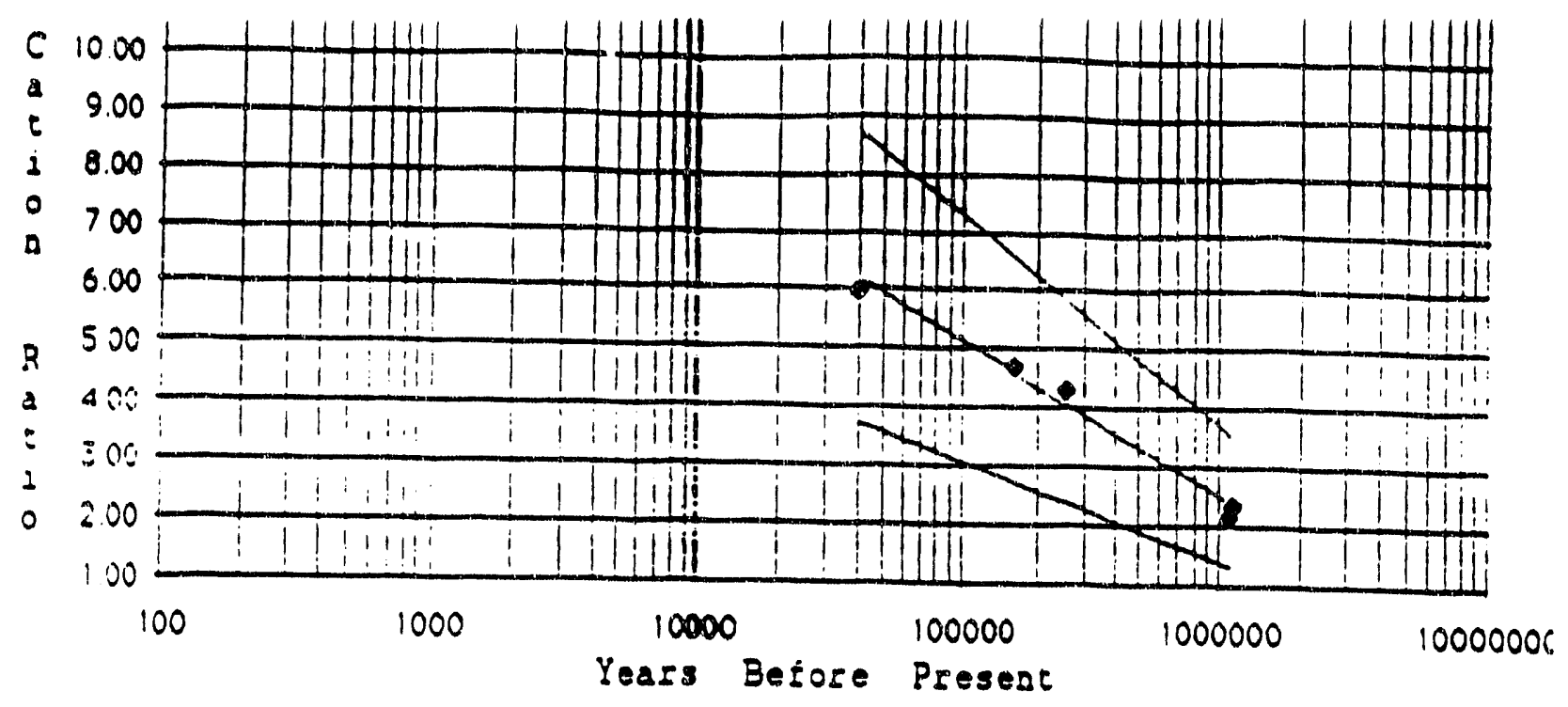

b

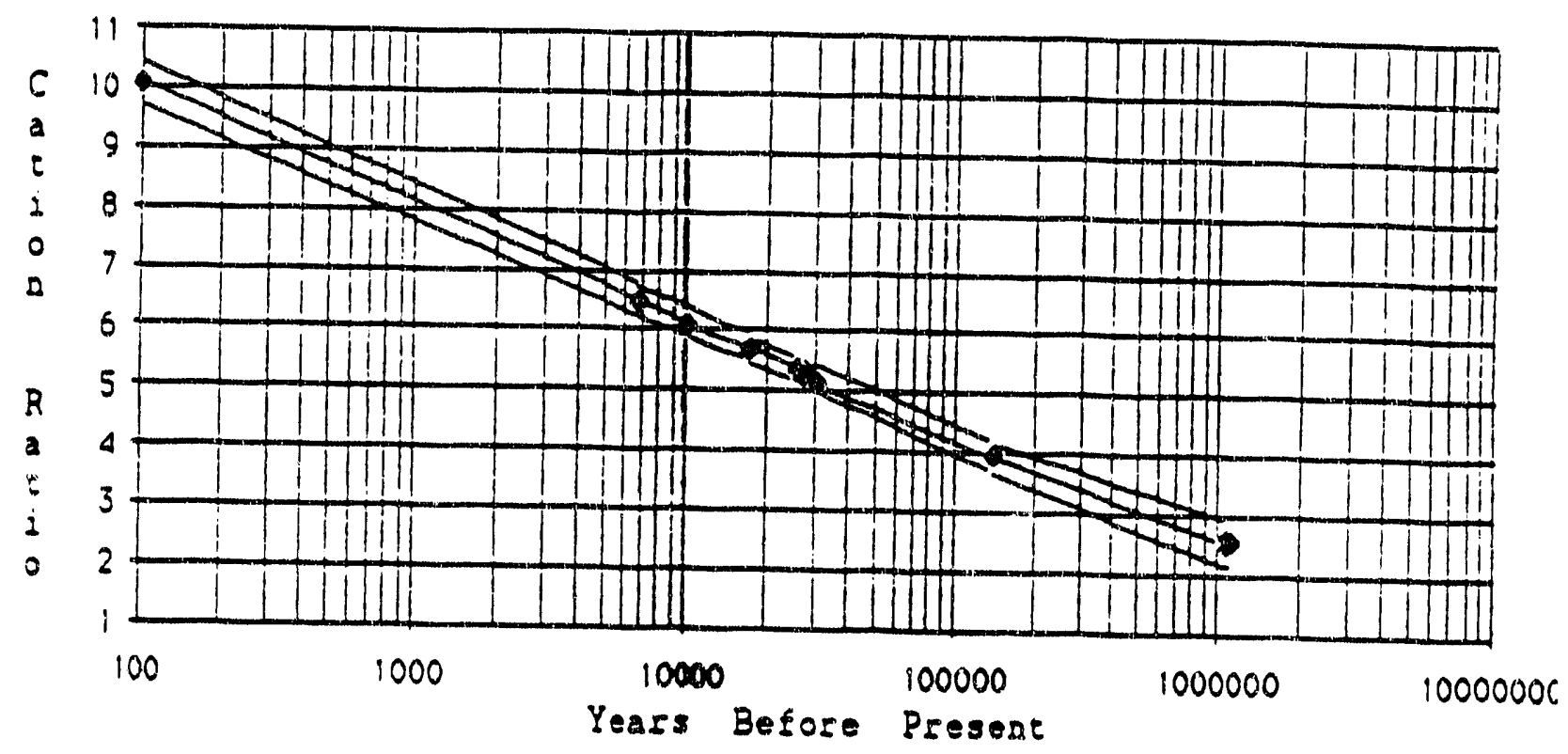

C

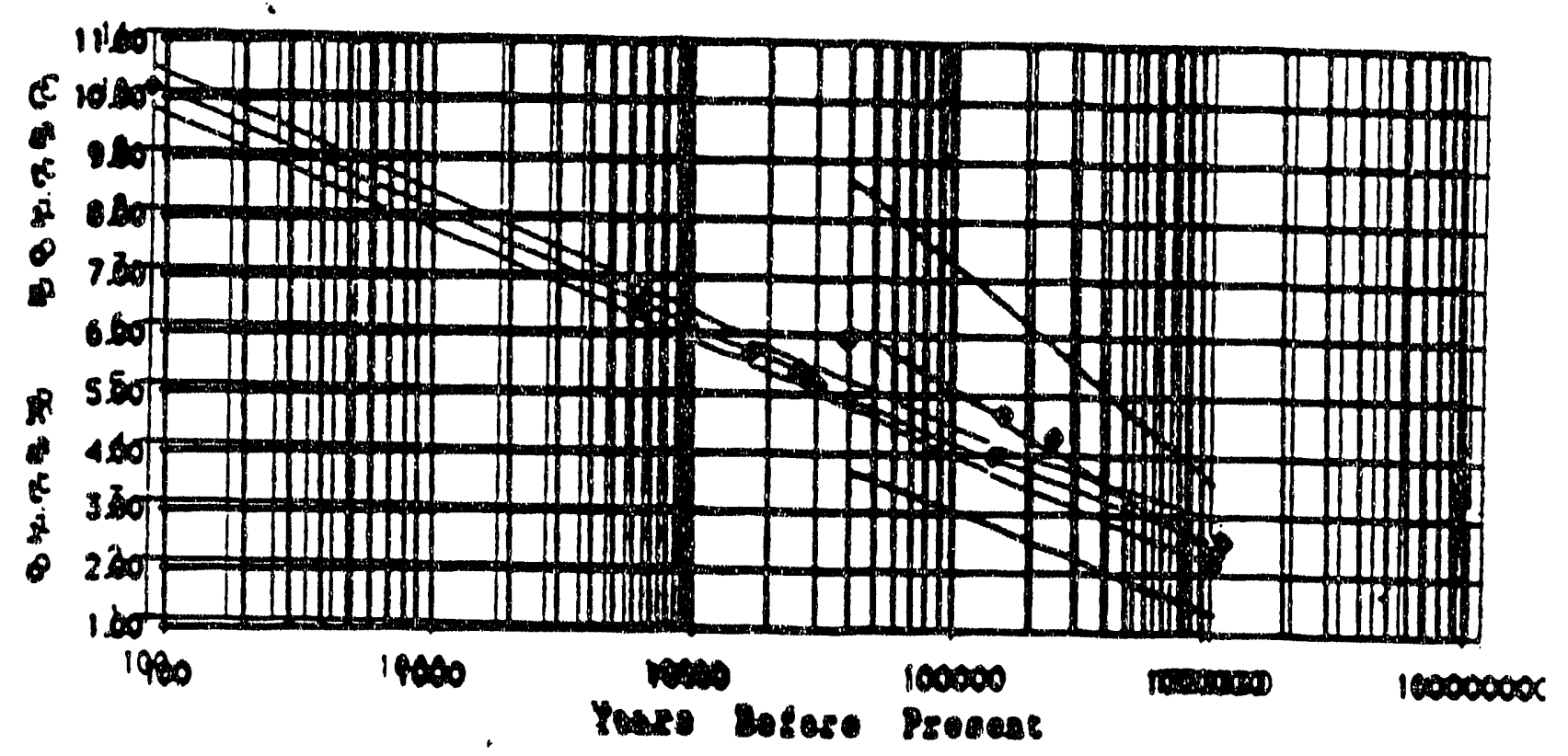




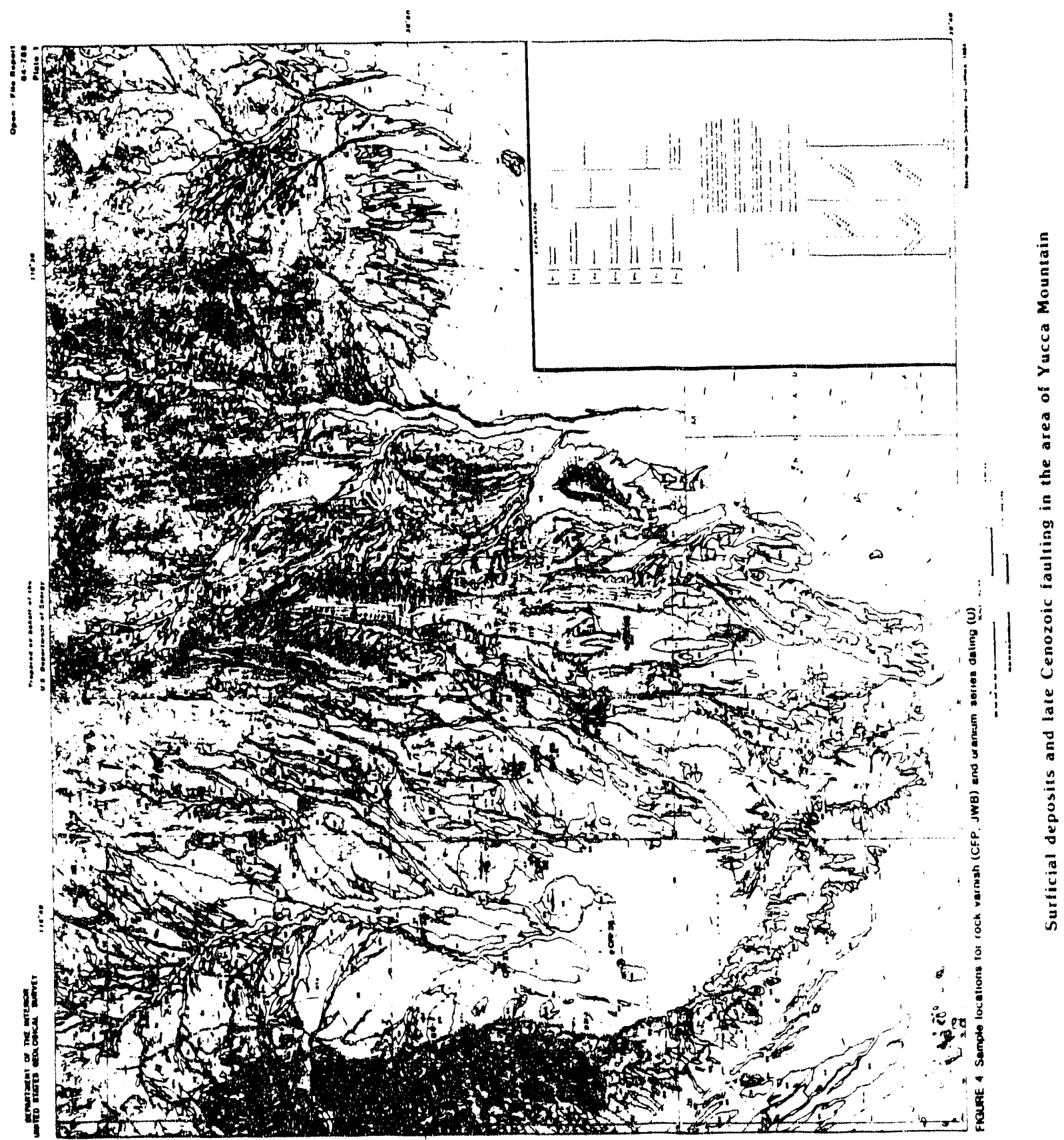




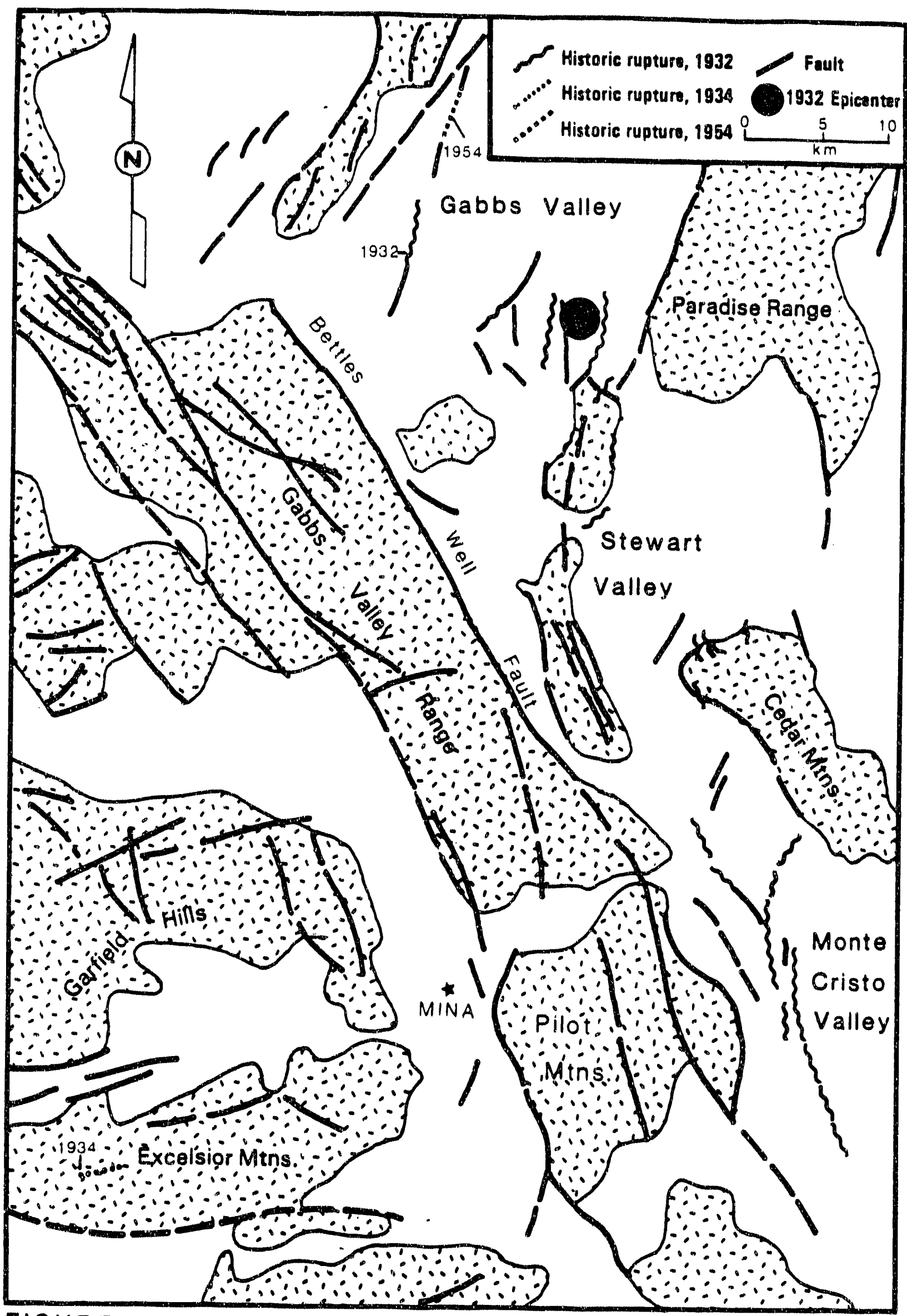

FIGURE 5 Surface faulting associated with the 1932, 1934, and 1954 earthquakes. 


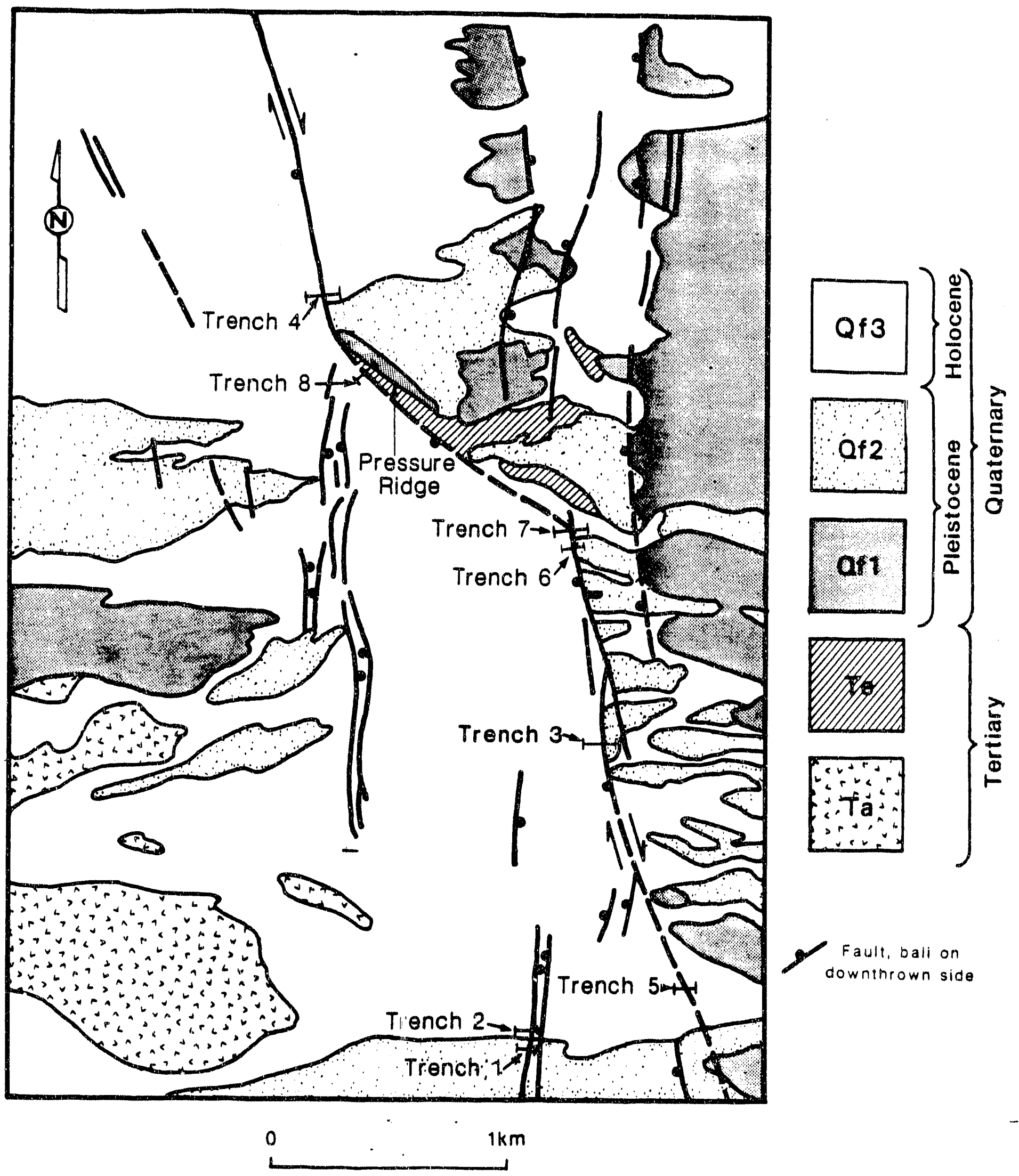

FIGURE 6 Surficial geology of Monte Cristo Valley. 


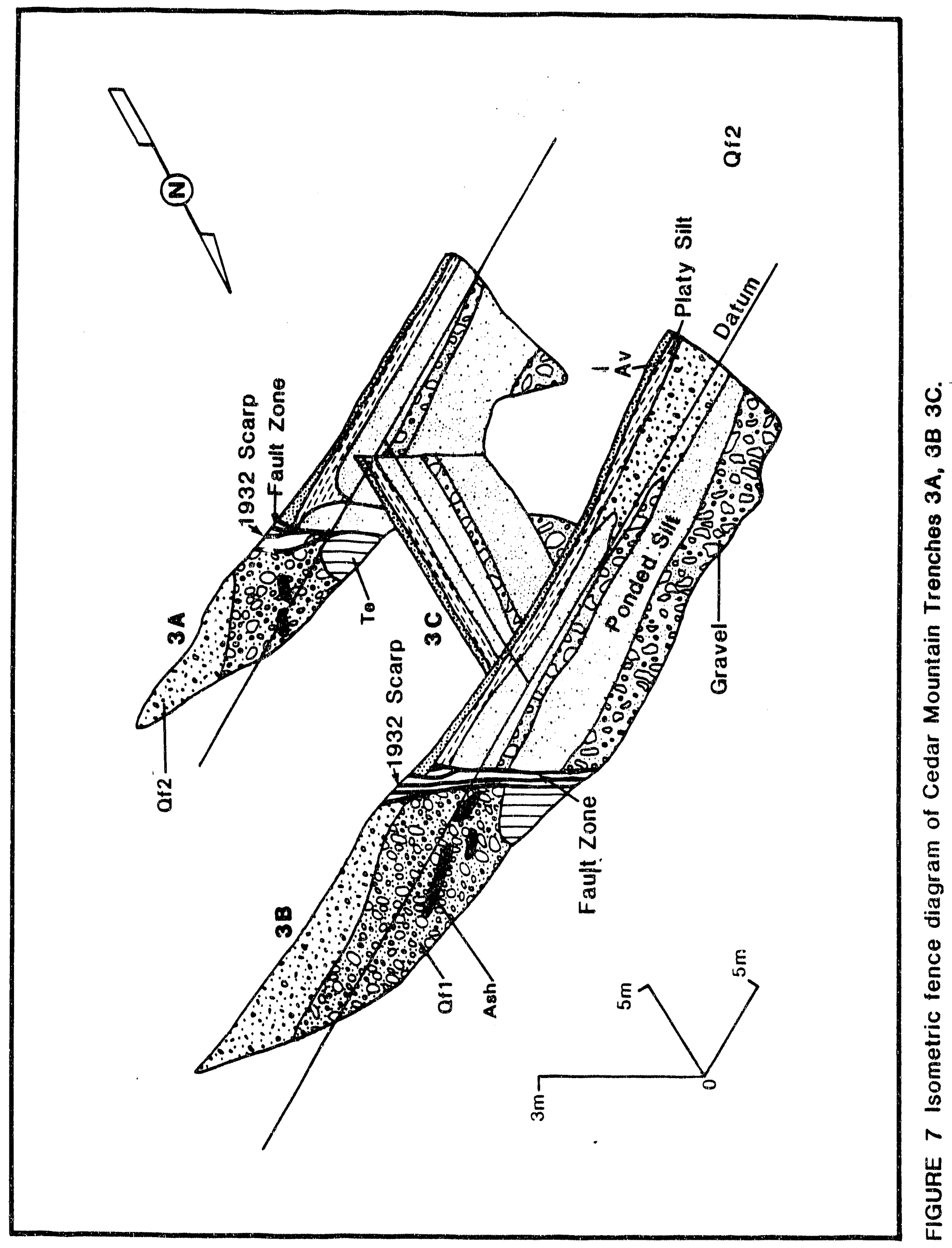




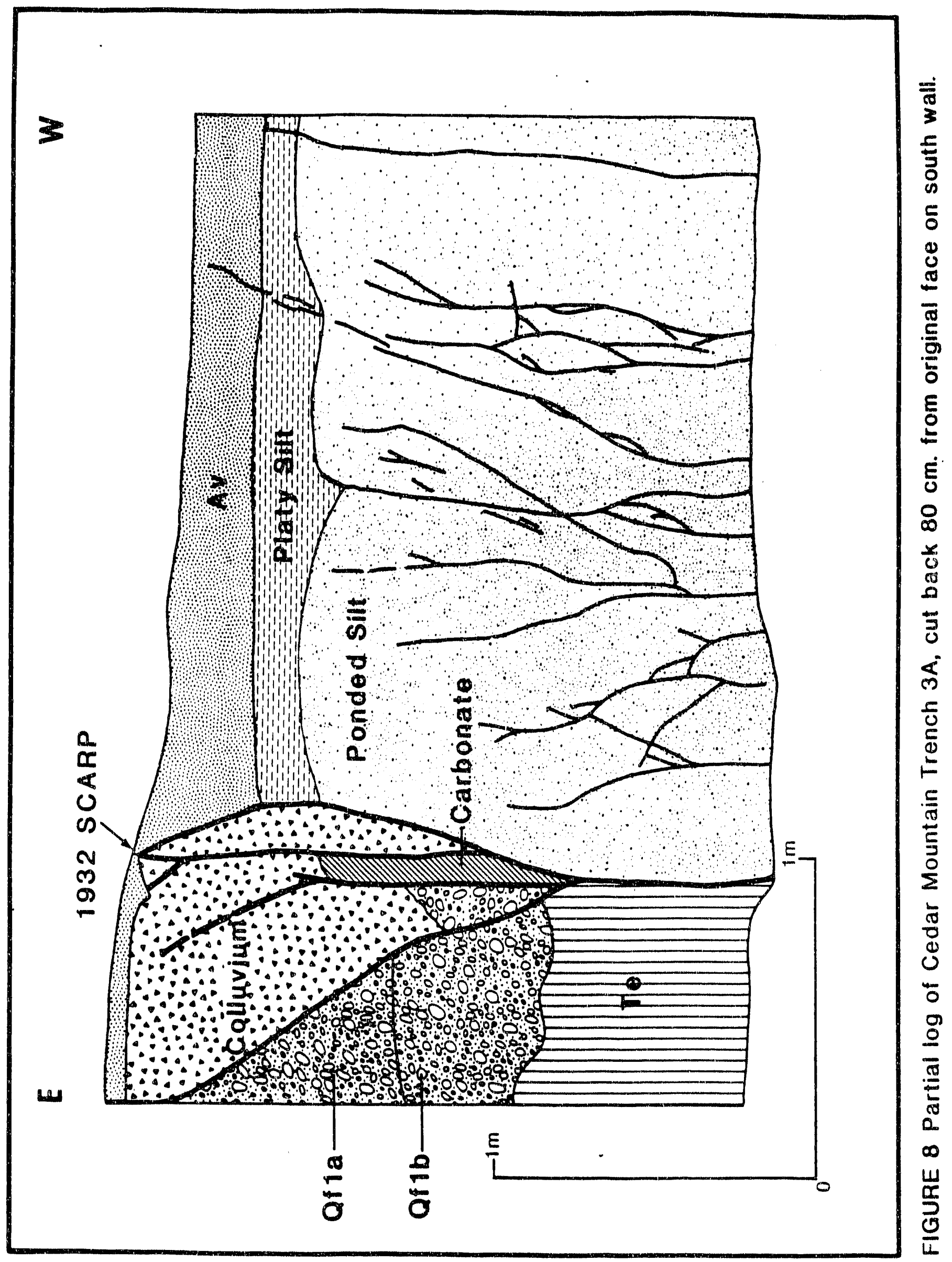




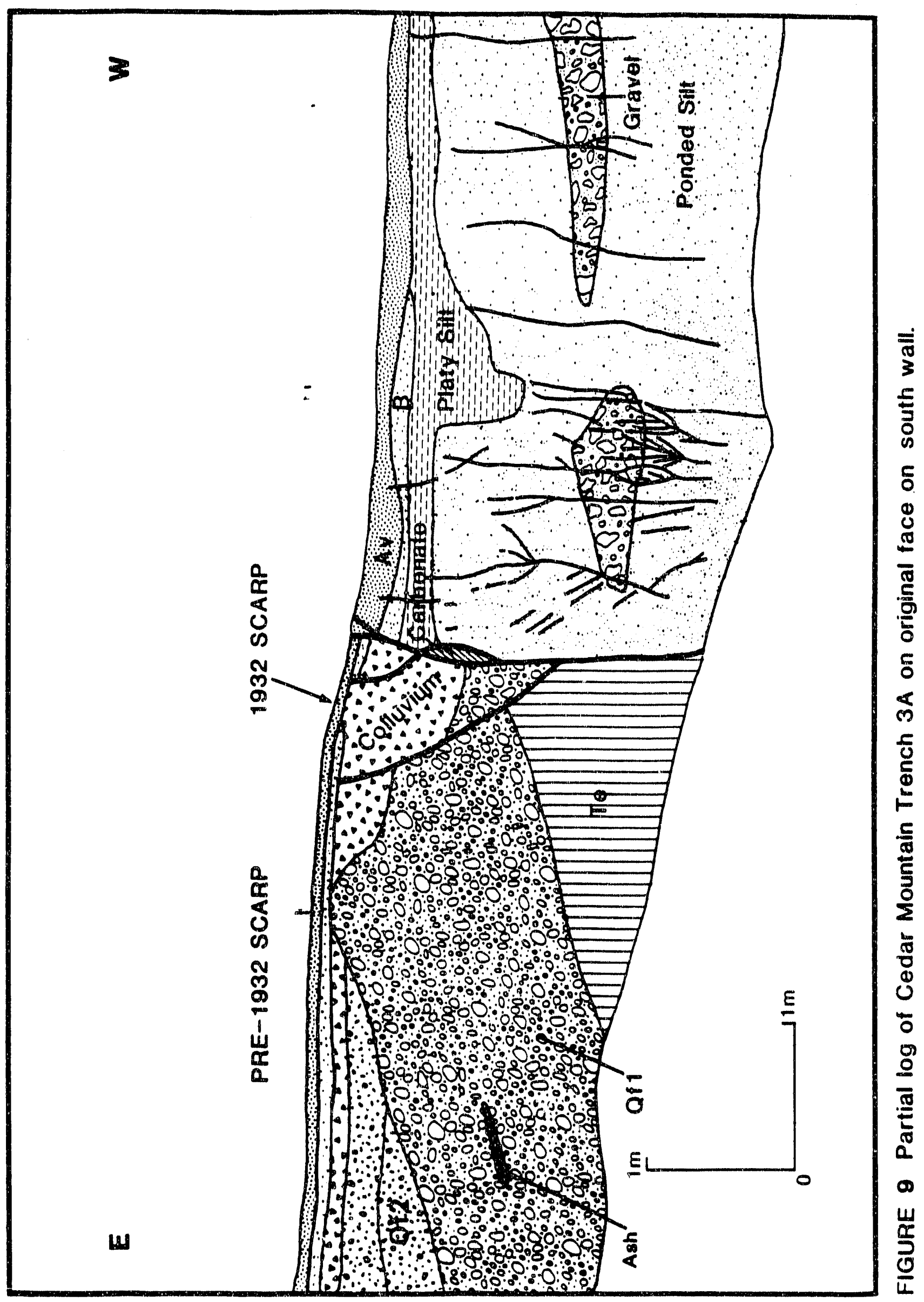


Trenches 3B-3C Stratigraphy (see figs, 10, 11)

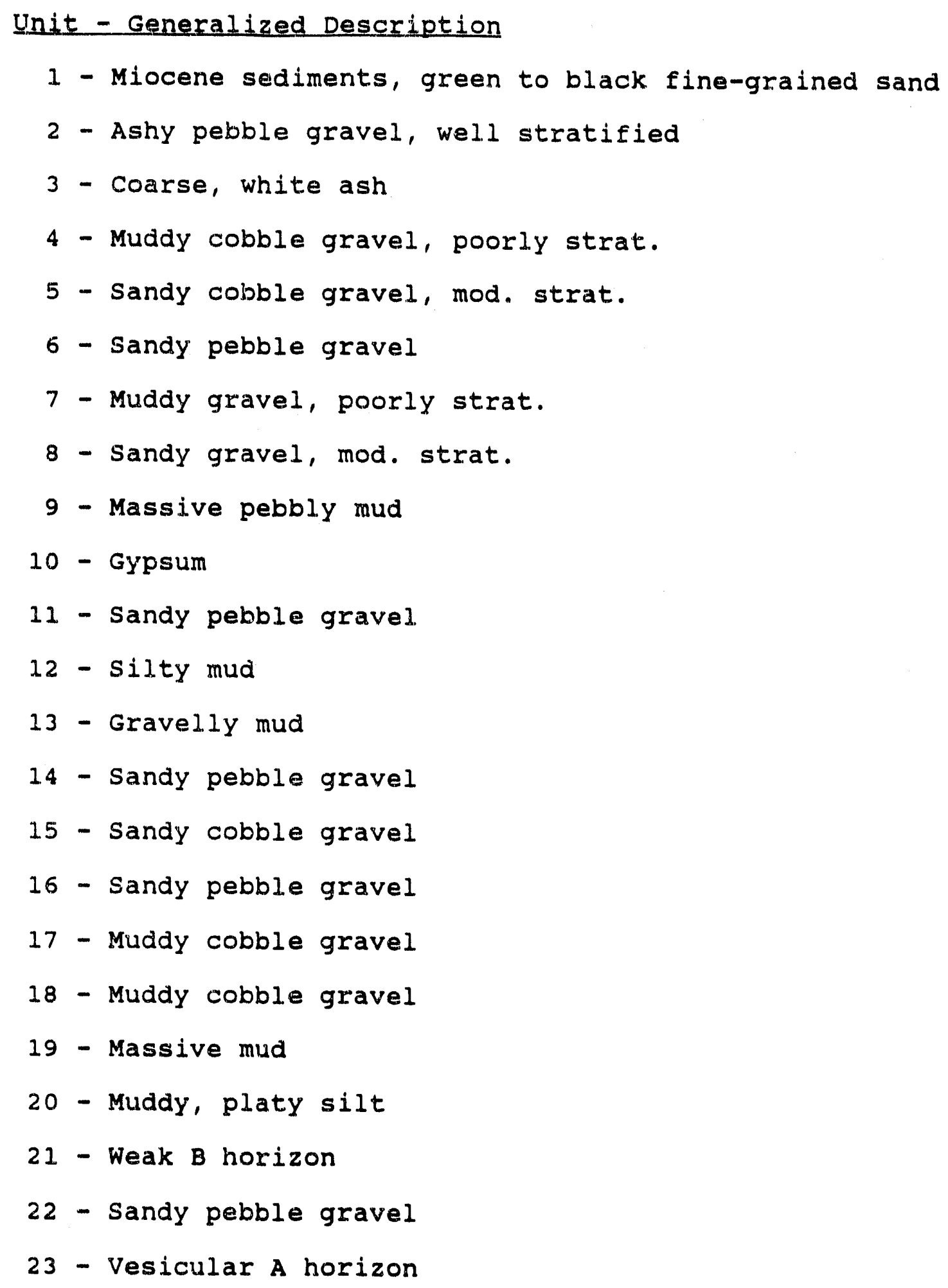




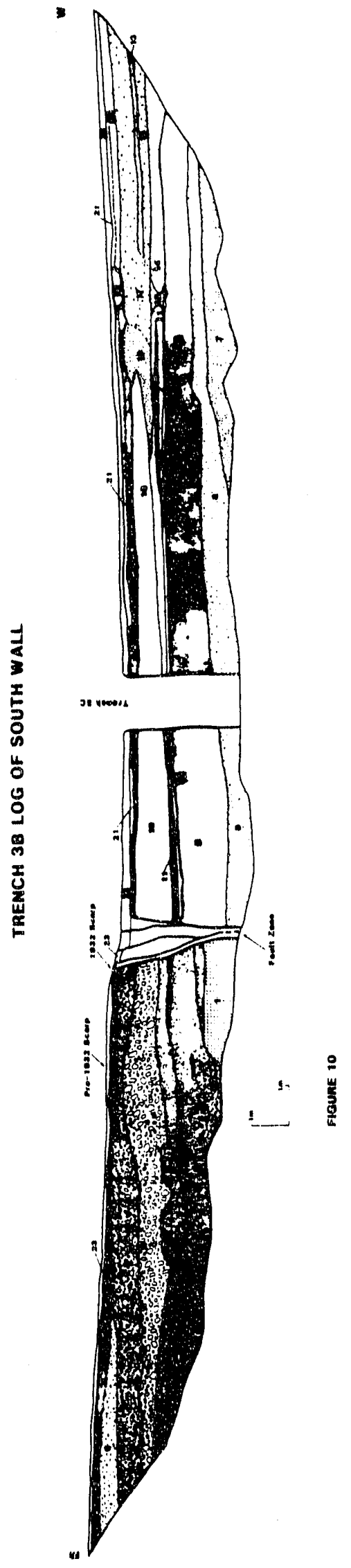


TRENCH 7 LOQ OF NORTH WALL

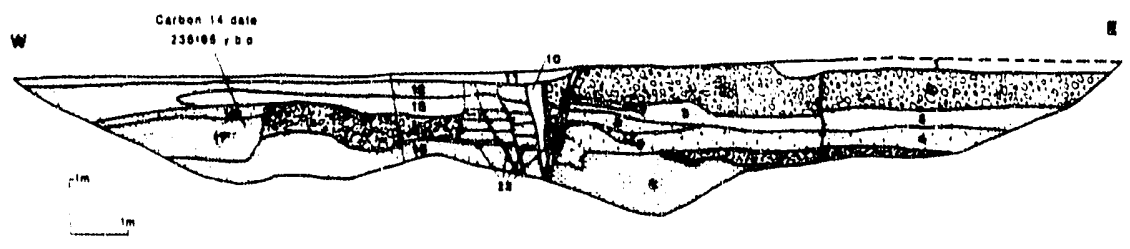

FIouna 13

TRENCH 3C LOG OF EAST WALL

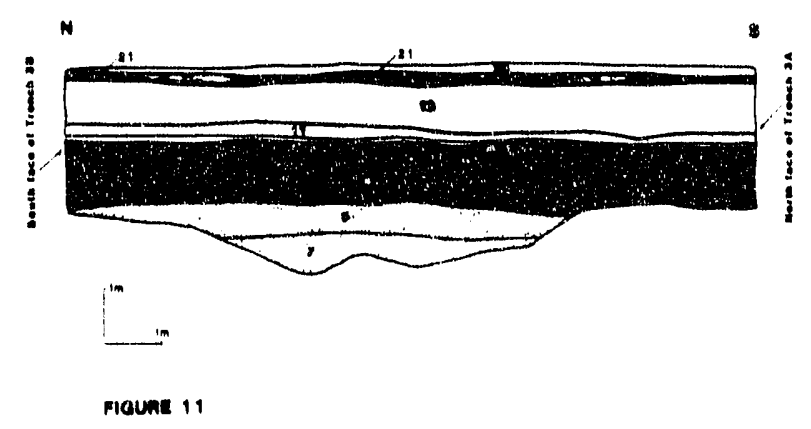

at anold

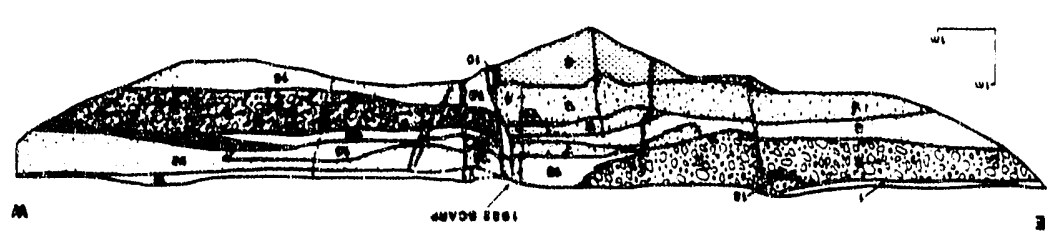

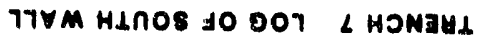




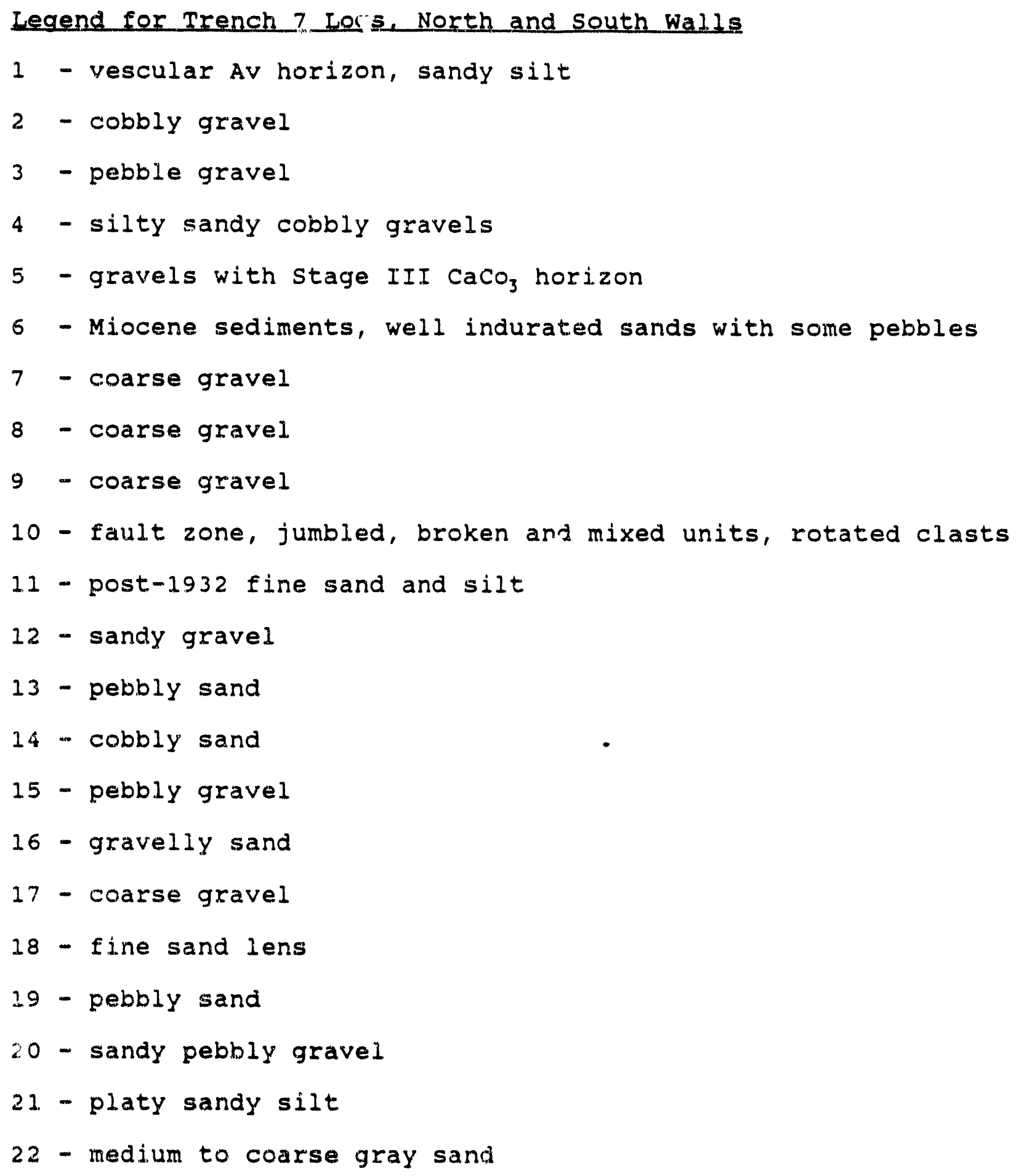




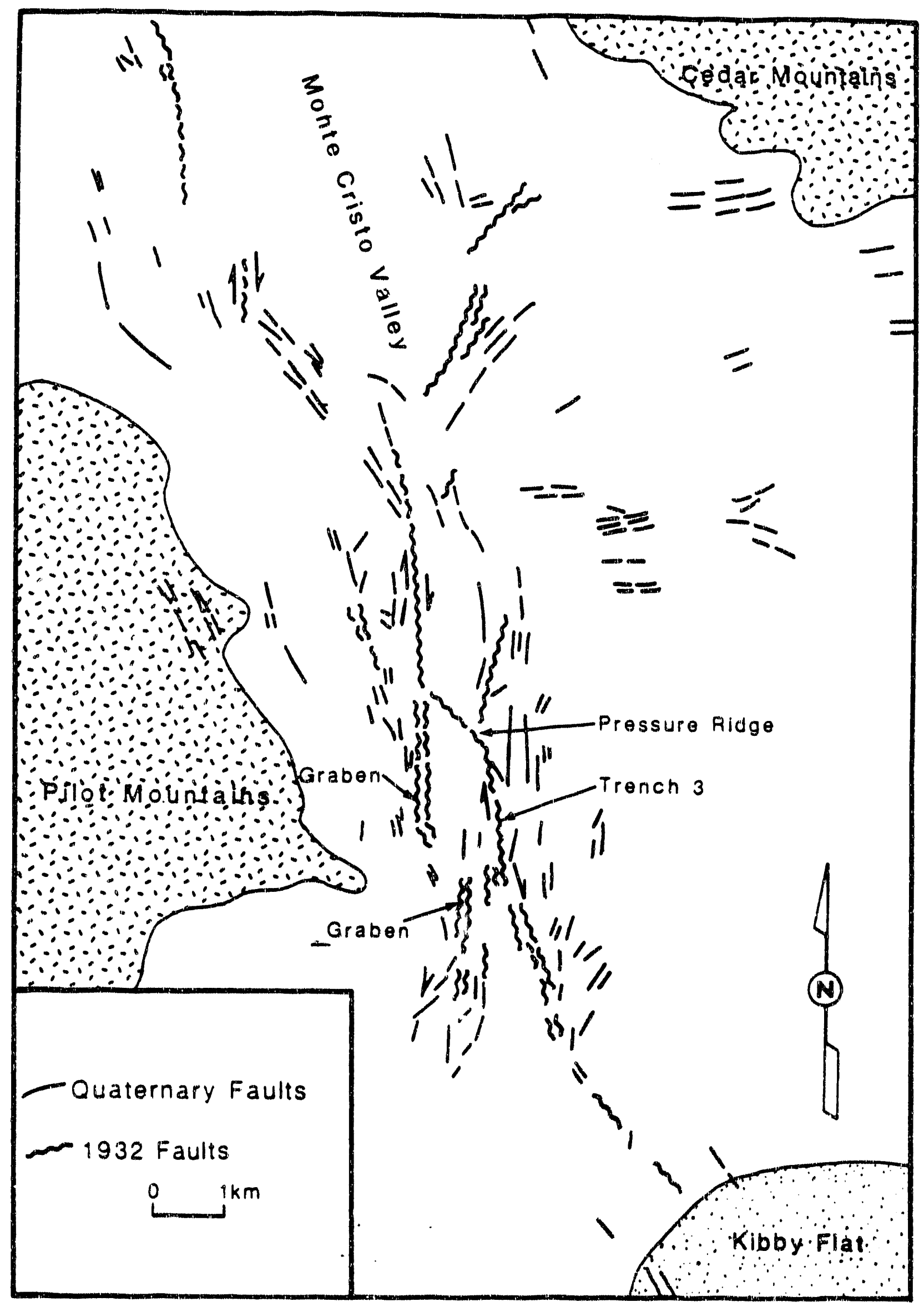

FIGURE 14 Quaternary and 1932 faulting in Monte Cristo Valley. 


\section{Aopendix A}

Consultant's report: A critical evaluation of cation-ratio dating of rock varnish, and an evaluation of its application to the Yucca Mountain repositoxy by the Department of Energy and its subcontractors

by R. I. Dorn 


\title{
A CRTMCAL EVALUATION OF CATION-RATIO DATING OF ROCX VARNISH, AND AN EVALUATION OF ITS APPLICATTON TO THE YUCCA MOUNTAN REPOSTTORY BY THE DEPARTMENT OF ENERGY AND ITS SUBCONTRACTORS
}

\author{
by \\ Dr. Ronald I. Dorn \\ Department of Geography \\ Arizona State University
}

Tempe AZ 85287

\begin{abstract}
A Final Report for the
Nevada Bureau of Mines and Geology

for the Period January 1987 - June 1988
\end{abstract}

June 1, 1988 
Table of Contents

Sunmary

p. 1

I. Introduction

p. 2

II. Assumptions of Cation-Ratio Dating

p. 4

III. Inherent Limitations of Cation-Ratio Dating

p. 20

IV. Evaluation of the Role of Cation-Ratio Dating

ค. 22

for Use on the Yucca Mountain Nuclear Waste Repository Project.

A. Evaluation of DOE Application of SEM to

p. 22

Cation-Ratio Dating

1. Introduction

2. Concerns Unique to the SEM Method

3. Pocential Sampling Difficulties

4. Potencial Sample Analysis Difficulties

5. Potential Problems with the SEM Curve

6. Potential Problems in Applying SaM Curve

7. Preliminary Review of Varnish as a an indicator of ash deposition

p. 26

?.32

p. 36

p. 38

3. Review of the Scraping-PIXE Method

C. Comparison of the SEM and PIXE Methods

D. Results of Varnish Analysis at Crater flat Conducted for the Nevada Bureau of Mines and Geology

E. Perspectives on Future of Cation-Ratio Dating

p. 39

p. $\$ 1$

p. 41

?. 50

V. Use of Radiocarbon Dating Rock Varnish in the Yucca Mountain Investigation

p. 51

A. Preface

5. 51

p. 51

B. Method

C. Discussion: Support and Complications

D. Preliminary Varnish Radiocarbon Dating of Lathrop Wells Cinder Cone

p. 54

E. Concluding Remarks on Radiocarbon nating of Varnish

p. 63

p. 66

References

อ. 67 
1. Incipient Varnishes on Historical Surfaces p.5

2. Varnish Development in Different Microenvironments 0.12

3. Cation.Racio Variations with Depth p.13

4. cossoder of paleo-erosion p.15

5. Thin Section Observations on Cation-Ratio Dating p.17

6. New Cation-Leaching Curve for the Coso Range p.19

7. Effect of Microcolonial Fungi p.25

8. Irregular Subsurface Boundaries $\quad 0.27$

9. Biological Lowering of Cation Ratios p.28

10. Subsurface Titanium-Rich Detritus p.30

11. Hypothetical Scenarios of SEM Method Incorporating Underlying Rock Material into a Cation Ratio 0.31

12. Comparison of Cation-Leaching Curves for Yucca Mtn p.35

13. SEM Stereo View of Detritus Removed in Scraping 9.40

14. SEM Analysis of Varnish on Volcanic Bombs of 0.64 Lathrop Wells Cinder Cone 


\section{LIST OF TABLES}

1. Initial Ratios

0.7

2. Microenvironmental Factors Affecting Cation Ratios

p.9

3. Coso Range Cation-Ratios by PIXE and SEM Methods

p. 21

4. Varnish Cation Ratios and Calibration for Yucca Mtn

p. 34

5. Comparisons of Age-Estimates by PIXE and SEM Methods

A. Test Comparison or Hypothetical Ratios $\quad$ p.37

B. Comparison on Cation-Ratios for Crater Flat Units

of the Nevada Bureau of Mines and Geology

6. Complete PIXE Data Used for Crater Flat Study

p. 46

7. Effect of Microbial Activity and Carbonate on stable

Carbon Isotope Values of Laboratory Varnishes

8. Tests of Varnish Radiocarbon Dating

p. 58

9. Effect of Microcolonial Fungi on Varnish stable

p. 61

Carbon Isotope Values, near Crater Flat 
There are three interrelated aspects to this report. The first is a complete overview of the theoretical Iimitations of the cation-ratio dating method, regardless of the particular method used to determine a cation.ratio. The second is an evaluation of the rock varnish work of the DOE and its subcontractors, Los Alamos and the U.S. Geological Survey, as it regards the Yucca Mountain Repository. The third is to present the results of cation.ratio and radiocarbon analyses of varnish conducted for and with the Nevada Bureau of Mines and Geology. These themes are separated into distinct sections where possible, alchough they are necessarily woven together throughout the report. The results of this report reflect work completed during 1987 and the first half of 1988. (Some analyses are still in progress. This is difficult to avoid as the radiocarbon and cation-ratio analyses are completed by outside laboratories.)

Cation-ratio (CR) dating is a biogeochemical method that requires calibration through numerical age-determination methods (dating terminology from colman et al., 1987). It only works when the compared varnishes have experienced similar cation-leaching conditions, similar inputs of varnish cation-ratios, and varnish stability. This report outlines the assumptions of $C R$ dating in detail and presents the inherent limitations of the $C R$ method. While $C R$ dating has many potential difficulties, it provides one of the few ways to obtain some degree of age-control in circumstances where most other methods are not usable.

Given the current use of cation-ratio (CR) dating by the DOE (through LOS Alamos and the U.S. Geological Survey) at Yucca Mountain, and its intended use to evaluate neotectonic hazards, Quaternary geomorphic events, and volcanic hazards (Harrington and Whitney, 1987), a careful scrutiny of this work is warranted. Several severe problems are found with the SEM method used to determine varnish CRs by fiarrington and Whitney (1987). Selected ones are presented in this summary. For example, there is no way presented to assess the accuracy of the CRs determined by the SEM method by independent means; assumptions of rock and varnish chemistry may be invalid because they are untested and because chemistry can vary spatially over the scale of the SEM-EDAX analysis. The curve used to calibrate varnish CRs, derived by the SEM method, is based mostly on Uranium-trend dating and is much steeper than a curve derived by the scraping-PIXE method using radiocarbon and $K$ - Ar calibration points. The direction of bias in the DOE curve would be to systematically everoredict age and underestimate hazard. There are no calibration poines for the DOE curve in the last 40,000 years. As $C R$ dating is practiced by Harrington and Whitney (1987), the SEM method systematically overweights the surface 
layer of the varnish. It does not correct for an overlap of barium with titanium, unlike the PIXE method. There are far more objections than these listed in the report. It is concluded that there are very serious uncertainties about the SEM method used by the DOE through LOs Alamos and the U.S. Geological survey; these concerns warrant a continued close scrutiny of the DOE varnish research.

Varnish radiocarbon dating and cation-ratio analyses were completed in conjunction with the Nevada Bureau of Mines and Geology in the Crater Flat area. These results show that the calibration curve used by Harrington and Whitney may be seriously off. Also, radiocarbon dates for varnishes formed on Quaternary units at Crater Flat provide some of the first mumerical age-control for the Quaternary geology of Crater Flat. CR dates on varnishes too old for radiocarbon dating provide insight into the ages of old quaternary units in Crater Flat. The Quaternary units span a time range from older than about 650,000 years to the Holocene.

Tests are in progress to assess the effect of "bomb" carbon on the varnish-radiocarbon dates. Tests are in progress to assess the potential to use Uranium-series dating on varnish in the Crater Flat area with DE. T.L. Ku. Tests are in progress to Eill-in "gaps" on the NBMG cation-leaching curve in the late Holocene, and to explore the use of varnish-radiocarbon and $C R$ dating in neotectonic studies in the vicinity of Yucca Mountain. 


\section{Introduction}

Rock varnish is a thin coating of mostly clay minerals and manganese and iron oxides (cf. Potter and Rossman, 1977, $1979)$ that forms on rocks in all terrestrial weathering environments, but is most common in arid and semiarid lands (Dorn and Oberlander, 1982). Over the past cencury Quaternary scientists have proposed various means of determining the age of this varnish, and hence place a minimum age for the underlying geomorphic or archaeological surface. These early methods such as changing color, thickness and general appearance are discounted in Dorn (1983). The adsorption and enhancement of $\mathrm{Ni}, \mathrm{Cu}$ and $\mathrm{Zn}$ in rock varnish, first suggested by Dorn and Oberlander (1982), remains largely unexplored. Hope has been expressed for Uranium-series dating of varnish (Knauss and Ku, 1980; this report), but questions remain over whether the system is closed because thorium accretes to varnish with clay detritus. The two techniques of assigning numerical and calibrated ages (cf. Colman et al., 1987) to rock varnishes that have been explored the most are accelerator mass spectrometry (AMS) radiocarbon dating of rock varnish (Dorn et al., 1986, 1987b, 1987c) and cation-ratio dating (Dorn, 1983; Dorn et al., 1986; Dorn et al., 1987a; Glazovskiy, 1985; Harrington and Whitney, 1987). Cation-ratio dating is the major topic of this report.

Since the first review of cation-ratio (CR) dating by Dorn (1983), a number of new issues and applicatjng have been raised and with good reason. Rock varnish offers one of the few means of assessing the ages of geomorphic surfaces in many arid and semiarid environments. Appropriately, applications of $C R$ dating have expanded and controversies have burgeoned. It is the hope of this report to place $C R$ dating in perspective by providing an evaluation of the method to date. The purpose of this review is to provide the reader with a realistic view of the imitations of the dating techrique.

CR dating is based on observations of the progressive lowering of the ratio of $(\mathrm{K}+\mathrm{Ca}) / \mathrm{TI}$ in rock varnishes over time, where the rock varnish has formed on geomorphic surfaces of established relative or numerical age. It is reasonable that such a CR lowering should occur, since $K$ and $\mathrm{Ca}$ are more mobile than $\mathrm{Ti}$ in the biogeochemical environments where varnish forms (Dorn, 1983). It is classified as a chemical-biological method of estimating calibrated ages in the nomenclature of Colman et al. (1987).

The usefulness of $C R$ dating in Quaternary research is predicated on the ability to calibrate the varnish CRs with 
established radiometric ages in a cation-leaching curve (CLC). Dorn (1983) and Dorn et al. (1987a,b) have presented CLCs of varnish CRs with K-Ar dated volcanics and AMS radiocarbon dated varnishes in the Coso, Cima and Big PineOwens Valley volcanic fields in eastern California. Glazovskiy (1985) examined varnish CRs in the parmirs of the U.S.S.R., and Harrington and Whitney (1987) constructed CLCs for the Espanola Basin in New Mexico and the Yucca Mountain area of southern Nevada.

Different methods have been used to establish a varnish CR. Dorn (1983) and Dorn et al. (1987a,b) primarily use a method called hero scraping-PIXE, where the varnish is first mechanically scraped off the rock, cleaned to remove any material from the underlying rock, and then analyzed by particle-induced X-ray excitation (PIXE) (Cahill, 1980; Cahill et al., 1984). Varnish scrapings have also been analyzed by neutron activation, $x$-ray florescence, wet chemical and other means. Dorn (1983, p. 58) also used a scanning electron microscope (SEM) to generate $x$-rays for energy-dispersive analysis (EDAX) and an electron microprobe to examine varnish CRs. Glazovskiy (1985) used SEM-EDAX on varnish on glacial deposits in the pamirs, U.S.S.R. Harrington and Whitney (1987) have also used a SEM-EDAX method to develop their CLCs. The two major methods that have emerged to assess varnish CRs are scraping-PIXE and SEM. EDAX. These methods will be evaluated in detail later. The following discussion examines some of the uncertainties and limitations of $C R$ dating, regardiess of how the $C R$ is determined.

\section{General Assumptions/Limitation of Cation-Ratio Dating}

As presented in Dorn (1983), there are several assumptions and associated uncertainties regarding CR dating. Some of these have been tested since 1983. Others have not been fully evaluated. These concerss are grouped together into three general assumptions.

General Assumption \#1. The initial ratio (IR, airborne fallout that is incorporated into varnish on subaerial rock exposures) bas been similar for the deriod of rime under examination at all comoared sites.

The particle size that is incorporated into varnish is typically $<2 \mathrm{\mu m}$ (Dorn, 1983, 1986). Hence, subaerial varnishes should have IRs that start out at the CR of this matorial. The results of Rabenhorst et al. (1984) suggest an assumption of similar airborne fallout may not be unreasonablo at present for the Edwards plateau of west Texas. Pewe et al. (1981) argue that this is not unreasonable Eor much of the Quaternary in central Arizona. 
Figure 1. Scanning electron micrographs of tncipient varaishes on historical surfaces.

A. Fort Pfute constructed in 1868 in the Mojave Desert, CA.

B. 1884 engravings, near Mannahil1, South Australia. Note the microorganisms on the patch of varnish.

C. Stone face, constructed about 1900 in Bodie, eastern CA.

D. Swansea, near the Coso Range, from a surface faced about 1872. 

a 3 (t)

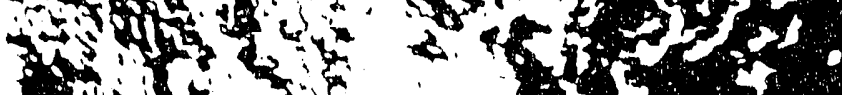
$74.50 \%$ $x+1, k$

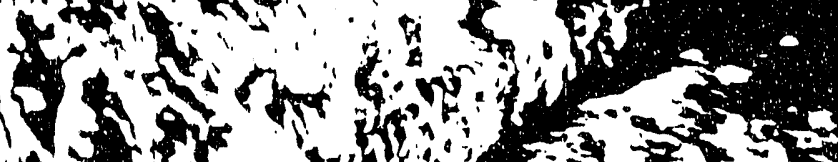
at. $d y$ $-2+w 10$ stur

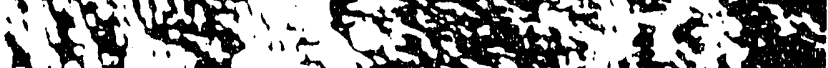
s. 20151

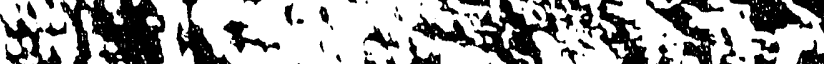
$1+2+2$

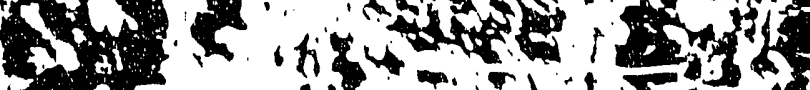
$12+-1,33$

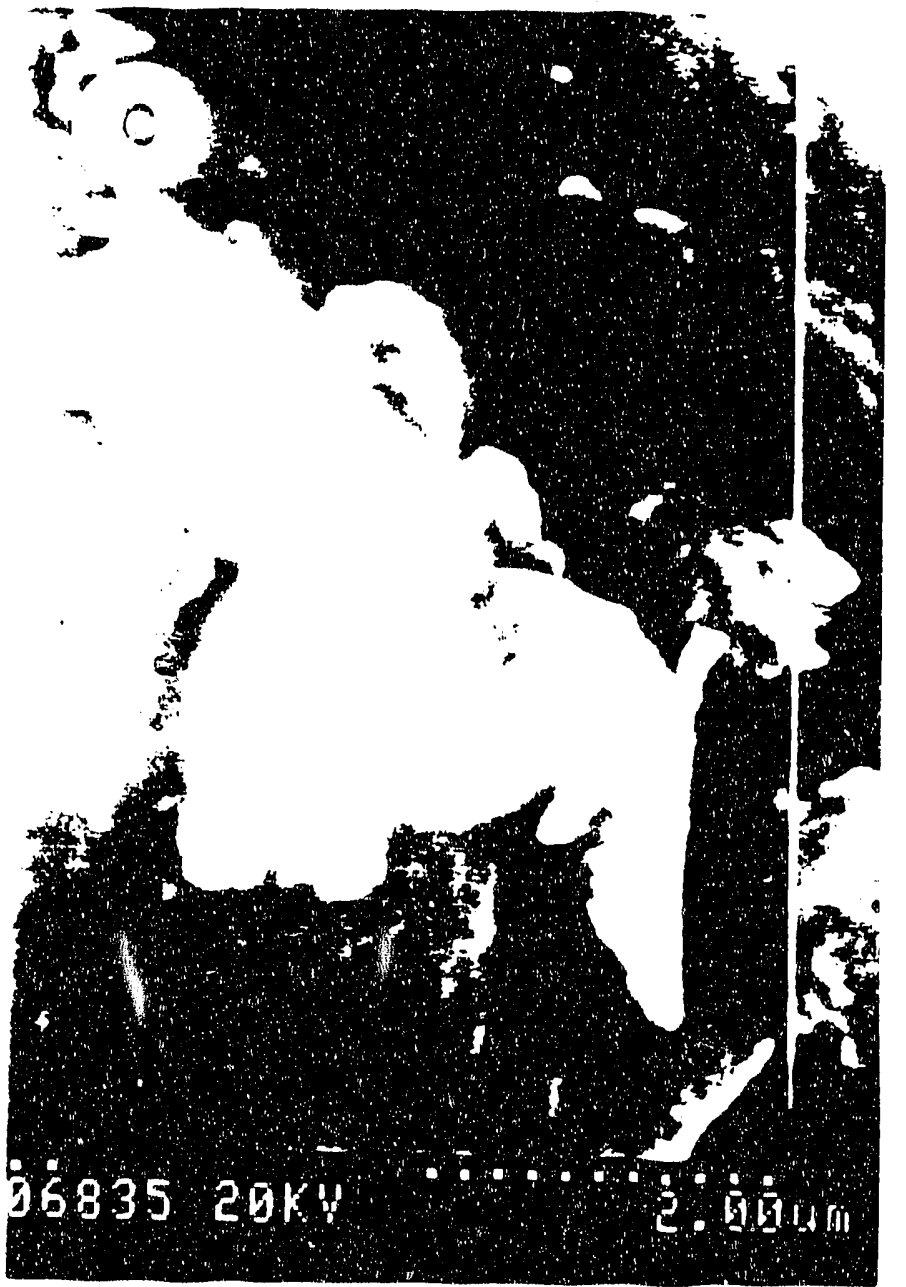

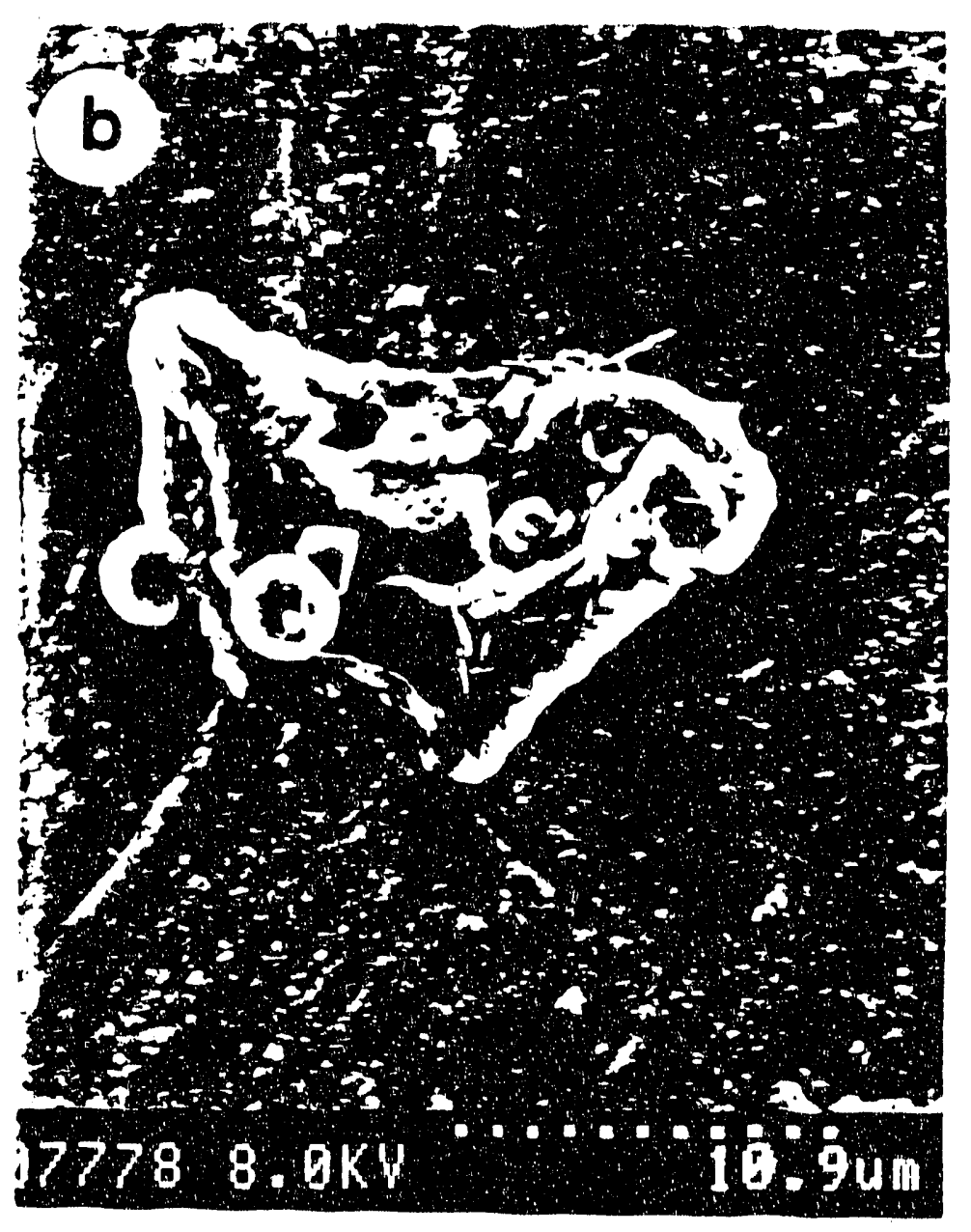

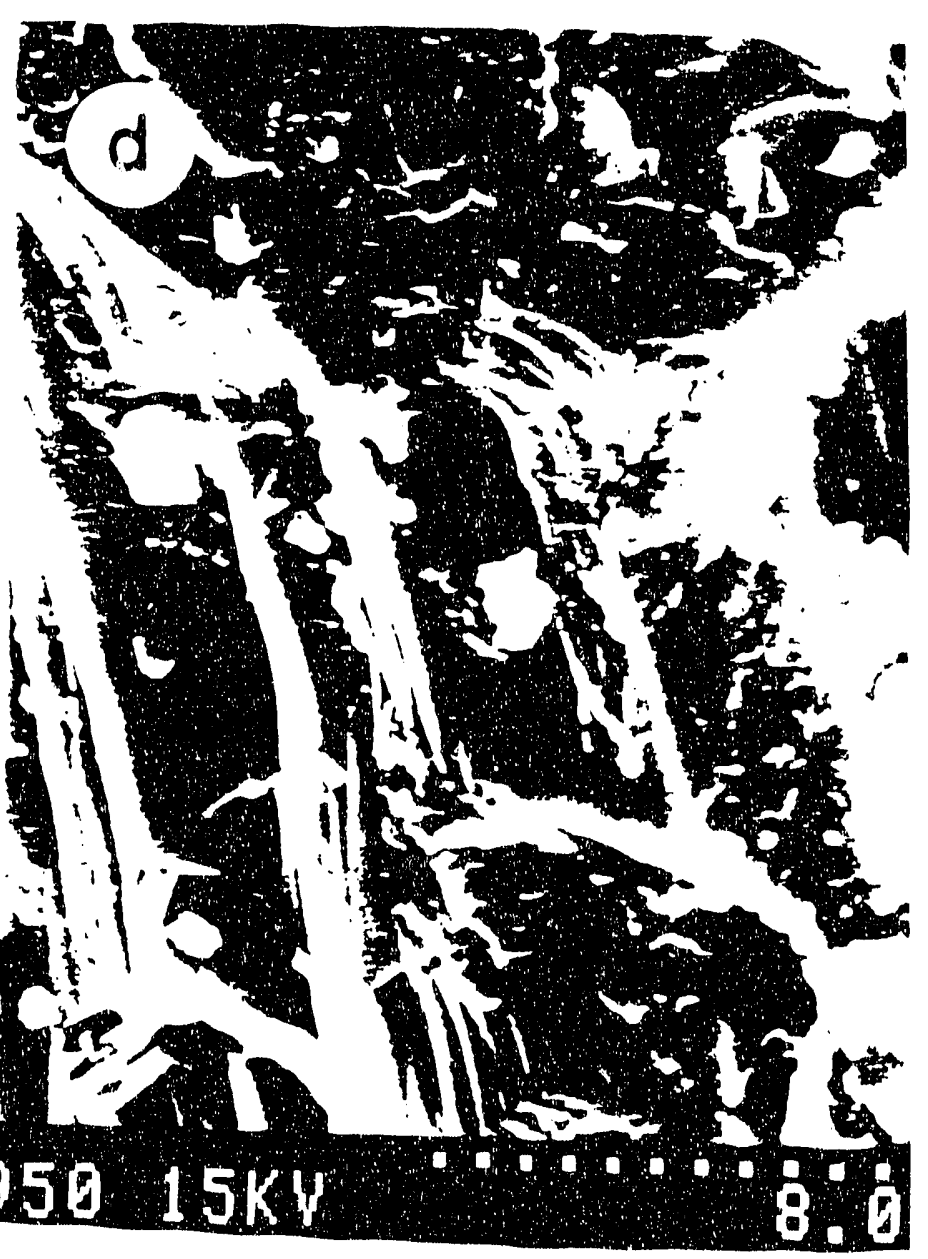


present airborne fallout, however, may not reflect natural conditions due to modifications of the aeolian environment that generally increase amounts of $\mathrm{Ca}$ and $\mathrm{K}$ in the atmosphere (Barone et al., 1981; Eldred et al., 1984; Malm et al.. 1986). To minimize this anthropogenic effect, IRs have been collected from sites of long-term dust accumulation, such as the uppermost part of the Av soil horizon or the deep depressions on rock surfaces. The CR of the < $2 \mu \mathrm{m}$ fraction of these natural sites of aeolian fallout have been relatively similar within each Cic area, but somewhat different from region to region. Of note, where the results of airborne collector devices have been compared with the CRs derived from these natural aeolian sinks, the CRs are about $1.1 / 2$ to 10 times higher in the placed airborne collectors, probably due to the anthropogenic effects of dust generation (R.I. Dorn, unpublished data).

The CR of the $C 2 \mu \mathrm{m}$ fraction of these natural "collectors" is assigned an age of about 100 years on a cation-leaching curve. This is based on SEM observations of microscopic varnish development on historic surfaces. Varnishing starts to be seen with an SEM after about 60 to 100 years in the southwestern U.S.A. and arid south Australia (Figure 1). The CRs of these microscopic varnishes tend to be similar to the IRs collected nearby (Table 1). While it is felt that EDAX analyses of in situ varnishes may not be completely accurate, the results are suggestive that the IR of varnishes can be approximated by the < 2 un fraction of airborne fallout.

What is most uncertain regarding this first assumption is that the chemistry of this IR and the abundance of dust fallout has remained similar over time for all compared samples. During the period of accretion of rock varnishes under study, major variations in lake levels, vegetation changes, and climatic fluctuations have occurred. It is important to point out, however, that short-term changes in airborne fallout over hundred of years or less are unlikely to affect a desert varnish, because rates of accretion are quite slow in arid and semiarid environments (Dorn and Oberlander, 1982; Whalley, 1983). 
Table 1. Initlal cation-ratios of rock varnishes collected from historical surfaces, as approximated by energy-dispersive analysis of 8-rays (EDAX). and EDAX CRs of < 2 micron fraction of dust collected from these sites.

\begin{tabular}{|c|c|c|c|}
\hline Site (nearest curva) & $\begin{array}{l}\text { Dace Surface } \\
\text { Exposed }\end{array}$ & $\begin{array}{l}\text { EDAX CR of } \\
\text { Dust at Site }\end{array}$ & $\begin{array}{l}\text { EDAX CR } \\
\text { of Varnish }\end{array}$ \\
\hline $\begin{array}{l}\text { Eort Piute, Mojave Desert, } \\
\text { CA. (Mojave) }\end{array}$ & ca. 1884 & $8.7+1-0.7$ & $8.8+1-0.5$ \\
\hline $\begin{array}{l}\text { Rearsarge, Owens Valley, } \\
\text { CA. (Owens Valley) }\end{array}$ & ca. 1867 & $9.5+1-0.5$ & $9.0+1-0.7$ \\
\hline $\begin{array}{l}\text { Bodie, Eastern CA. (environ- } \\
\text { ment most similar to Lunar } \\
\text { Crater curve) }\end{array}$ & ca. 1900 & $8.9+1-0.4$ & $8.6+1-0.5$ \\
\hline $\begin{array}{l}\text { Franklid Mines - Chloride } \\
\text { Cliff, CA (Crater Flat) }\end{array}$ & ca. 1916 & $10.0+1-0.6$ & $9.8+1-1.1$ \\
\hline $\begin{array}{l}\text { Swansea, Owens Valley, } \\
\text { CA. (Coso) }\end{array}$ & ca. 1872 & $9.3+1-0.4$ & $8.8+1-0.7$ \\
\hline $\begin{array}{l}\text { nr. Springfield, } C O \\
\text { (SE Colorado) }\end{array}$ & 1905 & $9.8+1-1.0$ & $9.2+1-0.6$ \\
\hline $\begin{array}{l}\text { nur. Yunta, South Australia } \\
\text { (Oulnina) }\end{array}$ & 1884 & $10.3+1-0.8$ & $9.9+/-1.2$ \\
\hline
\end{tabular}


General Assumprion \#2 Rock varnish gerves as a cation. exchance comelex where rates of $(K+c a) / L$ chance have been similar for comorad samoles.

This assumption appears quite reasonable at first. The theoretical capacity of the mixed-layer ilitice. montmorilionite clays and Mn.Fe oxyhydroxides in varnish to act as a cation-exchange complex as been argued (potrer. 1979; Jenne, 1968). Potassium and calcium are also recognized 0 be far more mobile than Ti le.g., Polynov, 1951; Marchand, 1974; Yaalon et al., 1974; Colman, 1982, $1986)$.

In reality, the complexities of rock varnish make the mechanics of cation-exchange uncertain. Micromorphological structures in varnish differ over short distances (Dorn. 1986), and these affect rates of $C R$ change (Table 2). In addition, variations in varnish thickness, inter-layer and intrallayer cementation, organometallic compounds, permeability, and other disparities can also insluence varnish CRs. For example, varnish thickness varies considerably on the latest-pleistocene (ca. 10,500 y5 B.P.) highstand of Searles Lake (Figure 2) (Smith, 1976, 1984); the percentage of $\mathrm{Mn}$ and $\mathrm{Fe}$ oxides varied from < 10 to about 50 \% in different microenvironmental positions on this shoreline. Subaerial varrish CRs varied, as much as 60 for thickness and 85t for chemigtry. On the optimistic side, the modemedian and mean of varnish chemistry, depth, and CR were similar when examined from the perspective of a larger population of varnishes at the searles Lake shoreline. The extreme figures presented here probably represent about 2 sigma errors, and these CRs outliers would be discarded as anomalous in the context of a complete data set. However. variations wuch as these do occur; they exemplify the complexity of this assumption, and they iliustrate the need for collecting and analyzing multiple samples of rock varnish.

A more serious uncertainty is the behavior of $\mathrm{K}, \mathrm{Ca}$, and $T i$ in varnish. At a simplistic level, the CRs of $k: T i$ and Ca:Ti should have a similar trend of a decrease with time, and the CRs of $K: T i, C a: T i$ and $(K+C a) / T i$ should decrease with greater depth (time) in the varnish. These changes do occur, but not always. It is not uncommon for two varnishes from the same site to have a similar $(\mathrm{K}+\mathrm{Ca}) / \mathrm{Ti}$ ratio, but have the relative abundances of $K$ and $C a$ vary considerably. Figure 3 illustrates how $(\mathrm{K}+\mathrm{Ca}) / \mathrm{Ti}, \mathrm{K}: \mathrm{Ti}$ and $\mathrm{Ca}: \mathrm{Ti}$ rarios vary with depth in different microprobe transects and an average of multip:- microprobe transects. Similar results of extreme variabi-ity are reported by Dragovich (1988). This has been the copic of considerable investigation since the pocential of $C R$ dating was realized. The causes of these variations 
Table 2. Microenviromental factors that have been found to alter varnish cation-ratios.

Factor

Effect on

Cation-Ratio

Assessment and Comments

$\begin{array}{ll}\text { Proximity to Lichens } & \text { Lowers } \\ & (\text { by } 10 \text { to } \\ & >50 \%)\end{array}$

Abundant MieroColonial Fungi ( $\mathrm{YCF}$ )

Abundant Filamentous Fungi

Proximity to Abundance of Previous Lichens or Previous MCF

Different Fossil Micromorphologies for same site

Soil Pioximity

Sheltered Locales

\section{Lowers \\ (by $<5$ to $>50 \%$ )}

Lower (by $<5 \%$ to 15\%) or Higher (by ca. 20\%)

\section{Lower (by $<5 \%$ to $>40 \%)$}

Higher or Lower (by ca. 5-10\%)

Higher (by $25 \%$ to $>100 \%)$ or Lower (by 10 to $>50 \%$ )

Higher (by 10 to > 100\%) Lower (by $<5$ to $>50 \%$ )
Best to avoid areas near lichens completely. In some riperian environments, however, licbens are associated with an increased cation-ratios.

SEM examinarion can reveal high concentration of MCF (Staley et al, 1983), as in Fig. 7. Avoid concentrations exceeding $5 \%$ or where MCF erode into varnish with a deasity over 1 in $100 \mathrm{sq}$. microns.

Where filamentous fungi have concentrations over 5\%, CRs can be seriously affected. In periglacial environments, CRs tend to be raised; in deserts CRs tend to be lowered.

SEM and thin section examination of varuish cross-section reveals paleopitting frow lichens or wicrocolonial fungi. Best to reject the sample if any cross-sectional evidence of paleoerosional episodes observed.

If there are fossil botryoids, CRs will be higher; if the structure is only lamellate, CRs will be lower

Effect depends on the local cationratio of the soils. Best to sample at least 1 above surrounding soil. if possible.

It areas of aeolian abrasion, sampling may be necessary in low energy environments. These may have a different initial ratio and the ratio should be carefully determined from these sites. 


\begin{tabular}{|c|c|c|}
\hline R, Ca, TI Anomalies & $\begin{array}{l}\text { Higher or } \\
\text { Lower } \\
\text { (extremely } \\
\text { variable) }\end{array}$ & $\begin{array}{l}\text { In each region, there are local } \\
\text { areas with anomalous concentrations } \\
\text { of } R \text {, } C a \text {, and/or } T \text {. } \\
\text { These need to be assessed by carion } \\
\text { ratio analysis of the } 2 \text { micron } \\
\text { fraction of airborne dust. }\end{array}$ \\
\hline $\begin{array}{l}\text { Where Runoff Collects, } \\
\text { or where dew collects }\end{array}$ & $\begin{array}{l}\text { Usual1y Lower } \\
\text { (ca.5-40\%) }\end{array}$ & $\begin{array}{l}\text { Small depressions and water running } \\
\text { over rock faces results in } \\
\text { more water contact with } \\
\text { the varnish. In cold deserts, } \\
\text { snow collection and melt water } \\
\text { accentuates leaching. }\end{array}$ \\
\hline Acid pH & $\begin{array}{l}\text { Lower (by ca. } \\
15 \% \text { ) }\end{array}$ & $\begin{array}{l}\text { Scrape varnish and analyze with } \\
\text { pH microelectrode in } 1: 1 \text { paste. }\end{array}$ \\
\hline Alkaline pH & $\begin{array}{l}\text { Higher (by ca. } \\
5-10 \% \text { ) }\end{array}$ & $\begin{array}{l}\text { Scrape varnish and ansiyze with } \\
\text { pH alcroelectrode in } 1: 1 \text { paste. }\end{array}$ \\
\hline Aspect & $\begin{array}{l}\text { Higher or } \\
\text { Lower } \\
\text { (on order } \\
\text { of }<10 \% \text { ) }\end{array}$ & $\begin{array}{l}\text { In semi-arid environments, } N \text {-NE } \\
\text { facing slopes have slightly } \\
\text { lower ratios, probably due to } \\
\text { more lichen, MCF, and fungi growth } \\
\text { that may have occurred in the past, } \\
\text { but was not recorded by random } \\
\text { examination of varnish cross-sections. }\end{array}$ \\
\hline Substrate & $\begin{array}{l}\text { Higher or } \\
\text { Lower } \\
\text { (variable) }\end{array}$ & $\begin{array}{l}\text { Friable substrates have higher } \\
\text { ratios, because the varnish is } \\
\text { eroded with the underlying rock. } \\
\text { Microbial colonization is slower } \\
\text { on smooth surfaces like quarti and } \\
\text { the varnish maye higher ratios, } \\
\text { if not sampled in motrofractures } \\
\text { where growth is not aa time } \\
\text { transgressive. To test substrate } \\
\text { effect, it is best to obtain } \\
\text { radiocarbon-calibrations } \\
\text { on the substrace(s) in question. }\end{array}$ \\
\hline
\end{tabular}


Surface Roughness

Organic Mater

Exposure
Higher or

Lower (on

order of

$<5$ to 15\%)

Lower (by

ca. $(5-20 \%)$

Usually Highex

(by 10 to

$>50 \%)$
Rough surfaces will trap larger aeolian detritus. SEM reveris size of fallout. Cation-ratio analysis of this larger size fraction reveals if there are anomalies present.

Contact with abundant organic natter usually lowers the cation-ratio.

Spalling of former rock crevices produces subaerial varnishes with a higher ratio. With aeolian abrasion, ratio higher than expected for original exposure of rock surface to subaerial processes. 
F1gure 2. Varash from different microenvironments of the ca. 10,500 year-01d highstand of Searles Lake (Smith, 1976, 1984).

A. From alkaline weroenvironment, relatively unsuitable for varnish development.

B. From more mesic microenvironment, for more rapid varnish growth. 

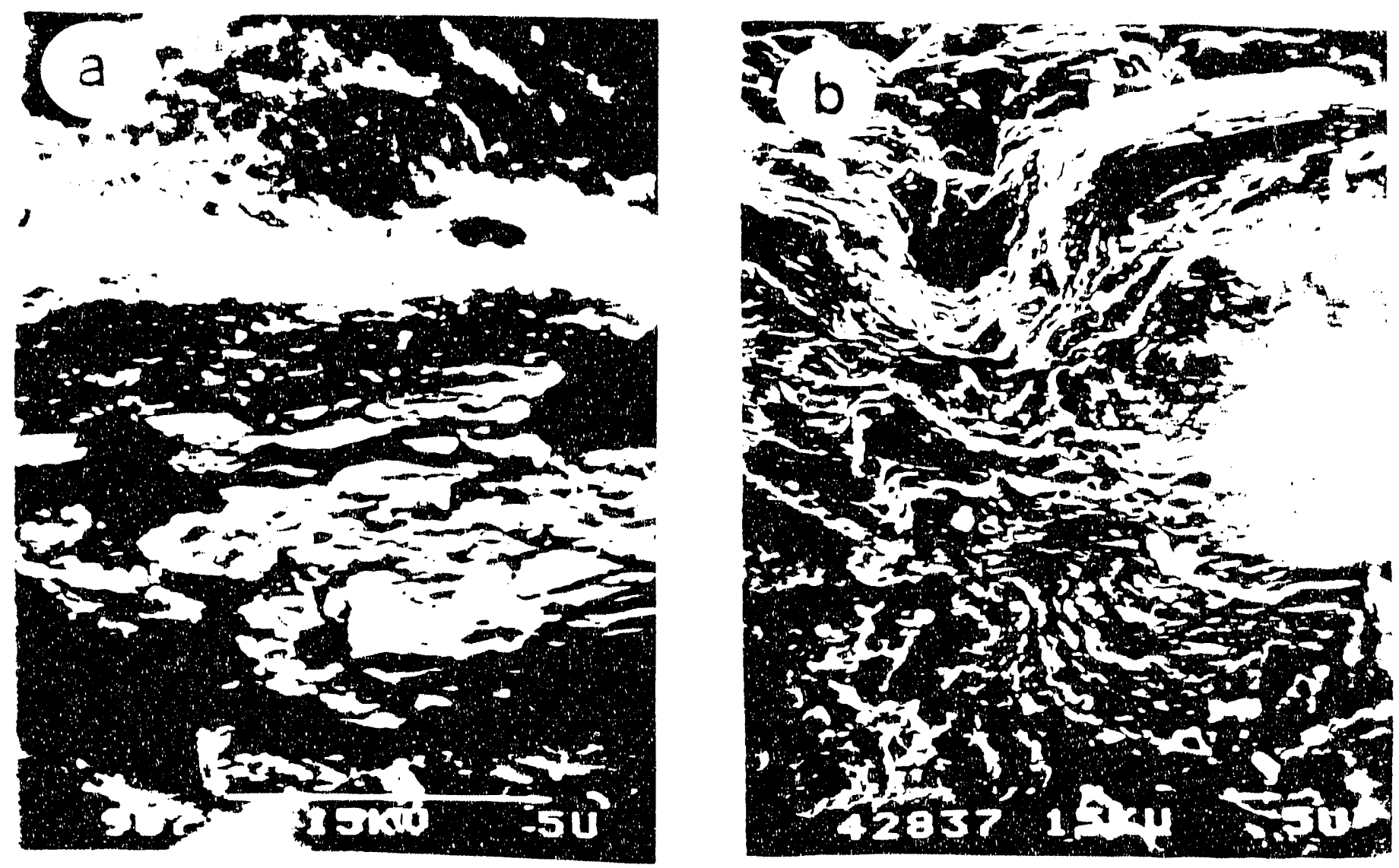
Figure 3. Varlations in varnish cation ratios with depth in arid varnishes, as messured by electron aicroprobe analysis.

A. Average of multiple microprobe transects for varnish on Coso volcanic 32 (Duffield et al., 1980). Depth variations in varnish profiles have been normalized by the $\mathbb{R}-A r$ age for the onset of varnishing at about $1.07+/-0.12$ wa (Duffield et al. 1980).

B. A single microprobe profile of Coso 32, showing the extreme variability of cation ratios with depth in a single profile.

C. This variability is also typical of ocher arid region varnishes, such as this profile of just Ca:Ti ratios in a varnish on the Q2a unit of Galena Canyon Fan, Death Valley (Dorn, 1988). 

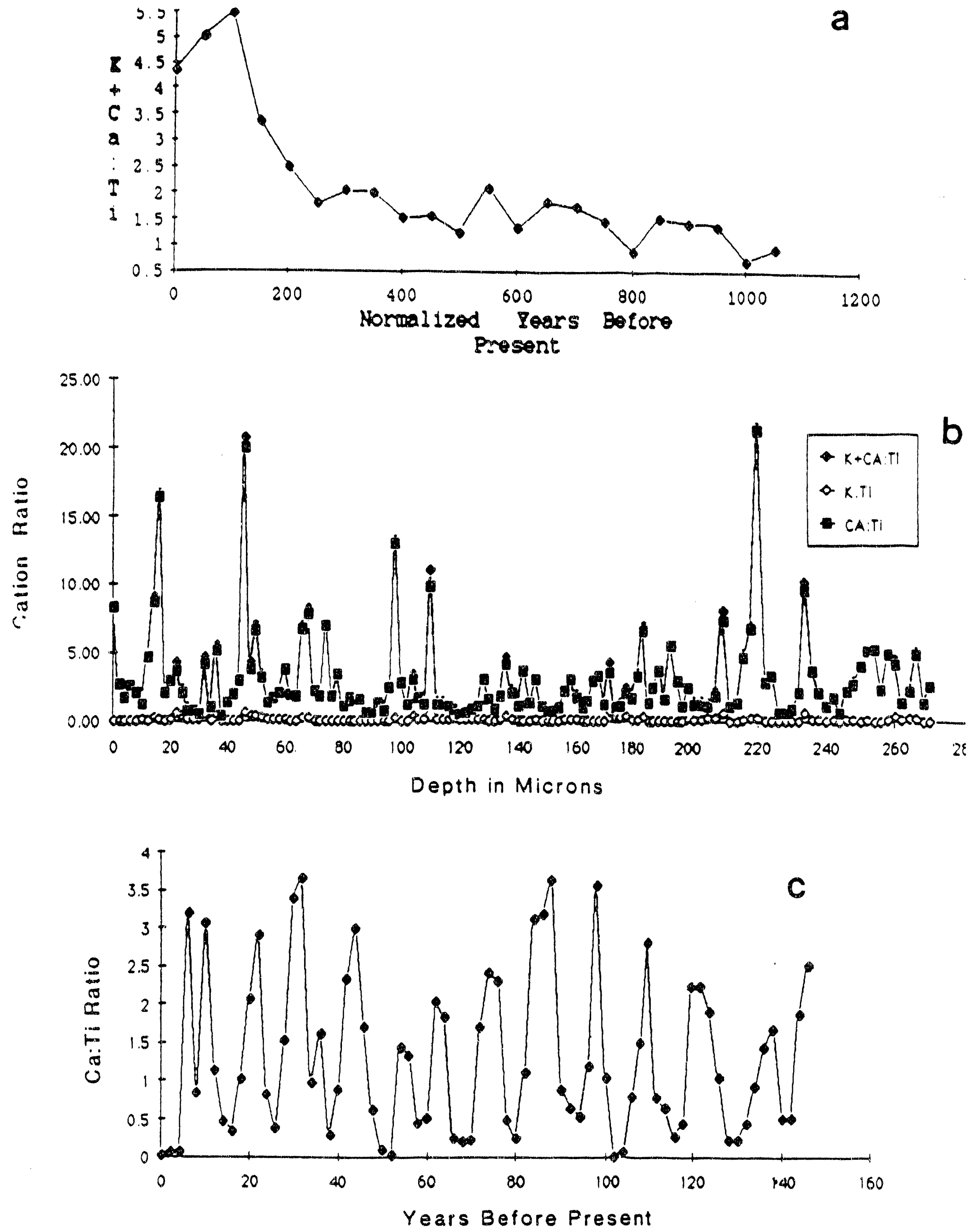
relate to the kinetics of $C R$ change, and are still uncertain. However, they probably relate to clay mineralogy-oxide interactions.

A further complexity is the behavior of titanium. Dorn (1983) observed that Ti may be enhanced in varnish by the development of "titanium domes", but it may also be possible to enhance titanium by other diagenetic mechanisms (e.g., Sudom and St. Arnaud, 1971; Morad and Aldahan, 1986).

How varnish CRs relate to climatic changes is a point of substantial uncertainty. That varnish CRs appear to decrease regularly on a semilog scale is not unreasonable; weathering phenomena in geomorphology tend to behave in a semilog Eashion. The CLC simply indicates that it becomes progressively more difficult to remove the $k$ and $C a$ relative to the Ti with time. What makes this method so uncertain is that this change occurs all while new varnish is being deposited and during major cïimatic changes. That only minor slope breaks are reported on most CLCs suggests that the $C R$ system is largely buffered against climatic changes. This may be due to the cumulative nature of the deposit, or it may be due in part to the mechanics of the exchange process.

General Assumption \#3: Envirenmental Eacters affect varnish CRs at comparaile sites in 3 similar fashien. In other words, rock varnishes that are compared for CRs must be from similar environments.

Several initial environmental preconditions must be met before $C R$ dating can be considered. The varnishes must have started to form on a subaerial surface soon after deposition or exposure of the rock surface. The nature of the varnish growth on the rock type(s) should not be heavily time transgressive, but starting at small patches and coalesces horizontally before starting major vertical growth. If this is not the case, the varnish should oniy be sampled from the microsites (for example, cracks in quartz) that Eavor the initial development of varnish and subsequent continuous growth. Lastly, the varnish must not have experienced erosional episodes, either mechanical or biochemical, during its growth.

These preconditions are for the large part testable. Historic lurfaces in a region can be examined for the lag time between the exposure of a surface and the onset of varnishing groweh (Eigure 1; Table 1). Chronos squences of geomorphic surfaces of different relative ages can be examined qualitatively in the field to assess whether and how varnish growth transgresses time on the lithology that is sampled. Varnish cross-sections can be examined by SEM and optical thin.section analysis for evidence of erosional episodes (e.g., Figures 4,5$)$. Recent research by Douglas 
Figure 4. Eptsodes of paleoerosion of varnish, observed by cross-sectional analyses.

4A. Varntsh on the Q3bl unit of Deach Valley Canyon Fan, Death Valley, $C A$. The pit on the right would be visible by surface analysis. However, the paleoerosional pit on the left would be missed by a purely surface analysis as conducted by Harrington and Whitney (1987).

4B. Varnish from the Q3bl unit of Warm Springs Fan, Death Valley, CA., illustrating two paleoerosional pits that have been filled in and covered up. The microcolonial fungi now growing on the surface were a likely cause of this type of biogeochemical erosional pit. 

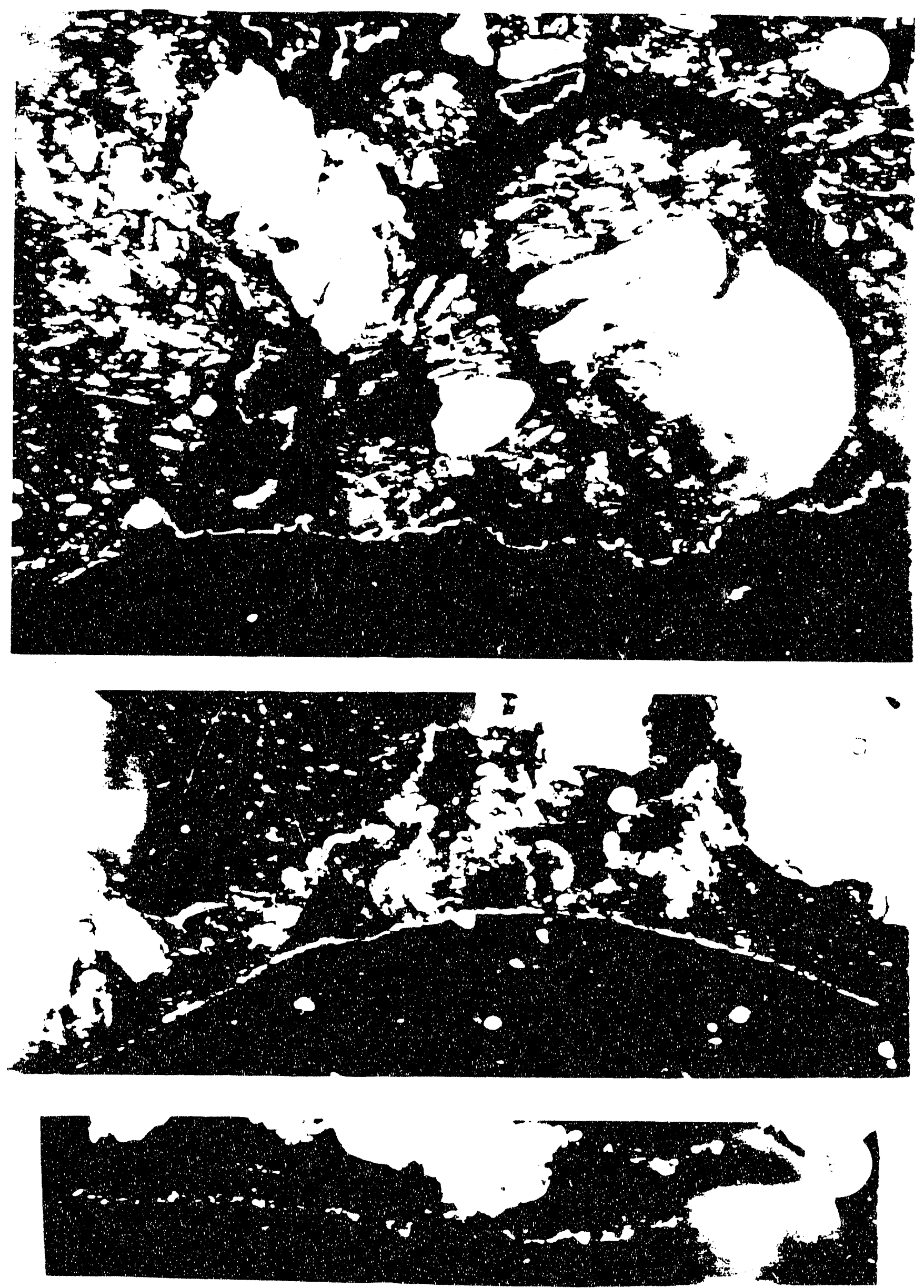
Figure 4. (Continued) Episodes of bleoerosion of varnish, obsarved by :ross-sectional analyas.

4C. Blogeochemical erosional pits fo varnigh from Crater Flat site CFP-26. In the Crater Flat area, varnishes have paleoerosional pits of:en not visible by only surface analygis. These pits obviously would be viaible by surface SEM viewing and should indicate to the observer that this sample should be rajected.

4D. In this thin section Erom (NT-40, from Crater Flat, a paleopit (see arrow) would not be visible by surface analysis. Also, note that this varnish has experienced some acolian truncation of microlamilations. This is not uncomon in Crater Flat varnishes; however, aeolian abrasion cef varnish can be easily spotted. 
F1gure 5. Aspects of cation liatio analysis illustrated by thin sections of rock varnish.

A. Varnish on a clast from site CFP-29, Cracer Flat. A regular layering is an indication that the varnish has not experienced erosional. episodes. (Varnish thickness about 60 microns).

B. Varnish from site CFP-2. This varnish has been subjected to some aeolian abrabion. Note how the layering in the varnish has been truncated in tise left and right hand parts of the imgge. (Varnish thicknegs on the left margin about 30 microns).

C. Varnish frow Hanaupah Canyon Fan, unit Q3a. Note how the darker varnish has penetrated into the crevices in the anderlying rock. An issue is how SEM-EDAX would resolve the various pockets of varnish. Hould the SEM-EDAX operator stop when he/she encountered the first rock oytlier, or when the entire pit was analyzed? Remember, the SEM-EDAX operator would have no idea what the subsurface varnish-rock boundary lookel like. The operator would only observe a relatively regular surface. In scraping-PIXE, however, the anomaly wuld be recogrized in the scraping process and the sample would not be used. 
(1987) demonstrates that rock rarnishes can degrado under certain biogeochenical conditions.

Table 2 presents a list of some microenvironmental factors that have caused a $C R$ to deviate from its condition on an unaffected microenviroment. This list was prepared as each CLC was developed. Tarnishes that generated extreme residuals were carefuliy reexamined and often recollected. For example, the entire coso curve in Dorn (1983) has been cestudied (Table 3 ). In addition, varnishes in microenvironments that were not chosen based on the partly intuitive criteria listed in Dorn (1983) (and repeated in Harrington and Whitney, 1987 ) were collected to examine the quantitative effects of different microenvironments of varnish CRB. The new list in Table 2 is not complete. Several variables are still under study. When the author's study of micro. and macro-environmental variables is completed, a biogeochemical model of varnish CR change will be presented. This model will hopefully be used to transfer curves from one region, where many data points are available, to another region that only has a limited number of calibration points. It is unlikely that this model would permit the transfer of a CLC to a region without any calibration points. To litele is known about the kinetics involved in the $C R$ process, although this would be goal of Euture work.

Even if it becomes possible to control contemporary envicommental disparities, the influence of climatic changes offers two major challenges. First, while it is possible to assess the presence of paleo-erosional episodes (e.g., Eigure 4.5), it may be impossible to discover past microenvironmental influences that affected varnishes. Fnr example. chere is no way to know for how many centuries a rock varnish regted under a dwarf conifer during more moisture-effective periods of the pleistocene, but is now far away from even desert scrub vegetation. Second, major climatic fluctuations must have affected $C R$ processes. However, this effect is anbiguous when CLCs are examined. A major break in the coso curve of Dorn (1983) at the Pleistocene-Holocene transicion, for example, appears to have been exaggerated by using the searles Lake highstand as a calibration point instead of more local calibrations. A small break may still be present in the coso Range (Figure 6), but not for the Cima-Mojave Desert curve (Dorn et al., 1987 a) where a greater density of radiocarbon calibrations are availabla. The only consistent slope break that has been observed in the Coso. Cima and Big Pine volcanic fields has been at around $100.140 \mathrm{ka}$. This slope break is minor and is probably not related to the major climatic change from oxygen-isotope stage 6 to stage 5 , because the slopes of the CLCs lessen in the time of greater moisture effectiveness. The log-inear plot indicates the CR system is largely 
Figure 6. New cation-leaching curve for the Coso Range. Data for these curves found in Table 3 .

A. Curve constructed only by scraping-PIXE.

B. Curve constructed only by SEM-EDAX.

The central curve represents the central regression(s) relating varnish $(\mathbb{Z}+\mathrm{Ca}) / \mathrm{T}$ i ratio to the log (base 10 ) of time. The upper and lower curves represent regression(g) fitted to the 2 siga errors of varnish cation ratio and age. In other works the extreme two sigma cation-liatios and two sigma age errors from the data set are used. This is an empirical approach to representing the error of a cation-leaching curve. The regression for scraping-PIXE can be expressed as follows:

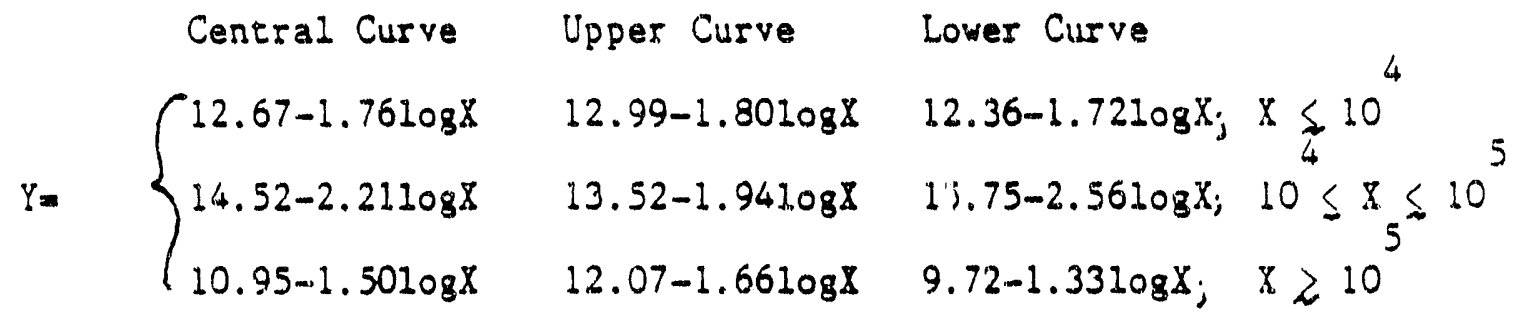

$Y$ is the $(X+C a) / T i$ ratio and $X$ is years before present.

Following the approach of Harrington and Whitney (1987) for SEM-EDAX, only I regression is used for the central tendency to describe the SEM-EDAX data for the Coso Range, and 2 regressions are added for the upper and lower error curves.

$Y=12.72-1.80 \log X$ (Central Curve)

$Y=13.85-1.86108 X$ (Upper Error Curve)

$Y=11.80-1.6010 \mathrm{X} X$ (Lower Error Curve) 
a

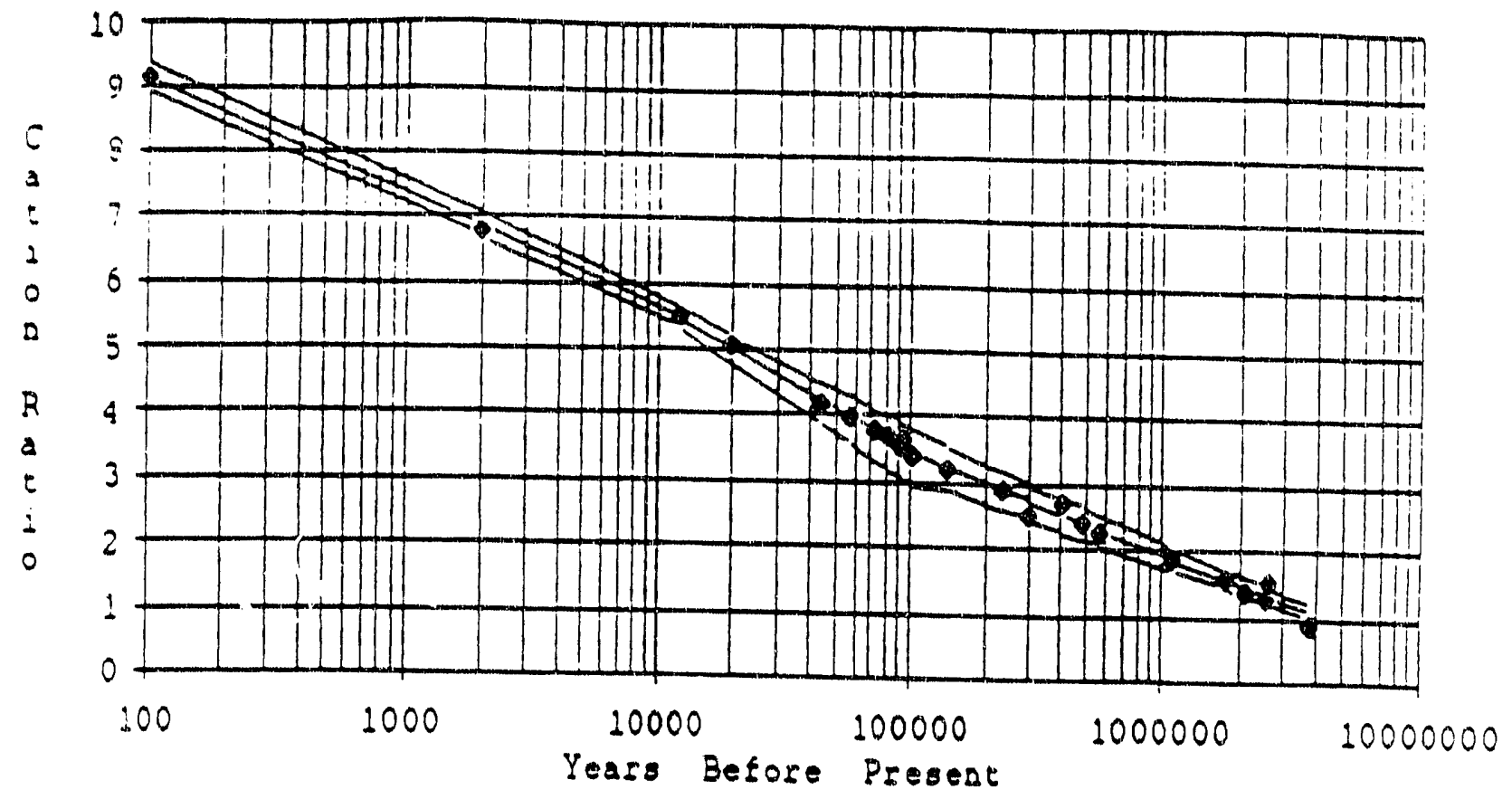

b

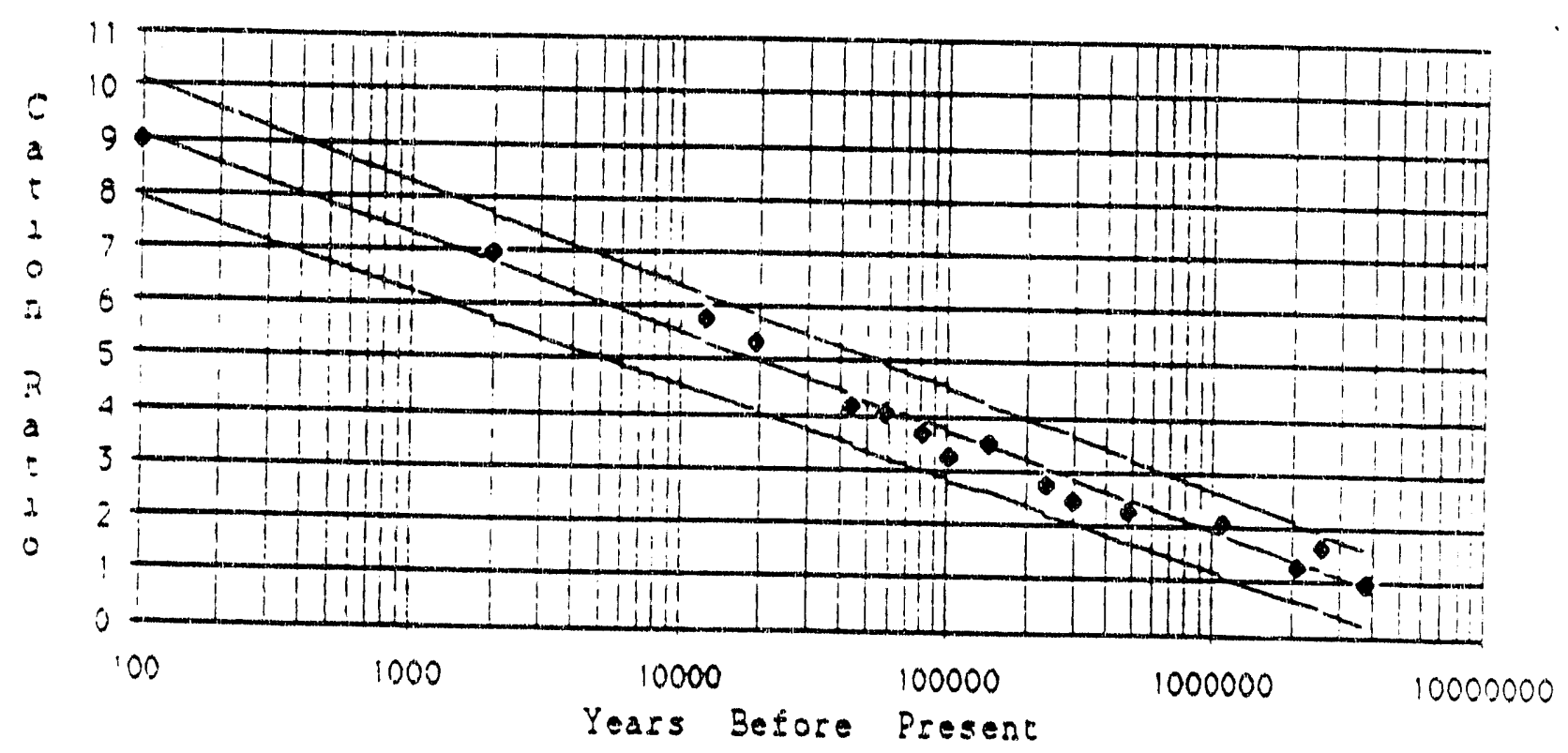


bufferod againgt tho effects of climatic changes, probably due to the cumulative nature of rock varnish. The major climatic effect appears to be the overall slope for a CLC. Differences in slope may relate to the percentage of warm season versus cold season precipitation (Dorn et al., 1987a); steeper slopes occur in climates that experience at present more warm season precipitation, and perhaps during previous interglacials.

In summary, the lack of understanding of the detailed mechanisms of changes in varnish CRs underscores the still early stage of understanding of $C R$ changes in rock varnishes.

II. Inkerent Iimitations of CR Datino

There are several difficulties that have been encountered over the last decade of varnish study that may not disappear. I feel it is important to outline these limitations.

(1) Any $C R$ age-estimate is based on a CLC and is therefore tied to the calibration points. If the K-Ar, U. series, U.trend, radiocarbon or orher dating method yields imprecise or inaccurate numerical ages, the CLC suffers in proportion to the weight of the sample(s) on the least. squares regression.

(2) The statistics of curve construction are not well worked out. Early CR dates in Dorn and Whitley (1984), Dorn et al. (1986) and Whitley and Dorn (1987) were based on a single least-squares semilog regression Eitted to the mean calibration dates and mean varnish CRs. Harrington and Whitney (1987) also use a single cation-leaching curve, based on a regression of the means. It is argued here that a better approach is to use 3 empirical regressions: a central tendency built by the means; a lower curve built by the lower standard errors associated with the CRs and the numerical ages of the calibration points; and an upper curve built by the upper standard errors. The central tendency CR age. estimate is derivud by comparing the mean $C R$ of the unknown with the central curve. The lower standard error of the $C R$ (older) is assigned a plus error based on the upper (older) regression. The upper standard error of the CR (younger) is assigned a minus error based on the lower (younger) regression. It is possible to develop error curves based on theory; an ampirical approach is preferred here, however, because of the incomplete understanding of the mechanisms of $C R$ change over time.

(3) A CR calibrated-age on rock varnish date can only be considered a minimum-limiting age-estimate for the stabilization of the underlying rock surface. 
Table 3. Comparison of varnish cation-ratios and calibration ages for the Coso Range. Calibritions less than 40,000 B.P. by varnish-radiocarbon and historical ages; remainder of the calibrations by $\mathrm{K}-\mathrm{Ar}$ ages from Duffield et al. (1980). CRs are listed by the scraping-PIXE wethod and SEM-EDAX. NA means not available.

\begin{tabular}{|c|c|c|c|c|c|c|c|c|c|c|}
\hline -aiteis!s & & Calioraion sace & Enor & & ग1XE-5 & & ग1XE Error & 1 & $50 \mathrm{M} \times \mathrm{CA}$ & Esax Eror \\
\hline & & & & & & & & ! & & 1 \\
\hline $1: 1212 a: 10$ & & 00 & 3 & & $3: 7$ & & 022 & 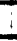 & 9 & 23 \\
\hline $50 s 0: a n 1$ & & 975 & 60 & 1 & 581 & $\begin{array}{c}1 \\
1 \\
3\end{array}$ & 016 & 1 & 7 & 24 \\
\hline$=250 \mathrm{Fan} 2$ & & 12300 & 310 & 1 & 55 & $i$ & 211 & 1 & 58 & 35 \\
\hline Reowill & 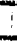 & 13380 & 300 & 1 & 508 & & 009 & 1 & 54 & 35 \\
\hline$=55025$ & & 44000 & 1000 & $i$ & 419 & 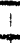 & 019 & $\therefore$ & 42 & $\therefore 2$ \\
\hline$=25017$ & 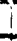 & 57000 & 6000 & 1 & 398 & & 311 & 1 & 41 & 32 \\
\hline$=090 \Delta$ & & 72000 & 31000 & $i$ & 378 & 1 & 012 & 7 & $N$ & $V A$ \\
\hline 50501 & . & 31000 & 3000 & 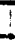 & 969 & 1 & 008 & T & 37 & 23 \\
\hline$=05025$ & 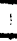 & 90000 & 25000 & 1 & 356 & 1 & 0.14 & 1 & $M$ & $\sqrt[V A]{A}$ \\
\hline$=05027$ & & 93000 & 26000 & 1 & 365 & 1 & 012 & 1 & Na & VA \\
\hline 50506 & & 01000 & 33000 & $!$ & 339 & & 015 & & 33 & 26 \\
\hline 505028 & & 180000 & 40000 & 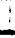 & 319 & 1 & 018 & & 35 & 33 \\
\hline 503036 & 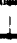 & 234000 & 22000 & 1 & 2.91 & 1 & 005 & & 28 & 32 \\
\hline$=03015$ & & 293000 & 35000 & 1 & 252 & $i$ & 231 & & 2.5 & 03 \\
\hline$=05030$ & 1 & 399000 & 45000 & & 2.73 & & 0.17 & & $N$ & NA \\
\hline 0.03031 & T & 486000 & 108000 & & 2.42 & & 026 & & 23 & 24 \\
\hline $\cos 05$ & & 560000 & 24000 & & 2.26 & 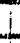 & 018 & & $N$ & $N$ \\
\hline 505032 & I & 1070000 & 120000 & 1 & 195 & & 007 & & v & vi \\
\hline 505033 & 1 & 1080000 & 60000 & & 180 & & 016 & & 21 & 02 \\
\hline$=05060$ & 1 & 1750000 & 100000 & - & 16 & & 003 & $!$ & $\mathrm{Na}$ & $\sqrt{A}$ \\
\hline$=09029$ & 1 & 2060000 & 340000 & 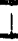 & 14 & 1 & 309 & 1 & 13 & 01 \\
\hline $\cos 052$ & & 2510000 & 50000 & 1 & 131 & I & 21 & & N & NA \\
\hline$=09061$ & - & 2540000 & 50000 & & 152 & 1 & 009 & & 17 & 03 \\
\hline$=29042$ & & 3670000 & 50000 & & 289 & & $2: 1$ & & 1 & 32 \\
\hline
\end{tabular}


(4) The semilog nature of a varnish CLC means that there is a low-level of dating precision for oldor samples. The most simple way to describe a CLC has been a semilog least. squares regression. The log nature of the time scale directly implies that only a small change in a $C R$ results in a comparatively large change in age. The problem becomes severe in the range of 100,000 to 300,000 years, depending on the slope of the curve. This can be illustrated by using the most precise CLC, the new Coso curve. Figure 6 and Table 3 illustrate a revision of the work reported in Dorn (1983). This revision was completed as a study to more Eully assess microenvironmental factors affecting rock varnish CRs.

To illustrate the effect of the semilog relationship on errors, the new coso Curve will be used. since it is the curve with the tightest fit. Hypothetical varnish CRs will also be used with a 1 sigma error of $2.5 \%$. If a CR of 3.04 is compared with the mean regression on Figure 6 , a mean age of $186 \mathrm{ka}$ is found. If 1 sigma $C R$ error of \pm 0.08 is compared against the lower and upper 1 sigma curves, an error margin of between $94 \mathrm{ka}$ and $350 \mathrm{ka}$ is found. If a 2 sigma CR of \pm 0.16 is compared with the 2 sigma curves, an error margin of $42 \mathrm{ka}$ to $680 \mathrm{ka}$ is found. The lack of precision worsens with less well-defined curves and with greater age.

There is an alternative approach to lower the errors associated with $C R$ dating, if enough resources are available to generate multiple $C R$ age-estimates. A given $C R$ date has a large analytical error, especially for older samples. If multiple CR dates are obtained, the central tendency of these dates could be used to estimate an error for the mean of the sample set. An error could be assigned using the average (and standard error) of only the mean dates. In this way, a statement could be made about the central tendency of a multiple dating effort. This was the approach used in a study of rock varnishes in Death Valley (Dorn, 1988) and to a lesser extent of glacial deposits in the sierra Nevada of California (Dorn et al., 1987b).

IV. Evaluation of Cation-Ratio Dating for use on the yucca Meuntain Nuclear Waste Reposicory Project.

\section{IV.A. Evaluation of SEM Method of CR Dating}

\section{IV.A.1. InEroduction}

Harrington and Whitney (1987) presented a valuable contribution to the varnish literature by strongly advocating SEM-EDAX as a method for CR dating. It is possible that their data are accurate and their approach is the best one available at present. It is not my desire to be overly critical of fellow varnish-enthusiasts, who obtained results that are basically in agreement with my observations of $C R$. 
changes over time. The following critique may be incorrect. However, I feel there is no choice but to press these concerns over the Yucca Mountain project. Given the national importance of the Yucca Mountain study area, a potential high-level national nuclear waste repository site, and given the potential use of the DOE supported varnish research in this site evaluation, the use of SEM-EDAX at Yucca Mountain deserves a very careful review at all stages: sampling; sample analysis; development of the Yucca Mountain CLC; its potential application to dating varnish in the region; and the possible use of varnish an a recorder of volcanic ash events (harrington, 1988). I hope the reader will not treat these comments as a Einal criticism of Harrington and Whitney's (1987) approach, but rather as a list of concerns that reed a more careful evaluation. The national, state and local importance of the Yucca Mountain site wartants this review.

\section{IV.A.2. Concerns Unique to the SEM Method of CR Dating}

Dorn (1983, p. 58), Giazovskiy (1985), Harrington (1986, 1988), Harcington and Whitney (1987), and Whitney et al. (1987) have used SEM to generate $X$-rays EOL analysis by EDAX in order to determine varnish CRs. The general approach is to analyze only the $x$-rays emitted from the varnish and not the $X$-rays generated from the underlying rock by varying the accelerating voltage of the SEM. This section will Eocus on general problems with the seM method, regardiess of the specific details of the method applied by different investigators.

(1) SEM-EDAX is biased cowards the surface layer of varnish. The shape of the envelope of $x$-ray generation supplies a bias towards the generation of $X$-rays cowards the more surface layers of the varnish, and hence should bias results towards a higher net $C R$.

(2) SEM-EDAX cannot be reproduced by other analytical methods. Once on an SEM-stub, the sample cannot be analyzed by other analytical methods such as XRF, PIXE or neutron activarion.

(3) Barium overlaps with titanium. In EDAX, unlike PIXE, the barium contribution cannot be separated from titanium. This could effect the CR of $(\mathrm{K}+\mathrm{Ca}) / \mathrm{Ti}$ in an uncertain fashion. Barium is present in varnishes in variable amounts. up to several percent but typically less than $0.5 \%$ and at the same order of magnitude in concentration as titanium.

(4) SEM-EDAX is not a testable method of varnish $C R$ determination. There is no independent way to test that $x$. rays are not generated Erom the underlying rock. Establishing a criteria on assumed differences in chemistry between a varnish and the underlying rock, meering this 
assumed criteria, and concluding minimal contamination does not constitute an independent test.

These and other doubts led to an early test of the SEMEDAX method for the Coso Range. Principal component analysis was used to establish a criteria to best distinguish a varnish signal from the underlying rock. Slices of the underlying rock material were analyzed separately by SEM. EDAX, PIXE and microprobe to characterize the bulk chemistry of the rock and how the chemistry of the rock varied on the scale of a broad SEM-EDAX analysis. Varnish from the site was analyzed by PIXE and hy electron microprobe to assess the chemical variability while knowing that the rock was not included in the analysis. The hope was that it wouid be possible to remove the effect of the underlying rock. statistically, in these tests. The best criteria to assess rock penetration were found to be percentage of $M n+F e$, percentage of $\mathrm{Ni}+\mathrm{Cu}+2 \mathrm{n}$, ratio of $(\mathrm{Ni}+\mathrm{Cu}+\mathrm{Zn}) / \mathrm{Mg}$, ratio of $(\mathrm{Mr}+\mathrm{Fe}) / \mathrm{Mg}$, and the ratio of $\mathrm{Mr} / \mathrm{Mg}$. The results for the EDAX test of the Coso Range are presented in Figure 6 and Table 3.

On the basis of the results of these tests, the SEM-EDAX method was rejected ezrly on (Dorn, 1983, p.58), despite the realization that the actual procedure was far easier to carry out. SEM-EDAX was found to be less precise and less accurate than the scraping-PIXE alternative. SEM-EDAX yielded a higher $C R$ than independent microprobe tests of thin section from the exact same sample analyzed by EDAX (Table 3). The lack of precision of EDAX, as compared to PIXE in Table 3 , was felt to be from a much smaller volume of varnish analyzed than PIXE and probably a substantial (but uncertain) level of contamination from K-rich and $\mathrm{Ca} \cdot \mathrm{cich}$ grains in the underlying rock. It was felt that the only way SEM-EDAX results would be usable would be that if the level of concamination could be tested independently for each sample.

Microprobe was also rejected (Dorn, 1983, p. 58), because it would be far too time consuming and expensive to analyze enough volume in transects through the varnish to make it a practical method. The preliminary results of Dragovich (1988) also bears this out. Scraping-PIXE was felt to be the best alternative and was presented in Dorn (1983).

\section{IV.A.3. Potential Sampling Difficulties}

(1) No attempt appears to have been made to identify an initial ratio for the Yucca Mountain curve. Nor does it appear that any attempt was made to assess $\mathrm{K}$, Ca or TI anomalies at the calibration sites of Harrington and whitney (1987). My own research in the area has identified some $k$, $\mathrm{Ca}$ and $\mathrm{Ti}$ anomalies in the Crater Flat area (see Table 6 in later section). 
Figure 7. Microcolonial fungi are common on ignimbrite, an important lithology for the curve constructed by Harrington and Whitney (1987). The surface weathering of this lithology is favorable for their growth.

A. Microcolonial fungi on Crater Flat CFP-38. Note how the colonies erode pits into the varnish.

B. Decayed microcolonial fungi on Crater Flat CFP-26. The honeycombed structure is typical of wicrocolonial fungi that have died, but the structure still remisins. The occurrence of former microcolonial fungi would not be noticeable by a surface analysis by SEl. 


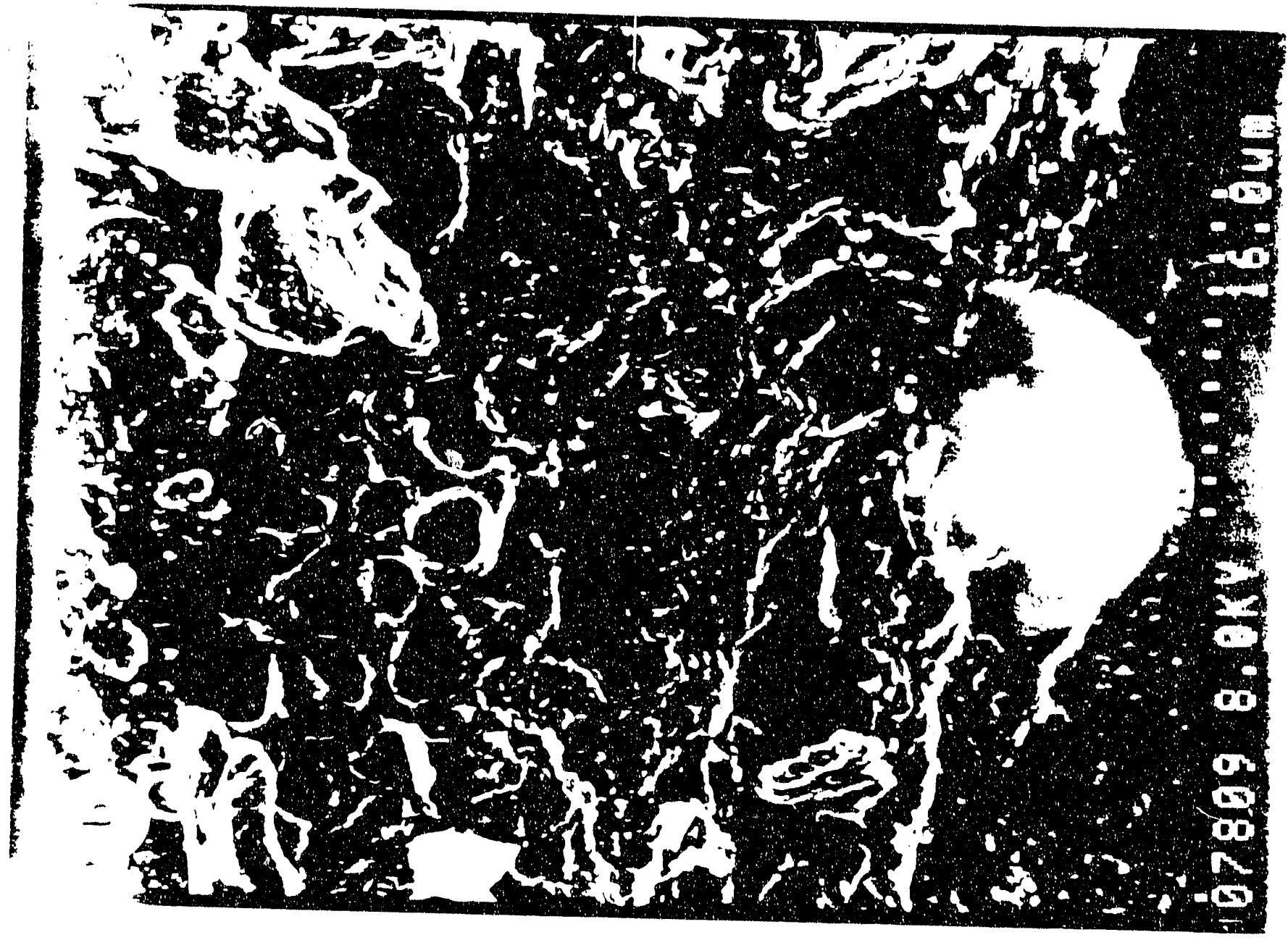

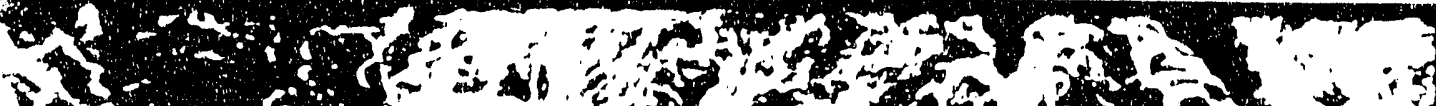

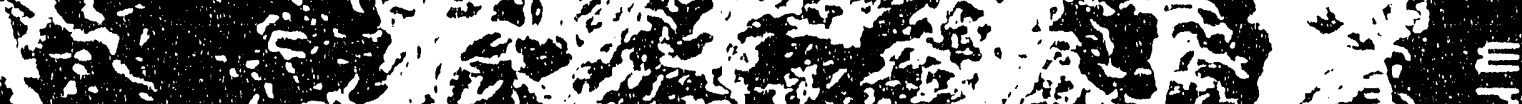

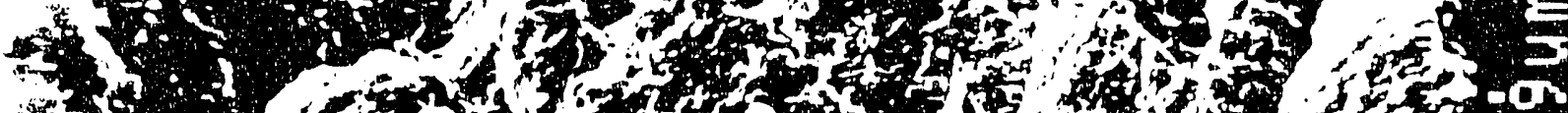

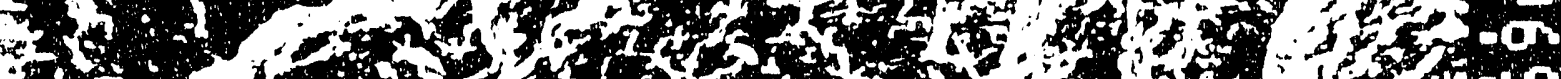

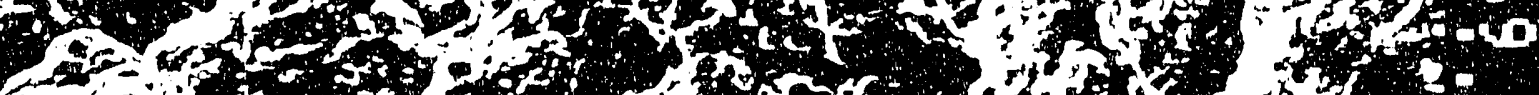

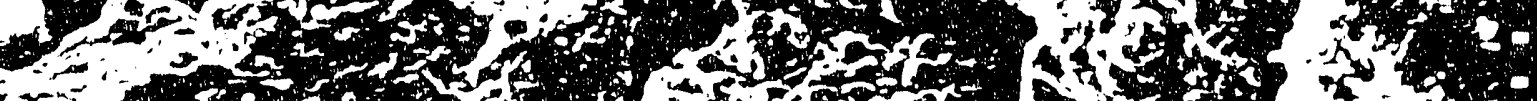

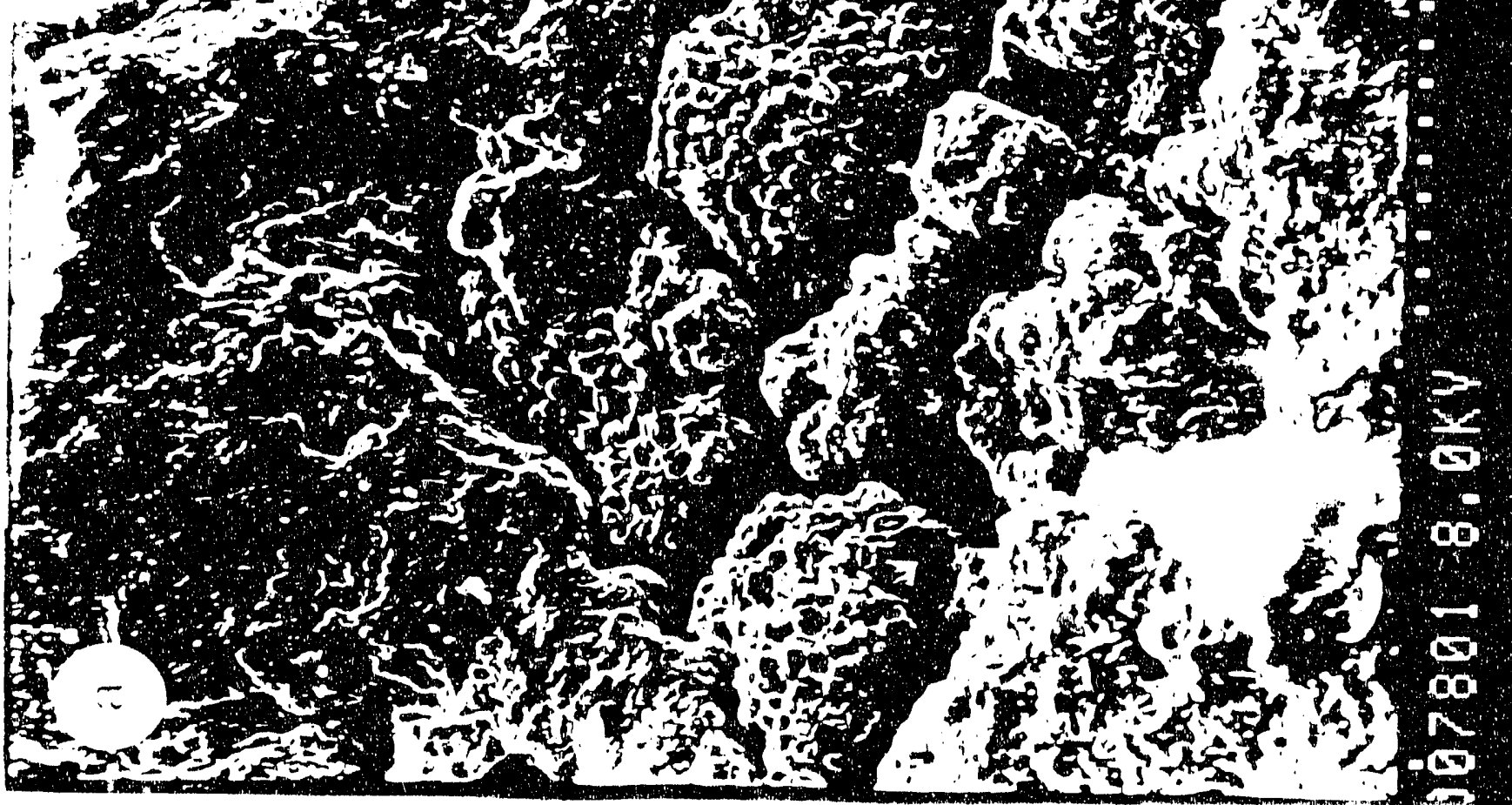


(2) No attempt appears to have been made to evaluate most of the environmental concerns that can affect a varnish cation-ratio (e.g., Table 2). While Harrington and Whitney (1987) did sample "similar environmental conditions", few of the problems discussed in the earlier section on assumptions were not even hinted at in their article. It is also uncertain whether cross-sectional analyses were conducted to assess erosional episodes, since only observations of the surface of the varnish were discussed by Harrington and Whitney (1987).

(3) Welded tuff in Crater Flat may suffer from problems of abundant microcolonial fungi. Only welded tuff was collected for the U-trend calibration points (Harrington and Whitney, 1987). Observations of varnish on welded tuff in Crater flat indicate that microcolonial fungi occur commonly on this substrate at present and in the past (Figure 7). No mention was made of this environmental influence. Also, it would have been better to examine varnishes from different lithologies to assess a degree of CR variability on different substrates as affected by the SEM-EDAX method. This is particularly important because volcanic clasts might not be available at all the sites where CR dating is to be applied in their subsequent research. Little faith will exist for these CR measurements when the degree of contamination from the underlying rock is uncertain.

\section{IV.A.4. Potential Difficulties in Sample Analysis}

(1) No mention was made of analysis of varnish cross. sections to evaluate paleo-erosional episodes le.g., Figure 4). This is an important first step that is not covered when only surface examinations are conducted (Harrington and Whitney, 1987).

(2) No mention was made of evaluating the regularity of the varnish-rock boundary. Some varnishes have irregular boundaries that would call for greater care and smaller spot sizes for EDAX analyses (e.g., Figure 5,8).

(3) No mention was made of a procedure to collect observations about surface biological phenomenon such as microcolonial or filamentous fungi. Surface biological agencies can affect a varnish CR (Table 2; Figure 9).

(4) Samples of late-Holocene and latest-Pleistocene age were not examined by the DOE researchers. Based on my experience, I suspect that the "low" $10 \mathrm{KeV}$ accelerator voltage that was used to start out is still too high for very thin, young varnishes. voltages of $10 \mathrm{keV}$ might generate $x$. rays from rock that underlies thin varnishes.

(5) Discarding the highest $C R$ appears to be an arbitrary procedure. Harrington and whitney (1987, p. 967) note that 
Figure 8. Irregular subsurface boundaries in rock varnish.

A. Rock varnish relatively low in monganese on the northern basalt flow at lathrop Wells. Note that while the surface is smooth, the varnish-rock boundary is extremely irregular: thin varnish on the right; thick varnish on the left.

B. Varnish from Johnson Canyon Fan unit Q2a, Deach Valley, CA. Note that while the surface is regular, the varnish-rock boundary is extremely irregular with varnishes formed in this deep crevice. The issue here is how the SEM-EDAX operator would hendle this varnish, when there would be no way of knowing the nature of the subsurface varnish-rock boundary. The scraping-PIXE operator would readily identify this as a pocket anomaly and the sample from this section of varnish would not be included for analysis. 

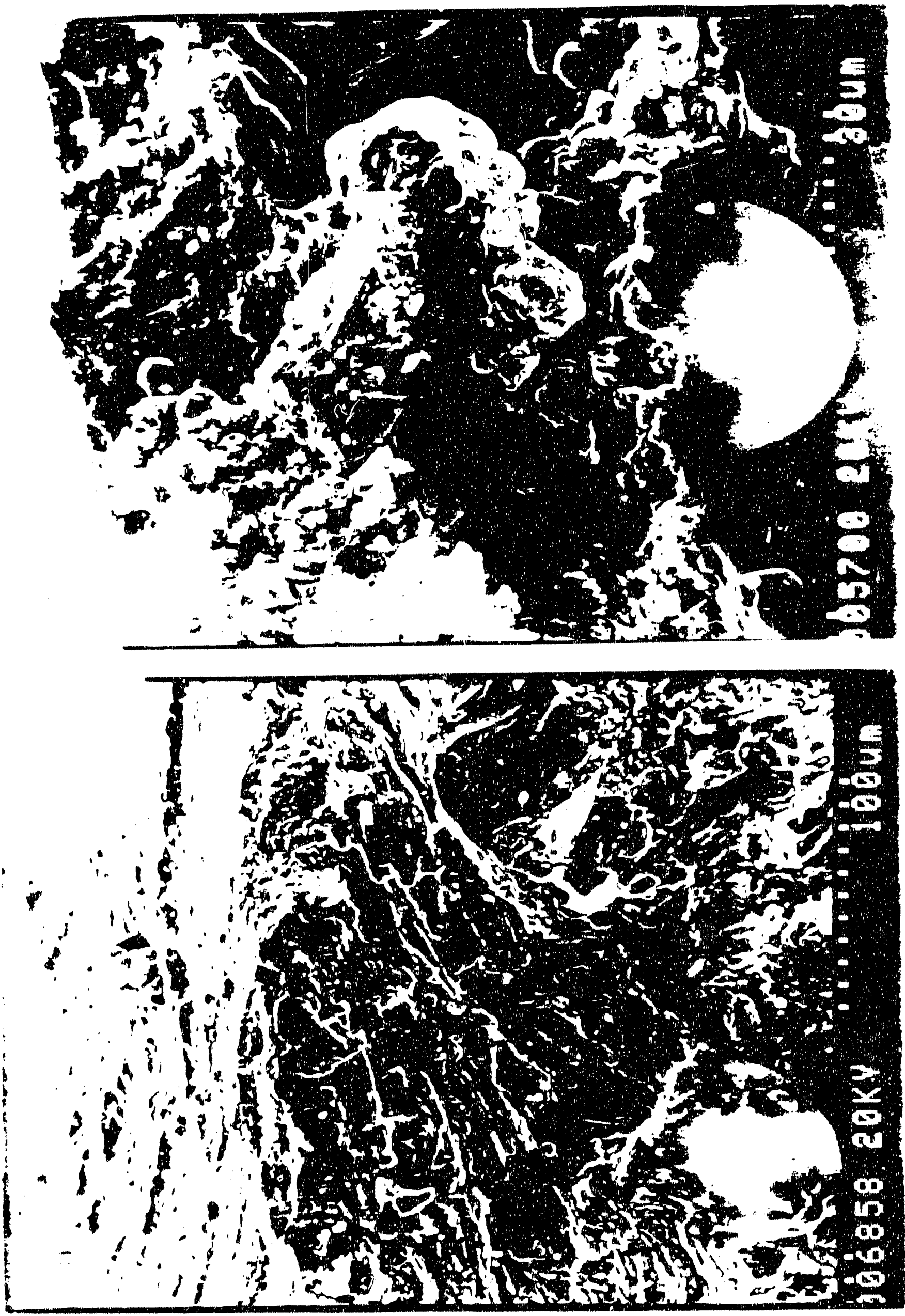
Figure 9. Blological agencies that have lowered varnish cation-ratios. These agencies are not examined by the sampling or analysis procedure used by Harrington and Wiliney (1987).

A. Microcolonial fungi, on varaish on Warm Springs Fan unit Q3bl, Deach Valley, Cd.

B. Filamentous fungi, on varaish on Lunar Crater basalt flow, LCN-5, Nevada. 
4.

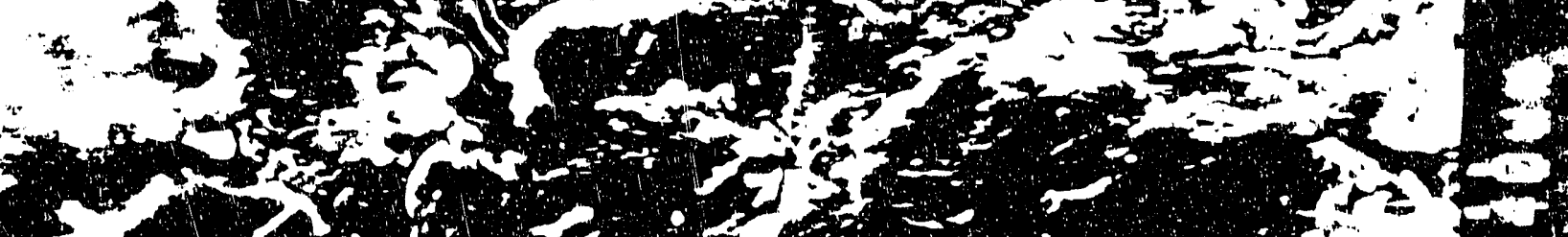

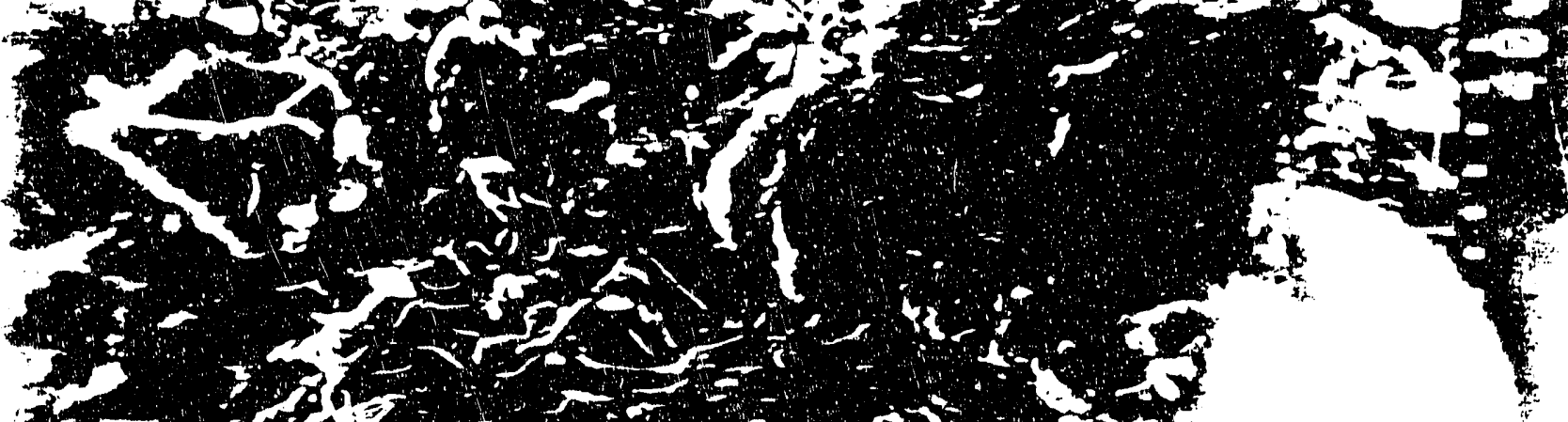

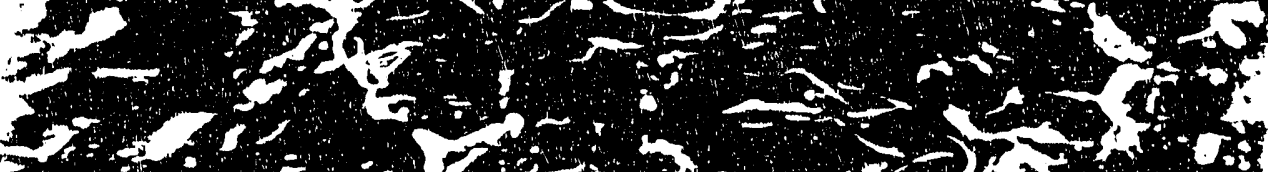

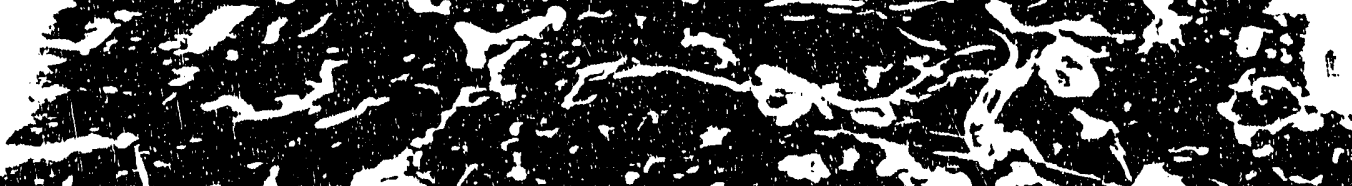

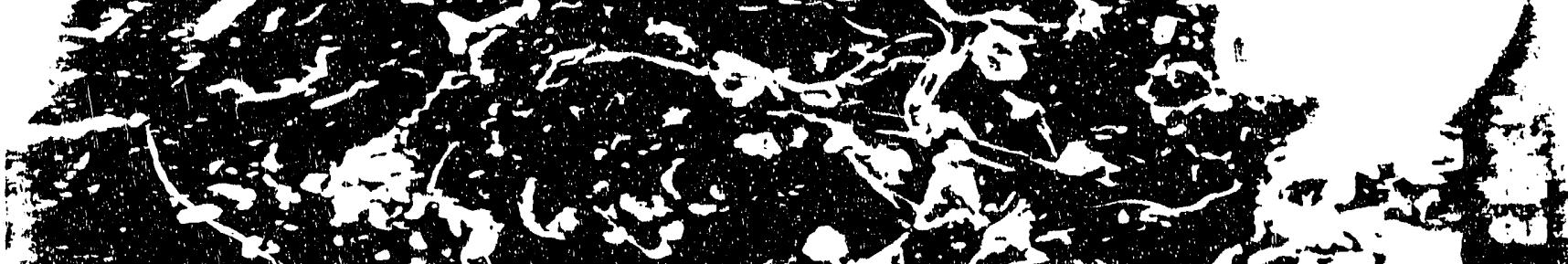

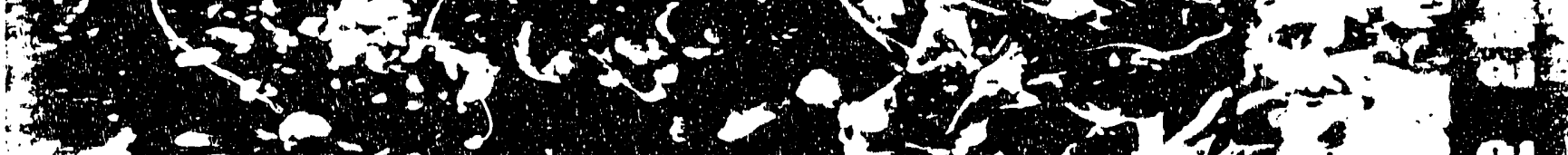

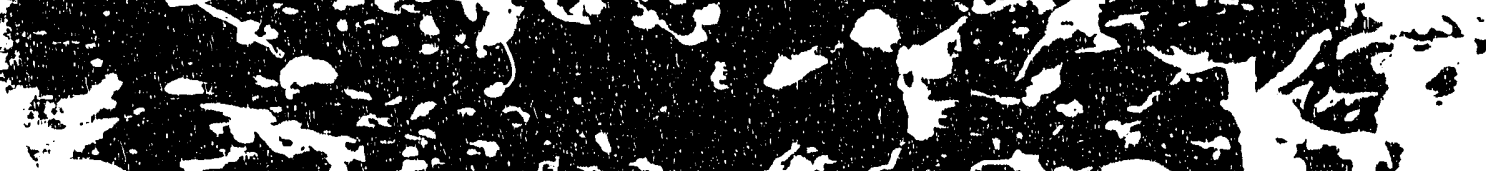

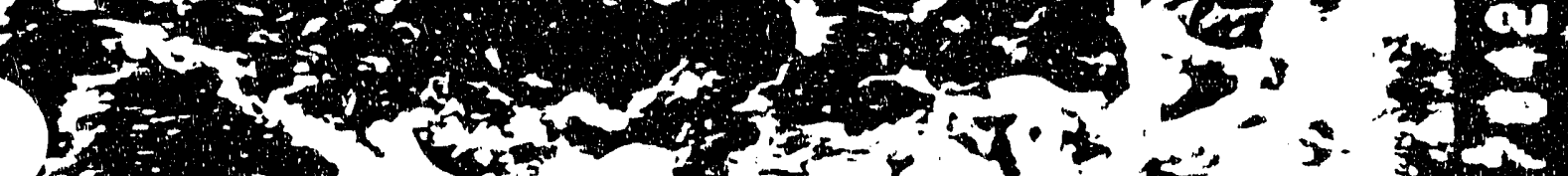

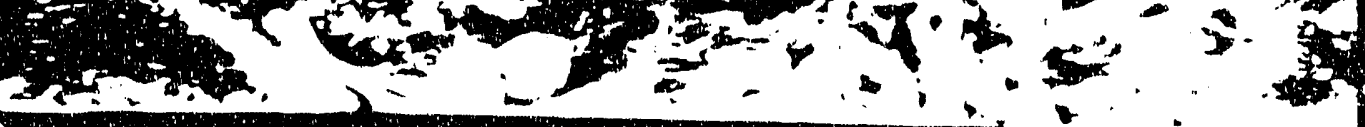

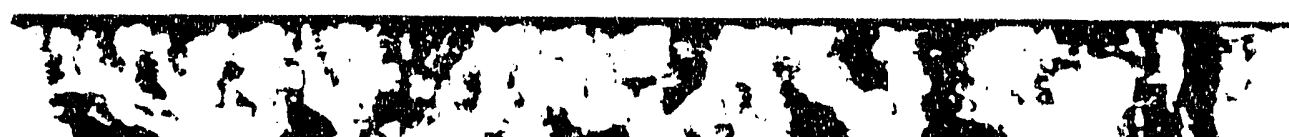

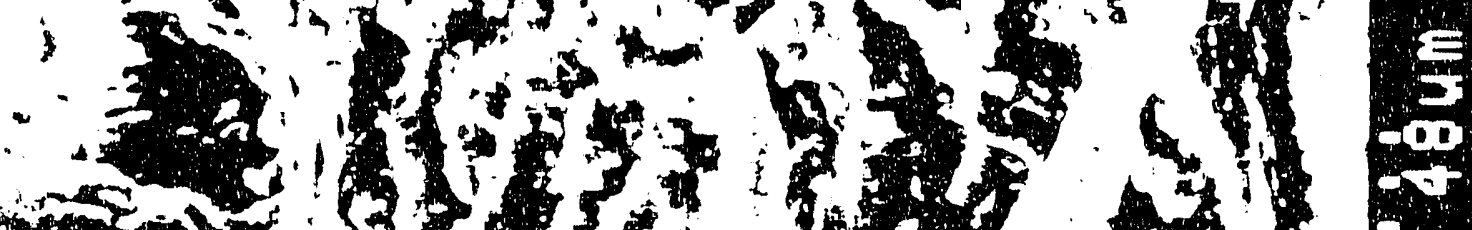

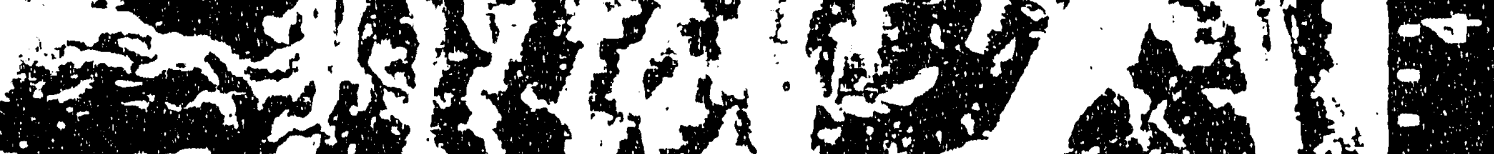

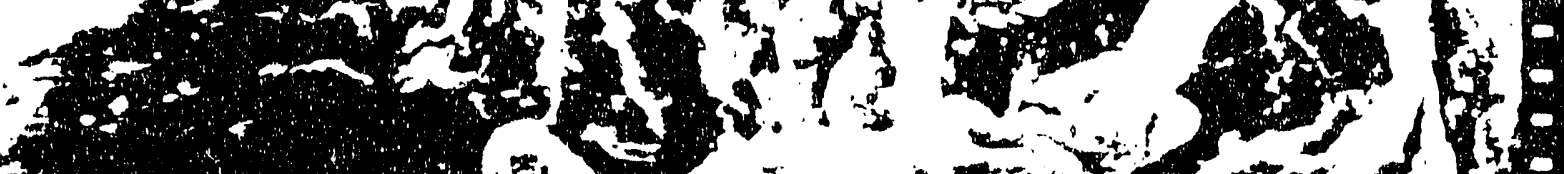

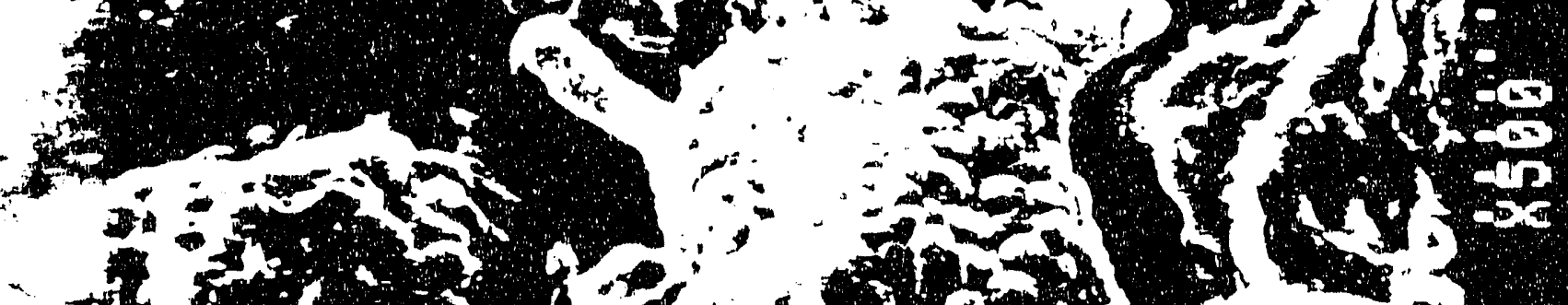

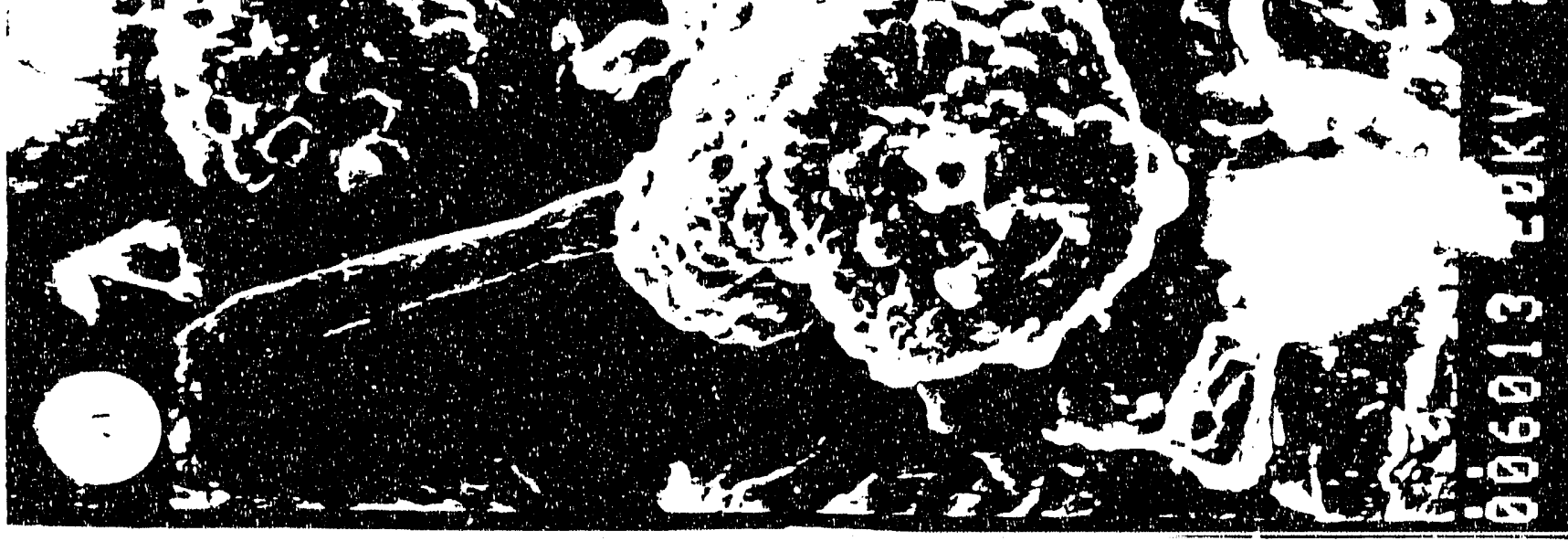


anomalously low ratios "can often be recognized during SEM varnish surface examination..." Their discussion appears to assume that a major (or sole) source of anomalously lower CRs would be surficial accumulations of titanium. Titanium anomalies can be found in the subsurface (Figure 10) and hence would not be included by theil published analytical procedure. More importantly, there are several other sources of low CRs that were not dealt with by their method of analysis that are listed in Table 2 .

(6) It is possible that the chemical criteria used by Hacfinaton and Whitnev $(1987)$ to distinguish rock from varnish may be in eart flawed. The criceria listed include $\mathrm{Mg}, \mathrm{Mn}, \mathrm{Ti}$ and $\mathrm{Fe}$, but specific statistical thresholds were not reported.

(a) Mg is particularly important to the Dog research because it is assumed that $\mathrm{Mg}$ concentrations are low in varnish and high in the underlying rock.

To make untested assumptions about consistenty high levels of $\mathrm{Mg}$ in minerals underlying the varnish is questionable. It is also questionable to assume that there are low concentrations of $\mathrm{Mg}$ in the varnish. In extensive microprobe work, I have often found pockers of high Mg (and low Mn) within a varnish that could give the SEM operator a false signal. that the underlying rock was penetrated. It is, therefore, essential that independent tests be conducted on the microchemical variability of the varnish and the underlying rock. An optimistic note is that vaniman et al. (1982) found consistent levels of MnO around 4.8.5.94 for the volcanics at Crater Flat; these include only the Red Cone and Black Cone collected by Harrington and Whitney (1987). It should be stressed that EDAX does not analyze X-rays generated Erom a bulk sample, but from relatively small volumes with potentially diverse chemistry. It is important to assess the degree of chemical variability of the underlying substrate (or even a proxy sample). Also, no discussion was made of the chemistry of the welded tuff on which the varnish was deposited at the calibration sites.

(b) Manganese concentration is aiso an important criteria in that the lack of manganese would indicate penetsation of the underlying rock. It is not uncommon, however, to find a layer of varnish that is low in manganese, at which point the EDAx operator could decide that the underlying rock was reached. This decision could easily occur if this section is tich in Mg, which can occur. The work of Hooke et a.l., (1969), Perry and Adams (1978), Dorn (1984) and Dragovich (1988) demonstrated that manganese and iron concentrations are variable in varnish. 
Figure 10. Subsurface titanium- and iron-rich detritus incorporated into varnish on the south basalt flow at Lathrop Wells, Nevada. Arrows identify the characteristically angular pieces of what may be titanomagnetite detritus. Some pieces were exposed at the surface ar this site, but it is not uncommon to find varnishes where ti-rich detritus is only noticeable by cross-sectional analysis. 


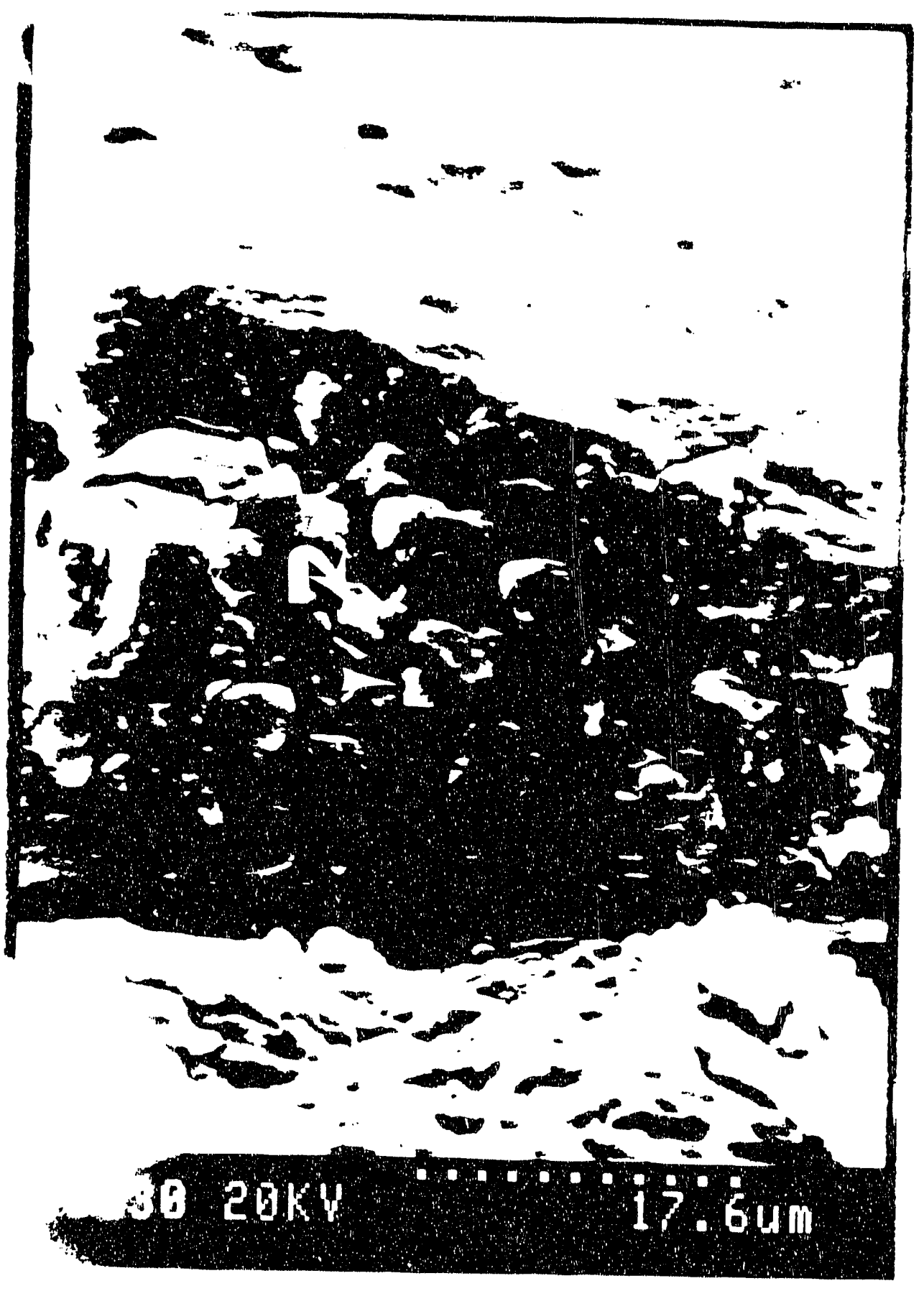


Figure 11. Hypotherical scenarlous whereby SEM-EDAX would either include the underlying rock in an analysis or would not analyze the entire varnish.

Circumstance \#1: The 8 -ray generation envelope grazes the rock that is low in manganese and the operator lowers the accelerating voltage. The entire varnish is not analyzed.

Cicumstance \#2: The $x$-ray generation envelope grazes the rock that is low in manganese, but the operator "sees" the manganese generated from the varnish. However, when a section of the rock rich in $\mathrm{Mg}$ is encountered the operator stops. A substantial amount of the rock is included in an analysis.

Circumstance \#3: An internal layer in the varnish that is rich in $\mathrm{Mg}$ and low in $\mathrm{Mn}$ is encountered. The operator stops, and the entire varnish is not analyzed.

Circumstance \#4: The botton layer of the varnish is low in manganese and rich in iron, but the underlying rock in this section of the varnish is aiso rich in iron and low in magnesium. The operator either stops when the manganese is reduced (and does not analyze the bottom layer of the varnish) or analyzes the rock until a section rich in magnesium is reached.

Circumstance \#5: There are uncertainties in the level of $\mathrm{Ti}, \mathrm{Mg}, \mathrm{Mn}$ or other chemical criteria. These uncertainties force the operator to either stick to a rigid criteria, not based on a knowledge of the chemistry of the rock irmediately underlying the varnish, or to adapt to the microchemical variability of the varnish. If the latter choice is made, the "objectiveness" of using a spectfied criteria is rejected. If the former cholce is made, the particular criteria used may not be appropriate. 


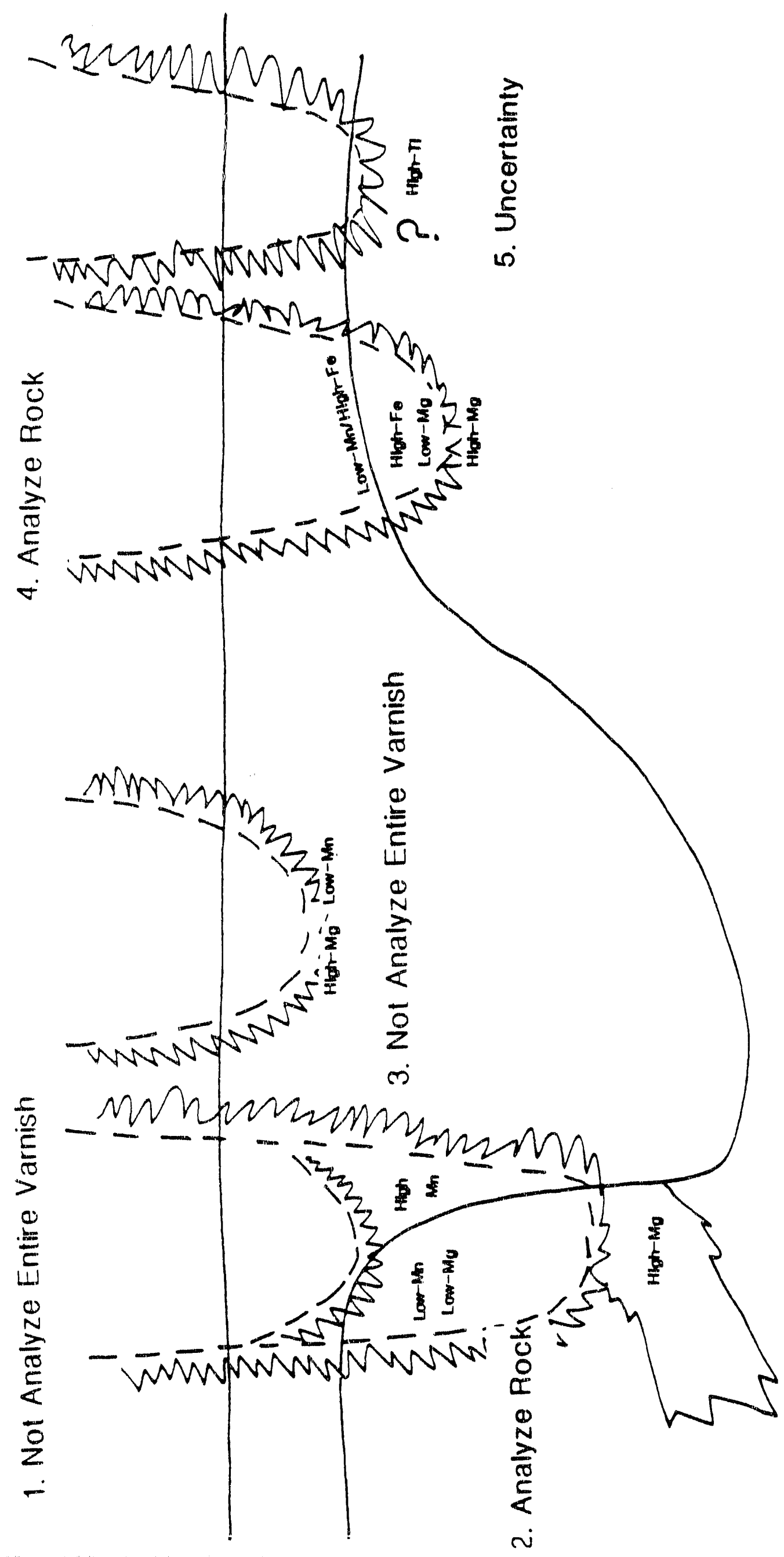


Figure 11 illustrates several hypothetical scenarios whereby the underlying rock is analyzed by sEM-EDAX or the varnish is not completely analyzed. The bottom line of this objection is that assumptions of rock and varnish chemistry may be invalid because they are untested and because chemistry can vary spatially over the scale of the SEM-EDAX analysis used by Harrington and Whitney.

(8) Precision may be confused with accuracy. Harrington and Whitney (1987, p. 969) "believe that sample selection, not analytical accuracy, is at present the major limiting factor for varnish age-determinations." I would argue that "precision" should be substituted for accuracy, since no independent tests have been made by Harrington and Whitney (1987) of the accuracy of their SEM-EDAX measurements.

IV.A.5. Potential Difficulties with the Yucca Mountain Curve of Harrington and Whitney (1987)

(1) The number of calibration points is limited. To conduct age-determinations on tectonic, climatic or volcanic hazards associated with the siting of high level nuclear wastes, more calibration points are required. As the DOE curve stands at present, if any one calibration age is substantially off, it could seriously affect the calculated least-squares regression.

(2) There are no calibration points for the lateQuaternary. Any calibrated age-determination made for the last $40 \mathrm{ka}$ would be hazardous.

(3) Uranium-trend analysis is very important to the Yucca Mountain curve of Harrington and whitney (1987). All calibrations of less than a million years are based on this still experimental dating method. This should be kept in mind when interpreting the varnish $C R$ age-estimates that are based on this curve.

(4) The DOE YuCCa Mountain curve is anomalous in its high initial ratio and its steep slope, when compared to other CLCs (o.g. Coso, Cima, Owens Valley, Espanola Basin). The explanation for these differences requires a close examination. The high initial ratio (if slope is projected to $Y$ intercept of age=0) is about 18. This is very unusual. Harrington and whitney (1987) claim this is reasonable based on the greater abundance of pleistocene eolian fallout in the area and the lack of a substantially more moisture-effective phase in the area. The assertion of a greater pleistocene eolian fallout cannot be evaluated here because no data were presented by Harrington and Whitney (1987) to support this claim.

Another explanation is the claim that the "yucca Mountain area did not experience a significant climatic 
amelioration..." This is puzzling given the paleoenviromental evidence from the area. Working with Neotoma middens Spaulding (1985, p. 1) concluded for the Nevada Test site and vicinity that "during the wisconsin glacial age, from at least 45,000 years ago to about 10,000 years, Juniperus osteosperma woodland was widespread below elevations of $1800 \mathrm{~m}$ in the desert lowlands... Late Wisconsin subalpine conifer woodland...occurred at elevations about $1800 \mathrm{~m} . "$ This is a very different vegetation than the desert scrub and Joshua Tree found at present. Claassen (1986) observed that recharge occurred in the nearby west-central Amargosa Desert, Nevada, from about $17 \cdot 10 \mathrm{ka}$ during a mean annual temperature that was about $8^{\circ} \mathrm{C}$. less than at present. Winograd et al. (1987 observed substantial fluctuations in di80 at nearby Devil's Hole, NV, over the last $300 \mathrm{ka}$. Quade (1987) argues that vigorous ground-water discharge occurred in the playas of southern Nevada during the full-glacial.

(5) The DOE curve constructed by SEM-EDAX differs substantially from the one constructed by scraping-PIXE.

Both curves use K.Ar dated calibration points around 1 myr. For Red Cone and Black Cone, the SEM-EDAX and scrapingPIXE results are within a 2 sigma overlap of each other (rable 4). If the difference is real, it is possible that subsurface $T i$ anomalies were not identified by Harrington and Whitney (1987) for these sites.

The curves diverge greatly for calibration poincs younger than a milition. The SEM-EDAX curve relies of U-trend dating, while the scraping-PIXE relies on a younger K-Ar date and radiocarbon dating for calibration. Figure 12 presents both curves, with 2 sigma errors. Harrington and Whitney (1987) did not report error curves. The error curves in Figure 12A were generated in the same Eashion as 12B, as presented earlier.

The DOE curve has a much higher $C R$ for a given age. This results in a steeper curve. The differences between the curves could be from the difference between the $k$. Ar/radiocarbon and U-trend methods. It is also quite possible that the higher CRs in the DOE curve would be from contamination from $k$ and $C a$ in the underlying welded tuff, combined with the SEM-EDAX signal being biased towards the more surface layer of the varnish that would yield higher ratios.

Since the differences could be from the radiocarbon versus U-trend calibrations, a separate section has been included in this report to present all the data on AMS radiocarbon dating of varnish. Radiocarbon dating has been subjected to a battery of tests at sites where conventional ages have been established by conventional methods. It could 
Table 4. Comparison of varnish cation-ratios and calibration ages for the Yucca Mountain area. Th CRs obtained by the SEM method are from Harfington and Whitney (1987), and the PIXE results are detailed in table 6 .

\begin{tabular}{|c|c|c|c|c|c|c|c|}
\hline Facerials & Methoo & Dace & Eiror & $01 \times E C A$ & DIXE Error & $50 A \times C A$ & $i \equiv 0 A \times \equiv \cdots O r$ \\
\hline & & & & & & & 1 \\
\hline $\ln 11|a| 2 a c 10$ & Historical & ca. 100 & 0 & 101 & 019 & na & 72 \\
\hline CFo-2 & 2adlocaroon & 6,545 & 245 & 65 & 011 & na & 19 \\
\hline$C F=-26$ & Radlocaroon & 10,180 & 270 & 61 & 0.1 & na & na \\
\hline CFD. 33 & Radlocaroon & 17280 & 370 & 574 & 009 & na & 12 \\
\hline 67.27 & 2adiocaroon & 25,700 & 360 & 537 & 011 & $9 a$ & $\mathrm{na}$ \\
\hline CED-35 & 2adlocaroon & 26,990 & 375 & 529 & 009 & 19 & na \\
\hline $675-36$ & Aadlocaroon & 28.920 & 400 & 527 & 008 & 18 & 13 \\
\hline$C F-32$ & Radiocaroon & 30,320 & 460 & 515 & 008 & na & 93 \\
\hline Dachrog Flow & $x-A r$ & 137,000 & 13.000 & 396 & 005 & .20 & na \\
\hline Blacx Cone & $K-A r$ & $1,080,000$ & 200,000 & 2.51 & 0.07 & 2.18 & 227 \\
\hline Litile Cone & $k-4 r$ & $1,100,000$ & 150,000 & 261 & 008 & na & 17 \\
\hline Red Cone & $K-A r$ & 1120,000 & 135,000 & 259 & 009 & 233 & 011 \\
\hline Crater flat Sumace & U-ereng & 40000 & & & & & \\
\hline 40 MIle 020 & $\frac{\text { U-trend }}{U \text {-ind }}$ & $\frac{40.000}{160.000}$ & $\frac{10,000}{20000}$ & $\frac{n a}{n a}$ & $\frac{n a}{n a}$ & $\frac{5}{468}$ & $\frac{1}{052}$ \\
\hline 40 mile $02 \mathrm{C}$ & U-treng & 255000 & 15000 & na & $\frac{n a}{n a}$ & $\frac{468}{434}$ & $\frac{052}{04}$ \\
\hline
\end{tabular}


Figure 12. Comparison of carion-leaching curves for the Yucca Mountain area.

A. Curve based on SEM-EDAX, as presented by Harrington and Whitney (1987) and represented in Table 4. The central regression is:

$Y=18.36-2.65 \log X$

The Y-intercept of the central curve differs from Harrington and Whitney (1987), because an age equals 0-intercept is used here. A different intercept is used by Harrington and Whitney (1987), probably age equals 100 years. The 0-intercept is used to allow an easy comparison of all equations.

The 2 sigma error curves can be represented by:

$Y=25.20-3.58 \log X$ (Upper Curve)

$I=11.63-1.71 \log x$ (Lower Curve).

B. Scraping-PIXE curve, based on data presented in Table 4.

The curves can be described by the following equations:

Central Curve Upper Curve Lower Curve

$Y=14.01-1.96 \log X \quad 14.50-2.02108 X$

$13.54-1.91108 x, \quad x \leq 10^{5}$

$Y=11.84-1.54 \log X \quad 11.44-1.42108 X$

$12.42-1.70 \log X ; \quad X \geqslant 10$

C. Overlay of the SEM-EDAX and scraping-PIXE curves. Note how the SEM-EDAX curve is considerably higher and it ends at $40 \mathrm{ka}$. Also note how the limited data set from 40 ka to $160 \mathrm{ka}$ does not permit a fair assessment of whether a slope break should occur at about 100-140 ka; Harrington and Whitney (1987) argue there should be no slope break. 


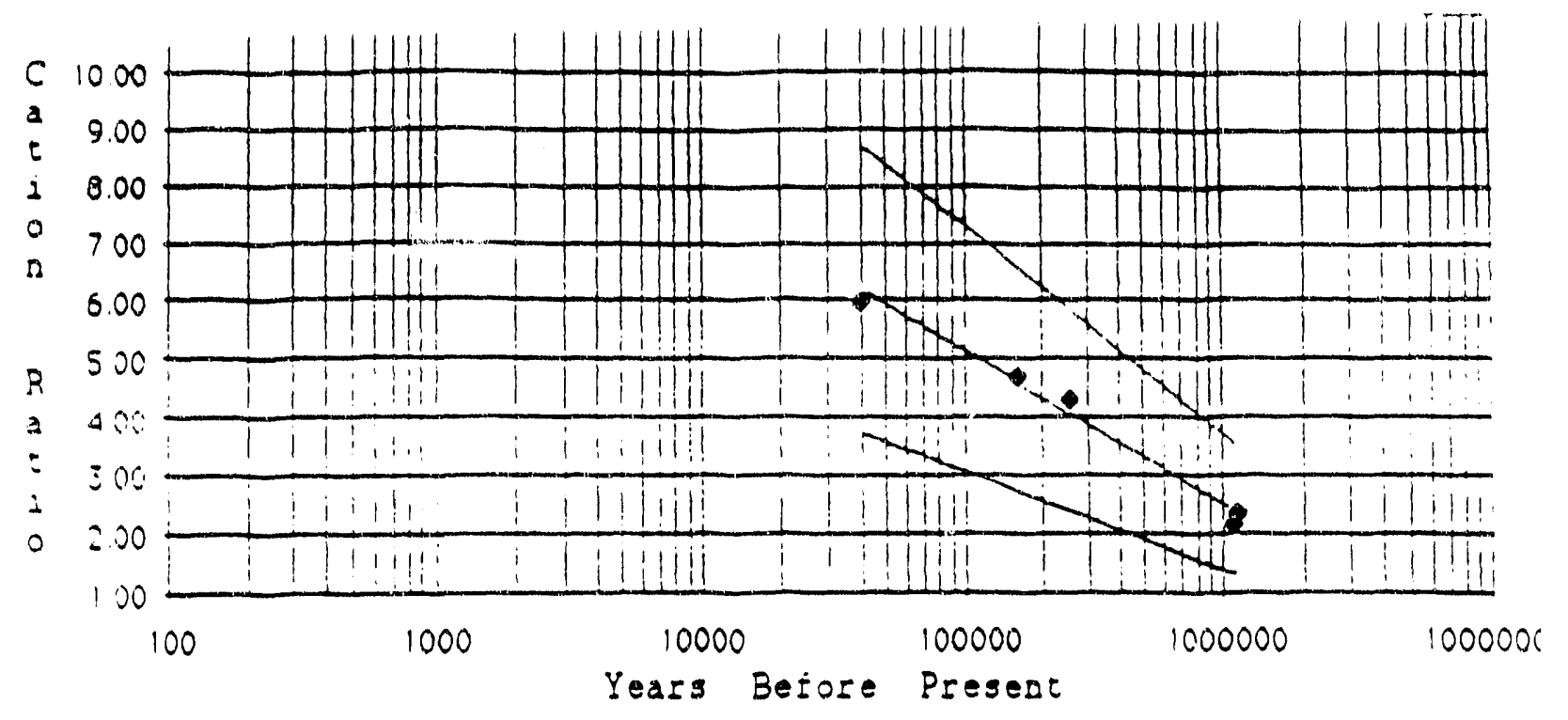

b

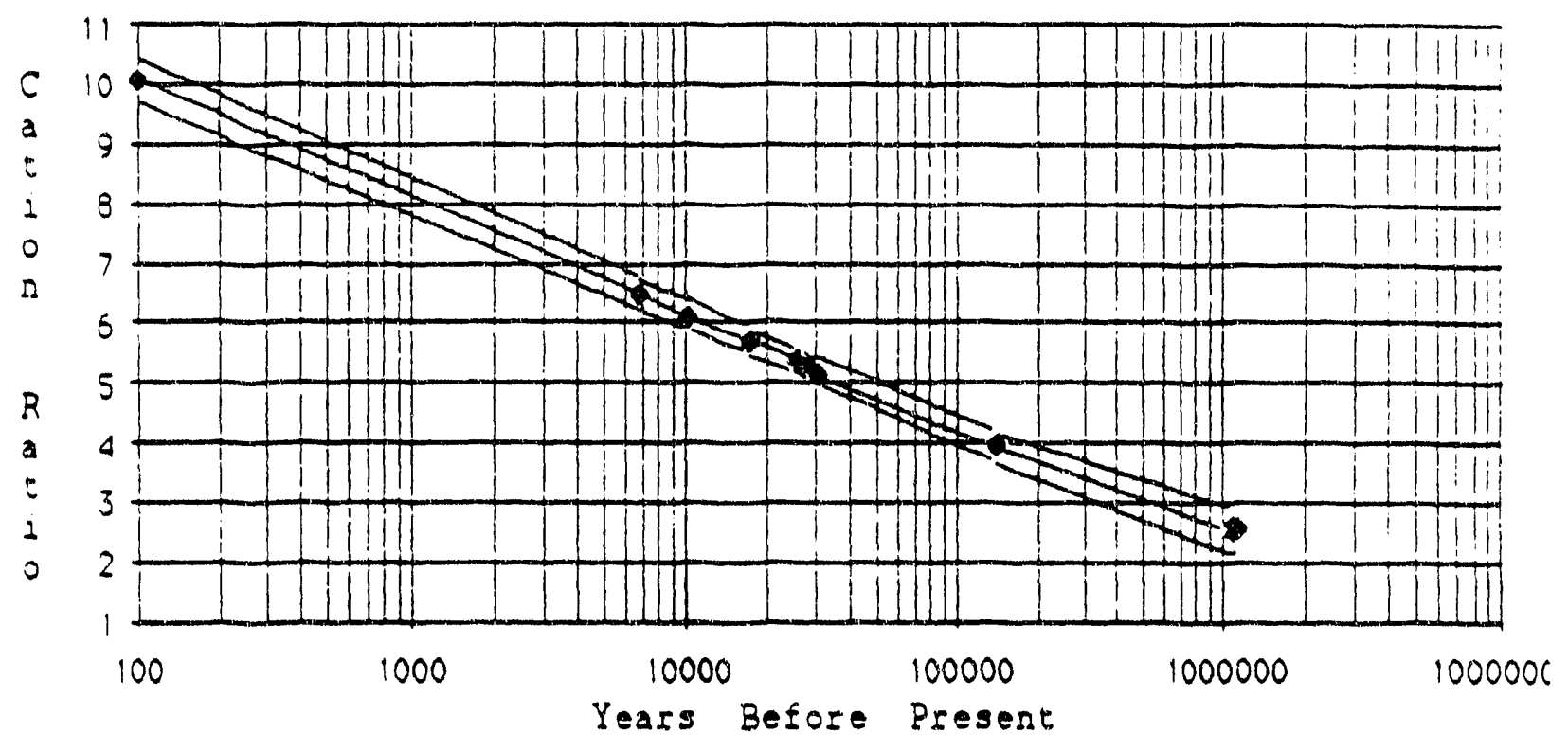

c

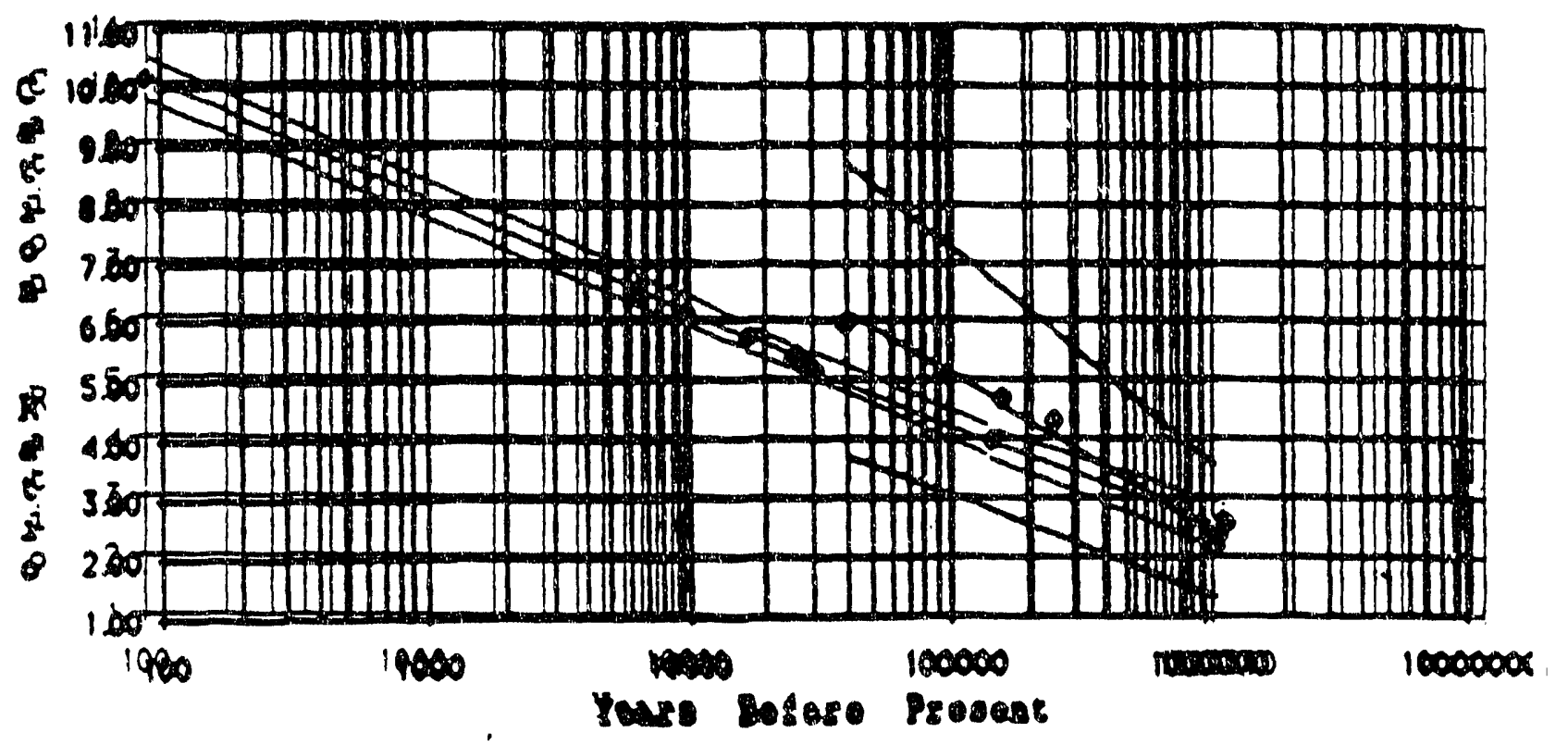


be important to compare U-trend dating with more conventional dating results, such as K-Ar dates in the Cima or coso volcanic Eields.

If the SEM-EDAX curve is incorrect in that it is too high and has too steep a slope, serious interpretive problems would be created, because the CLC curve of the DOE would generate $C R$ age-estimates that would be far older than the real age. If used to estimate neotectonic activity, for example, a CR date from the DOE curve would provide a serious overestimate age and underestimate of tectonic activity.

IV.A.6. Potential Problems in Applying the Yucca Mountain Curve

The CLC for Yucca Mountain and vicinity proposed by Harrington and Whitney $(1987)$ is being used to obtain cationratio age-estimates on a variety of geomorphic surfaces, that are in turn being used to assess neotectonic activity, climatic geomorphic studies, and erosion rates (Harrington and Whicney, 1987; Whitney et al., 1988). Since the exact procedure used to provide these calibrated ages is not provided by Harrington and Whitney (1987) or whitney et al. (1988). I can only present some generalized, potential hazards.

(1) There may be serious problems in dating varnish on a rock that is a different lithology than a calibration site. The sEM method does not independently evaluate the chemistry of the rock, nor does it independently evaluate the chemistry of the varnish. Instead, it tries to sort out a composite $X$. ray signal. If the unknown varnish has a different underlying lithology than a calibration site, serious questions of accuracy are raised.

An example would be if varnish on chert or quartzite was analyzed as an unknown. Chert and quartzite typically has Ear less $K$ and Ca, relative to $T i$, than the calibration lithologies of basalt and welded tuff. Assuming that some level of contamination influenced the calibration CRs (even if it was as low as $5 \%$ ), the calibration $C R$ would be higher than it would be for a varnish on quartzite of the same age. The varnish on quartzite, therefore, would provide a $C R$ age older than its true age of surface exposure. If this varnish was being used to assess neotectonic activity, for example, the result would be an underestimate of faulting rates.

(2) The SEM method does not, at present, permit an assessment of local sources of $C a, K$ or $T i$ anomalies, microcolonial fungi, filamentous fungi, and many of the other environmental factors listed in Table 2 and not discussed by Harrington and Whitney (1987) or Whitney et al. (1988). 
Table 5. Comparison of Age-Estimates by scraping-PIXE versus the SEM-EDAX methor in the Yucca Mountain area.

Table 5A. Comparison of predictive ages of 4 test cation-ratios. Mean ages are based on the central regressions pre ented in the text and figure 12. CRs are compared in a matrix against the 1 sigma and 2 sigma errors of the curves and of the CRs themselves. The 1 sigma error for the hypothetical varnish cation-ratio was selected as $4 \%$, since this is the best performance by the SEM-EDAX method reported for the Yucca Mountain area by Harrington and Whitney (1987). All calibrated-ages are presented in thousands of years before present. The number in parentheses represent the predictive error margin for the respective 1 or 2 sigms errors of the varnish CRs.

\section{SCRAPING-PIXE CURVE}

Test $C R$

$\operatorname{Mean} 3.00$

$10 \pm 0.12$

$20 \pm 0.24$

Mean 4.00

$16 \pm 0.16$

$26 \pm 0.32$

Meas 5.00

$10+0.20$

$2 \sigma \pm 0.40$

Mean 6.00

$16 \pm 0.24$

$2 \sigma \pm 0.48$
16

577

$(381-880)$

$(321-1062)$

126

$(93-196)$

$(77-252)$

39

(27-56)

$(21-70)$

12

$(7.8-18)$

$(5.9-24)$
26

577

$(297-1114)$

$(253-1354)$

126

$(82-234)$

$(68-303)$

39

(23-63)

$(18-79)$

12

(6.7-21)

$(5.0-27.5)$
SEY-EDAX CIRVE

10

$2 \sigma$

636

(93-2214)

$(79-2444)$

$(130-1843)$

267

(62-920)

(55-1102)

267

$(23-1004)$

(19-1146)

$$
\begin{gathered}
112 \\
(27-455) \\
(23-537)
\end{gathered}
$$

112

$(5.7-497)$

(4. 3-565)

47

47

(12-207)

$(9.7-252)$ 
(3) Varnish age-determinations should include the error of the calibration. When $C R$ calibrated-datos are assigned by the DOE varnish investigation, the error margin for the date strould include the \pm of the $C R$ for the unknown as well as some sort of error estimate for the calibration. Table 5 A compares the results of the SEM-EDAx curve for estimating the ages of hypothetical CRs with the scraping-PIXE curve. The \pm on the CRs were arbitrarily assigned the lowest standard error listed by Harrington and Whitney (1987) of $\pm 4 \%$.

(4) Whitrey et al. (1988) attempt to use the yucca Mountain curve in a region far to the south of where the calibration has been established. This may be possible, but not without local calibration points in this a:ea, and not without a study of microenvironmental effects. Neither were discussed in the abstract, although they may be examined in an expanded presentation in the future.

IV.A.6. Preliminary Evaluation of the Use of Varnish as a Recorder of Volcanic Ash Plumes at Lathrop Wells

Hartington (1988) presents an innovative use of rock varnish, to detect components of volcanic ash in rock varnish. This could, in turn constrain the age of volcanic ejecta plumes. The case study used is the varnish on basalt Elows adjacent to the Lathrop Wells Cinder Cone, NV.

The evidence presented in the abstract and reviewed listening to the oral presentation at the Geological society of America Cordilleran Meeting in Las Vegas (March, 1983) was preliminary. I am skeptical of this method for several reasons. (1) Tho varnishes shown were quite thin, some less than 10 microns. The varnishes collected by the author on the Lathrop welis basalt flows that were not affected by aeolian abrasion and were not in microenvironments unsuitable for CR dating were generally thicker (Figure 8A,10). Alternatively, it is possible that tre microenvironments sampled by C.D. Harrington for this study were designed to select for conditions not appropriate for CR dating, but favorable for the accretion of volcanic ash (such as crevices that later opened, or protected pockets). (2) Many varnishes have pieces of angular, ipicich detritus and orher minerals that are incorporated into the varnish matrix, and these are not acound sources of volcanic ejecta. (3) The rate of varnish formation is deserts is not consistent with the incorporation of volcanic ash. I have not found a unique geochemical signature (or structural component such as glass) that could be correlated with any volcanic ash events in the Coso Range. This is despite extensive SEM observations and hundreds of electron microprobe profiles of varnishes from cens of volcanic units of different ages. It is possible that the microenvironments sampled in the coso Range were not favorable for the incorporation of volcanic ejecta. To elaborate, the formarion of Mn-rich varnishes is very slow, 
often taking thousands of years to cover a rock surface in a desert environment (Dorn and oberlander, 1982; Whalley, 1983). To expect volcanic ejecta to be incorporated would require a very high level of microbial activity and concomitant deposition of clays, all at the same time as a volcanic event. On a well-exposed subaerial varnish appropriate for CR dating, the ejecta would not be expected to remain on the varnish surface for a long-enough period of time to be incorporated. However, if the varnish was sampled from a crevice, or protected environment, it might be feasible to incorporate ash into varnish. (4) The Ti-rich detritus observed at Lathrop Wells (e.g., Figure 10) came Erom different depths in different varnishes: from the surface to the bottom. Even given a variable rate of varnish growth, I would not expect such variability from a single depositional event. The likely source is from detritus from an ongoing influence like soil material, that with proper sampling could be eliminated form affecting a CR. (5) Dr. J.O. Davis asked a question at the G.S.A. presentation whether glass shards had been observed. The answer was basically negative. Glass would be diagnostic of ash. I have not observed glass shards in the varnishes collected from the Lathrop Wells basalt flows, but once again, my samples were for $C R$ dating. If the analyzed samples were collected from pockets where ash would collect, there could possibly be some glass.

In summary, varnish could theoretically be used to record volcanic ash events. However, it would be very unlikely to expect to see events on a regular basis. The accretion of varnish is too slow and sporadic over the time scale of a volcanic event to expect the pieces to get incorporated. The only microenvironments where one might find evidence would be in microsites where ash can collect and sit for a long period: in crevices or deep pockets. These environments are unsuitable for $C R$ dating, and any $C R$ results from these microsites would not be relevant to $C R$ dating in the area.

\section{IV.B. Review of the Scraping-PIXE Method}

Black rock varnish is collected from the tops of larger clasts at a site, preferably over a meter in diameter, but this is note always possible on quaternary units in the vicinity of Yucca Mountain. Microenvironments listed in Table 2 are avoided, as well as surfaces that are unstable because they are undergoing spalling (such as angular pieces from the break-up of a rounded, Eluvially transported cobblel or granular disintegration. The samples are collected from a combination of at least 15 different rock surfaces. These different rock surfaces are placed in 5 groups, based on similarity of microsite variables. 
Figure 13. SEM stereo-pair of detritus scraped from a rock underlying varnish from site CFP-2. For viewing, remove the images from the holders and place under a normal stereoscope. In this case, the chemical signature was almost entirely silica, so no chemical contamination would have occurred. By evaluating random scrapings, the volume and chemistry of the contamination can be determined. The remainder of the flakes in the image are varnish pieces. The percentage of contamination of CFP-2 is estimated at $4 \%$ by volume and less than $1 \%$ by its chemical effect on $\mathrm{Ca}, \mathrm{R}$ or $\mathrm{Ti}$. 

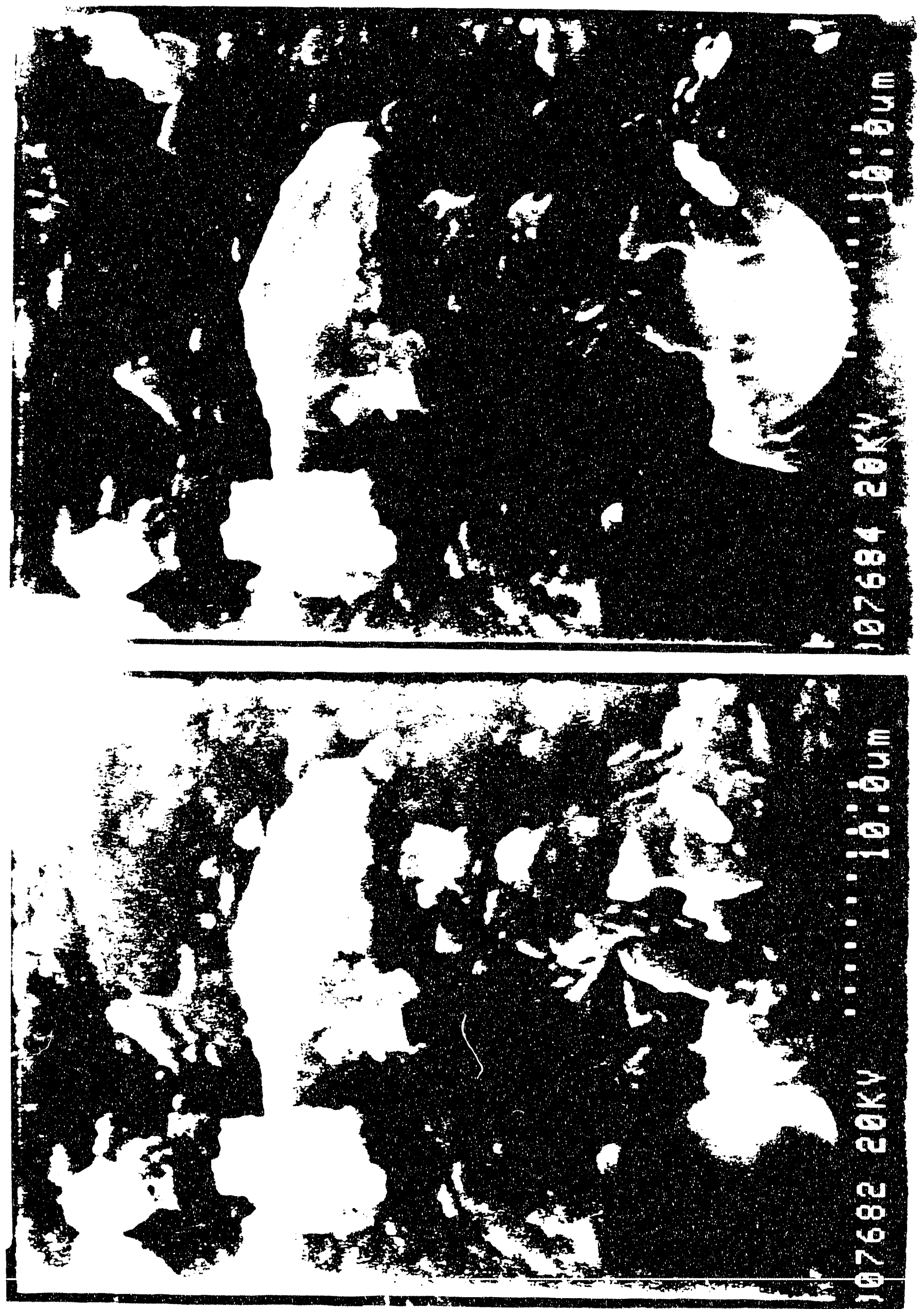
In the laboratory, the samples are blown with compressed air to remove loose detritus. Random chips are taken Eor SEM and thin section analysis. A sample is not processed for $C R$ determination if concentrations of Eilamentous fungi, microcolonial fungi, or bioetchpits exceed those concentrations listed in Table 2 .

Samples are processed by the following procedure (1) Varnishes are scrubbed lightly with deionized water to remove loose detritus and air dried for 5 to 24 hours. (2) The varnishes from the 5 different groups are scraped from the underlying rock under $10-45 x$ magnification with a tungstencarbide needle. The scrapings are passed through a system with nucleopore filters of $45,15,2$ and $0.2 \mathrm{um}$. This allows rock contaminants to be easily separated from the varnish. Also, varnish pieces that are larger than $2 \mathrm{um}$ can be reduced in size to avoid matrix effects during PIXE analysis. (3) Contamination from the underlying rock is estimated for volume and chemistry by SEM examination of randomly selected scrapings (e.g. Figure 13). The criteria for distinguishing varnish from rock Eragments is morphological (Dorn, 1986) and mineralogical (Potter and Rossman, 1979). (4) The scrapings of each of the 5 groups are then mounted on Kapcon film with a lead-Eree spray Eixative. (5) Analysis for a varnish $C R$ is by particle-induced X-ray excitation (PIXE) (Cahill, 1980; Cahill et al., 1984). (6) At each site, the ( 2 um fraction of the dust that has accumulated in natural dust traps is analyzed by PIXE. If the CR of this dust is more than 2 standard deviations beyond others for the region, the site is carefully examined for the source of the anomalous $C R$; it may be possible that varnish from the site cannot be dated by the CR method. (7) A PIXE analysis of varnish is not to be used in computing a $C R$ if it is anomalously high or low, and $a$ specific cause can be found. Typical sources of anomalies are Ti or Ca detritus, or biological causes that got past the initial examination. If a particular PIXE analysis is not used, the reported $C R$ represents only 4 PIXE analyses.

IV.C. Comparison of the SEM method with the scraping-PIXE method

Harrington and Whitney (1987) claim several advantages for the SEM method over scraping. PIXE: that the original varnish surface cannot be reexamined after scraping; that SEM-EDAX can be used for varnishes that are not on smooth. surfaced rocks; and that less contamination from the underlying rock is incorporated into the varnish $C R$.

The first advantage of SEM-EDAX presented by Harrington and Whitney is correct. Substitute samples must be studied to examine anomalies, although the slide prepared Eor PIXE can be analyzed by SaM-EDAX to see if the chemical anomaly is concentrated at discrete points or if it is averaged throughout the sample. This is helpful in determining 
whether the anomaly was something like calcium carbonate or titanium detritus (tends to sccur in discrete locations) or from microcolonial fungi (generally lower ratio without discrete loci of lower ratios).

This potential advantage of SEM-EDAX is tempered, however, by all of the factors discussed previously. The analytical results of SEM-EDAX cannot be reproduced by other methods. PIXE is non-destructive, and the material prepared can be analyzed by XRY, DC Plasma, neutron activation or even SEM-EDAX. In contrast, the core prepared for SEM-EDAX cannot be analyzed by any of these other methods.

The other two advantages outlined by Harrington and Whitney (1987) require reexamination. They argue that topographic ifregularities can be avoided by SEM-EDAX. In support, they argue that minor surface irregularities produce no significant changes in varnish CRs. The reason for this could be because the underlying rock affects the varnish CR signal across the microtopographic change. They also argue that higher SEM magnifications effectively eliminate major surface irregularities. This is true, but this effectively reduces the volume of varnish analyzed by the SEM method to statistically unacceptable levels. Also, increasing the SEM magnification does nothing to affect the subsurface topographic irregularities that can be considerable over short distances (e.g., Figure 5,8).

I argue here that scraping.PIXE is a far superior method for analyzing all varnishes, especially young-thin varnishes. The assumptions of the sam method require a smooth surface and smooth subsurface, or the difficulties faced in Figure 11 would be greatly magnified. Scraping does not require regularity. Support for this is not based on assertions and no samples younger than $40 \mathrm{ka}$. It is based on experience. Scraping-PIXE has a documented precision of $\pm 10 \%$ on refitted artifacts in the Mojave Desert (Dorn et al.. 1986) and compares well with varnish-radiocarbon ages into the late. Holocene (Dorn et al., 1987a). SEM-EDAX has not been tested for young varnishes by Harrington and Whitney (1987). Based on my experience with young varnishes in the coso Range, SEM. EDAX suffers from the severe problem of low volumes of analyzod varnish and extreme difficulty in avoiding $x \cdot r a y$ generation from the underlying because the varnishes are thin.

Harrington and whitney (1987) argue that SEM-EDAX controls the level of contamination. As SEM-EDAX is portrayed in the DOE research, there is no evidence presented to support this assertion, and there are many reasons presented earlier why this is not the case. It may be possible to control the level of contamination in the future, but not by circular reasoning. Testing must be completed by 
an independent assessment of rock chemistry and varnish chemistry.

In contrast, scraping.PIXE does provide a testable way of assessing contamination. Randomly isolated scrapings are placed on a stub EOr SEM-EDAX examination. Using morphological and mineralogical criteria, a volumetric assessment of contamination can be made. Levels of < 2 f for Pleistocene varnish and < 5\% for Holocene varnish are common (Dorn et al., 1987a). Ar assessment of operator error was conducted by R.I. Dorn and D.L. Tanner for basalt flow sites near Yucca Mountain at Lathrop Wells basalt flow, Black cone Elow, Little Cone flow, and Red Cone flow. Operator variation was small: 20\% to $30 \%$ of the standard error of the cation-ratios themselves (Table 4), or less than $1 \%$ of the total CR. At sites in Death Valley (cf. Dorn, 1988), the highest operator error was $4.5 \%$ of the cation.ratios for late-Holocene varnishes. The typical difference was about 1 . $2 \%$ of the total CR.

There are other differences between the two methods of $C R$ determination, as they are practiced.

(1) SEM-EDAX is less precise. Whether the results from the Coso comparison are used (Table 3; Figure 6) or the Yucca Mountain comparison (Table 5; Figure 12), SEM-EDAX generates CRs with lass precision. The reasons for this may be from a smaller volume of varnish; hence microchemical variations in varnishes are not as well averaged as in the larger volumes used by scraping-PIXE. Alternatively, it could be from including the microchemical variations in the underlying rock.

(2) SEM-EDAX is destructive of the sample. This is not a problem for geomorphic work, but it is unacceptable and unnecessary for archaeological dating. Scraping.PIXE only removes the varnish from a rock surface and does not disturb the artifact. To analyze enough varnish for reliability, especially in Holocene samples, SEM-EDAX would end up destroying the ontire artifact.

(3) Sample preparation for scraping-PIXE is similar to preparation for varnish-radiocarbon dating (to be discussed in a later section). A varnish investigator unwilining to train for scraping-PIXE will be unable to take advantage of this varnish dating method.

(4) There is a difference in sampling philosophy implicit in these two methods. Scraping-PIXE attempts to average together large area and large volumus of varnish. Due to the high cost of time on most SEMs with EDAX, the SEM-EDAX method must analyze considerably lower volumes of varnish, more than an order of magnitude less than scraping-PIXE. SEM-EDAX is forced to rely on an approach of sample optimization. 
The "sample optimization" approach in CR dating is to be very careful in sampling to avoid anomalies like those listed in Table 2. Even with future work by the DOE varnish researchers that included cross-sectional analyses on the side of a core, and avoidance of these anomalies, there would be uncertainties about what an SEM-EDAX is analyzing beneath the surface of the varnish away from the edges of a core. Therefore, the problem of having to use "proxy" samples to assess subsurface anomalies is not unique to scraping-PIXE.

Part of the sampling philosophy behind scraping-PIXE is to sample and pre-check samples carefully. Hopefully, this eliminates the gross microenvironmental anomalies. At the same time, it is probably impossible for an investigator to observe all the paleo-erosional pits, every piece of $\mathrm{Ca}$. detritus, or every microcolonial Eungi that has been buried by newer varnish. The other half of the scraping.PIXE approach is that if a large enough area/volume of varnish is analyzed, the relatively minor anomalies become part of a composite CR. Due to machine time and cost limitations, it is not Eeasible for SEM-EDAX to take this dual approach. The scraping-PIXE approach is capable of analyzing 2 orders of magnitude more varnish than SEM-EDAX in the sam time period and with less cost, based on my experience.

IV.D. Results of Varnish Analysis at Crater Flat Conducted for the Nevada Bureau of Mines and Geology

Table 4 presents results of AMS radiocarbon dating of varnish on Quaternary units CFP-2, 26, 33, 27, 35, 36 and 32 . The methods and complete discussion of the varnish radiocarbon method is found in section $V$. However, keep in mind that the raw analytical radiocarbon dates are minimum. limiting estimates, and the true age of surface exposure is probably 10\% greater than as listed in Table 4. For example, while the organic matter extracted from the bottom layer of CFP. 32 is $30,320 \pm 460$ (2 sigma), a better estimate for the exposure of the surface would be about $33 \mathrm{ka}$. However, because some of the tests for varnish radiocarbon dating are still in progress, the exact correction figure is not available (see section $V$ ).

Table 58 presents the $C R$ age estimates for the older units in Crater Flat: CFP.40; 38; 39; 20; 37 ; and JBW. 20 . These were estimated by $C R$ analysis. The error of these dates is derived by the standard error of 5 separate PIXE analyses listed in Table 6. The error of a calibrated-date could be improved by sampling more varnishes to obtain more dates; these could then be averaged to obtain a central tendency age with a smaller error. The $C R$ age for CFP-4O should be considered a minimum-age, since the quaternary unit has experienced degradation; the varnished cobbles that were sampled may have been eroded out from a subsurface position 
Table 5B. Comparison of ages assigned to the varnistes on units sampled for the Bell-peterson Quaternary mapping project. The errors presented are a combination of 1 sigma CRs and 1 sigma curve errors. Calibrated ages are presented in thousands of years B.P. The scraping-PIXE results are the CRs ages of the Quaternary units, using the scraping-PIXE curve in Figure 12. The SEM-EDAX results are the CRs ages, using the SEM-EDAX curve in Figure 12.

\begin{tabular}{lllll}
\hline & & \multicolumn{2}{c}{ SCRAPING-PIXE } & \multicolumn{2}{l}{ SEM-EDAX } \\
Unit & Cation Ratios & Mean (Error) & Mean (Error) \\
\hline CFP.40 & $2.92 \pm 0.07$ & $660(450.965)$ & $680(150.2400)$ \\
CFP-38 & $3.31 \pm 0.07$ & $380(260.550)$ & $485(150.1740)$ \\
CFP.39 & $3.32 \pm 0.11$ & $360(255.515)$ & $480(110.1850)$ \\
JWB-20 & $3.75 \pm 0.12$ & $190(145.260)$ & $330(70.1320)$ \\
CFP.29 & $3.94 \pm 0.13$ & $137(115.162)$ & $280(60.1150)$ \\
CFP-37 & $3.98 \pm 0.08$ & $128(106.153)$ & $270(63.1020)$ \\
\hline
\end{tabular}


Table 6. Complete PIXE (particle induced X-ray excitation) data for cation-ratios used in this report.

The cation-ratios in the first column are $(\mathrm{K}+\mathrm{Ca}) / \mathrm{Ti}$. Results are originally reported in $\mathrm{ng} / \mathrm{cm}^{2}$, but have been normalized here to $100 \%$.

The abbreviations relate to the sampling site and the type of sample. IR stands for "initial ratio" or the $<2 \mu \mathrm{m}$ fraction of dust collected from the varnish sites. Black refers to BLack Cone, Northern to Northernmost Cone, Little to Little Cone, Lathr. to Lathrop Wells (N-north side; $\mathrm{S}$. south side), and CFP to Crater Flat peterson soil pit locations. The letters $a, b, c$ ect. refer to the particular cation-ratio measurement. At the Lathrop Wells basalt flows, there were 15 measurements made of samples prepared by two operators (Dorn and Tanner). Tanner worked on the north-side varnishes; Dorn worked on both the North and South-side varnishes.

In many cases, CRs were anomalous and were rejected in computing a $C R$ for a site. The rejection was based on the identification of an anomaly and an identifiable cause. Red Cone (e), Lathrop Wells (Ne,Si, Sj, LathrTan-e) and CFP-4OE were rejected due to anomalously high levels of titanium detritus. Black Cone (e), CFP-26 (e), CFP-26 (E), CFP.33 (e) and CFP-38 (e) were rejected due to high levels of microcolonial fungi causing anomalously low ratios. CFP-2 (E) and CFP-39 (e) were rejected due to anomalously high levels of $\mathrm{Ca}$ and $\mathrm{K}$, respectively. 


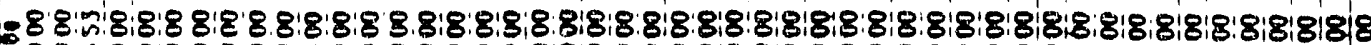

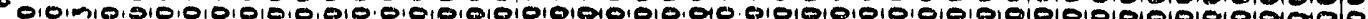

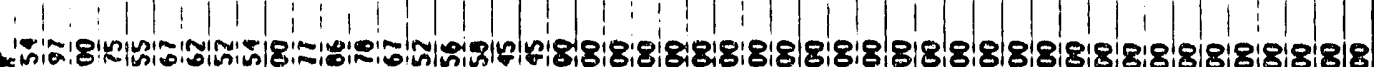

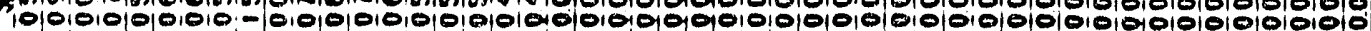

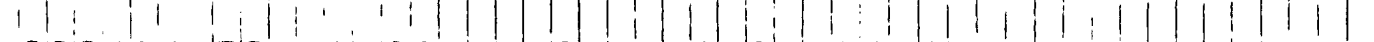

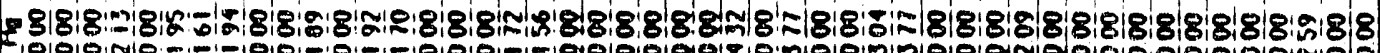

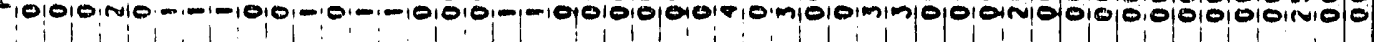

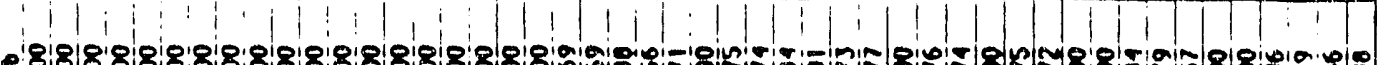

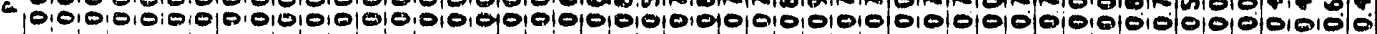

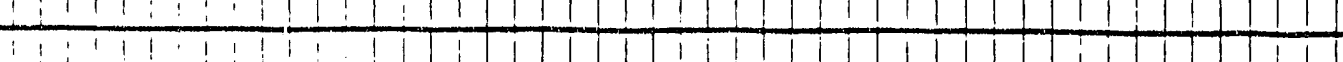
s. , 818.

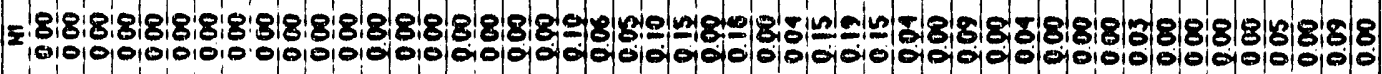

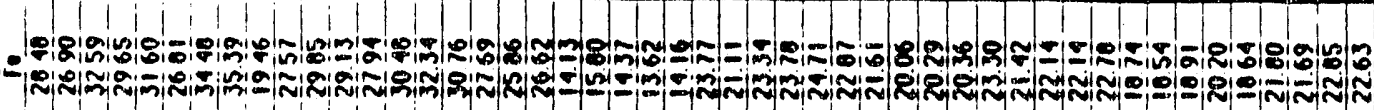

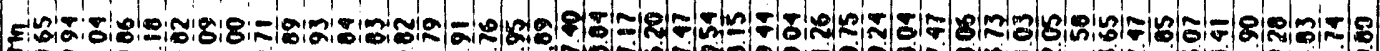

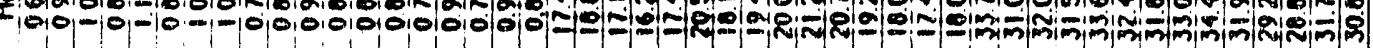

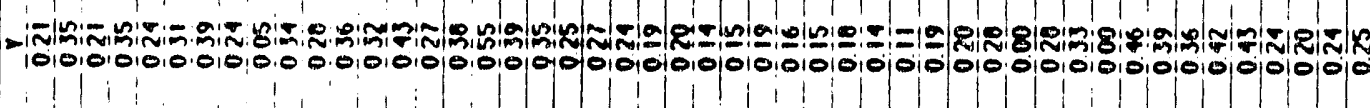

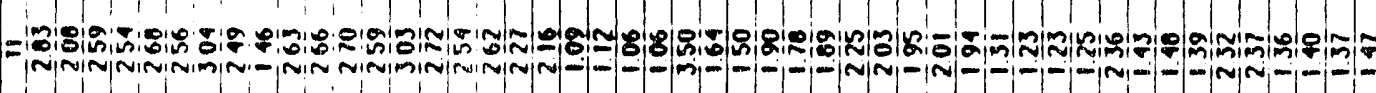
i \% F-

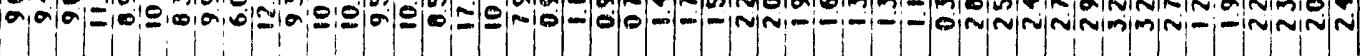

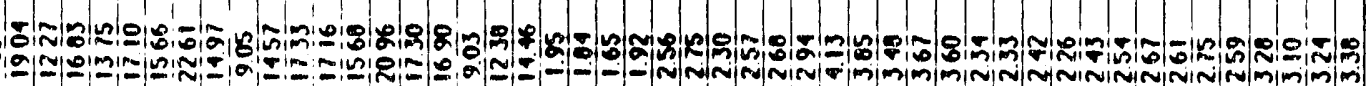

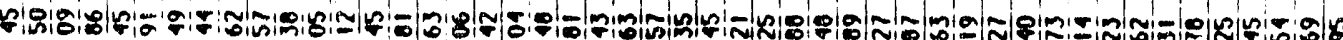

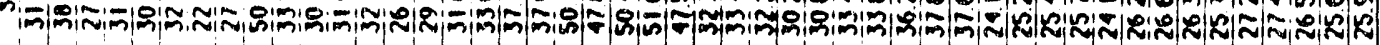
$=8$ ñ (4) \& 8

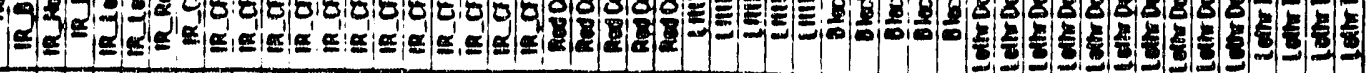
Fó \$ 


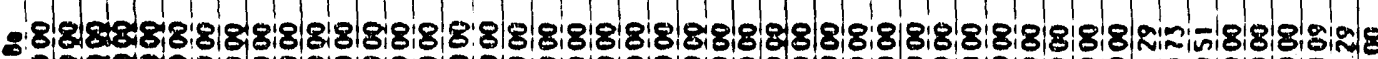
-

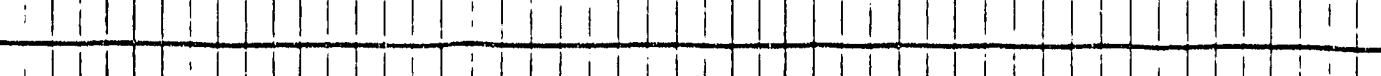

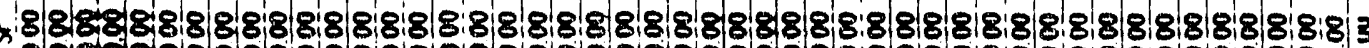

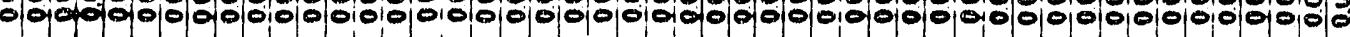

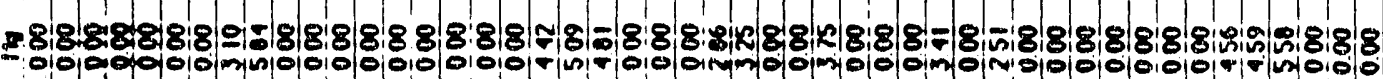
:00ja

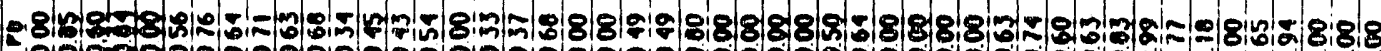

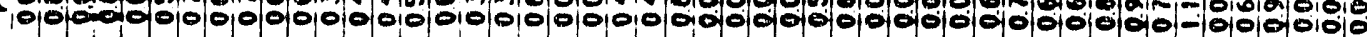
(1)

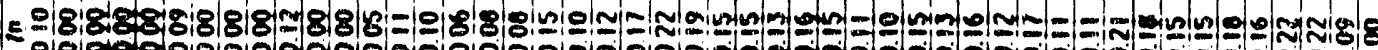

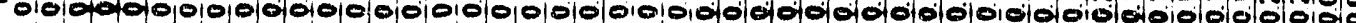
$\vdots:$

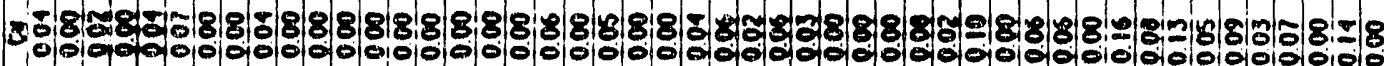
- 8 8. $+$

-

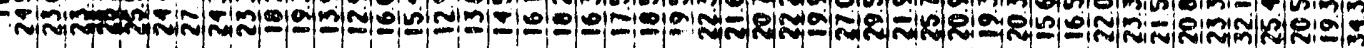
1

E ma

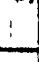

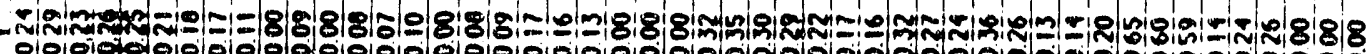

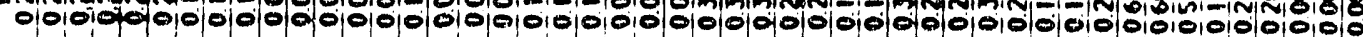

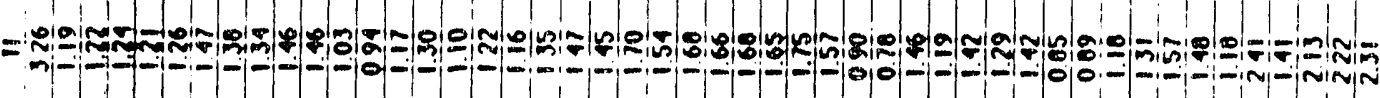

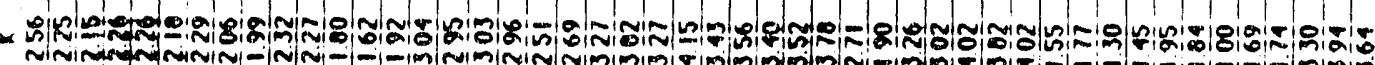

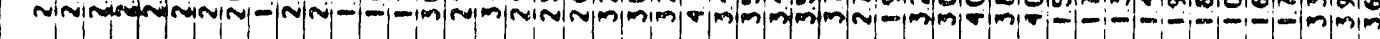

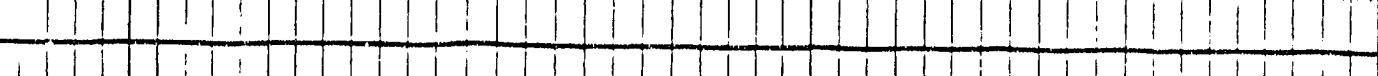

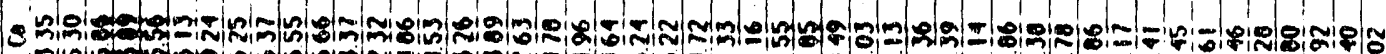

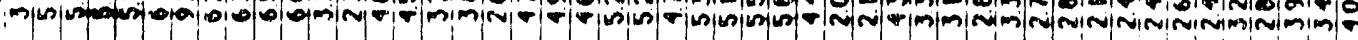

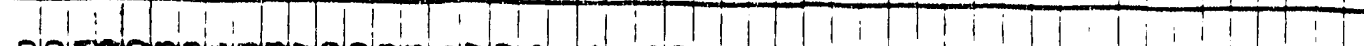

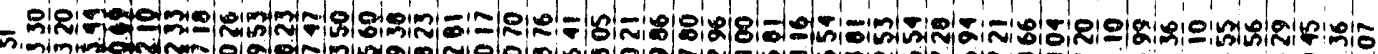

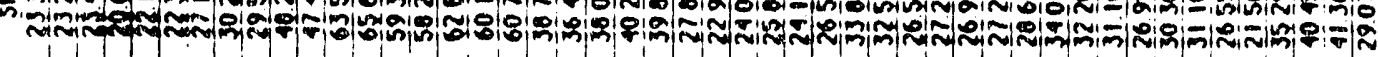

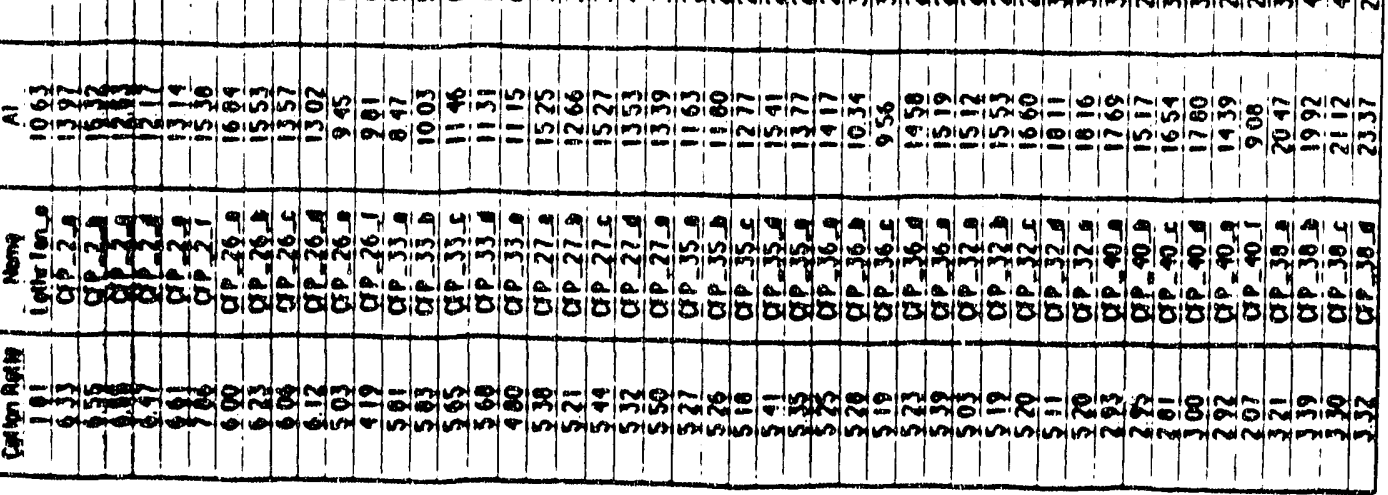




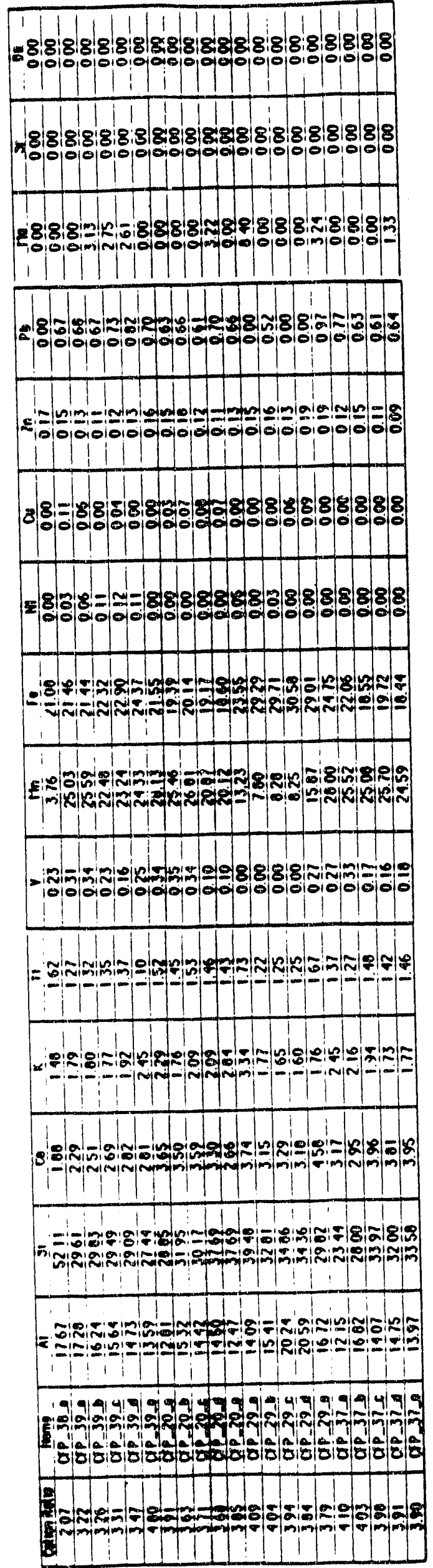


and might not represent the time of deposition of the unit. Table $5 B$ also includes a comparison of how the varnish CRs obtained by scraping-FIXE would compare with the CLC curve reported by harrington and whitney (1987) for the SEM-EDAX method. This is simply to show that the error curves surrounding the SEM-EDAX data are less precise than those for the scraping-PIXE data.

The geomorphic and soils interpretacions of these data are beyond the scope of this report.

A project is in progress to assess the possibility of Uranium-series dating varnish at Crater Flat and vicinity. A sample of varnishes collected from the north side of the Lathrop wells basalt flow were carefully prepared to remove only the bottom layer of the varnish. Great care was taken. as in CR dating, to avoid contamination from the underlying rock. This sample was sent to DI. T.L. Ku at USC Eor Uranium-series analysis. Dr. Ku (personal communication, 1988) indicated very high levels of $U$ and $T h$. He noted that the age can be constrained to be younger than $150 \mathrm{ka}$, which is consistent with new $K \cdot A r$ age determinations for the flows of Lathrop wells by B.D. Turrin (personal communication, 1988); Dr.Ku tentatively interprets the very high levels of Th in varnish as not indicative of transport in the detrital phase, but perhaps as a slow accumulation in varnish over time, perhaps related to the great capacity of $M n$ and $F e$ oxides to adsorb trace elements (e.g. Jenne, 1968; Balistrieri and Chao, 1977; Chao and Theobald, 1976; Lockwood and Chen, 1973; Mckenzie, 1972).

\section{E. Perspectives on Future Uses of Cation-Ratio Dating}

Given the above uncertainties and limitations, I feel the long-term future of $C R$ dating is iimited. While analysis of varnish CRs have tremendous potential to estimate minimum ages of geomorphic surfaces currently not datable by conventional means, there are a range of surface exposure techniques related to the accumulation of cosmogenic nuclides such as He-3, Be-10, Al-26 and C1-36 (Phillips and Elmore, 1986; Lal, 1987; Kurz et al., 1987; Klein et al., 1987). These are likely to replace $C R$ dating for most geomorphic work requiring precision in the near future. Some are bejng used with considerable success already (Phillips et al., 1987). I believe that these surface exposure methods wili prove to be far more precise than CR dating, more accurate, and of comparable cost to $C R$ dating (especialiy when the cost of putting together a curve in each area of interest is considered). Importantly, these methods may be used in a region where numerical dating calibrations, such as K-Ar, are not available.

Having developed $C R$ dating, however, I would like to believe it is a technique that will not live and die in the 
1980s. There are at least three future uses of $C R$ dating. First, $C R$ age-determinations could be used to cross-check other Quaternary dating methods, as the $C R$ system is very different from many other methods. Second, $C R$ dating can be used to estimate the ages of surface exposure where material is unsuitable for cosmogenic dating because it has "inherited" a prior exposure history. For example, if a cobble rests on the surface of an alluvial fan, accumulates cosmogenic nuclides, and is then transported a short distance. This transport would remove the varnish, but it might not abrade off all the surface material that had accumulated cosmogenic nuclides. Third, CR age-estimates have a definite future in archaeological studies in arid lands. Rock engravings and surface artifacts accumulate varnishes in arid and semiarid environments. A varnish $C R$ would provide a minimum-limiting estimate for the time of artifact/petroglyph manufacture. CR dating by the scraping. PIXE method is not destructive of the artifact. In contrast, the SEM-EDAX method is very destructive.

V. Role of Radiocarbon Dating of Rock Varnish in the Yucca Mountain Investigation.

\section{V.A. Preface}

The rock varnish investigation of the DOE through Los Alamos and the U.S. Geological Survey has not incorporated a component for the radiocarbon dating of varnish. The purpose of this section is not a review of the DOE investigation per se, but rather a support section that fully explains the methods and limitations of radiocarbon dating of rock varnish. ${ }^{14} \mathrm{C}$ dating of rock varnish is related to the Yucca Mountain project in that it provides calibration dates in the latest-Pleistocene and Holocene; it provides numerical age control for late-Quaternary units of the Nevada Bureau of Mines and Geology project in Crater Flat; and some prelinninary work has been conducted to assess the age of the cinder cone at Lathrop Wells, NV.

\section{V.B. Method}

\section{V.B.1. Introduction to the Method}

Organic matter is present in rock varnishes in small quantities, generally less than $2 \%$ by weight. This has been recognized since the work of Laudermilk (1931). Hunt (personal communication, 1987) observed the presence of fungal Eilaments in varnishes using optical microscopes to examine thin sections of varnish in the 1950s. In recent years, the biological origin for rock varnish has been supported by several researchers including Krumbein (1969), Krumbein and Jens (1981), Dorn and Oberlander (1981, 1982) and the Washington Group (Ferry and Adams, 1978; Staley et 
al., 1982, 1983; Taylor-George et al., 1983; Palmer et al., 1985). It should not be surprising, therefore, that sufficient organic matter can be extracted from rock varnish for an accelerator radiocarbon date (cf. Suter et al., 1984; Jull et al., 1986).

Dorn and DeNiro (1985) undertook the Eirst analyses of varnish organic matter (VOM), by analyzing its ${ }^{13} \mathrm{C}$ content. In the process of learning how to extract voM for this study, several different types of VOM were observed. There are the microorganisms growing at the surface (and infrequently extending through the varnish in microcracks). There are pieces of organic detritus worked into the varnish as it accretes, such as pieces of pollen and assorted dry fall (cf. Webber, 1986). There are organics loosely adsorbed to the clay minerals (cf. Dashman \& stotsky, 1982; Hedges and Hare, 1987), and there are organics more tightly adsorbed by the manganese and iron oxides (cf. MCBride, 1987; shindo and Huang, 1982). B.R.T. Simoneit conducted preliminary GC-MS analyses of varnish from the Rainbow Basin, Mojave Desert, CA., and indicated a composition of microbial lipids and plant detritus (reported in Dorn and DeNiro, 1985). More work is in progress on this topic (B.R.T. Simoneit, personal communication, 1988).

The object of radiocarbon dating of rock varnish is to approximate the time of exposure of the rock underlying the varnish. The VOM should, therefore, be extracted from the basal layer, and the fraction of the basal layer that is most stable ( $M n$ and Fe oxides). In this way, a minimum-limiting age can constrain the exposure of the underlying rock.

Dorn et al. (1986, 1987b, 1987c) reported accelerator mass spectrometry (AMS) radiocarbon dates of VOM from the basal layers of varnishes. The ${ }^{14} \mathrm{C}$ analyses by AMS represent minimum-limiting ages for geomorphic surfaces such as alluvial fans, fluvial terraces, prehistoric shorelines or glacial tills that could not be dated, because conventional deposits of carbon are not present.

\section{V.B.2. Sample Collection and Processing}

The field procedure used for collecting varnishes for radiocarbon dating is similar to $C R$ dating, described earlier. The same microenvironmental instabilities should be avoided (Table 2). In brief, biogeochemically unstable microsites and macrosites are avoided, such as microcolonial fungi, lichens, where water collects, or where acid leat litter collects. Time transgressive lithologies are avoided, as are unstable geomorphic substrates and varnishes that have indications of episodes of erosion in the past (by cross section analysis). The purpose of this type of scrutiny is to collect varnishes that have experienced only gradual 
accretion of varnish without erosion since the surface of interest was exposed.

Laboratory processing of the samples for AMS radiocarbon dating involves several steps.

(1) The samples are washed in distilled water and scrubbed lightly with a soft toothbrush. The samples are sorted into 10 groups of equal surface area. A random chip is broken off of a random sample from each of the groups for examination by SEM-EDAX. The depth of the unscraped varnish in the different micropositions (ridge, depression) is characterized by SEM. In addition, the occurrences of anomalous concentrations of paleo-MCF, paleo or current bioetchpits, or filamentous fungi are checked (cf. Dorn and Oberlander, 1982; Dorn, 1986). If found in great abundance in this initial random sampling, random chips are taken from each rock in the sample set. Rejection of a rock piece for further processing occurs if the abundance of bioetchpits is greater than 1 in a 100 square micron area, or is MCF are eroding into the varnish and have a concentration of greater than 5\% on the surface, or it the Eilamentous fungi have a concentration greater than $5 \%$ of the surface area. If more than 25\% of the rock samples are rejected, the site is resampled, if it can be dated successfully at all.

(2) Using 10.45x magnification under a stereomicroscope, all but the lowest $10 \%$ of the varnish is removed by mechanical scraping with a tungsten-carbide needle. Thickress of the remaining varnish is established by SEM analysis of candomly selected pieces from each of the rocks sampled. If the thickness of the remaining varnish is less than 10 of the depth of the unscraped varnish, it is ready for the next step. If not, the particular rock is rescraped. A subaerial black varnish scraped to such a thin layer has a distinctive milky.brown appearance under $45 x$ magnification.

(3) This basal layer is then completely scraped off, and random samples are again checked by SEM to determine complete removal of a varnish.

(4) A sample of similar volume is collected from the underlying rock. This is to assess the potential addition of carbon from the underlying rock that is incorporated into the sample.

(5) The basal layer of the varnish land the rock control samplal is processed to concentrate the stable organic matter deposited when this basal layer formed. The procedure to concentrate the stable organic matter is as follows. (a) The sample is placed in a centrifuge rube. All processing is conducted in the fume hood. (b) The sample is treated with $35.38 \% \mathrm{HCl}$ and digested for 3.45 minutes, centrifuged, and decanted. The sample is washed in distilied 
woter and centrifuged 6 to 10 times. (c) The sample is equilibrated with concentrated HF $(52.55 \%)$ for 1 to 36 hours, depending on the length of time needed for digestion. Longer times are usualiy required for the control sample of the underlying rock. The samples are centrifuged, and washed in distilied water 6 to 10 times. (d) The varnish sample is dispersed in distilled water and $4.5 \%$ sodium dithionite is added. The mixture is digested for 30 to 50 minutes is $40 \mathrm{C}$ water bath, centrifugad and decanted. The procedure may be repeated 1 to 2 more times. The sample is then washed/centrifuged 3 times in distilled water. This is similar to the process described by Deb (1950). (e) The sample is then equilibrated with $0.3 \mathrm{M}$ hydroxylamine hydrochloride in $0.1 \mathrm{M}$ nitric acid $(\mathrm{pH} 2)$ for 15 to 90 minutes. The supernatent is decanted and the sample is washed in distilled water and centrifuged 3 times. This step may be repeated. It is similar to the procedure used by chao $(1972)$. (E) It is unusual to find detectable levels of organic matter in the control samples of the underlying rock. If organic matter is found, however, the varnish sample from the site is not suitable for radiocarbon dating. This is because contamination from the underlying rock would likely affect the AMS radiocarbon analysis. A more suitable lithology is selected when the site is resampled. In addition, a scraping procedure is used where the rock is not scraped. This is much more labor intensive and hence is not used unless detectable carbon is found in the underlying rock.

(7) The sample is then analyzed by accelerator mass spectrometry (AMS). A detailed description of AMS radiocarbon daring is presented in surer et al. (1984) and Jull et al. (1986).

Experiments are in progress that involve the effect of differenc ways of processing the varnish samples. The available results are discussed in the following section.

V.C. Discussion: Complications and Support for the Mechod

\section{V.C.1. Assessment of Contamination from Older Carbon}

The possible sources of contamination from older carbon might be from the plastic material that the varnish is exposed to during sample collection and processing, from the underlying rock, or from carbonate detritus that blows in.

In an experiment to assess the effect of placing plastic wrap around varnishes, a duplicate sample was taken of a 2030 \pm 80 yr old lava flow of Hualalai, HI, dated by Rubin and Moore (1987). One set of samples was wrapped in plastic: another in aluminum foil. The results listed in table 8 show no significant different between the two samples. 
Although it is kept to a minimum, some material from the underlying rock is incorporated into the sample of the basal layer of varnish. Tests must, therefore, be performed to assess the amount of carbon in the underlying rock by removing a similar volume of the rock (scraped after the varnish) and treating it to the same extraction procedure. In only one sample processed thus Ear has there been. detectable levels of organic matter from the rock sample. Nodules eroded out of the Coconino formation on the flank of Meteor Crater, AZ, have some carbon that turned a varnish radiocarbon date into an anomalously old direction, by about 2000 years (R.I. Dorn, unpublished data). Importantly, this source of contamination is assessed for every sample.

Calcium carbonate detritus can get trapped in varnish. Although the calcium carbonate is removed by the HCl treatment, some might argue that autotrophic organisms could obtain carbon from this dust, and older carbon could contaminate the signal. There is no evidence, however, to suggest this is a problem. First, no autotrophic microorganism that obtains carbon from carbonate has been observed on varnish (Krumbein and Jens, 1981 ; Dorn and Oberlander, 1981, 1982; Taylor-George et al., 1983; Palmer et al., 1985). Second, Dorn and DeNito (1985) Found that the d $13 \mathrm{C}$ composition of the varnish reflects the adjacent vegetation, and there is no reason to suspect that organic matter from adjacent vegetation be fractionated towards an older radiocarbon signal. Third, culturing and $213 \mathrm{C}$ experiments on varnish-forming microorganisms indicate that pedogenic carbonate is not taken up, as the carbonate a $^{3} \mathrm{C}$ signal does not affect the $2{ }^{13} \mathrm{C}$ values of the bacterial-made laboratory varnishes (Table 7). The slight changes from the source dis values by bacteria in rable 7 may be from fractionation associated with metabolic pathways (Macko et al., 1987); these changes are not systematic with regards to the carbonate ${ }^{13} \mathrm{C}$ signal.

V.C.2. Assessment of Factors Making the ${ }^{14} \mathrm{C}$ Signal Too Young and How to Correct for It

There are several reasons why the ${ }^{14} \mathrm{C}$ age of basal VOM should be younger than the exposure of the underlying surface. Four general reasons are presented. (1) There is a lag of about 60-100 years between the exposure of a surface in arid and semiarid regions and the onset of varnishing (Table 1; Figure 1). This lag is less for periglacial varnishes (Dorn and Oberlander, 1982; Douglas, 1987). (2) As varnish grows laterally and vertically, the basal layer of varnish may form earlier on one spot than another. This problem of time-transgressive growth can be addressed by sampling different microsiees/lithologies on a surface that were exposed at the same time and in a chronosequence, and by sticking to microsites that have been tested in this fashion. 
Iable 7. Effect of Mcroblal Activity and Carbonate on Stable Carbon Isotope Values

7A. EFFECT OF MICROBIAL ACTIVITY ON STABLE CARBON ISOTOPE VALUES OF VARNISH Mscroorganism: Mecallogenium or Arthrobacter

\begin{tabular}{lll}
\hline & C-4 Sources & C-3 Sources \\
\hline Ray Organic Matter & -14.7 & -22.5 \\
Cultured Only & -14.1 & -21.2 \\
Macrobial Varaish & -15.0 & -23.3 \\
\hline
\end{tabular}

7B. EFFECT OF MICROORGANISIMS AND CARBONATE ON STABLE CARBON ISOTOPE VALUES MAcroorganion: Metallogeniun or Arthrobacter

\begin{tabular}{lll}
\hline & $C-4$ Sources & $C-3$ Sources \\
\hline Raw Organic Matter & -15.7 & -23.3 \\
Pedogenic Carbonate & -6.7 & -4.6 \\
Cultured Only & -15.4 & -23.0 \\
Microbial Varnish & -16.7 & -23.8 \\
\hline
\end{tabular}


(3) Varnishes in alkaline environments such as deserts are considered stable (Elvidge and Iverson, 1983; Dorn, 1983). The pH.Eh conditions are not acidic enough to mobilize the manganese and iron oxides that cement the varnish. If, however, the environment changed to an acidic enough condition to reduce $M n$ and $F e$, the varnish would erode chemically. Similarly, if aeolian activity abraded off the varnish, the varnish clock would be reset. Any date on surfaces that had experienced the erosion of varnish would. therefore, be a minimum age. This is why erosional and paleo-erosional criteria are important (Table 2; Figures $4,5,7)$. (4) The basal 10 of the varnish reflects the accumulation of VOM over a period of time, not the instant of surface exposure. This is perhaps the most important reason why the varnish radiocarbon age must be a minimum-limiting estimate.

Empirical Tests of $14 \mathrm{C}$ dating of varnish organic matter. A concerted effort has been made to compare the results of varnish radiocarbon dating with other, independent estimates for the surface exposure. By correcting for the above cumulative effects, through testing varnish on surfaces where the surface exposure age is known, the corrected varnish radiocarbon age should approximate the timing of surface exposure. Table 8 compares $14 \mathrm{C}$ of varnish with loosely constrained surface exposure ages, and more tightiy constrained tests. The latter are the conventional radiocarbon dates on charcoal beneath the lava flows of Hualalai Volcano, HI. (Rubin et al., 1987). More samples are in process, from shoreline locations in the western U.S.A. and other situs. In brief, the samples analyzed at present tend to be about 10 younger than the conventional ${ }^{14} \mathrm{C}$ ages. However, the lag may be less for the more xeric sites and greater for the more mesic sites, perhaps due to undetected biogeochemical erosion.

How the varnish radiocarbon ages should be reported. Depending on how the tests turn out, there might be a correction for the desert sites and one for semiarid sites. The eventual reporting of a radiocarbon date would account the empirical correction. The error would include the plus/minus of this correction:

Corrected Varnish ${ }^{14} \mathrm{C}$ Age = [Raw AMS Age] * [Correction Factor] Error for Corrected Age $=$ [Analytical Error + I Uncertainty]

There would also have to be another correction for the radiocarbon age calibration (stuiver et al., 1986). 
Tabie 8. Comparison of l4C ages of the basal layer of rook varnishes, as compared to independent ages for surface exposure.

\section{LOOSEIY CONSTRAINED CONTROL}

SURFACE EXPOSED VAPNISE 14C INDEPENDENT AGE CONTROL \& COMAIENT

\begin{tabular}{|c|c|c|}
\hline ard & $\begin{array}{l}14,600 \div 800 \\
(14-356)\end{array}$ & 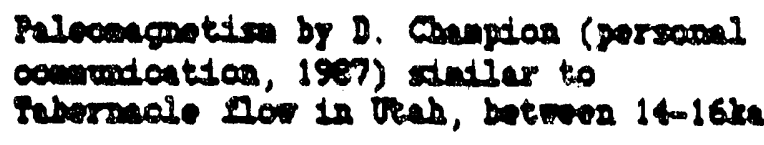 \\
\hline $\cos$ Dow 25 & $\begin{array}{l}42,900 \cdot 3900 \\
(14-1417)^{-2600}\end{array}$ & 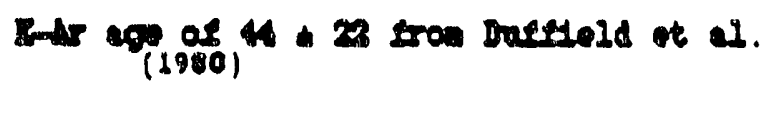 \\
\hline 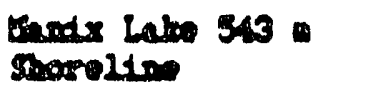 & $(16,800 \div 700$ & 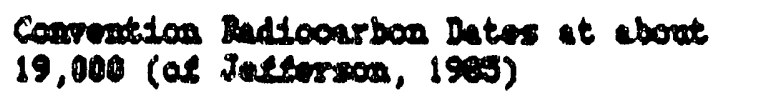 \\
\hline $\begin{array}{l}\text { Lake bojere } \\
\text { Sporeldse " }\end{array}$ & $\begin{array}{l}9050 \div 160 \\
(M-2185)\end{array}$ & 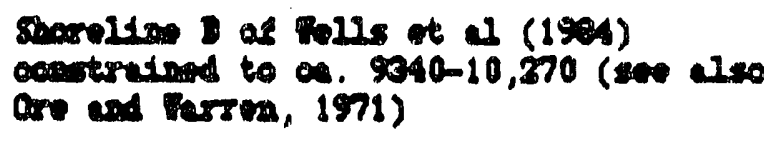 \\
\hline 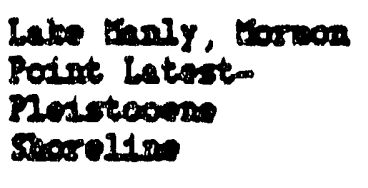 & $\left.{ }_{(12,630}^{12}+124\right)$ & 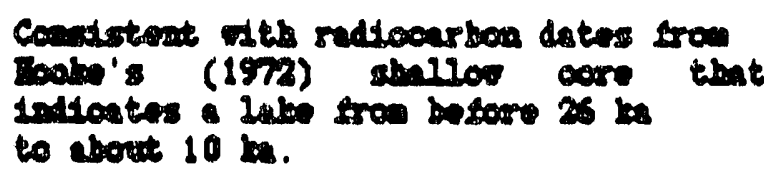 \\
\hline 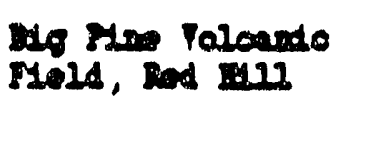 & 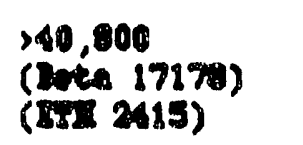 & 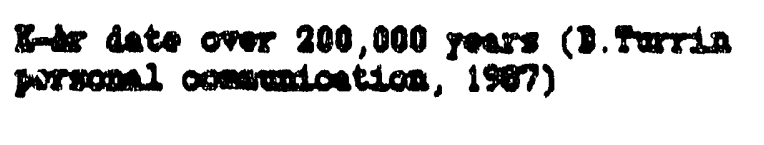 \\
\hline
\end{tabular}


TIGUTLY CONSTRAINED CONTROLS

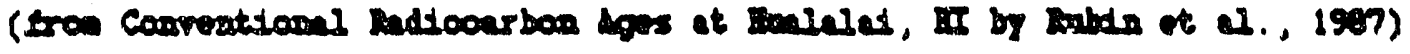

\begin{tabular}{|c|c|c|c|}
\hline $\begin{array}{l}\text { SURFACE } \\
\text { EXPCSED }\end{array}$ & $\begin{array}{l}\text { YARNISH } \\
\text { I\&C }\end{array}$ & $\begin{array}{l}\text { SUBTLON } \\
\text { CHARCOAL }\end{array}$ & COMIINTS \\
\hline Tab Pele & $\begin{array}{l}604: 69 \\
(14-2137)\end{array}$ & $710 \div 150$ & Pery foung and soraping difstoult \\
\hline Pou sonbols & $\begin{array}{l}1908 \div 49 \\
(4-2018)\end{array}$ & $20000 \cdot 80$ & $\begin{array}{l}\text { Deplicato; test af elfect of } \\
\text { plastio wrop }\end{array}$ \\
\hline 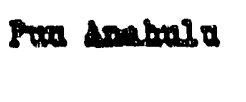 & $(193+2132)$ & $20030+80$ & 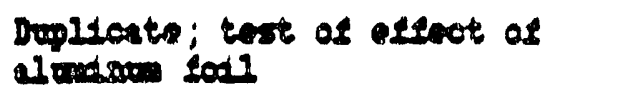 \\
\hline 8001 st coses & $\begin{array}{l}2450+100 \\
(\operatorname{set}+17855) \\
(\sec 2400)\end{array}$ & $2670 \cdot 80$ & Propared by D. ranor \\
\hline sootst cones & $\begin{array}{l}2470+65 \\
(M-2012)\end{array}$ & $2570+80$ & Ireparad by R.I. Dows \\
\hline Pwo Fander & $\frac{2065}{(4-2016)}$ & $3000 \cdot 200$ & 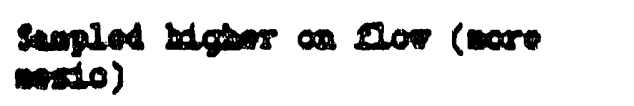 \\
\hline Pwos Peame & $\frac{2530+00}{(14-2013)}$ & $3000+200$ & 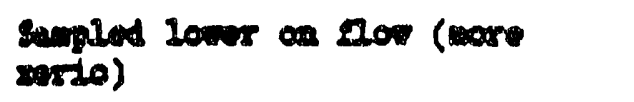 \\
\hline$\frac{10101}{630}$ & $\frac{2023+80}{(14-2123)}$ & $6550-100$ & 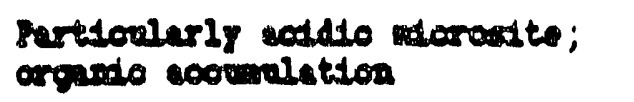 \\
\hline $\begin{array}{l}\text { Soniclat } \\
\text { Sonde }\end{array}$ & $\begin{array}{l}7216+84 \\
(4-2120)\end{array}$ & $8770+200$ & $\begin{array}{l}\text { Suburtaly exposed, thon } \\
\text { buried }\end{array}$ \\
\hline Bun Am & 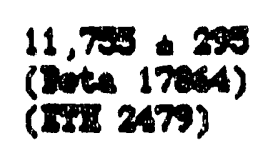 & $12950+150$ & 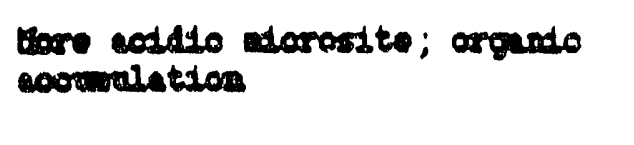 \\
\hline
\end{tabular}


V.C.3. Assessing Why the Varnish Radiocarbon System is Closed and the Cation-Ratio System is Open

Table 8 shows that the ${ }^{14} \mathrm{C}$ ages of basal vom approximates the ages of surface exposure for a variety of surfaces, obtained by independent means. An implicit consequence is that the dated VOM was deposited soon after the surface was exposed and not reworked. In contrast, $C R$ dating is based on the relative mobility of cations like $C a$ and $\mathrm{K}$. and the relative immobility of cations like Ti. The varnish radiocarbon system appears to be closed. The varnish CR gystem appears to be open.

This apparent contradiction can be resolved by the type of VOM that is being dated. It is the organic matter that remains after the removal of carbonates and silicates (and organic matter adsorbed to the silicates) in varnish. It is what is the organic detritus and organic matter locked up in the oxides (cf. MCBride, 1987), probably deposited soon after the surface was exposed to the subaerial environment.

This hypothesis is supported by preliminary results of ongoing experiments on different ways of pre-treating the varnish. When the basal layer is not treated as described in the methods section above, the AMS ages are much younger. The ca. $43 \mathrm{ka}$ age for Coso 26 reported in Table 8 yields an AMS age of $28,140 \pm 550$ (AA-2011) with treatment by only HCl and NaOH. A basal layer age of $21,760 \pm 280$ (AA-2130) Eor a unit of Galena Canyon Fan, Doath valley with normal. processing turns to be a much younger $5357 \pm 94$ (AA-2131) when treated with only HCl. These experiments, although preliminary, indicate that the organic matter in varnish can be in both a closed and open system, depending on what fraction is removed. Experiments are in progress to test other ways of sample processing.

There is some possibility that some fractionation does occur by the treatment process. A sample of wood was split into two parts to test this. One portion was treated as described in the methods section; the other portion was not. After gas proportional counting at UCLA, the radiocarbon age of the treated sample was about 5\% older $13150 \pm 60 ; 3155 \pm$ 50) than the untreated portion $(2995 \pm 65 ; 3020 \pm 60)$ (D. McJunkin, personal communication, 1985). The differences could be due to different rings in the foxtail pine, of by the processing. 
TABLE 9.

EFTECT OF MICROCOLONIAL FUNGI ON VARKISA STABLE CARBON ISOTOPE VALUES

Transect from Crater Flat to Bare Mourtain, Southern Nevada

\begin{tabular}{lllll} 
Elevation & $\begin{array}{l}\text { Eroding } \\
\text { Marnish } \\
\text { Baneath } \\
\text { Broding } \\
\text { MCF }\end{array}$ & $\begin{array}{l}\text { Non-Eroding } \\
\text { MCF }\end{array}$ & $\begin{array}{l}\text { Varnish } \\
\text { Beneath } \\
\text { Non-Eroding } \\
\text { MCF }\end{array}$ \\
\hline $1830 m$ & -22.2 & -21.9 & -22.5 & -21.4 \\
$1220 m$ & -22.4 & -21.0 & -19.3 & -18.8 \\
$915 m$ & -23.8 & -20.8 & -18.2 & -17.8 \\
\hline
\end{tabular}


An important test of the closed sygtem of dated Vom is in progress. Varnishes from surfaces far, far older than the $40 \mathrm{ka}$ limit of radiocarbon were collected and processed from areas close to open-air bomb explosions near the Nevada Test Site and the Trinidad site, NM. If the varnish system for the extracted organics is truely closed, bomb carbon should not affect the date. If is it open, the bomb carbon could affect the date. The AMS analyses have not been completed. Away from the immediate influence of bomb carbon, a volcanic Elow in the Big Pine Volcanic Field was sampled Eor radiocarbon analysis. At the time of collection, it was thought that the flow might be around $25 \mathrm{ka}$ (B.D. Turrin, personal communication, 1985). As the results in Table 8 indicate, the AMS age was $>40,800$ and the $K$-Ar age for the basalt flow turned out to be around $250 \mathrm{ka}$. In other words, at a site known to be "dead" by k-Ar dating, the varnish radiocarbon age did indeed turn out to be at background.

\section{V.C.4. Assessing the Importance of stability of Rock} Varnish

Even if the varnish has not been completely eroded by chemical dissolution or aeolian abrasion, partial erosion may change an AMS radiocarbon date. This could be the reason for the greater lags at more humid sites in Table 8 .

An example using the role of microcolonial fungi. illustrates this. Microcolonial fungi are fairly common on varnishes in the southwestern U.S. (cf. Staley et al., 1982; Taylor-George et al., 1983) and Australia (staley et al., 1983). They appear to erode varnishes (Dori, .1986; Figure 7 ), and they can affect a varnish cation-ratio (Table 2 ). Table 9 illustrates the effect of microcolonial fungi on the stable carbon isotope values of varnishes on an altitude transect near Crater flat. When the inicrocolonial Eungi are present, the $213 \mathrm{C}$ values are affected. Note how the values change beneath the eroding microcolonial fungi as compared to varnish beneath the microcolonial fungi that are not appearing to erode the varnish.

It, therefore, seemed logical to investigate the. possibility that abundant, eroding microcolonial fungi could affect the varnigh radiocarbon signal. Based on one example, it appears there can be an effect. In Table 8, the ca. $9 \mathrm{ka}$ age Eor black subaerial varnish on shoreline $B$ of lake Mojave, CA. (cf. Wells ot al., 1984) contrasts with the 4320 \pm 105 (AA-2133) age for the varnish beneath the microcolonial fungi. Both samples were processed the normal way, as listed in a $n$

a 51 i e I $s e c t i \circ n$. 


\section{V.C.5. Other Concerns and Other Tests}

Another test of the method is to divide the varnish into layers and assess the AMS ages of the different layers. On Death Valley Canyon Fan, Death Valley, $C A$, the basal layer on a fan unit has an age of $4350 \pm 88$ (AA-2017). The outer composite layer of the varnish gave a net, cumulative age of $2308 \pm 71$ (AA-2135). This trand of older/lower layer to younger/upper layer is what would be expected if the method is correct.

Operator error could be a problem, if an individual attempted to sample and process varnishes without being properly trained. The effect of operator error (by trained persons) was tested at a few sites. Table 2 present 2 samples of the 8001 ft cone of Hualalai by different operators and different laboratories. The results are similar. In addition, tests at Meteor Crater, AZ, on varnishes collected Erom the same boulder yielded statistically identical results (R.I. Dorn, D.L. Tanner, D. Roddy, in preparation). The effect of operator error by a relatively untrained person is still being evaluated.

Varnish radiocarbon dating shows potential for assessing the ages of buried varnishes. For example, the varnish on Cima flow A.1 (Table 8) at ca. $14,600 \pm 800$ can be compared with a varnished pavement that was buried by the flow. The radiocarbon age on the top layer of the varnish on a desert pavement buried by the lava flow has an AMS radiocarbon date of $19,520 \pm 240$ (Beta 17536).

\section{V.D. Preliminary Varnish Radiocarbon Date on Lathrop Well Cinder Cono}

Rock varnishes were collected from the tops of 19 bombs on the rim of the crater at the cinder cone near lathrop Wells, NV. The depth of the varnish is illustrated in Figures 14A and 14B. The samples were processed for AMS radiocarbon dating, as described in the method section. Figure 14C illustrates the basal layer of varnish before removal, and Figure 14D after removal. No observable organic matter was detected in the control sample of the underlying rock. About $15 \mathrm{mg}$ of organic mateer was extracted and sent to Beta Analytic for processing and analysis at zurich (Suter ot al., 1984). The analytical date is $19,940 \pm 270$ (Beta 17866).

This AMS radiocarbon date should be viewed only as a tentative age-estimate. There may be special concerns to dating cinder cones. For example, there is a possibility that 
Figure 14. SEM analysis of varnish on volcanic bombs of Lathrop Wells Cinder Cune.

A. Representative depth of rock varnish on bombs. Note how the basal layer of the varnish has a botryoidal (rounded) structure. This is characteristic of varnish formation in a more hunid climate of greater vegetation abundance (cf. Dorn, 1986). The bocryoidal layer, however, is laterally discontinuous due to variable concentrations of manganese. High manganese concentrations are needed to preserve fossil botryoids. If concentrations are not too low, they will undergo a diagenesis to a layered lanellate strusture, as in the bottom layer of Figure 148 .

B. Representative depth of rock varnish on bombs. Note how the bottom layer is lamellate. Manganese concentrations are not high enough to preserve the botryoidal structure.

C. Removal of varnish down to the lowest $10 \%$ (or less). organic mater is extracted from this layer.

D. Complete cemoval of the varnish. 


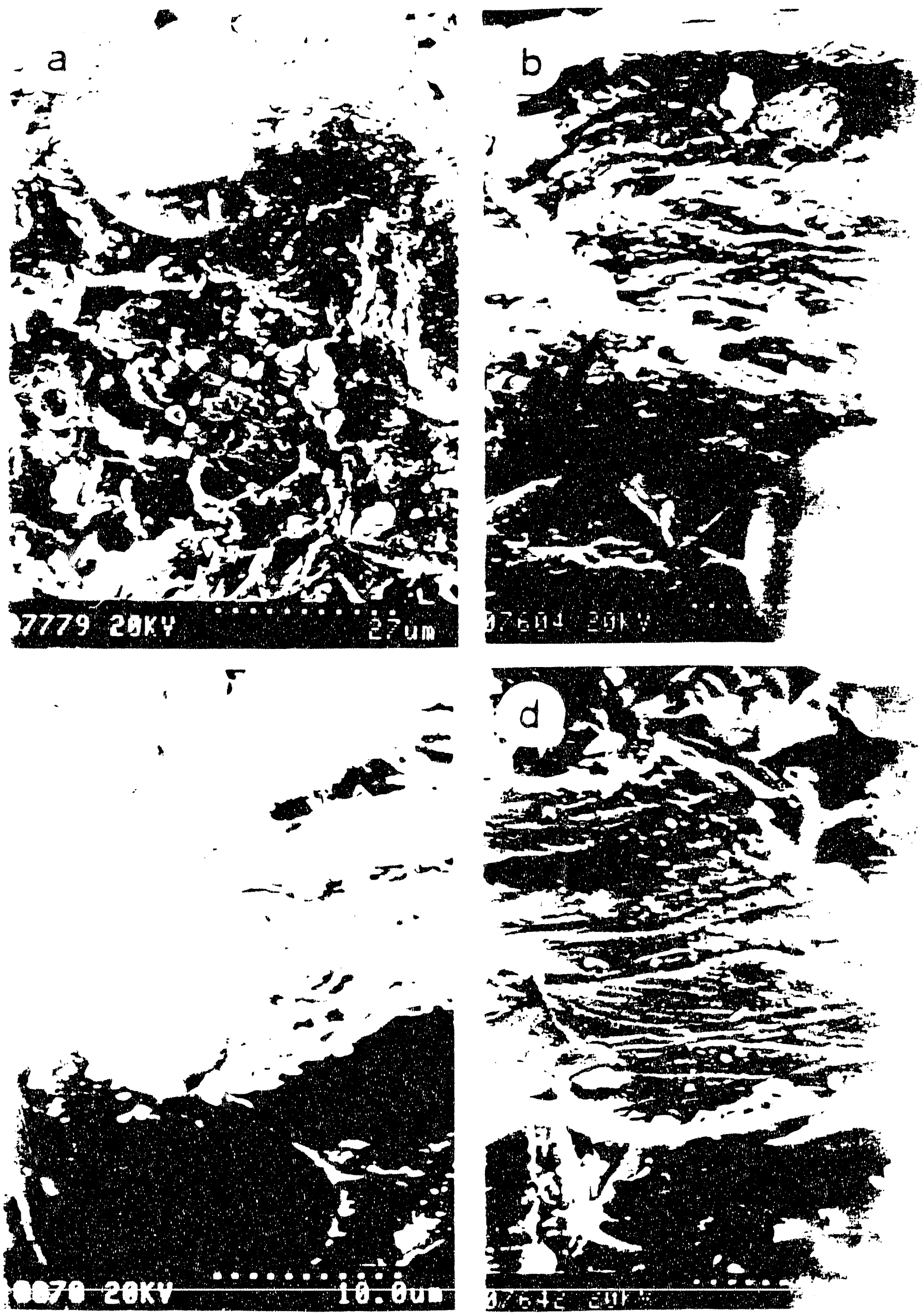


dead carbon may get incorporated into varnish by "dead" carbon dioxide erupted and used by plants, that then shed organic matter into the varnish.

The micromorphology of the varnish also supports a latest-Pleistocene age. It is unlikely that the varnish is less than about $9.12 \mathrm{ka}$, because of the botryoidal layer in Mn-rich varnishes (Figure 14A). Dorn (1986) Eound that where dust is less abundant and plant cover is greater than about 40\%, a botryoidal layer forms on varnishes in a subaerial environment. If there is enough manganese to preserve the botryoidal structure, it can remain as an indicator of past environmental conditions. This fossil layer can serve as a chronostratigraphic marker. Most of the varnishes observed on the Lathrop Wells cinder cone do not have a high enough manganese content to preserve the botryoidal structure, and this layer has undergone a diagenesis to a lamellate structure (Figure 14B). In some protected microenvironments, however, enough manganese exists to preserve a subsurface botyroidal layer at the Lathrop wells cinder cone (Figure $14 \mathrm{~A}$ ). Based on observations made at other sites in the southwestern U.S. (Dorn, 1986), this subsurface layer would have likely formed during a period of greater-effective moisture, that may have ended in the Anargosa Desert by about 9 to $12 \mathrm{ka}$ (Spaulding et al., 1984; Spaulding, 1985; Claassen, 1986).

There are some reasons why I suspect this particular varnish radiocarbon date may be flightly too young. Aeolian abrasion is evident, and while sampling was conducted to avoid this effect, more samples should be analyzed to be sure. Also, volcanic bombs may undergo spalling, and the radiocarbon date may reflect the stabilization of the bomb surfaces. Once again, multiple sampling of different varnish microsites would be needed to rule of this effect. It is also possible that varnish formation on the volcanic bombs might transgress time; in other words, if tle basal layer did not form evenly, the radiocarbon date might combine much younger with older varnishes. To rule out this effect, the best thing would be to date varnishes on different types of microsites on the bomos. Lastly, some fungal filiments may have been incorporated into the radiocarbon sample that was radiocarbon dated by AMS. After the sample was processed and sent, subsequent reexamination of unscraped chips by SEM revealed the presence of fungal filaments that had worked into microcracks in the varnish on the bombs. More samples, carefully sampled, should be analyzed to rule out that these fungal. hyphae affected the date. It is for the above reasons that I must stress that the ca. $20 \mathrm{ka}$ age is only a rough estimate. The real solution is to conduct more tests of radiocarbon dates on different microsites, and to attempt to date the Lathrop Wells cone by other surface exposure dating methods, such as Cl-36. 
It is interesting to note, however, that other work on the geomorphology of the cone (Wells te al., 1988) argues for a latest-pleistocene age, on the order of 15,000 years.

V.E. Concluding Remarks on Varnish Radiocarbon Dating

Accelerator-radiocarbon dating of rock varnish opens up a wide variety of late-Quaternary desert surfaces to numerical age control. Varnish radiocarbon dating is a much superior method to $C R$ dating in the time range. Its systematics are easier to model; the method is easier to test. It is moro precise. A difficulty is the greater expense in sample preparation labor costs and the greater analysis costs of AMS radiocarbon dating. 


\section{References}

Balistrieri, L.S., and Chao. T.T. 1987. Adsorption of selenium by iron and manganese oxides: eavironmenial implications. U.S. Geological Survey Open Fill Report 87-0109: E19-20.

Barone. J.B., Asmbaugh. L.L.. Kusko, B.H., and Cabill. T.A. 1981. The effect of Owens Dry Lake on Air Quality in the Owens Valley with Implications for the Mono Lake Area In E.S. Macias and P.L. leds.l, ACS Symposium Series, No. 167 Atmospheric Acrosol: Source/Air Quality Relationships : 328-346. Washington D.C.: American Chemical Society.

Cahill. T.A. 1980. Proton microprobes and particle-induced X-ray analytical systems. Ansual Review Nuclear Particle Science 30:211-252.

Cabill, T.A., Eldred, R.A., Stadoan, D., Feeney, P., Kusko, B. and Matsuda, Y. 1984. Complete lemental analysis fo aerosols: PIXE, EAST, LIPM, and MASS Nuclear Instruments and Methods in Physics Research B3: 291-295.

Chao, T.T. 1972. Selective dissolution of manganese oxides from soils and sediment with acidified bydrorylamine bydrochloride. Soil Science Society America Proceediags 36: 764-768.

Chao, T.T. and Theobald. P.K. 1976. The significance of secondary iron and manganese oxides in geochemical exploration. Economic Geology 71:15601569.

Claassen. J.C. 1986. Late-Wisconsin paleohydrology of the west-central A margosa Desert. Nevada, U.S.A. Chemical Geology (Isolope Geoscience Section) 58 : $311-323$.

Colman. S.M. 1982. Chemical weathering of basalts and andesites: evidence from weatheriag rinds. U.S. Geological Survey Professional Paper 1246.

Colman. S.M. 1986. Levels of time information in weathering measurements, with examples from weathering rinds on volcanic clasts in the westera United States. In S.M. Colman and D.P. Dothier leds.l, Rates of Chomical Weathering of Rocks and Minorals: 379-393. New York: Academic Press.

Colman. S.M., K.L. Pierce and P.W. Birkeland. 1987. Sugsested terminology for Quaternary dating methods. Puateraary Research 28: 314-319.

Dashman, J. and Stostky, T. 1982. Adsorption and binding of amino acids on homoionic toontmorillonite and kaolinite. Soil Biology and Biochemistry 14: 447-456.

Deb. E.C. 1950. The estimation of free iron oxides in soils and clays and ineir removal. Jouraal of Soil Science 1: 212-220.

Dohrenwend. J.C., McFadden. L.D., Turria, B.D., and Wells, S.G. 1984. K-Ar dating of the Cima volcanic field. Molave Desert. California: Late Cenozoic volcanic bustory and landscape evolution. Seology 13:163-167. 
Dora. R.l. 1983. Cation-ratio dating: a new rock varnigh age-determination cechnique. Quateraary Research 20: 49-73.

Dorn. R.l. 1984a. Geomorphological interpretation of rock varnish in the Mojave Desert. In J.D. Dohurenwend led.l. Surficial Geology ar the Eastern Mojavo Desert, Califoraia : 150-161. Reno: Geological Society of America Guidebook. No. 14.

Dorn. R.\%. 1984 b. Cause and implications of rock varnish microchemical la minations. Nature 310: 767-770.

Dorn. R.l. 1986. Rock varnish as an indicator of aeolian environmental change, in W.G. Nickling led.I, Aeolian Geomorphology: 29!-307. London: Allen \& Unwin.

Dorn, R.l. 1988. A rock varnish interpretation of alluvial-fan development in Death Valley, California National Geographic Research 4: 56-73.

Dorn. R.l., Bamforth, B.D., Cahill, T.A., Dohreawend, J.C., Turrin, B.D., Jull, A.J.T., Long, A., Macko, M.E., Weil, E.B., Whitley, D.S. and Zabel, T.H. 1986. Science 231: $830-833$.

Dora, R.I., and DeNiro, M.J. 1985. Stable carbon isotope ratios of rock varnish organic matter: a new palecenvironmental indicator. Science 227: 1472-1474.

Dorn. R.l. and Oberlander, T.M.. 1982. Rock varnish. Progress in Physical Geography 6: $317-367$.

Dorn. R.l. and Oberlander, T.M. 1981. Microbial origin of rock varnish. Scieace 213: $1245-1247$.

Dorn. R.I., Tanner, D., Turrin. B.D. and Dohrenwend, J.C. 1987a. Cation-ratio dating of Quaternary materials in the east-central Mojave Desert, California. Physical Geograpay 8: 72-81.

Dora. R.I., Turria, B.D., Jull, A.J.T., Linick. T.W. and Donabue, D.J. 1987b. Radiocarbon and cation-ratio ages for rock varnisb on Tioga and Tahoe morainal boulders of Pine Creek, eagtera Sierra Nevada in California, and Paleoclimatic Implications. Quatoraary Research 28: 38-49.

Dorn, R.I., Jull, A.J.T., Linick, T.W., and Donabue, D.J. 1987 c. AMS radiocarbon dating of rock varnish. EOS 68: 1288 (Abstract).

Dorn. R.I. and Wbitley, D.S. 1984. Chronometric and relative age determination of petroglyptas in the western Uaited States. Anaals of the Association of American Geographers 42: 308-322.

Duffield, W.A., Bacon. C.R., Dalrymple, G.B. 1980. Late Cenozoic volcanism. geochronology, and structure of the Coso Range, Inyo County. Jouraal of Ceophysical Research 85 (B5): $2381-2404$.

Duffield, W.A. and Smith. G.I. 1978. Pleistocene river erosion and intracanyon lava flows near Litlle Lake, Inyo County, CA. Califormia Geology April issue: 81 89. 
Douglas, G.R. 1987. Manganese-rich rock contings from Iceland. Earth Surface Procosses and Landfor cas 12: 301-310.

Dragovich. D. 1986. Minimum age of some desert varnist near Broken Hill, New South Wales. Search 17:149-151.

Dragovich. D. 1988. A preliminary electron probe study of microcheouical variations in desert varnish in westera New South Wales. Earth Surface Processes and Landforms 13:259-270.

Eldred, R.A., Cahill. T.A. Ashbaugh, L., and Nasstron. J.S. 1984. Long range transport and transformation of anthropogenic pollutants observed in a PIXE-based montoring network. Nuclear lastrumeats and Methods in Physics Research
Bd: $79-482$.

Elmore, D. and Phillips, F.M. 1987. Accelerator mass spectrometry for measurement of long-lived radioisotopes. Science 236: 543-550

Elvidge, C.D. and IVerson. R.M. 1983. Regeneration of Desert Pavement and Varnish. In Webb, R.H., and Wilshire, H.G. [Eds.], Environomental Erfects of Orf-Road Vebicles, 225-243. New York: Spriager-Verlag.

Glasovskiy. A.F. 1985. Rock varnish in the glacierized regions of the Pamirs. Data of the Glaciological Studies. (Moscow), 54: 136-141. (In Russian).

Harrington. C.D. 1986. The use of rock varaish as a Quaternary dating method within the ceatr! Rio Grande Rift. New Mexico and the Nevada Test Sites. Geological Society of America Abstracts with Programs 18:360

Harrington, C.D. 1987. Application of rock varnisb dating of Quaternary surficial deposits in determining times of lault movement. U.S. Geological Survey
Opea File Report $87-673 \cdot 70-75$.

Harrington, C.D. 1988. Recognition $\alpha$ components of volcanic ash in rock varnish and the dating of volcanic ejecta plumes. Geological Society of America
Abstracts with Programs 20: 167 .

Harrington. C.D. and Whitney, J.W. 1987. Scanaing electron microscope method for rock varaish dating. Geology 15: 967-970.

Hedges, J.I. and Hare, P.E. 1987 . Amino adsorption of clay minerals in distilled water. Goocheonica et Cosmochimica Acta 51:255-259.

Hooke, R. LeB. 1972. Geomorphic evidence of late Wisconsin and Holocene tectonic 33: 2073-2098. Hooke, R. LeB., Yans, H., and Weiblen. P. W. 1969. Desert varaish: an electron
microprobe study. Journal or Geology $77: 279-288$.

Jefferson. G.T. 1985. Stratigraphy and geologic bistory of the Pleistocene Maniz formation, central Mojave Desert, California. Reynolds, R.E. (compiler) In 
Geolonic Investiratiens alons Loterstate 15: Caion Pass to Manir Lake. Califoraia 157-169. Redlands: San Bernadino County Museum.

Jenne, E.A. 1968. Controls on Mn. Fe, Co, Ni. Cu and $\mathrm{Zn}$ concentrations in soils and water: the signifiant role of bydrous $M a$ and Fe oxides. In Gould. R.F. IEd.I Erace Inorganics in Water, 337-387, Washington D.C.: American Chemical Society

Jull, A.J.T., D.J. Donabue, A. Hatheway, T.W. Liaick and Toolin, L.J. . 1986. Production of grapbite targets by deposition irom $\mathrm{CO} / \mathrm{H} 2$ for precision accelerator ${ }^{14} \mathrm{C}$ measurements. Radiocarbon 28(2A): $191 \cdot 197$.

Klein, J., Middleton, R., Sharma. P., Giegengack, R., Nishizumi. K and Lal. D. 1987. Determining erosion rates and exposure ages in in situ produced $B e-10$ and Al-26 in quartz. EOS 68: 1286.

Kurz, M.O.., Colodner, D., Troll, T.W., and Sampson, D.E. 1987, Exposure age dating with cosmogenic He-3: influence of the earth's magnetic field. EOS 68: 1286

Krumbein, W.E. 1969. Uber den Einfluss der Mikroflora auf die Exogene Dynamik (Verwitterung und Krustenbildung). Geologische Rundschave 58: 333-363.

Krumbein, W.E. and Jens, K. 1981. Biogenic rock varnishes of the Negev Desert (Israel): an ecological study of iron and manganese transformation by cyanobacteria and Sungi. Decologia 50: 25-38.

Lal. D. 1987. Erosional and depositional studies based on in situ produced cosmogenic auclides. EOS 68: 1286.

Laudermilk. J.D. 1931. On the origin of degert varsist. American Jouraal of Science 21: $51-66$.

Lockwood, R.A. and Chen. K. 1973. Adsorption of Hg by hydrous manganese oxides. Environmental Science and Technology 7: 1028-1034.

Macko, S.A. Fogel. M.L., Hare, P.E., and Hoering, T.C. 1987. Isotopic fractionation of aitrogen and carbon in the syathesis of amino acids by microorganisms. Che mical Goology (Isotope Geosciences Section) 65: 79-92.

Malm, W.C., Johnson, C.E. Bresche, J.F., Cahill, T.A. 1986. An eigenvector analysis of particulate data in the western U.S. Presented at the Air Pollution Control Association laternational Specialty Conference. "Visible Protection -. Research and Policy Aspects. Grand l": on National Park. Wyoming, Spet 7 10.

Marchand. D.E, 1974. Cbemical weatbering, soil development and geochemical fractionation in a vart of the White Mountains. Mono and Inyo Counties. California. U.S. Geological Survoy Professional Paper 352-j: 379-424.

McBride, M.B. 1987. Adsorption and oxidation of phenolic compounds by iron and manganese oxides. Soil Science Society America Jouraal S1: 1466-1472. 
Mckenzie, R.M. 1972. The sorption of some beavy metals by the lower oxides of manganese. Geoderma 8:29-35.

Morad, S. and ALDahan, A.A. 1986. Alteration of detrital Fe-Ti orides in sedimentary rocks. Geological Society of America Bulletin 97: 567-578.

Ore, H.T. and Warren. C.N. 1971. Late-Pleistocene - early Holocene geomorphic history of Lake Mojave, California. Geological Socjety of America Bulletin 92: $2553-2562$.

Palmer, F.E., Staley, J.T., Murray, R.G.E. Counsell, T., and Adams, J.B. 1985. Identificarion of manganese-oridizing bacteria from desert varnish. Geomicrobiology journal 4: 343-360.

Perry, R.S. and Adams, J. 1978. Deseri varnish: evidence of cyclic deposition of manganese. Nature 278: 489-491.

Pewe, T.L., Pewe, E.A., Pewe, R.J., Journauz, A. and Slatt, R.M. 1981. Desert dust: characteristics and rates of deposition in centra! Arizona. Geological Society of Aarerica Special Paper 186:169-190.

Phillips. F.M., Lea:vy, B.D., Jannik, N.O., Elmore, D., and Kubik, P.K. 1986. Surface Exposure Dating with Cl-36. Science 222.

Phillips, R.M., Leavy, D.D., Jannik, N.O., Smith. G.I., Elmore, D. and Kubik, P.T. 1987. Cl-36 -- a dew tool for paleobydrology. EOS 68: 1286.

Polynov, B.B. 1951. Modera ideas of soils formation and development. Solls and Fertilizers 14: 95-101.

Pother, R.M. 1979. The tetravalent manganese oxides: clarification of their structural variations and relationships and characterization of the ir occurrence in the terrestrial weathering environmeat as desert varnish and other conganese oxides. Ph.D. Dissertation. California Institute of Technology, Pasadena.

Potter, R.M. and Rossman, G.R. 1977. Desert varnish: the importance of clay minerals. Scieace 196: 1446-1448.

Potter, R.M. and Rossman. G.R. 1979 The manganese- and iron-oxide mineralogy of desert varaish. Chemical Geology 25: 79-94.

Quade, J: 1987. Regional ground-water discharge pattern in southern Nevada during the late-Wisconsin -- sedimentary and faunal evidence. INQL/A 1987 Abstracts 247.

Rabenhorst, M.C. Wilding, L.P., and Girdaer. C.L. 1984. Airborne dust in the Edwards Plateau region of Tiezas. Soil Science Society of America joural 48: $621-627$.

Rubin. M., Gargulinksi. L.K. and McGeebin. J.P. 1987. Kawaiian radjocarbon dates. U.S. Geological Survey Professional Paper 1350: 213-242. 
Shindo, H. and Huang. P.M. 1982. Role of $\mathrm{Mn}(I V)$ oxide in abiotic formation of humic substances in the environmeat. Nature 298: 363-365.

Smiley, T.L. 1958. The Geology and dating of Sunset Crater, Flagstaff, Arizona. ONew Merico Geological Socjety. Guidebook 9ta Field Confereace, p. 186-190.

Smith, G.I. 1976. Paleoclimatic record in the upper Quaternary sediments of Searles Lake, Califortia, U.S.A. In S. Horied led.l. Paleolimnology of Lake Biwa and the lapanese Pleistocene Volume 4 577-604, Kyoto: Kyoto University Press.

Smith, G.I. 1984. Paleohydrologic regimes in the southwestern Great Basin, 0-3.2 my ago, compared with other long records of "global" climate. Quateraary Research 22: 1-17.

Spaulding, W.G., Robinson, S.W., and Paillet, F.L. 1984. Preliminary assessment of climatic change during late isconsin time, southern Great Basin and vicinity, Arizona, California, and Nevada. U.S. Geological Survey Water Resources Investigations Report 84-4328. $40 \mathrm{p}$.

Spauldiag, W.G. 1985. Vegetation and climates of the last 45,000 years in ine vicinity of the Nevada Test Site, South-Central Nevada. U.S. Geological Survey Professional Paper 1329. 83 pp.

Staley, J.T., Palmer, F.E., and Adams, J.B. 1982. Microcolonial fungi: common inhabitants of desert rocks? Scieace 215: 1093-1095.

Staley, J.T., M.J. Jackson. F.E Palmer, J.B. Adams, D.J. Borns, B. Curtiss and TaylorGeorge, S. 1983. Desert varnish coatings and microcolonial fungi on rocks of the Gibson and Great Victoria Deserts, Australia. BMR Journal of A ustralian Geology and Goopaysics 8: 83-87.

Suiver, M., Kromer, B., Becker, B. and Ferguson. C.W. 1986. Radiocarbon age calibration back to 13.300 years B.P. and the $14 \mathrm{C}$ age matching of the German oak and U.S. Bristlecone Pine chronologies. Radiocarbon 28 (2B): 969-979.

Sudom, M.D. and St. Arnaud. R.J. 1971. Use of quartz, zirconium and titanium as indices of pedological studies. Canadian journal of Soil Science 51:385-396.

Suler, M., Balzer, R., Bonari. G., Hormann, H., Morenzoni, E., Nessi, M., Wolfli, W., Andree, M., Beer, J. and Oeschger, H. 1984. Precision measurements of C- 14 in AMS - Some results and prospects. Nuclear lnstruments and Methods in Paysics Research BS: 117-122.

Taylor-George, S., Palmer, F., Staley, J.T., Borns, D.J., Curtuss, B., and Adams. J.B. 1983. Fungi and bacteria involved in desert varnish formation. Microbial Ecology 9: 227-245.

Turria. B.D., Dohrenwend, J.C. Drake, R.E), and Curtiss, G.H. 1985. K-Ar ages frow the Cima volcanic field, eastern Mojave Desert, CA. Isochron West 44: 9-16. 
Vaniman, D.T., Crowe, B.M., and Gladney, E.S. 1982. Petrology and geochemistry of Hawaite lavas from Crater Flat, Nevada. Contributions to Mineralogy and Petrology 80:341-357.

Webber, D.B. 1986. Dryfall: an important constituent of atmopheric hydrocarbon deposition. Organic Geochemistry 9:57-62

Wells, P.V. 1983. Paleobiogeography of montane islands in the Great Basin since the last glaciopluvial. Ecological Monographs 53:341-382.

Wells, S.G., McFadden, L.D., Dohrenwend, J.C., Bullard, T.F, Feilberg, B.F., Ford, R.L., Grimm, J.P., Miller, J.R., Orbock, S.M., and Pickle, J.D. 1984. Late Quaternary geomorphic history of Silver Lake, eastern Mojave Desert. California: an example of the influence of climatic change on desert piedmonts. In J.D. Dohrenwend led.l, Surficial Geology of the Eastern Mojave Desert, California: 60-87. Reno: Geological Society of America Guidebook, No. 14.

Wells, S.G., McFadden, L.D., Renault, C., Turrin, B.D., and Crowe, B.M. 1988. A geomorphic assessment of Quaternary volcanism in the Yucca Mountain area, Nevada Test Site, Southern Nevada. Geological Sociery America Abstracts with Prograas 20: 242.

Whalley, W.B. 1983. Desert Varnish. In A.S. Goudie and K. Pye leds.], Chemical Sediments and geomorphology: 197-226, New York: Academic Press.

Whitley, D.S. and Dorn, R.I. 1987. Rock art chronology in eastern California. World Archaeology 19:150-164.

Whitney, J.W., Harrington. C.D. and Glancy, P.A. 1988. Deciphering Quaternary alluvial history in Las Vegas Wash. Nevada by radiocarbon and rock-varnish dating. Geological Society America Abstracts with Program 20: 243.

Winograd, I., Szabo, B.J., Coplen, T., and Riggs, A. 1987. Continuous 300,000 year record of oxygen-18 and carbon-13 variations in Great Basin groundwater Geological Society America Abstracts with Prograals 19:893.

Yaalon, D.H., I. Brenner and Koyumdsisky, H. 1974. Weathering and mobility sequence of minor elements on a basaltic pedomorphic surface, Galilee. Israel. Geoderma 12: 233-244. 


\section{Appendix B}

Consultant's report: Soll-geomorphology studies in the crater Flat, Nevada, area

by F. F. Peterson 


\section{CONSULEANY'S REPORT: SOIIM-GBOMORPEOLOGY STUDIIS DY THE CRATER FLAT, MEVADA, AREA}

$$
\text { for }
$$

TAST 1: REVIEW OF QUATERNARY GBOLOGY AND EVALUATICA OF POTEATTIAL FOR OTDETECTED QOATERNARY FAULTS AT AND NEAR YUCCA MET.

$$
\text { pert of }
$$

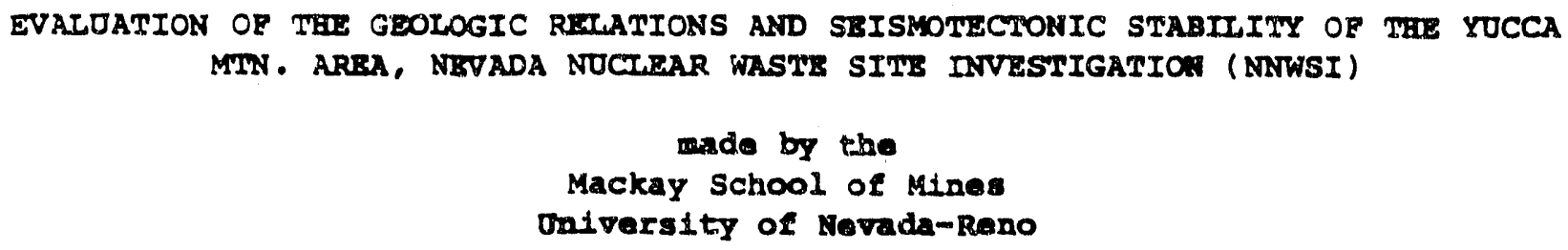

Raport by F.P. Peterson, Conseltant

June 30,1988 


\begin{abstract}
Reconnaissance study of geomorphic surfaces and soils in crater Flat has shown that there are Eive geomorphic surfaces, the crater Flat (modern to mid-Holocene), Little Cones (early-Holocene to late-pleistocene), Black Cone (late- to mid-pleistocene), Yucca (mid-pleistocene), and Solitario (mid- to early-pleistocene), and that distinctive kinds of soils occur on each. Av horizon formation due in part to dust-fall, infiltration, and finally surficial dust-accumulation, is both a pleistocene and early-Holocene phenomenon in Crater Flat. The A horizons of previously-leached Pleistocene solls are being re-carbonated. Mid- to late-Holocene soils are Typic Torriorthents. Early-Holocene solis have minimal. Av horizons, cambic horizons and stage I-II BK horizons; they can be Typic Camborthids or Typic porriorthents, depending on an arbitrary rule in soll Taxonomy that depth to the bottom of the cambic horizon must be 25 cm or greater for Camborthlds.

Pleistocene soils on volcanic fan alluvium are Durargids, or where partially stripped on ballenas, are Durorthids. Only pleistoceneage solls have argillic horizons and these become progressively more clayey in older soils. Only pleistocene age soils have silica-carbonate-cemented duripans; those of late-pleistocene soils are haplic duripans, most typic duripans apparently are mid-Pleistocene age or older. Pan formation in crater flat is probably at about the same rate as predicted for petrocalcic horizons in southern New Mexico.

Surficial-deposit mappling by Swadley and Hoover (1983) and Swadley et al (1984) in Crater flat failed to separate the Little Cones surface from the Black Cone surface in their essentially BlackCone-age $Q 2$ map unit, falled to separate the Black-Cone surface remnants from the rucca surface remnants in their gra map unit, and failed to distinguish the solitarlo surface from the Yucca surface in their gra map unit. These errors in mapping are reflected by ineffective stratigraphic interpretations for trenched faults. The "surficial deposits" concept of Hoover et al (1981) is fatally flawed, and should be abandoned for geomorphic surfaces defined in terms of soils.
\end{abstract}




\section{INTRODDCTION}

The surficial depostts of hoover and swadley were defined and mapped in crater flat in such fashion that three potentiajly important age breaks were missed (Hoover et al, 1981, Swadley and Hoover, 1983, Swadley et al, 1984; cf., Peterson, 1981, pp. 42-44). Although Hoover et al (1981, p. 7-8) recognize that surficial deposits are not the same as the geonorphic surfaces on top of them, and presumably recognize that pedogenic soils are time-related to geomorphic surfaces rather than the age of the underlying surficial deposits, Hoover et al (1981), Swadley and Hoover (1983), and swadley et al (1984) did not describe their surficial-deposit map units in ways that allow one to determine what kind of solls occur in a map delineation 2. Furthermore, they did not define their nap units in ways that adequately reflect the progressively older ages of certain soll horizons, or progressive horizon expressions, or soil features that are critical for stratigraphic interpretation of fault trench exposures.

In reaction to these problems, my 1987 reconnaissance field work in Crater Flat was intended, inasmuch as possible in limited time, to: (1) Determine what major geomorphic surfaces occur in Crater Flat. (2) Determine what major kinds of sol $1 \mathrm{~s}^{3}$ have fo.med on the major geomorphic surfaces and what pedogenic soil features, if any, are distinctive of the various geomorphic surfaces. (3) Determine how Swadley and Hoover's "surficial deposits" mapping relates to geomorphic surfaces and soils.

Field study: During the 1987 consulting year, I spent a first field-week (5/25-29/87) reconnoltering for the obvious geomoxphic surfaces and related soils in Crater Flat basin and closely-adjacent Amargosa Valley, and trying to understand how Swadley and Hoover tapped their "surficial deposits" (Hoover et al, 1981, Plate I, Swadley and Hoover, 1983, Fig. 2, Swadley et al, 1984, plate 1). A second week (6/8-12/87) wa used to confirm critical geomorphic sufface separations. Inasmuch as possible, on Crater Flat's eastern fan pied-

1

Hoover et al (1981; recognize that a geomorphis surface may be the same age or younger than the surficial deposits that underlies it, but they then treat many, if not al, pedogenic soil horizons as if they do date the surficial deposit in which the horizon occurs, rather than recogrizing that the maximum age of a pedogenic soil horizon is the age of the geomorphic surface under which the soli horizon first started to differentiate, not necessarily the age of the articial deposit. Neither do Hoover et al seem to recognixe that pedogenic soll horizons can contain features that are age-related to younger geomorphic surfaces formed on top of them, or to changed environments operating on the initial or a younger geomorphic surface and the horizons under it (i.e., poly-pedogenesis).

2

Part of the difficulty in undergtanding Hoover a.. Swadley' a surficial deposits map is that some map units are consociations (i.e., each delineation has one kind of named component) whereas others are assoclations or complexes of two or more named components. Another part of the problem is that they do not at least in part define their unitg by type examples in the field, i.e." by type "sections."

3 "Kinds of soils" named at the fanily level of soll taxononic identification. 
mont and basin floor and to make detailed pedon descriptions. Rock varnish for age-dating was sampled July 12-13, 1987, from several of my pedon description sites in company with R. Dorn, J. Bell, C. Purcell, C. Depolo, and $A$. Ramelil. Detailed pedon descriptions were completed during a third week (8/17-21/87) in company with $C$. Purcell, and are presented in Appendix II.

My field studies lasted only long enough to: (1) Grasp that the features Hoover et al (1981), Swadley and Hoover (1983), and swadley et al (1984) used to draw boundaries for their "surficial deposit" units are mogtly good geomorpbic features, but that the classification of their units by the geologic, geomorphic, and soils features that they apparently used are fatally Elawed (cf., Peterson, 1981, pp. 46-48). (2) To identify two unrecognized geomorphic surfaces in Crater Flat. And, (3) I saw enough soil morphology to suggest that there is a much tighter relation of soil morphology to surface age (and exosional-depositional history) than swadley and koover describe. I also can conciude that Dorn's (1988) rock-varnish dates fit reasonably to the relative geomorphic-surface ages and progressive soil development; also, his absolute age values fit my concepts of soil ages as sefn for Aridisols in a similar creosote-bush desert in southern New Mexico. 


\section{MUOR GEOMORPBIC SUEACES AND SOILS II CRATER FLAT AND ADJACLST AMDRCOSA DESERT}

The five major geomorphic surfaces on the piedmont slopes in crater Flat, and on the alluvial plain of adjacent Amargosa valley, are listed in Table 1 along with a speculative correlation between these surfaces and the "surficial deposits" (effectively, geomorphic surfaces!) of Taylor (1986) and Swadley and Hoover (1983). The Crater Plat, Little cones, Black cone, Yucca, and Solitario surfaces are each "bajor" surfaces inasmuch as (1) I found one or more locations where a fan-remant sumit (i.e., a surface remnant) was topographically clearly above or below the next younger or older fan-remant sumit, $i, e$. , they show an inset relationship which is demonstration of relative age. Also, (2) each surface romant has a soil that is distinctively different than the soil of a physically adjacent, younger or older surface, and this soil, or soils with very similar features are characteristic of each surface.

I field-checked to see that there are mappable boundaries, at roughly $1: 24,000$ scale, for one or several delineations of each of my major surfaces (and in many cases swadley and hoover show the same boundaries on their surficial deposits maps), but I did not make geomorphic-surfaces or soils maps. Rather, the sites at which I dascribed the soils associated with one of the mappable delineations of a surface are shown on Fig. 1 (a copy of swadley et al's 1984 surficial deposits map), and each of these surfaces and sites is discussed here. Also, the sitn locationg are pin-pricked on 1:24,000 color aerial photos in John gell's files and the site locations are deseribed in the podon descriptions in Appendix II.

The sites, or "pedons" are mumbered from 1 to 18 for ease of discusaion in this report; euch also carrias a "CEP", or "Cratar flat pedon" number that was given to the site during the field study of these and numerous other stops and is shown on the back of the color aerial phntos. Table 2 11sts the $3 i t e s$, or pedons, the Family-level taxonomic name, the geomorphic surface, and the approximate rock-varnish date for the surface it there is one. Table 3 gives the exact rock varnish ages determined by Dorn (1988). 
TABUE 1 -- GEOMORPRIC SURFACES ON TER PIDDMONT SLOPES IN CRATHR FIAT, KEVADA

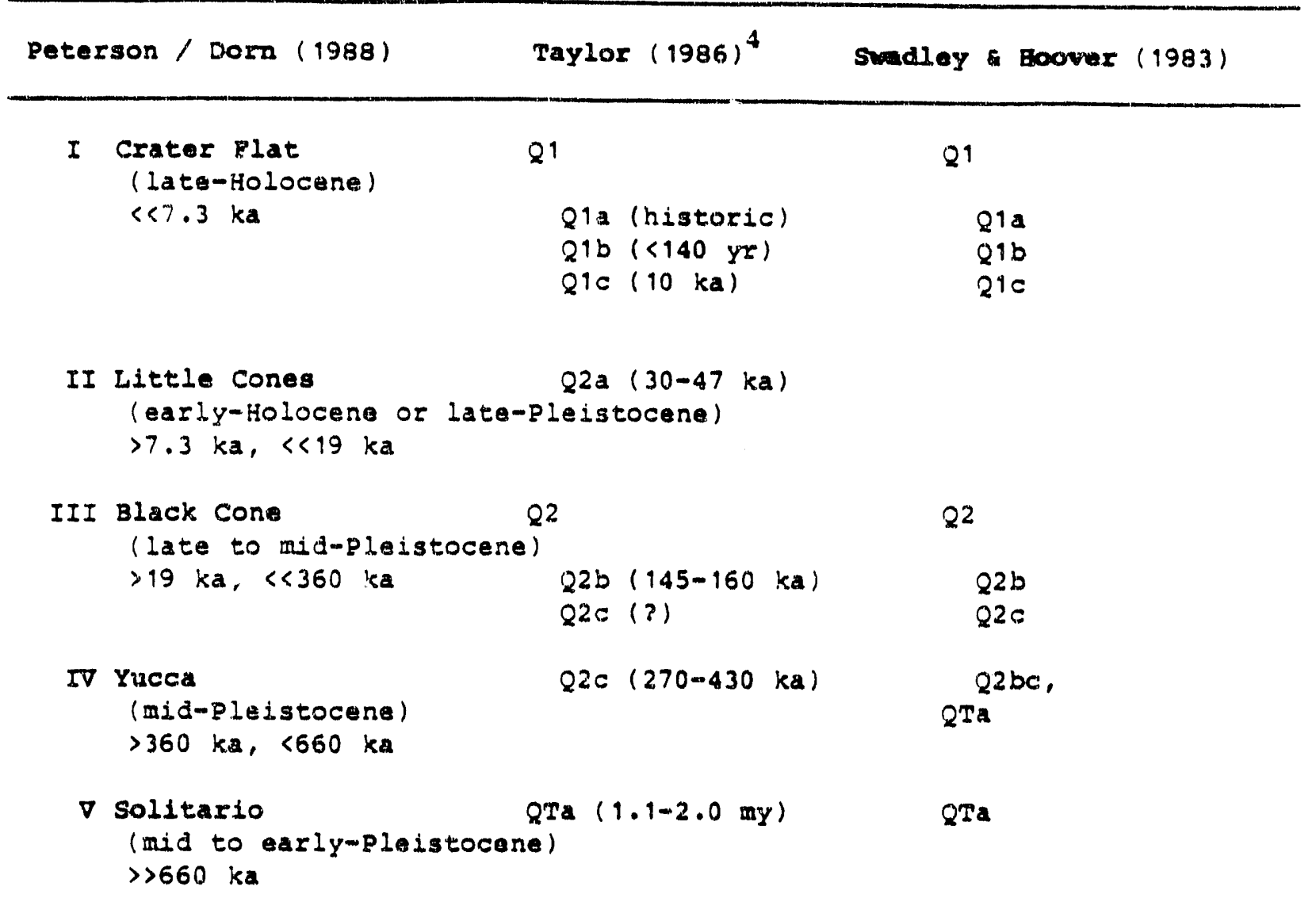

4 Taylor (1986) worked alony Forty Mile Wash on the east side of Yucca Mountain, rather than in crater Flat, so correlation with her surficial deposits is specuiative. The ages in this coluan are raylor's, in thousands of years berore present ( $k$ ). 


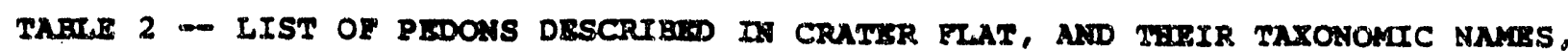
LOCATIOAS, GEONDRPEIC SURPACES MND ROCR-VAPAISR AGE ESTITATES

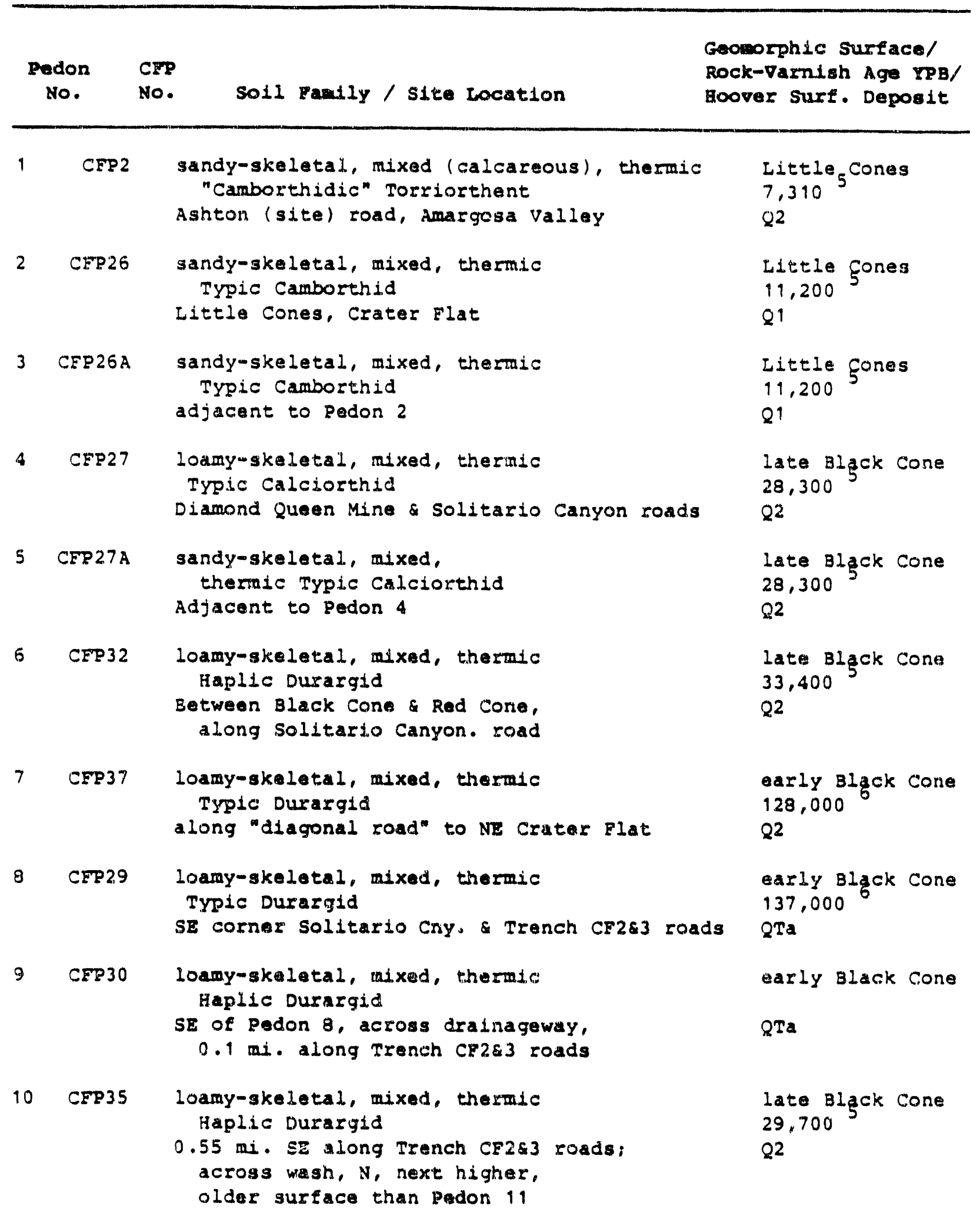


TARTB 2 -- Continued.

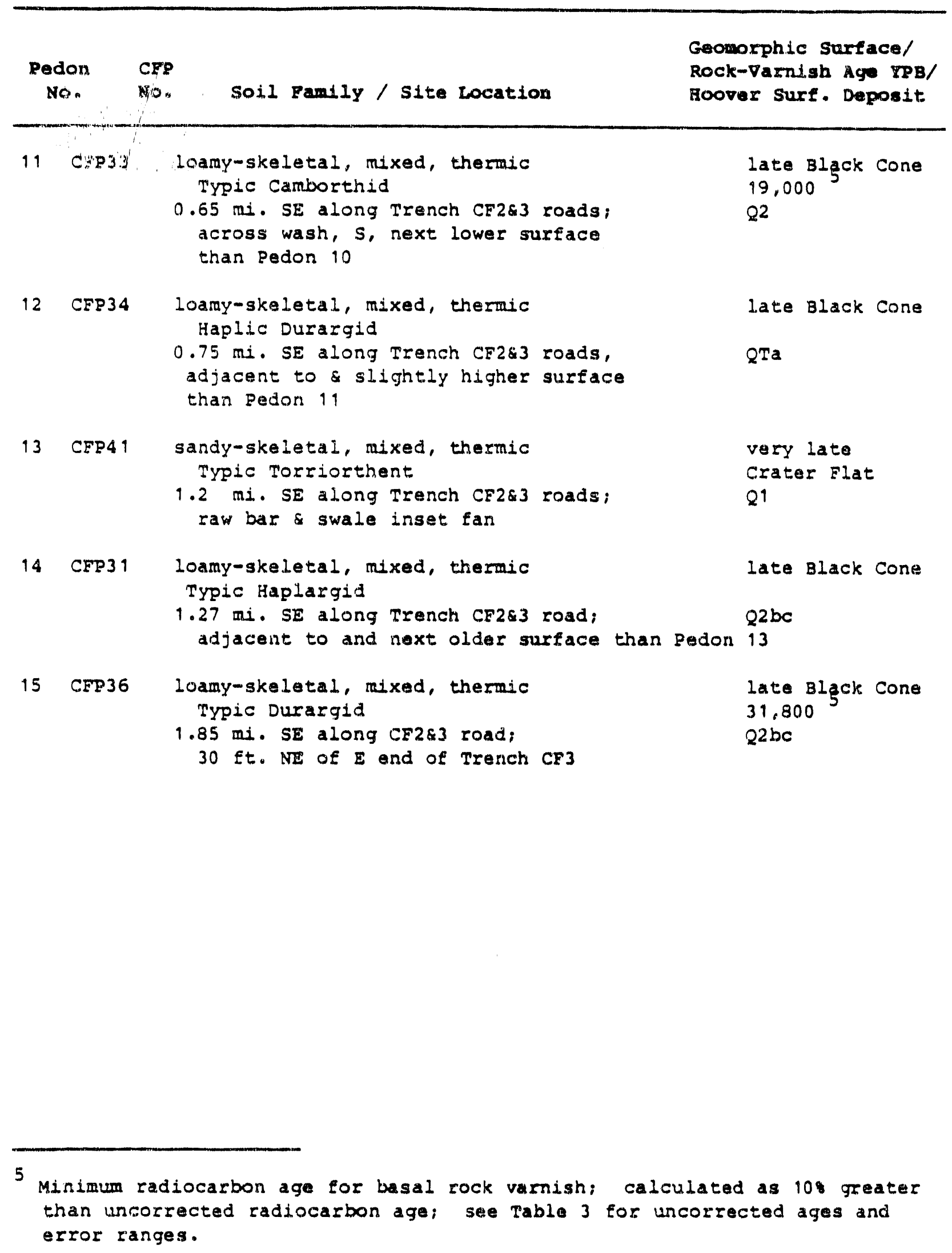


mathe 2 - continued.

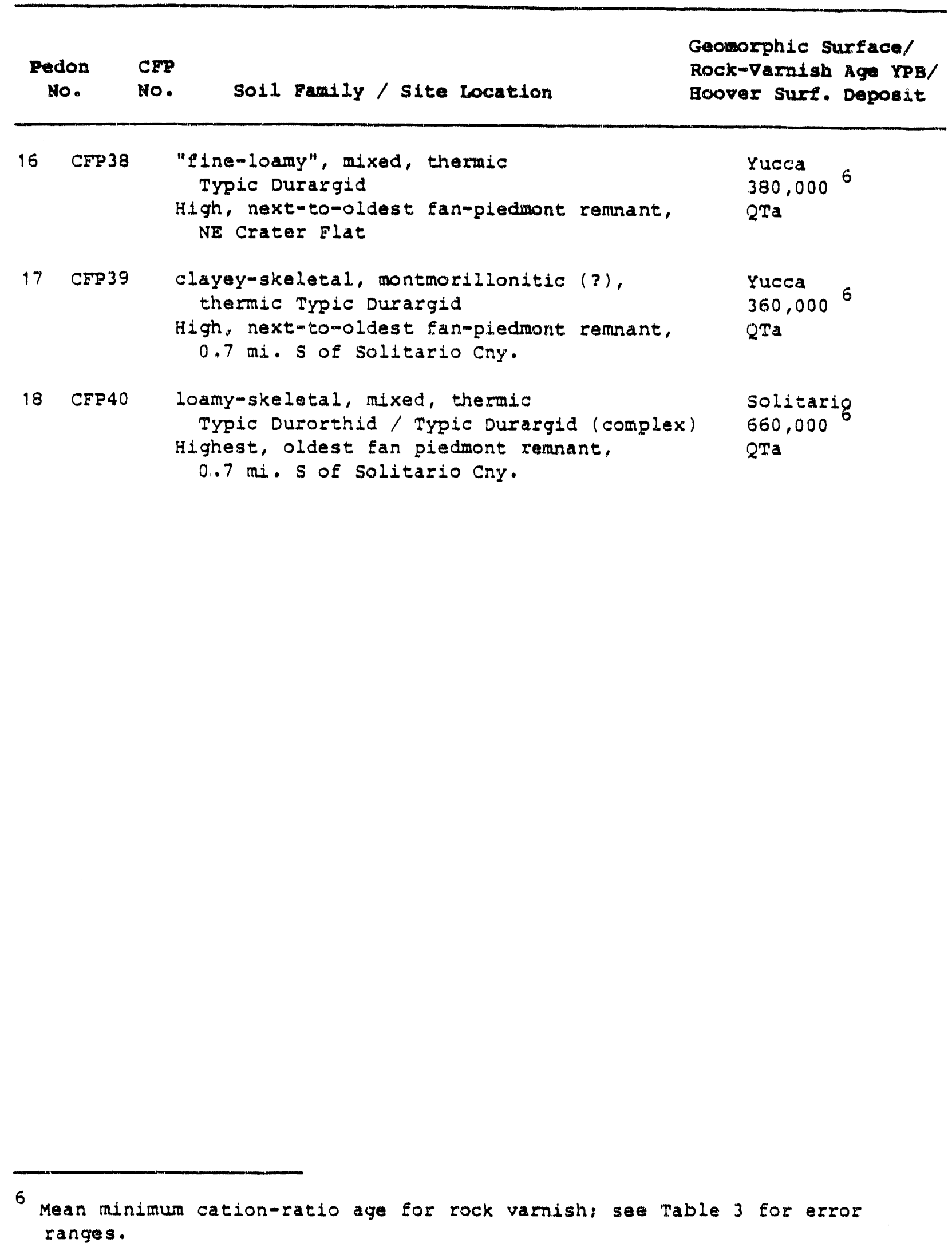


TABKI 3 -- LIST OF ROCT-VAREISE AGIS FOR PEDONS IN CRATER FLAT ${ }^{7}$

\begin{tabular}{|c|c|c|c|c|c|}
\hline $\begin{array}{l}\text { Pedon } \\
\text { No. }\end{array}$ & CFP & $\begin{array}{c}\text { Uncorrected } \\
\text { Ace }\end{array}$ & +108 Gorrected & Est.9 & Datipg \\
\hline 1 & CFP 2 & 6.645 & 7,310 & +-245 & $\mathrm{RC}$ \\
\hline 2 & CFP26 & 10,180 & 11,200 & +-270 & RC \\
\hline 3 & CFP26A & & & & \\
\hline 4 & CFP27 & 25,700 & 28,300 & +-360 & $\mathrm{RC}$ \\
\hline 5 & CEP27A & & & & \\
\hline 6 & CFP 32 & 30,320 & 33,400 & +-460 & RC \\
\hline 7 & CEP 37 & 128,000 & & $106 k-153 k$ & $C R$ \\
\hline 8 & CFP29 & 137,000 & & $115 \mathrm{~K}-162 \mathrm{~K}$ & $\mathrm{CR}$ \\
\hline 9 & CEP 30 & & & & \\
\hline 10 & CFP 35 & 26,970 & 29,700 & +-375 & RC \\
\hline 11 & CEP 33 & 17,280 & 19,000 & +-370 & $\mathrm{RC}$ \\
\hline 12 & CEP 34 & & & & \\
\hline 13 & CFP41 & & & & \\
\hline 14 & CEP 31 & & & & \\
\hline 15 & CFP 36 & 28,920 & 31,800 & +-400 & RC \\
\hline 16 & CFP 38 & 380,000 & & $260 \mathrm{~K}-550 \mathrm{~K}$ & $C R$ \\
\hline 17 & $\operatorname{crp} 39$ & 360,000 & & $255 K-515 K$ & $C R$ \\
\hline 18 & CEP4O & 660,000 & & $450 K-965 K$ & $C R$ \\
\hline
\end{tabular}

The Av Horizon and Site Selection for Pedon Descriptions

Evidence for recent fault movement is of prime importance in the Yucca Mountain studies, and the $A$ v horizon is one of the most important soil features for establishing relative ages of Modern, or late-, mid-, or earlyHolocene or late-pleigtocene soils that might be broken by faulting. Hoover et al (1981), Swadley and Hoover (1983), Swadley ot al (1984), and Taylor (1986) all apparently use the occurrence of an Av horizon as their major criterion for separating Pleistocene from Holocene surfaces. This could be a very effective criterton if the Av horizon wre operationally defined and the time is determined for enough dust accumulation to allow the Av to form.

7 Ages from Dorn, 1988.

8

Dorn (1988) estimates the actual radiocarbon ages are about 108 older than the uncorrected values.

9

For radiocarbon dates the probable "plus or minus" error in YPB is given; for cation-ratio dates the "uncorrected age" is the mean value of several cation-ratio age determinations and the "error" is shown as the probable younger to older error-range of age in thousands of years (" $\mathrm{K}$ ").

10

$R C=$ radiocarbon dating of basal rock varnish. $C R$ = cation ratio of rock varnish. 
None of the previous authors describe their concept of the Av hortzon in moxphological torms, but the vesicular horizon can be defined as a ganatic horizon (sensu peterson, 1981, p. 43) that is (a) a surficial horizon that (b) crusts and cracks into coarse "polygons" (i.e., coarse prismatic structure) when dry, that (c) that are elther massive or massive in their upper part and platy in their lower part; (d) the horizon has coarse vesicular pores in at least its upper part; (e) the hortzon can be under a desert pavement, but regardless, is less graveliy than the subjacent horizon if the original parent material was gravelly and the subjacent horizon is not clayey; the horizon (f) is light colored and low in humus, it $(g)$ is a sandy loam, fine sandy loam, very fine sandy loam, silt loam, ve occasionally a loam or sandy clay loam or clay loam, but in any case has a high percentage of very fine sand and/or silt that encourages "dilatentcy" when the soil is saturated. The Av horizon also commonly is (h) a "ruptic" horlzon, 1.e., it starts and stops horizontally, interchanging with an ordinary A horizon that is not crusting and lacks coarsely-vesicular pores, because of their microtopographicaliy higher positions where they are not apt to saturate surficially.

The "Av horizon" is a peculiar genetic epipedon that is characteristic of many desert soils (Peterson, 1977, Eckert et al, 1978, Nettleton and peterson, 1983), but it is not officially recognized in soil Taxonony as a kind of horizon, in the sense a mollic epipedon, petrocalcic horlzon, or duripan are kinds of pedogenic horizons. Rather, it is merely one of several types of ochric epipedons; the " $\mathrm{v}$ " postscript in the "Av" designation even is illegal for National Cooperative Soil survey pedon-description standards!

An Av horizon that formed in originally coarse-toxtured parent material, such as that on the piedmont slopes of crater Flat, is the sesult of long-term dust-fall on the originally coarsely-porous soil surface followed by recurrent dust-infiltration to the depths of rapid, "gravitational" water infiltration during large storms, i.e., to some 12-18 inches depth in the Crater Elat vicinity. When the coarse interstitial pores between sand grains become plugged with the very fine sand, silt, and (minor) clay of the infiltrated dust and water infiltration becomes slow "capillary" movement, subsequent dust accumulation is at the surface, $1.8 .$, between and imediately below any desert pavement that might be present. Animal activity mixes some gravel and sand with the dust into this thin surficial horizon and ejects some gravel onto the surface to join the pavement, but regardless, the surficial layer becomes more silty-loany and less sandy and gravelly.

Formation of the Av horizon's coarsely-vesicular pores and its diagnostic crusting behavior depend on additional factors after sufficient dust has accumulated for the horizon to form: The surficial horizon must have remained Low in hums content and unstructured, so that when it is strongly wetted it will have a slow infiltration rate, hence saturate and act as a thickly-viscous liquid that allows entrapped alr bubbles to migrate and join together to form progressively larger bubbles, l.e., vesicular pores (Miller, 1979). Saturation also causes the horizon to consolidate enough that on drying the saturated part becomes a crust (Hillel, 1960). The high percentage of silt and very fine sand in the accumulated dust encourages this sort of "dilatent" behavior when saturated, but limited biological activity in the surface layer is essential to prevent formation of soil structure that would increase infiltration rates, decrease dispersion, and hence decrease the probability of periods of surficial saturation. 
Conditions for Av horizon formation are best in the barren, paved areas between desert shrubs. Under the shrubs, copplce dunes of eollan-sand accumulate; they are the site of litter accumulation and the greatest insect and animal activity. Low but significant amounts of hums accurulate and the soil is mixed to some depth; soil structure may be formed, but regardless, the soil material rematns pervious to water and does not saturate under heary rainfall. Within the creosote bush vegetation of the Mojave Desert (Crater Flat is at the northern edge of that desert) accumulation of colian sand occurs not only as single coppice dunes under single shrubs, but as thin sheets joining several, spaced-apart shrubs and their coppice dunes. These slightly-raised microtopographic features, or blocopplces, to coin a term, also are the site of the most intense rodent digging and the least likely spots for Av horizons to form undisturbed over long periods of time. Between the biocoppices, the barren soil is flattish, if not microtopographically slightly-concave, and if a desert pavement is present, it is most promirent in the flattish or depressed spots. Such paved spots are called parettes here, to coin another term. They are least frequently mixed, become saturated in their surface few centineters during heavy storms or snow melt, and havo the most closely-packed, best size-sorted, darkly-varnished desert pavement, and most prominent Av horizon.

It is nc: unreasonable to conclude that the effects of slow dust infiltration, accunulation, and Av horizon formation will be best preserved in the pavette microtopographic position, and that is where soils were described for this study unless otherwise noted.

\section{Grater Flat surface and solls}

The active and recently-active washes, inset fans, and far. skirts that show no significant formation of genetic soil horizons comprise the laterHolocene and historic Crater Flat surface. The soils are thermic Typic Torriorthents. Alluviun in Crater flat is ubiquitously very to extremely gravelily, or cobbly, or stony sand or loamy sand, so the soils are in sandy skeletal families. On the pledmont slope directly below the limestones of Bare Mountain, these soils are in carbonatic wineralogy classes, whereas the Torriorthents of the pledmont slope below the volcanic rocks of Yucca Mountain are in mixed mineralogy classes. Pedon 13 is a representative soll from an inset Ean (a Swadley \&oover Q1b deposit).

Within the cratex Flat geomorphic surface age-span, age distinctions are best made by microtopography, and are puite effectively reflected by Swadley \& Hoover's Q1a (raw channels), glb (raw, rough, bar \& swale inset fans with little "smoothing"), and Q1C (inset fans with "muted" bar a swale microtopography and proto-desert-pavement) distinctions. With the exception of the large area of Little cones surface in southwestern crater Flat, Swadley et al's (1984) mapping of their 21 deposit $(1.0,21 a+21 b+21 c+21 s+2 i e)$ quite correctly shows, at their small scale, the distribution of the crater Elat surface.

The "muting", or smoothing of the rough bar \& swale microtopography that occurs from $Q 1 a$ to $Q 1 b$ to $Q 1 C$ surfaces possibly is caused by rodent digging that lowers stones by undercutting and by accumulation of eolian sand in swales. An open, poorly sorted, "proto-desert-pavement" has formed in the 
swales of Q1C areas, but there is only a morphological hint of dust accumulation in the surface horizon, 1.0., the surficial few um of some glc areas barely coheres in the wakest of crusts, and in some situations there is effervescence associated with slight "greying" due to slight dust accumulation at a few an depth in sand whereas the surficial sand is noneffervescent, or "Ieached", in this area calcium carbonate and soluble sodium salts obviously are being added by dust fall.

At most, microtopographic-muting is accompanied by slight dusting of, or filaments of pedogenic calcium carbonate on pebble bottoms at 20-50 cm depths, i.e., Stage I carbonate accumulation (Gile et al, 1966). There is no apparent opal accumulation

A "Crater Flat age soil" could not be distinguished from raw alluvium by its morphology in a trench. Such a soil has identity only by its location under a Crater Flat-age surface.

Little cones surface and soils

The Iittle cones surface comprises one large fan-skirt remnant surrounding Little cones in southwestern Crater Flat (Fig. 1, shown by Swadley et al (1984) as a 21 area), and several low basin-Eloor remnants in adjacent, northern Amargosa Desert that are shown as 22 areas by Swadley et al. The remant surrounding Little Cones is bounded on the east by the main wash from northwestern Crater Flat and an extensive area of bar and swale crater Flat surface formed by this wash and the main wash from the northeast. To the west and southwest the Iittle cones remant is bounded by the lateral drainageway at the base of the Bare Mountain piedmont slope. To the northeast, just to the west of Red Cone, this LittlemCones fan-skift, femnant stands some seven feet above the $\mathrm{Q} 1 \mathrm{~b}$ bar-and-swales of the main wash and is inset into and some eight feet below the dissected. Black Cone-age fan piedmont sloping down from Bare Mountain. The scarp between the Black Cone and Little cones surfaces feathers out in an arc to the southwest.

The inset relationshipg demonstrate that the little cones surface is a younger surface than the Black Cone surface (most of Swadley and Hoover's 22 areas are Black Cone surface remants) and an older surface than the Crater Flat surface (most of Swadley and Hoover's $Q 1$ is Crater Flat surface). The clear-cut morphogenetic differences between the rypic camborthids of the Iittle Cones surface and the Typic Calciorthids of the Black cone surface or the Typic Torriorthents of the crater Flat surface demonstrates that the three surfaces are different enough ages that they should be recognized as separate

11 Taylor's (1986) classification of pedogenic stages of opal accumulation will not be used here since it is a too simplistic analogy to Gile, peterson, and Grossman's (1966) stages of calcium carbonate accumulation. Otherwise, Taylor's study is excellent.

12 Beneath the Black Cone surface, thick layers of carbonate-sidica cemented gravel outcrop on the wash scarp. whereas below the little cones surface the sandy-skeletal alluvium has only stage I or II carbonate accumulation on pebbles. 
geomorphic surfaces. At Ifttle Cones, Swadley et al (1984) did not separate the Little cones surface remant from their large $Q 1$ delineation to the eagt, even though it has a fully-smoothed surface with abstracted, though shallow dralnageways, and an evident, though only slightly varnished desert pavement, and with a clearly pedogenic soil. Since they accurately drew the boundary of the 22 area to the north, they must have wittingly included this Little Cones remrant in their holocone 21 unit; perhaps they did not think its av horizon "strongly enough developed" to be a pleistocene soil feature or recognize that it has a cambic horizon and evident Bk horizon.

Pedon 2 (in a pavette) and pedon 3 (in a blocoppice) illustrate the soil features of the Iittle Cones surface at Little Cones (Appendif II). The Av horizon is only $5 \mathrm{~cm}$ thick and barely exhibits the dilatentcy of the usual Av horizon, but it crusts, is cracked into polygons, and has coarsely-vesicular pores. The Av horizon occurs only under the pavettes; under the biocoppices it either has been mixed by animals, or is buried by a few inches of eolian sand and has lost its vesicularity and crustiness, though it retains its color and takes on a prominent tubular porosity. There is a prominent but non-cemented, late-Stage I, $2 B k$ horizon that has relatively thick pebblebottom carbonate coatings. It underlies a roughly $60-\mathrm{cm}$ thick layer that I consider to be loamy due to dust infiltration and that now comprises the $\mathrm{Av}$ horizon, an Ak horizon of recent carbonate accumulation, and a Bwk, or camblc horizon that has had carbonate leached through it (the $2 \mathrm{Bk}$ is evidence) even though it still has thin pebble-bottom coatings of carbonate in transit to the 2Bk. A very few, very thin, pustulose, brittle, carbonate-laminae occur on the bottom of some of the Av horizons coarse prisms (polygons), such carbonate laminae are common in the lower Av horizons of soils on the Black Cone, Yucca surfaces and are interpreted as evidence of shallow carbonate accumulation during, perhaps, later flolocene to present. The high pH values just below the Ak horizon are evidence of eolian addition of soluble sodium salts and their accumulation just below the current depth of carbonate accumiation.

Pedon 1, from a basin-floor remnant in the Amargosa Desert basin, that was mapped by Swadley as a 22 deposit, is quite similar to pedon 2 . It has been identified as a "Camborthidic" Torriorthent, rather than as a Typic Camborthid, only because its $22 \mathrm{~cm}$-deep Bwk horizon is $3 \mathrm{~cm}$ shy of the arbitrary 25 cm depth required by Soll Taxonomy for diagnostic camblc horizons. Rock varnish from pavement pebbles on Pedon 1 gives a 7,310 YPB mirimum age for the surface and soll, whereas varnish from pebbles on pedon 2 give a 11,200 YPB age (Table 2, 3). The 8-22 cm deep Bwk horizon of Pedon y contains some greyish layers that are considered buried av horizons; the about 4,000 year younger date of Pedon 1, compared to Pedon 2, may reflect a late additior. of sediment.

13 "Dilatentcy" is a term attributed to soil mechanics, perhaps incorrectly, that describes the viscous-liquid-like behavior of saturated soil material with high contents of silt and very fine sand. A blob of the saturated material will collapse and flow out into a broad disk, or "dilate", when jiggled; it also will drool from the fingers.

14 operationally, a soll crust is a layer that forms at the surface when a soil dries and tha: will break out as plate-like fragments that can be handled wi.thout braking. 
The rock varnish dates, the thinness of the varnigh, and the minimal Bk and $A v$ horizon differentiation of Pedons 1, 2, and 3 all suggest either a very early-Holocene or latest-Pleistocene age for the Little cones surface and soils. Similar soils under creosote bush vegetation on the Leasburg surface at Las Cruces, New Mexico, are about 10,000 years old and are considered latest-pleistocene (Gile and Grossman, 1979, p. 166).

\section{Black Cone surface and Soils}

In the crater Flat basin, the Black Cone surface (much of Swadley and Hoover's 22 deposits) comprises small to large fan-pledmont remants that in aggregate are about as extensive as the crater Flat surface. Defining the Black Cone surface is difficult because mapping the surface is difficult. Boundaries to younger surfaces are readily mapped because they commonly are at an erosional scarp, or at the least are at the boundary from the unvarnished or slightly varnished pavement of Crater-flat or Little-Cones-surface solls to the blackish-shiny-varnished desert pavement of the solis of the Black cone surface. However, boundaries to older Yucca or solitario surface remants are difficult to determine, unless there is a scarp reflecting an inset relationship, because the darkness of rock-varnishing or closeness or extensiveness or sorting of desert pavements are not consistently different. There are soil differences between the Black cone and Yucca or Solitario surfaces that are due to confirmable age differences, $1 . e .$, that can be observed where there is an inset-surface relation. But, between various remnants of the Black Cone surface there are noticeable differences in soil development that can be related to confimable surface age differences in the field in only a few cases. However, progressively older rock varnish dates do seem to correlate with these differences in degree of development of the Black-cone-surface soils.

\section{Late-Black-Cone Age Solis fron Idmestone Allurium}

Pedons 4 \&: Pedon 4 (in a biocopplee) and adjacent pedon 5 (in a pavette) are on a lower-fan-piedmont remnant that was paped 22 by Swadley and Hoover. The remnant has two more somowhat lower and younger levels, but they have soils so similar to pedons 4 and 5 that these younger levels are included in the Black Cone surface. This remnant is to the north of Pedons 2 and 3 of the Little Cones surface and near Bare Mountain (Fig. 1). Pedons 4 and 5 represent the Typic Calciorthids that form from mixed limestone-volcanic fanmalluvium on the Black Cone surface. Iimestone pebbles in the pavement (Pedon 5) are deeply solution-etched whereas volcanic pebbles are darkly-varnished; the pavement is wil-sorted and closely-spaced. Under the parement, there is a moderately thick, fully dilatent, prominently crusted and coarsely-vesicular Ay horizon that is notably greyer than the underlying cambic horizon. This Av horizon is easily distinguished from the thinner, less-silty Av horizon of the Little cones surface. In the non-animal-mixed pedon 5, the cambic horizon (Bwk1, Bwk2) has non-calcareous parts indicating that it was once fully leached, and that the calcareousness of the Ao horizon (which has thin, brittle, pustulose carbonate laminae on plate bottoms) represents later, probably Holocene carbonate accumulation. The 2Bk horizon contains about 208 volume of stage II-III, weakly carbonate-cemented gravel lenses in a stage I matrix; the $2 B k$ horizon has enough pedogenic carbonate to be a calcic 
horizon, but not a petrocalcic horizon. Rock varnish age is about 28,300 XPB. In southern New Mexico, one would expect at least a minimal petrocalcic horizon to have formed in a soil this old.

There are Paleorthids with petrocalcic horizons on the Bare Mountain fan piedmont on surface remnants that look to be within the Black cone age-spread, but I did not study them. There also are petrocalcic paleargids high on that limestone fan piedmont on probably yucca-age fan remnants.

\section{Late-Black-Cone Age Soils from Volcanic Alluvium}

Pedon 6: Pedon 6 is a Black-Cone-age Haplic Durargid formed from volcanicrock alluvium from Yucca Mountain that has no admixed limestone. It is between Red and Black Cones (Fig. 1) on an elongate, low, fan-pledmont remnant that Swadley and Hoover mapped 22 , and that is just above g1e Torriorthents. It is some 33,400 years old, by rock varnish dating, and has a very gravelly sandy loam, minimal, argillic horizon and a haplic (i.e., minimal) duripan rather than the cambic and calcic horizons of pedon 5, which had limestone in its parent material. The Av horizon of pedon 6 is fully-dilatent, moderately thick, and leached of carbonates. An underlying Ak horizon reflects tiolocene carbonate accumulation, since parts of the Bt are noncalcareous, i.e., previously leached. A $\mathrm{pH}$ of 9.4 and dark, 1-2 wh thick bands of alkali-solubilized humus in the Ak horizon indicate soluble sodium salt accumulation as well.

This soil represents one the younger, less-differentiated Durargids of the Black Cone surface. Its argillic horizon has clay skins, but a relatively low clay content. Its duripan has only a single thin laninae on top, and though coherent in place, is only weakly cemented when tested as broken-out chunks. Since this soil is about the same age as Pedon 5, a Calciorthid, the two demonstrate that, in later pleistocene soils, moderate amounts of limestone in the origtnal parent material will prevent the fornation of an argilitic horizon, a relationship woll known in Nevada.

Pedons 10, 11, 12, 14, 15: These solis (and Pedons 8, 9, 13 ) were sampled along a transect from the corner of the solitario canyon road and the dozer road to USGS Trenches CF2 \& 3 , along the CF2 \& 3 road (Fig. 1). This transect was intended to determine the soil properties of the gra and $Q 2$ deposits, and to test if Swadley and Hoover had consigtently mapped these two deposits across this dissected fan piedmont. Swadley ot al (1984) mapped most of the large fan-pledmont-remnant sumits along this transect as oTa deposits on their generalized 1:62,500 map, but they did cut out some inset-fan-remnant summits as 22 deposits. On Swadley and Hoover's (1983) more detailed, largerscale map of the CF2 \& 3 trenches site, they cut out additional, small $21 \mathrm{ab}$, 21c, and $22 b c$ areas from the broad gra areas.

In my assignments of Swadley and Hoover's surficial-deposit designations in Table 2, I have attempted to give them the benefit of the doubt where one wouli think they should have identifled deposits as 22 rather than $2 T a$ because their thap is small scale and necessarily generalized. In Table 4, my geomorphic surface and their surficial-deposit designations are repeated for ease of reading. 


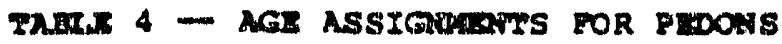

\begin{tabular}{|c|c|c|c|}
\hline Pedon No. & Geomorphic Surface & $\begin{array}{l}\text { Rock Varmish } \\
\text { Age YBP }\end{array}$ & surficial jeposit ${ }^{16}$ \\
\hline 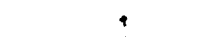 & Little Cones & 7,310 & 22 \\
\hline 2 & Littlo Cones & 11,200 & 21 \\
\hline 3 & Littele Cones & 11,200 & 81 \\
\hline 4 & late Bdack Cone & 28,300 & 82 \\
\hline 5 & late Black Cone & 28,300 & 22 \\
\hline 6 & late Black Cone & 33,400 & Q2 \\
\hline 7 & early Black Cone & 128,000 & 22 \\
\hline 8 & arly Black Con & 137,098 & gra \\
\hline 9 & early Black Cone & $137,000^{17}$ & Qra \\
\hline 10 & late Black Cone & 29,700 & 22 \\
\hline 19 & Late Black Cone & 19,000 & 82 \\
\hline 12 & late Black Cone & n.d. & 212 \\
\hline 13 & very late crater flat & n.d. & 21 \\
\hline 14 & late Black Cone & n.d. & $22 \mathrm{bc}$ \\
\hline 15 & late Black Cone & 31,800 & $22 b c$ \\
\hline 16 & Yucea & 380,000 & gra \\
\hline 17 & Yueca & 360,000 & QTa \\
\hline 18 & solitario & 660,000 & QTa \\
\hline
\end{tabular}

Pedons 10,19 , and 12 , rempectively, are on a highest fan-piedmont remnant, an obviougly lower and younger inset-fan remnant, and another highest fan-piedmont romant, all adjacent to each other along this north-to-south transect. Inasmuch as I could determire in the Eluld, pedons 10 and 12 are on what looked to be positions that Swadley and hoover would have mapped as $2 T$ Ta jeposits on this particular part of the dissected fan piedwont, even though Pedon 10 appears to be in a mappod 82 arad on the $1: 62,500$ map; Pedon 12 is mapped as QTa. Pedon 11 looked as if it should be on mapped 22 and is. sill soils have gravelly gandy loam $B$ horizons, but Pedons 10 and 12 are Haplic Durargids with weak argillic Bt horizons and duripans, whereas Pedon 11, in keeping with its younger relative-geomorphic and rock-varnish age, is only a Typje camborthid with a cambic bw horizon and no pan. According to its rockvarnish age, Pedon 11 is some 7,000 years older than pedon 2, which also is a Typic Camborthid but is on the Little cones surface. Except tor the rock-varnish ages, I would put Podon 11 together with Pedon 2 as little conos age. gedons 10 and 12, compared with Pedoris 8 and 9 , demonstrated to the the Black Cone surface ( $(2)$ could not be separated from the yucea surface (QTa)

15

Corrected radiocarbon age or cation ratio age of rock ramish (Dorn, 1988).

16

Suzicial deposit as mapped by Swadley \& Hoover (1983) or swadley et al

$(1984)$.

17 Age assumed to be the same or somewhat younger than adjacent pedon 8 because pedon 8 and 9 are on zemants that are at the sane level. 
during mapping on this broadly-convex, deeply disacted fan piedmont without careful examination of the soils.

Undated Pedon 14 , a Typic Haplargid gomewtat farther south on the CF2 6 3 road transect, is siaflar to pedons 10 and 12 , but has so few cemented lenses in its Bk horizon that is cannot be sald to have a duripan. It is on a erue inset-fan-remnant sumit that was mapped by Swadley and Hoover (1983) an $22 b c$ and is inset into what they called ora daposits.

Pedon 15, Iypic Durargid next to the usGs CF3 trench, is on a mapped Q2bc deposit. It has a rock-varnish date of 31,800 YPB, but its profile, perticularly its duripan, is more like those of the "early-Black cone" Pedons 7, 8 , and 9 than the late-Black Cone Pedons 10,12 , and 14 .

All of the soils on this CF2 \& 3 road transect have well developed Av horizons. They also have holocene-age zones of accumulation of carbonate in the lower A horizon. Except for obviously inset-fan remnants, there are no consistent visual clues in the field for separating these late-Black cone soils and surfaces from the early-Black cone ones during thapping; the soils must be examined.

\section{Bardy-Black-Cone Age Solis Erom Volcanic Allurima :}

If the pedon $4,6,10,11$, and 14 rock-varnish, radiocarbon ages are correct $(28,300 \mathrm{KPB}, 33,400$ IPB, 29,700 YPB, 19,000 YPB, 31,800 YPB, respectively), and the rock-varnish, cation-ratio ages of pedon 7 nd 8 are correct (128,000 YPB, 137,000 YPB, respertively), then one could argue for splitting the Black Cone surface into two geomorphic surfaces. However, I did not split it bacase I know of no place in the fleld whore the younger and older surfaces are juxtaposed and show an inset or overplaced relation, therefore there is no eridence independent of the rock-varnish dates and comparative soil morphology to argue for splitting the Black cone suriace.

Pedon 7, 8, 9: Fedon 7 is a Typle Durargid (128,000 YPB, cation ratio age). It is along the main, diagonal road to northeastern crater Flat, on the sumet of an elongate, fan-piedmont-remant that is prowinently inset be low the large Yucca-age fan-piedmont ramants in northern crater plat. Swadley and hoover mapped the pedon 7 remant as a 22 deposit and the higher yucca-age remrants as a gTa deposit. The texture of the argillic horizon of pedon 7 (very sticky, plastic very-extrenely graveliy clay loan suggestg that it is older than the very graveliy sandy loan Bt horizons of the late-Black Cone Durargids. The duripan has only a single laminae on top, but strongly to weakly cemented lenses are closely enough imbricated below it that I called it a typic pan.

Pedon 8 is a Typie Durargid described in the southeast corner of the solitario canyon and CF2 \& 3-Trenches road comers. It has a rock-varnish, cation-ratio dete of 137,000 YBP. Pedon 9, was described directly to the south, across a wash on another "higtrest" fan-piedmont-remant sumit that appears to be at the same level and of the sam age surface as that of pedon 8. However, Pedon 9 is only a haplic Durargid, because its duripan is not as continuously or strongly cemented as that of pedon 8 . Both solls were identified as in gra depositg by swadley and hoover (1983), but the rock-varnish 
date for Pedon 8 forees it into the next younger than yucca surface, and the argillic horizon and pan development of podon 9 are not as grat as those of Yucea-age soils.

The argilite horizon of pedon 8 is distinctly reddish hued (a fuli $7.5 Y R)$, sticky, plastic, and a clay loam at least. It has been opalized, particularly in its flaty lower subhorizon, and has the "crunchy" feeling, moigt, of strongly opal-agglomerated, clayey Bt horizon material. This argillic horizon opalization is a prominent feature of Yucca-age pedon 16 , and is noted fol" QTa-age soils by Hoover et al (1981). But, the argillic horizon of Pedon 9, though also a clay loam and crunchy, is not opalized strongly enough to thake it platy. Pedons 8 and 9 could be older than their rock-varnish dates suggest.

\section{Yucca surface and Solls}

The Yucca gurface can be readily distinguished from the Black Cone and Crater flat surfaces (and by implication, the little cones surface) by aerialphoto patterns, by topographic sepazation, and by soil differences. On both color and black \& white photos, tratisverse bands of darkly-varnished desart pavement on low, Av-horizon slump-stepg contrast with light-colored biocoppice areas to give a distinetively banded photo pattern for the Yucca surface remrants. This contrasts with the photo partern of the Black cone surface fan-piedmont remnants-- for both the Black Cone's younger and older reunants-where the dark patches of desert pavement are irregularly-shaped, or tiend to be longltudinally-alongated and the light-colored biocoppices are semi-circular spots, of "dots." The crater flat, Holocene surface is raw sediment and hence digtinctively light colored on the aerial photos, compared to either Black Cone or Yucca surface remiants.

The rucca surface comprises three areas of fairly-extensive, relativelyhigh, deeplymdigsected, Elattish-topped (transverse to the slope), fan-pietmont remnants. Yucca-age padon 16 is on the area of Yucca rennants in nortieastarn Crater Flat (color photo 24 NF8OBC 8-44-20, southeast $1 / 3$ ). The extensive Black-Cone age, dissected fan-piedmont remnant that is just to the northwest of the Yucca tian-piedmont resnants has fedon 7 on it and is prominently inset into and som 10-20 feet below the Yucca remants. This inset relationship demonstrates the relative ages of the Black Cone and Yucca surfaces and solls. There are well-preserved ramants of two younger erosion surfaces that re cut into this yucca-age fan piedmont near the heads of the deep quilies that dissect it. The desert parement, Av, and upper Bt horizon of the remants are similar to those of the Yucca surtiace, so tne remnants probably reflect there baing more than one level of yucca-age remants. The lowegt remants could be of Black-Cone age, but they were not traced-out.

Yuccamage pedon 17 is on the southarnmost of three remantal Yucca areas imediately goutheast of the mouth of Solitario canyon on the east side of Crater Flat (black \& white photo GS fan-piedmont reminants are inset into and below these yucca reanants. The third group of presured yucca renants is in the northwest corner of crater Flat, just above the main drainageway (color photo BLM 24 NVBOBC 8-43-20A). I got only one look at the edge of this third area, and could only note that the 
soil apparently has an argillic horizon and a thick, strongly-indurated duripan.

Both Pedons 16 and 17 have strongly differentiated Av horizons that are very dilatent. Note that Av horizons are not significantiy thicker than the Av horizons of the Black-Cone age soils, even though the ages of these pedons $(380,000,360,000 \mathrm{YPB})$ are several times older. Since the formation of the Av horizon is attributed largely to dust accumulation by most current workers in soil genesis, one would expect thicker Av horizons in the older soils on wellpreserved surface remnants. There are two problems with applying this theory. First, the fine earth in the Ak and Bw or Bt horizons (in this area) also probably is largely of eolian orlgin, therefore measuring the thickness of the Av horizon alone must be a poor measure of dust accumulation. The Av horizon is a morplologically distinct layer of very-coarsely-prismatic ("polygons"), coarsely-vesicular, internally massive or platy, light colored, crusting soil rnaterial. Its morphology reflects currently on-going processes that will recreate the morphology if it is disturbed. It is the depth of effect of these processes, not dust accumulation, that determines the depth of the Av horizon once dust accumulation has exceeded the depth of effect of Aviforming processes.

Secondly, all of the surfaces older than the raw Crater flat surface have abstracted drainages. That is, at least occasionally water sheets off the soil surface rapidiy enough to have led to formation of shallow, dendritic, "on-fan" drainage systems. It is reasonable to conclude, as Taylor (1986) suggests, that there has been some sheet erosion of the Av, at least on the older surfaces.

The vertical pattern of leached Av horizon over calcareous Ak, over partly-carbonate-leached Bt horizon again demonstrates recent, relatjuely shallow, presumably Holocene-dge carbonate accumulation in soils that were leached of carbonates in the Pleistocene. High pH values in the Ak again show that soluble sodium salt accumulation from dust fall is occurring.

Both Pedon 16 and 17 have thick $(60$ and $40 \mathrm{~cm})$, basically clay-textured argiljic horizons. In pedon 16, opal "agglomeration" has weakly cemented the Bt horizon; it is very brittlemcrunchy throughout and promsnently platy and firm and "orangish-looking" in its lower part-mall well known effects of silical accumulation. The apparent texture is a loam in the upper part of the Bt and loamy sand in the lower part, but the "sand" is merely weakly silicacemented aggregates of clay. Pedon 17 has not had its argililic horizon opalixed, and feels like a clay without as long and vigorous a working as pedon 16 's Bt requires to begin feeling clayey. In my experience, opalization of argillic horizons is sorne sort of evidence of considerable age, but it is so variable within and between polypedons that it is not a consistently-applicable criterion for identifying a particular age of soil.

Both Pedon 16 and 17 have a foot or two of stronglymcemented duripan; the former has several prominently opaline surficial landna, whereas the latter apparently has a single surficial laminae. I do not know if this apparent difference in degree of opalization of Bt and Bqkn horizons is a reflection of age or environmental. differences between the two pedons. Decent exposures of the pans were not possible in my hand-dug pits, and gully-wall outcrops must be distrusted because of "case-hardening." Regardless, the 
duripans on well-preserved Yucca surface remants are as thick and as strongly cemented, or more so than on Black cone remants.

\section{Solitarlo suriace and soils}

The solitario surface comprises a single ballena, or fully-rounded, ridge-line remnant, just to the southwest of the mouth of solitario canyon. There are, however, spur-remants up solitario canyor and in valleys in Yucca Mountain above the northeast side of crater Flat that suggest the solitario surface was once much more extensive. The ballena-form remant near solitario Canyon, where pedon 18 was described, is $5+$ feet higher than the adjacent, well preserved Yucca-age fan remnant where pedon 17 was described. The Yuccaage fan piedmont clearly is inget into and bolow the pro-existing solitarioage fan-piedront remant.

No actual, Solitario-ago soil was found. Rather, there is a complex of more extensive Typic Durorthids and small spots of Typic Durargids on the baliena that results from stripping of the original $A$ and Bt horizons, mixing with part of the duripan, and later dust accumulation. Pedon 18 is a Typic Durargid that represents the truncated remants of the original soil. It was described on a ballena crest that marks the pnsition of the former solitario surtace. The ballena is littered with chips of the duripan lamina, showing that animals have been vigorously scraping at the duripan. The 19-crn, Av-AkBtk solum of Pedon 18 was found in a slight depression of the duripan. In a second pavete location, there is a Typic Durorthid that has only a $0-5$ cm Av and 5-19 cm ak over the duripan. In a third pavette location, the Durorthid is only a 0-7 cm Av over the duripan. In one of the larger, raised biocoppices on the ballena crest, under a pale wolfberry shaub, the Durorthid comprises $40 \mathrm{~cm}$ of rodent-mixed earthy material over the pan.

The duripan has $1-3 \mathrm{~cm}$ thick, opalized lamina on top of it. USGS faulttrench CE1 is dug into the side of the ballena and shows that the duripan extends on over the sides of the ballena, but that the strongly-cemented part is thickest (a couple of Eeet) at the ballena crest and thinner on the yourger sides lopes.

on color aeflal photos, this ballena-form remant of the solitario surface is notably lightex colored, and tan colored, apparently due th the conmon chips of duripan lamina scattered across its surface. A similar, duripanchip-strewn, but lower ballena is just notheagt of USGS fault-trenches CF2 i 3 , and may be another solitario remnant, or could be a stripped, rounded Yucca remant. The hilitock on the upthrown, eastern side of usgs fault-trenches CF2 * 3 could have either a Solitario or Yuccamage duripan in it. 


\section{concrosions}

(1) There are five major gemorphie surfaces, i.e., groups of land-surface remants, in the crater flat basin: the Crater plat, fittle cones, Black Cone, Yucca, and Solitarto surfaces. Each has a distinctive arial photo pattern. Where is, somewhere in Crater Flat, a situation where remants of each surtace are topographically separated from remnants of surfaces higher (older) and lower (younger) than themselves, thus demonstrating inset relations and relative ages.

(2) The soils of each surface have distinctive differences from those of the other rajox surfaces:

(2A) The soils of the crater flat-age surfaces are Torrtorthents without genetic horizons.

(2B) In pavettes, the soils of the Little cones-age surfaces have slightly-dilatent AV horizons, that are more sandy than those of older surfaces, and have cambic horizons and stage I BK horizons.

(2c) In pavettes, the soils of the Black Cone-age surfaces all have prominent $A v$ horizong that are dilatent. Those from limestone-containing parent material have cambic horizons and stage I-III calcic horizons, whereas those from solely volcanic alluvium have sandy loam or loam textured argilitic horizons and haplic (discontimously or weakly cemented) to barely typic duripans. Some of the youngest Black-cone age remants have solig with cambic horizons, rather than argillic horizons, and no curipan, and some with argillic horizons lack the weak duripan.

(2D) In pavettes, the soils of the Pucca-age surfaces all have prominent Av horizons that axe dilatent and have soliflucted into broad, low, slump-steps that show a transversely-banded pattern on aerial photos. The solis have relatively-thick, clay-textured, or opalized-clay argillic horizons. Their duripans ar relatively are strongly cemented than those of the Black Cone surface. Black Cono-age argillic horizons are not as thick or as clayey as those of Yuccamage soils.

(2E) The Typic Durorthids of the solltario-age surfach remants, which are ballenas, have a distinctive litter of duripanlamina chips across their surface and are very shallow to a strongly-comented duripan that has thick opal lamina on its top. The ballena surface has been stripped of the original $A$ and $B t$ horizons, so there is only a shallow, dilatent $A v$, or Av and Ak horizon except where a thin, very gravelly clay loam bt horizon has been preserved in a shallow depression in the duripan. Where the Bt: horizon is preserved, the spot. is a Typic Durargid. 
(3) Av hortzon formation depends on dust-fall, dust-1nfiltration, and pluggirig of cropores that then causes surficlal dust accumulation. There has been enough dust fall during, or during and since early Holocene to form the minimal, slightly didatent Av horizon of the littele cones soils, but no Av horizon in the mid-Holocene to Modern Crater-plat age Torriorthents. Dust-fall must have been significant in the pleistocene because all of the soils on the Black Cono, Yucca, and Solitario surfaces have prominent, very dilatent Av horizons; there probably has been erosion of Pleistocene AV horizons, since there are wellabstracted, on-fan drainage systems on the old fan remnants.

(4) There has been shallow, limited, yolocene to Modern carbonate and sodiumsalt accumulation in the A horizons of all solis. The $A$ and $B$ horizons of the Pleistocene-age soils were once leached of carbonate, and have not been completely re-carbonated.

(5) Swadley and Hoover's (1983), and Swadley et al's (1984) mapping of "surticial deposits" in crater flat failed to distinguish three clearly separate geomorphic surfaces and related soils in their gra unit (my black Cone, Yucca, and solitario surfaces), and in their Q2 unit included two separable geomorphic surfiaces, the Little cones and Black cone surface.

(6) Hoover and Swadley's "surficial deposits" concept and mapping are fatally flawed, and should be abandoned. Geomorphic surfaces, defined and mapped in terms of soils and stratigraphic relations, should be used as the geomorphic dating tool for neotectonic studies. 


\section{ITTERATURE CIMSD}

Dorn, R.I. 1988. A Critical Evaluation of Cation-Ratio Dating of Rock Varnish, and an Evaluation of Its Application to the Yucca Mountain Repository by the Department of Energy and Its Subcontractors. Einal Report for the Nevada bureau of kines and Goology for the Period January 1987-Jure 1988.

Eckert JI., R.E., M.R. Wood, W.H. Blackburn, F.E. Peterson, J.L. Stephens, M.S. Meurisse. 1978. Effects of surface soil morphology on improvement and management of some arid and semi-arid rangelands. Proc. ist Int. Rangeland Congress, venver, Color., Am. Soc. Range Manage., pp. 299-302.

Gile, I.H, F.F. Peterson, and R.B. Grossman. 1966. Morphological and genetic sequences of carbonate accumuation in desert soils. Soil Sci. 101:347360 .

Gile, I.H., and R.B. Grosmman. 1979. The Deseft Project Monograph. U.S. Dept. Agr., Soil Consv. Seruice., Washingron, D.C. 984 pp.

Hillel, D. 1960. Crust formation in loessial soils. Trans. 7th Int. Songress soil sci. 1: $330-339$.

Hoover, D.I., W.C. Swadley, and A.J. Gordon. 1981. Correlation characteristics of surficial deposits with a description of surficial stratigraphy in the Nevada Test site region. U.3. Geol. Surv. Open-Pile Rept. 81512. Denver, colorado. 27 pp.

Miller, D.E. 1971. Pormation of vestcular structure in soil. Soil Sci. Soc. Am. J. $35: 635-637$.

Nettleton, W.D., and F.F. Petierson. 1983. Aridisols. In: Wilding, L.P., N.E. Smeck, and G.F. Hall (Eds.). Pedogenesis and Soll Taxonomy. Vol. II: The soil orders. Elsevier, Amsterdam. pp. 165-216.

peterson, F.F. 1977. Dugt inflitration as a soil forming process in deserts. Agron. Abstr., Meetings, Am. Soc. Agron., Los Angelos, Calif., p. 172.

Peterson, F.F. 1981. Landforms of the Basin \& Range Province Defined for Soil survey. Nev. Agr . Exp. Sta. Tech. Bul. 28., Univ. Nevada-Reno.

Swadley, W.C., and D.L. Hopver. 1983. Goology of saults exposed in trenches in Crater Flat, Nyo County, Nevada. U.S. Geol. Surv. Open-File Report 33-608. Denver, Colorado.

Swadley, W.C., D.L. Hoover, and J.N. Rosholt. 1984. Preliminary report on late cenozolc taulting and stratigraphy in the vicinity of Yucca Mountain, Nye County, Nevada. U.S. Geol. Surv. Open-file Report 84-788.

Taylor, E.M. 1986. Impact of time and climate on Quaternary soids in the Yucca Mountain area of the Nevada Test Site. M.S. Thesis. University of Colorado, Boulder, Colorado. 
APPENDIX I - SCIENTIYIC NAMES OP COWMON PLANTS IN THE

GRATLR RTAY, NLSTAA, ARAA

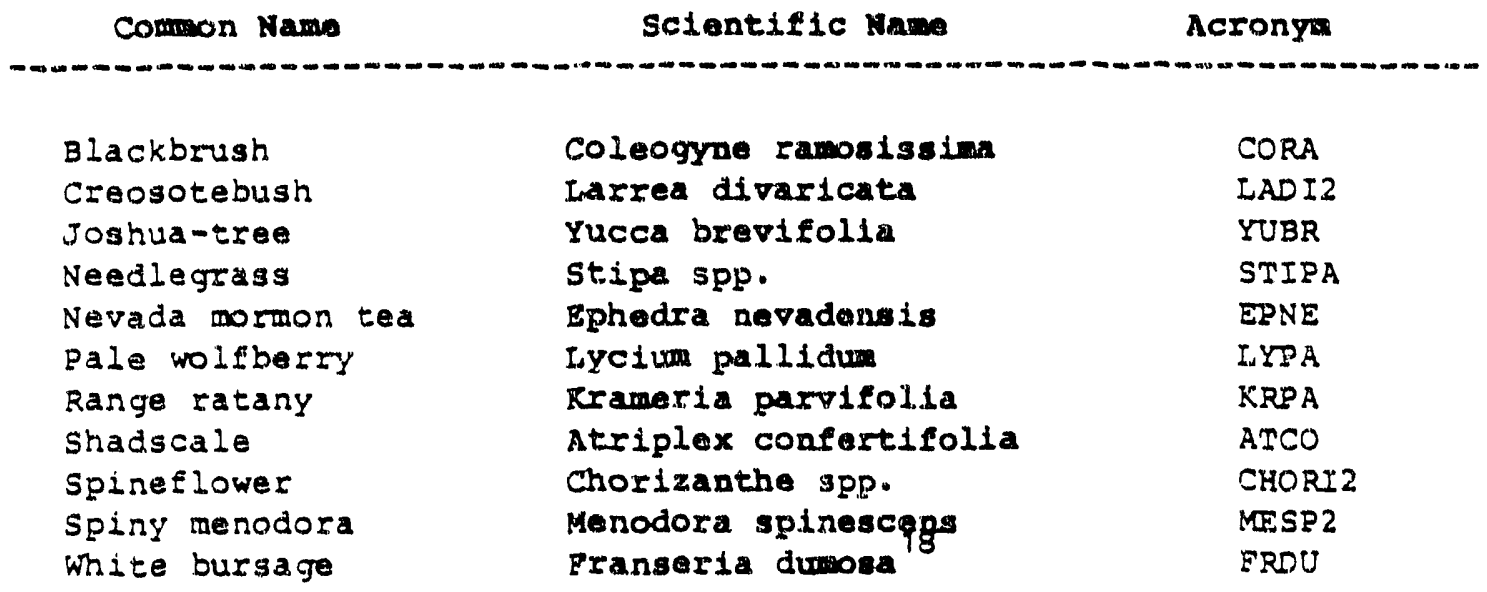

18 Alternative name: Ambrosia dumosa. 
APPEDIX II -- PEDON DESCRIPTIONS

Pedons 1 to 18 


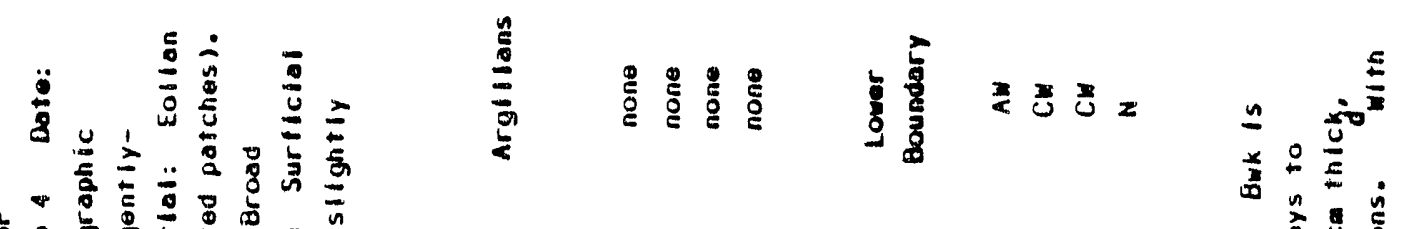

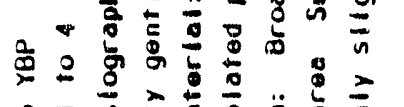

ห⿻ำ

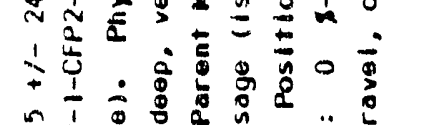

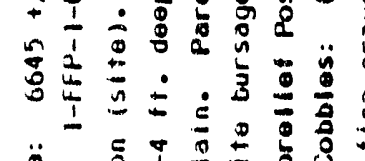

3.

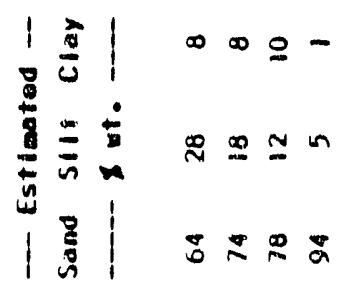

$\left|\frac{2}{1}\right| 000$

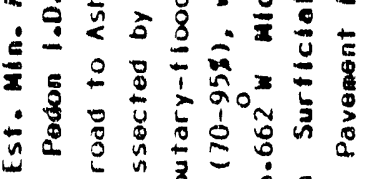

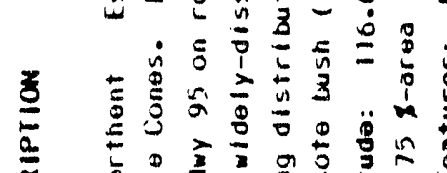

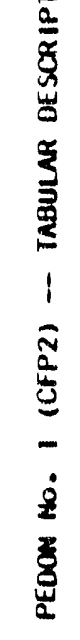

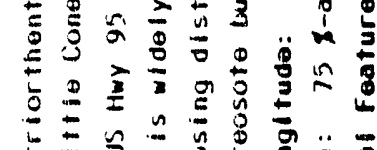

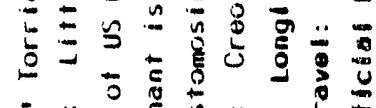

(5)

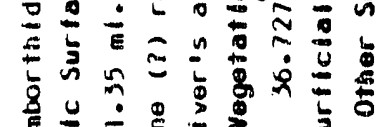

ร)

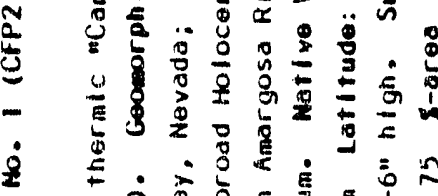

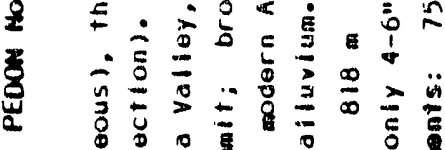

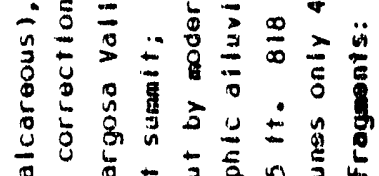

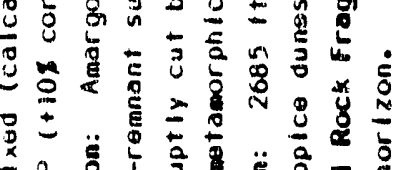

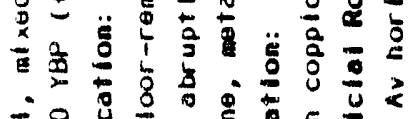

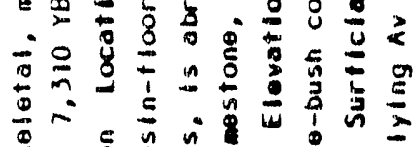

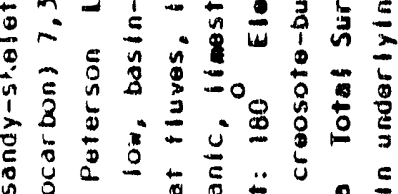

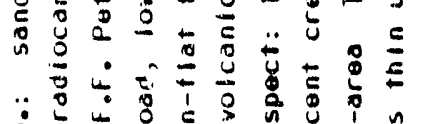

कุ

$\frac{1}{8}$

$\left|\frac{1}{3}\right|=2020$

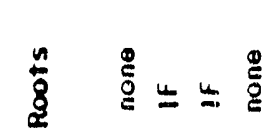

$\because$ 要

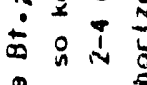

ํํㄹำ

(1)

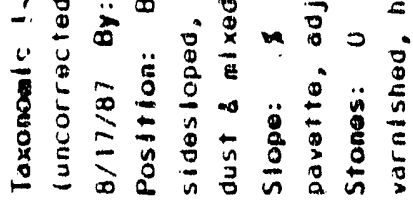

ริง

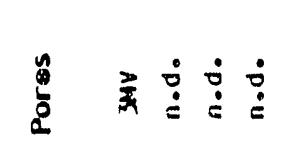

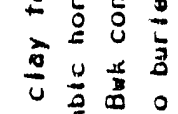

,

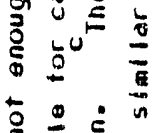

ระ

三

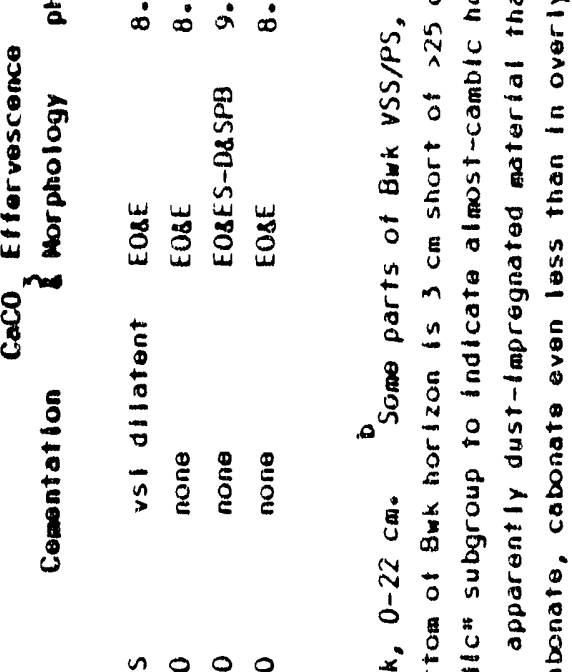

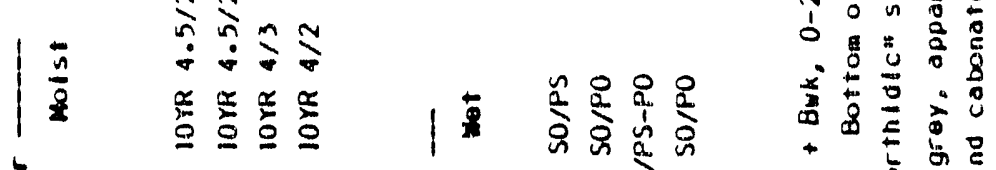

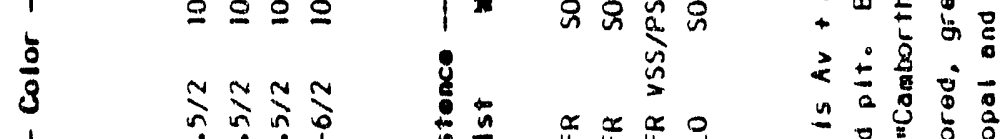

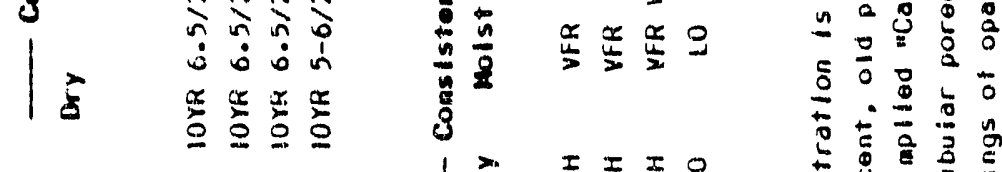

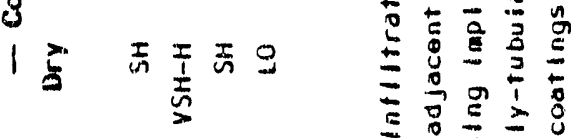

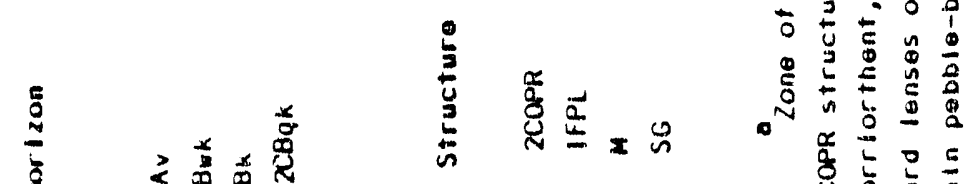

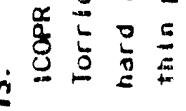

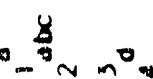

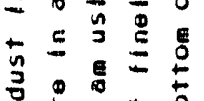

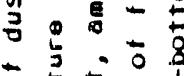




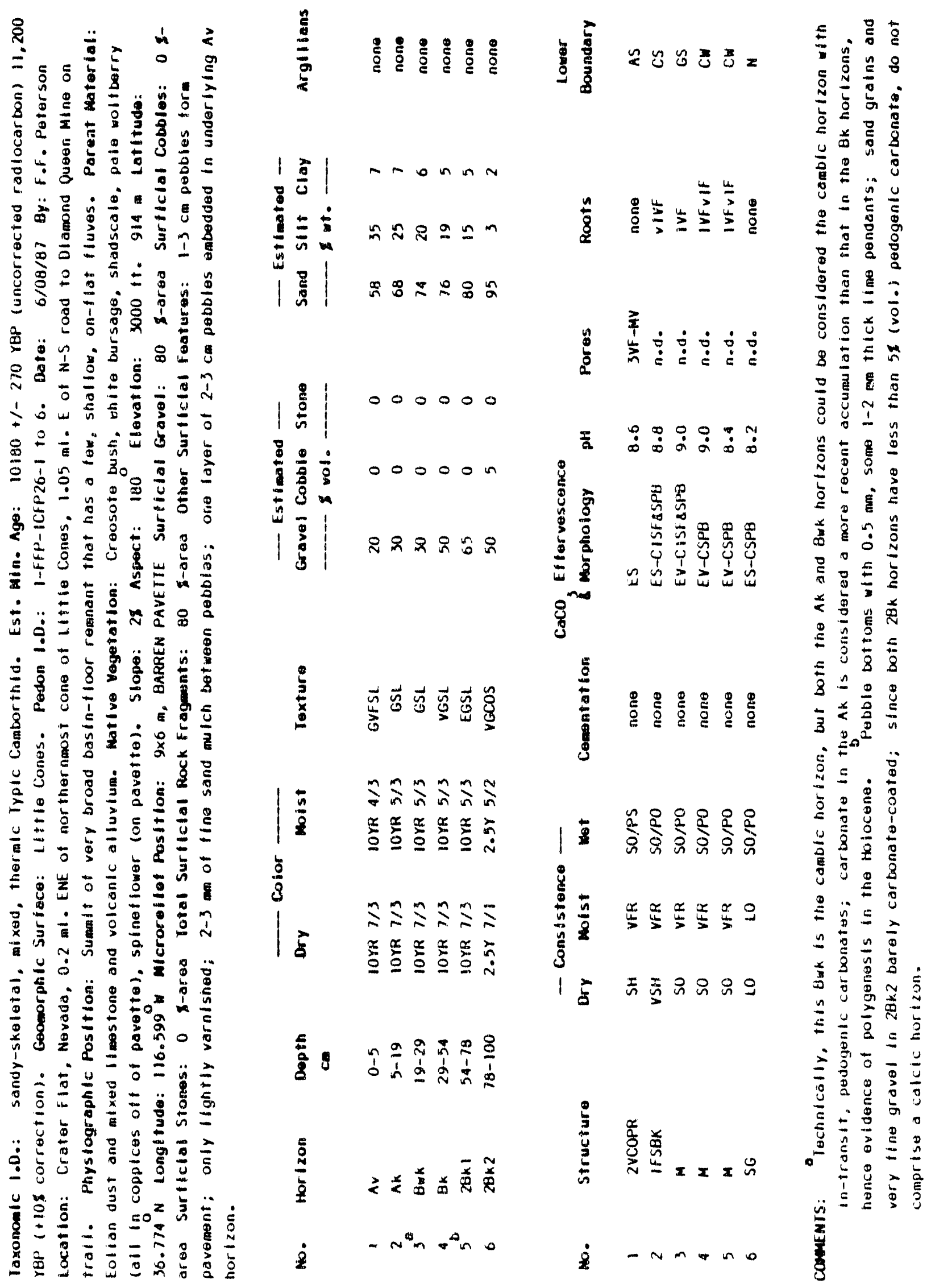


0
0

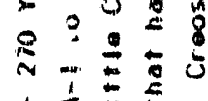

童管

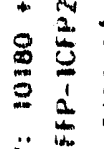

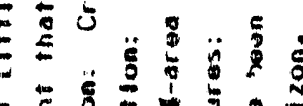

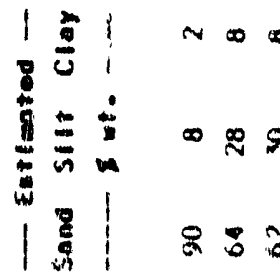

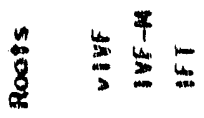

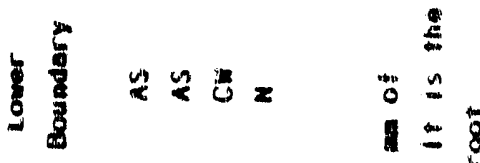

1)

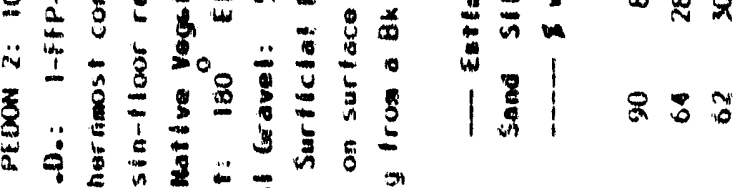

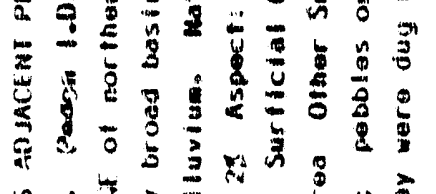

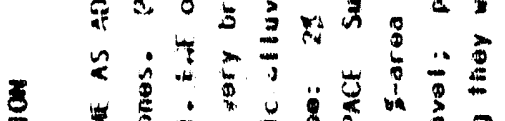

$1 \frac{8}{2} 1000$

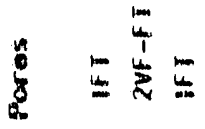

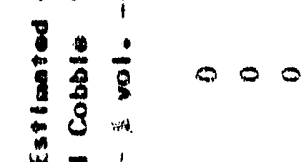

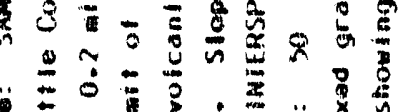

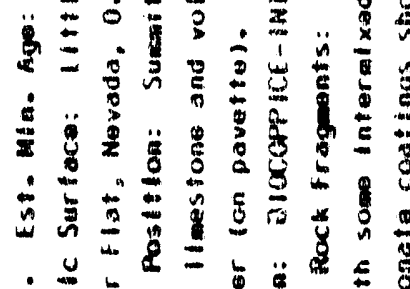

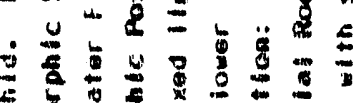

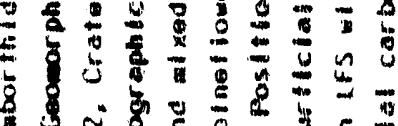

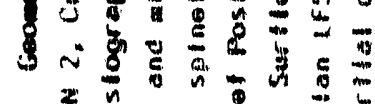

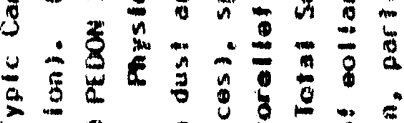

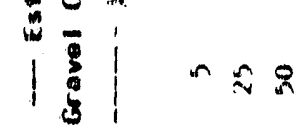

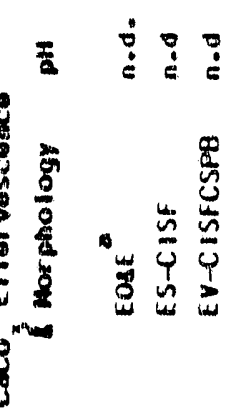

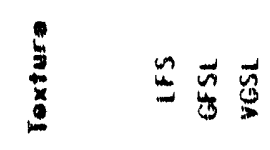

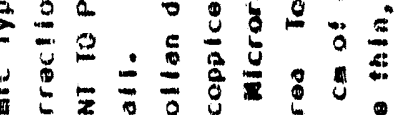

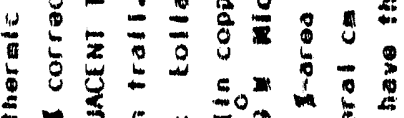

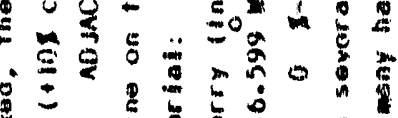

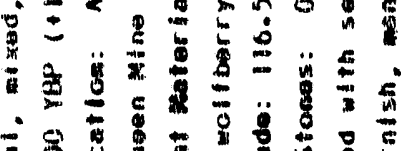

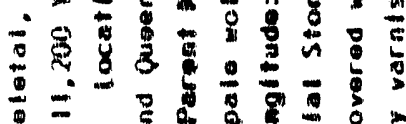

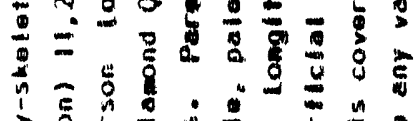

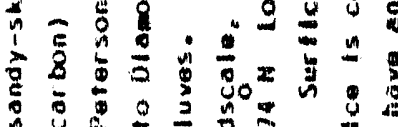

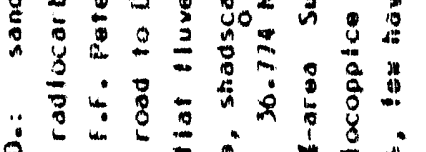

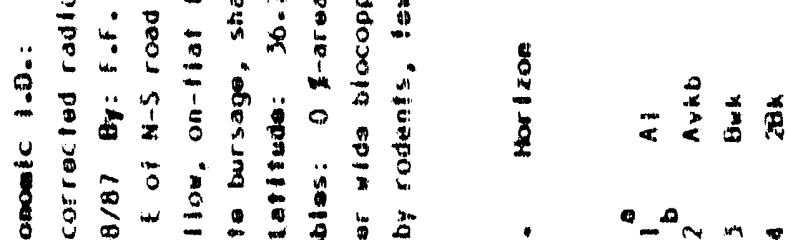

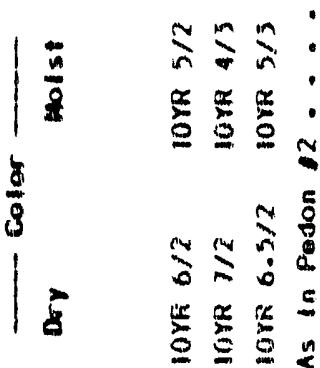

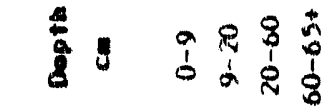

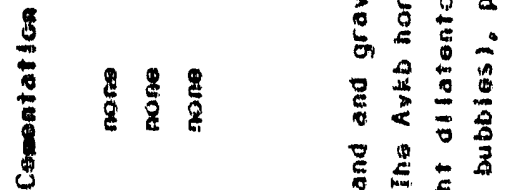

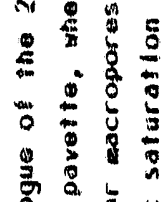

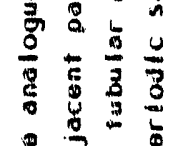

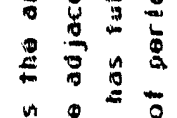

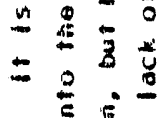

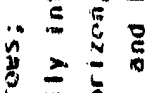

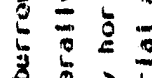

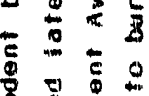

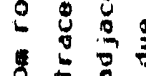

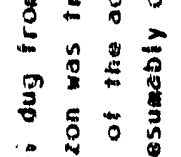

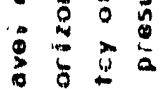

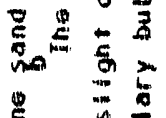

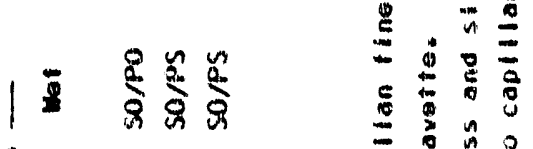

+

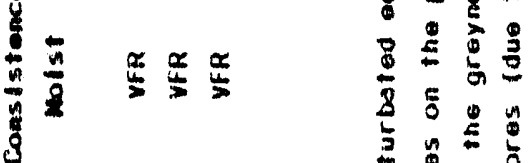

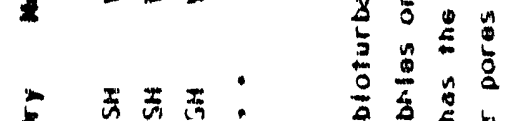

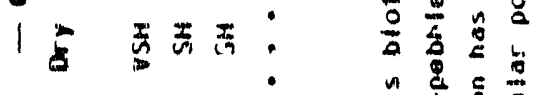

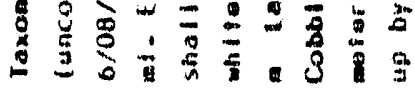

a $a^{2} m$.

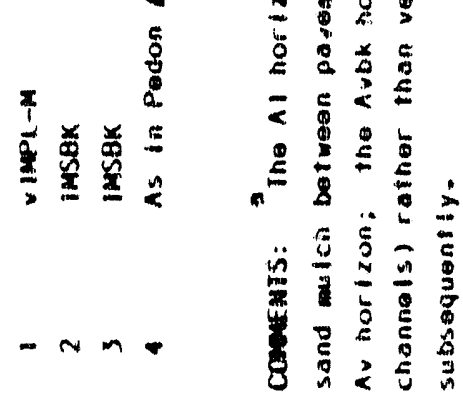




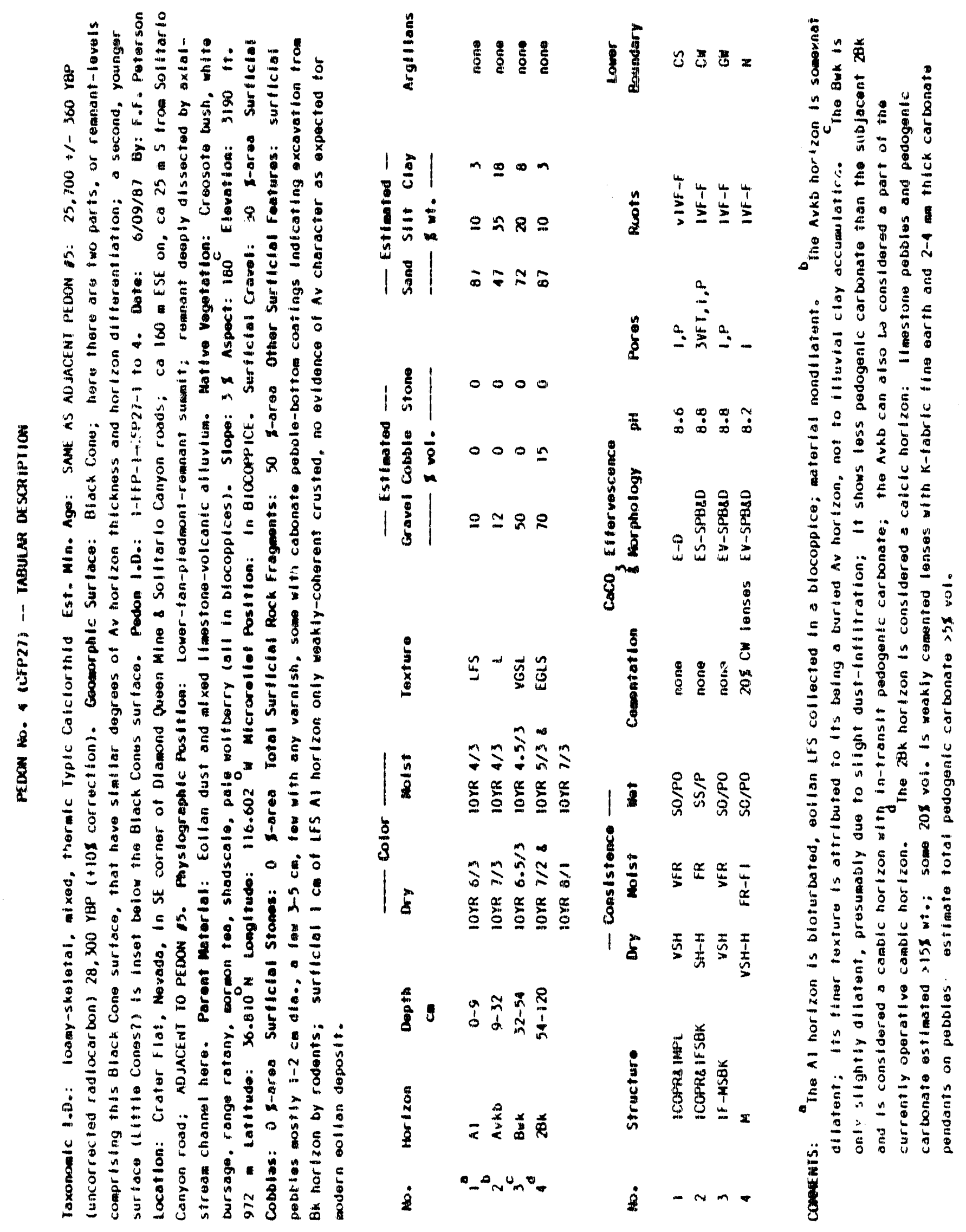




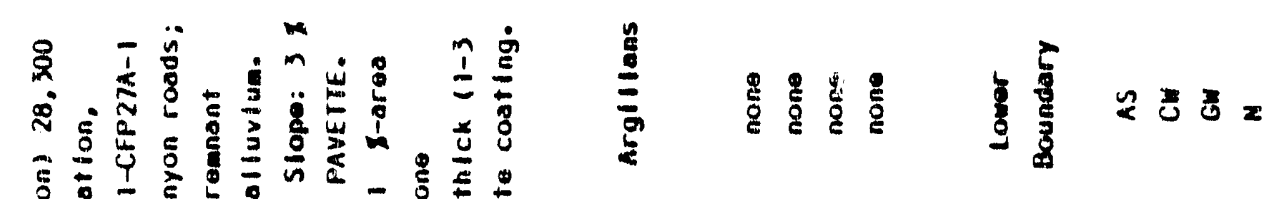

Hyln:

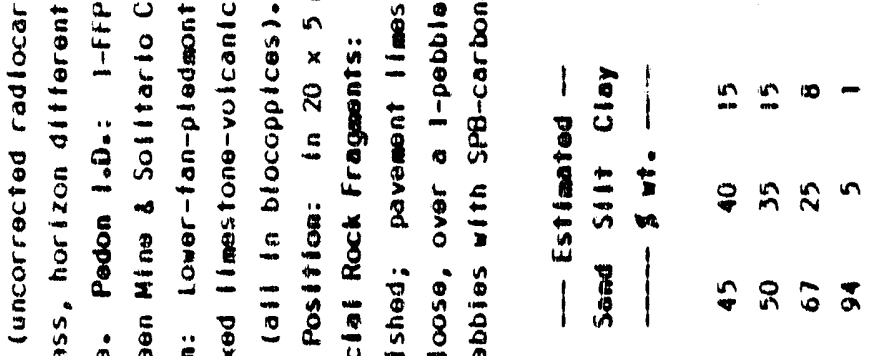

Mn

औด

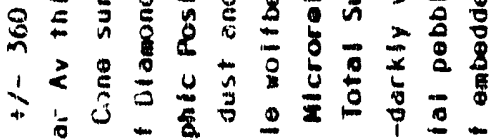

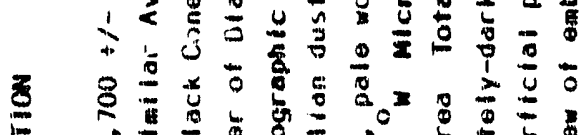

ช้

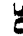

यद

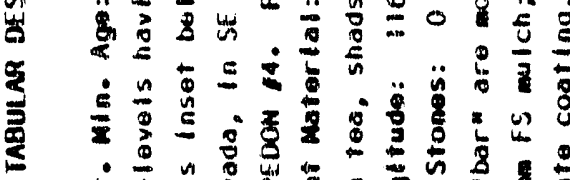

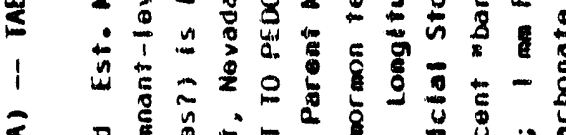

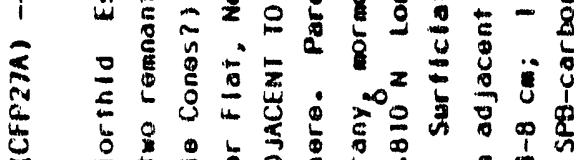

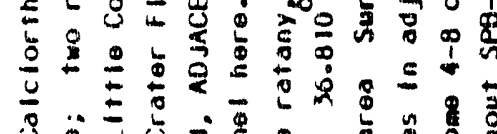

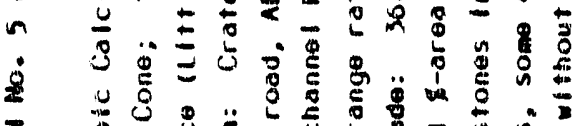

홍

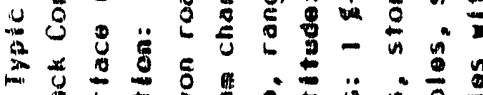

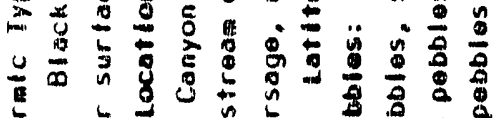

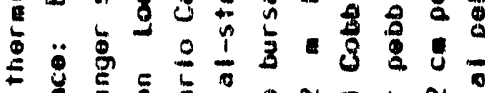

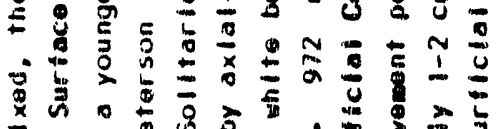

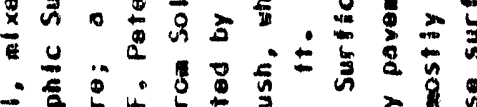

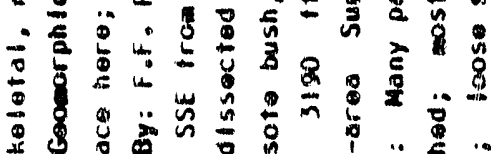

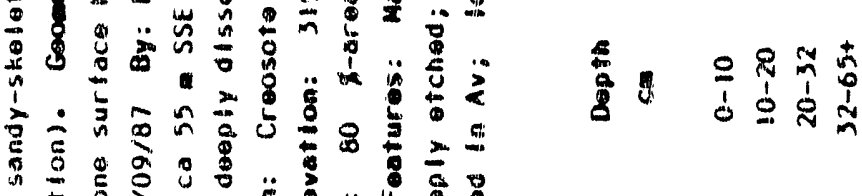

$\left|\frac{1}{2}\right| 0000$

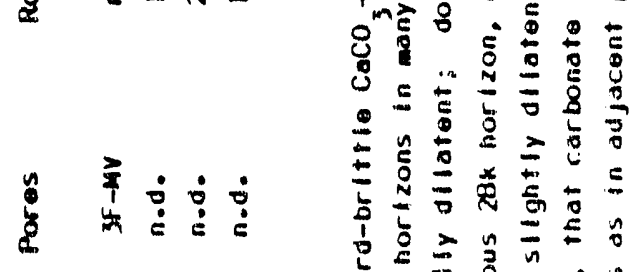

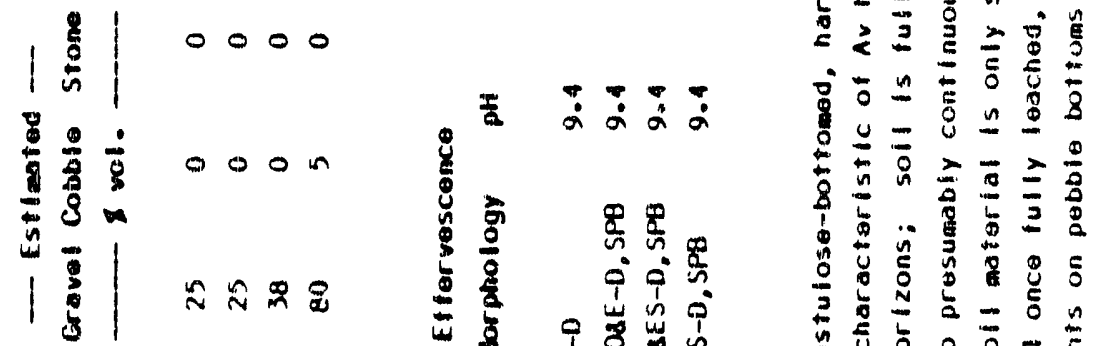

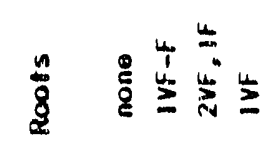

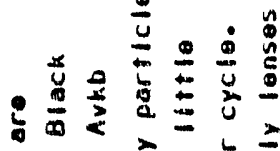

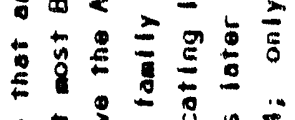

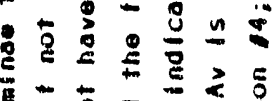

$\frac{1}{1}=\frac{9}{10}$

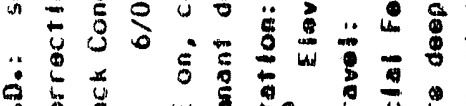

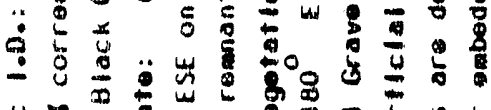

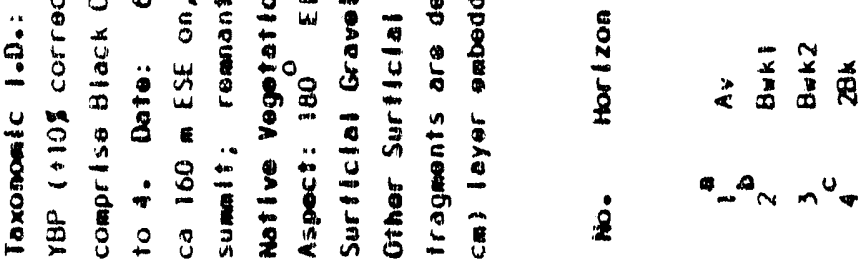

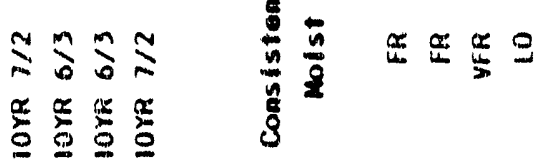

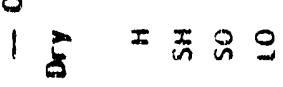

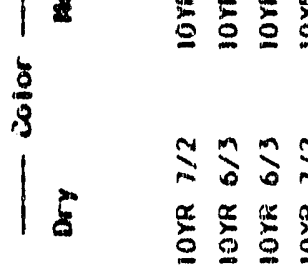

|

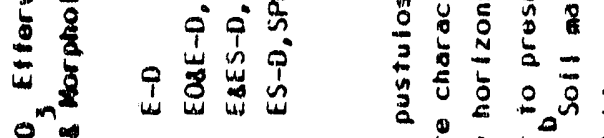

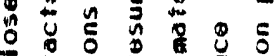

8

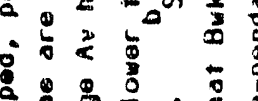

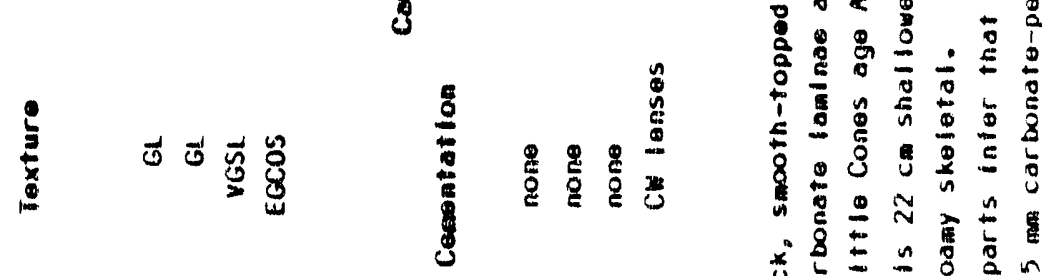

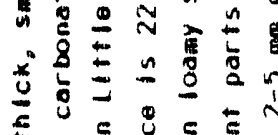

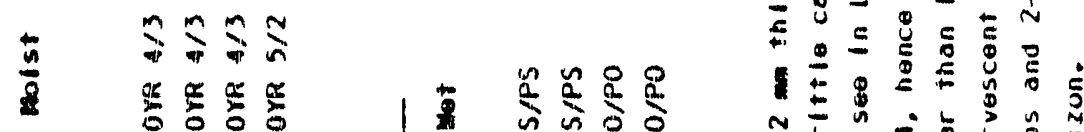

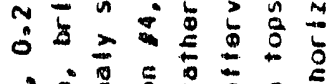

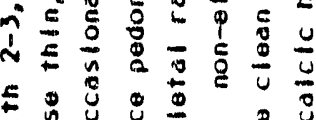

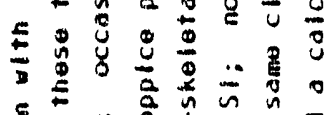

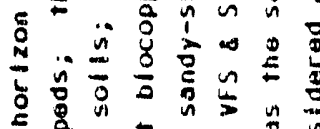

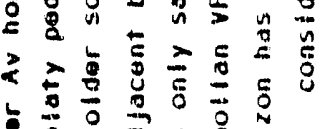

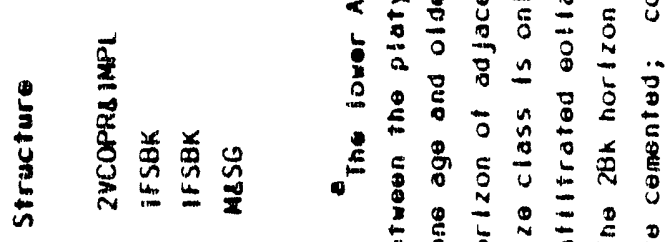

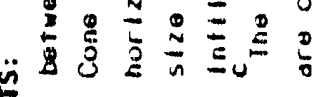




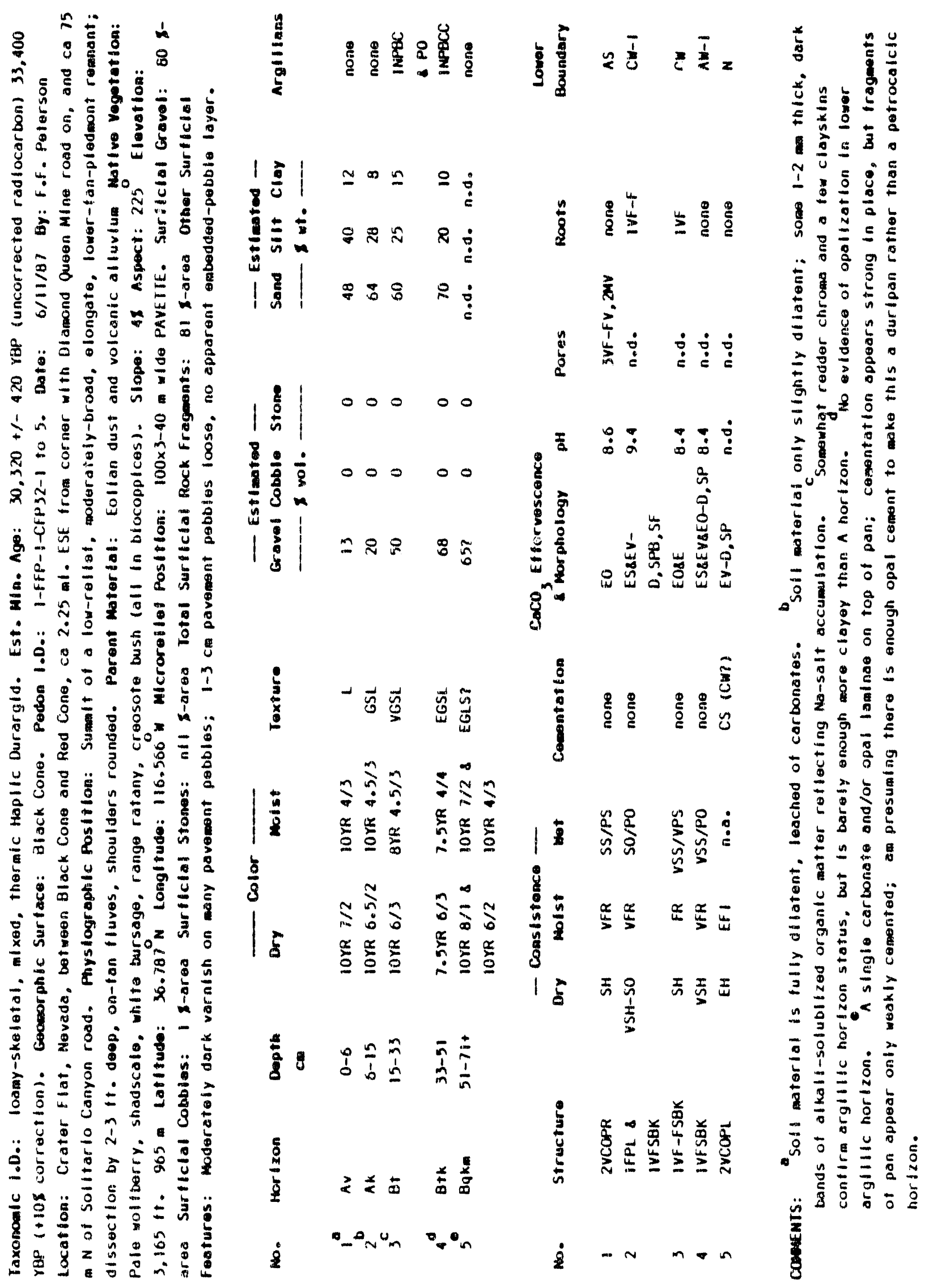




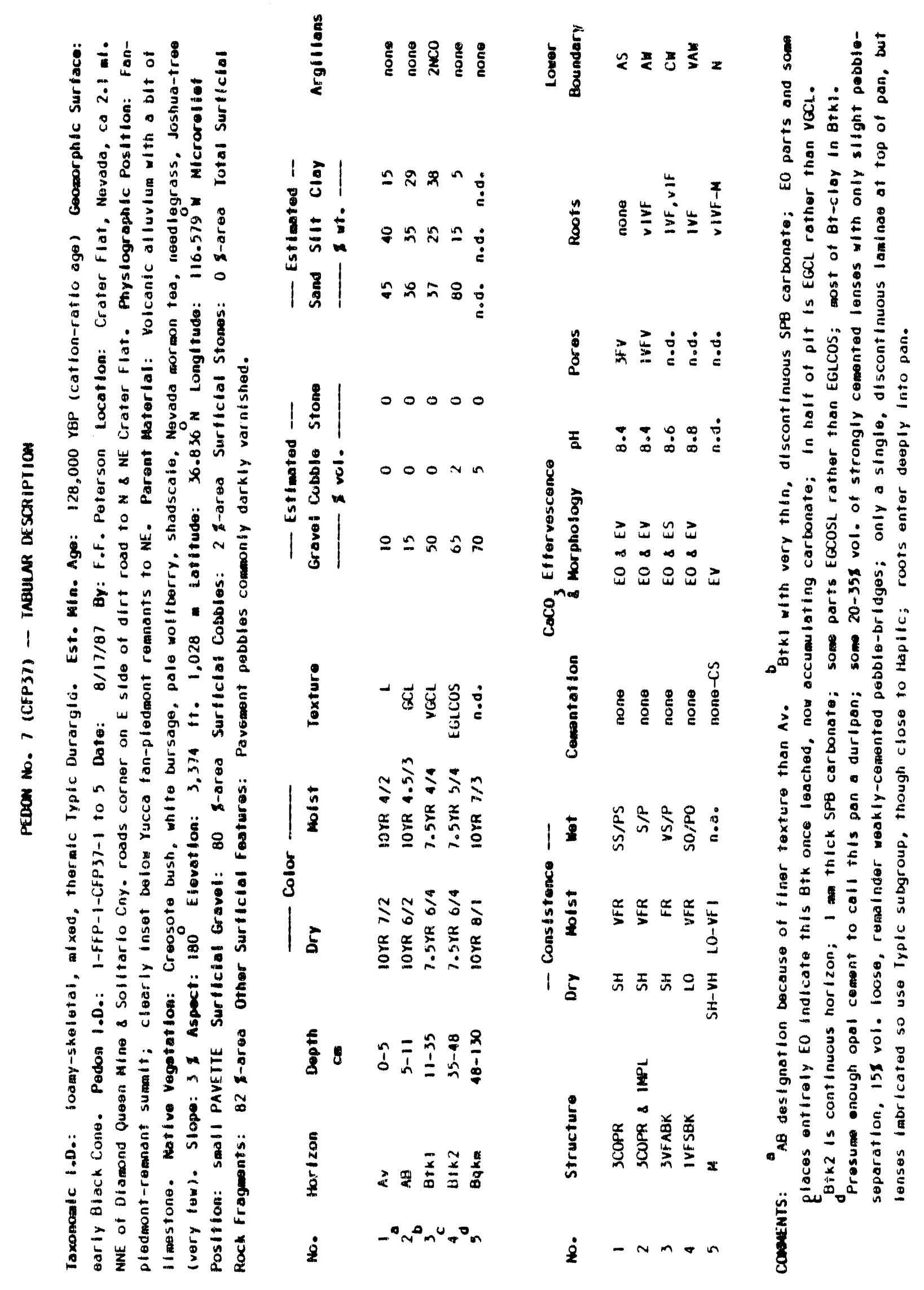




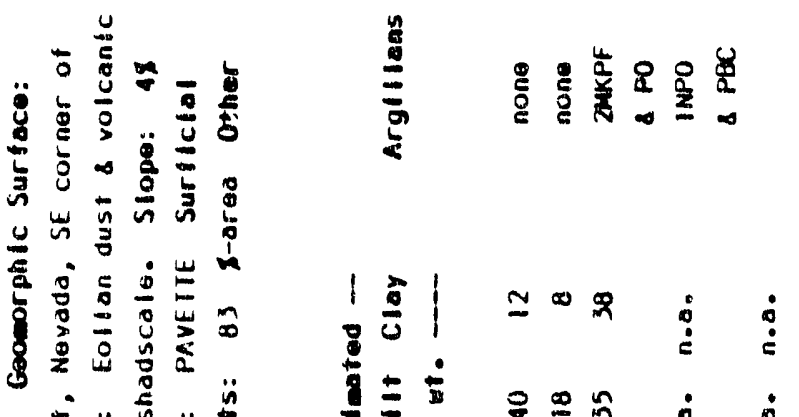

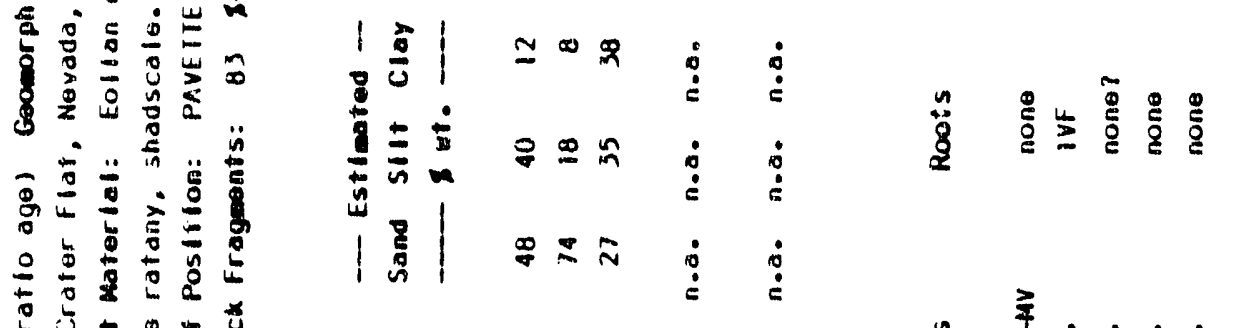

1)

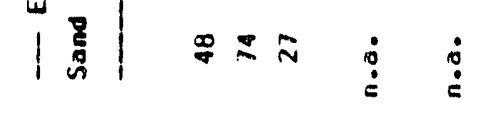

ำ

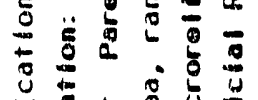

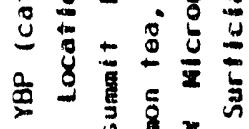

5.

勿

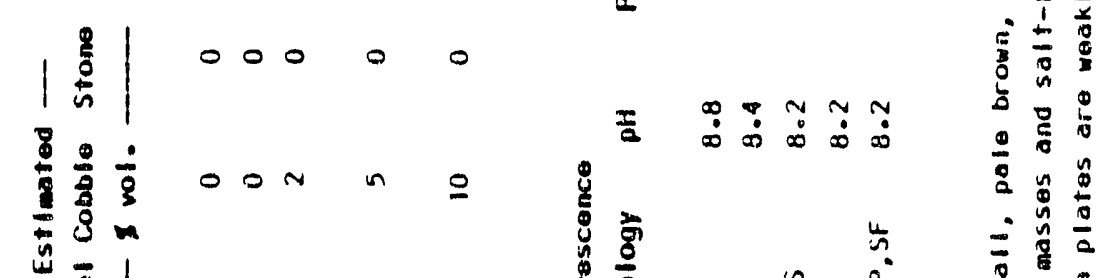

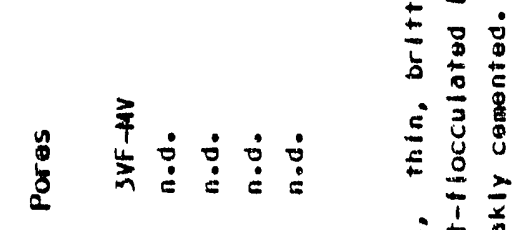

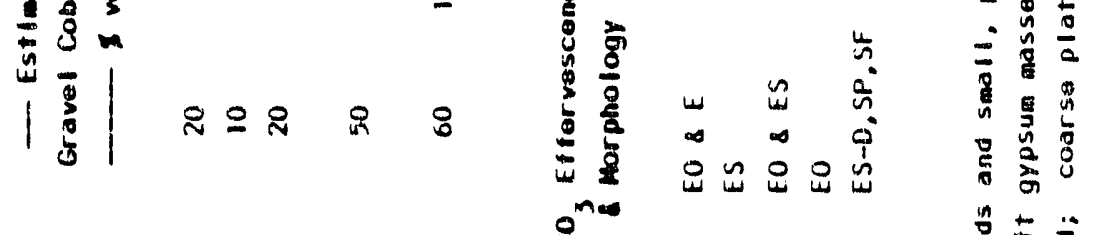

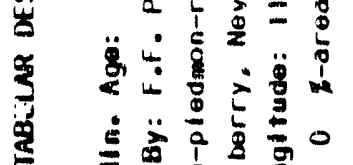

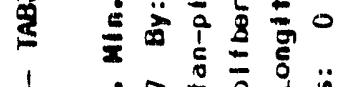

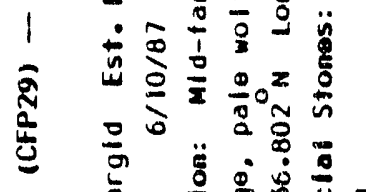

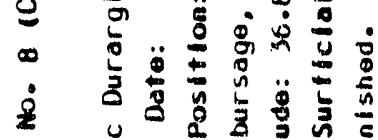

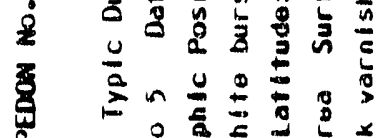

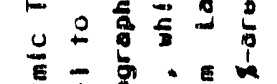

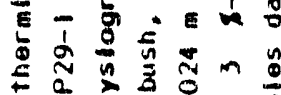

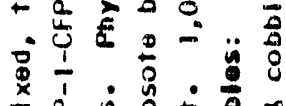

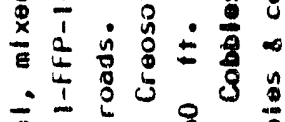

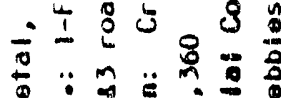

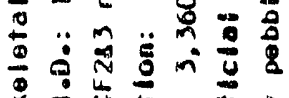

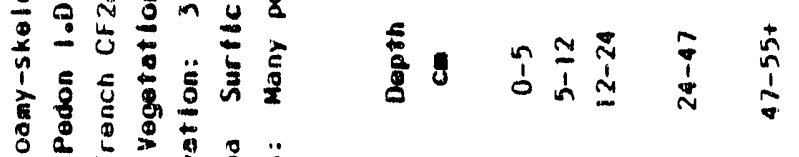

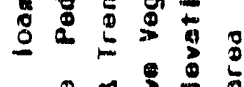

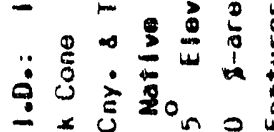

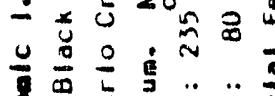

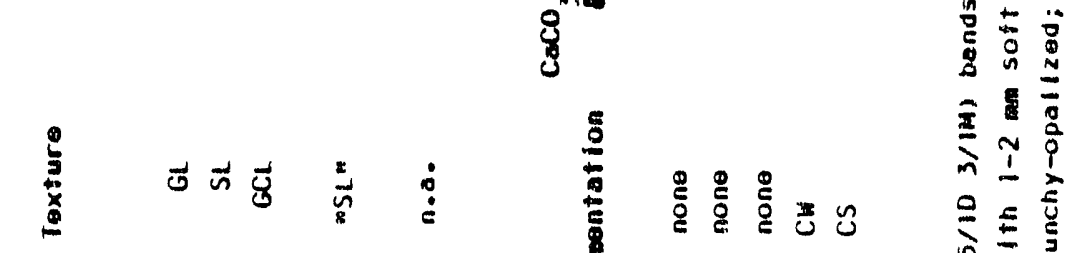

\&ु

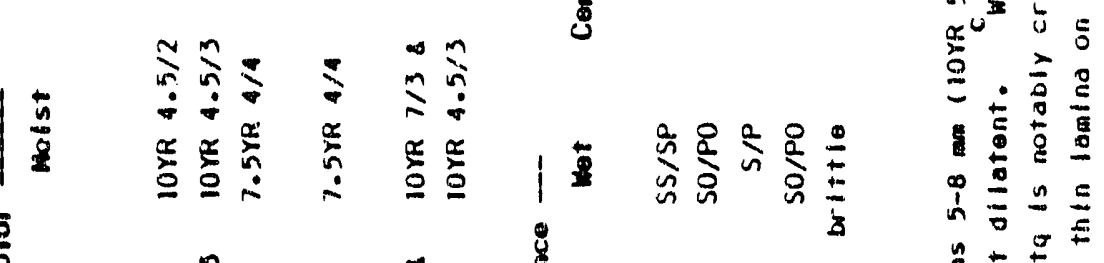

交

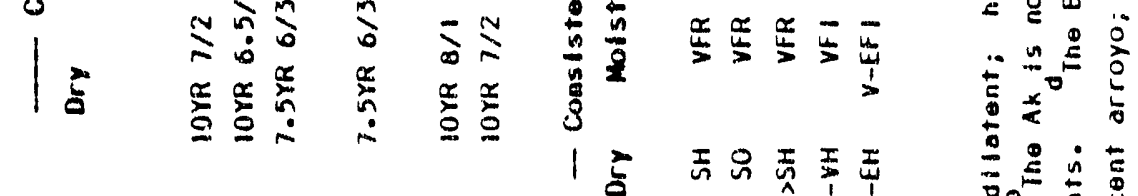

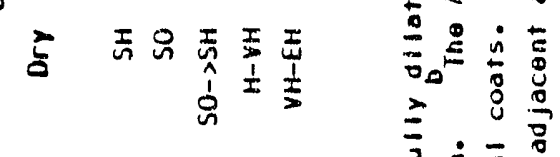

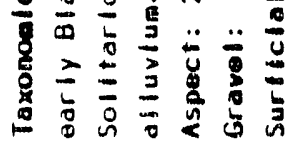

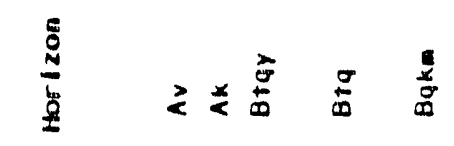

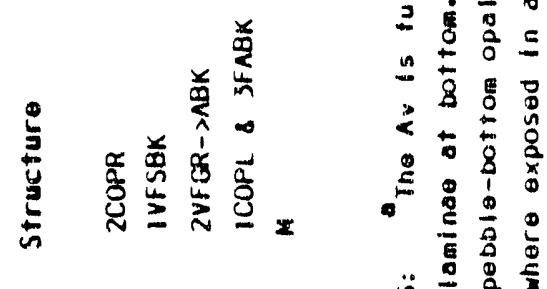

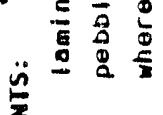




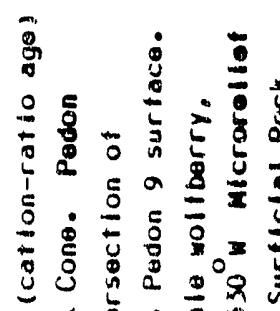

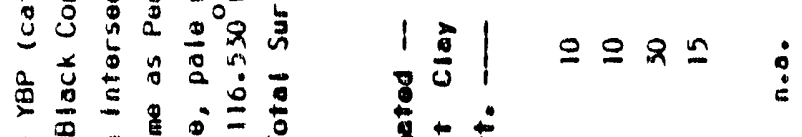

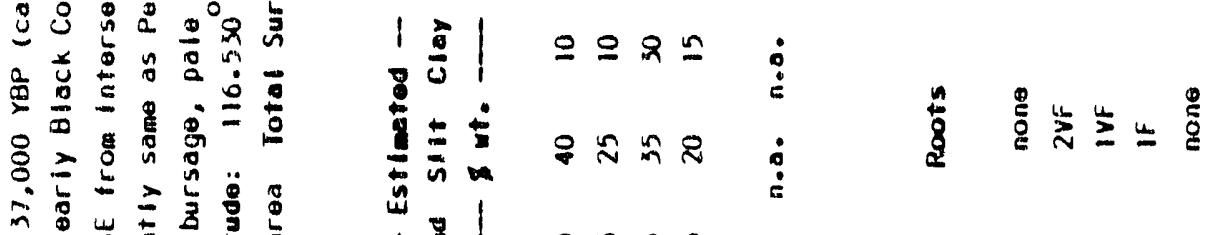

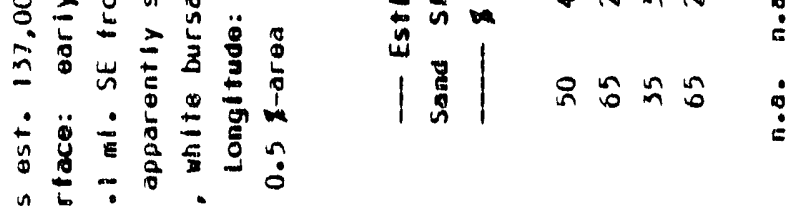

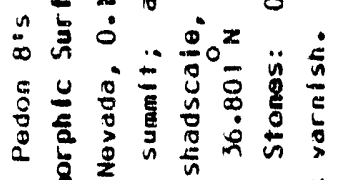

|

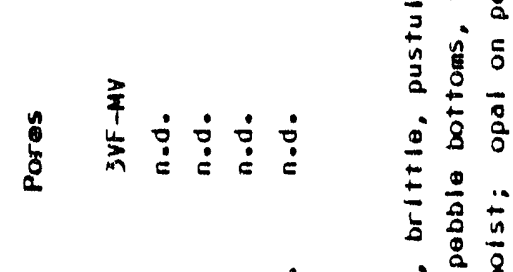

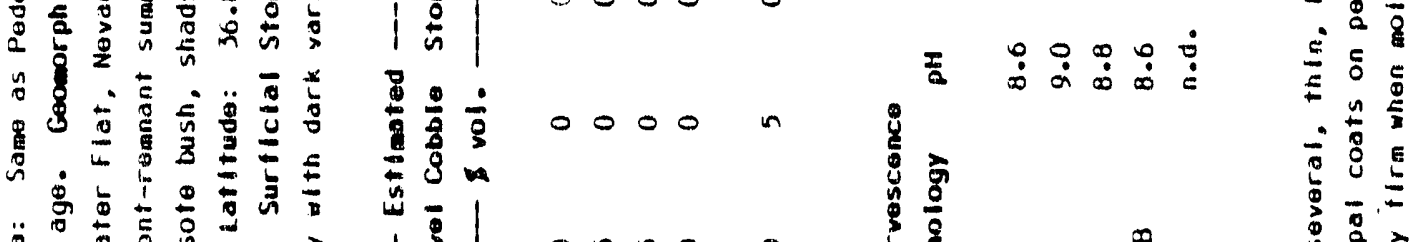

औด

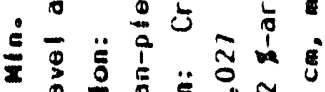

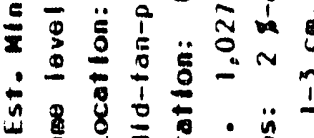

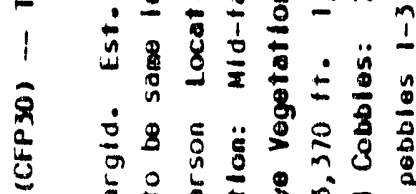

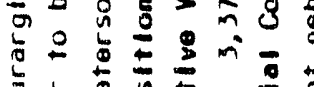

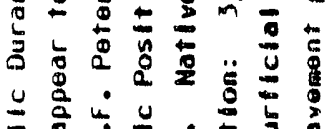

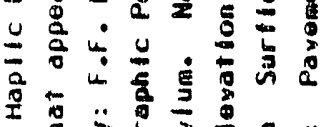

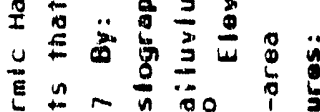

ข้อง

1)

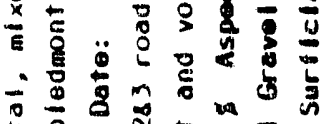

|

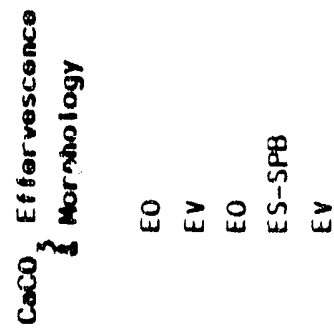

कुषुठ

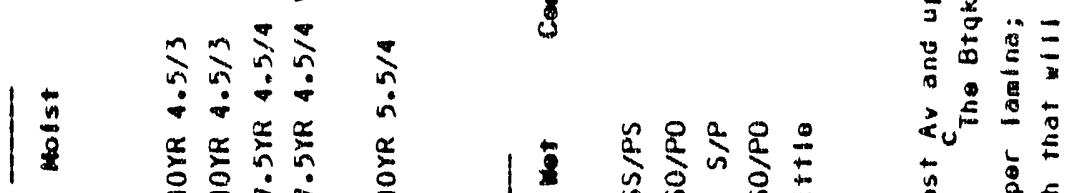

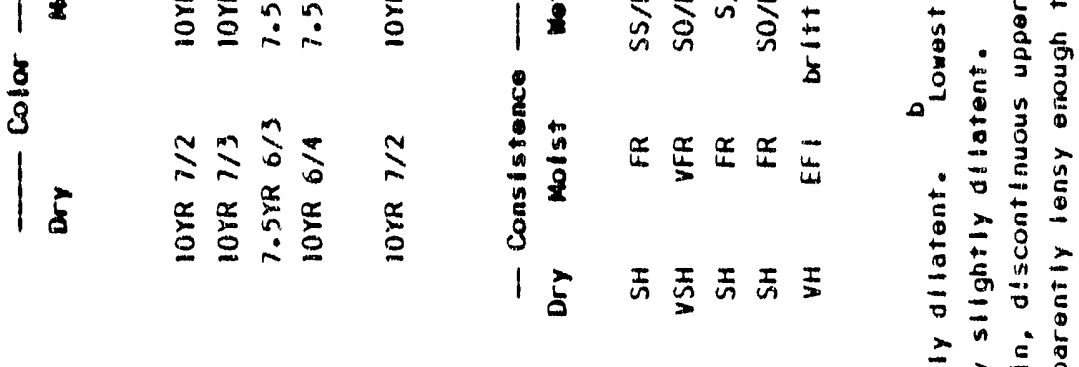

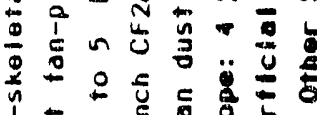

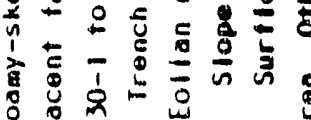

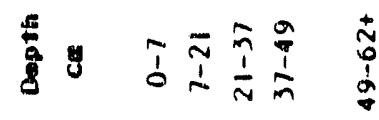

ำ

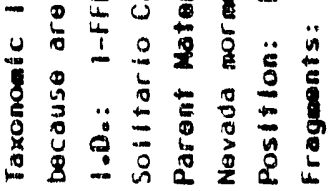

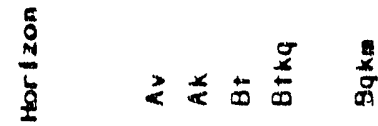

-

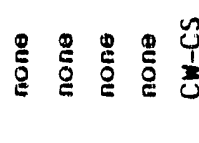

$\div \frac{0}{5}$

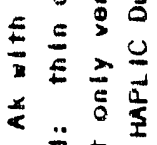

$\div \ddot{\circ}$ 


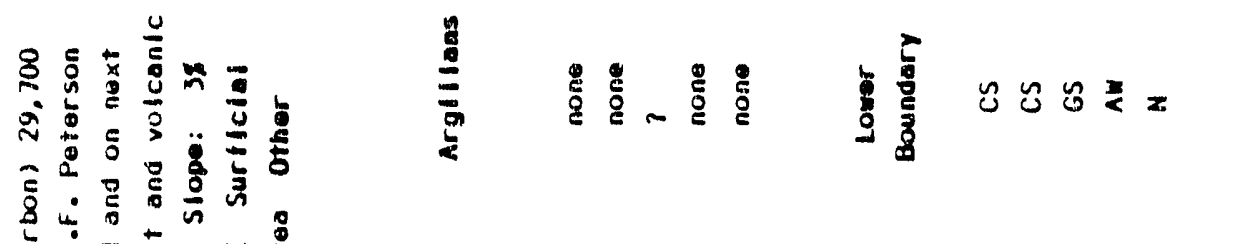

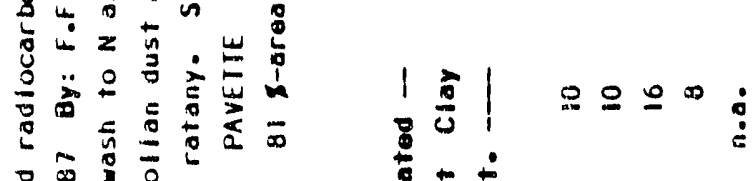

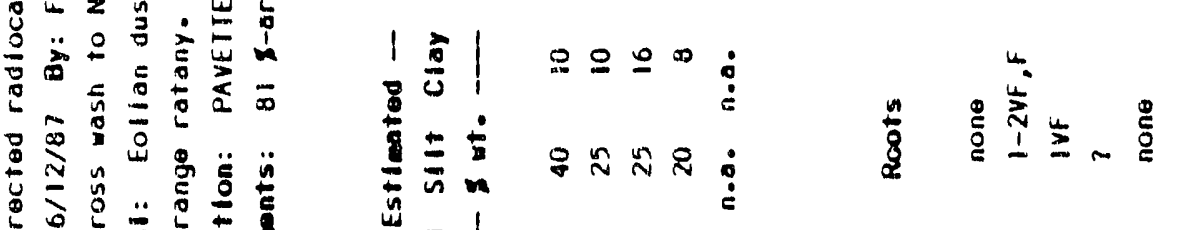

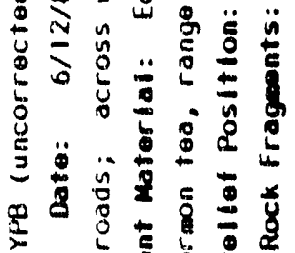

2.

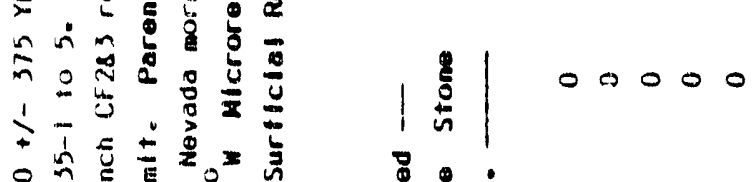

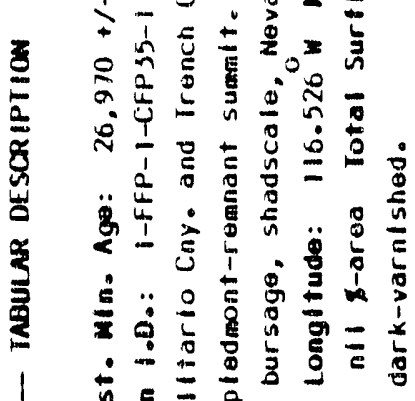

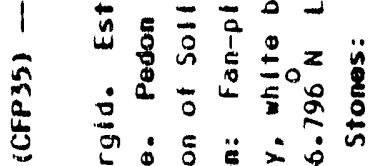

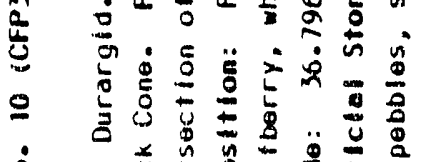

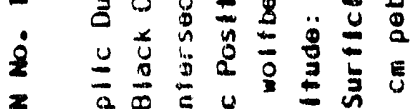

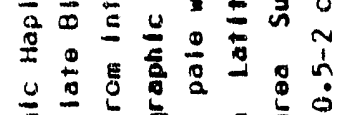

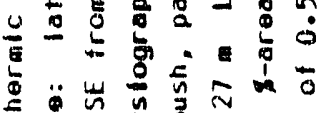

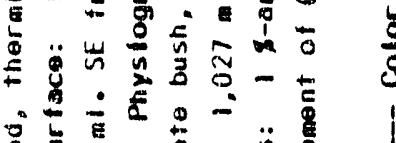

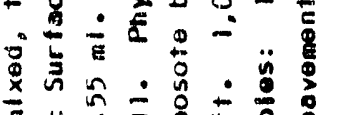

Е

-

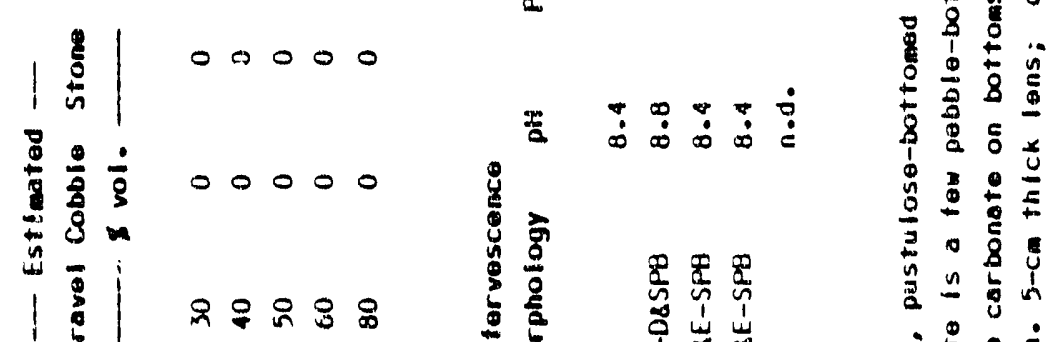

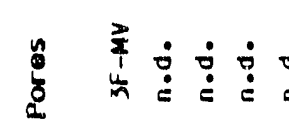

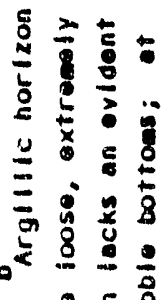

|最| 용요

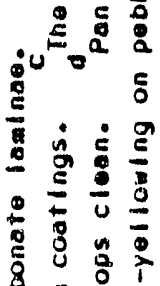

\$

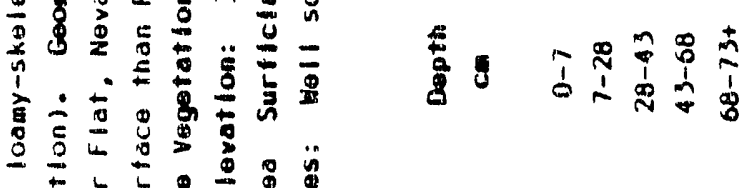

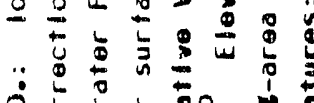

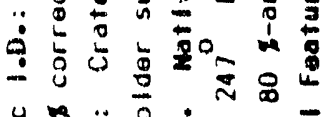

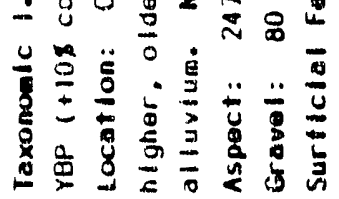

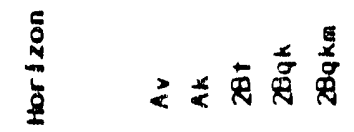

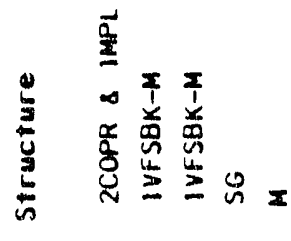

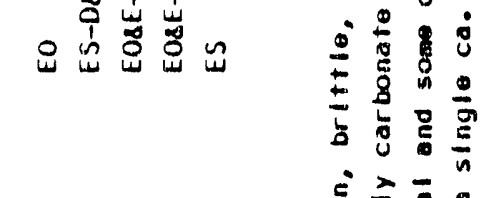

$8^{m}$

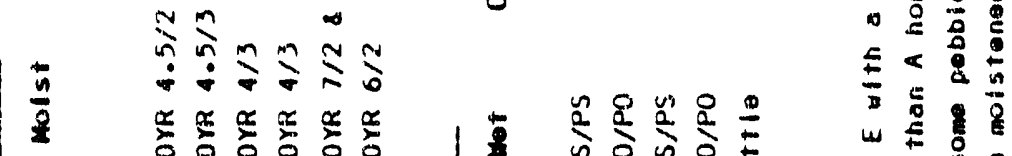

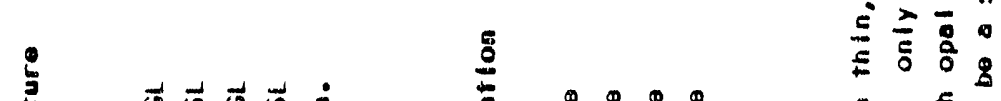

¿̊ํำ

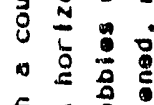

家

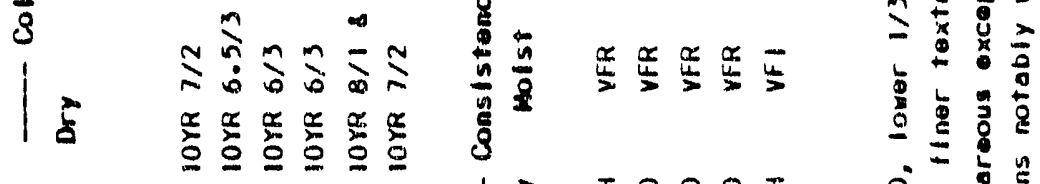

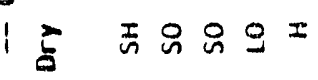

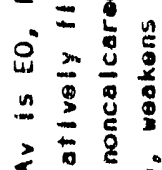

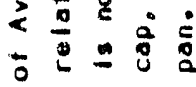

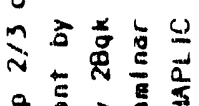

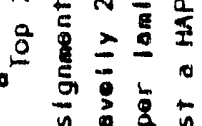

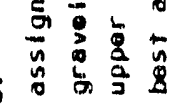

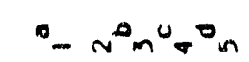

$\dot{8}-N m+n \quad \overbrace{}^{\circ}$ 


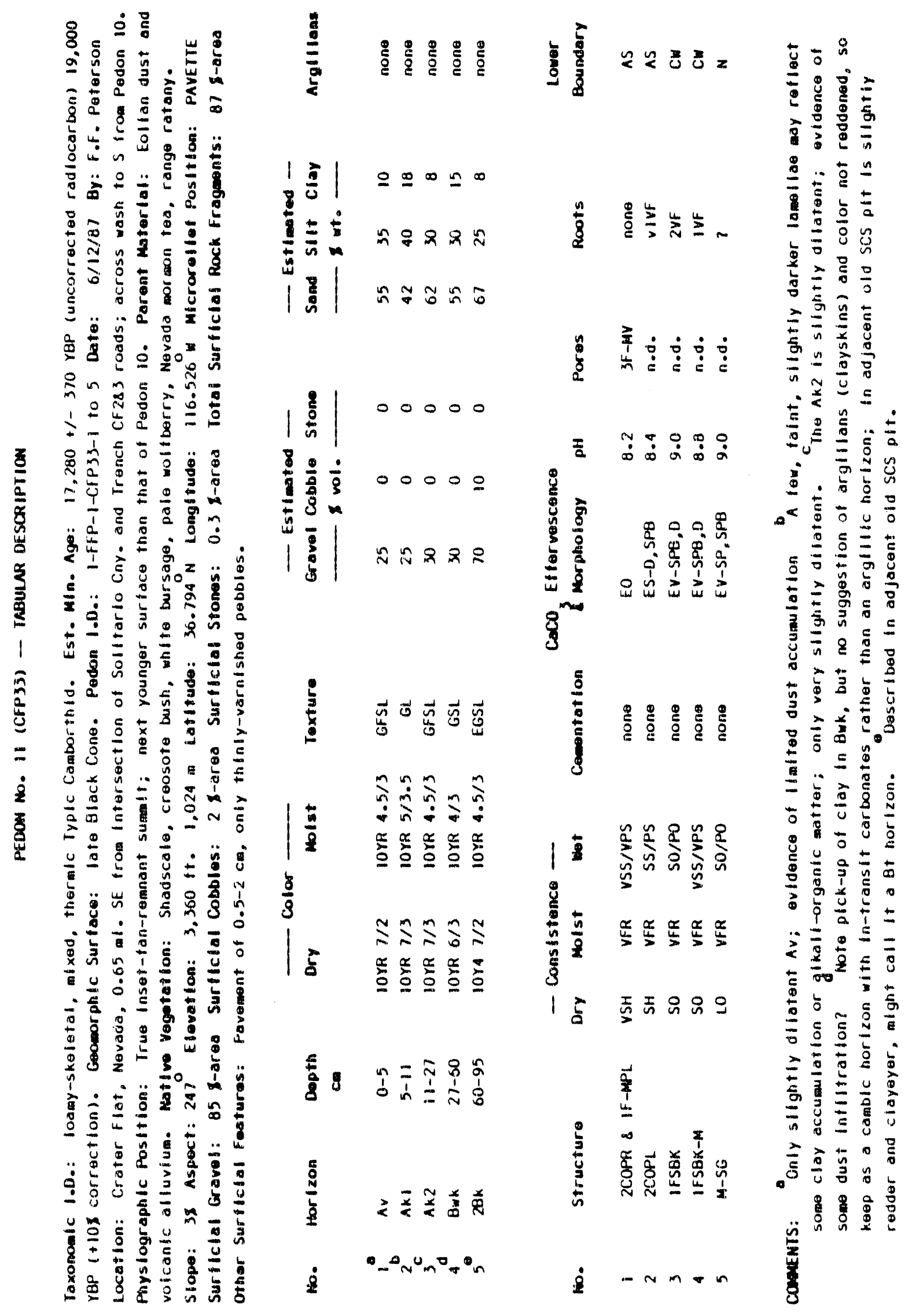




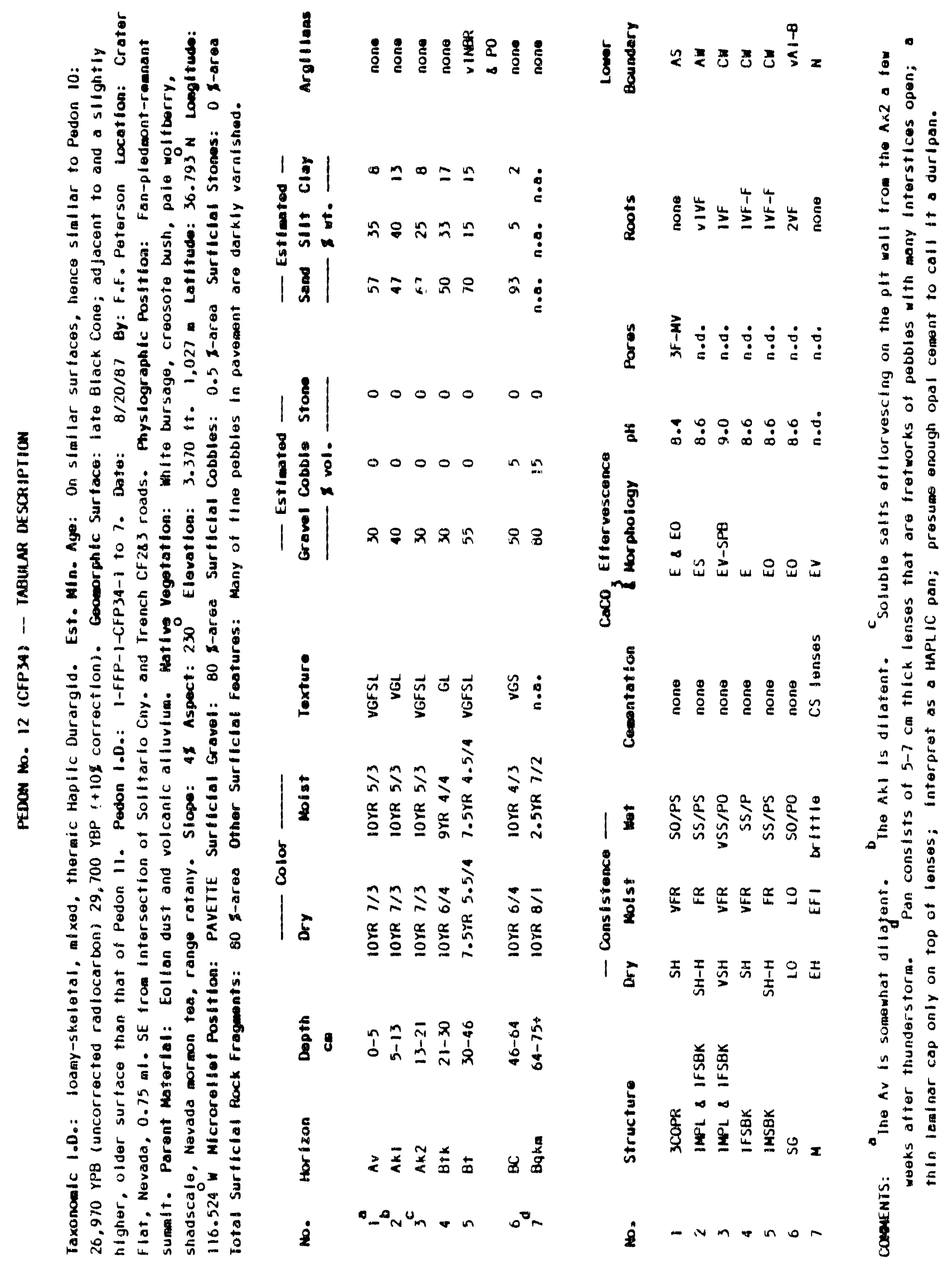




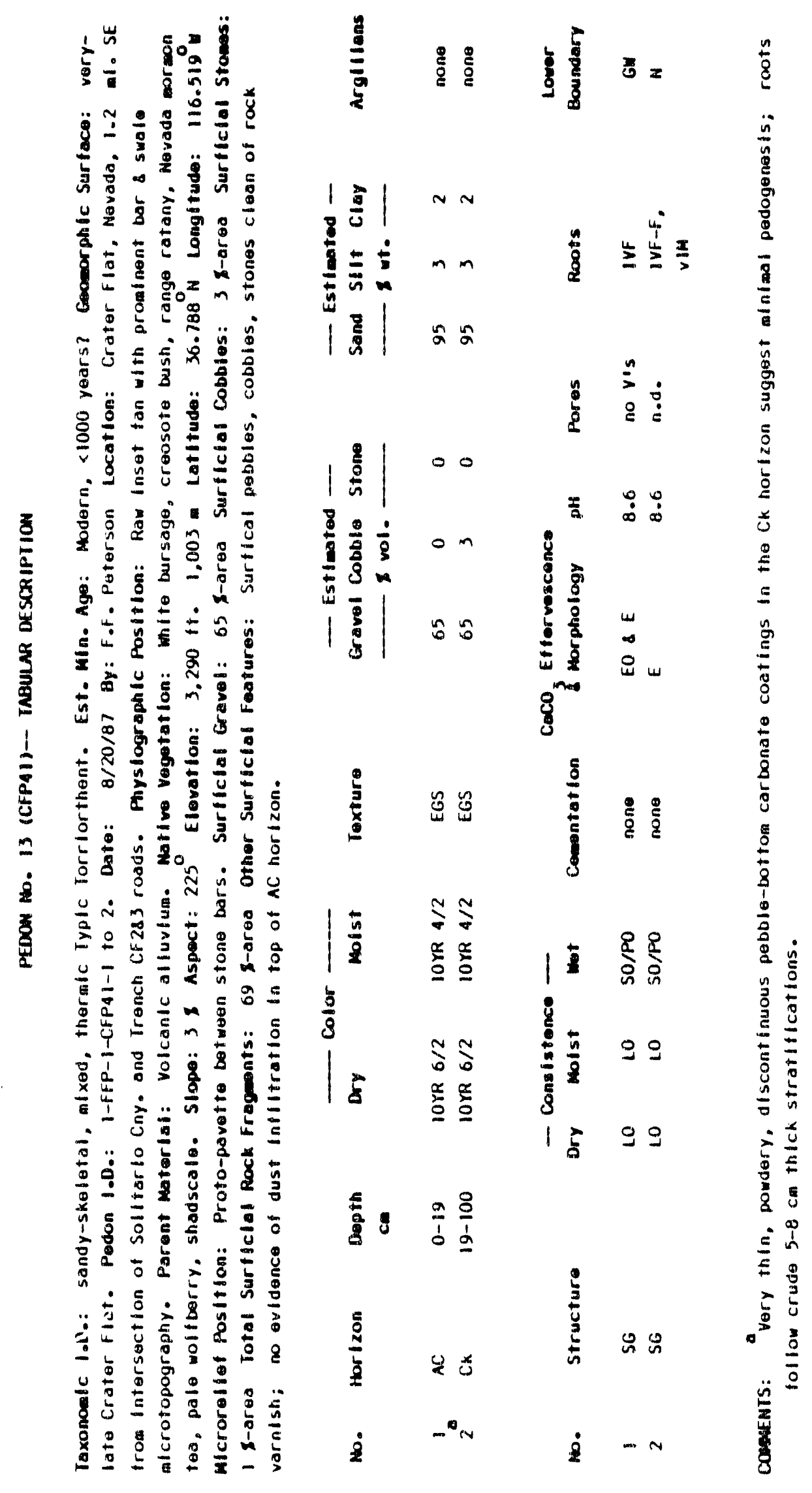


芒荌

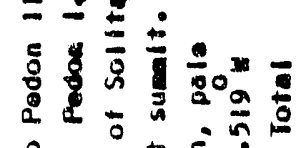

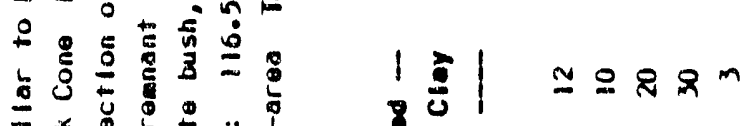

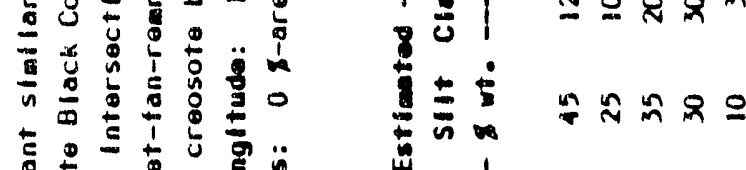

章 11111 ||

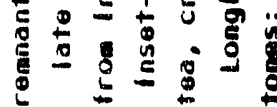

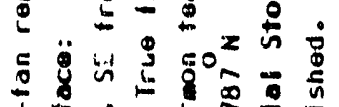

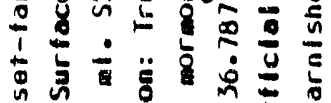

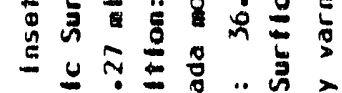

3.

IIII

tin:

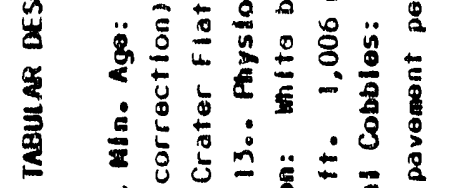

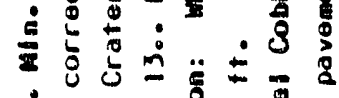

(1)

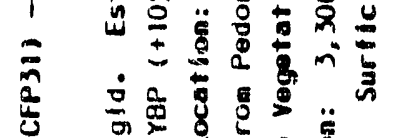

की

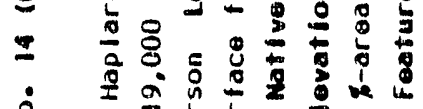

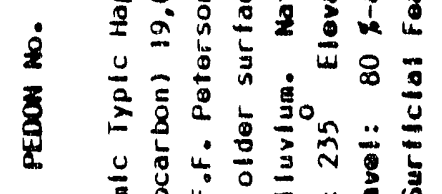

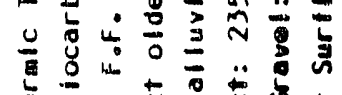

औy

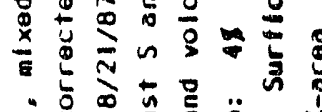

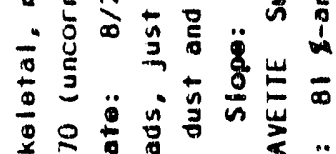

$1 \frac{1}{1} \mid \cdots 0$

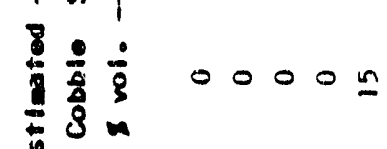

|

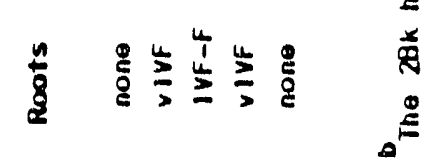

$|3|=2082$

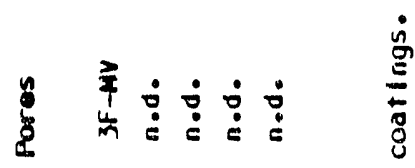

รา

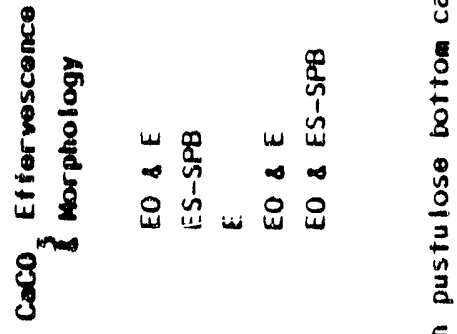

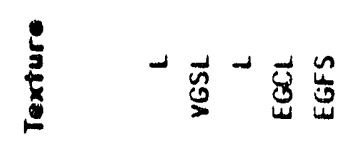

รั)

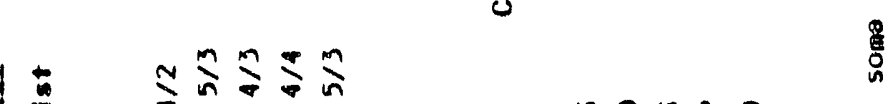

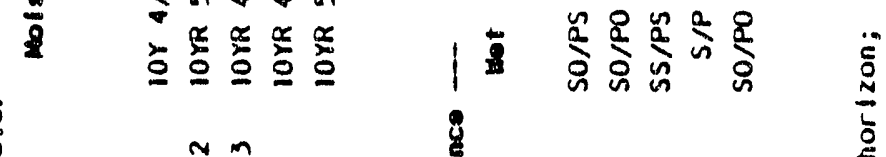

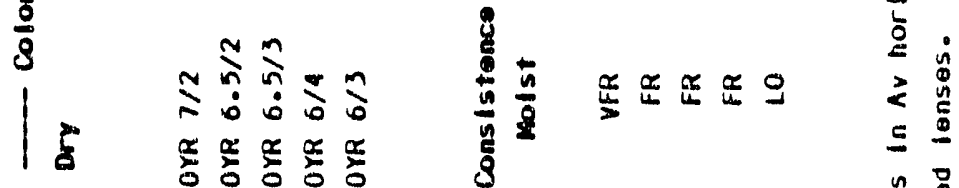

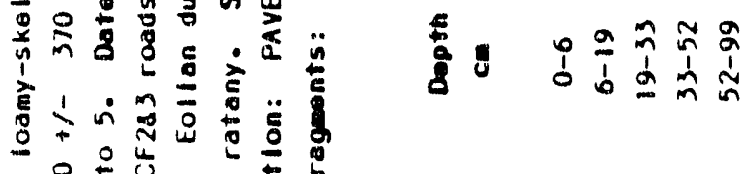

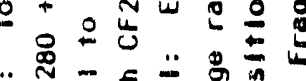

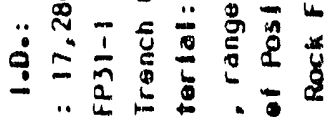

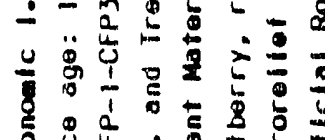

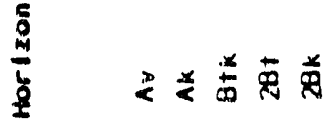

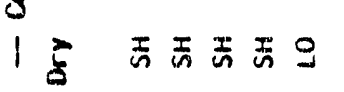

है

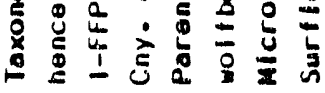

i $\quad-r m+\infty$

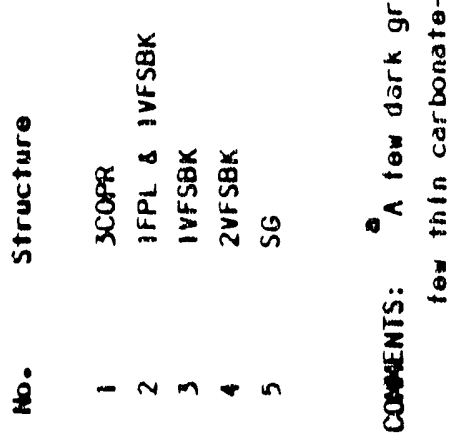




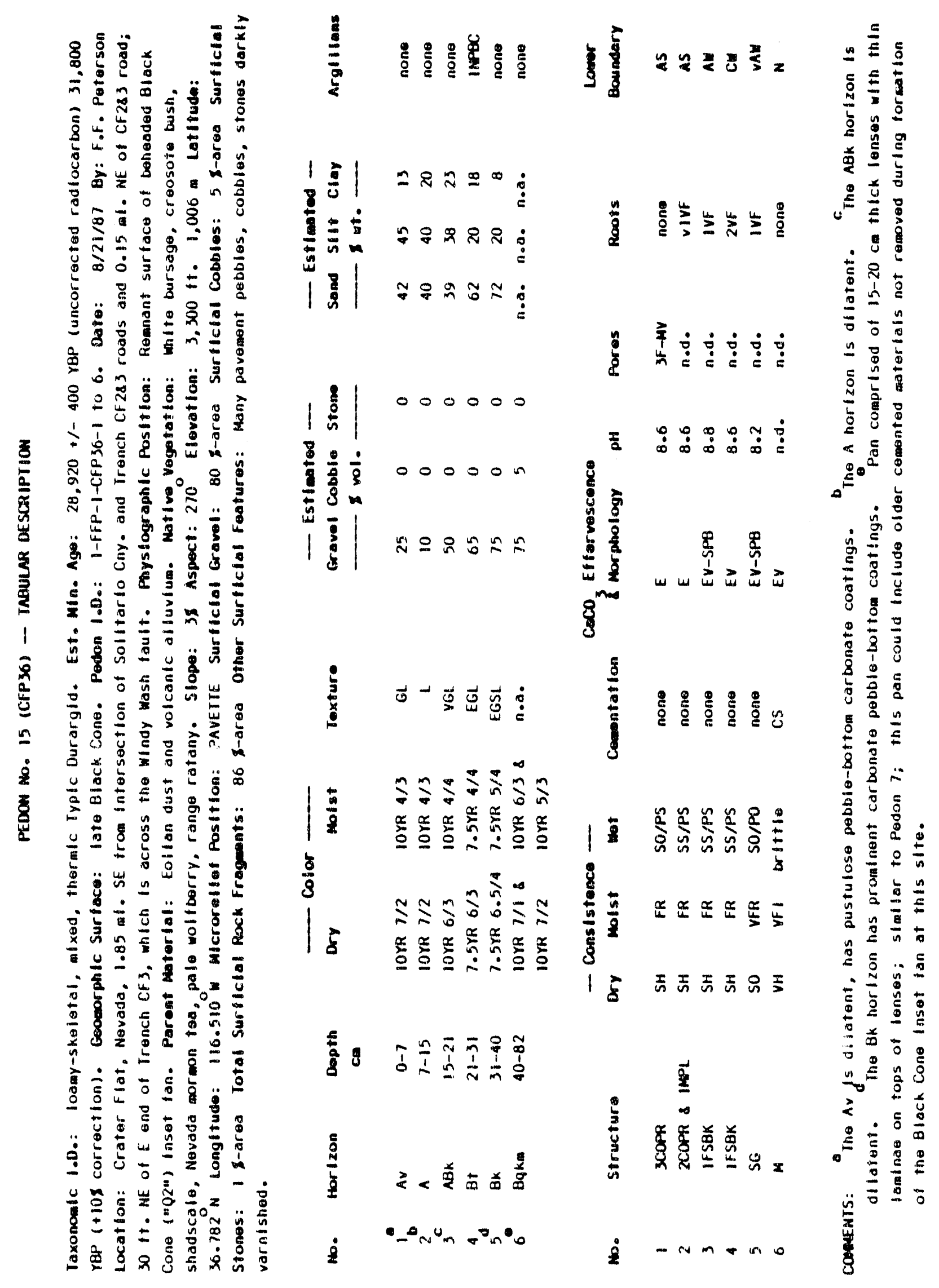




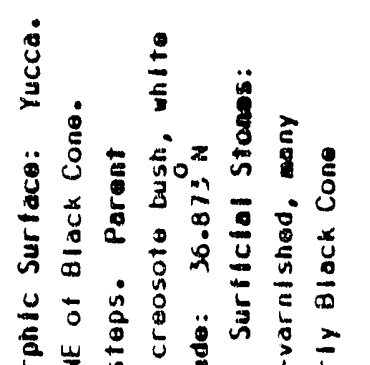

If

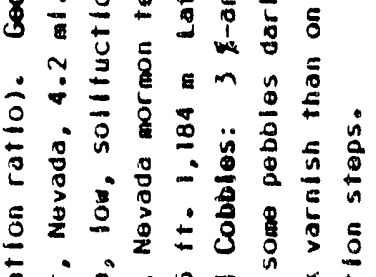

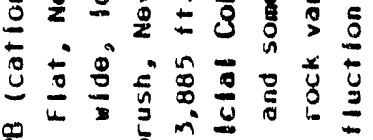

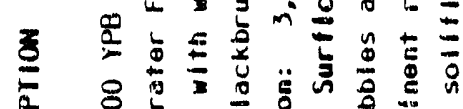

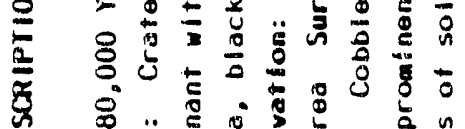

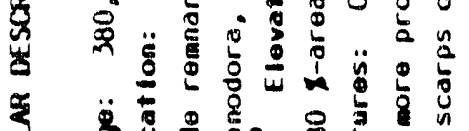

产

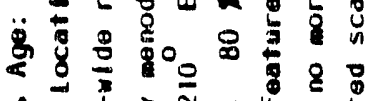

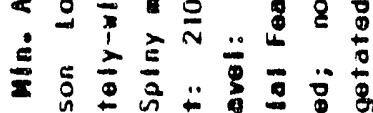

1 ำ

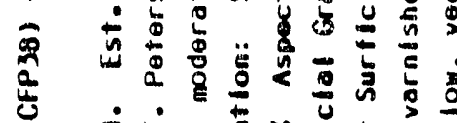

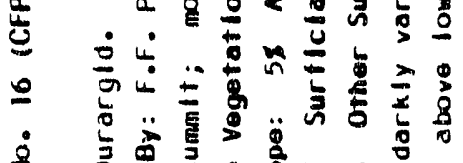

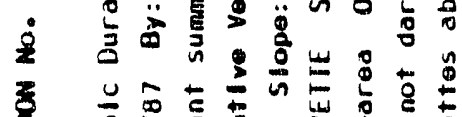

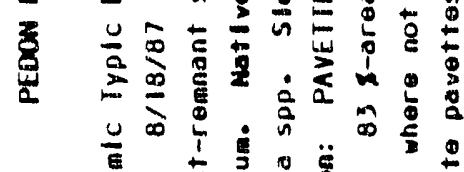

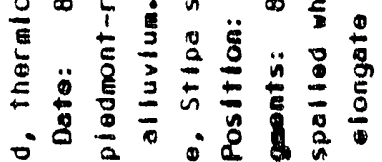

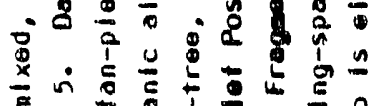

(1)

है

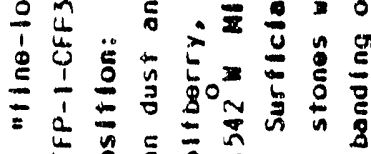

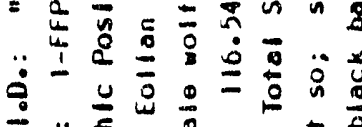

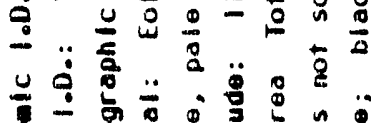

है

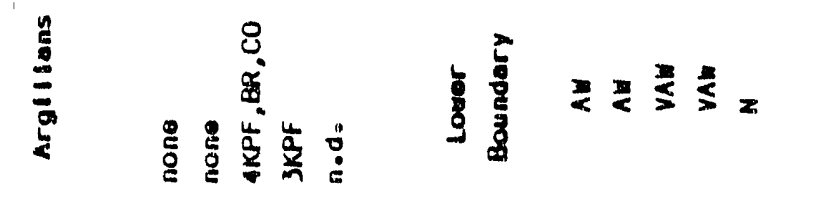

政

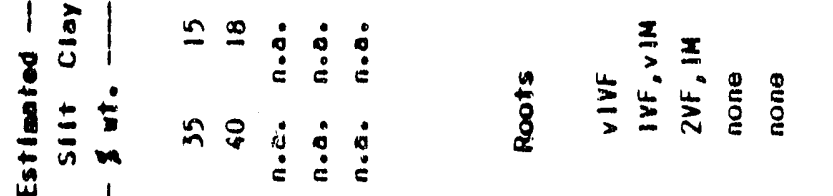

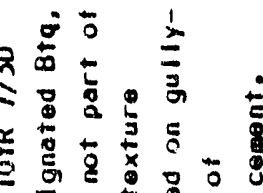

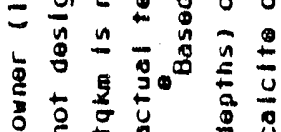

|

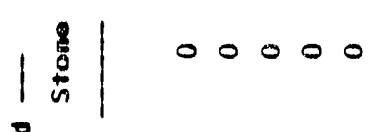

$\frac{1}{8} \frac{1}{8} 00000$

5

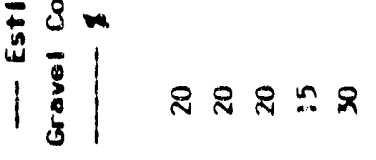

药

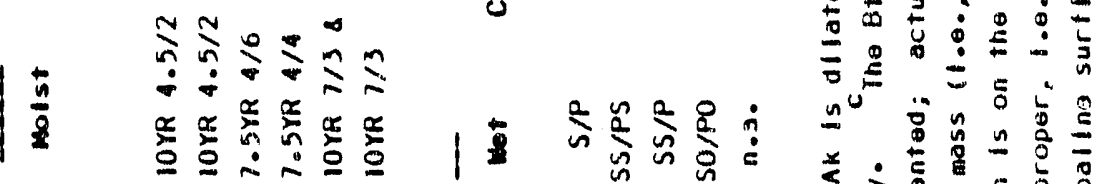

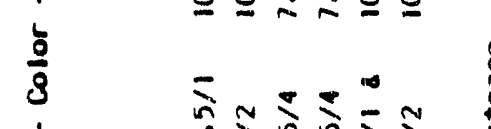

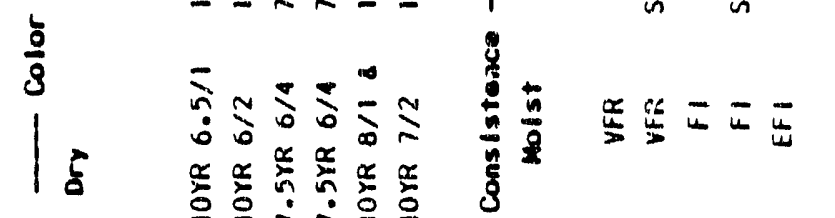

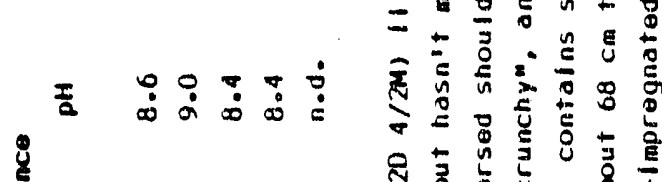

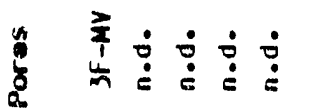

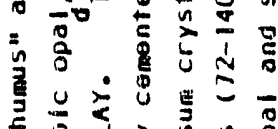

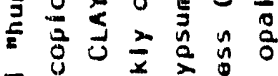

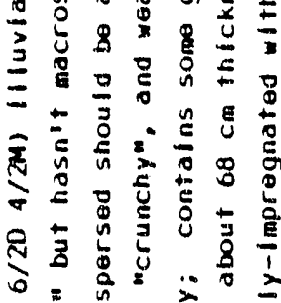

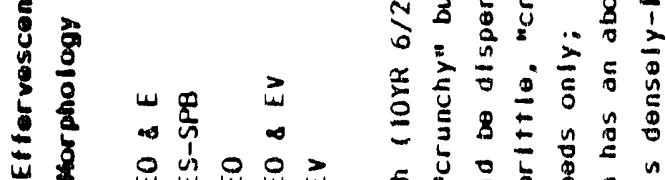

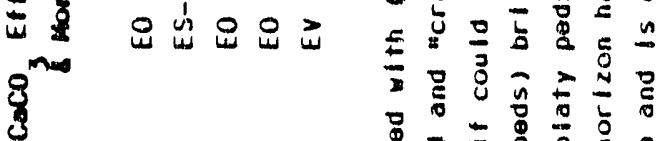

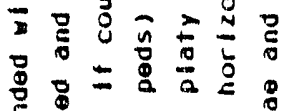

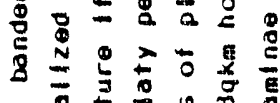

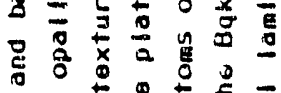

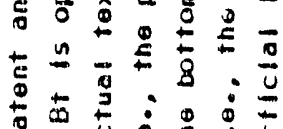

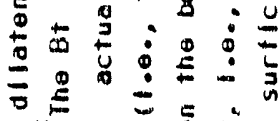

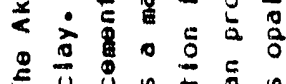

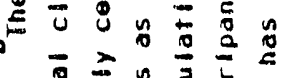

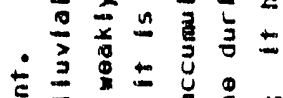

Ë

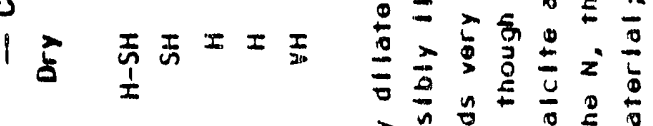

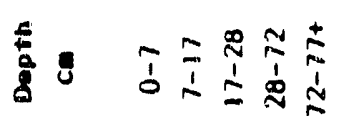

$\frac{5}{\frac{5}{5}}$

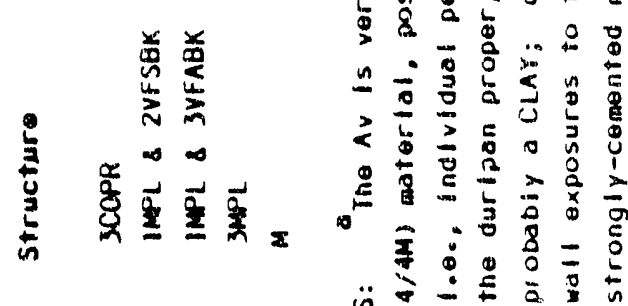

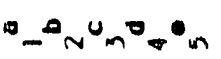

$\dot{z}-N m+n \frac{\ddot{n}}{8}$ 


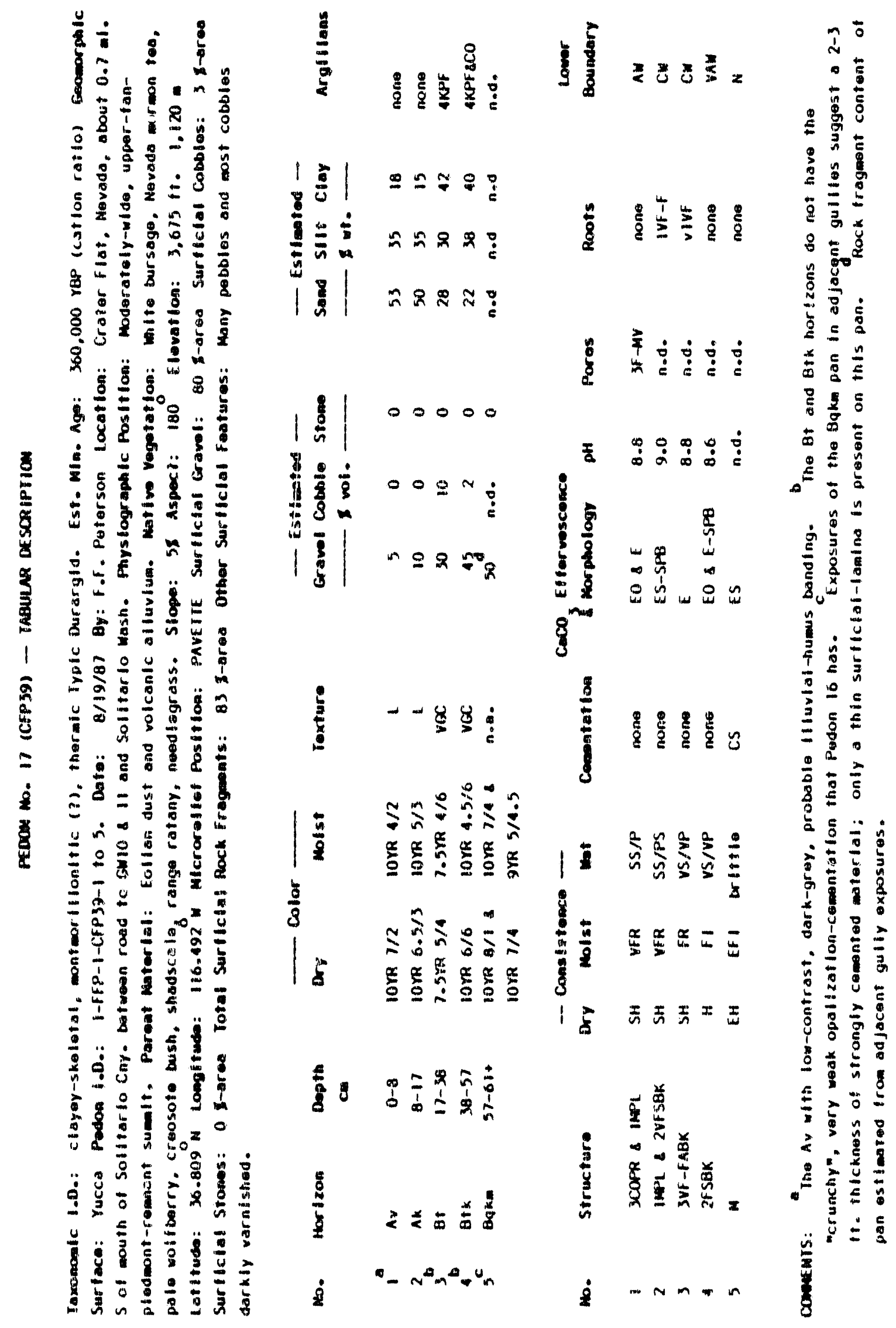




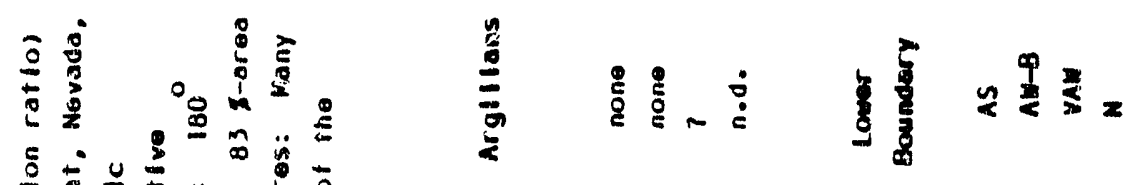

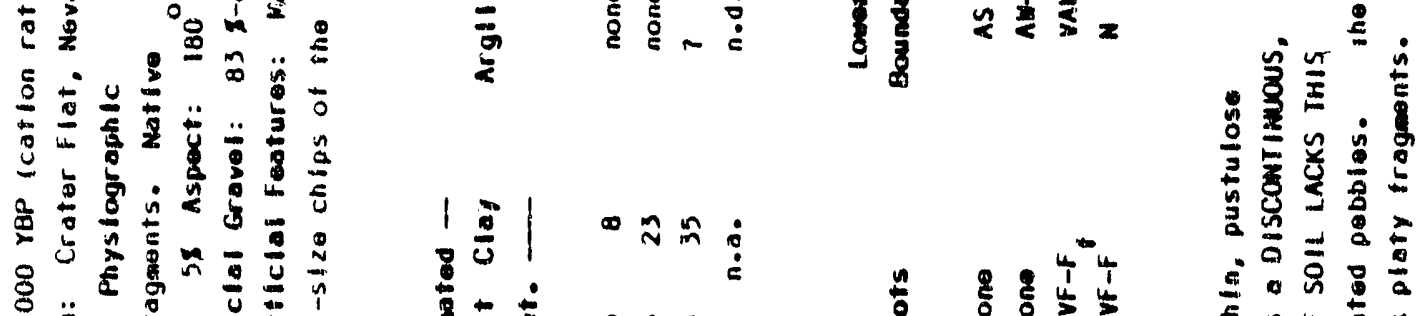

8.

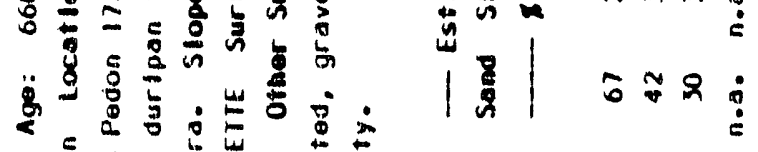

(3)

ing

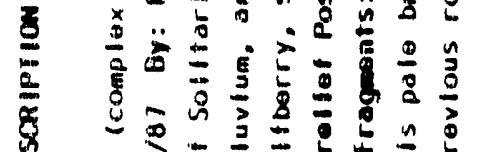

3. ำ

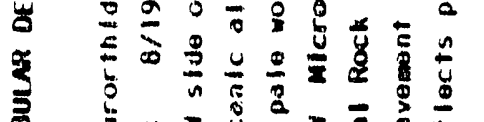

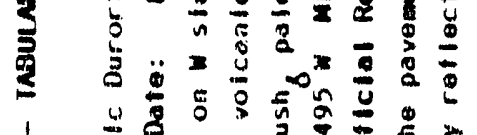

1.

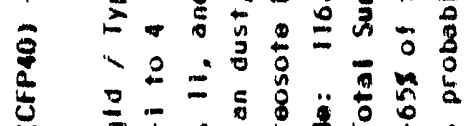

औด

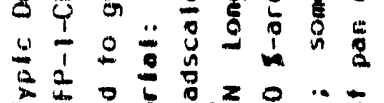

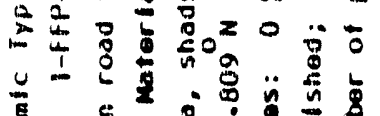

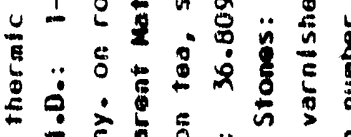

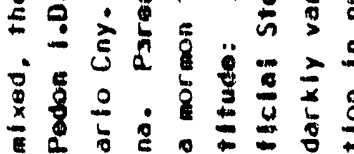

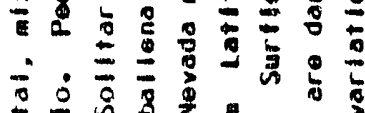

$\left|\frac{1}{2}\right| \cdots 00$

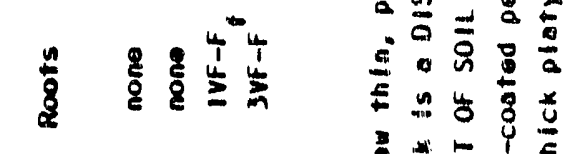

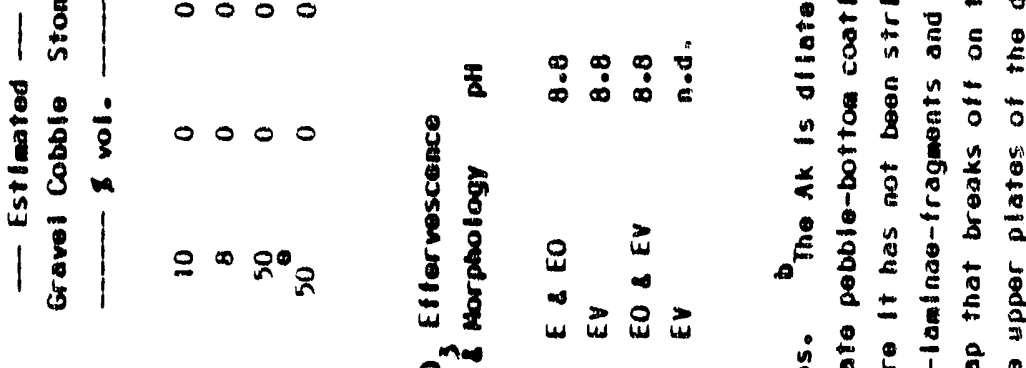

รู

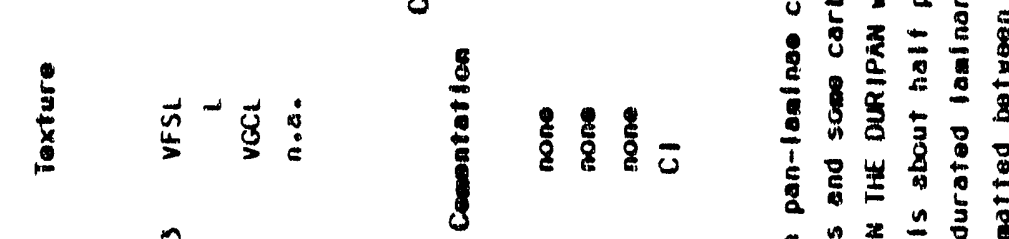

a

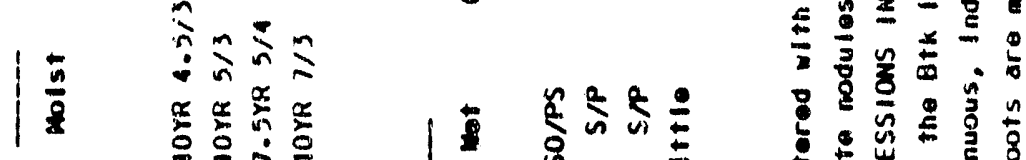

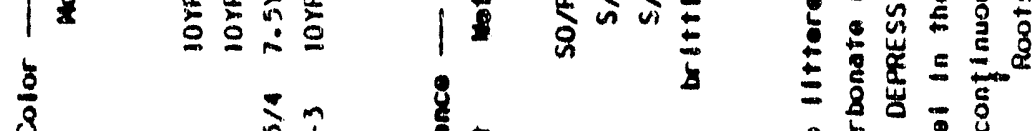

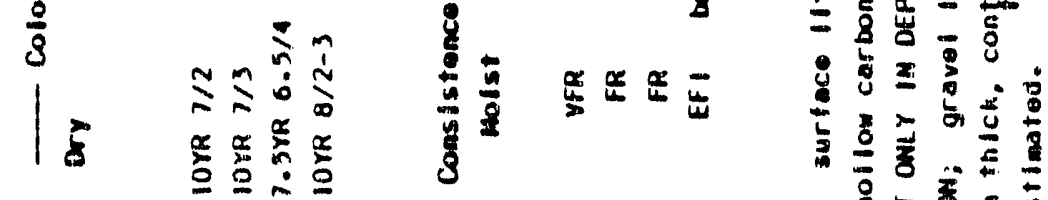

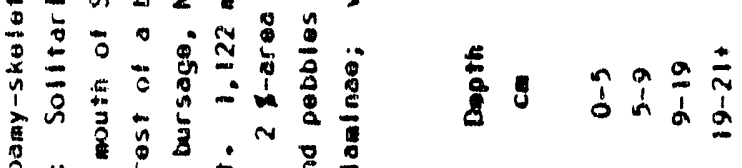

ำ

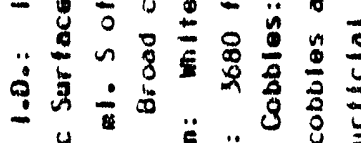

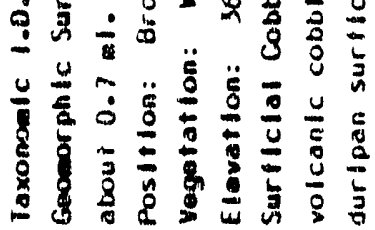

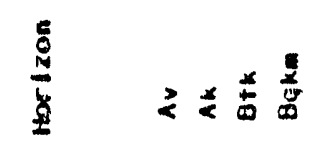

1与齿齿

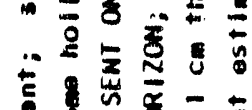

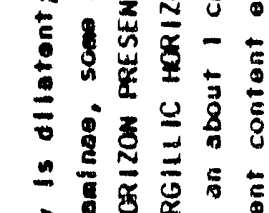

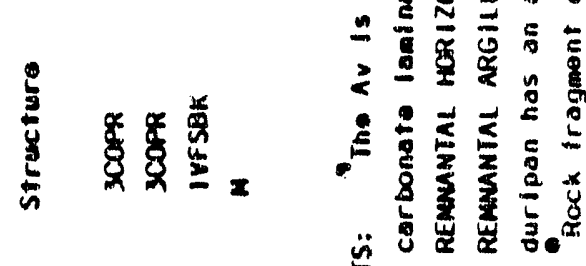

- inume.

ï 


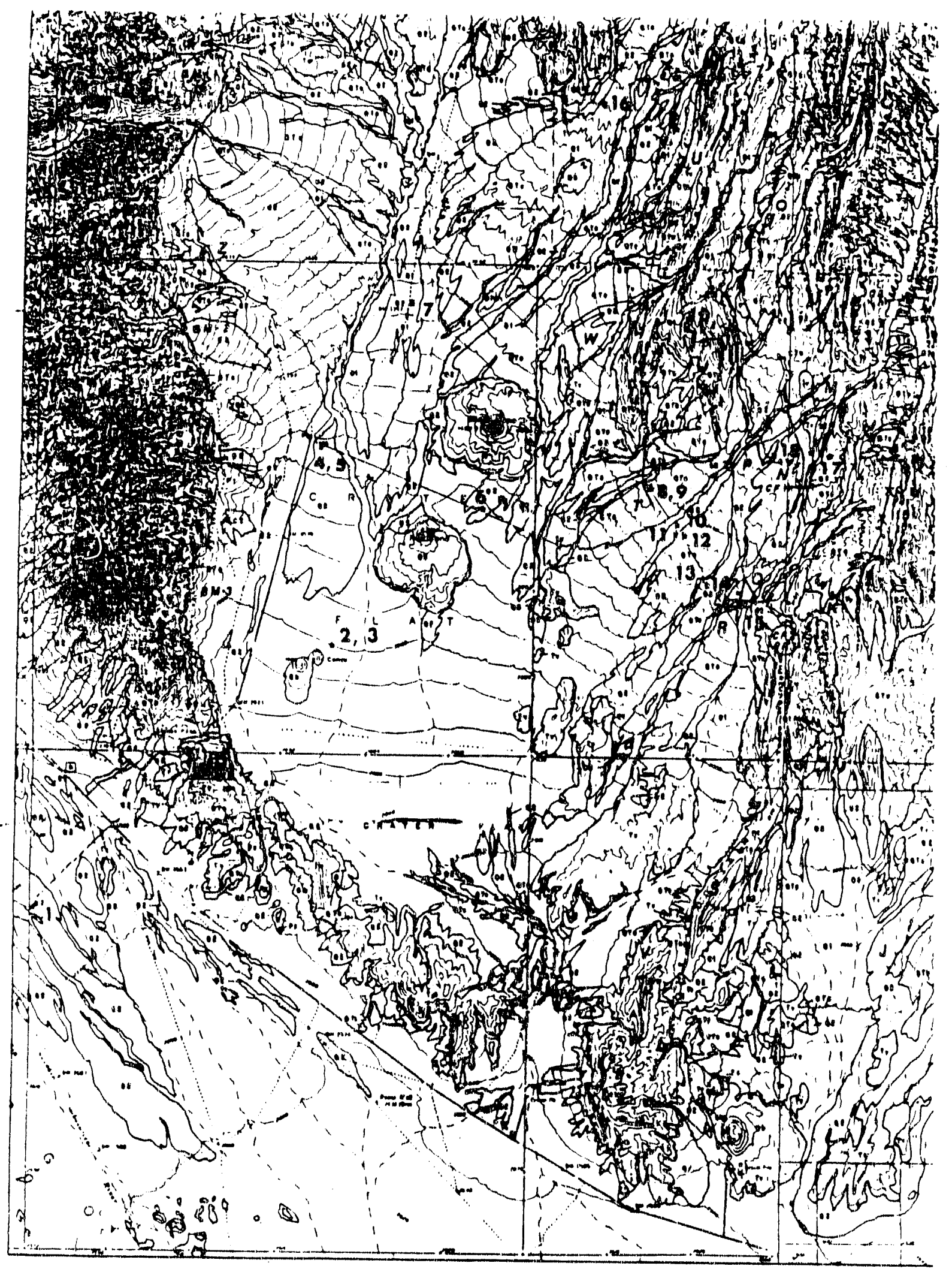

Fig. 1 Pedon locations

SCA1)

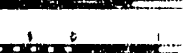




\section{Appendix $C$}

Consultant's report: Assessment of the applicability of the thermoluminescence (TL) dating technique to natural hazard evaluations at the high-level nuclear waste repository site, Yucca Mountain, Nevada

by $S$. L. Forman 


\title{
ASSESSMENT OF THE APPLICABILITY OF THE THERMOLUMINESCENCE (TL) DATING TECHNIQUE TO NATURAL HAZARD EVALUATIONS AT THE HIGH- LEVEL NUCLEAR haste REPOSITORy Site, yUCCA MOUNTAIN, NeVAdA
}

by

\author{
Steven L. Forman \\ Center for Geochronological Research \\ INSTAAR, University of Colorado \\ Boulder, Colorado 80309-0450
}

For

The Nevada Bureau of Mines and Geology

State of Nevada

May 24, 1988 
INTRODUCTION

The seismic and volcanic hazards of rucca Mountain and adjacent areas must be assessed and mitigated for the safe containment of nuclear wastes. A crucial component of natural hazards evaluation is the dating of tectonic and volcanic eruptive events. Previous natural hazard studies in the Basin and Range have mostly relied on radiocarbon dating of rare organic matter or relative weathering indices to constrain the timing of faulting or volcanic eruptive events. Because of the paucity of organic material and the inprecision of weathering indices, many past events remain poorly dated. Indeed, a recent report by the National Academy of sciences entitled "Active Tectonics" (1986; 17) recognizes the problems of dating paleoearthquakes and stresses the need to develop and apply new techniques.

\section{During the past decade there has been significant} advancement in Quaternary geochronology with the refinement of techniques and the establishment of new methods, like thermoluminescence dating. Only in the last few years has the the TL technique been applied to date falting in the western U.S.A. (Whitney et al, 1986; McCalpin, 1986; Forman et al, 1986; Forman et al; 1987; Forman et al, in press; Forman et al, submitted). These studies clearly show the potential of TL to date paleoseismic events. However, the application of the TL 
technique is not routine and requires careful field sampling and extensive laboratory work.

Information used in this evaluation is from unpublished data (courtesy of John whitney, U.S.G.S.), one published abstract and from a one day visit of Trenches CF-2 and CF-3, adjacent to Yucca Mountain. The thermoluminescence analyses reviewed in this report were produced by the commercial laboratory Alpha Analytic inc. in 1984 and 1985 . Since the mid 1980 's there has been significant development in TL techniques and technology. Thus, some of the methodology used by Alpha Analytic inc. has been recently amended. This review benefited from the cooperation of John whitney and Ralph shroba; they should be applauded for their pioneering application of the TL technique.

The aim of this evaluation is: 1) to critically review past applications of the IL technique to date paleoearthquakes near Yucca Mountain, Nevada; and 2) to recommend future directions in TL dating research with particular reference to assessing natural hazards. The fundamentals of thermoluminescence (IL) dating are presented prior to the evaluation.

\section{PRINCIPLES OF THERMOLUMINESCENCE DATING}

The basic principles of the technique for dating Quaternary sediments are similar to those used in daring 
archaeological materials. However, for pottery the exposure to heat during firing removes any th signal that has accumulated in the minerals, whereas in sediments the inherited ru signal in quartz and feldspar grains must be reduced (bleached) by exposure to sunlight prior to deposition (Figure 1 ). The TL signal of feldspar is reduced by visible and ultraviolet wavelengths; the TL of quartz is most sensitive to ultraviolet light (Kronborg, 1983 ).

During the past decade, the thermoluminescence technique has provided chronologic control in a variety of geologic settings (see reviews by Singhvi and Mejdahl, 1985; Mejdahl, 1985; Forman, in press). The TL technique directly dates mineral grains, reflecting the time since the sediment was last exposed to sunlight (cf. Wintle and Huntley, 1980). Full sunlight exposure for at least 8 hrs eliminates (bleaches) the inherited TL signal, thus resetting the TL clock to time "zero". If the sediment is buried and shielded from further light exposure, nuclear radiation (mostly from the decay of uranium and thorium and their daughters, and potassium) progressively imparts a TL signal. This radiation ionizes electrons of mineral grains, which are subsequently trapped at lattice-charge disequilibrium sites, called electron traps. Heating during laboratory analysis or natural light exposure of the sediment causes vibration of the mineral lattice and eviction of electrons from traps. A number of these electrons are conducted to recombination sites from which light is 


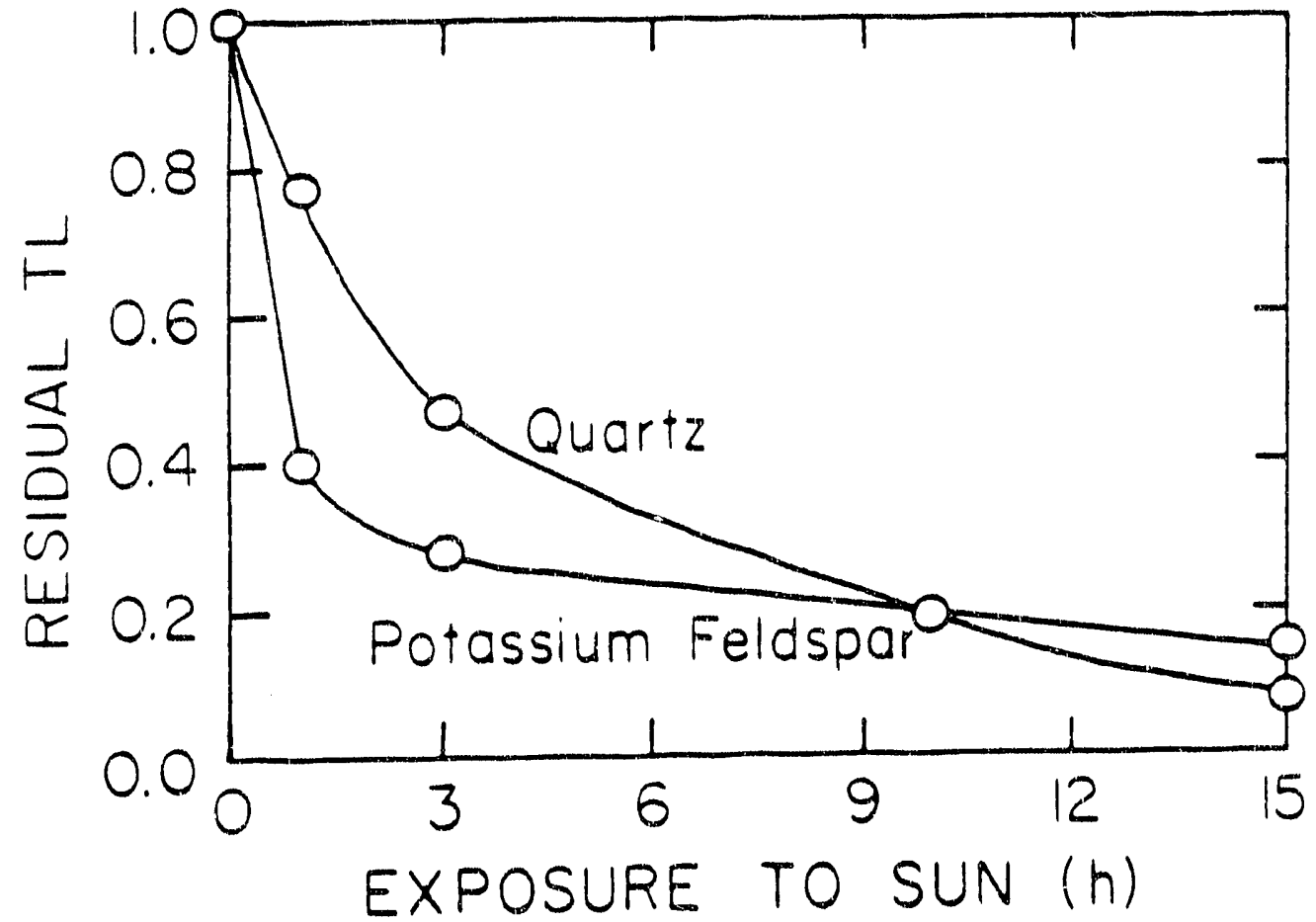

Figure 1: The reduction in natural TL for quartz and potassium feldspar from the exposure to sunlight. The natural dose was about 100 Gy (from Mejdahl, 1986) 
emitted. It is the intensity of this light signal that is a measure of the time since burial of the mineral grain.

This light signal is actually three dimensional, defined by temperature, and the light intensity and wavelength of light emission (Eigure 2a). In most $T$ ) dating procedures the ultraviolet or blue regions are selected for analysis (Figure 2b).

Quartz and feldspar grains within sediment act as long-term radiation dosimeters, with the $T L$ signal being a measure of radiation exposure during burial. In the laboratory, this radiation induced TL signal is calibrated to a known cadiation level, which is called the equivalent dose (ED; measured in grays $(100$ rads = 1 gray (Gy)). Determining an ED is but one half of the TL age-equation (Equation 1). The other half of this equation is the dose rate, which is an estimate of the enviconmental radioactivity of the sediment for the time of burial. For a thorough treatment of thermoluminescence dating the reader is referred to Aitken (1985).

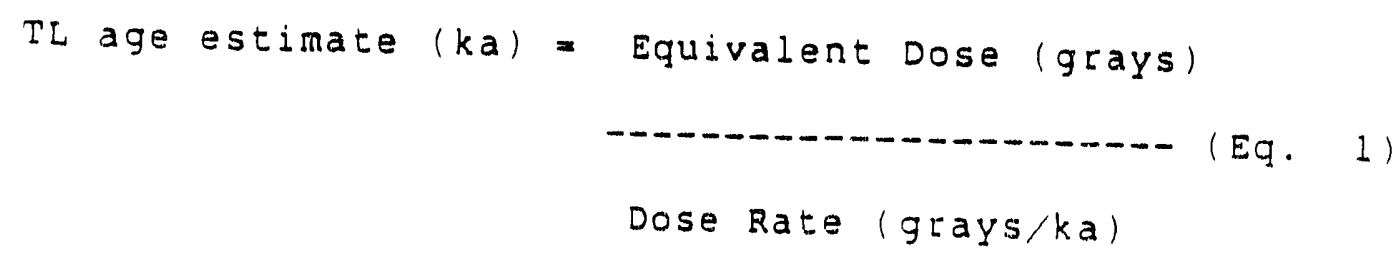

Sediment that receives at least 8 hrs of unfiltered sunlight exposure prior to deposition are preferred for TL analysis. Previous studies indicate that deposits commonly 

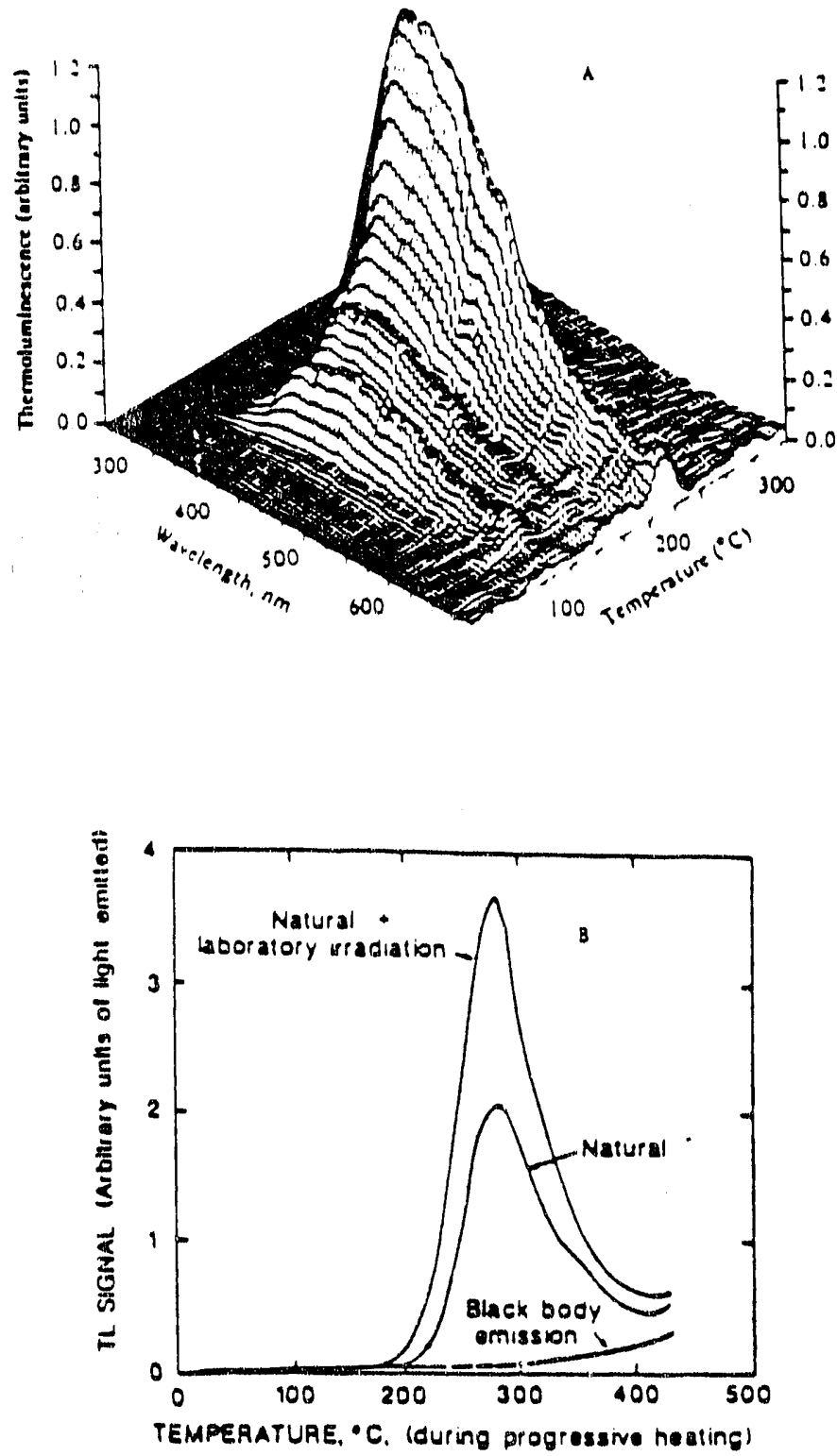

Figure 2: (A) Isometric plot of the thermoluminescence emission spectrum for irradiated lithium fluoride (From Mckeever, 1985; P.46). The TL signal of mineral grains is three dimensional, with the intensity of light emission dependent on temperature and wavelength. (B) TL emission in the ultraviolet $(300-400 \mathrm{~nm})$ range for polymineral fine-grains as a function of heating temperature. This sample was preheated at $150^{\circ} \mathrm{C}$ for 16 hours prior to analysis. 
found in the Basin and Range such as loess, buried A horizons, sag pond-muds (playa lake) and fine grained colluvium are fully light bleached prior deposition and yield accurate TL ages (Forman et al, in press). Presently TL can provide accurate dates on sediment in many stratigraphic situations for at least the last 75-100 ka. The precision of TL age estimates is usually 10-15\%, though in a few situations errors may be $<10 \%$. The maximum resolution of the method for Holocene deposits is approximately 500 yrs (cf. Forman et al, submitted).

\section{PREYIOUS APPLICATION OF THE TL TECHNIQUE AT YUCCA MOUNTAIN}

There has been only limited application of the TL technique to Quaternary geologic studies at Yucca Mountain. Approximately 16 TL dates were produced on surface eolian material (Av horizon) from Trenches $C F-2$ and $C F-3$ excavated across the windy wash fault. These TL dates, which are the focus of this evaluation, provide maximum estimates on the latest faulting at $3-6.5 \mathrm{ka}$ ago (Whitney et al, 1986). This faulting vertically displaced the surface Av horizon $<10 \mathrm{~cm}$ and has an unknown strike slip component (Whitney et al, 1986).

This evaluation addresses the suitability of these eolian sediments for TL dating and the appropriateness of laboratory procedures. The TL technique measures the time elapsed since the last exposure to sunlight. Thus the mode of deposition and post depositional changes of the sediment affects the TL age 
determination.

\section{Genesis of AV Horizon}

Eolian enriched surface horizons, like an Av horizon, are a common constituent of desert soils in the arid southwestern U.S.A. (Birkeland, 1985). Particles (mostly silt) in Av horizons are derived from playas or alluvial fans or other surficial deposits by wind erosion and like most eolian material are well exposed to light prior to deposition (wintle, 1982). This eolian material is inherently suitable for TL dating.

Av horizons are believed to accumulate below the desert pavement as a result of infiltration of eolian material (cf. McFadden et al, 1986). The formation of an Av horizon is accelerated after the infilling of voids in the $B$ and $C$ horizons. If the Av horizon is cumulative and is not pedoturbated, then this horizon contains an undisturbed record of eolian deposition. Thus, the base of the Av horizon should yield the oldest TL age estimate and provide a maximum limiting age on faulting.

The tectonic significance of the TL age estimates relies on the assumptions that an Av horizon is cumulative and has not been homogenized by pedoturbation. Sample sites appear to have avoided bioturbation and other disturbances. However, it is difficult to unequivocally ascertain whether the sampled Av 
horizons are pedologically homogenized or record a vertical stratigraphy of eolian deposition. The 3 to 6.5 ka age span of the TL ages suggest that there may be an internal stratigraphy in an Av horizon.

\section{Equivalent Dose Determinations}

Equivalent doses by the regeneration (Wintle and Prószynska, 1983), total bleach (singhvi et al, 1982) and partial bleach (wintle and Huntley, 1980) methods are in agreement at one standard deviation. These sediments appear to be well light bleached prior to deposition and are amenable for TL dating. However, there is some uncertainty in determining the residual TL level of the sediment prior to deposition. This uncertainty results in an increase in the average error in ED determinations to 20-50\%. Much of the doubt in the definition of the residual level can be alleviated by comparing results to the partial bleach method or by bleaching samples with natural sunlight for extended periods.

Some samples exhibited significant anomalous fading $(12-25 z)$ which, if not totally compensated for, may lead to underestimates in age. For most samples it appears that ED analyses were corrected for anomalous fading. The recent advent of preheating of samples prior to TL aralysis is a quick and effective method of circumventing anomalous fading (forman et al, 1987). 


\section{Dose Rate Determinations}

The dose rate (DR) is a measure of the enviconmental radioactivity of the sediment over the time of burial. For most sediment, nearly all of the dose is p-ovided by potassium-40, and the thorium and uranium decay series; the remaining few percent comes from rubidium-87 and cosmic rays. When nuclei of potassium-40 decay beta particles and gamma rays $a=\epsilon$ emitted; rubidium-87 emits only beta particles. The cadioactive decay of natural thorium and uranium releases alpha and beta particles and a small amount of gamma energy.

This emitted radiation is responsible for imparting a $T L$ signal in mineral grains. Alpha, beta, and gamma radiation have penetration distances in sediment of approximately $1.0-20$ micrometers, $2 \mathrm{~mm}$, and $30 \mathrm{~cm}$, respectively. Sampled Av horizons are usualiy 15 to $30 \mathrm{~cm}$ thick thus 50 to 75 of the gamma dose originates from outside the Av horizon. However, dose rate was only measured on the Av material, thus the gamma component may not be correctly cepresented. The reported $\mathrm{TL}$ age estimate could be under-or over-estimated or the same, if the gamma dose from the surrounding sediment is less, more or the same as that of the Av.

Because most samples were taken from a 15 to $25 \mathrm{~cm}$ depth from the surface, the sample did not receive a full three dimensional gamma-dose during burial. The calculated dose rate 
was not compensated for departure from full 3-dimensional geometry, thus the dose rate is over-estumated by 5-15\%. This miscalculation in dose rate results in a corresponding underestimate in age.

\section{Concluding Remarks}

It is unknown if AV horizons are homogenized by pedologic process or contain an internal stratigraphy. If the Av horizon is homogenized, TL age estimates provide a consideratly less precise maximum estimate on latest faulting. The cumulative total additional error from uncertainties in determining the residual level in ED analyses and possible miscalculations in dose rate is probably between 10 to $40 \%$. Thus, a more realistic possible age span for the sampled Av horizons may be 2 to $8 \mathrm{ka}$.

FUTURE APPLICATIONS OF THERMOLUMINESCENCE DATING

Within the auspices of site characterization for the high level nuclear waste respository site, the following studies are recommended to further the development and application of TL dating in geologic hazard evaluation.

1). Detail Pedologic and Sedimentologic study of Av Horizons

A better understanding of how this horizon forms is needed 
if TL age estimates on Av horizon silt are used to constrain the most recent tectonic or volcanic eruptive event. To gain insight on the genesis of an Av horizon additional data is needed on contemporary dust inputs and the micromorphologic and SEM characteristics of this horizon.

2). Detail stratigraphic sampling and TL Dating of Av Horizons TL dating of different levels in the Av horizon may shed some light on the age structure of the horizon. New micro-sampling containers would have to be constructed to efectively sub-sample Av horizons.

3). Eield Measurement of Dose Rare Portable gamma ray spectrometers are available that quickly and accurately measure on-site radionuclide contents. Such measurements would provide full gamma radiation readings and identify any radioactive inhomogenities. Such instruments may greatly increase the precision of dose rate estimates and the resultant Ti age estimate.

4). Apply the TL Technique to other sediments Efforts should be concentrated to extend the technique to other neotectonic settings. Offset playa sediments or sag ponds mud or other eolian sediment are 
particularly suited for Th dating.

5). Apply Multiple Dating Techniques at one site

TI, radiocarbon, cation-exchange ratio, Uranium series and trend dating should be applied together at an appropriate site to test the accuracy and precision of each technique.

6). Integrate Geochronology Earty into Geomorphic and Stratigraphic studies

Geochronology should not be practiced in isolation of field geology. Many of the problems in the laboratory may be from mis-sampling in the field. Geochronologist should collaborate directly in field research to maximum sampling and identify possible complications. 


\section{REFERENCES CITED}

Active Tectonics. (Studies in Geophysies), National Academy of Sciences, National Academy Press, 266 pp., 1986.

Aitken, M. J., Thermoluminescence Dating. Academic Press, New York, $359 \mathrm{pp} ., 1985$.

Birkeland, P. W. Quaternary soils of the western united states. In: Boardman, J. (ed), Soils and Quaternary Landscape Evolution, J. Wiley, New York, N.Y., 303-324, 1985.

Forman, S.L., Applications and limitations of thermoluminescence to date Quaternary sediments. Quaternary Science Reviews, in press.

Forman, S.L., wintle, A.G., Thorleifson, L.H. and wyatt, P.H., Thermoluminescence properties and preliminary dates for Quaternary raised-marine sediments, Hudson Bay Lowland, Canada. Canadian Journal of Earth Sciences, 24, 2405-2411, 1987.

Forman, S.L., Jackson, M.J. and McCalpin, J., Thermoluminescence (TL) studies on colluvial and alluvial sediments from Utah and Colorado: Preliminary results. Geological Society of America Abstracts with Programs, 19(5). 506,1987 .

Forman, S.L., Maat, P. and Jackson, M.E., Thermoluminescence dating of paleoearthquakes: Recent results and future prospects. Geological society of America Abstracts with Programs, 20(3), 161, 1988 .

Forman, S.L., Jackson, M.E., Mccalpin, J, and Maat, P., The potential of using thermoluminescence to date buried soils developed on colluvial and fluvial sedimente from Utah and Colorado, U.S.A.: Preliminary results. Quaternary Science Reviews, in press.

Forman, S.L., Machette M.N., Jackson, M.E. and Mat, P., Evaluation of thermoluminescence dating of paleoearthquakes on the American Eork segment, wasatch fault zone, Utah. journal of Geophysical Research. (submitted)

Kronborg, C., Preliminary results of age determination by TL of interglacial and interstadial sediments. PACT (Journal of the European study Group of Physical, Chemical and Mathematical Techniques Applied to Archaeology) 9. 595-605, 1983.

McCalpin, J., Thermoluminescence (TL) dating in seismic hazard evaluations: An example from the Bonneville Basin, Utah. proceedings of the 22nd symposium on Engineering Geology and Soils Engineering, 156-174, 1986 . 
Mcradden, L. D., S.G. Wells and Dohrenwend, J.C., Influences of Quaternary climatic changes on processes of soil development on desert loess deposits of the Cima volcanic field, California. Catena, 13(4), 361-389, 1986.

Mckeever, S.W.S., Thermoluminescence of Solids, Cambridge University Press, New York, N.Y., 379 pp., 1985.

Mejdahl, $i$. Thermoluminescence dating of sediments. Radiation Protection Dosimetry, 17, 219-227, 1986.

Singhvi, A.K., Sharma, Y.P. and Agrawal, D.P. Thermoluminescence dating of dune sands in Rajasthan, India. Nature, 295, 313-315, 1982 .

Singhvi, A.K. and Mejdahl, V. Thermoluminescence dating of sediments. Nuclear Tracks and Radiation Measurements, $10(1 / 2)$ $147-161,19 \overline{85}$.

Whitney, J.W., Shroba, R.R., Simmonds, F.W. and Harding, S.T., Recurrent Quaternary Movement on the windy wash Fault, Nye County, Nevada. Geological Society of America Abstracts with Programs, $18(6), 787,1986$.

Wintle, A.G., Thermoluminescence properties of fine grain minerals in loess. Soil science, 134(3), 164-170, 1982 .

wintle, A.G. and Huntley, D. J., Thermoluminescence dating of ocean sediments. Canadian Journal of Earth Sciences, 17, $348-360,1980$.

Wintle, A.G. and Prószynska, H., TL-dating of loess in Germany and poland. PACT (Journal of the European study Group of Physical, Chemical and Mathematical Techniques Applied to Archaeology), $9,547-554,1983$. 


\section{Appendix D}

Consultant's report: Radiometic dating with $U$ - and Th-series isotopes in the Nevada Test Site region - a review

by T. L. Ku 
Radiometric Dating with $U$ - and Th-series Isotopes

in the Nevada Test Site Region - A Review

\author{
Teh-Lung Ku \\ (June 1988)
}

\title{
Introduction
}

This document is a literature review of the uranium and thorium decay series dating of Quaternary deposits in the Nevada Test Site (NTS), Nevada. In evaluating the Yucca Mountain at NTS as a possible suitable site for nuclear waste repository, geological age information of the Site is of fundamental importance. Our ability and efforts to obtain such information have yet to be strengthened. There is a general dearth of both the material and the methods available for absolute dating in continental settings. The methods involving the $\mathrm{U}$ - and $\mathrm{Th}$-series isotopic disequilibrium relationships can be looked upon as among the most promising. In the meantime, however, one recognizes their being in the evolving stage, requiring further research to be carried out.

In the following, I will first present the principles of the U/Th dating methods applicable to the NTS material, pointing out their merits, shortcomings, and assumptions involved. I will then review the quality of the data obtained to date and suggest future work for possible improve ment.

\section{The Methods}

The disequilibrium relationships among $230 \mathrm{Th}-234 \mathrm{U}-238 \mathrm{U}$ are used in two basically different ways to extract the age, or time of sedimentation, for a deposit at NTS. They can be referred to as the closed-system and the open-syste $m$ approaches. The former approach is used conventionally in the 
U-series dating, by noting the extent of daughter ingrowth toward secular equilibriua with its long-lived radioactive parent (Ku, 1976). It applies mostly to authigenically precipitated carbonate deposits. The latter approach is embodied in a method called uranium-trend dating (Rosholt, 1980). In this method, the age of a deposit is derived from the timedependence of isotopic distribution in the deposit through which a solution (soil water or groundwater) carrying the isotopes has moved. Such a deposit can be largely detrital sediments of alluvial, glacial, and eolian origin, among others.

\section{Closed System Datins - The 'Conventional' U-Series Methods}

It is well known that uranjum is much more soluble than thorium in natural solutions. So minerals like calcium carbonate or silica precipitated from such solutions usually contain a few Ppm of uranium but virtually no chorium. Subsequent to their formation, if the minerals act as a closed system with respect to $U$ and $T h$ isotopes, the age $(t)$ of the minerals can be derived from the following radioactive growth and decay equation:

$$
\left.{ }^{230} \mathrm{Th}-238 U\left(1-\exp \left(-\lambda_{0} t\right)\right]+(234 U-238 U)\left(\lambda_{0} / \lambda_{0}-\lambda_{4}\right)\right)\left[1-\exp \left(\lambda_{4} t-\lambda_{0} t\right)\right]
$$

where $\lambda_{0}$ and $\lambda_{4}$ are decay constants of $230 \mathrm{Th}$ and $234 \mathrm{U}$, respectively, and the notation for nuclides refers to their specific activities $(\mathrm{dpm} / \mathrm{g})$. The last ter $m$ of the above equation accounts for the effect of the excess $234 \mathrm{U}$ over $238 \mathrm{U}$ generally found in natural waters. The unknown, $t$, can be solved iteratively or estimated from a graphic solution as shown in Fig. 1. The marimum age dateable using this method is about 350,000 years. This technique has been 
used for dating a wide variety of pure carbonate material such as corals and mollusks.

In applying this technique to material from the terrestrial environments in general and from the NTS area in particular, two problems have to be overcome. First, the samples selected for dating must meet the closed system requirement. In the absence of independent cross-checks of age results, the criteria for the sample selection usually call for dense, compact material devoid of leaching and reprecipitation features (Ku et ad, 1979). For carbonate precipitates at NTS, an approximate, generalized order of reliability might be: calcite crystals or veins $\sim$ dense pebble coating from Cca soil horizon travertine > calcrete $\sim$ tufaceous travertine > caliche nodules soil caliche (Knauss, 1981). Secondary silica deposits (opal or opal + euhedral quartz) have also been shown to approximate a closed-system for $U$ and its daughters (Ludwig et al., 1980; Knauss, 1981; Szabo and O'Malley, 1985).

The second problem is detrital $230 \mathrm{Th}$ contamination, for terrestrial carbonates are seldom pure and contain detrital minerals (mostly aluminosilicates or 'clay') of significantly older age. There have been several publications dealing with measures to eliminate or correct the detrital contamination effect. A summary paper was published by $\mathrm{Ku}$ and Liang (1984). Usually the approach consists of a combined chemical leach and numerical or graphical correction procedure. The procedure that has been used in the NTS studies (e.8., Knauss, 1981; Szabo et al., 1981) is the one originally reported by Rosholt (1976) and Szabo and Sterr (1978). It entails dilute acid leaching of the impure carbonate sample, followed by radiochemical analysis of both the leachate and the residue. Under the assumption that the acid leaching step does not fractionate the $U$ and $T h$ 
isotopes, the $230 \mathrm{Th} / 234 \mathrm{U}$ and $234 \mathrm{U} / 238 \mathrm{U}$ ratios of the pure carbonate phase in the sample can be obtained from the slopes of $230 \mathrm{Th} / 232 \mathrm{Th}$ vs. $234 \mathrm{U} / 232 \mathrm{Th}$

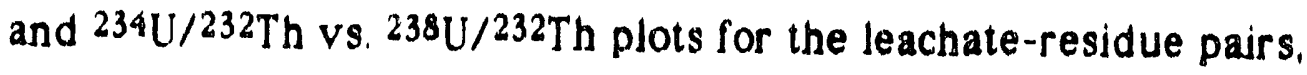
respectively. An example of the plots is shown in Fig. 2 for a caliche sample from a unit that is cut by the Yucca Fault at NTS (Knauss, 1981). The age of the sample calculated from the $230 \mathrm{Th} / 234 \mathrm{U}$ and $234 \mathrm{U} / 238 \mathrm{U}$ ratios using a rearranged Equation (1) is $108 \mathrm{ky}$.

There is one aspect in regards to this second problem to be noted. That is, even if no attempt at correction for detrital contamination is made, or if doubts arises as to the correction procedures used, data on $230 \mathrm{Th},{ }^{234 \mathrm{U}}$ and $238 \mathrm{U}$ in the whole sample (carbonate plus detrital 'clay') should give an upper-limit age estimate, which in some cases should still be of value. Thus in the use of the conventional U-series dating of carbonate and silica material, the key requirement is sample acting as a closed system in a geochemical sense, as the heading of this section denotes.

\section{Open System Dating - The Uranium Trend Method}

An 'unconventional' method has been devised to date fine-grained sediments such as alluvial/colluvial deposits and soils of Quaternary age using the $U$-series isotopes. It is unconventional in the sense that, unlike all the age dating methods which require enclosure of radioisotopes in a sample to be dated, this so-called "uranium-trend dating method" determines the age by modelling the behavior and distribution of isotopes in the sample which acts as an open system for the isotopes. A preliminary model for $U$ trend dating was presented by Rosholt (1980) and Szabo and Rosholt (1982), which was revised later by Rosholt (1985). This dating technique has been applied rather extensively at NTS (Rosholt et al., 1985; Shroba et al., 1988). 
The principles of U-trend dating are briefly summarized below. For more details, referred to Rosholt (1985) and Muhs et al (1987). The U-trend clock starts with the inception of water movement through sediment or soil. the timing of which may coincide with the initiation of sediment deposition or soil development. This water contains some uranium (238U) which decays to $234 \mathrm{U}$ and $230 \mathrm{Th}$. These daughter nuclides are adsorbed or driven into (via alpha-decay recoil mechanism) sediment grains. This daughter emplacement process results in solids having $234 \mathrm{U} / 238 \mathrm{U}$ and $230 \mathrm{Th} / 238 \mathrm{U}$ activity ratios higher than the secular equilibrium ratio of unity. At the same time, a counter process takes place by which $234 \mathrm{U}$ produced by decay of $238 \mathrm{U}$ structually incorporated in sediment grains is preferentially released from the sediment via leaching and alpha-recoil. This 234U displacement process is responsible for the widely known phenomenon that natural waters often exhibit 234U/238U activity ratios of $>1$.00. According to Rosholt (1985), in arid or semiarid environments, emplacement of $234 \mathrm{U}$ and $230 \mathrm{Th}$ is the dominant process initially. With time, continuous exposure of leachable $234 \mathrm{U}$ sites to percolating water results in eventual domination of the displacement process.

The essence of the uranium-trend method is thus a model which describes the migration of uranium in a solid-fluid matrix through time. leaving in its wake a trail of daughter products such that the distributions of the isotopes involved (238U, $234 \mathrm{U}$, and $230 \mathrm{Th}$ ) are modelled in terms of the above-mentioned parameters of daughter emplacement and $234 \mathrm{U}$ displacement, and uranium-flur factor. This latter parameter is related to the flur of mobile uranium through a deposit, assumed to decrease exponentially with time. Emplacement by recoil-adsorption processes is a function of the concentrations of dissolved uranium and of the sorptive 
properties on the solids. Displacement by recoil-leaching is controlled by the concentrations of uranium in the solid phase and by the solubility of uranium in the leachate. The uranium-flux factor depends on the quantity of water migrating through a deposit and the concentration of uranium in this water relative to that in the solid phase. All these parameters should vary from deposit to deposit and are unknown. They also are not amenable to rigorous mathe matical description. To circumvent these difficulties, $U$ trend dating writes empirical model equations expressing $234 U-238 U$ and $230 \mathrm{Th}-234 \mathrm{U}$ as a function of sample age $t$ and $U-f$ lur factor $F(0)$; the latter is expressed as "decay" constant $\lambda_{0} \mid=\ln 2 /$ half period of $F(0) \mid$ from the assumed exponential decrease of $F(0)$. As shown in Fig. 3, by plotting (234U $238 \mathrm{U}) / 238 \mathrm{U}$ vs. $(238 \mathrm{U}-230 \mathrm{Th}) / 238 \mathrm{U}$ for a suite of samples of the same age (i.e., from a given unit), the age $t$ can be determined from the slope of the plot if

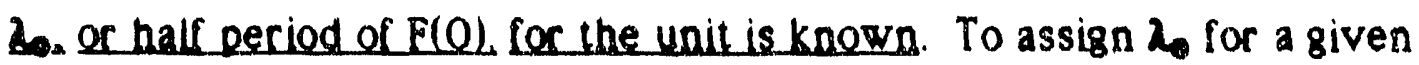
suite of samples, the method again uses the empirical approach of getting a relationship between the half period of $F(0)$ and the $\mathrm{X}$-intercept in a ${ }^{234} \mathrm{U}$ $238 \mathrm{U}) / 238 \mathrm{U}$ vs. (238U - $230 \mathrm{Th}) / 238 \mathrm{U}$ plot for suites of samples of known age, as shown by Fig. 4. The half period of $F(0)$ for a sample of known age is calculated from the empirical equations of $234 \mathrm{U}-238 \mathrm{U}$ and $230 \mathrm{Th}-234 \mathrm{U}$, both

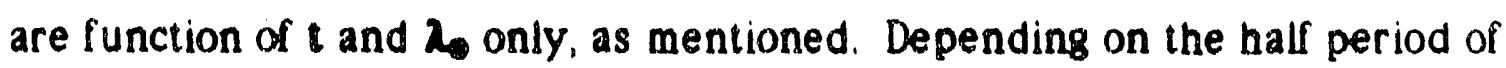
$F(0)$, or $\lambda_{0}$, as shown in the example of Fig. 5 , the U-trend dating applies to samples with ages ranging approximately from 10 to 800 thousand years.

\section{Merits and Demerits of the Two Approaches}

The closed-system approach requires that the sample acts as a closed system with respect to isotopic exchange with the its surroundings. If this requirement is fulfilled, procedures and assumptions used in deriving age 
information are much more straight-forward and easier to be substantiated than those used in the open-system approach. On the other hand, the conventional closed-system U-series dating to NTS has the following limitations:

(1) It is generaily limited to dating carbonate and perhaps silica deposits, the ages of which may not be close to those of geomorphic surfaces or of neotectonic events in the area.

(2) The marimum age dateable is limited to 350 thousand years.

(3) There are no well-established criteria for sample screening to ensure closed system.

The uranium-trend method is potentially applicable to a wide variety of material including soil, alluvial, lacustrine, marine, eolian, and glacial deposits (Rosholt, 1985). It applies to a relatively large age range (10-800 $\mathrm{ky}$, though more sensitive in the range of 60-600 ky). However, at this stage of development of the method, it can still be considered as experimental, in view of the following major points of concern:

(1) An important component of this empirical model is the uranium flux, $F(0)$. This factor should be related to the concentration and amount of uranium moving through a deposit, which is a function of climate and sediment lithology/compaction. The time variation of this function has to be very complex. The adopted function of a simple exponential decay with time for the uranium flux is certainly an oversimplified one, not to mention the possibility of being incorrect in certain cases. For example, to what extent the uranium-flux in the NTS area could be affected by the pluvial climate during the last glaciation in the western U.S.?

(2) As far as age assignment by the U-trend technique is concerned. the empirical relationship of Fig. 4 forms a key element to that assignment. 
Yet there exists room for clarification or improvement of that relationship. First, its physical meaning is by no means clear, so is the significance of the coordinate $\mathrm{x}_{i}$ of the plot. The latter question becomes an even more pertinent one to be clarified when one notes that the algebraic sign of $\mathrm{x}_{\mathrm{i}}$ is of no consequences; that is, the plot only takes positive values whereas $x_{i}$ 's for the data points delineating the curve have both positive and negative values Here, one assumes priari the existence of a symmetrical relationship between half period U flux and degree of 230Th-238U disequilibrium. Whether this relationship holds in theory or empirically remains an open question. Second, although the curve in Fig. 4 is defined by 10 data points, only Lour of the points (units $3,8,11$ and 12) represent samples independently dated by ${ }^{14} \mathrm{C}, \mathrm{K}$-Ar or fission track and thus can be considered as primary calibration calibration points. (It should be noted that unit 12, Tuff $B$ of Lake Tecopa, was co- sidered to be the distal facies of the Bishop Tuff, and thus was dated indirectly.) The remaining sir calibration points are of secondary nature. The ages of these six samples are assessed by local correlai ion (Rosholt et al, 1985b; J.N. Rosholt, pers. comm., 1988) only, and their accuracies, hence uncertainties in their half period $F(0)$ estimates, are difficult to determine. Thus, it is reasonable to view the Fig 4 relationship as beins preliminary, pending further refinement.

(3) There is the "sensitivity" problem of how well one is able to resolve or determine ages from the analytical data. A linear fit of the data displayed in plots like Fig. 3 give intercept $\mathrm{x}_{\mathrm{i}}$ and slope $\mathrm{m}$; both of these parameters are needed in caiculating the age of the sample. The uncertainties attached to these parameters depend on how well the lifiearity is defined. Data such as those shown in Fig. 6 for two of the samples from NTS obviously will impart considerable uncertainty to the estimation of $x_{i}$ 
and $m$, hence to their age assignment. It should also be pointed out that even if error in $x_{i}$ is small, the corresponding estimate for half period of $F(0)$ could still be large because of the preliminary nature of the empirical relationship shown in Fig. 4 , mentioned above. According to the present relationship, an uncertainty of $100 x$ in half period of $F(0)$ may cause an error of the order of $50 x$ in age (J.N. Rosholt, pers. comm., 1988; also of. Fig. 5 of Rosholt, 1985).

\section{Curreat Data}

Uranium-trending dating has been reported for $\mathbf{4 0}$ suite of samples from the Nevada Test Site (Rosholt et al., 1985a; Shroba et al., 1988). Each suite consists of 4 to 12 samples from a stratigraphic unit or section. Eight of the suites have been analyzed in two different size fractions (denoted as $m$ and $\mathrm{f}$ ). By inspection of the goodness of the linear fits for the 4 to 12 data points of each suite in a (234U - 238U)/238U vs. (238U - 230Th)/238U plot such as shown in Fig. 4, one gets some idea as to how good the determination of the age for a given unit is. The following list is an evaluation of the data at hand. Very qualitatively, category $A$ includes suite of samples giving sufficientiy well defined slopes and I-intercepts in the $(234 \mathrm{U}-238 \mathrm{U}) / 238 \mathrm{U}$ vs. $(238 \mathrm{U}-230 \mathrm{Th}) / 238 \mathrm{U}$ plots such that their ages will have 10-20\% errors.

Category $C$, on the other hand, are those units with "clustered" data arrays, causing age estimations with large uncertainties of $>100 x$, if not impossible The in-between category $B$ will have age uncertainties of $\sim 50 x$.

Category A: F2, RV1-AD, RV1-EI, RV1-PU, RVI-VZ, TSV-307, S9. SCF 4, TSV396 (m and f), CF1, CF2 ( $m$ and f), YM2U ( $m$ and $f$ ), YM2L, ( $m$ and $f$ ), YMI $3 U$ ( $\mathrm{m}$ and $f$ ), YMI $3 \mathrm{~L}$ ( $\mathrm{m}$ and $f$ ), YMI4B, YM14U, COB, deposit F 
Category B: RV 2-U, RV 2-L, JD, YMI 4M, YM14L, S3, deposit H

Category C: SFF, FFPG, S1, F3, RV1-JO, Q2E, Q2S, SCF1 (m and f), SCF2

(m and $f$ ), SCF3, CF6, FHA, Deposit $C$, deposit D.

The conventional uranium-series dating carried out thus far at NTS (Knauss, 1981; Szabo et al., 1981; Szabo and Kyser, 1985; Szabo and O'Malley, 1985; Shroba et al., 1988), while showing its value in contributing to the geochronology of the region, has pointed to the need for further systematic sampling and measurement. Because of the method's reliance on the closed-system assumption, consistency of age data based on multiple analyses and field relationships is of utmost importance. By multiple analyses is meant the use of different methodologies on the same sample or on different material from the same stratigraphic unit. They have yet to be performed in a consistent manner.

\section{Suggestions for Puture Work}

Future geochronological work with U-series isotopes at NTS should strive for consistency check. Both internal and external consistencies should be sought. The internal check refers to (1) reproducibility of results obtained on a single sample and (2) ages obtained for a group of samples are consistent with their relative stratigraphic positions; in both cases, the same dating lechnique is employed. The external consistency refers to crosschecks made with different age dating methods on a given sample or on samples in the same depositional unit.

The uranium-trend dating uses mo. 21 approach. Models always involve assumptions, and some of the assumptions used by the U-trend method (such as the exponential uranium fluxes) are difficult to verify. Furthermore, the method completely relies on empirical data for calibration, 
and the quality and appropriateness of such data become very crucial and at this time still need refinement. As it stands, while having an encouraging start (thanks to the efforts of Rosholt and his associates), the method can be looked upon as in the evolving stage. For these considerations, it is suggested that the conventional closed-system dating should be emphasized in future geochronological work at NTS, with priority being placed on samples of pure carbonate (i.e., calcite veins) and/or opal deposits. Preliminary studies made on dating secondary silica (opal) material from the region using uranium-series disequilibrium have obtained encouraging results (Knauss, 1981; Szabo and Kyser, 1985). These include high U/Th ratio and equilibrium $238 \mathrm{U}-234 \mathrm{U}-230 \mathrm{Th}$ relationship in the samples studied. suggesting that opal fulfills initial conditions and closed-system requirements for $U$-series dating. In the NTS area, waters obtain silica from the hydrolysis and dissolution of glass contained in tuffaceous deposits which can be a source of uranium when they are vitrified (Rosholt et al., 1971; Zielinski, 1978). Further work on the dating of Quaternary secondary silica is warranted. Because opal contains much higher uranium concentration than carbonates in the area, it is possible that the age signal for the silica precipitates will be preserved even if the analyzed opal is not pure.

In the dating of secondary calcium carbonate such as pedogenic precipitates, the strategy should be to select (ever though extremely painstaking efforts may be required) samples containing as little detrital silicate impurities as possible, so as to avoid the detrital $230 \mathrm{Th}$ correction routine. The correction, if unavoidable, requires little or no fractionation of Th and $U$ isotopes in the acid leaching procedure, which can be best checked by either replicate analyses or successive leaching (see Ku and Liang, 1984) 
In order to establish for the uranium-trend dating a stronger footing than it has had, it is suggested that the empirical curve of Fig. 4 should be verified by addition of calibration points with truly independently dated samples. The U-trend plot should show well-defined linearity. Muhs et al. (1987) have suggested a linear correlation coefficient of at least 0.7 , with a confidence level of at least $90 \%$. These are reasonable criteria for data acceptance. In this context, the following words of caution are noteworthy (Muhs et al., 1987): ".... a complex geological history can result in an inaccurate U-trend age even when a U-trend plot shows reasonable linearity. For example, the lower part of a deposit to be dated might experience little or no interaction with U-bearing water during its history. At some later time, however, the upper part of the deposit is removed by erosion and the lower part begins to experience interaction with U-bearing water. The Utrend age will reflect the time of sediment/water interaction, not the original time of sediment deposition. This is a condition that can be assessed only by geological evidence and/or independent age control, because the deposit may yield well-defined Th-inder and U-trend plots."

The above quote touches on two important aspects. One aspect points to the difficulties one might face in attempting to model a natural system which of ten has too many variables. The other aspect points out the fact that the ultimate cross-check for reliability is comparison with ages obtained by independent means. In this regard, Rosholt and Szabo (1982) have reported agreement between U-trend ages of U.S. Atlantic coastal sediments and conventional $230 \mathrm{Th} / 234 \mathrm{U}$ ages of corads from the same sediments. Rosholt et al. (1986) and Machette et ad. (1986) also reported U-trend ages for terrace alluvium along the Colorado River in Grand Canyon National Park which are in agreement with the depositional sequence of the terraces. 
However, these reports are in abstract form, lacking formal documentation. More recently, Muhs et al (1987) have attempted similar comparison studies on terrace deposits in Palos Verdes Hills and San Nicolas Island, California. We anticipate continuous progress made toward the improvement of the Utrend method. This is important, for there is a lack of means to determine the deposition time of fine-grained sedimeats of Quaternary age.

\section{References Cited}

Knauss, K.G. (1981) Dating fault associated Quaternary material from the Nevada Test Site using uranium-series methods. Lawrence Livermore National Laboratory, Liver more, CA, UCRL-53231, 51 p.

Ku, T.L. (1976) The uranium-series methods of age determination. Ann. Rev. Earth Planet. Sci. 4 347-379.

Ku, T.L., W.B. Bull, S.T. Freeman and K.G. Knauss (1979) 230Th-234U dating of pedogenic carbonates in gravelly desert soils of Vidal Valley, southern California. Geol. Soc. Amer. Bull. 20 1063-1073.

Ku, T.L. and 2.C. Liang (1984) The dating of impure carbonates with decayseries isotopes. Nucl. Instru. Meth. in Phys. Res. 223 563-571.

Ludwis, K.R., D.A. Lindsey, R.A. Zielinski and K.R. Simmons (1980) U-Pb ages of uraniferous opals and implications for the history of beryllium. fluorine, and uranium mineralization at Spor Mountain, Utah. Earth Planet. Sci. Lett. $46,221-232$.

Machette, M.N., J.N. Rosholt and C.A. Bush (1986) Uranium-trend ages of Quaternary deposits along the Colorado River, Grand Canyon National Park. Arizona. Geol Soc. Amer. Abstr. with Programs 18.393. 
Muhs, D.R., J.N. Rosholt and C.A. Bush (1987) The uranium-trend dating method: Principles and application for southern California marine terrace deposits. Submitted to Quat. Sci. Rev.

Rosholt, J.N. (1976) 230Th/234U dating of pedogenic carbonates in desert soils. Geol. Soc. Amer. Abstr. with Programs 21976.

Rosholt, J.N. (1980) Uranium-trend dating of Quaternary sediments. U.S. Geological Survey Open-File Report 80-1087,65p.

Rosholt, J.N. (1985) Uranium-trend systematics for dating Quaternary sediments. U.S. Geological Survey Open-File Report 85-298, 34p.

Rosholt, J.N., C.A. Bush, W.J. Carr, D.L. Hoover, W.C. Swadley and J.R. Dooley, Jr. (1985a) Uranium-trend dating of Quaternary deposits in the Nevada Test Site area, Nevada and California. U.S. Geological Survey Open-File Report 85-540, 37p + 35 Figs.

Rosholt, J.N. C.A. Bush, R.R. Shroba, K.L. Pierce and G.M. Richmond (1985b) Uranium-trend dating and calibrations for Quaternary sediments. U.S. Geological Survey Open-File Report 85-299, $48 \mathrm{p}$.

Rosholt, J.N., W.R. Downs and P.A. O'Malley (1986) Uranium-trend ages of surficial deposits in the central Grand Canyon National Park. Arizona. Geol. Soc. Amer. Abstr. with Programs 18.408.

Rosholt, J.N., Prijana and D.C. Noble (1971) Mobility of uranium and thorium in glassy and crystallized silicic volcanic rocks. Econ. Geol. 66 10611069.

Rosholt, J.N. and B. Szabo (1982) Comparison of uranium-series dating of coral and uranium-trend dating of coral-bearing terraces on the U.S. Atlantic coastal plain. Geol. Soc. Amer. Abstr. with Programs 14603. Shroba, R.R., D.R. Muhs and J.N. Rosholt (1988) Physical properties and radiometric age estimates of surficial and fracture-fill deposits along a 
portion of the Carpetbag Fault System, Nevada Test Site, Nye County, Nevada. USGS-10583-1, 45p.

Szabo, B. and T.K. Kyser (1985) Uranium, thorıum isotopic analyses and uranium-series ages of calcite and opal, and stable isotopic compositions of calcite from drill cores UE25a" 1 , USW G-2 and USW G-3/GU-3, Yucca Mountain, Nevada. U.S. Geological Survey Open-File Report 85-224, 25p.

Szabo, B. and P.A. O'Malley (1985) Uranium-series dating of secondary carbonate and silica precipitates relating to fault movements in the Nevada Test Site region and of caliche and travertine samples from the Amargosa Desert. U.S. Geological Survey Open-File Report 85-47, 12p. Szabo, B. and J.N. Rosholt (1982) Surficial continental sediments. In: Ivanovich, M. and R.S. Harmon, eds., Uranium Series Disequilibrium: Application to Environmental Problems. Clarendon Press, Oxford, p.246267.

Szabo, B. and H. Sterr (1978) Dating caliches from southern Nevada by ${ }^{230} \mathrm{Th} / 232 \mathrm{Th}$ versus $234 \mathrm{U} / 232 \mathrm{Th}$ and $234 \mathrm{U} / 232 \mathrm{Th}$ versus $238 \mathrm{U} / 232 \mathrm{Th}$ isochron-plot method. U.S. Geological Survey Open-File Report 78-701. p.416-418.

Szabo, B., W.J. Carr and W.C. Gottschall (1981) Uranium-thorium dating of Quaternary carbonate accumulations in the Nevada Test Site region, southern Nevada. U.S. Geological Survey Open-File Report 81-119, 35p.

Zielinski, R.A. (1980) Uranium in secondary silica: A possible exploration guide. Econ. Geol. 75 592-602. 


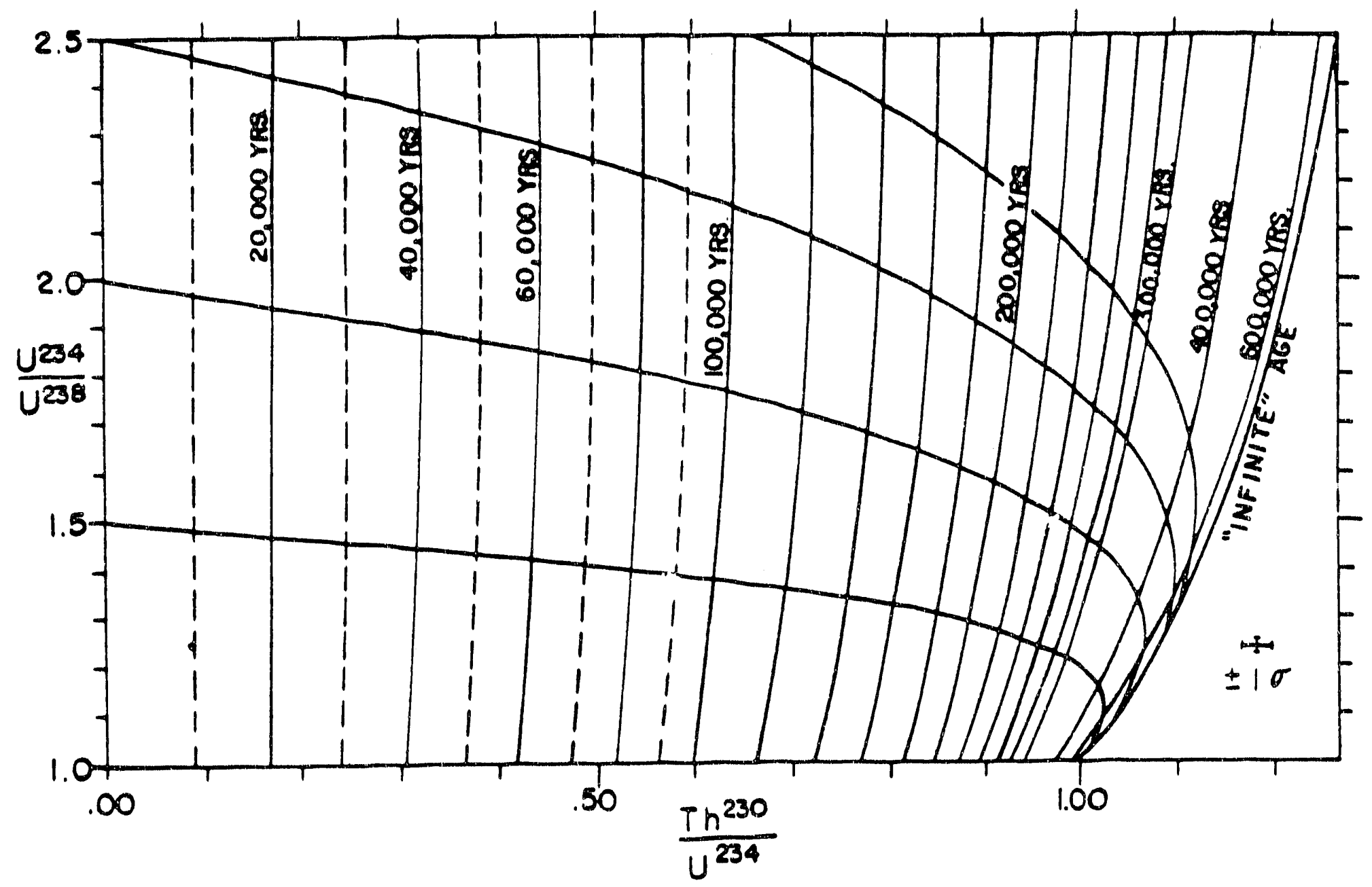

Fig. 1. Graphic solution for Eq. (1). The near-vertical curves are isuchrons. The near horizontal lines are growth curves along which carbonates with initial U-234/U-238 ratios of $1.5,2.0$ and 2.5 would evolve with time. The error bars shown at lower right corner are for a typical analysis. 


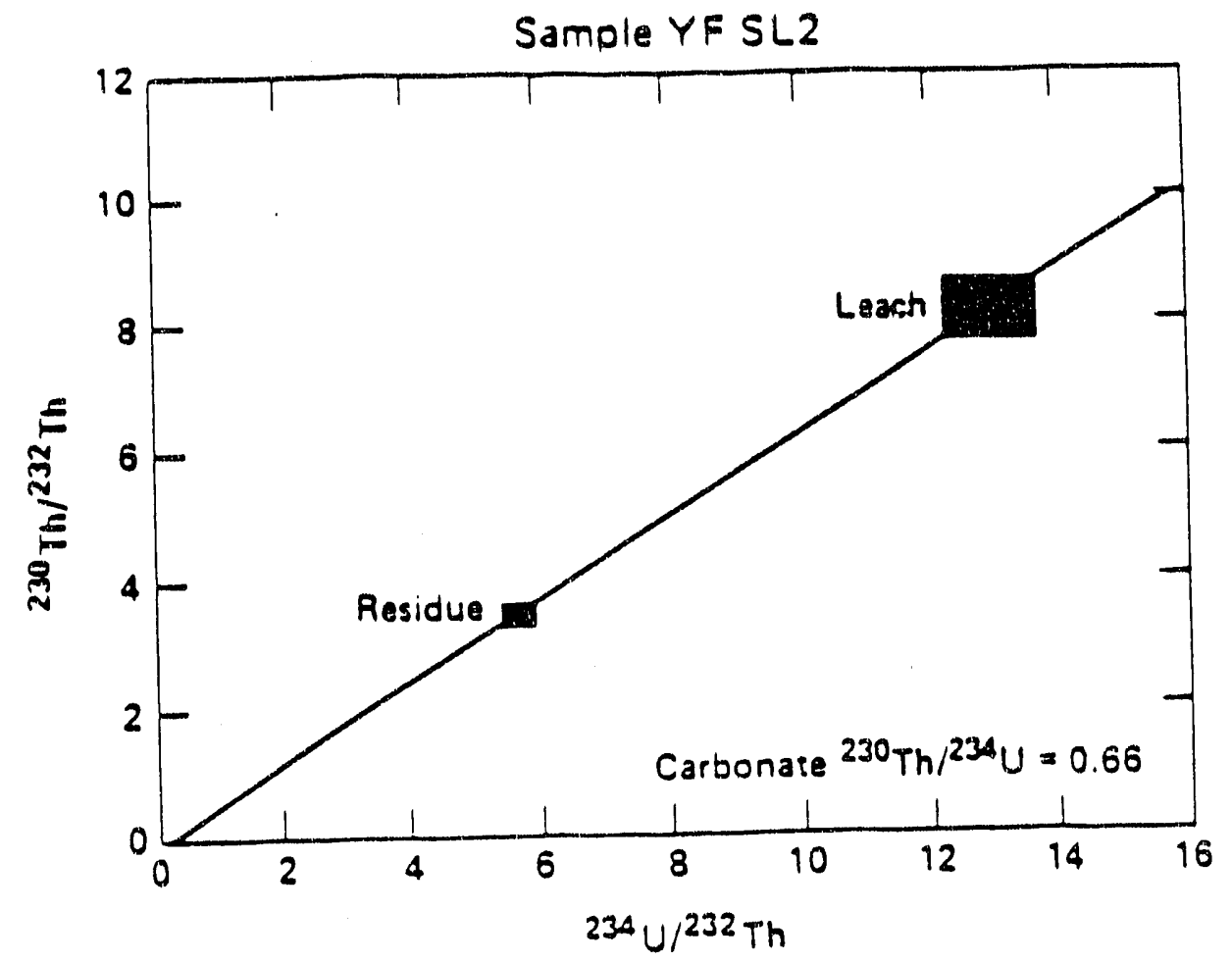

FIG. 2a. Graphical calculation of the $230 \mathrm{Th} / 234 \mathrm{U}$ activity ratio in carbonate.

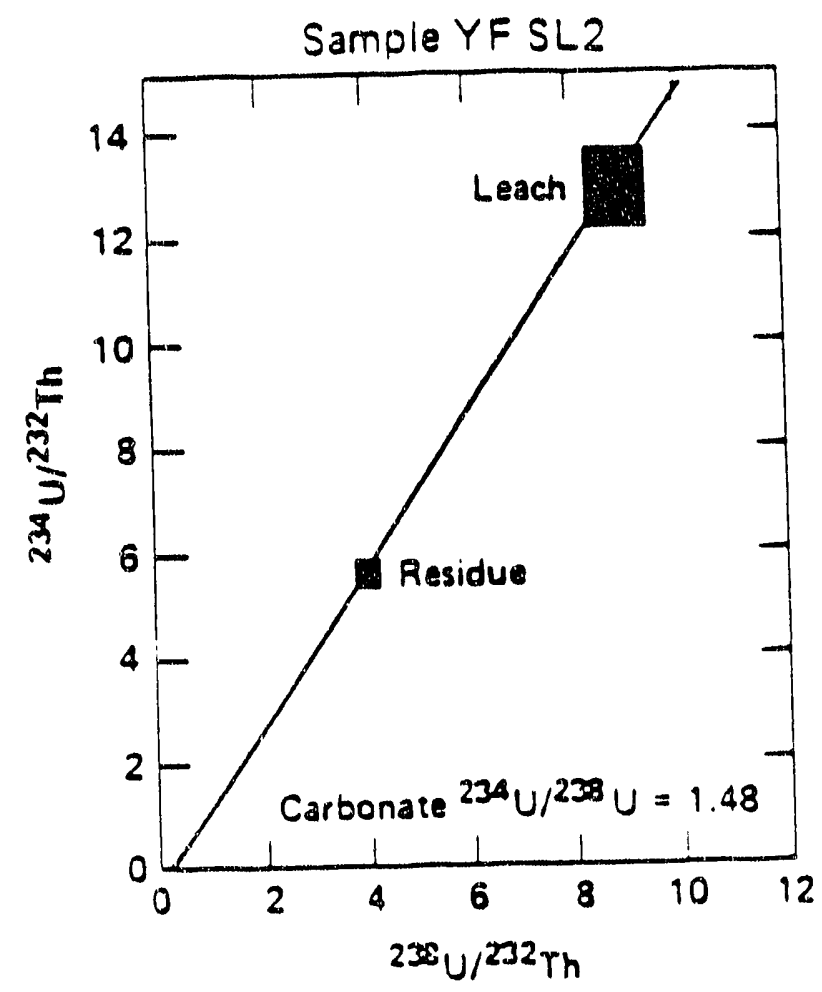

FIG. 2b. Graphical calculation of the $234 \mathrm{~g} / 238 \mathrm{~b}$ activity tatio in casbonate. 


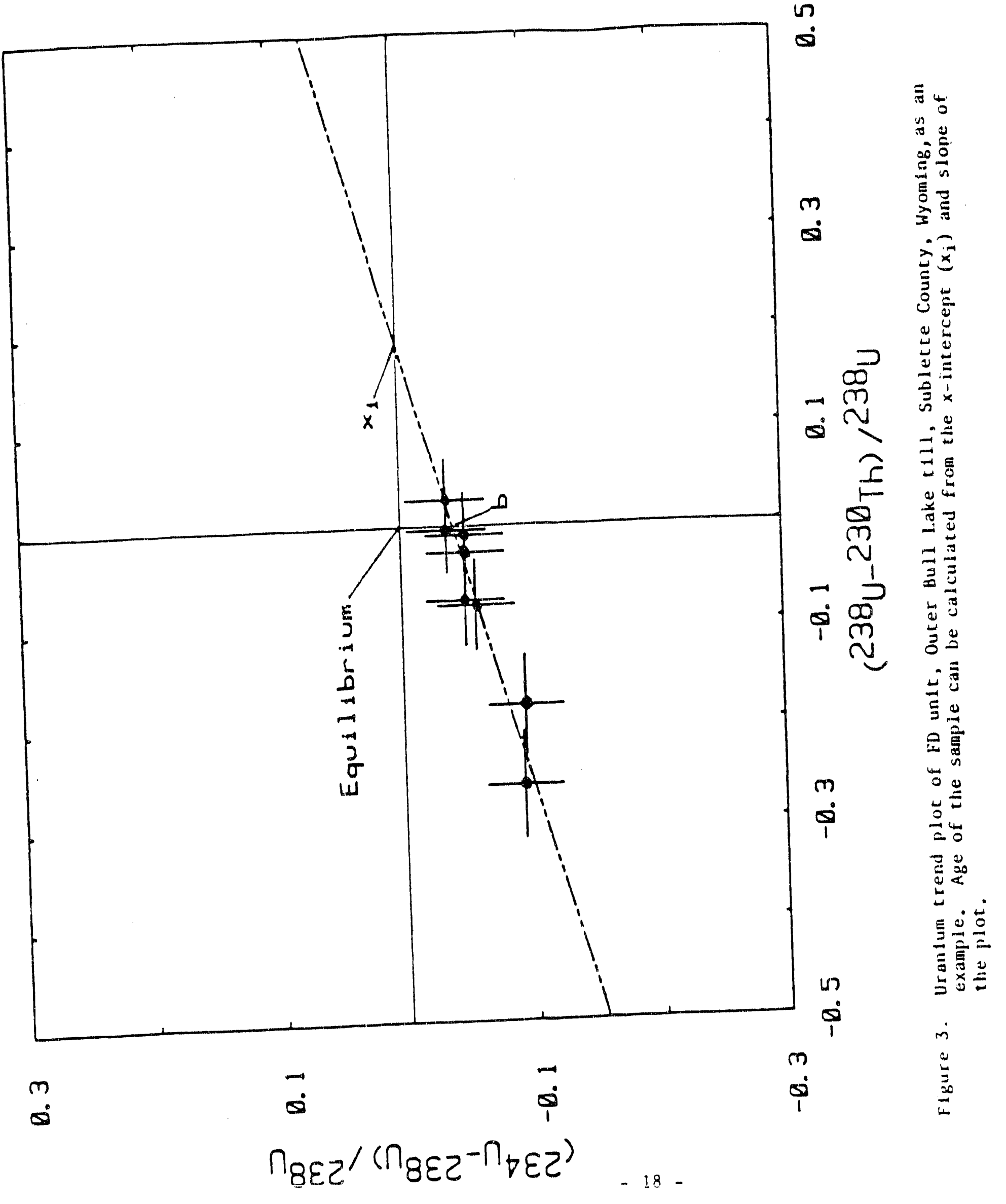


Half period of $F(0)$, ria

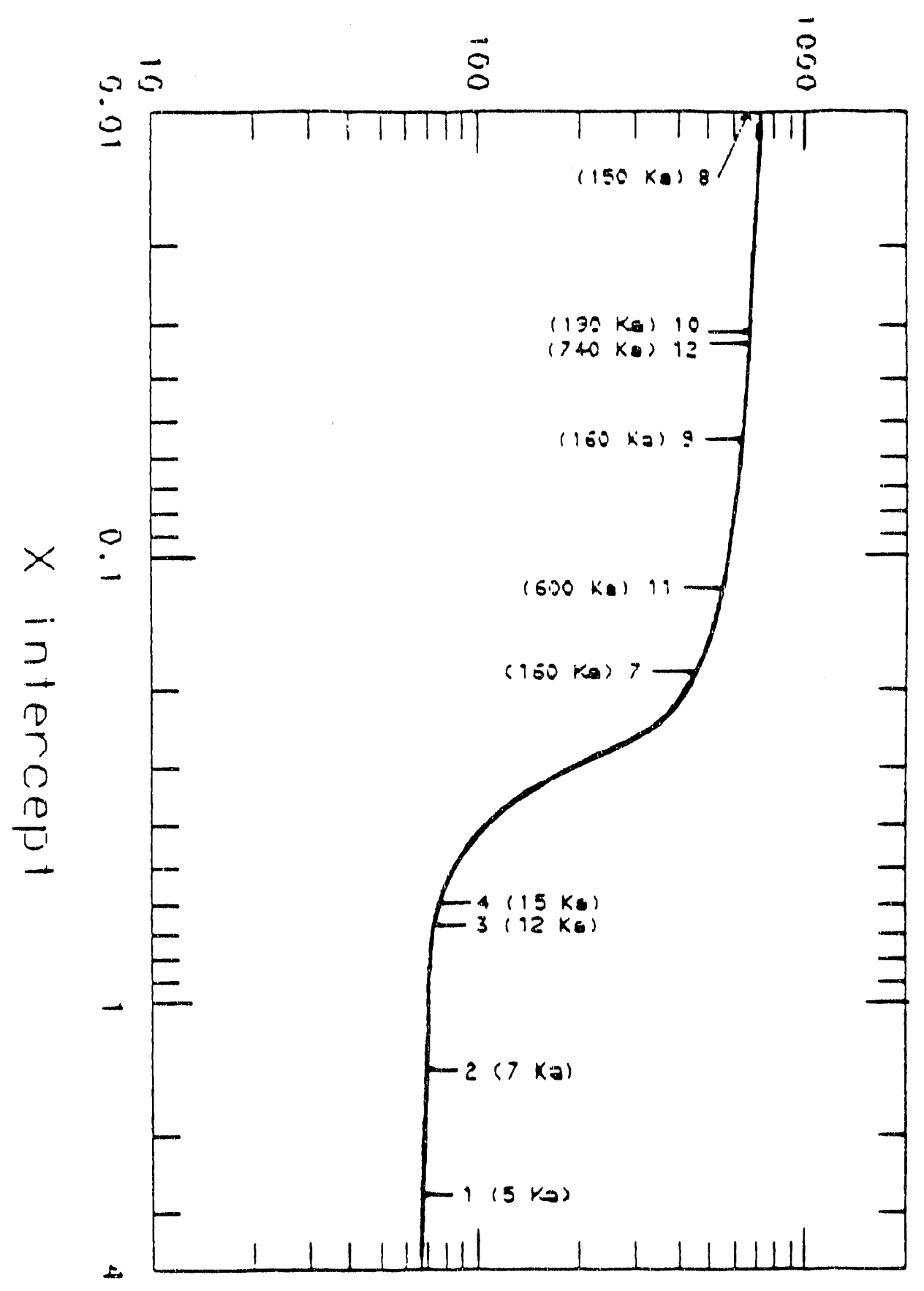

Fig. 4. Empirically derived curve for determination of $F(0)$ from $x$-intercept value. The primary calibration points are $3,8,11$, and 12 ; the remainder are "secondary" calibration points. Knowing $F(0)$ and slope of plots as shown in Fig. 3, the age of the deposit to be dated can be ascertained from plots such as Fig. 5 . 


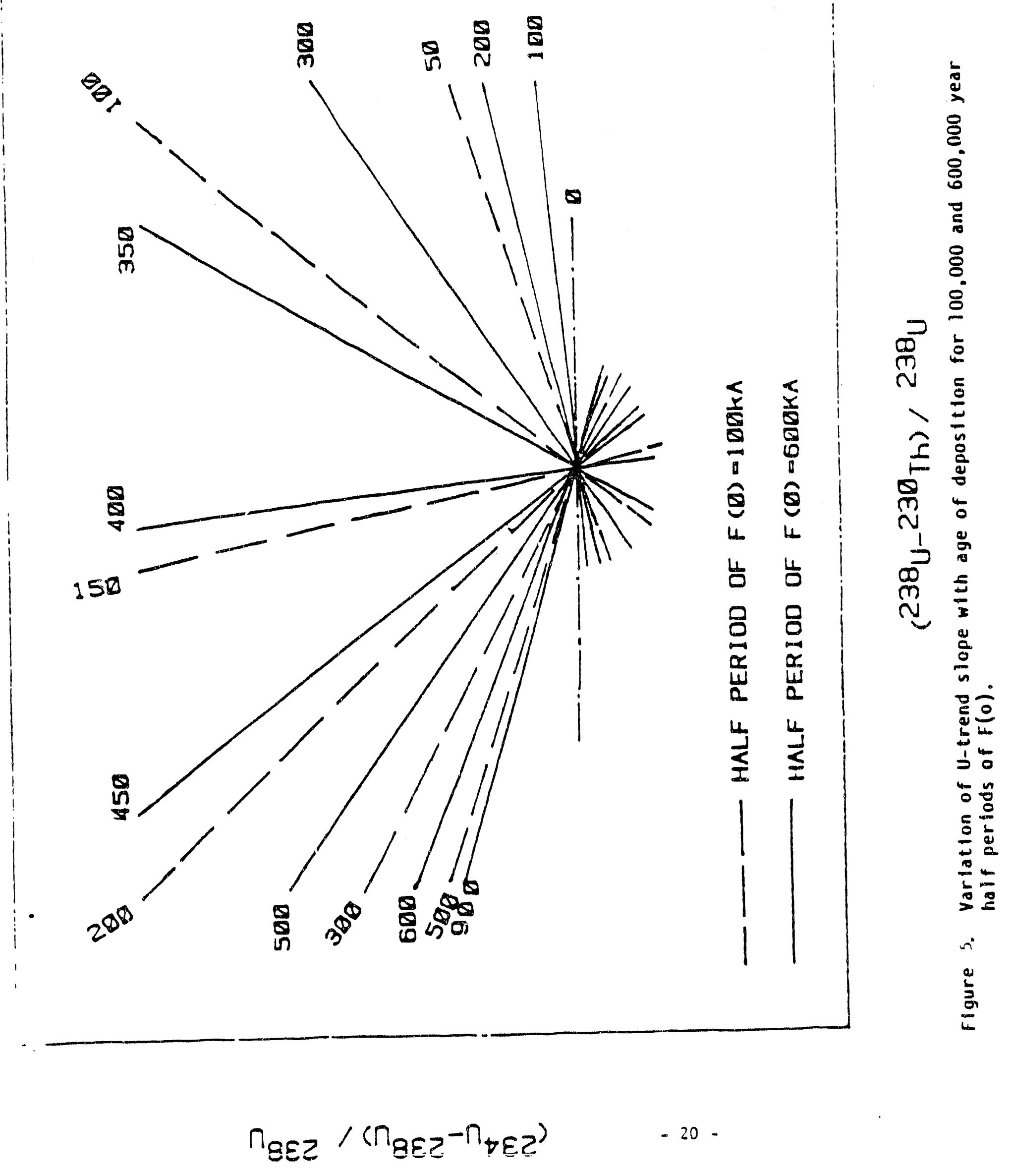




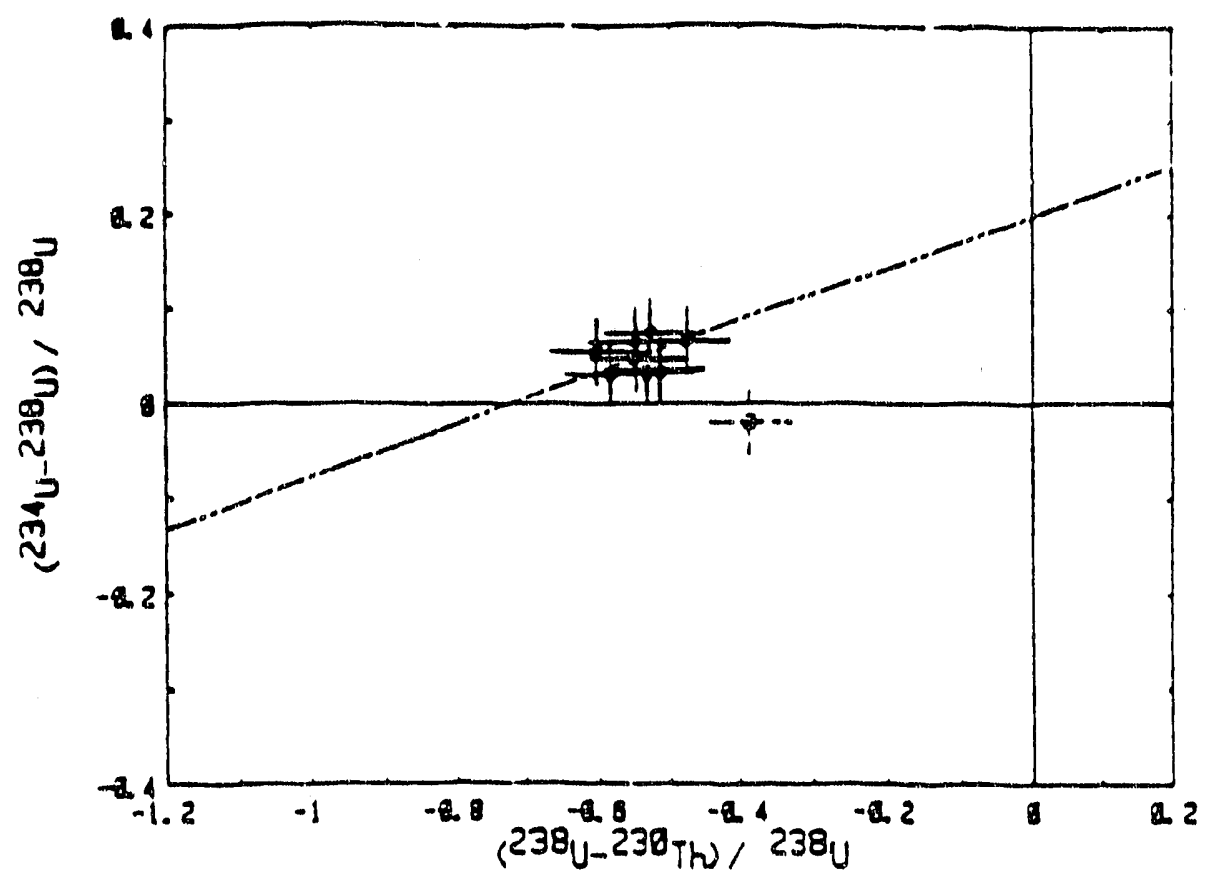

Plots of FFPG unit, colian sand in Frenchman flat irench.

The uppermost sample, $\square$, is not included in U-trend

slope because ie my contain terial from overlying deposit.

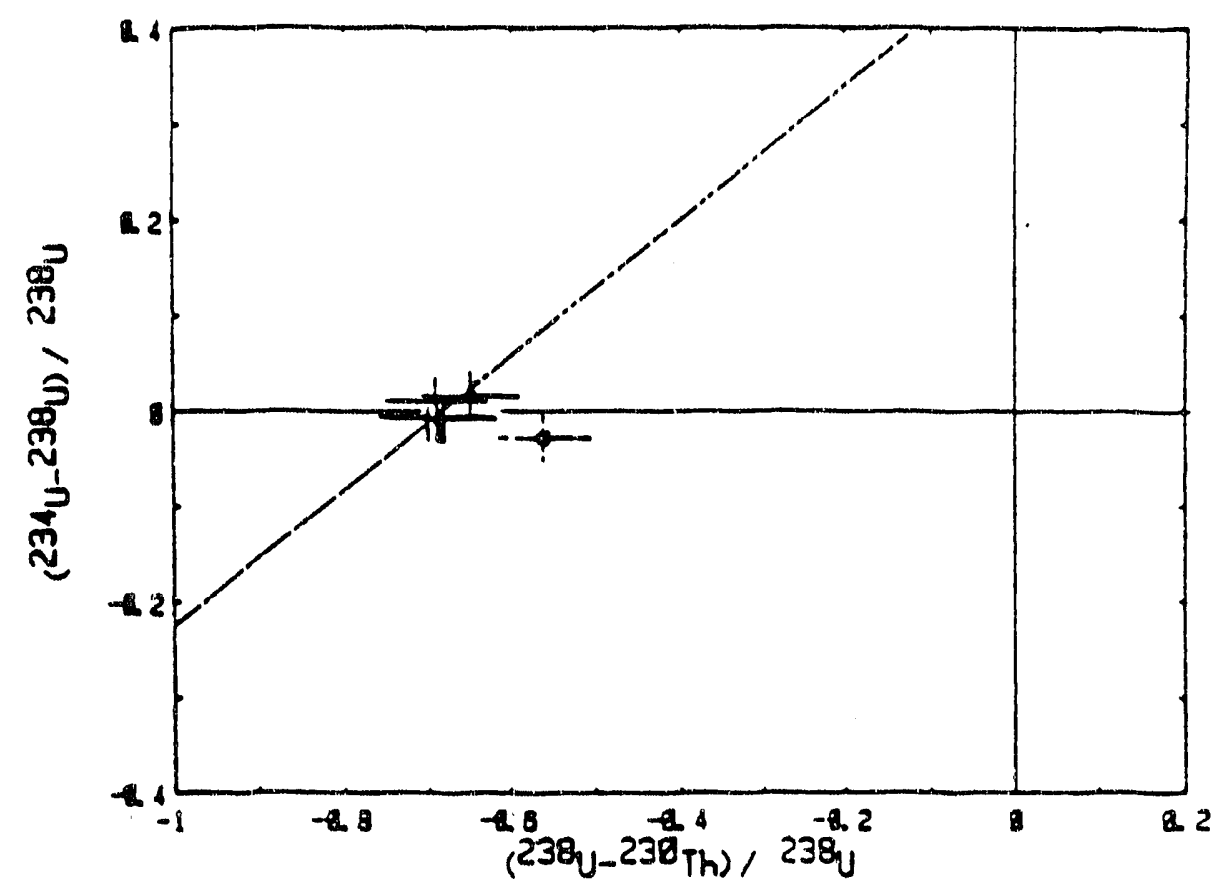

Plots of Sl unit, dluvium infrenchman flac Trench.

The uppermose sample. $Q_{0}$ is not included in the U-trend slope because it ma conta in material from the overly'm! deposit.

Fig. 6. Two examples of the U-trend nlots for samples from NTS showing ill-defined slone and $x$-intercent determinations for the data arrays. In the text, we place these samples in the "Category C". 


\section{Appendix E}

Cedar Mountain field guide: Visit to trenches along the southern part of the 1932 Cedar Mountain earthquake ruptures, Monte Cristo valley, Nevada

by C. M. depolo, A. R. Ramelli, and J. W. Bell 


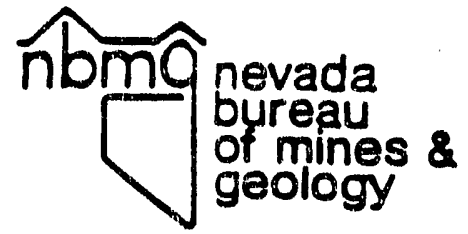

Visit to Irenches along the southern part of the 1932 cedar Mountain Earthouake Ruptures, Monte Cristo Valley, Nevada

Craig M. depolo, Alan R. Ramelli, and John W. Bell November 10,1987

The 1932 Cedar Mountain earthquake, with a felt area of $850,000 \mathrm{~km}^{2}$ and a surface wave magnitude $\left(M_{S}\right)$ of 7.2 , ranks as one of the three largest events in Nevada's historical earthquake record. Surface faulting from the 1932 earthquake occurred in southern Gabbs, stewart, and Monte cristo Valleys (see location map, Figure 1). This earthquake is part of a group of moderate and large historical earthquakes that Wallace (1984) refers to as the "Central Nevada - Eastern California Seismic Zone (Eigure 2).

This earthquake is one of the largest historical earthquakes to have occurred within the Walker Lane. The terminology "walker Lane" refers to a zone of strike-slip faults and topographic breaks occurring along the eastern side of the Walker Lane Belt. This structural zone has been the subject of several differing interpretations as to its significance. It is not clear whether this represents a major tectonic boundary, or is a secondary feature related to overall Basin and Range tectonics. Observations of dominant strike-slip displacement along the Stewart - Monte cristo Valley fault zone (SMVFZ) during the 1932 earthquake suggest that this zone is characterized by walker lane style faulting. understanding of this event could lead to a better appreciation of the significance of the Walker Lane.

The surface faulting associated with the 1932 earthquake occurred in a highly distributed pattern. Without detailed study of paleoseismic events, it is unlikely that this could have been predicted prior to the event. Based on the surface faulting, this earthquake appears to have resulted from a complex, probably multiple, seismic source involving a number of faults. Surface fallting also appears to be distributed in conjugate patterns (Riedel shears) associated with wrench faulting. Many areas in the Basin and Range have complicated fault patterns and are poorly understood with respect to seismic potential (e.g. Yucca Mountain). Studies of the 1932 earthquake will hopefully reveal clues as to the nature of the walker Lane Belt and serve as a possible model for seismic events in the Basin and Range province which are strike-slip and/or distributed in nature. 


\section{The 1932 cedar Mountain Earthouake}

The Cedar Mountain earthquake occurred at 10:10 pm (PST) on December 20, 1932. The main shock was preceded by about 40 minutes by a foreshock felt in Hawthorne. The foreshock was also felt by a number of cows in stewart valley who reportedly startled and became uneasy.

The main shock was widely felt in Nevada, California, and Utah (see isoseismal map, Figure 3). Three Nevada newspapers were reviewed to research the effects of the 1932 earthquake. These were Reno's "Reno Evening Gazette", Carson City's "Nevada state Journal", and Virginia city's "Territorial Enterprise". The duration of the earthouake, as felt by Nevada residents, ranged from one to two minutes. Accounts from Tonopah reported the severest temblor lasted 40 seconds, but did not cease for 15 minutes. Tonopah "skyscrapers" survived unscathed. An inspection the following morning found the Mizpah Hotel and the Tonopah Banking Corporation Buildings with no damage whatsoever. Hawthorne reported a prolonged shock of about one minute, with much rumbling. Quartz Mountain (SE of Austin) also reported one minute of shaking, followed by heavy rumbling, which want on for about another minute. At Ely, the earthquake began with a sharp peak, dwindled, and swelled again to a last sharp quake. Las yegas reported that the temblors continued for about two minutes.

There is no record of any deaths related to the 1932 earthquake, primarily due to the sparseness of population in the epicentral area, although several miners and cattiemen were in the area at the time. John Dieringer and his men (from Austin) were driving cattle through stewart valiey and had settled in for the night. They felt pretty lucky to have come upon an abandoned log cabin in Finger Rock wash, enabling them to escape the cold of a December night. When the main shock came, the ground shook so hard it threw cattle of their. feet and the herd stampeded. The men managed to get out of the cabin before it completely collapsed, but then had the unwelcomed task of digging their bedding out of the collapsed cabin. Joe Emons was sleeping in a cabin at the summertield rungsten mine in the pilot Mountains. He reported the disturbance threw him 8 feet out of his bad onto the midale of the 1loor. At daybreak, Joe made immediately for Mina stating, "in such times, a fellow wants to be where there is company."

In Mina, one adobe house partially collapsed, slightly injuring two children, and 13 of 14 chimneys of southern pacific's company houses were thrown down. Chimneys were also reported down in Falion and virginia city. In Reno, the earthquake was widely felt and many people ran to the streets. Damage was limited to over 200 windows shattering at Eddy Floral Company Nursery. In Elko, a stovepipe was shaken down inside one house. A large fire was burning in the stove at the time and might have caused considerable damage, had the occupants not been up. 
Aftershocks were numerous and continued for months. Dr. Gutenberg from California Institute of Technology reported that about 2,000 aftershocks were recorded at the Tinemaha station near Bishop. He comnented that the aftershocks appeared to be spread ove $=100$ miles in an north-south direction.

Surface faulting associated with the earthquake occurred ove $=$ a zone about $60 \mathrm{~km}$ in length and $6-14 \mathrm{~km}$ wide (see Figure 4). In the northern part of this zone, in the Gabbs and stewart Valley areas, the surface faulting was mapped by Gianella and callaghan (1934a, 193ib) as being widely spaced. Many ruptures in this area were surely missed during this study, since it was ony zeconnaissance in nature and there was some cover of postearthquake snow. In the southern area of surface faulting, riptures were longer and apparently confined to a narrower zone. Giarella and Callaghan noted that over half of the surface faults weze rifts (zones of many small fractures or grabens) ard occurzed along pra-existing ruptures. Some detailed rupture pattern maps are presented in Figures 5 and 6 . The nurbers $g$ iren for these riptures aze keyed to the numbers on Figure 4.

Gianelia and callaghan further noted that the rifts wezo distributed in a crude, en echelon fashion, and that the average trend of the irdividual fitss is to the east of the direction of the overall suzace faulting area. They report the overall sufface faulting area had a trend of $\mathrm{N}^{\circ} \mathrm{O}_{\mathrm{W}} \mathrm{W}$ Examination of theil map gives the potential range of N15-27\% $\mathrm{W}$. They reported 30 rifts with an average trend of N11.0E, 9 rifts with an average trend of $N 61^{\circ} \mathrm{E}$, and 16 rifts with average trends of N110W. They identified right-lateral offsets along some of the surface faults and reported that the maximum vertical offsets were about 1 meter.

Gianella and callaghan suggested that the southeastward shift of the Paradise Range - Cedar Mountain Block relative to the Gabbs Valley Range - Pilot Mourtains Block could be responsible for the surface faulting pattem (Figire 17).

\section{Recent Studies on the 1932 Cedar Kountain Eartharake}

Mark Molinari studied the Quatermary geology and neotectonics of the 1932 Cedar Mountain earthouake area for his master's thesis at Oniversity of Nevada - Reno (Molinari, 1983, 1984a, 2984b). This study involvad acquisition and analysis of low sun angle photography of the "Stewart - Monte Cristo valley faul zone", as Molinari named it. With this photography, he made surescial geolcgl and fault maps of both stewart and Monte Cristo valleys. vtilizing soils, he estimated ages for these suzsaces, ranging from mid-pleistocene through late-Holocene. He found that ma:y of the smaller rifts mapped by Gianella and Caliaghan were no longer distinct at the surface, and cound several 1932 surtace breaks missed in the earlier study. Molinaz: proposed that horizontal detachment between ashelow 
units, in a fashion described by Hardyman (1978), might be responsible for the distributed pattern of surface faulting and warping (Figure 7). He also endorsed Gianella and Callaghan's notion that the surface deformation was related to wrench faulting. Figure 8 is Molinari's structural geologic interpretation of the stewart and Monte cristo Valleys.

The general stratigraphy of stewart and Monte Cristo Valleys consists principally of Quaternary alluvium, overlying generaliy lacustrine Miocene sediments and volcanic rocks. Molinari (1984) has compiled regional age constraints on these sediments and brackets them between about 11 and $15 \mathrm{Ma}$, consistent with mammalian and molluscan fossil assemblages which are early Barstovian to early Clarendonian age. The Miocene sediments are commonly tilted or folded, and many of these folds appear closely related to the stewart - Monte Cristo valley fault zone. Molinari proposed that some of the surface deformation was taken up by folding of the Miocene sediments and, in some cases, the Quaternary alluvium. The unit underlying the Miocene sediments is not well exposed in the valleys, but presumably consists of Tertiary volcanic rocks, probably with some ashflows that are exposed in surrounding ranges.

Diane Doser of the University of Texas at El paso has reexamined seismograms of the 1932 earthquake (Doser, 1987, and in preparation). She has prepared a first motion focal mechanism for the main event (Figure 9) and has modeled the long period waves from this event to place constraints on focal mechanisms and estimate the earthquake's size. Figure 10 shows focal mechanism solutions for the waveform modeling and Figure 11 shows some of the waveforms used. As identified by Doser, and as can be seen in these wavefomms, the Cedar Mountain earthquake had a complicated source, probably consisting of multiple mptures. such a model would be consistent with the distributed surface rupture pattern.

The Nevada Bureau of Mines and Geology began research on the 1932 earthquake ruptures in the fall of 1986 under the direction of John Bell. Efforts have been concentrated in the Monte Cristo Valley area where the surface ruptures are the largest and the most continuous. A trenching program was undertaken in order to eurther characterize the late Quaternary activity of this lault zone. The objectives of this work were to provide better information on ages and senses of displacements for individual events, recurrence intervals, structural relations, and consistency of amounts and directions of slip from event to event. The Quaternary geology is also being examined through soils studies and tephrochronology. Frevious researchers were contacted and copies of Slemons and Cluff's (flown 1968) and Molinari's low sun angle photography were obtained. Figure 12 is an example of Molinari's photography and Figure 13 is an example of slemmons and cluff's photography. 


\section{STOP 1: Microwave Relay Station}

This stop provides an overview of Stewart and Monte cristo Valleys. Monte Cristo Valley lies to the right (southeast), stewart valley off to the left (northeast), and Cedar Mountains straight ahead (east). The 1932 surface ruptures extend from Kibby Flat, at the southern end of Monte Cristo Valley, northward to Gabbs Valley in the distance north of Stewart Valley. Unlike many Basin and Range faults that lie at or near mountain fronts, most faults of the stewart - Monte Cristo Valley fault zone lie in the valley, well out from the range front.

Through Monte cristo Valley, the main fault traces trend approximately due north (Figure 14). Late Quaternary and 1932 displacements along these traces have been right lateral and normal-right oblique. other fault traces have varying orientations and/or senses of displacement. Northeast-trending faults have more dominantiy normal displacements. A few such faults are present on the far side of the valley, due east of this location, and are more numerous to the north, particularly in Gabos Valley.

Northwest-trending faults form steps or bends in the main
traces and appear to have a component of compressional
deformation. The most striking example of this is where the main
fallt makes a l km left step, with north-south traces connected
by a northwest-trending ridge. This appears to be a "pressure
ridge" resulting from the change in orientation of the fallt in a
right-lateral system. We will pass by this feature on the way to
stop 2 (Figure 12 shows this feature in the upper center). While
l932 surface ruptures along the front of this ridge have not been
well documented, scarps do exist along part of it and trench
exposure has revealed reverse displacements, with Miocene
sediments falted against Quaternary alluvium. Another group of
faults are north-south trending normal faults forming narrow
linear grabens. These generaliy trend off bends in the main
fault, most notably one extending south from the north end of the
pressure ridge. These grabens may be related to adjustments to
the bends in the main fault.

Field work along the fault has revealed evidence of the amount of displacement resulting from the 1932 earthquake. Features such as bar and swale topography and stream channels appear right-laterally offset by up to 1 to $2 \mathrm{~m}$. Figure 14 shows estimations of surface offsets in the vicinity of trench 3 . The vertical displacement is more easily determined and along this trace ranges from 0 to about $1 / 2 \mathrm{~m}$ at the north end. Vertical displacement is down-to-the-west, creating a back-facing scarp that has ponded sediments at the fault. 


\section{STOP 2: Trench 3}

Trench work has been concentrated along the main fault traces, with a few trenches along the pressure ridge and linear grabens. Most of the work to date has been focussed on the trench 3 site. Figure 13 shows the site of trench 3 by the arrow along the fault. At this location, three interconnected trenches have been excavated in an $H$-shape, with two trenches ( 3 a and $3 b$ ) perpendicular across the fault and a connecting trench (3c) parallel to the fault in the ponded deposits on the downthrown side. Figure 15 is an isometric diagram of trench 3 , showing trench $3 a$ in the upper-right, trench $3 b$ in the lower-left and trench $3 c$ connecting the two. This site is located on one of the older surfaces cut by the 1932 breaks and has therefure revealed the best evidence of the long term history of the fault.

These trench exposures have revealed a well developed, vertical fault zone juxtaposing Miocene sediments and Bishop-age gravels against Holocene and late-Pleistocene Hine-grained ponded deposits and gravels. Although displacement is dominantly strike-slip, the vertical component is large enough to have ponded a minimum of 3 meters of Quaternary alluvial and/or eolian deposits at the fault. The fine-grained nature of much of these materials makes them potentialiy suitable for age dating techniques, such as thermoluminesence dating, paleomagnetic determinations, etc., that would usually not be possible in a typical Basin and Range piedmont environment. Such studies are currently in progress or planned for the future.

Interpretations of age relations of deposits exposed at this location are preliminary and will hopefully be better constrained in the future. Gravel deposits on the upthrown sile of the fault are mid-Pleistocene in age ( 0.7 to 1.0 million years B.P.), based on analysis of ash present throughout much of the exposure. Aralysis of the ash exposed in trench $3 a$ and $3 b$ has been conducted by Andrea Sarna-Wojcicki of the O.S. Geological survey. The ash shows the highest correlation with Glass Mountain "G" (-I Ma) but the possibility of it being another of the tephras from the Glass Mountain-Bishop tephra group can not be ruled out. These deposits overlie Tertiary sediments, mostly silts, presumed to be closely correlative to the Miocene Esmeralda Formation. 
So flar, there are no good age constraints on the deposits on the downthrown side of the fault. Ash was not encountered, so it is believed that these deposits are all younger than the Bishopage gravels. In order to verify this idea, samples have been collected for paleomagnetic analysis. A reversed paleomagnetic direction (Matuyama reversal) would likely be present if any of these deposits are older than Bishop ash $(-0.7 \mathrm{Ma})$. Unfortunately, no samples have been found that could be radiocarbon age-dated. It is hoped that alternative age-dating methods (thermoluminesence, paleomagnetic secular variations, etc.) used in combination may at least provide approximate ages.

The currently forming soil is weakly developed throughout the trench. A silty, platy, vesicular A horizon (Av), thin (<10 $\mathrm{cm}$ ) on the upthrown side and thicker (up to $30 \mathrm{~cm}$ ) on the downthrown side, is underlain by a weak cambic $B$ horizon. This is a much younger soil than the age of the gravels on the upthrown side. However, apparent remanents of an older, well developed soil are present near the surface on the upthrown side and buried by up to $1 \mathrm{~m}$ on the downthrown side. This older soil has been observed near the surface in a number of localions in the surrounding area on both sides of the fault. It is present as thick (Stage II to III) carbonate rinds that are highly degraded. This appears to represent a long period of stability, followed by an erosional event that stripped the upper part of the soil horizon, down to the more resistant carbonate. It is therefore tentatively interpreted that most of the deposits on the downthrown side are late pleistocene in age.

Some three dimensional trenching has been done by progressively slicing back the south wall of trench $3 a$. The goal of this work was to investigate the small-scale fault structure in the trench to see if the sense of displacement could be inferred. Observations made are consistent with right-lateral displacement, but not diagnostic. Figure 16 is one of our trench logs from this exercise showing the small-scale structures observed. This trench log illustrates one example of the "flower structures" seen at several places along this fault zone.

\section{STOP 3: (optional) Trenches 4 and 8}

Trench 4 was excavated along a north-south trending fault trace, just north of the pressure ridge. Studies of offset surficial geomorpholgic features suggests right-lateral offset along this trace of up to $1 \mathrm{~m}$. About $1 / 2 \mathrm{~km}$ to the north of trench 4, the 1932 rupture becomes fairly indistinct where it faults Holocene and late Pleistocene alluvium.

The fault zone exposed in trench 4 is vertical with flower structures near the surface. The eastern side of the fault has a soil with an argillic $B$ horizon, and rather spectacular calcic and petrocalcic horizons below. The west side of the fault is apparently made up of late (?) Pleistocene gravels. 
Trench 8 was recently excavated across the base of the pressure ridge near it's north end. The trench confirms the compressional component of the ridge by exposing at least four probable reverse faults. The Miocene sediments are tilted vertically in the trench and significant bedding plane slip may also have occurred. This trench has also not been yet logged. Please do not disturb the walls of this trench.

\section{Discussion}

our studies to date clearly confirm that, in Monte cristo valley, the SMCVFZ, and specifically the 1932 fault ruptures are mostly the result of right-lateral translation. A dominant right-lateral strike-slip sense of displacement is indicated by offsets of smali-scale geomorphic features along surface traces and subhorizontal striations and grooves observed on the fault zone carbonate deposit in trench $3 \mathrm{a}$. Other observations consistent with this interpretation are changes in sense of displacement with changes in fault orientation, right-lateral overprints on secondary faults such as left steps in the graben zones, and Doser's focal mechanism studies. Figure 17 is Gianella and Callaghan's interpretation of deformation creating the 1932 surface rupture pattern.

The distributed nature of the fault zone could be due in part to rupture of multiple faults, but also appears to have a pattern consistent with conjugate shears in a right-lateral wrench system. The multiple rupture notion is important, because it illustrates the possibility of small, simple events progressing into larger events through the triggering of multiple faults. Several historical earthquakes and earthquake sequences in the Basin and Range province have involved a number of different faults at or near the surface, and have resulted in large earthquakes.

Precise delineation of pre-1932 events and recurrence interval estimations have not yet been accomplished. Along some parts of the main fault, a bevel just above the 1932 scarp exists and appears to be evidence of a pre-1,932 event. Investigations, including profiling studies, will be conducted at these and other sites. Studies will continue for earthquake occurrence information. Gianella and Callaghan (1934a) report that ruptures at the northern end of the 1932 rupture zone (near the epicenter in southern Gabbs Valley) occur along preexisting scarps. one question is whether the pattern ruptured in 1932 occurs characteristically from event to event. This question may be answered thlough examination of the various faults making up the 1932 mpture zone, and determining the age of the most recent pre-1932 faulting event. 
Savage, J. C., 1983, Strain accumulation in western United States: Annual Reviews Earth and Planetary sciences, v. 11 , p. 11 .

Slemmons, D. B., Jones, A. E., Gimlett, J. I., 1965, Catalog of Nevada earthquakes, 1852-1960: Bull. Seismological Soc. of America, v. 55, p. 519 .

Wallace, Robert E., 1984, Notes on surface faulting in Dixie Valley, Nevada, in Western Geological Excursions: Guidebook, Geological soc. of America, Annual Meeting, v. 4, p. 402 


\section{References}

Abe, Katsuyuki, 1981, Magnitudes of large shallow earthquakes from 1904 to 1980: Physics of the Earth and planetary sciences, v. 27, p. 72 .

Askew, Bonny and Algermissen, S. T., 1983, An earthquake catalog for the Basin and Range province, 1803-1977: $U$. $S$. Geological Survey, open-file report $83-86$.

Coffman, Jerry 1. and von Hake, Carl A., 1973, Earthquake history of the United States: $U$. S. Dept. of Commerce, publication 41-1.

Doser, D. I., 1987, Source parameters of the December 20, 1932 Cedar Mountain, Nevada earthquake: Seismological society of America, Seismological. Research Letters, v. 58, p. 19.

Doser, Diane I., in preparation, Source mechanisms of earthquakes in the Nevada seismic Zone (1915-1943) and implications for deformation in the western Great Basin.

Gianella, V. P. and Callaghan, E., 1934a, The earthquake of December 20, 1932, at Cedar Mountain, Nevada, and its bearing on the genesis of Basin and Range structure: Jour. of Geology, v. 42, p.1.

Gianella, V. P. and Callaghan, E., 1934b, The Cedar Mountain, Nevada, earthquake of December 20, 1932: Bull. Seismological soc. of America, v. 24, p. 345.

Gutenberg, B. and Richter, C. F., 1954, Seismicity of the earth and associated phenomena: Princeton University Press, Princeton, NJ.

Hardyman, R. F., 1978, Volcanic stratigraphy and structural geology of Gillis Canyon Quadrangle, northern Gillis Range, Mineral County, Nevada: University of Nevada - Reno, PhD Thesis.

Molinari, M. P., 1983, wrench fault tectonics of the southeast margin of the central Walker Lane, west-central Nevada (abs.): Geological Soc. of America, Abstracts with Programs, v. 15 , p. 384 .

Molinari, Mark phillip, 1984, Late Cenozoic geology and tectonics of Stewart and Monte Cristo Valleys, west-central Nevada: University of Nevada - Reno, Masters Thesis.

Molinari, Mark P., 1984, Late Cenozoic structural geology of Stewart and Monte Cristo Valleys, Walker Lane of westcentral Nevada, in Western Geological Excursions: Guidebook, Geological Soc. of America, Annual Meeting, v. 4, p. 402 . 


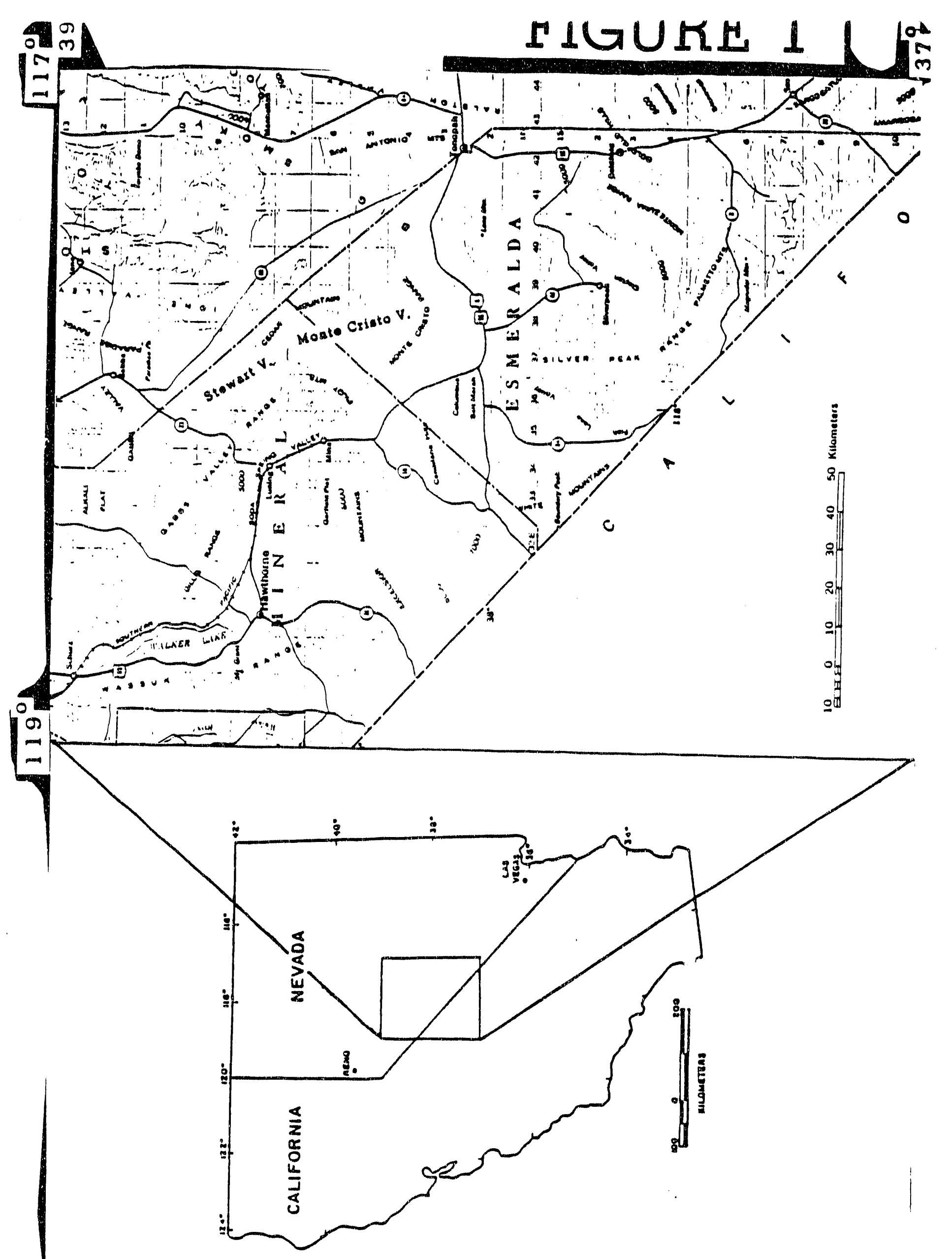




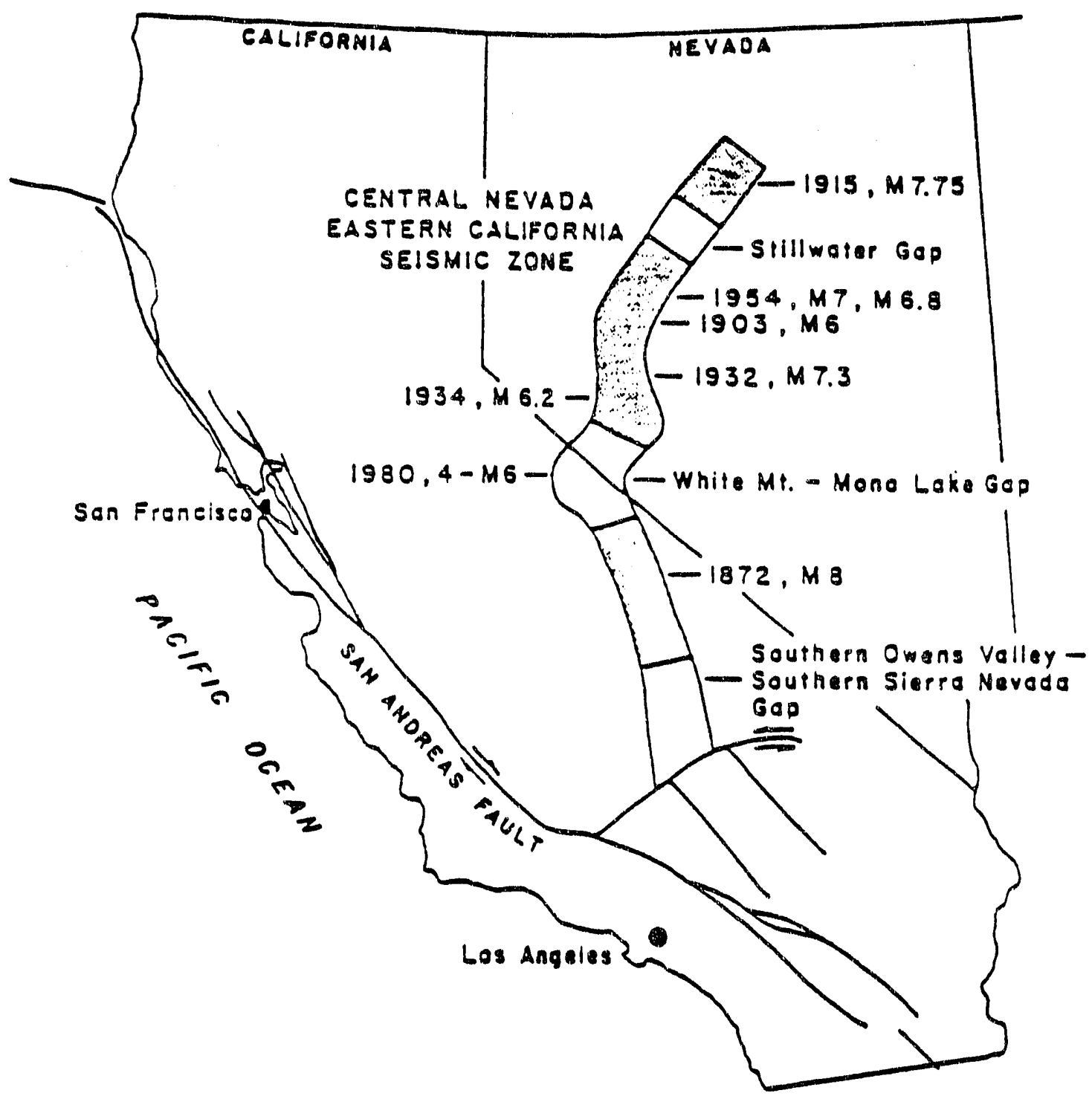

Seismic Zones Showing Historical Surface Faulting and Seismic Gaps. (Wallace, 1984) 


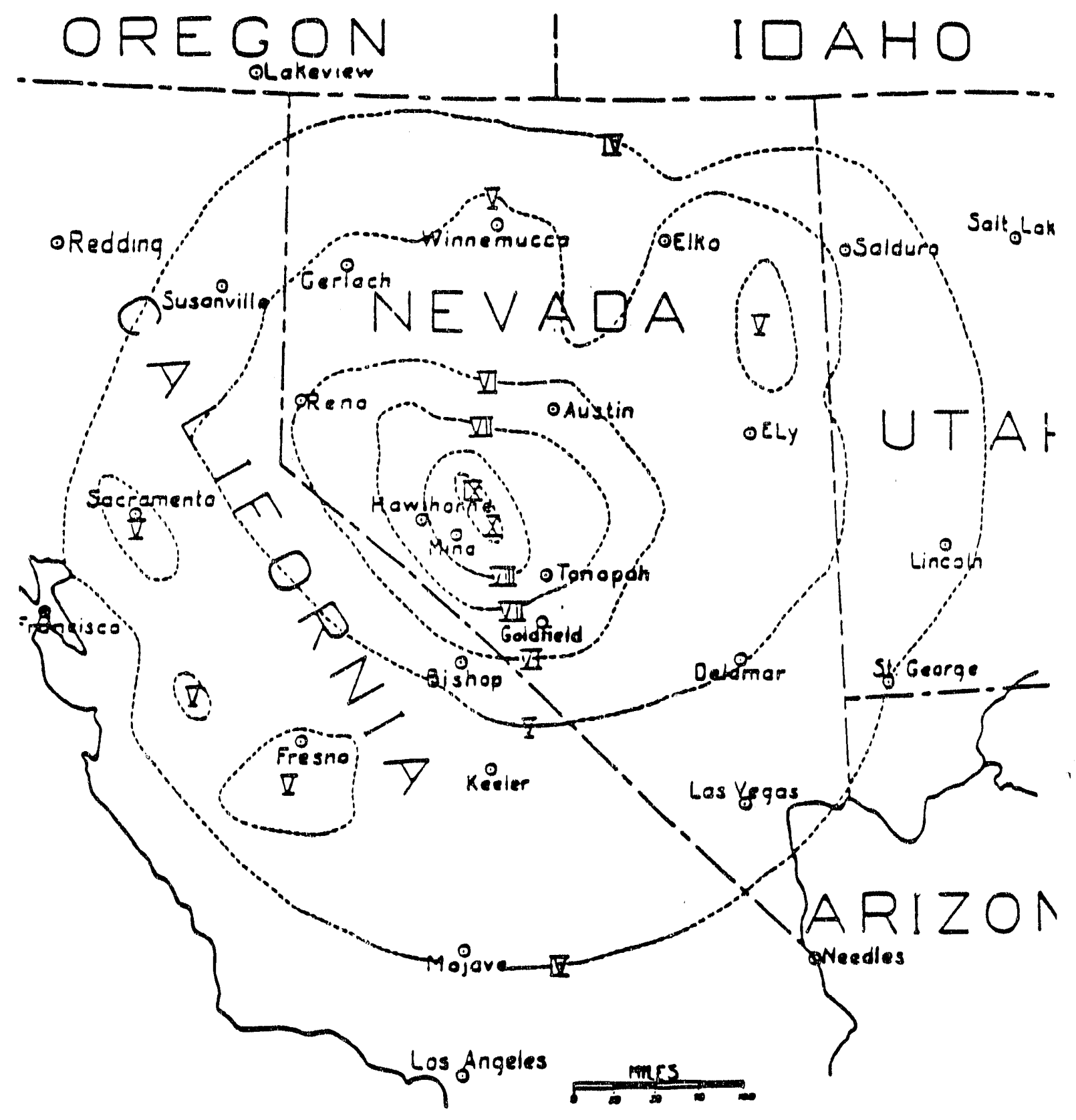

Rossi-Forel Isoseismal Map of the 1932 Cedar Mountains Earthquake (Gianella and Callaghan, 1934) 


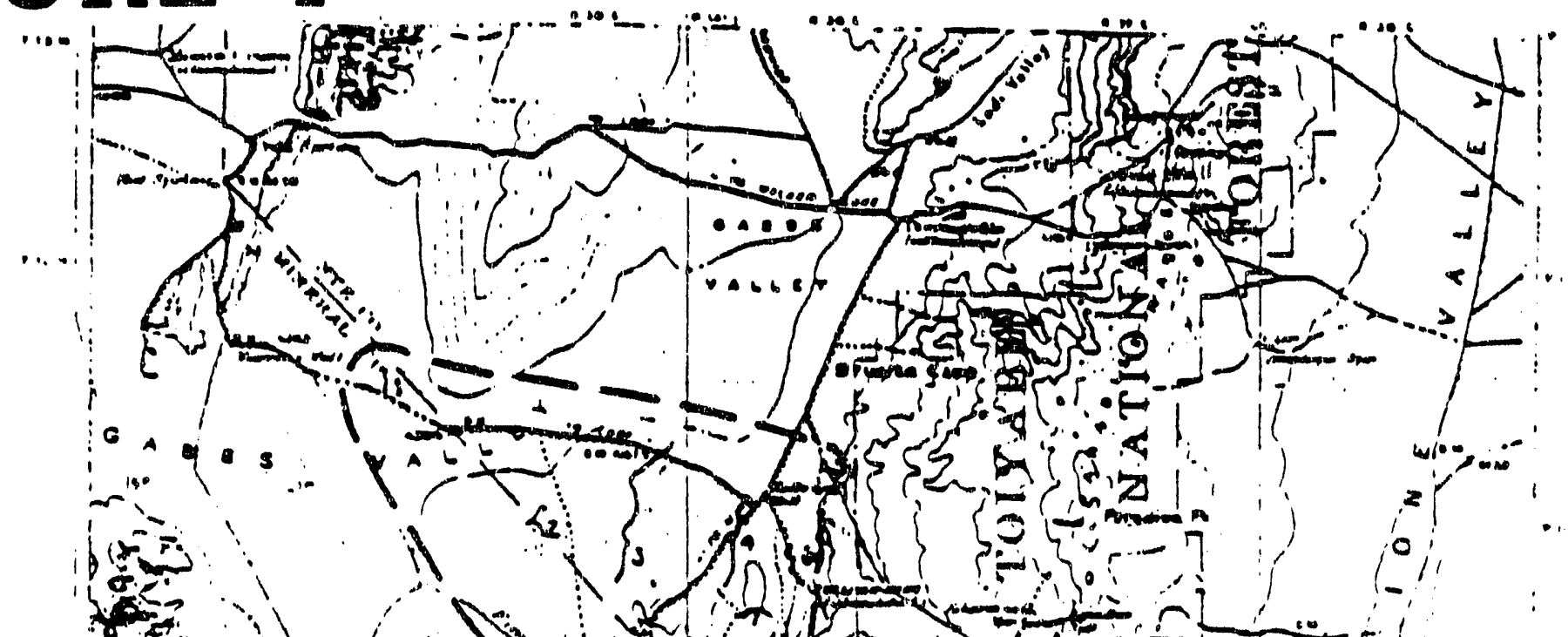

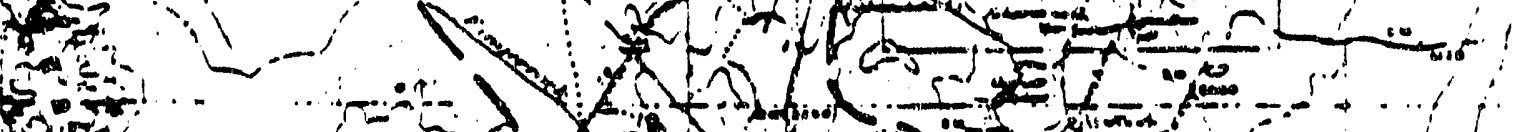

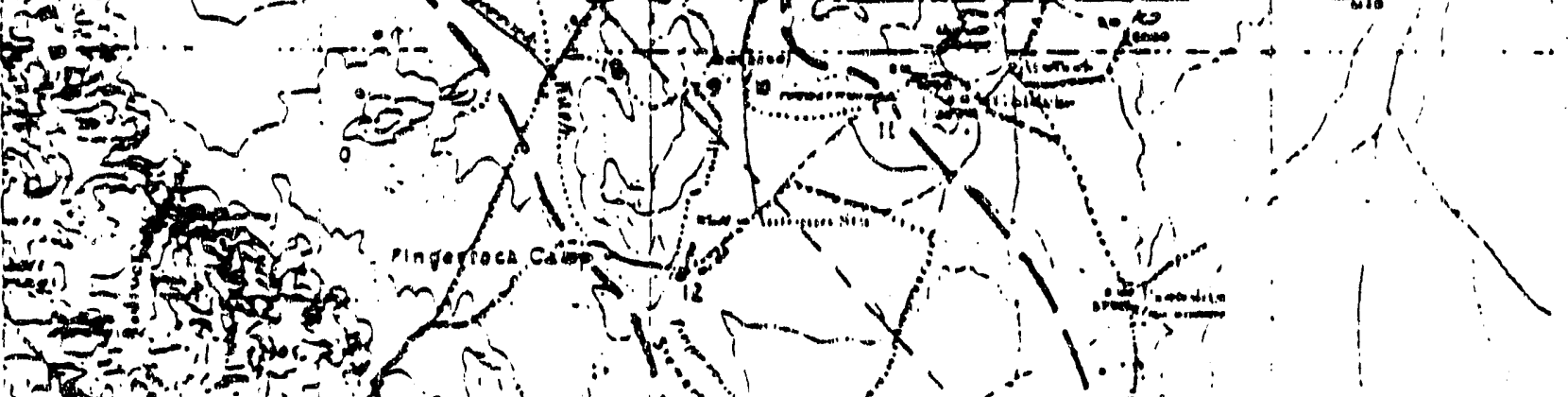

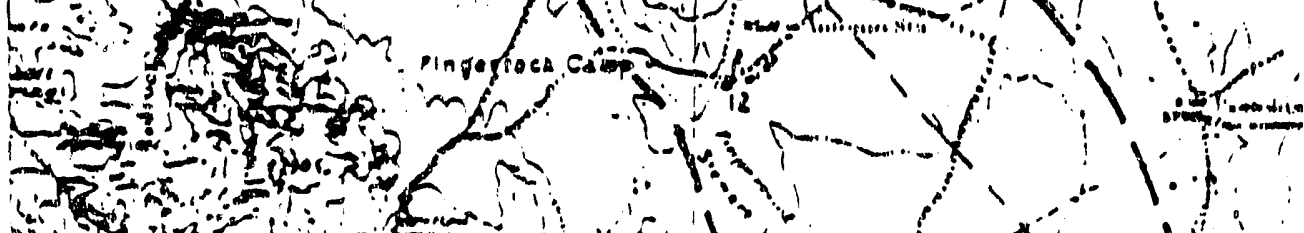

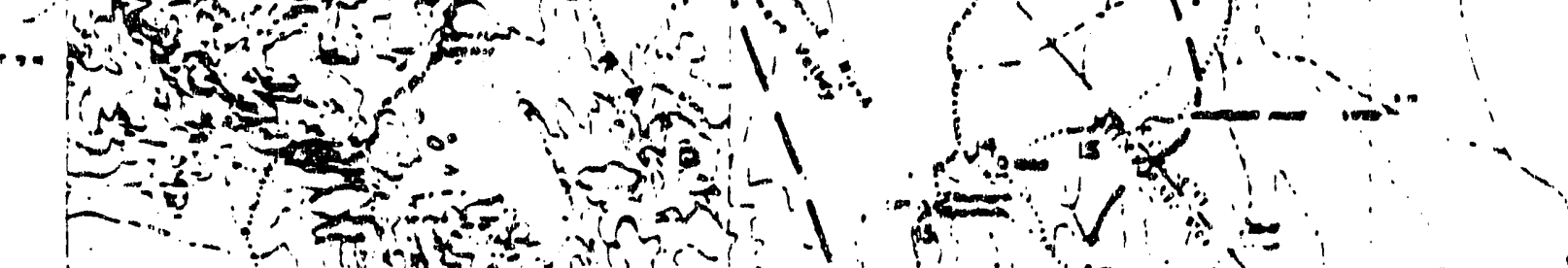

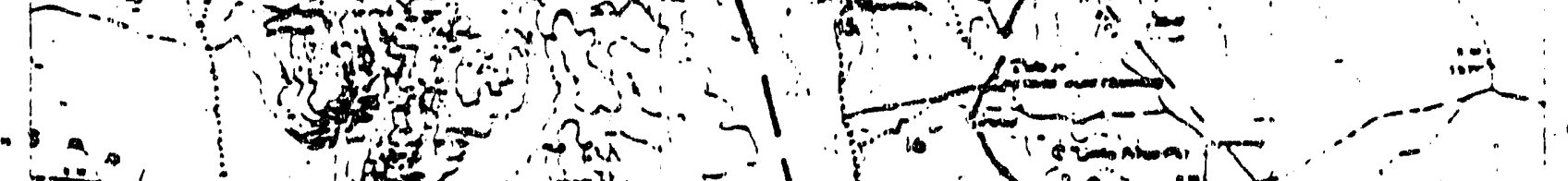

400 o

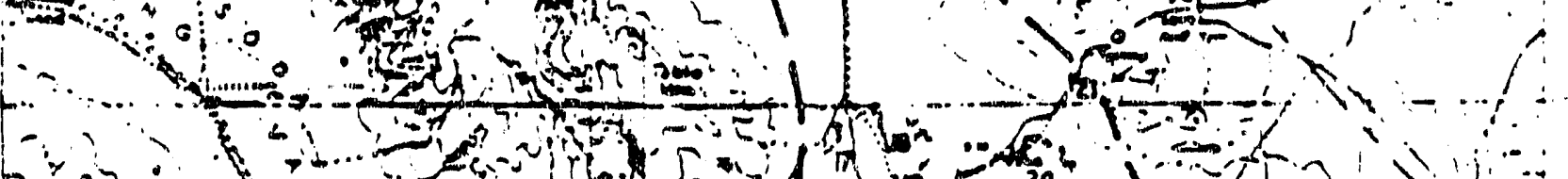

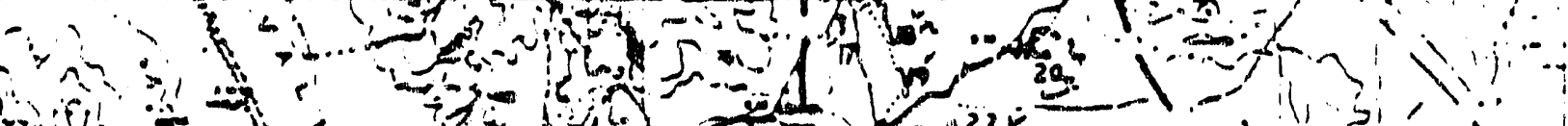

ayin ate

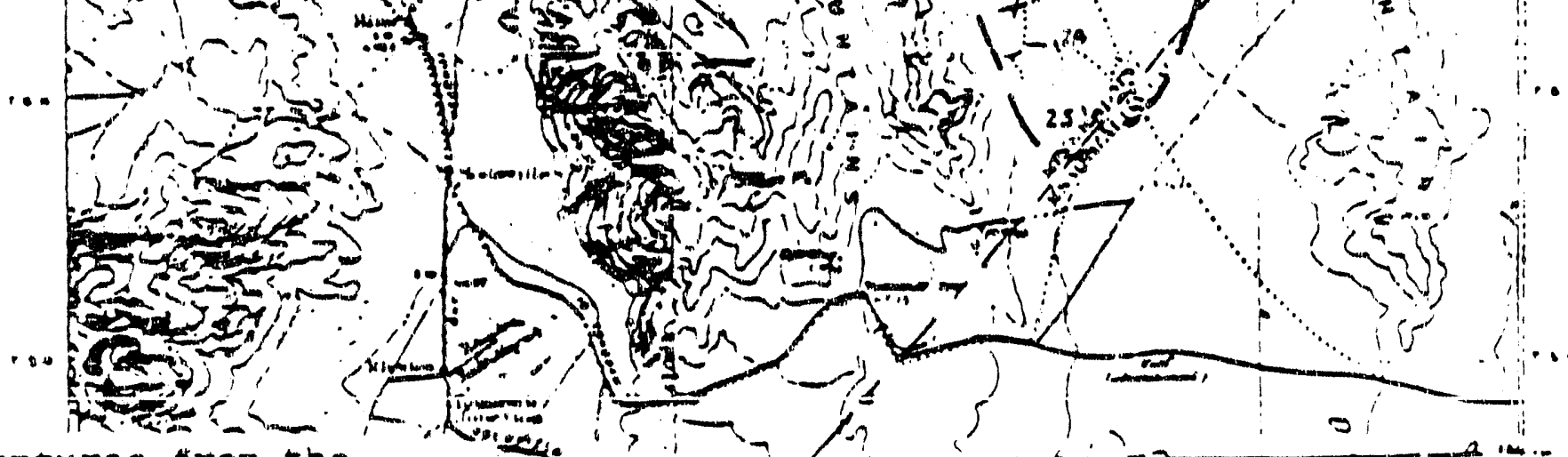




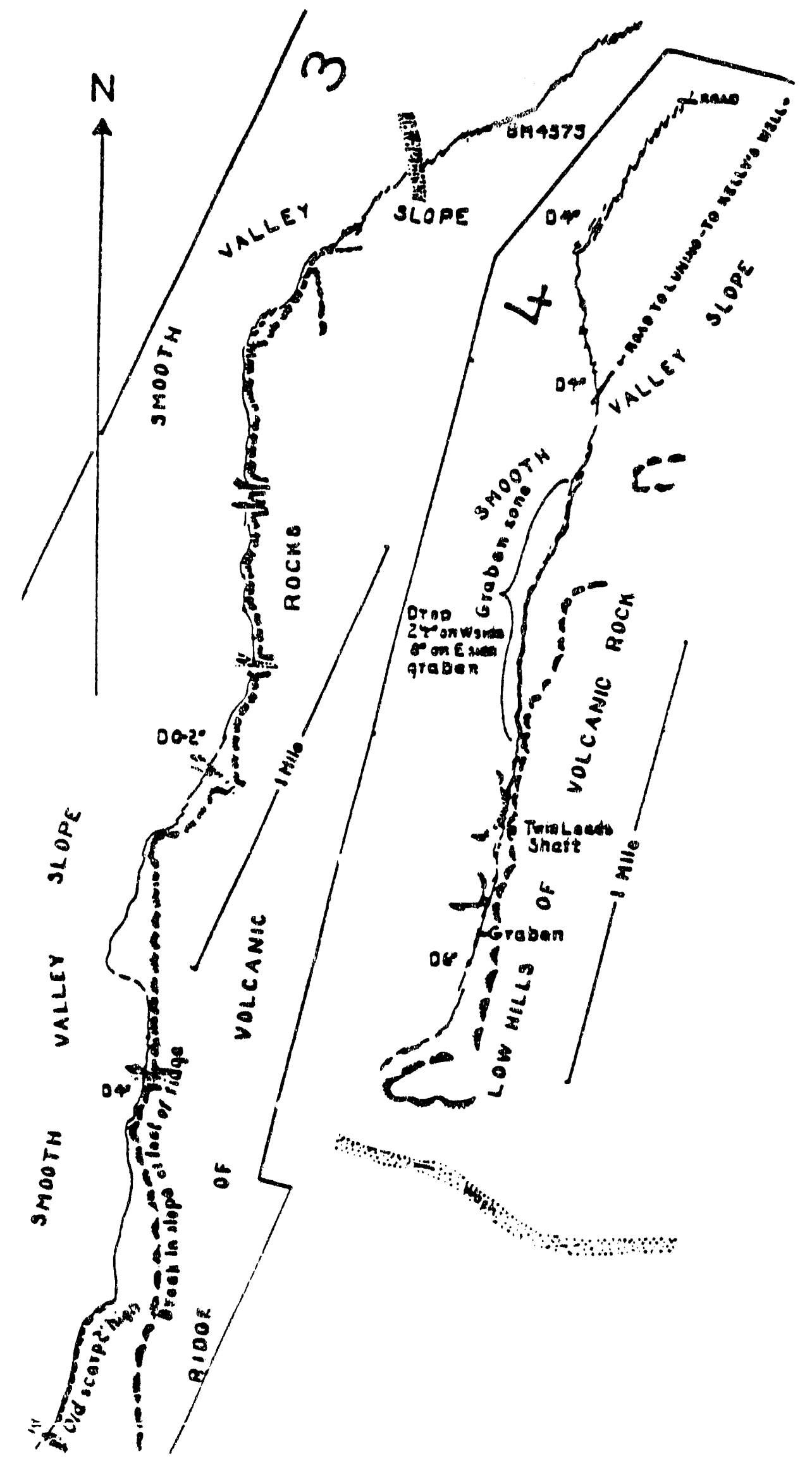

Detajled Surface Ruptures

(Gianella and Callaghan, 1934) 


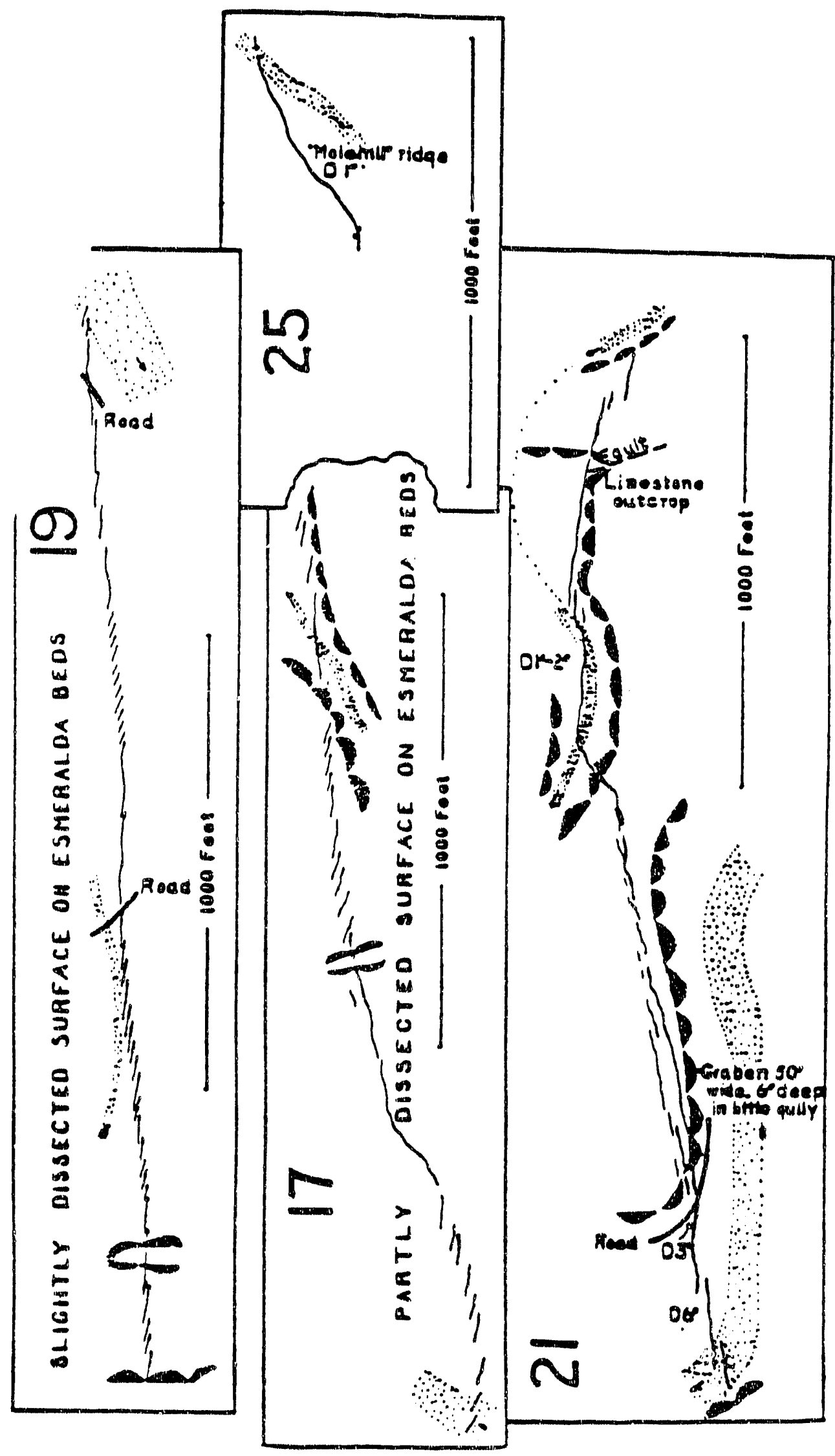

Detailed Surtace Ruptures

(Gianella and Callaghan, 1934) 

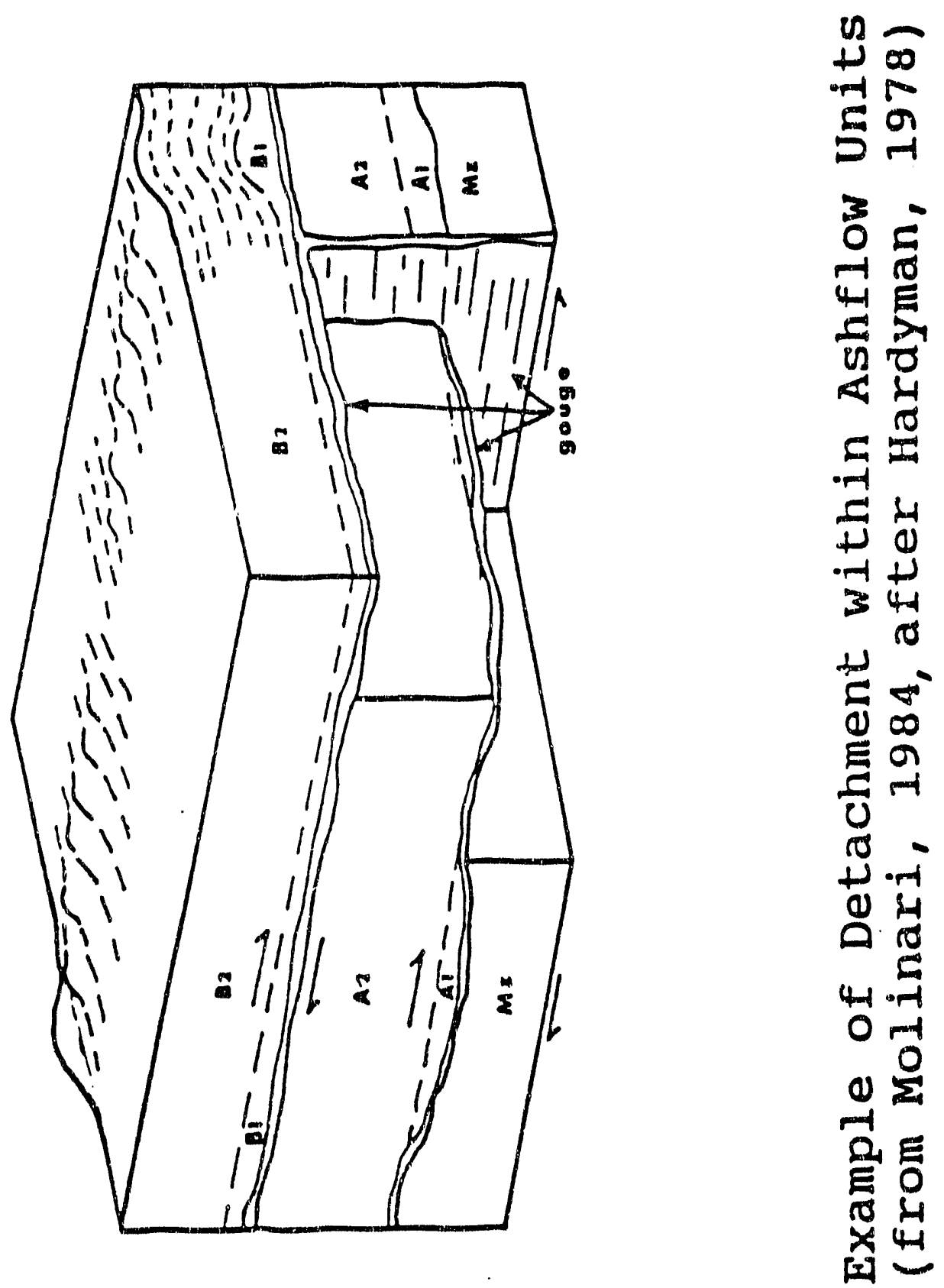
trats and Monte Cristo Valleys

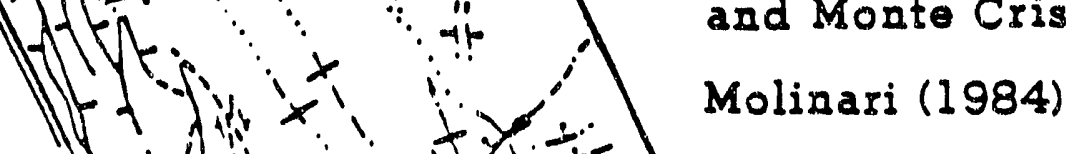
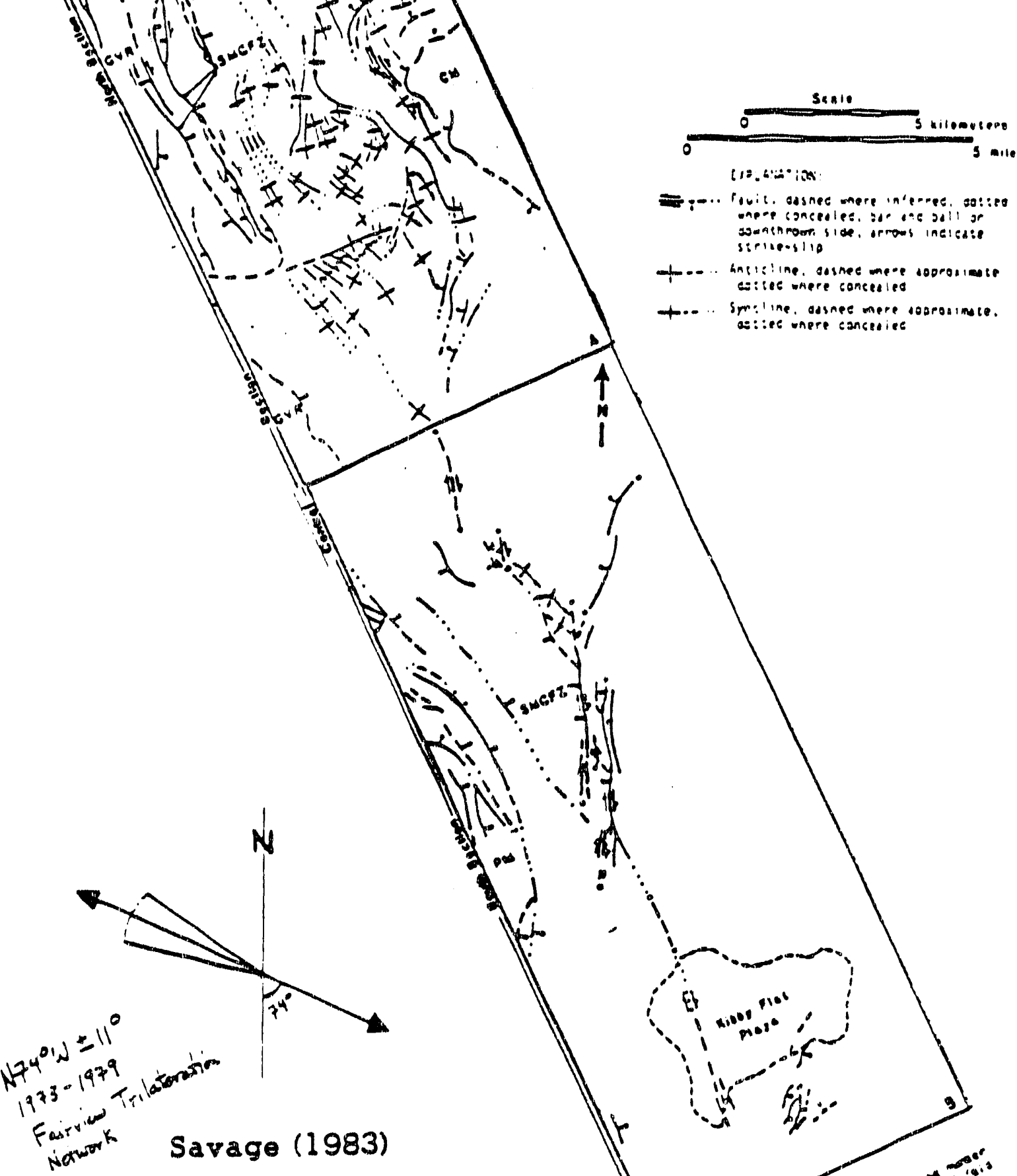

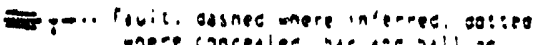

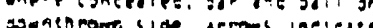
sodathrown side, orrous inelsa:e

7 -...

cailes wape concelled

+... Smoline, adsnes mere lospoalmule.
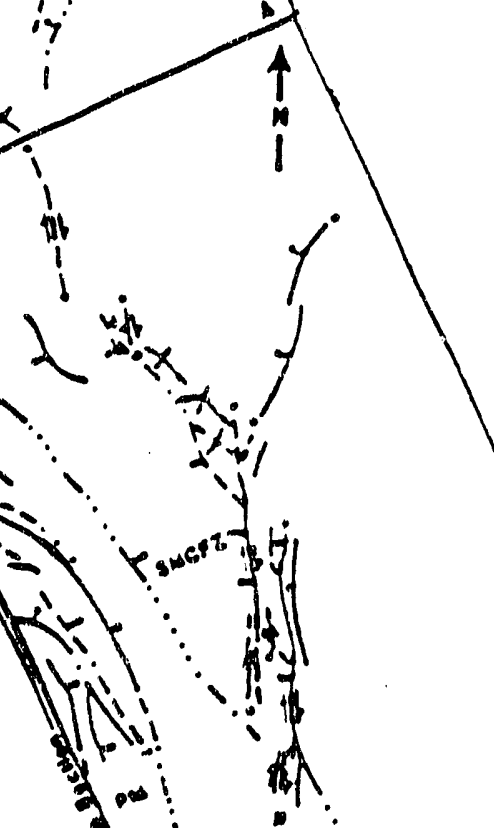

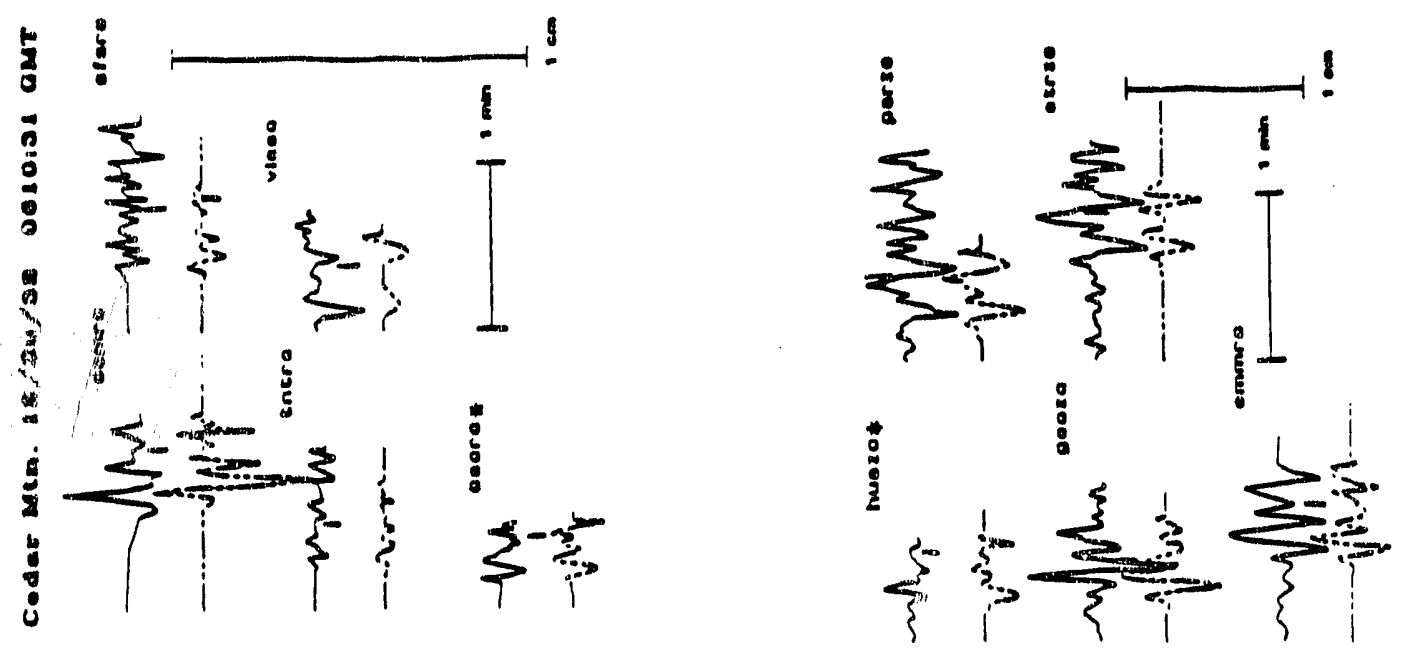

空
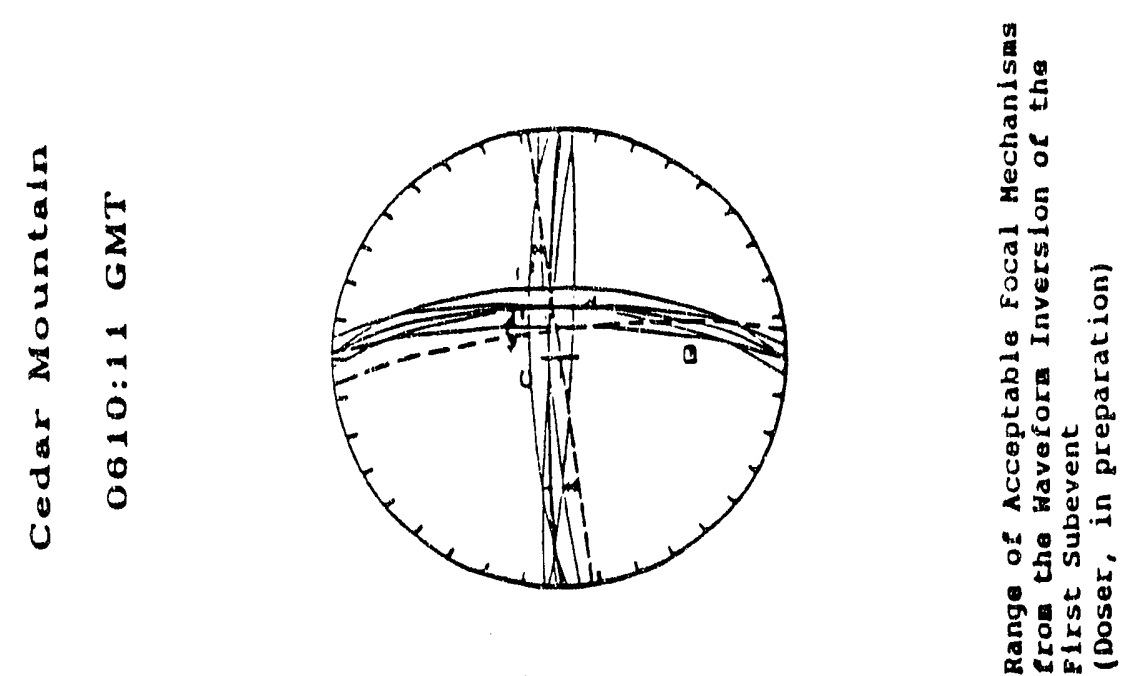

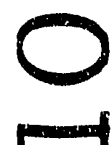
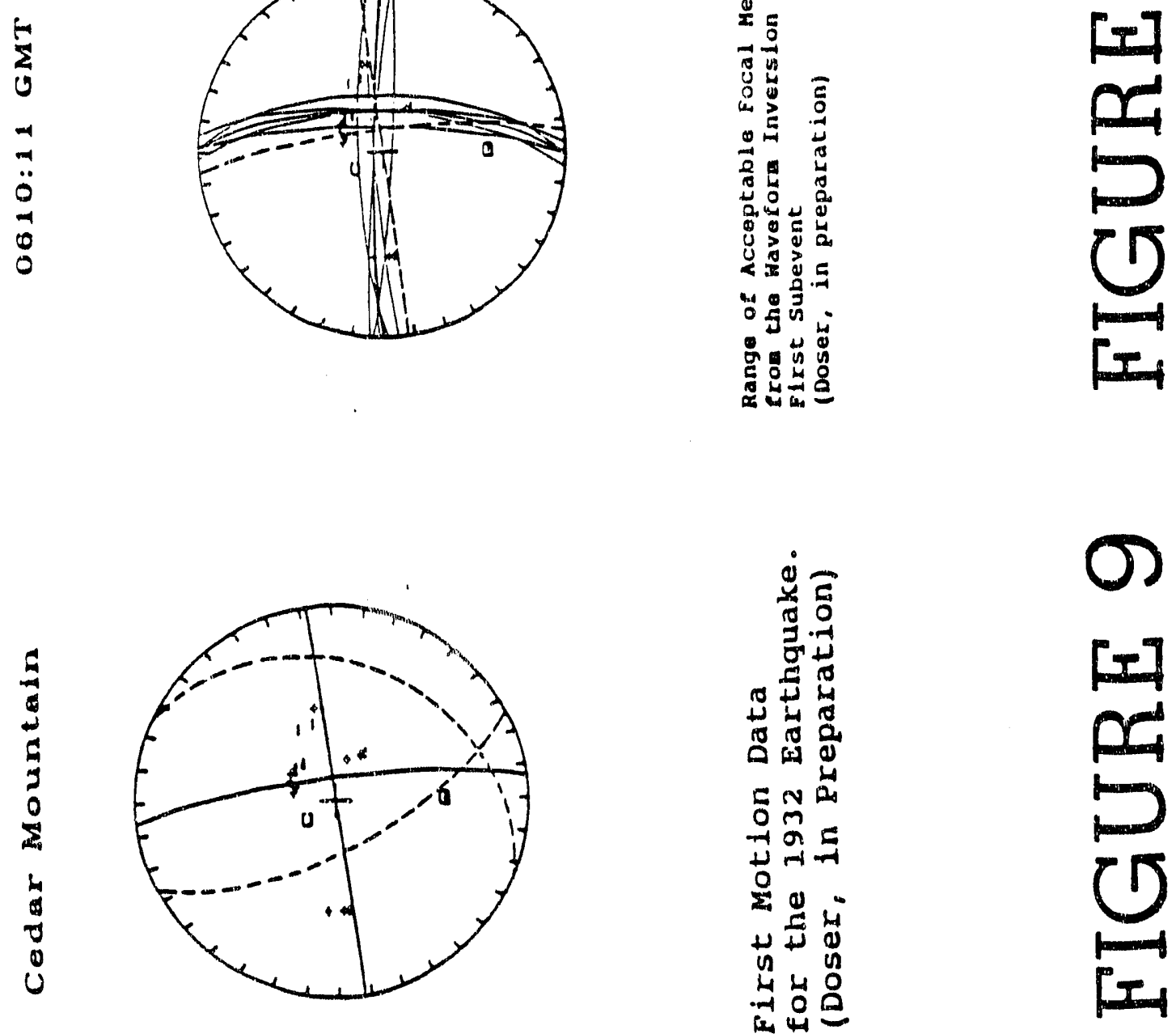

$\sigma$
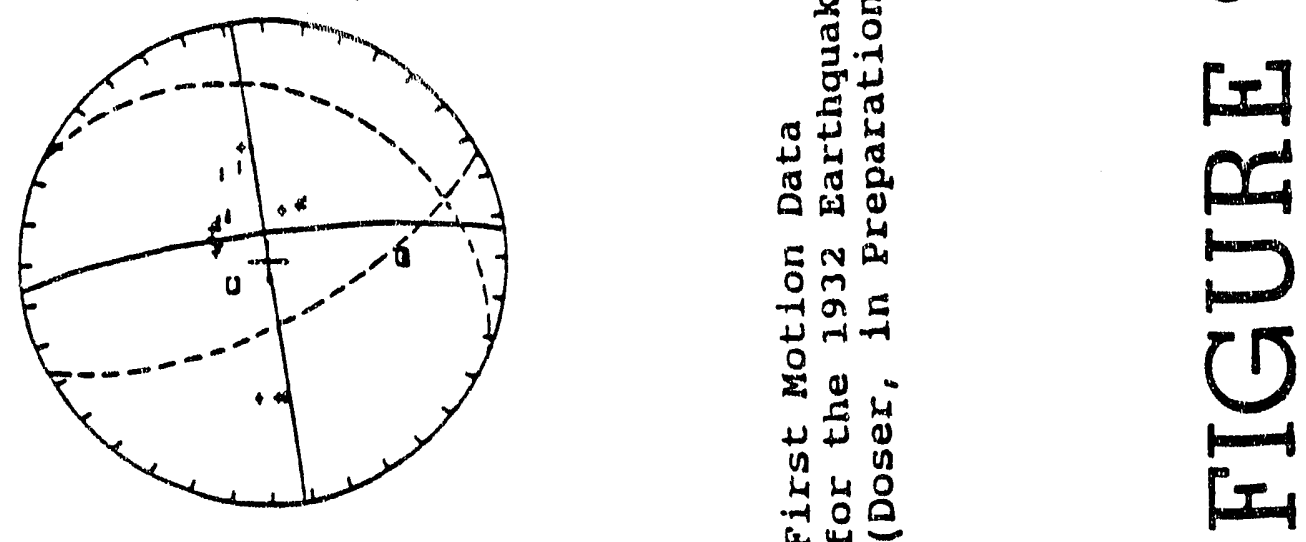


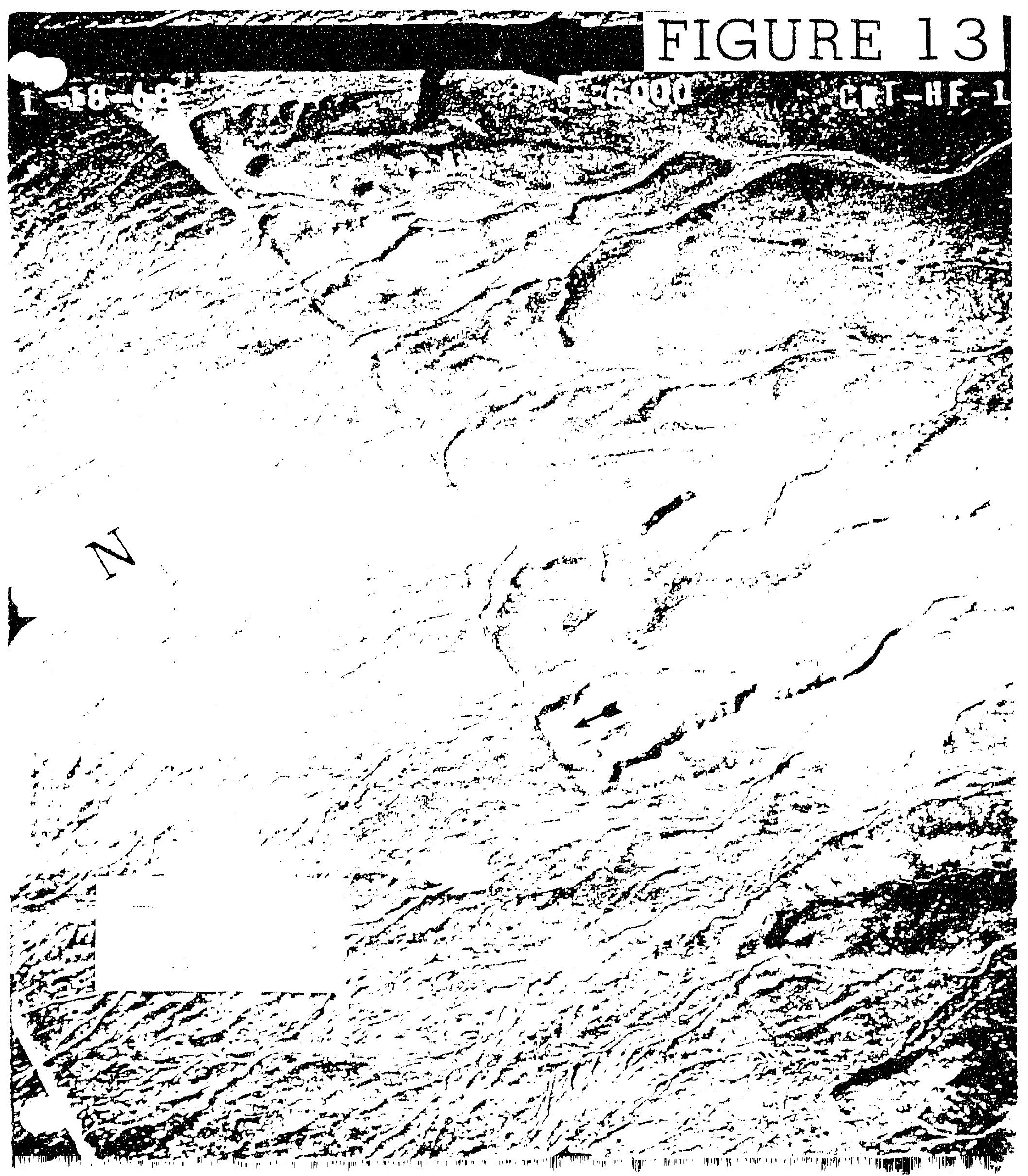


FIGURE 14

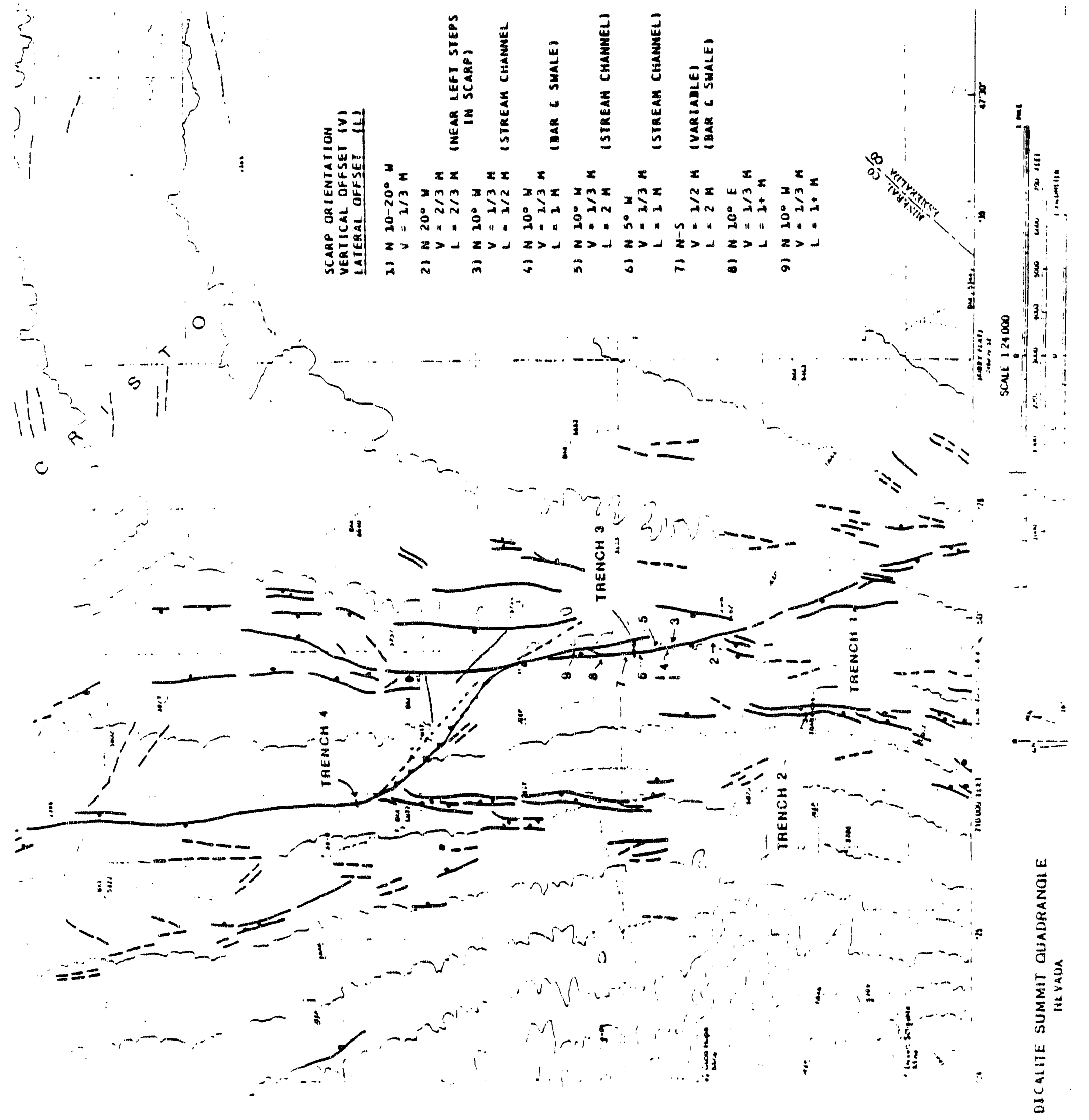




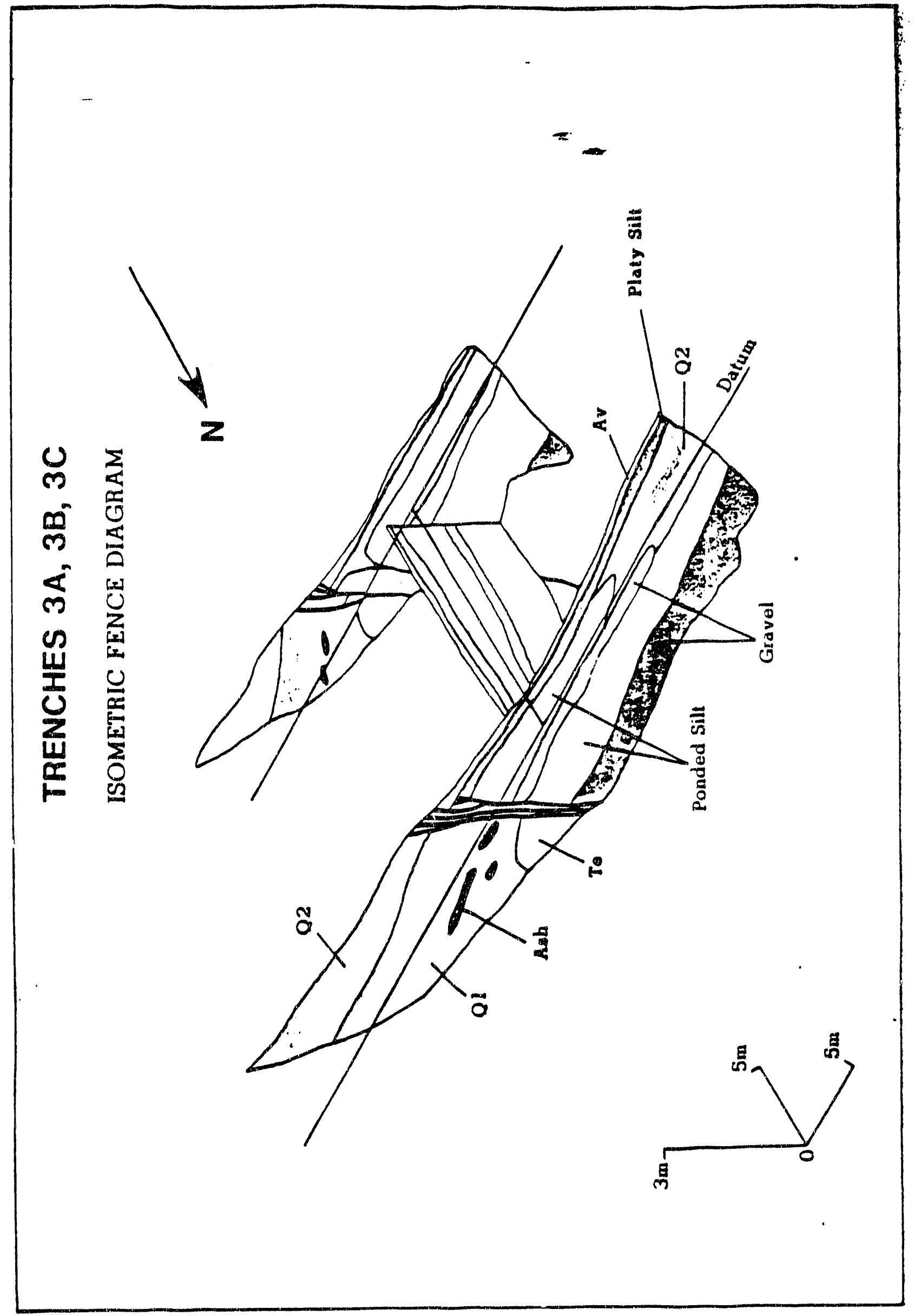




\section{FIGURE 16}
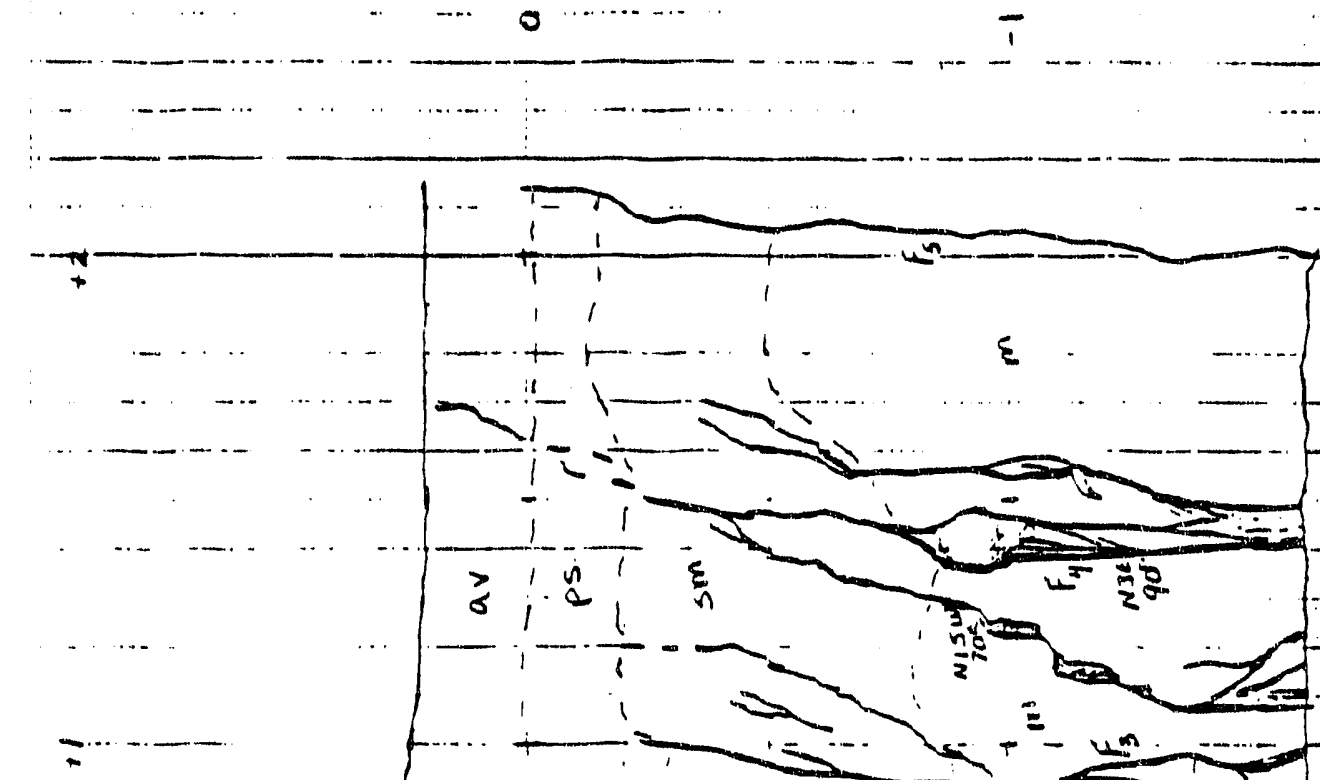

$=$
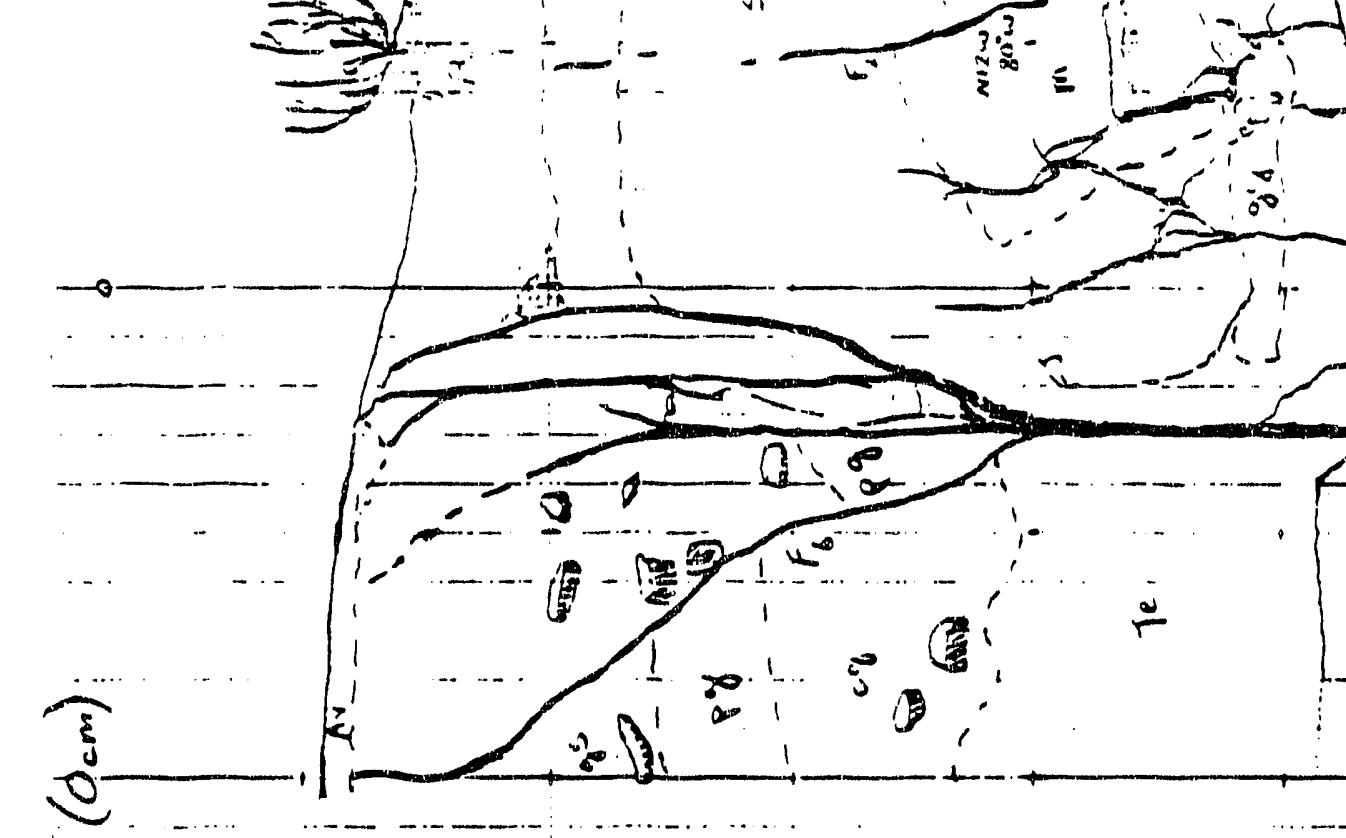

ते है 


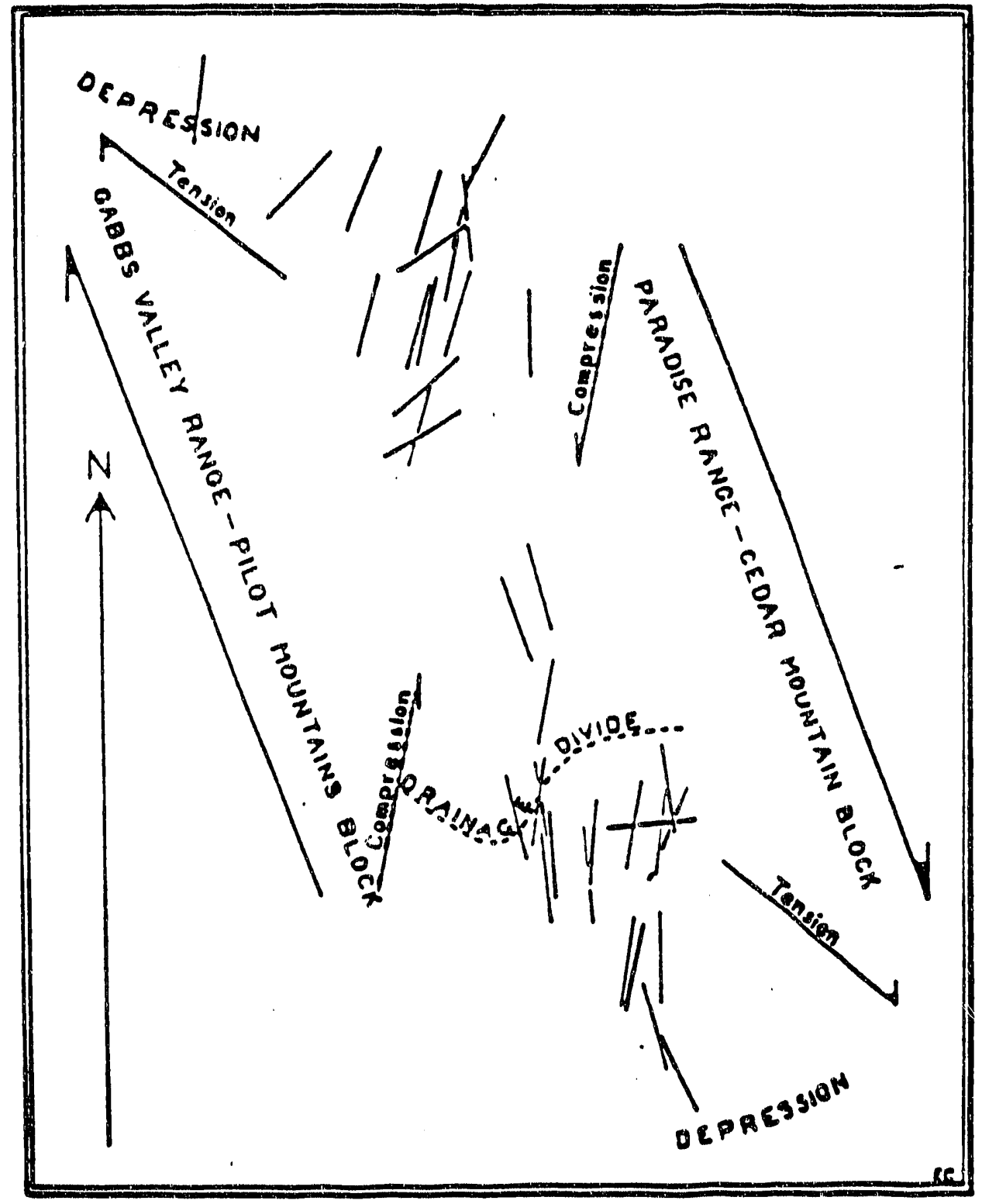

Average Trends of Surface Ruptures in Their Relative Mapped Positions. (Gianella and Callaghan, 1934) 


\section{FIGURE 18}

UNHSL

Seismicity

1970 - Sep 1987

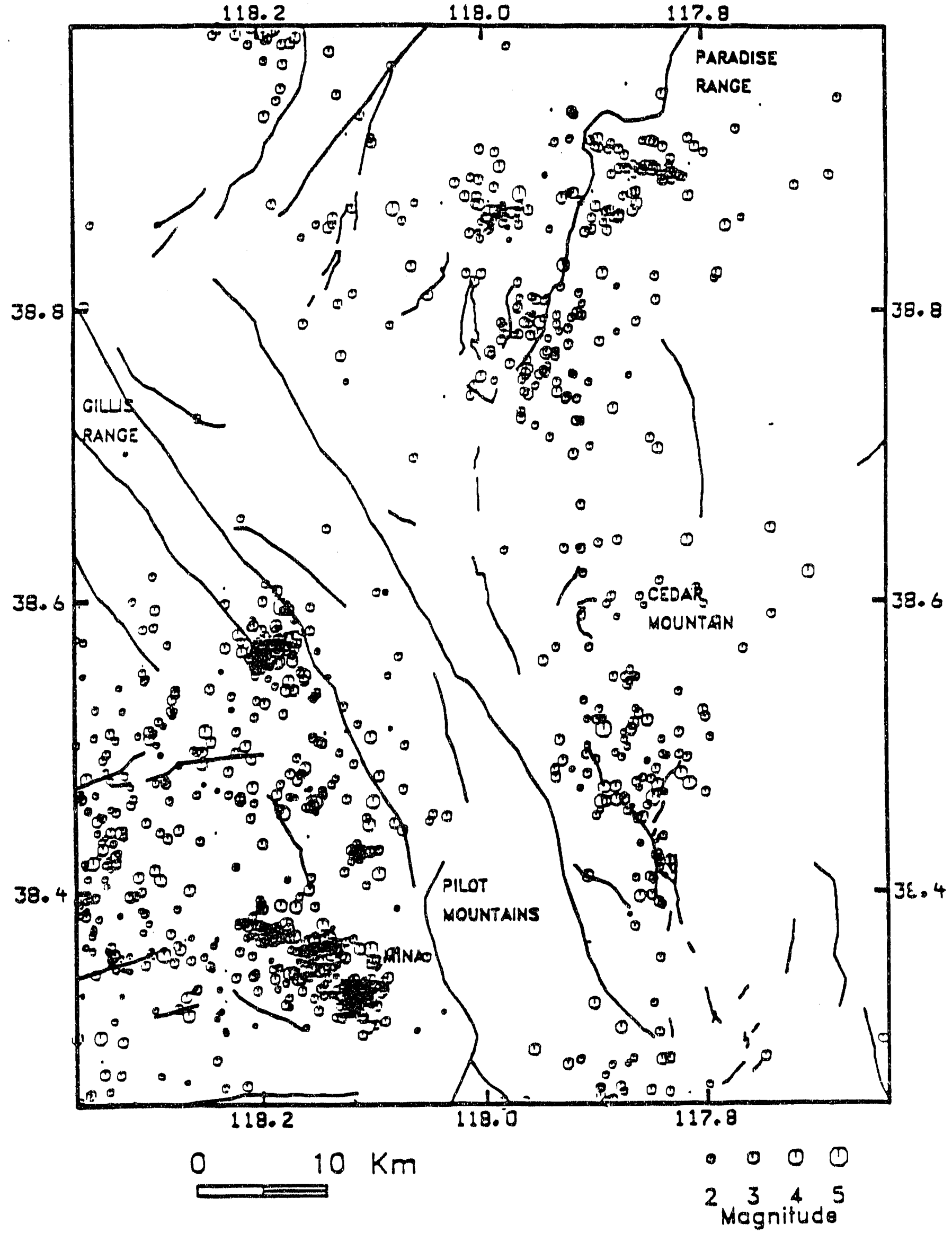


ง

-

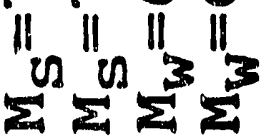

-

r

il

$\pm$

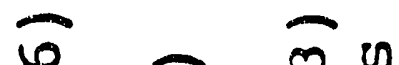

$n-\pi \quad \infty$

o $10 \pi$ o

$\rightarrow 6$ or $\rightarrow 0=$

- O I $\longrightarrow>$

HU

(1) 14 व

+ U1 Un

ए

- 1 \&

म

0 or 0

ส

ช $E \sim$

o

H n $\infty$ E.d.A

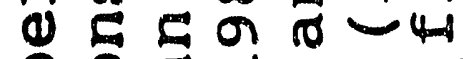

20 10

¿ $E$ E 34

ఏ)

ชั $\sum_{0}^{0}$

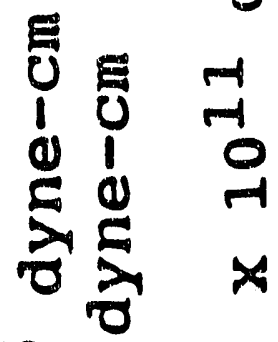

(2)

ก 1 เก

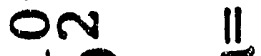

- 02

$x \quad E$

ด $N$

$\rightarrow \infty$

$+10$

$n^{+1} a^{\infty}$

- 12

-1 0

$+\infty$

도

.

E $\Omega$ 空

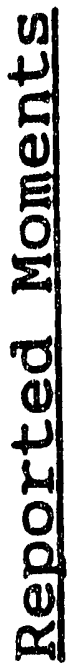

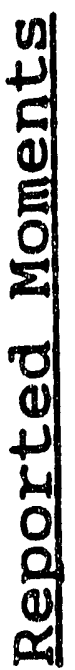

c E - II

- ब Q \& 30

Q $>>$ U

(1) अ 0 o $=0$

4.

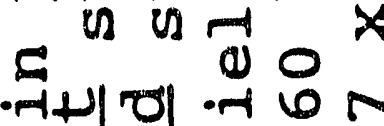

4 $\rightarrow N-H N$

$\begin{array}{ll}0 & 0 \\ 0 & 2 \\ 0 & \frac{1}{2}\end{array}$ 


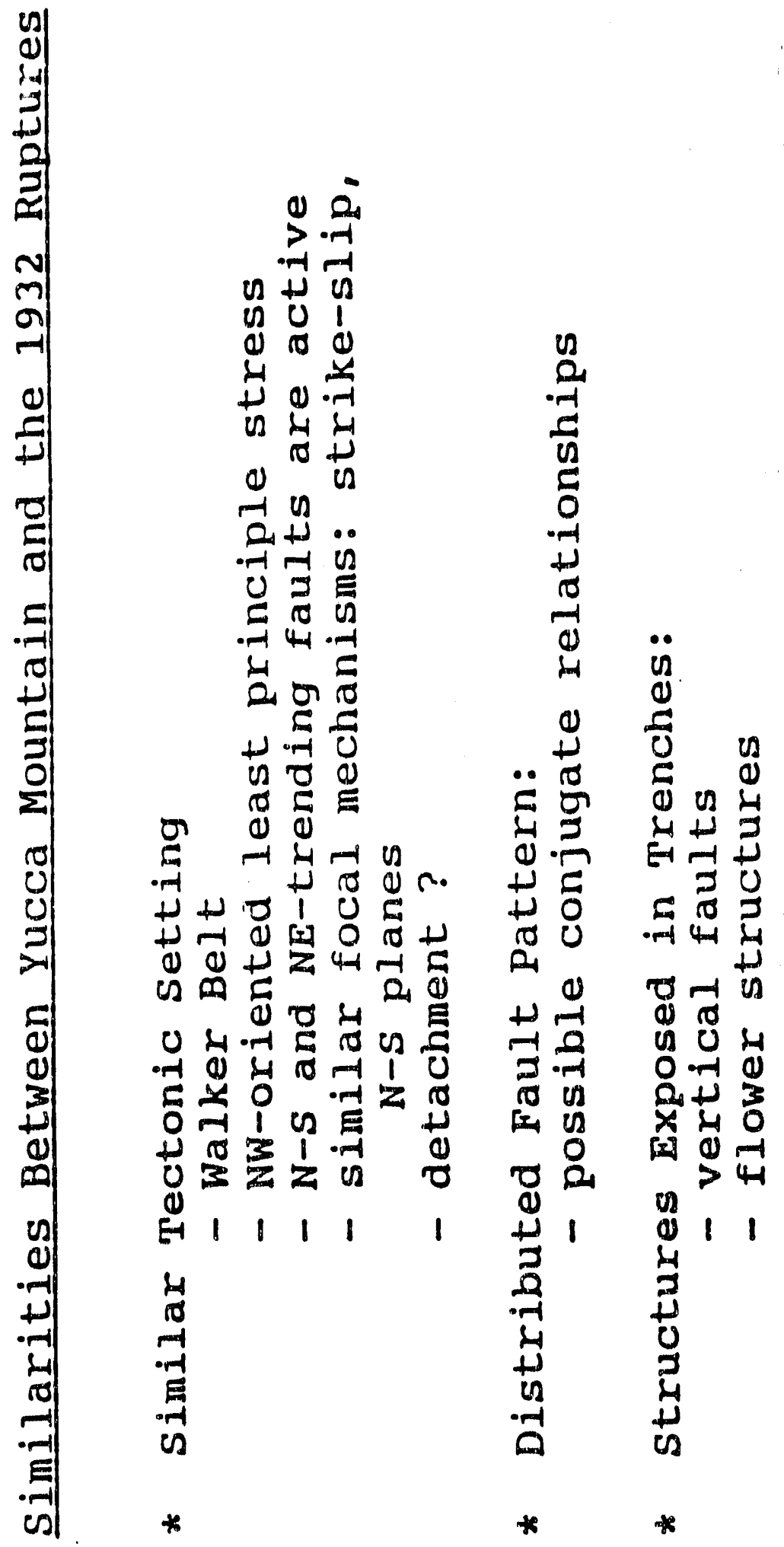




\section{Appendix $F$}

Abstracts presented and/or submitted 
Presented at: Late Cenozoic Evolution of the southern Great Basin: A Workshop: University of Nevada - Reno, 1987

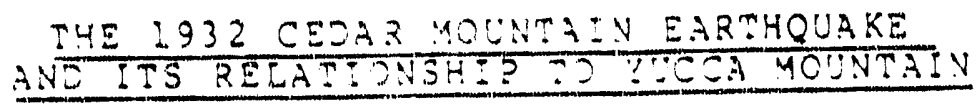

John is. Bell, Craig Y. Jepolo, and Alan R. Ramelli vevada $3 u r a d u$ of vines and jeology, university of vevada-Reno

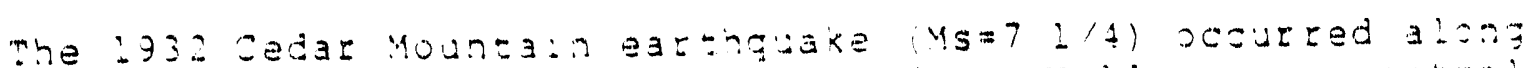

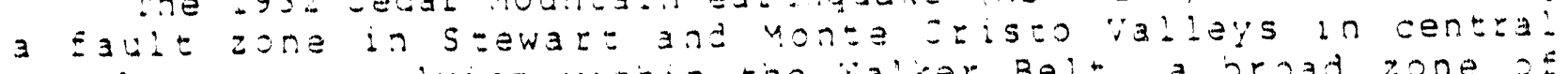
verada, an area lyang w: thin the ialier Belt, a oroad zone os

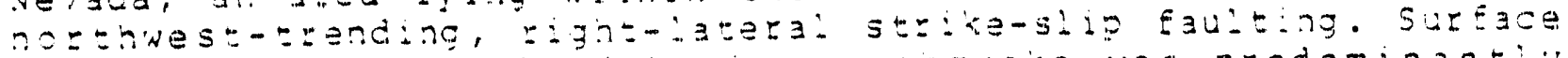

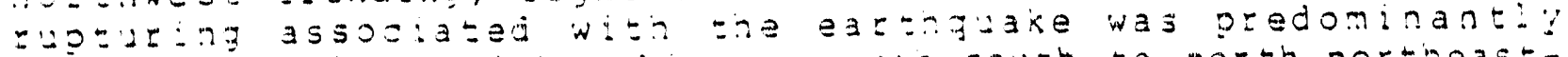

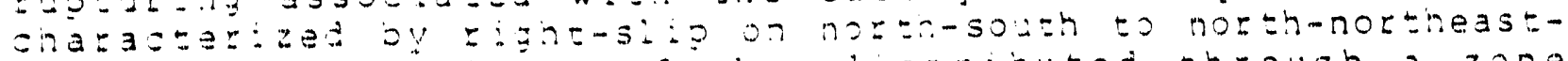
trending, discontinuous zad:s d:s:zibuted theough a zone approximately $15 \mathrm{~km}$ wide and $5 \mathrm{~km}$ Long. This rupture pattern is bes: explatred by conjugaze asuling within a not thest-trending hrench Eall: system wherein the 1332 faults would be regarded as synthetic (Riedel) shears, a model proposed in yarious ways by several other pravious anestigarors.

Dezalied sureicial napo.ng and exploratory trenching o se:ected i332 ruptures in Monte cr:sto Vabley indicate tha: recurrent quaternary movement has occurced in this zone, with the mos: recent pre-1932 event possibly being Hoiocene age. Jetailed recurzence interval investigations are in progress. Results oj the crenching indicate that movement on north-south-oriented talits is characterized by right-lateral stike-sili? disolazement. Near-horizontal slickensides and grooves suggest that $15-30$ on of vertical ofEset and $2-2 m$ of lateral offset occurred in 1932; these values are consistent with previous estimates 2 displacement of surface jeomorphic teatures, and in pazticilaz agree well with the Eirst-motion focal mechanism soudies oz poser (1987). The zzenching also shows that the falit: exace is narked by a prominent wpward splaying, a zommon geanza

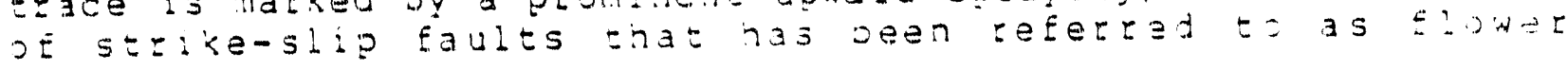
s=actices.

Sinilarities between the zectonia settings os whe cedar Mountain and the Yucca Mountali areas are recognized and should be considered in evaluatiag the porential for iarge-magnituce st:ike-silp Eajlting at qucaz Mountain. These similarities include: stress regimes which have northwest-oriented least principle stress directions; active right-lateral strike-slip Eauits oriented in a north-south to north-northeast direction; focal mechanisms with north-south nodal planes and right-iateral sirike-sil? motions; possible conjugate relationships between northwest and north-south-trending structures; and exposures $\supset$ s Elower structures along falits in trenches. 


\section{No $\quad 17862$}

QUATERNARY GEOLOGY STUDIES IN THE 2954 DIXIE VALLEY ANO I932 CEDAR MOUNTAIN EARTHQUAKE AREAS, CENTRAL NEVADA BELL, John W., Nevada Bureau of Mines and Geology, Universiz: of Nevada-Reno, Reno, NV 39557

The 1954 Jixie taliey (M6.9) and i932 Cedar Mounsain (M7.3) earthquakes resulted in extensive surface rupturing aiong faults exnibiting recurrent late quaternary movement. In order to better understand the nature and rate of this recurrent movement, Quaternary stratigrapnic and jeomorphi= studies were conducted in selected areas. Surficial deposits were ditferentiated on the basis of ailuvialjeomorphic characteristics: genesis, suzsace morphology, s = atigraphio position, so:L-ptotile development, and absolute-age data. Mapping establ sned the chronostratiaraphic relationstips of faulted and untalted deyosits, and exploratozy serahing and at:Ling provided detalled control on faul = history.

In Dixie valiey, late puacernar: faulting has occurred a-ong tivo najor zones: a range-feont sab: zone at the eastern base of uhe 3t:Livater Range, and a piedmont zone :ying a tew kilometers east of the range front. Although most of the 1954 displacement (3-t $m$ of normal slip) sccurred on the range-front faul:, the piedmont zone has een nore active during she Hobocene. Tro Holocene tephra oracket an earlier event on the pledmont zone, while no comparaole event is recognized at the range front.

in Monte cristo valley, i932 fauling (1.-2 m of rightatera: and $30 \mathrm{~cm}$ of yertical offset) was related to stzike-silp movement along a nid-yaliey wrench system. Late xuternary ozfser is substantially greater than suggested by surficial reiationships die to the strike-slip nature of the novement. Mid- to late Quaternary teohra in faulted ailuvial-fan deposits help constrain prior events.
I2

CATEGOAIZE ALL ABSTRACTE - Chinck JNE diecrouno unow in whith oviduers would be best

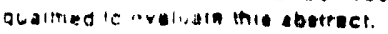

- i icmacological georogr

D 2 con geology

a i aconomie goology

C. angineering gecrogy

Q Senvironmential geotosy

a b ganorar geology

$=$ goosnomistry

I g goology oducation

$=7$ goomoronolegy

$=10$ geophysics

Cli geoscionce intormation

012 giaciel goology

Zi 3 mision ol geology

Eid myerogsology

=.5 marire gociogy

Lis micisosioniology

Z17 minuralogy/erystallogerany

= ocanogiany

$=19$ ouleoniology palooboluny

020 Dolloloum goology

221 polrology exporimentes

222 petrology gnoous

Q23 ourology moumoronic

224 doirclagy seolmenten

225 renoleri groixay

J26 A.ocamurian goology

Z27 Ouaternang geology

Dil temole sonsing

Q28 sedimeniviogy

$=30$ stratigruony

Z3i stive:ural gnology

$=32$ ocionics

zo3 iecionics/goodivalcs

234 volcanology
TYPES OF SESSIONS AVALLALI.E

A SPECIAL - NVITED ABSTRACT FOR A SYMPOSIUM LX This aosiract was invitod lor tho symoosium nited

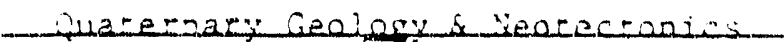

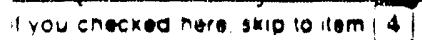

B VOLUNTEERED ABSTRACTS

(1) SPECIAL-THEME SESSION. ANNUAL MEETING ONLY - would like inis aosiract considered lor oral orosentailon a! the lollowing Theme Somssion lor the Annual Meeling. Denver 1988

C. Oenensesio of lecustrino rock*

E 2 Georggy \& Pubite Politey lor the 2.191 Century

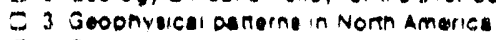

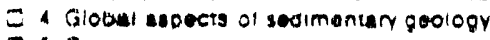

Es Organic comoounds in ground water

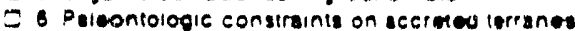

- Phyzics ano chumisiry or mylonites

E 8 Sectiar wariotior in the secimencen recoro

it not accopled tor the theme session do you want it considered for a ingular imennical session?

J Yes a NO

2) O CRAL SESSION D POSTER SESSION I ETMERTYPE = Ill acced a changer in NDO (ORAL DPCSTERI 1 necossary:

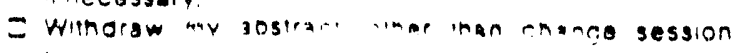
ine

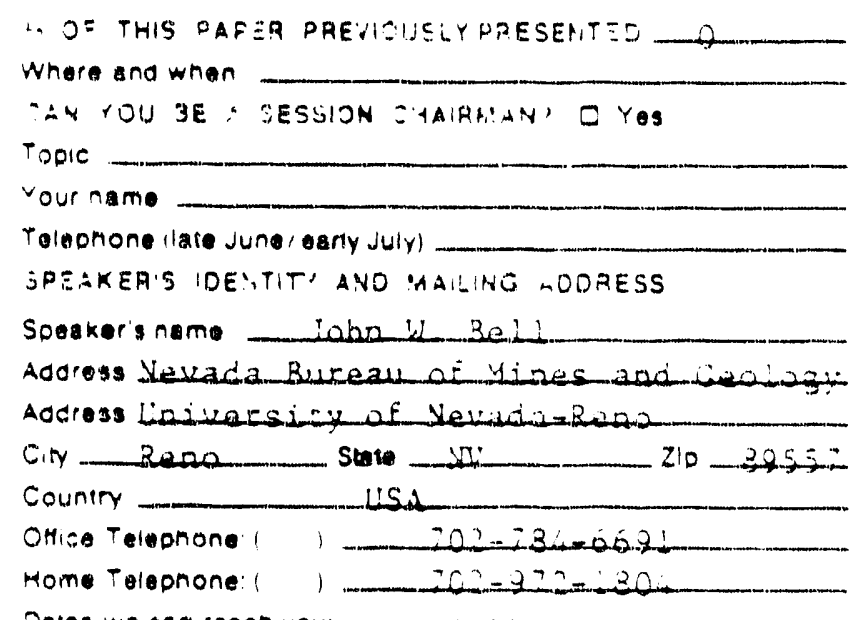

Dates wan ceen you:

SENJ OAIGINAL - J IOUMES OF A3STAACT TO LPPACPALATE

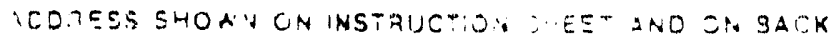

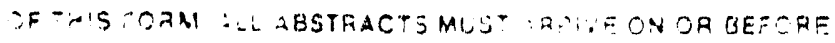

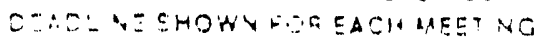




\title{
ABSTRACT FORM FOR ALL GSA MEETINGS IN 1988
}

\author{
Complete soetions $\frac{1}{!}$ inrough $\bar{T}$ beww
}

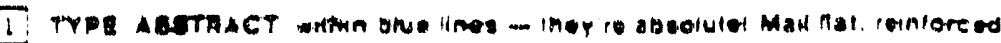

\section{No 27231}

EVIDENCE FOR DISTRIBUTIVE FAUITING AT YUCCA MOUNTAIN, NEVADA RAMELLI, ALan R., BELL, John W., and DEPOLO, Craig M.:

Nevada Bureau Mines \& Geol., Univ. of Nevada-Reno, 89557

Yucca $M$. is the sole site being considered for underground storage of the nation's high-level nuclear waste. Low-sunangle aerial photography indicates more widespread recent faulting than previously believed and suggests similar histories for the principal faults. Differing offsets of surfaces along the solitario Canyon fault indicate multiple late Quaternary events; small vertical displacement (about $20 \mathrm{~cm}$ ) of the youngest faulted surface suggests Holocene activity, similar to age-estimates from the windy wash fault (Whitney and others, 1986). Morphology of the windy Wash scarp as defined on low-sun-angle photography supports the incerpretation of a small Holocene displacement superimposed on a compound Quaternary scarp. Scarps along the Bow Ridge fault and at Busted Butte indicate more extensive and recent falizing than previous interpretations (e.g. Swadley and others, 298t). Morphology of the Fatigue Wash Eault, which has received relatively little attention, indicates activity similar to the other principal faults in this area.

complex seismic events involving several faults luay be are characteristic of faulting at rucca Mt than simple,

igle-fault ruptures. Close spacing $(<2 \mathrm{~km})$ of Quaternary tauits with similar morphology and the presence of basaltic ash from a local source in narrow fault fractures suggest the possibility of complex, large magnitude events. Such events would involve rifting and dike intrusion in the lower- to mid-crust and distributive rupture across several faults in the upper-crust and at the surface. Evidence of Holocene or latest-most Pleistocene ages of faulting and basaltic volcanism suggest such an event may be reasonably possible over the next 10,000 years.
[2]

GATECOAIZZ ALL AGSTAACTS - Choet ona diserpuna batow in whien cerremere woula be best quaktiod 10 molusto inte entuset.

O I ienmeotagical growogy

$02 \cos g$ geology

a i economic geotogy

D a ongineenng goovogy

OS envirenmental gostogy

Q o gereral geology

Z 7 guvenomisir

Is zoology oducalion

I 9 gromoronologr

210 geopnrsics

Ell gorscience intormation

Q13 glacial geolugy

213 nisiory of geology

214 nyorogeology

2.5 marino goology

=.6 miciodaicomionogr

="7 minclalogy/engiallography

-1s oceanogisonr

=.9 saiboniology dolloobolany

$=20$ soltoloum goology

221 palrology exporimanew

222 soirology gneous

Q23 perrology meismorphic

224 detrology sedimamiary

T25 Dianmary georogy

Q20 Procamoran goology

027 Ouatermany goology

028 emote sensing

029 secimentology

030 sizeligradony

Q31 siruetural geology

232 :ocionics

C33 locionics/gooonysics

O34 rolcanology
3 TYPES OF BESSIONS AVAILABLE

- SPECIAL - INVITED ABSTAACT FOR A SYMPOSIUM = This acstract was inwted for tho gymoosium ntiod

\footnotetext{
1, OU ckecked have $2 \times 10101 \mathrm{~mm}$ a

3. VOLUNTEERED ABSTRACTS

1) SPECIAL-THEME SESSION ANNUAL MEETING ONLY I would like inis aosiract consigered lor oral presentation a ine lollowing Theme Session for the Annual Meoting Denver. 1988

Q1 Oinganasis of lecustrina rocks

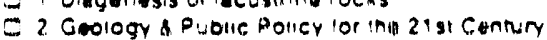

Z 3 Gooonvaical dartarns in Nonth Ammica

E. Gluoai asoecty ol sedimenian goology

Es Organic compounds in grouno water

a s paleoniologic consirainis on accietea lerranes

D. Physics ina enemisiry ol muionices

- S Socular variation in ine sadimenumin iocord

if not accedoc lor the Theme Sossion Ju you want if considered or a reqular tecrnical session?$$
\text { OYes D NO }
$$

2) CRAL SESSION O POSTEA SESSHON = ETTHEA TYPE

- III acced a cnange of session VD ORAL $\rightarrow$ POSTEAI 1 mecessary

Z Withoraw my austract arther man charigo session woe
}

4 W OF this papea paeviously paesenteo t Where and when

5 CAN YOU BE A SESSION CHAIAMAN? O Yes

TODIC

Your name

Toleonon* (late June/ oarly July)

b SPEAKEA'S IOENTIT ANO MAILING VORESS

soevkers name ALAN R. RAMELLI

Adaress NEVADA 3UREAU IF MINES \& GEOLQGY Addross WNIVERS IY OF NEVADAT-RENC

Cir RENL NV NV 29597

Country LSA

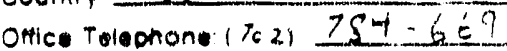

Hume Tolephone $(\pi 2) 322-3105$

Dates we can ceach you: any ane

7 SEND ORIGINAL - S COPIES OF ABSTAACT TO APPROPRIATE ADORESS SHOWN ON INSTAUCTION SHEET AND ON BACK OF THIS FORM ALL AESTRACTS MUST ARAIVE ON OR BEFORE OE' JLINE SHOWN FOR EACH MEETING 
No $\quad 10923$

IMPLICATIONS OP ROCK YARNISH DATING AT CRATER FLAT, NEAR YUCCA MOUNTAIN, NEVADA.

JCRN, Ronald I., Geograpry Jepe., Arzzone stace univ. Tempe Az 35287 : BELL, John, Hevada Bureal of Mines and Geology.

University of Nevada, Reno 39557; PEmERSON, Fred, Dept Range w:ldlife and Foregiry, Universiey of Nevada, Reno,89557.

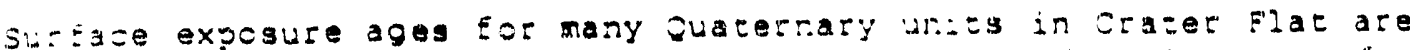
provijed by ana-ysis oz :xk varmist. RV:. AMS radiocarbon ages tor

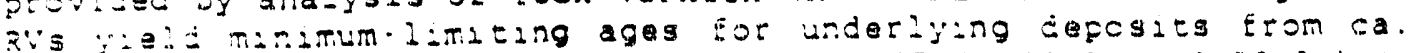
$3 . j<3=030 . j$ <a $36.6,10.2,17.3,25.7,27.3,28.9$, anci $30.3 \mathrm{kal}$.

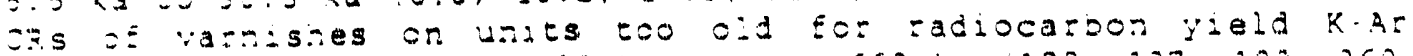

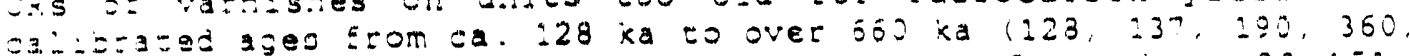
$33 j^{3}$,

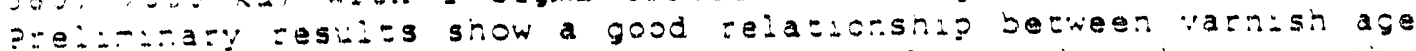

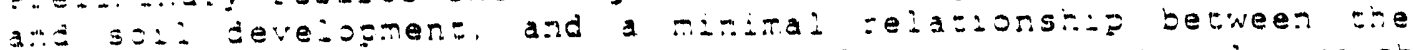

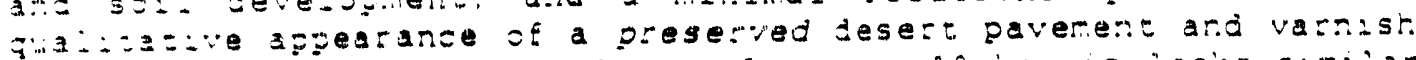

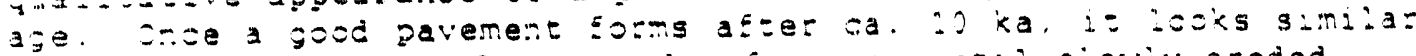

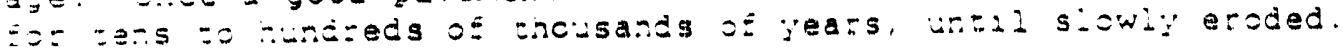

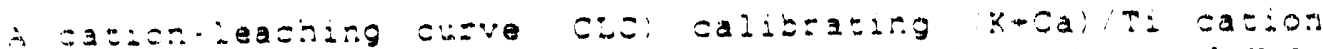

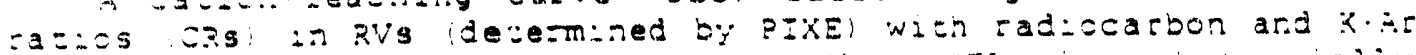
ages os sulsace expcsire az Crazer Fiat, NV, is substarzialiy

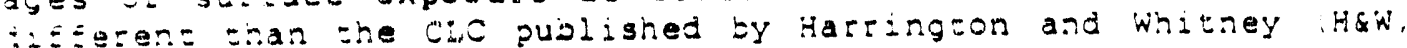
.3 37 . Seclogy, $v .25$ that was cerermined by sem.eDAx and calibraceci

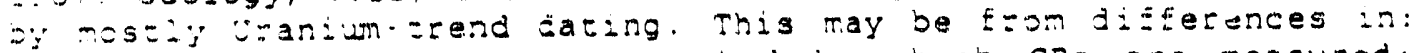
samp:ing; baboratory tests; method by which CRs are measured;

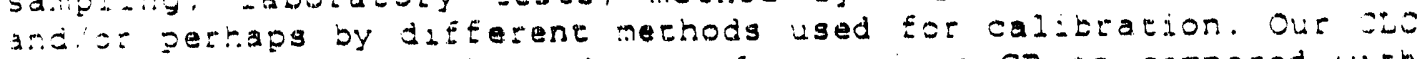
arvijes younger caliorazed aces for a given CR as compared wltw ra $\because$ in

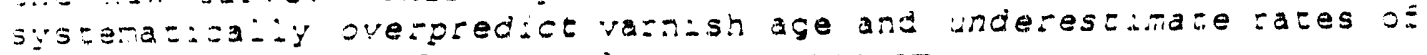
geo: $09: 0$ aczivizy, for example, reozectonism.
2

CATEOOADE NUL ARTRACTS

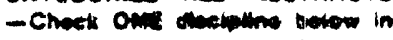
when remberm would be bet

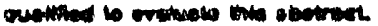

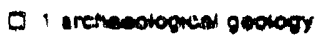

Q 2 cost geonosy

O 3 economic goovoor

Q 4 mpenemento geotogy

D 5 emmronmenter geotogy

Q 8 yomoral goology

Q 9 geochemistry

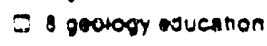

O 9 goomoronologr

010 goophynics

Q' peosecione intormation

$=12$ grecial georogy

=13 nistor of geology

Ela myerogerogy

Z15 maring geology

$=18$ micropaleomiology

=1, mineralogy/ersuallogreny

$=18$ oceenograbny

219 deleoniology/daloodotary

220 serrohum geology

221 omrology expertmental

C22 derrobogy. innmous

Q23 Derrology metamoronic

Q24 omtrology sodimuntary

025 denerarr geology

C20 Piocamenan grology

Ex7 Ouatornen goology

C26 remote senerng

O29 sodmemology

Exo stratigraphy

C3i structural gootogy

032 iectonics

033 inctonicy/guophysics

D34 votcanotogy
3 TYPES OF SESSIONS AYALLALE

A SPECIAL - INVITED ABSTRACT FOA A SYMPOSIUM - This aostract was inmuad lor the symoosium btloo

rou enockeo nare skip $10 \mathrm{rtem}$

9 VOLUNTEERED ABSTRACTS

" SPECIAL-THEME SESSION ANMUAL MEETING ONLY wowle like inis absiract conwdored for oral presentation at he lollowing theine Session for the Annual Mooting. Jenver. 1988

= Jiogenusis of locustrine locks

2 Geology \& Public Polley lor the 21 a Century

3 Goophysical penterns in worm Amente

* Gloosi ascocts ol secimantary geosogy

5 Diganic compounds in grour i

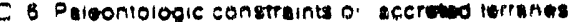

- Pmysics ano chemiatry of myionime

- A secular veriation in the sovimantan recora

if not accopied for the Theme Sassion. do you want it considered lor regular lecmnical session?

I Vey J NO

2: ORAL SESSION D POSTER SESSION D GTHERTYPE

= II acCePt chango or session Mpe (ORAL — POSTER) Inecessary

Z Withoraw my absiract rainer inan change session roe
$0 \%$

4 OF OF THIS PAPER PAEVIOUSLY PAESENTEO Where and when

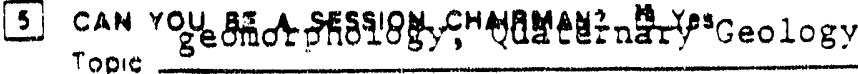
Your nam - Benadd I Pofrn Tolophone (late Jurne / early July)

6 SPEAKEA'S IOENTITY AND MAILING ADOAESS Somaker's nome Ronald I. Dorn Adoruss Department of Geography Addruss Arizona Scace University Ciry Iempe Suto Country ÜSA Omice Telephone: $602,965-7475$

Hore Teleonune:

Dates we can ieech you

7 SENO OAIGINAL - S COPIES OF ABSTAACT TO APPAOPAIATE ADORESS SHOWN ON INSTRUCTION SHEET ANO ON BACK OF THIS FOAM. ALL ABSTRACTS MUST MRAIVE ON OR BEFORE DEADLINE SHOWN FOR EACH MEETING 


\section{TASK 2: Geochemistry}

F. W. Dickson, Prinipipal Investigator

Maureen $P$. Leshendok, Fesearch Associate

Department of Geologi ial Si

Mackay School of Mines

University of Nevada Reno

Reno, NV 89557-0047

FINAL REPORT, GRANT PERIOD 1-1- 17 to 6-30-88.

The main objective of "Task 2: Georhemistry" has been a broad review of literature pertaining to geochemistry at Yucca Mountain. Geouhemistry requires field, experimental, and theoretical investigations by many approaches. Work dorie dire:tly on Yucia Mountain received most attention; these inilude documents produced by DOE sponsored researchers at the national laboratories, the U.S. Geologilal Survey and universities. Both foreign and domesti: documents were examined, on diverse subject matter in journals on radioactive waste and also in mineralogy, petrology, geochemistry, soil sciences, chemistry and engineering. A list of journals is appended (Appendix 1).

The computer program "Ref11" was acquired and used to categarize and store 659 citations. A key word index and relative importance scale permits construction of sets of important papers by topic. The index terms are listed in Appendix 3 . A sample record showing index terms is included (Appendix 2A). A doizument given an importance scale of 8 to 10 (on a scale of 1 to 10) is considered highly significant. Accordingly, an abstract of the document is entered on a 5 " $x 8^{\prime \prime}$ card, filed in a card file and the term "Abs" is entered on the Refli index list for that citation. A sample 5" $x 8^{\prime \prime}$ card is reproduced in the appendix (Appendix 4). The program allows the printing of bibliographies with the citation style of the Geological Society of America. The citation of the record in Appendix $2 A$ formatted in publishable form is reproduzed in Appendix $2 B$.

References acquired in the last quarter are listed in Appendi: 5 .

The assembled set of documents was the basis for developing an overview of existing work in georhemistry on Yucca Mountain and to evaluate the status of sperific studies. Prior to 1982 , when Congress passed the Nuclear Waste Policy Aist, most work was by the U.S. Geoliggiral Survey and Los Alamos National Laboratory on properties of the ron-fluld systems. NFI regulations have been specific on the need to develop understanding of the geochemistry of Yucca Mountain before any licensing wiould be possible. Following the 1982 legislation, which required comparisons of several candidate areas for waste disposal, the

$$
2-1
$$


DDE-supported work on Yuc:a Mountain was expanded in topics and approaches, and the pace quickened. Experimental studies on the interactions of groundwaters from Yuba Mountain with rows and minerals were begun, chiefly at Los Alamos and Lawrenig Livermore laboratories. Increasing efforts were applied to conieptual cumputer modeling that used geochemizal and other geological and geophysical parameters to predict performance of the Yucea Mountain site before, during and after closure.

\section{Evaluation of Geochemical Work}

The literature on geochemistry collected by Tasl: 2 serves as a basis fior detailed teinnical analyses of sperific studies done or planned by DOE. These technical reports will be made available in response to requests from appropriate state offices. Writing the critiques requires the same effort and care as writing sieientific papers. Individual researchers and research institutions must be dealt with evenly and fairly. The doruments must be in condition to stand up under intense scientific scrutiny. They are not appropriate for inclusion in this final report. Below are summary statements of important areas of geothemical researich.

Geochemical factors important at Yucra Mountain fall into several major subject areas.

\section{Field Materials}

Needed are the existing characteristics of the rock-fluid systeins from the surface to the Paleozoil basement (with emphasis on the target horizon, the Topopah Spring Tuff, about 1000 feet below the surfare) extanding in area beyond the permitted limit of bioturbation in 10,000 years. These data establish a baseline against which future changes can be evaluated and permit estimation of effects of past geochemical processes, such as the former presence of hydrothermal systems, and indeed, whether a mild hydrothermal episode exists now. Cyclic processes can be recognized from alternating textures in minerals. Ages of geologi: events are estimable from dating radioactive minerals. compositions of gas given of from active faults differ from compositions from inactive faults. Chemical and mineralogical properties of the mineral assemblages reveal in three dimensions distributions of glass and alteration assemblages. The data on rocks, groundwaters and associated gases in and around the site necessarily must be known to permit evaluation and measurement of reactions of site components with nearby substanies.

The data on the georhemistry of natural container materials at Yusca Musntain are incomplete, even though there was a relatively large effort to get it. Only approximations of the three-dimensional distributions of materials are possible. Part. of the problem is that only one drill-hole was deep enough to

$$
2-2
$$


penetrate the underlying Paleosoic rocks, leaving the underground configuration of the old faleozoi: surface a mater of conjecture. Further, in spite of the large number of drill-holes installed at the Nevada Test Site and Yucta Mountain area (more than 50) inany were dribled before Yucaa Mountain was being considered seriously as a repisitory site, with inadequate control on drilling methods and procedures for sampling racks, waters and gases. Even the recent cores Eulleited by members of the U.S. Geological Survey lacked quality control in transportatian and iuration (not the USBS respirisibility) to DOE standards, and rock material accordingly has not been available for study. There is strong need for a drilling program with holes located to furnish the maximum three-dimensional information, without injestion of iantaminating substanies, and sontris on sampling specifiz horizons for waters and gases. The program wold yield nezessary data on the compositions of fluids and rosks, above and below the repository horizon.

Geblomical parameters are useful in deduring fluztuating proisesses, absolute and relative times, temperatures, solution compositions, and original souries of constituents. The applization of georhemsial methods to deduce on-going and recent processes in a quantitative manner has been used to a limited extent at Yucra Mountain. Examination of the isotopic compasition of surface deposits of silica-iarbonate has not yielded definitive results, and further examinations of these and other materials clearly are needed.

\section{Analogue Studies}

Experiments on interactions among natural materials, and between Eanister components and natural materials, under present and future conditions at the site, are important in answering performance questions. Experiments have been done on sorption of individual nuclides onto clay surfaces and the reactions of glass with Yurca Mountain-type groundwater. However, the experimental studies fall short of providing satisfactory answers. More experiments were planned and described in the consulatation Draft of the SCF. The experiments will require much carefully planned and integrated work.

My experience in doing equilibrium and kinetic studies on aqueous-natural material systems leads me to make a statement on the experimental work. The Draft SCP outlined a large number of experiments which will be costly and time-ionsuming. For some topics the present experimental plans are not realistic. The complekity and departures from equilibrium of the reations may prevent outlining the steps in the times and with the funds available. 


\section{Computer Modelizng}

Initial efforts to develop a computer performamce model that utilizes the geuchemical data have been under way for several years. At at this time, these efforts can only provide first versions or approximations because vitally needed georhemical information is absent. However, they are worth doing in preliminary form if only for assessing needed information. Eventually a performance model for the entire repository will have tis be developed, and many years of research, in my opinion, will be necessary, befire such a model is possible.

\section{Chemical Reactions at Yucca Mountain}

Gourses of reactions generally are balculated or determined by experiment when insufficient data exist. Calculations are based on fundamental equations that have been derived for the kinds of system involved. These are in the language of physiral chemistry or chemical thermodynamiss. They fall into two categories, equilibrium and non-equilibrium. Equilibrium configurations ian be ealiulated from thermoghemical data. Nionequilibria can not, and require sperific studies of reastion steps as functions of the variables in the environment (kinetics). Equilibria can be described in terms of system boundaries, temperature, pressure and phase compositions, as developed by J. W. Gibbs in the last century. Reaction kinetics require knowledge of these variables plus potentially many other factors, some of which can control reaction paths. These include factors excluded by Gibbs, such as surface areas of solids, ratio of the weights of the phases, flow rate of solutions, presence of an electromagnetic field, and trace element concentrations.

Glassy volcanic rocks and groundwaters at Yucca Mountain are classic in their thermodynamically unstable condition. The rocks consist of glass or devitrified glass, plus a suite of igneous minerals, most of which are out of equilibrium with the system. They have been partly altered to various stable and netastable minerals by actions of groundwaters at past temperature and pressure conditions. Water, glass and crystal reactions up to $300^{\circ} \mathrm{C}$ must be ionsidered at Yucia Mountain as part of a worst case scenario. Problems are thereby posed.

The low pressure, low temperature regime of water and silicate rorks is notorious for sluggish reactions and the persistence of metastable phases. Unfortunately, the incumplete data base and partially developed conrepts cause great difficulties in the evaluation of reartion paths. Numerous assumptions, extrapolations and interpolations must be made.

My conclusion after reading the experimental papers is that the great problems inherent in the overall approach have not been volized or bept in mind. Individuals doing the researis are 
competent, but they have not been given the responsibility to view their work in context. The experimental work is incomplete and it remains to be seen whether future work will be more thoroughly integrated. 


\title{
LIST OF SCREENED JOURNALS
}

\begin{abstract}
(The goal of Task 2 is to sicreen all issues of the following journals back through 1980 . Every journal on this list has been examined, but not all have been checked through their entire run baik: to 1380. All are available on the University of Nevada Renis (ampus.)
\end{abstract}

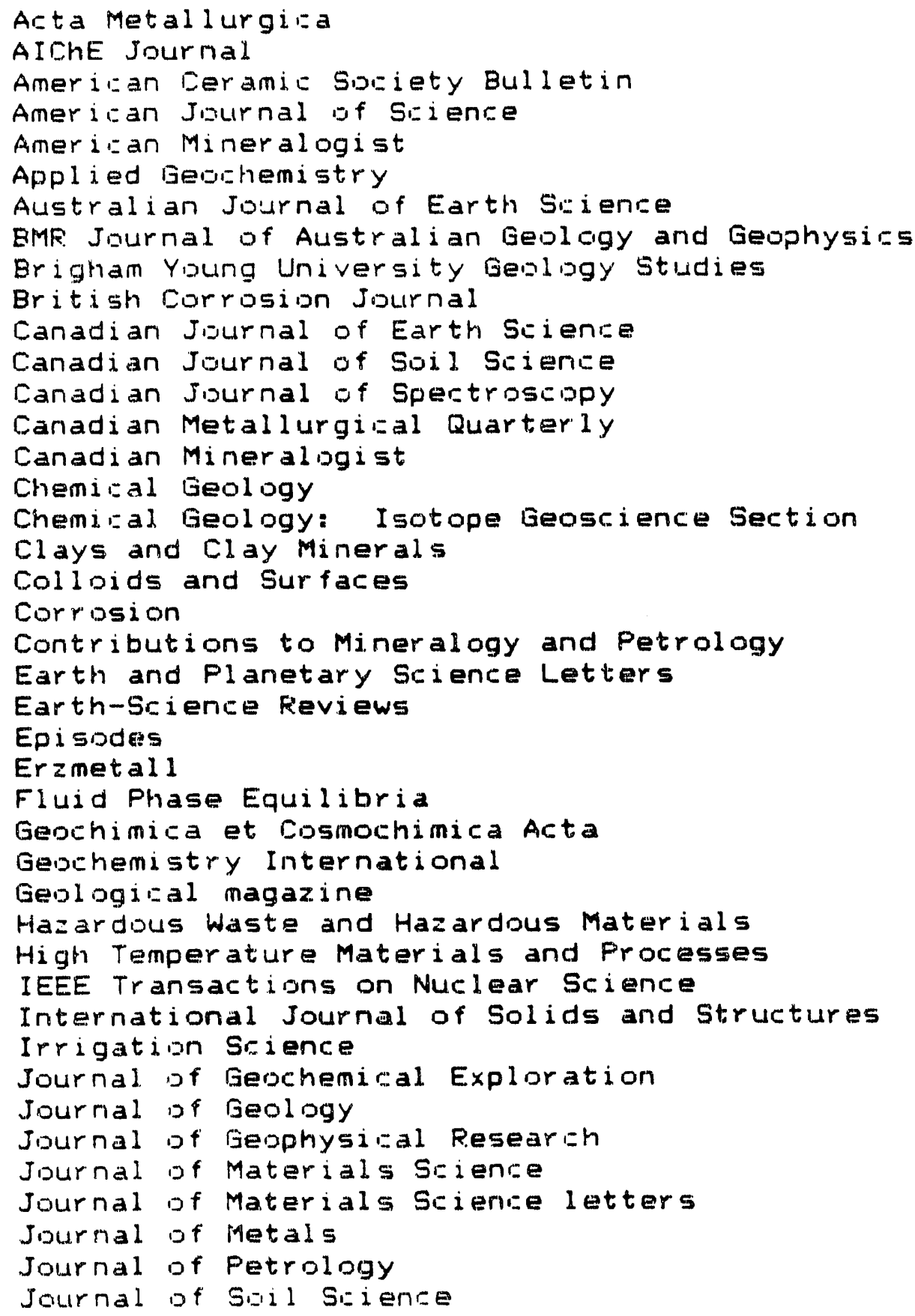




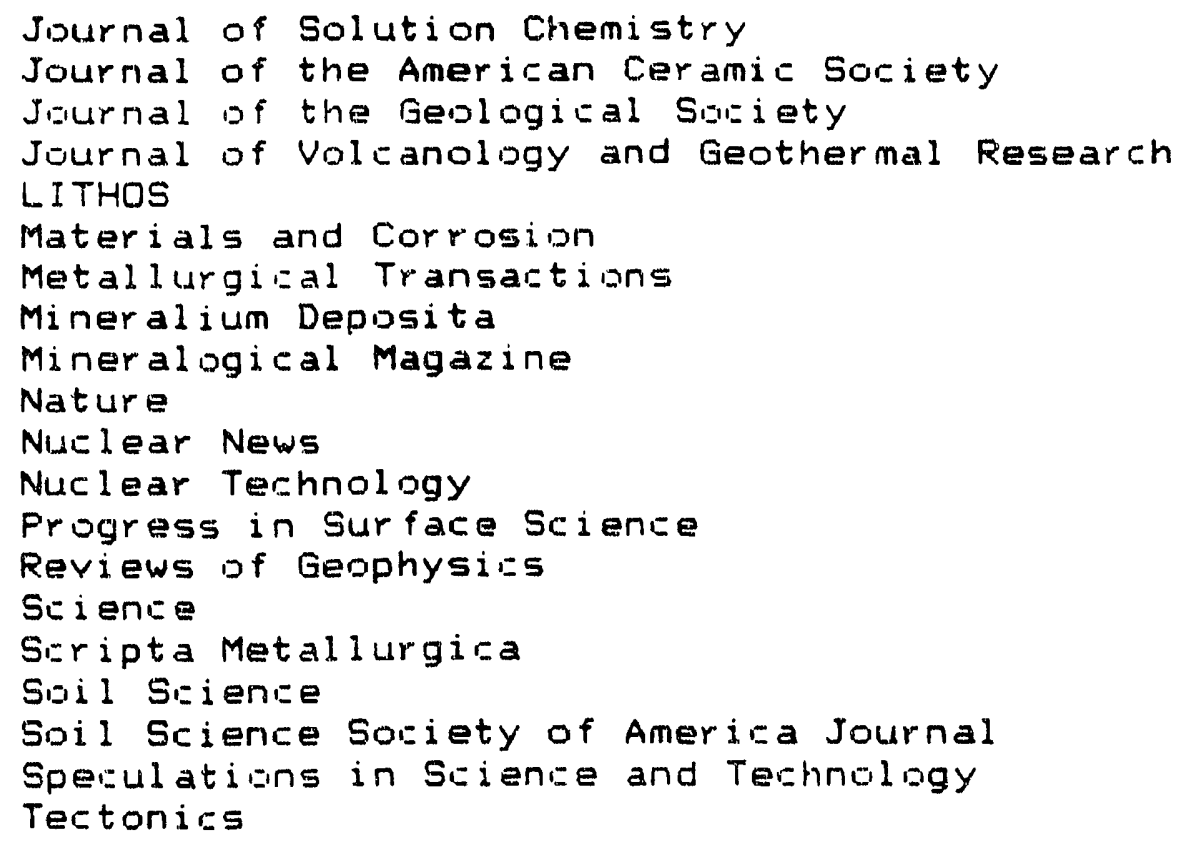




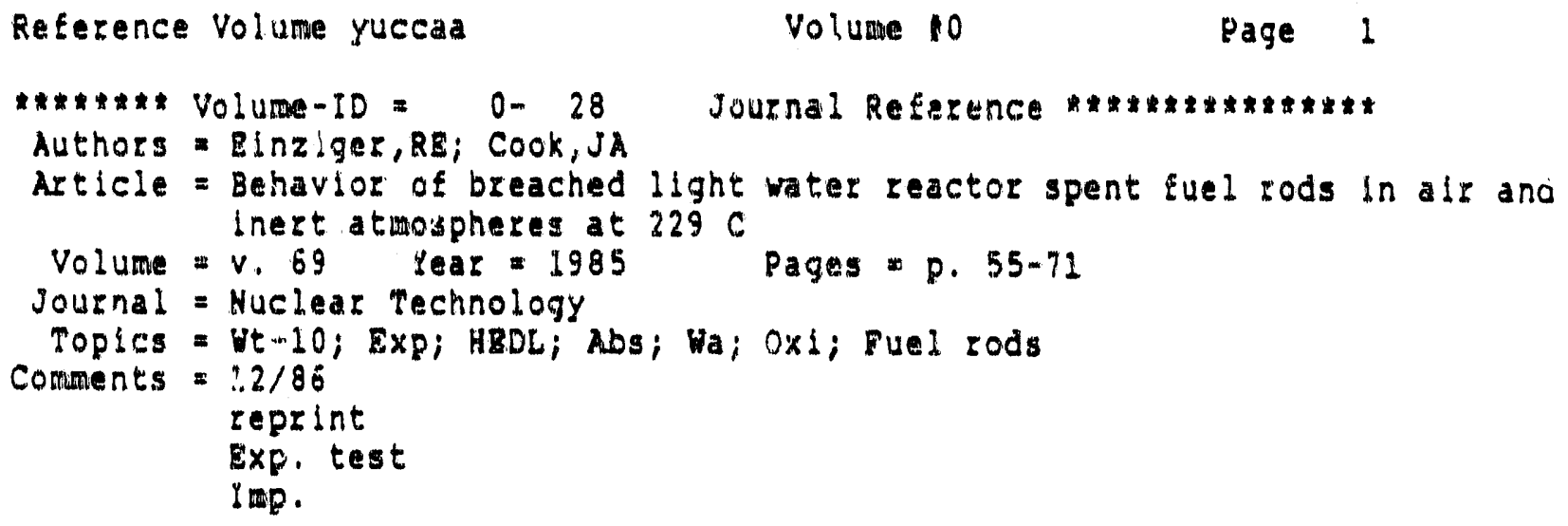


Append $1 \times 2 B$

Einziger, R. E., and Cook, J. A., 1985, Behavior of breached light water reactor spent fuel rods in air and inert atmospheres at $229 \mathrm{c:}$ Nuclear Technology, v. 69, p. 55-71. 
yucca Mountaln, Geechemistry, Subtect Headdngs

TERM

DEFINIIIION

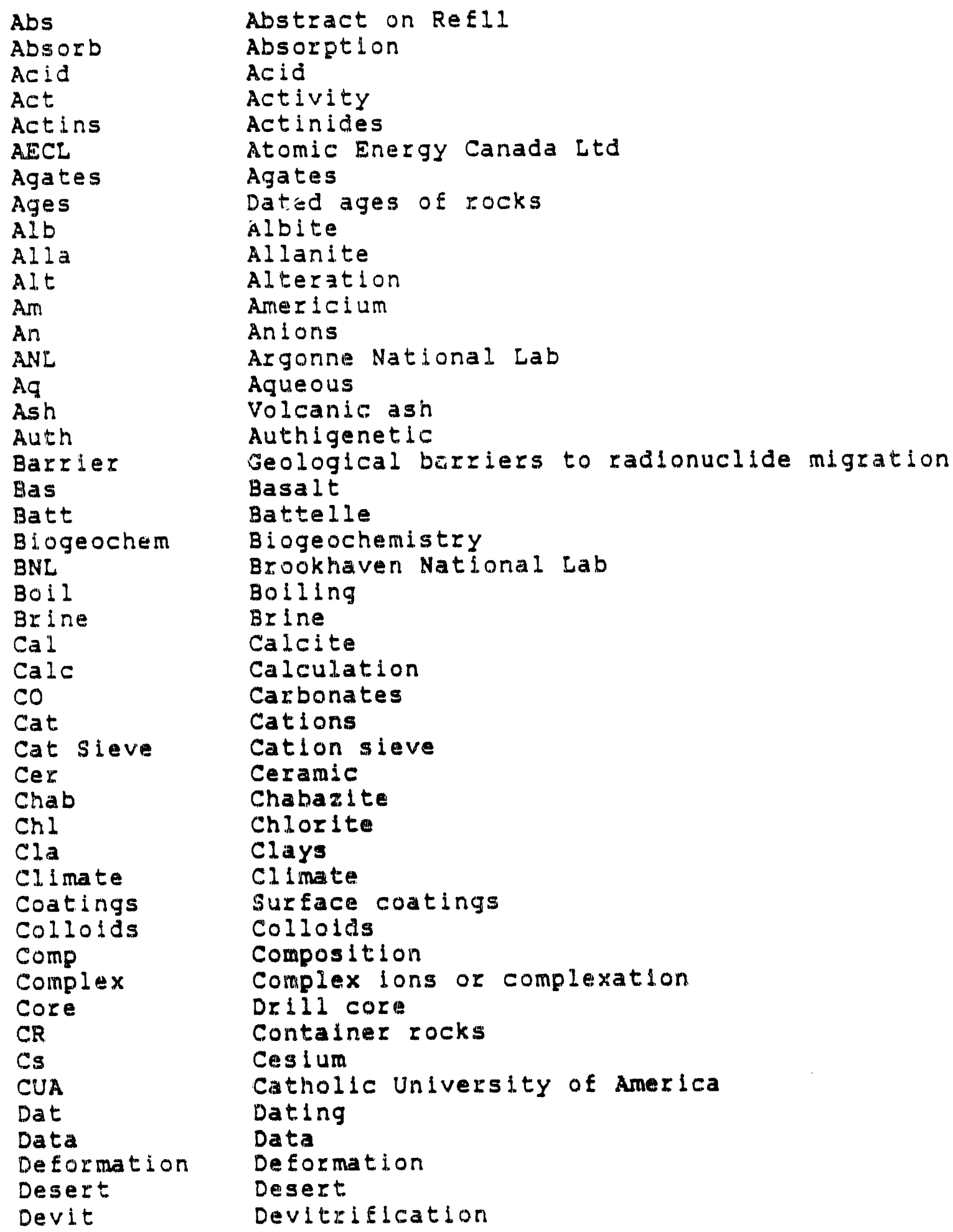




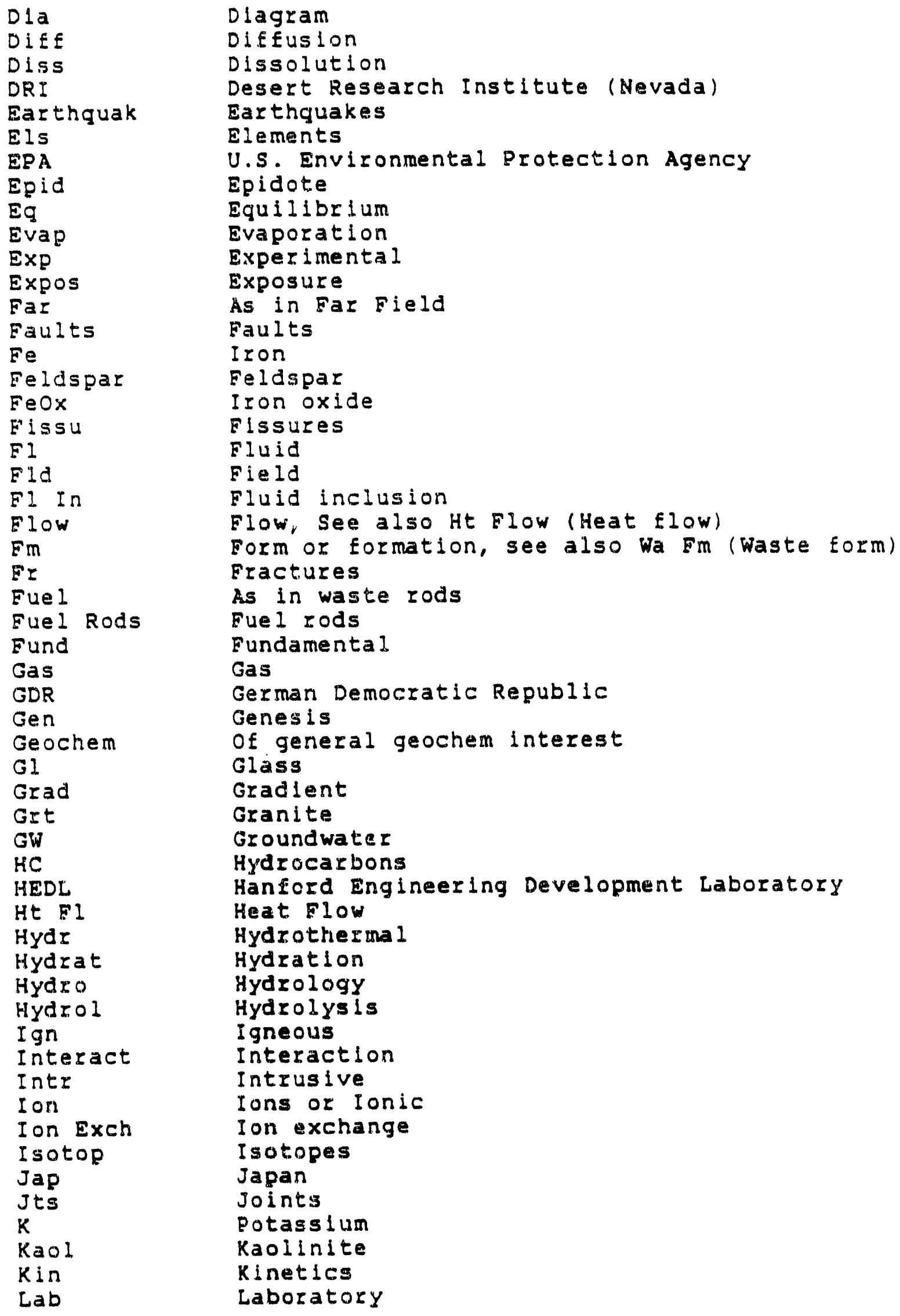




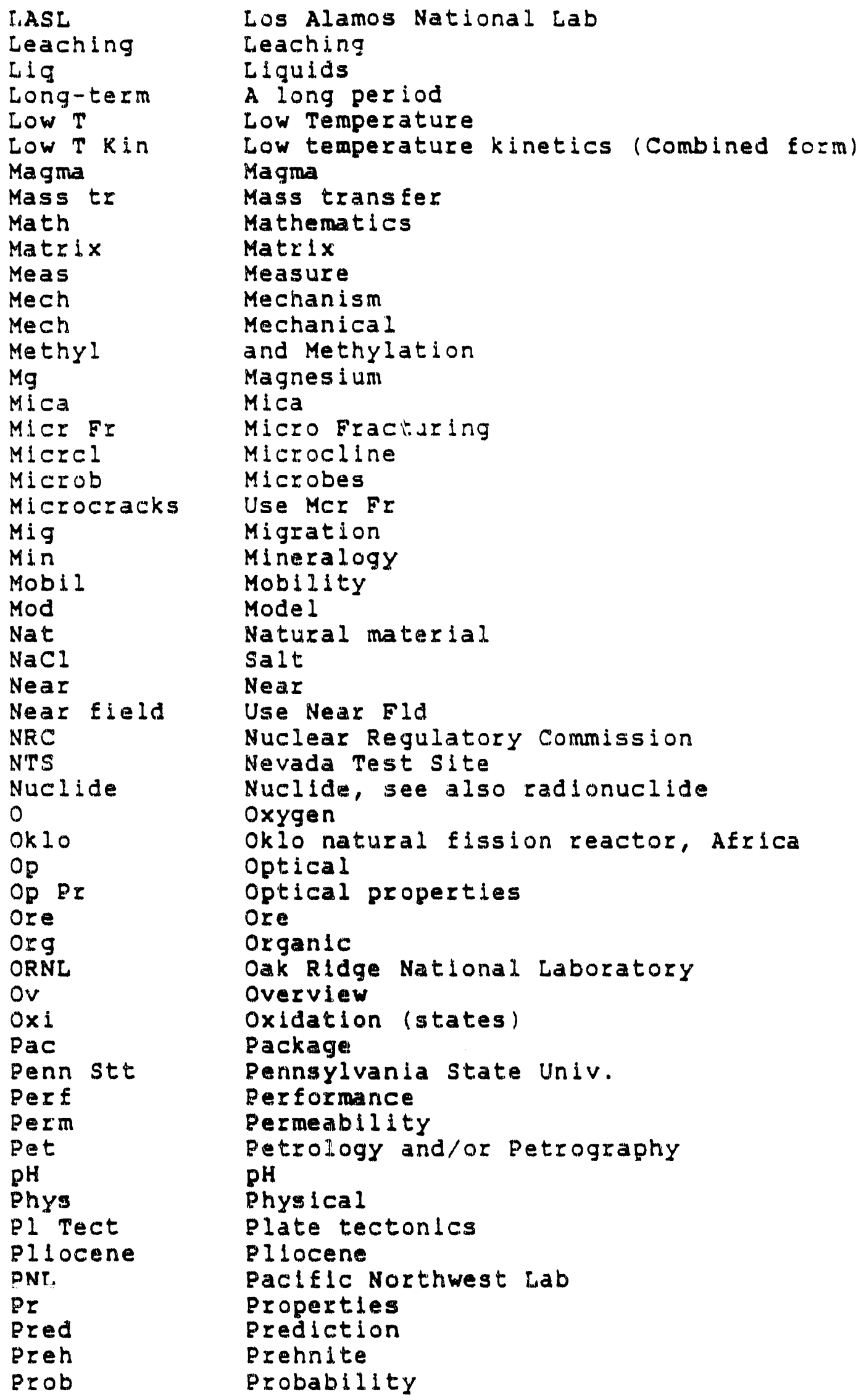




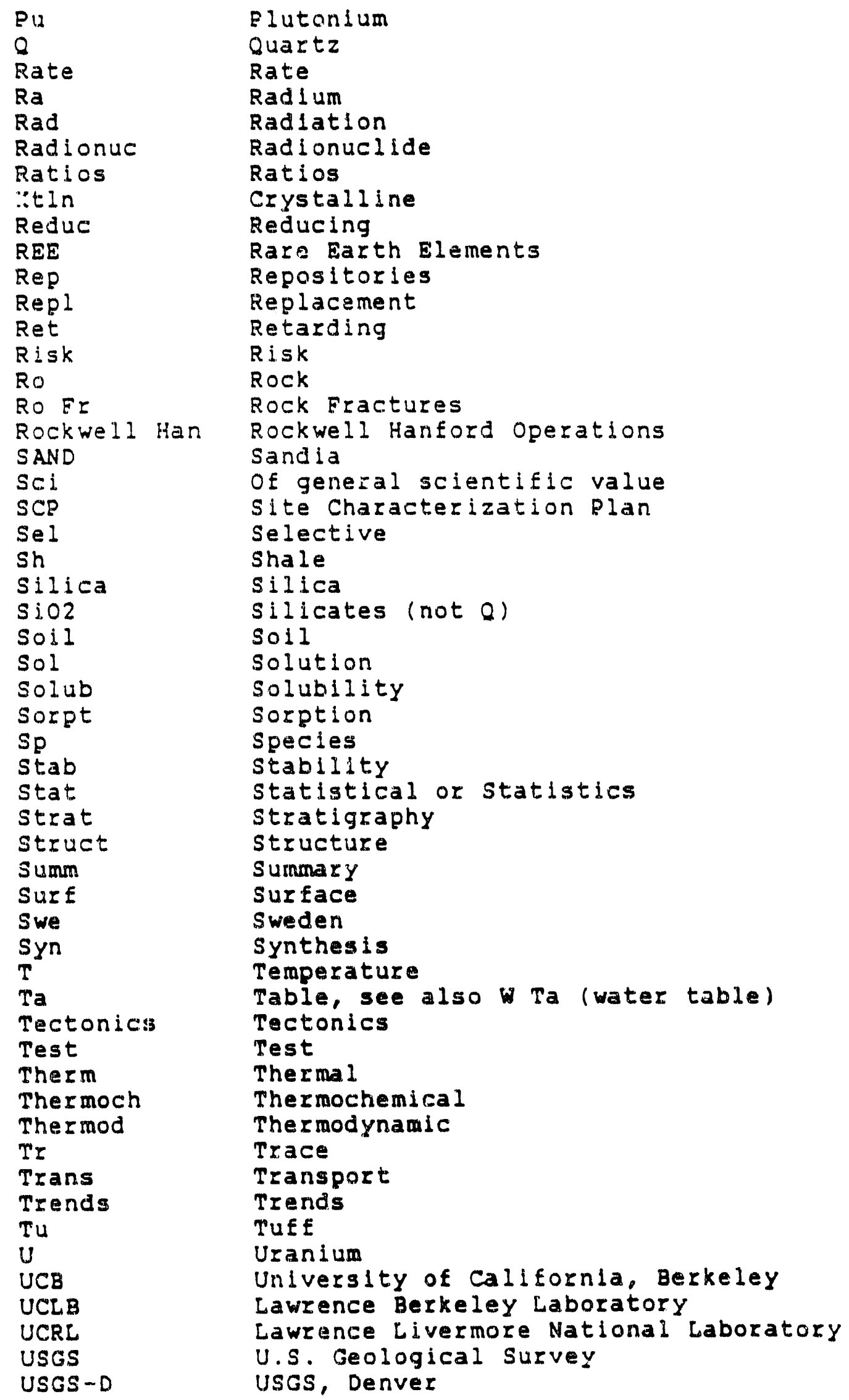




USGS-MP
USGS-R
Vad
Vitrie
Volc
Volu
W
W Ta
Wa
Wa Fm
Wa GI
Wa GI Diss
Wai
WaI
WIPP
Wt
Xenol
X-Iay
X-sect
XtIs
XtIn
YM
z

USGS, Menlo Park

USGS, Reston

Vadose zone (unsaturated zone)

Vitrification

Volcanic

Volume

Water

Water table

Waste

Waste form (combined form)

Waste glass (combined form)

Waste glass dissolution (Combined form)

Wairikite

Waste form

Waste Isolation Pilot Project

Weight/import or document $(1-10)$

xenoliths

$x-r a y$

Cross-section

Crystals

Crystaline

Yucca Mountain, Geochemistry

zeolite 
Einziger, R. E., and Cook, J. A., 1985, Behavior of breached

light water reactor spent fuel rods in air and inert atmospheres at $229^{\circ} \mathrm{C}$ : Nuclear Technology, $v .69$, p. 55-71.

A whole-rod test was conducted at $229^{\circ} \mathrm{C}$ to

Index investigate the long-term stability of light water reactor spent fuel rods with artifically induced defects stored in inert and unlimited air atnospheres. Both boiling water reactor (BWR) and oressurized water reactor (PWR) rods were tested. After $2235 \mathrm{~h}$, visual observations, diametral measurements, and radiographic smears were used to assess the degree of cladding deformation and parciculate release. The same examinations plus metallography and $x-r a y$ analysis were conducted after $5962 \mathrm{~h}$. Neither of the breached rods tested in inert atmosphere, nor the breached PWR rod tested in unlimited air, showed any measurable change from the pretest condition. The upper defect on the BWR rod tested in unlimited air had a 12.7 mm split after $2235 \mathrm{~h}$ and had $10 \%$ cladding deformation. The crack grew to $63.5 \mathrm{~mm}$ after $5962 \mathrm{~h}$. X-ray analysis indicated that the $\mathrm{UO}_{2}$ had oxidized to $\mathrm{U}_{3} \mathrm{O}_{8}$ at this defect. The difference in the behavior of the upper and lower defects is attributed to the accessibility of the air to the fuel due to the positioning of the defect with relation to the pellet/pellet interface. 


\section{REFERENCES}

Airey, P. L., Roman, D., Golian, C., Short, S., Nightingale, T., Lowson, R. T., and Calf, G.E., 1984, Radionuclide migration around uranium ore bodies--analogue of radioactive waste repositories, annual report 1982-83: Australian Atomic Energy Commission Research Establishment, Lucas Heights Research Laboratories, AAEC/C40, $144 \mathrm{p}$.

Airey, P. L., Roman, D., Golian, C., Short, S., Nightingale, T., Payne, R., Lowson, R. T., and Duerden, P., 1985, Radionuclide migration around uranium ore bodies-analogue of radioactive waste repositories, annual report 1983-84: Australian Atomic Energy Commission Research Establishment, Lucas Heights Research Laboratories, AAEC/C45, 142 .

Allard, B., 1983, Actinide solution equilibria and solubilities in geologic systems, : Svensk Karmbransleforsorjning AB/Avdelning KBS, $K B S-T R-83-35,48 \mathrm{p}$.

Allard, B., oloffson, U., Torstenfelt, B., Kipatsi, H., and Andersson, K., 1382, Sorption of actinides in well-defined oxidation states on geologic media: In w. Lutze (ed), scientific Basis for Nuclear Waste Management $v$, Proceedings, Materials Research Society International Symosium, Berlin, 1982. New York, North-Holiand Elsevier, p. 775-782.

Allard, B., and Torstenfelt, B., 1983, On the solubility of technetium in geochemical systems: Svensk Karnbzansleforsorjning AB/Avdelning KBS, Stockholm, Sweden, KBS-TR-83-60, 8 p.

Andersson, G., Rasmuson, A., and Neretnieks, I., 1982, Model for near field migration: In $w$. Lutze (ed), scientific Basis for Nuclear Waste Management $V$, Proceedings, Materials Research Society International symposium, Berlin, 1982. New York, North-Holland, Elsevier, p. 539-548.

Beckman, R., Thomas, K., and Crowe, B., 1988, Preliminary report on the statistical evaluation of sorption data: sorption as a Eunction of mineralogy, temperature, time, and particle size: Los Alamos National Laboratory LA-11246-MS, 26 p.

Bernkopf, M. F., and $\mathrm{Kim}, \mathrm{J}$. I., 1984, Hydrolysereaktionen und karbonatkomplexierung von dreiwertigem americium im naturleichen aquatischen system: Institut fur Radiochemie der Technischen Universitat Munchen, Federal Republic of Germany, RCM-02884, 200 p. Bidoglio, G., De Plano, A., and Chatt, A., 1983, studies on the speciation of americium, technetium and neptunium in simulated vitrified-waste leachates: In D. Brookins (ed), Scientific Basis Eor Nuclear Waste Management VI, Materials Research Society Symposium Proceedings, Boston, MA, November 1982. New York, North-Holland Elsevier, p. 373-382.

Bish, D. L., 1985, Effects of composition on the dehydration behavior of clinoptilolite and heulandite: Los Alamos National Laboratory La-Ur-85-1259, $15 \mathrm{p}$.

Boersma, M. D., 1984, Letter from M. D. Boersma (Savannah River Laboratory) to J. F. Kerrisk (Los Alamos National Laboratory), october 8, 1984; with enclosure tables of "DWPF product glass isotopes and radioactivity:, 59 p. 
Bradbury, M. H., Lever, D., and Kinsey, D., 1982, Agueous phase diffusion in crystalline rock: In $W$. Lutze (ed), Scientific Basis for Nuclear Waste Management $v$, Proceedings, Materials Research Society International Symposium, BerIin, 1982. New York, NorthHolland, p. 569-b78.

Branche, G., Chantret, F., Guillemaut, A., and Pouget, R., 1975, Donnes chimiques et mineralogicques sur le gisement d'oklo: International Atomic Energy Agency STI/Pub/405, p. 119-132.

Claassen, H. C., 1973, Water quality and physical characteristics of Nevada Test site water-supply wells: U.S. Geological Survey 474$158,141 \mathrm{p}$.

Curtis, D. B., 1985, The chemical coherance of natural spent fuel at the Oklo nuclear reactors: Svensk Karnbsanslehantering AB (swedish Nuclear Fuel waste Management Co.) Technical Report 85-04., 15 .

Curtis, D. B., and Gancarz, A. J., 1983, Radlolys is in nature: evidence from the Oklo natural reactors: Svensk Karnbransleforsorjning/Avdelning KBS Technical Report 83-10, 60 p.

Daniels, W. R., 1981, Laboratory and field studies related to the radionuclide migration project: Los Alamos Scientific Laboratory LA-8670-PR, $27 \mathrm{p}$. On inicrofiche.

Douhy, Z., 1982, Disposal of radioactive wastes: Amsterdam, Elsevier, p. $195-235$.

Fried, S. M., Friedman, A. M., Hines, J. J., and Quarterman, L.A., 1975, Annual report on DWMT Project ANO115A, FY 1975: Argonne National Laboratory ANL-75-64, 14 p.

Holly, D. E., and Fenske, P. R., 1968, Transport of dissolved chemical contaminants in ground-water systems: in Eckel, E. B., ed., Nevada Test site, Geological society of America Memoir, 110, p. 171-183.

Jensen, B. S., 1982, The migration of radionuclides with groundwater-a discussion of the relevance of the input parameters used in model calculations: In W. Lutze (ed), Scientific Basis for Nuclear Waste Management $V$, Materials Research Society International Symposium proceedings, Berlin, Germany, 1982. New York, North-Holland Elsevier, p. 765-774.

Keith, T. E. C., White, D. E., and Beeson, M.H., 1978, Hydrothermal alteration and self-sealing in $Y-7$ and $Y-8$ drill holes in northern part of Upper Geyser Basin, Yellowstone National Park, Wyoming: $U$. $\mathrm{S}$. Geological Survey Professional Paper 1054-A, 26 p.

Kim, J. I., Lierse, C. H.., and Baumgartner, F., 1983, Complexation of the plutonium(IV) ion in carbonate-bicarbonate solutions: in Carnall, W. T., and Choppin, G. R., Plutonium Chemistry: American Chemical society symosium series, 216, p. 317-334.

Kistler, R. W., 1968, Potassium-argon ages of volcanic rocks in Nye and Esmeralda Counties, Nevada: in Eckel, E. B., ed., Nevada Test Site: Geological Society of America Memoir, 110, p. 251-262.

Neretnieks, I., 1980, Transport mechanisms and rates of transport of radionuclides in the geosphere as related to the Swedish KBS concept: In (ed), Underground disposal of radioactive wastes, Proceedings of a symposium, Otaniemi, July 1979, IAEA-SM-243/108. Vienna, International Atomic Energy Agency, p. 315-339. 
Neretnieks, I., 1982 , Leach rates of hlgh level waste and spent fuel-limiting rates as determined by backelli and bedrock conditions: In W. Lutze (ed), Scientific Basis for Nuclear Waste Management $v$, Materials Research Society International symposium Proceedings, June 1982, Berlin. New York, North-Holland, p. 559-568.

Nitsche, H., and Edelstein, N. M., 1985, Determination of the solubilities and complexation of waste radionuclides pertinent to geologlc disposal at the Nevada Tuef Site: Lawrence Berkeley Laboratory Topical Report LBL-18900, $76 \mathrm{p}$.

NRC, 1984, Determination of radionuclide solubility in groundwater for assessment of high-level waste isolation: U.S. Nuclear Regulatory Commission (NRC) Technical Position, $16 \mathrm{p}$.

NRC, 1987, standard format and content of site characterization plans for high-level-waste geological repositories: U.S. Nuclear Regulatory Comnission (NRC) Regulatory Guide $4.17,45 \mathrm{p}$.

oloffson, U., Allard, B., Andersson, K., and Torstenfelt, B., 1982, formation and properties of americium collioids in aqueous systems: In S. Topp (ed), Scientific Basis eor Nuclear Waste Management, Materials Research Society Symposia Proceedings, v. 6, Boston, November 1981. New York, North Holland, Elsevier, p. 191-198.

Olofeson, U., Allard, B., Torstenfelt, B., and Andersson, K., 1982, Properties and mobilities of actinide colloids in geologic systems: In W. Lutze (ed), Scientific Basis for Nuclear waste Management $V$, Materials Research society International Symposium Proceedings, Berlin, 1982. New York, North-Holland, Elsevier, p. 755-764.

olofsson, U., Allard, B., Andersson, K., and Torstenfelt, B., 1981, Formation and properties of radiocolloids in aqueous solution--a literature survey: Goteborg, Sweden, Chalmers University of Technology, Dept. of Nuclear Chemistry, Nat'l. Council for Radioactive Waste Report Prav, 4.25, p. 12-20.

Pruess, K., Wang, J.S. Y., and Tsang, Y.W., 1988, Effective continuum approximation Eor modeling Eluid and heat Elow in Eractured porous tuff: Sandia National Laboratories Contractor Report SAND86-7000, $100 \mathrm{p}$.

Rai, D., ig84, Solubility product of Pu(IV) hydrous oxide and equilibrium constants of $\mathrm{Pu}(I V) /(V), \mathrm{Pu}(\mathrm{IV}) / \mathrm{Pu}(\mathrm{VI})$, and $\mathrm{Pu}(\mathrm{V})$ /Pu(VI) couples: Radiochimica Acta, v. 35, p. 97-106.

Rai, D., and Ryan, J. L., 1982, Crystalilinity and solubility of Pu(IV) oxide and hydrous oxide in aged aqueous sediments: Radiochimica Acta, v. 30, p. 213-216.

Rai, D., strickert, R. G., Moore, D. A., and Ryan, J.L., 1983, Am(III) hydrolysis constants and solubility of Arn(III) hydroxide:

Radiochimica Acta, v. 33, p. 201-206.

Rasmuson, A., and Neretnieks, I., 1982, Model for far Eield migration: In W. Lutze (ed), Scientific Basis for Nuclear Waste Management $V$, Materials Research Society International symposium Proceedings, Berlin, June 1982. New York, North-Holland, Elsevier, p. 549-558.

scott, R. B., and Bonk, J., 1984, Preliminary geologic map of Yucca Mountain, Nye County, Nevada, with geologic sections: U.S. Geological survey open-File Report 84-494, 3 sheets and 9-p. booklet. 
Sergeyeva, E. I., Nikitin, A. A., Khodakovskiy, I. L., Naumov, G. B., and Vernadskiy, V.I., 1972, Experimental investigation of equilibria in the system UO3-CO2-H2O in 25-200 degrees C temperature interval: Geochemistry International, v. 9, p. 900-910.

Shepard, A. O., and starkey, H. C., 1966, The effects of exchanged Cations on the thermal behaviour of heulandite and clinoptilolite: Minecalogical society of India, IMA Volume, p. 155-158.

Sherry, H. S., 1969, The ion-exchange properties of zeolites: In J.A. Markinsky (ed), Advances in ion exchange. New York, Marcel Dekker, p. $89-133$.

Silva, P. J., and Yee, A. W., 1981, Waste/rock interactions technology program, status report, uranium(VI) retardation mechanisms:

Lawrence Berkeley Laboratory Draft Report WRIT 81-3, 27 p.

Sllva, R, J., and Nltsche, H., 1983, Thermodynamic properties of chemical species of waste radionuclides: NRC Nuclear waste Geochemistry '83, Proceedings of the U.S. Nuclear Regulatory Commission, Aug. 30-31, 1983, Reston, VA, NUREG/CP-0052, p. 70-93

Silva, R. J., and Nitsche, H., 1985, Carbonate complexation of Pu(VI) in aqueous solution [Abs.]: American Chemical Society 189 th National Meeting, Miami Beach, Florida, April 28-May 3, 1985, Abstracts of Papers, \#44.

sposito, B., 1981, The thermodynamics of soll solutions: oxford, Clarendon Press, p. 66-83, 94-101.

stumm, W., and Morgan, J.J., 1981, Aquatic chemistry: New York, Wiley, p. 8-9, 68-73, 94-95, etc.

sudicky, E. A., and Frind, E. O., 1982, Contaminant transport in fractured porous media: analytical solutions for a system of parallel Eractures: Water Resources Research, v. 18, p. 1634-1642.

Thompson, J. L., 1985, Laboratory and field studies related to the radionuclide migration project: Los Alamos National Laboratory LA:0372-PR, $37 \mathrm{p}$. on microfiche.

Thompson, J. M., Presser. T. S., Barnes, R. B., and Bird, D.B., 1975, Chemical analysis of the waters of Yellowstone National Park, wyoming Erom 1965 to 1973: U.S. Geologlcal survey open-Flle Report $75-25,59 \mathrm{p}$.

Thompson, J. M., and Yadav, S., 1979, Chemical analyses of waters from geysers, hot springs and pools in Yellowstone National Park, Wyoming from 1974 to 1978: U.S. Geological Survey open-File Report $79-704,49 \mathrm{P}$.

Thordarson, W. 'i983, Geohydrologlc data and test results from well J13. Nevada Test Site, Nye County. Nevada: U.S. Geological Survey Water-Resources Investigations Report 83-4171, $57 \mathrm{p}$.

Travis, B. J., 1985, WAFE: A model Eor two-phase, multicomponent mass and heat transport in porous/fractured media: Los Alamos National Laboratory LA-10488-MS, $60 \mathrm{p}$.

Travis, B. J., and Nuttall, H. E., 1985, Analysis of colloid transport: Los Alamos National Laboratory LA-UR-85-2929, $10 \mathrm{p}$.

Travis, B.J., and Nuttall, H. E., 1987, Two-dimensional numerical simulation of geochemical transport in Yucca Mountain: Los Alamos National Laboratory LA-10532-MS, 69 p. on microfiche. 
Tripathi, V. S., 1984, Uranium(VI) transport modeling: geochemical data and submodels, Ph.D. Dissertation, Appendix I: Stanford, CA, Stanford University, p. 173-234.

Vaughn, D. E. W., 1978, Properties of natural zeolites: In L.B. Sand and F.A. Mumpton (eds), Natural zeolites: occurrence, properties, use. Oxford, England, Rergamon Press, p. 353-371.

wilder, D. G., 1987, Influence of stress-induced deformations on observed water flow in fractures at the climax Granitic stock: Lawrence Livermore National Laboratory preprint UCRL-95539 Rev. 1 , $9 \mathrm{p}$.

wolery, T. J., 1983, EQ3NR: A computer program for geochemical aqueous speciation-solubility calculations: User's guide and documentation: Lawrence Livermore Laboratory UCRL-53414, 3 microfiche.

wolfsberg, K., 1978, Sorption-desorption studies of Nevada Test site alluvium and leaching studies of nuclear test debris: Los Alamos Scientific Laboratory LA-7216-MS, $24 \mathrm{p}$. on microfiche.

Wolfsberg, K., Aguilar, R. D., Bayhurst, B. P., Daniels, W. R., DeVililers, S. J., Erdal, B. R., Lawrence, F. O., and Maestas, S., et al., 1981, Sorption-desorption studies on tuff, III. A continuation of studies with samples from Jackass flats and Yucca Mountain, Nevada: Los Alamos Scientific Laboratory LA-8747-MS, 66 p.

Wolfsberg, K., Bayhurst, B. P., Crowe, B. M., Daniels, W. R., Erdal, B. R., Lawrence, F. O., Norris, A. E., and Smyth, J.R., 1979, Sorption-desorption studies on tuff, I. Initial studies with samples from the J-13 drill site, Jackass Flats, Nevada: Los Alamos sclentific Laboratory Informal Report LA-7480-MS, 56 p.

Zlelinsk1, R. A., 1983, Evaluation of ashelow tuefs as hosts for radloactive waste: Criteria based on selective leaching of manganese oxide: U.S. Geological survey Open-File Report 83-480, 23 p. on microfiche. 
TASK 3 REPORT FOR JANUARY, 1987 - JUNE, 1988:

VOLCANIC GEOLOGY AND EVALUATION OF POTENTIAL MINERAL AND HYDROCARBON RESOURCES OF THE YUCCA MOUNTAIN AREA

Lawrence T. Larson and Donald C. Noble, Co-Principal Investigators

Steven I. Weiss, Research Associate

Mac Roy Jackson, Research Assistant

Alan K. Chamberlain, Research Assistant 


\section{PART 1: VOLCANIC.GEOLOGIC FRAMEWORK, CALDERA GEOLOGY AND EVALUATION OF POTENTIAL FOR ASSOCLATED MINERAL RESOURCES OF THE YUCCA MOUNTAIN AREA OF THE SOUTHWESTERN NEVADA VOLCANIC FIELD}

\section{INTRODUCTION}

Prior to 1987, evaluations of the mineral and hydrocarbon resource potential of the Yucca Mountain area were limited to studies of the existing literature [e.g., Bell and Larson, 1982a; USDOE, 1986] and an inventory of known prospects and mine workings [Quade and Tingley, 1983; 1984]. In 1987, Task 3 began to carry out direct field and laboratory investigations of the volcanic stratigraphy, volcanic-geologic framework, hydrothermal alteration and mineralization, and the hydrocarbon resource potential of the Yucca Mountain area. This report summarizes the results of our studies from January, 1987 through June, 1988, comprising a supplement to our quarterly reports of that period.

\section{TASK 3 ACTIVITIES OF APRIL-JUNE, 1988}

During the period April 1 through June 30, 1988, the final quarter of this contract, Task 3 work involved primarily review and writing activities. Field and laboratory analytical work was based on work carried out late in 1987 and in part based on the results of Task 3 studies during the first quarter of 1988. In addition to information pertaining to hydrothermal mineralization. Task 3 studies continue to contribute important information on the local and regional volcanic and structural geology of the Yucca Mountain area. Furthermore, studies by Alan K. Chamberlain have contributed significant information on the depositional environment of Mississippian rocks and on the hydrocarbon potential of the Nevada Test Site - Yucca Mountain region. The following summarizes our activities of the last quarter:

\section{Personnel Changes}

Mr. Alan Chamberlain and Mr. Mac Jackson left the staff of Task 3 when their Graduate Research Assistantships ended June 30. Ms. Katherine Connors, a new Phd candidate, and Mr. Lindsay Christensen, a second year MS student, were hired by Task 3 on Graduate Research Assistantships for the summer months. Ms. Connors and Mr. Christensen will assist in field, laboratory and writing activities under the supervision of the Co-Principal Investigators and Research Associate.

\section{Field Activity}

Fieid investigations were carried out by Chamberlain to continue stratigraphic studies begun during the first quarter. A summary of Chamberlain's observations and interpretations is presented in his progress report, Appendix 1. Short periods of field work were also carried out by Weiss in the Stonewall Mountain volcanic center, by Noble in the Sleeping Butte area and by Noble, Larson, Weiss, Connors and Christensen in the Beatty Bullfrog Hills area. Observations and interpretations from these periods of field work are summarized in subsequent sections of this report.

\section{Laborafory Work}

Noble, Weiss, Christensen and Conrors have continued laboratory studies of samples collected earlier in the year and those collected during the second quarter. Petrographic studies were performed and heavy liquids techniques were utilized to prepare mineral 
separates for radiometric dating of alteration and volcanic-stratigraphic relations. Analytical data for previous K-Ar determinations were received from E. H. McKee of the U.S.G.S. and were incorporated in the age compilation of Jackson [1988] (Appendix II). A new radiometric age of $6.20 .2 \mathrm{Ma}$, on sanidine from the post-basalt tuff at Currie Well, was received from McKee. This age is consistent with the age of the Stonewall Flat Tuff. A concentrate of mafic phenocrysts from glassy ash-flow tuff near the mouth of Beatty Wash, previously mapped as Thirsty Canyon Tuff [P. Orkild, unpublished mapping], contained abundant sodic amphibole and sodic pyroxene. On the basis of field appearance, distinctive phenocryst assemblage and the age determination and similar thin-section petrography of a specimen from the Jurrie Well exposure, we correlate this ash-tlow unit with the Spearhead Member of the Stonewall Flat Tuff. The stratigraphic and structural significance of this correlation is presented in Weiss et al., [1988] (Appendix III) and briefly discussed later in this report.

Review and Writing Activity

Technical Procedures: Considerable time was spent by Weiss and Noble on development of new Technical Procedures and revisions to existing Technical Procedures. The following were submitted to the General Task for transmittal to NNWPO during May, 1988:

QAP-1.3 POSITION TITLES, POSITION DESCRIPTIONS, EMPLOYEE EXPERIENCE RECORDS AND QUALIFICATIONS STATEMENTS FOR TASK 3

QAP-13.1 IDENTIFICATION, HANDLING AND STORAGE OF ROCK AND SOIL SAMPLES

\section{QAP-3.7 PROCEDURES FOR X-RAY DIFFRACTION ANALYYSIS}

QAP-3.8 COLLECTION OF ROCK AND SOIL SAMPLES

QAP-3.9 PREPARATION OF MINERAL SEPARATES FOR RADIOMETRIC AGE DETERMINATION AND CHEMICAL ANALYSIS

\section{QAP-3.10 PROCEDURES FOR PO'TASSIUM-ARGON AGE DETERMINATIONS}

\section{QAP-3.11 DETERMINATION OF MAJOR-, TRACE-AND MINOR-ELEMENT CONCENTRATIONS OF ROCK-CHIP AND SOIL SAMPLES}

\section{QAP-3.29 BASIC OPERATION OF THE PHILIPS APD3720 AUTOMATED DIFFRACTOMETER}

All of the above procedures have been implemented by Task 3 on a provisional basis pending comments from the Quality Assurance Manager of the NNWPO.

Review of the Consultation Draft Site Characterization Plan: Our general comments on Chapier 1.7 were included in the report for January - March, 1988. During the final quarter, Larson, Noble and Weiss reviewed selected portions of Chapter 8 of the CDSCP. is summary of our general comments on Chapter 8 was submitted, together with our individual specific comments, concerns and objections, to the General Task on June 17, 1988. A copy of our summary comments on Chapter 8 is appended (Appendix IV). 
Publications and manuscripts: Based on field and laboratory observations, Noble and Weiss co-authored and submitted an abstract entitled "Volcanic and Tectonic Significance of the Presence of the Late Miocene Stonewall Flat Tuff in the Vicinity of Beatty Nevada" (Appendix III) for presentation in November, 1988, at the national centennial meeting of the Geological Society of America. Jackson completed writing and revising the final version of his MSc thesis entitled 'The Timber Mountain Magmato-thermal Event: An Intense Widespread Culmination of Magmatic and Hydrothermal Activity at the Southwestern Nevada Volcanic Field". Jackson's thesis (Appendix II) comprises an integral part of this report.

The Noble, McKee and Weiss manuscript entitled "Nature and Timing of Pyroclastic and Hydrothermal Activity and Mineralization at the Stonewall Mountain Volcanic Center, Southern Nevada" was accepted for publication this year in Isochron/West (Appendix V). Weiss and Noble, with assistance from Connors, completed revisions and re-submitted the Weiss and Noble manuscript on the Stonewall Mountain volcanic center for the forthcoming special issue of the Journal of Geophysical Research (abstract is Appendix VI). Revisions to the Weiss, Noble and McKee manuscript on the timing of volcanism at the Black Mountain center have also been completed and the manuscript will be resubmitted shortly, also to JGR (abstract is Appendix VII).

\section{Other}

$\mathrm{K}$. Connors has successfully accomplished the software-hardware interfacing necessary to bring our Summagraphics digitizing tablet on-line with the latest version of GSDIG, GSMAP and GSDRAW [Selner and Taylor, 1988; Selner et al., 1988]. Connors and Christensen have digitized the latitude and longitude of all Task 3 geologic sample locations from the topographic base maps (Table 1). This data may now be efficiently added to our REFLEX sample information database.

\section{STUDIES OF VOLCANIC STRATIGRAPHY AND CALDERA GEOLOGY}

Geologic studies of the Nevada Test Site - Northern Nellis Bombing and Gunnery Range region were largely carried out by geologists of the U.S. Geological Survey between about 1960 and 1966 and to a lesser extent in the late 1960's and 1970's. This work was clearly of high caliber and resulted in many fundamental contributions to volcanic geology, petrology, and geochemistry. However, it has long been recognized by members of Task 3 that much more remains to be learned about the basic geology of the region, and that certain "known" relations may in fact be in part, or entirely, incorrect. One example is provided by the work of Noble et al. [1984], who demonstrated that the previously established stratigraphic relations and source areas of some of the youngest and best preserved and exposed ash-flow units of the southwestern Nevada volcanic field were incorrect. Similar fundamental errors have been recognized by R. A. Warren, F. M. Byers, Jr., and their coworkers at the Los Alamos National Laboratory [Warren et al., 1988; R. A. Warren, written and oral commurications, 1987 and 1988].

Because of the likelihood of important errors and uncertainties in previous work, Task 3 has embarked on a in-depth program to recognize those parts of the geologic picture that may be incorrect and to provide new data to lead to a more accurate and less equivocal understanding of the geological framework of the Repository Site and vicinity. The following summarizes the various specific studies and findings of Task 3. 


\section{Time of Inception of Magmatic Activity}

Statement of the problem: It has long been thought that magmatic activity at the southwestern Nevada volcanic field began about $16 \mathrm{Ma}$ [e.g., Byers et al., 1976b; Carr et al., 1986]. This belief has been based entirely on a single radiometric (K-Ar) age of 16.10 .6 $\mathrm{Ma}$ (recalculated using presently accepted constants and abundance values) obtained on the Tuff of Redrock Valley [Marvin et al., 1970], the oldest major ash-flow unit that can be assigned with confidence to the southwestern Nevada field. Marvin et al. [1970] preferred the age of $16.1 \mathrm{Ma}$ to an age of about $13.97 \mathrm{Ma}$ obtained on the same unit by Kistler [1968]. The ages of Kistler [1968] have, however, proven to be remarkably reliable [e.g., Marvin, et al., 1970; Noble et al., 1984; Weiss et al., in review], and based on the data that has been available for many years, we concluded that the age of the Tuff of Redrock Valley, and thus the time of inception of volcanism at the southwestern Nevada volcanic field, could as likely be 13.5 to $14 \mathrm{Ma}$ as $16 \mathrm{Ma}$.

A later inception of activity has important implications with respect to the mineral potential at depth of the Yucca Mountain Repository Site. Inception of volcanic activity at 14.0 $\mathrm{Ma}$ or later would mean that a large number of major ash-flow units (three ash-flow sheets of the Crater Flat Tuff, the Lithic Ridge Tuff, the tuff of Yucca Flat, the three unnamed ash-flow units present beneath the Lithic Ridge Tuff at Yucca Mountain, the two ash-flow sheets of the Belted Range Tuff, other relatively poorly known ash-flow units of the volcanic field), in addition to the Tuff of Redrock Valley, were erupted in a ca. 0.5 to $1.0 \mathrm{Ma}$ interval preceding eruption about 13.3 m.y. ago of the Topopah Spring Member of the Paintbrush Tuff. Certain of these major ash-flow units were almost certainly erupted from sources very close to the Repository Site. The focus of repeated episodes of magmatic activity within a very short period of time increases the probability that major metaldepositing hydrothermal systems were active in the Site area not only prior to the eruption of the Topopah Spring Member of the Paintbrush Tuff, but also after eruption of the unit.

Program of study and preliminary results: A program of radiometric dating of the tuff of Redrock Valley is now in progress. Bulk specimens have been collected from various levels within the tuff of Redrock Valley at its type area, and separates of phenocrystic sanidine and biotite have been prepared for radiometric dating by the $\mathrm{K}$-Ar method. These age determinations should be completed in a few weeks. Preliminary results from near the base and top of the type section suggest that, as suspected, the tuff of Redrock Valley is probably younger than about $14.2 \mathrm{Ma}$, about two million years younger than previously believed. Thus, most of the volcanic activity of the southwestern Nevada volcanic field - that is, all volcanism before the eruption of the Timber Mos 7 tain Tuff - may have taken place within a very restricted period of about 1-1.5 m.y. duration.

\section{Location of Calderas of the Timber Mountain-Qasis Valley Complex}

Introduction: For almost three decades the volcanic stratigraphy and caldera geology of the Timber Mountain-Oasis Valley caldera complex (Figure 1.) has been the focus of scores of man-years of effort by a large number of geologists, mainly of the U.S. Geological Survey and the Los Alamos National Laboratory [Byers et al., 19766; Carr et al., 1986]. Although work done by geologists of the U.S. Geological Survey in connection with the Yucca Mountain Repository Site has led to a better understanding of the ash-flow stratigraphy and source areas of the complex, we have obtained data that suggest important revisions may be in order.

Observations: In the Transvaal Hills, situated on the southwestern margin of the Timber Mountain caldera (Figure 1.), is exposed a very thick section of moderately to steeply dipping, densely welded ash-flow tuff. This unit lies stratigraphically below a unit of coarse landslide breccia, which in turn is beneath the Ammonia Tanks Member of the 
Timber Mountain Tuff. This thick unit of ash-flow tuff was mapped as the Rainier Mesa Member of the Timber Mountain Tuff [Lipman et al., 1966; Byers et al., 1976a]. Byers et al. [1976b] considered that the exposure may represent an intracaldera facies of the Rainier Mesa Member that had been tilted by central resurgence.

Our study of thin sections prepared from samples from various locations within the densely welded ash-flow tuff at T-ansvaal Hills reveals a phenocryst mineralogy that: 1 ) is unlike that reported for the Timoer Mountain Tuff [Byers et al., 1976b] and 2) matches the assemblages reported for the Prow Pass Member of the Crater Flat Tuff [Carr et al., 1986]. Most importantly, the unit in question contains phenocrysts of orthopyroxene, which has heretofore been recognized as unique to the Prow Pass Member.

Studies in progress and geologic implications: We are presently preparing separates of phenocrystic sanidine and biotite from the unit in question above for radiometric dating. The resultant ages should provide definitive evidence as to whether the pre-Ammonia Tanks Member tuffs at Transvaal belong to the Rainier Mesa Member (ca. 11.5 Ma) or to the Prow Pass Member ( $13.3 \mathrm{Ma}$ ).

Identification of the tuffs in question as part of the Prow Pass Member of the Crater Flat Tuff will have far-reaching consequences requiring major changes in the fundamental geologic framework. The Claim Canyon segment of the Timber Mountain caldera-complex could then be reasonably inferred to lie east of the Transvaal Hills, perhaps in the Timber Mountain caldera moat.

Another fundamental question, concerning the location of the source area of the Rainier Mesa Member, would be directly affected by the presence of Crater Flat Tuff in the Transvaal Hills. The sphene-bearing unit of ash-flow tuff mentioned in Carr [1986], and thought by Byers et al. [1976a] to underlie the Grouse Canyon Member of the Belted Range Tuff along the Sleeping Butte caldera segment, has been recognized by us to be a separate, southeast-dipping cooling unit that mantles the northwest-dipping, pre-Grouse Canyon Member, Tuffs of Sleeping Butte. Petrographic examination suggests the sphene-bearing unit may be part of the Ammonia Tanks Member of the Timber Mountain Tuff. If this is the case, a large, pre-Ammonia Tanks depression was present from the Sleeping Butte segment, extending to the southeast, and possibly encompassing much of the Oasis Valley area. A thick section of the Prow Pass Member in the Transvaal area, if present, could be a remnant of the southeast wall of such a pre-Ammonia Tanks depression, consistent with eruption of the Rainier Mesa Member from a caldera in Oasis Valley bounded by the Sleeping Butte segment to the north and the Transvaal Hills to the southeast.

Clearly, much additional work is required to test the above interpretation. Future petrographic, paleomagnetic and radiometric dating studies in the Sleeping Butte - Oasis Valley - Transvaal Hills area are planned by Task 3 to address this important aspect of the volcanic-geologic framework.

\section{New Caldera in the Sleeping Butte Area}

During reconnaissance field traverses along the Sleeping Butte caldera segment, Noble and Connors observed the presence of an extremely thick ash-flow unit of the Tuff of Sleeping Butte, lying stratigraphically beneath the Grouse Canyon Member. Their observations indicate a minimum thickness of $600 \mathrm{~m}$ of this unit is exposed near Sleeping Butte, and neither the base nor top of the unit was observed. Such thicknesses of ash-flow tuff in a single cooling unit are not commonly known except within calderas. This strongly suggests the presence of another, previously unrecognized major caldera in the Sleeping Butte area of the southwestern Nevada volcanic field. Petrographic study of collected samples is currently in progress and we have recently prepared sanidine separates from this tuff for radiometric dating. 


\section{Stonewall Flat Tuff in the Vicinity of Beatty. Nevada}

A thin unit of post-Timber Mountain ash-flow tuff present in the Bullfrog Hills, Oasis Valley and in the Beatty Wash area north of Bare Mountain was provisionally mapped as Thirsty Canyon Tuff [Maldonado, 1988; P. Orkild, unpub. map of Bare Mountain Quad]. Based on field appearance, distinctive phenocryst assemblage and a new sanidine $\mathrm{K}-\mathrm{Ar}$ age determination of $6.2 \quad 0.2 \mathrm{Ma}$, we correlate this unit with the Spearhead Member of the Stonewall Flat Tuff. The volcanic and structural significance of the presence of the Spearhead Member in the Bullfrog - Beatty area is summarized in Appendix III, [abstract by Weiss et al., 1988] and discussed later in this report.

\section{Bimodal Volcanism in the Beatty Area}

Mafic volcanism has long been recognized in the Bullfrog Hills - northern Bare Mountain - Timber Mountain caldera area, but has generally been thought to post-date Timber Mountain silicic volcanism in that area [Ransome et al, 1910; Byers et al., 1976a; Carr, 1984a; Carr and Monsen, 1988]. Recent unpublished mapping by M. D. Carr, north of Fluorospar Canyon, has shown that one or more major units of silicic ash-flow tuff are intercalated between basaltic lavas considered to be about $10 \mathrm{Ma}$ in age [Carr, 1984a]. The basaltic rocks locally overly Timber Mountain Tuff and both the basalts and intercalated silicic tuffs have been tilted by normal faulting in the hanging wall of the Fluorospar Canyon fault system. The silicic tuffs are presently unassigned and a distinct possibility exists that they are associated with the post-collapse silicic volcanism of the Timber Mountain-Oasis Valley caldera [c.f. Jackson, 1988]. If this is the case, mafic volcanism began before volcanic activity of the Timber Mountain magma system ceased, and apparently alternated with the late silicic volcanism. Such bimodal volcanism would be consistent with large-scale crustal extension in the Bare Mountain - Bullfrog Hills region as recently proposed by several workers [e.g., Maldonado 1985, 1988; Carr, 1988; Carr and Monsen, 1988; Scott, 1984].

\section{STUDIES OF PALEOHYDROTHERMAL SYSTEMS IN THE SITE REGION}

Although it is generally recognized thai hydrothermal activity is an integral part of the evolution of volcanic centers of the collapse-caldera type [e.g., Smith and Bailey, 1968], studies of the hydrothermal activity of the southwestern Nevada volcanic field have been consistently neglected since geologic work began there almost three decades ago. When Task 3 began their investigations there was very little descriptive geologic, mineralogic, geochemical, or radiometric data available for the many paleohydrothermal systems present in the southwestern Nevada volcanic field and nearby areas. Because the distribution, nature, and timing of hydrothermal activity and metallization is critical to any evaluation of the mineral potential of the Yucca Mountain Repository Site, Task 3 began the study of the many mines, prospects, and areas of hydrothermal alteration of the region as a high-priority aspect of our research. A large part of our observations and interpretations obtained from this study have been recently summarized by Jackson [1988], and in our quarterly progress reports. Radiometric ages of rock units and ages of alieration/mineralization of the southwestern Nevada volcanic field given in the available literature were evaluated, recalculated using current decay constants and abundance values where necessary, and tabulated by Jackson [1988; Appendix II]. Analytical data, sample localities and brief sample descriptions for new radiometric age determinations obtained by Task 3 are also given by Jackson [1988; Appendix II]. Other pertinent observations, interpretations and conclusions, particularly those requiring extra emphasis, are presented below. 


\section{Methods of Study}

Task 3 studies to date have combined review of available literature and reconnaissance-type field observations in the region, with standard hand-specimen, thinsection and immersion-oil petrography, $x$-ray diffraction analyses, inductively-coupled emission spectrographic chemical analyses, and radiometric dating by the potassium-argon method. Virtually all areas of hydrothermal alteration mentioned or shown on published maps and reports of the Mine Mountain - Calico Hills - Yucca Mountain - northern Crater Flat area were examined in varying detail to begin to ascertain the location, areal extent, exposed mineralogy and timing of alteration. The locations from which hand-specimen samples were collected for lithologic reference, thin-section or oil-immersion petrographic analysis, $x$-ray diffraction analysis, chemical analysis and(or) radiometric dating are listed in Table 1 .

Selected rock-chip and soil samples were analyzed for Au and indicator elements to begin to investigate the chemical signatures of selected paleohydrothermal systems of the Yucca Mountain region; the results are given in Table 2. Analyses were carried out by Geochemical Services, Inc., in their Torrance, CA laboratory using ICP-ES methods. Total acid digestion of -200 mesh splits was followed by solvent-extraction type matrix matching techniques. Detection limits were $0.001 \mathrm{ppm}$, or lower, for all samples except the northern Bare Mountain drill-hole cuttings which were analyzed at a $0.050 \mathrm{ppm}$ detection limit.

\section{HYDROTHERMAL ALTERATION AND POSSIBLE MINERALIZATION WITHIN AND NEAR YUCCA MOUNTAIN}

Our investigations as proposed included study of both subsurface and surface materials at Yucca Mountain to evaluate the possible presence of geochemical and(or) mineralogic features that would indicate or suggest the prior presence of hydrothermal systems that could have deposited economic or potentially economic concentrations of precious and(or) base metals.

\section{Inability to Study Core from Exploratory Holes}

A major part of the investigations proposed as part of the present contract were to involve detailed mineralogical and geochemical study of selected portions of the drill core obtained from exploration holes at Yucca Mountain and vicinity. To this end we requested access to the core early in 1987 and again in April, 1988. Because of the stop-work order placed on the U.S. Geological Survey several years ago, and the eventual decision to transfer the core from the U.S. Geological Survey Core Library in Mercury to a different facility under the supervision of Science Application International, we have been unable to obtain access to the materials required for this phase of our work.

It is our intention to begin to carry out this phase of our studies under the support of continued funding from the Nevada Nuclear Waste Projects Office as soon as we are able to obtain access to the core. Core/cuttings intervals totaling approximately $4000 \mathrm{~m}$ have been provisionally selected for initial review based on geologic relations and data contained in U.S.G.S. Open-file and other government agency reports. An initial priority will be to examine drill core intervals where faults, breccia, fracture zones and other highly permeable structures were intersected above $1000 \mathrm{~m}$ depths. Evidence for hydrothermal mineralization at shallow levels, if present, is more likely to be found in such structures.

Evidence for Hydrothermal Deposits in the Subsurface of Yucca Mountain

Pervasive hydrothermal alteration has been commonly reported but only briefly described from the deeper portions of test holes in Yucca Mountain [e.g., Bish, 1987; Broxton et al., 1986; Caporuscio et al., 1982; Carr et al., 1986; Maldonado and Koether, 
1983; Spengler et al., 1981]. The possibility of related metallic mineral deposits has been virtually ignored, except for the cursory discussion contained in Chapter 1 of the CD Site Characterization Plan [USDOE, 1988].

The literature indicates quartz-calcite-albite-potassium feldspar-illite -bearing alteration, epidote, fluorite, barite, pyrite, chlorite, analcime and zeolites, has pervasively affected a large volume of rock below about $900 \mathrm{~m}$ depths. Based on samples from the widely separated holes USW G-1, USW G-2 and USW G-3, Aronson and Bish [1987] and Bish [1987] presented evidence that temperatures as high as $275 \mathrm{C}$ were reached in the deeper parts of the north end of Yucca Mountain and that alteration was contemporaneous with, and possibly associated with Timber Mountain magmatic activity. The general aspect is that of a deep, laterally extensive hydrothermal system with alteration mineralogy similar to the quartz-adularia-sericite type [Heald et al., 1987]. The elevated Au and $\mathrm{Ag}$ values mentioned in Spengler et al. [1981] and the general similarities in alteration mineralogy and host-rock type, to ore mineralization elsewhere, suggests this system may have generated metallic mineralization. The general similarities, in age and alteration assemblages, to productive hydrothermal precious-metals deposits in the region (e.g., Bullfrog Hills, Sterling Mine) provides important support for this inference. It should be emphasized that substantial areas of high permeability, such as faults, fractures and breccia zones are known to be present in Yucca Mountain and are likely to have channeled much more fluid flow than the average bulk rock, possibly to much shallower depths, and thus should be rigorously investigated for evidence of metalliferous hydrothermal mineralization.

\section{Evidence for Possible Hydrothermal Deposits at the Surface of Yucca Mountain: Silicified} Breccia and Carbonate Veins in Faults

Detailed geologic mapping has shown that evidence for hydrothermal alteration or mineralization at the surface of Yucca Mountain is absent [Scott and Bonk, 1984]. However, studies of trenches indicate that silica-carbonate veins and(or) silicification are present at the surface on, or near, Yucca Mountain along more than one fault [Szabo and O'Malley, 1985; Taylor and Huckins, 1986; Vaniman et al., 1988]. Based on our brief field examinations of exposures in Trenches 14 and $14 \mathrm{a}$, we provisionally interpret the drusy quartz and silicification in the Tiva Canyon Member at Trench 14 to be older than the adjacent, cross-cutting silica-carbonate veins, and, possibly, to have been deposited by lowtemperature hydrothermal solutions. This interpretation is supported by preliminary data mentioned by Vaniman et al., [1988], that suggest the drusy quartz was deposited at higher temperatures and is older than the silica-carbonate veins.

Two lines of evidence are consistent with a low-temperature hydrothermal origin for the silicification of the Tiva Canyon Member near the Bow Ridge Fault in Trench 14. The first is textural. Silicification is stronger in breccia near the fault, locally resulting in nearly complete replacement by silica of fragments of densely welded ash-flow tuff of the Tiva Canyon Member. Also, jigsaw puzzle-type fragmental textures within the silicified breccia are similar to textures resulting from hydrofracturing, suggesting hydrothermal brecciation may have occurred [H.F Bonham, Jr., oral communication, 1987].

The second type of evidence is that preliminary chemical data (Table 2; also see Task 3 report for Jan. 1 - March 31, 1988) are more consistent with a hydrothermal chemical signature, than a deuteric or supergene signature. Clearly, more conclusive information is required, but these deposits may very possibly reflect at least one episode of past lowtemperature hydrothermal activity, at or near the surface of Yucca Mountain. Such faultchanneled activity would be consistent with the evidence summarized above for widespread hydrothermal activity at depth within Yucca Mountain. 
$\frac{\text { Studies of Hydrothermally Altered Areas Adjacent to the Northern Part of Yucca Mountain }}{\text { Reconnaissance field traverses directly nor hef Yon }}$ Pass and the Claim Canyon segment of the Tim north of Yucca Mountain, in the area of Prow complex, were conducted by Weiss and Jackson to Mountain - Oasis Valley caldera timing of hydrothermal activity mentioned by Byers et al 1976 sty ste, location, extent and exposed area of anastomosing quartz veins and silicified breccia, 1976b]. A large, poorly argillic alteration, was observed in a complex zone of numerous caldera-marrin fanded by by Paintbrush and pre-Rainier tuffs and lava in Claim Canyorous caldera-margin faults hosted of weak silicification and argillic alteration were faim Canyon. Areally less extensive zones faults at Prow Pass and in the upper parts of Windy Walong north-trending fractures and corroborating work is needed, data in Table 2 show Wash. Although more detailed arsenic and probably gold are associated, at least locally The relation of alteration immediately north of Yucca this hydrothermal alteration. Yucca Mountain remains to be determiately north of Yucca Mountain to that deep within alteration at the higher topographic and ed. However, it should be pointed out that Mountain would be consistent with a hydrothermal cell cels observed north of Yucca [Bish, 1987] and(or) the large number of faults and fractures north of Yucca Mountain Canyon cauldron segment. Therefore, until additional date associated with the Claim reasonably consider the hydrothermal alteration exposed in Claim Canyon Wilable way Prow Pass to be a higher-level expression of the exposed in Claim Canyon, Windy Wash and within Yucca Mountain.

\section{DETACHMENT AND HIGH-ANGLE FAULTING AND POSSIBLE ASSOCLATED MAGMATISM AND MINERALIZATION}

The low- to moderate-angle fault separating predominantly Tertiary volcanic rocks from structurally lower Paleozoic and Precambrian rocks in Bare Mountain and the Bullfrog geometry above it [Ransome, 1910]. On the basis of rese related to the complex fault metamorphic rocks and structural patterns in the volcanic rocks ages of Precambrian proposed that the fault is part of a detachment system above a more recent workers have [McKee, 1983; Maldonado, 1985; 1988]. However, workers disagree on questions
concerning the lateral extent and timing of movement 1985, 1988; Carr, 1984a, 1988; Carr and of movement on this structure [c.f., Maldonado, direct bearing on the fundamental regional geol 1988; Scott, 1984, 1988], which have a interpretations concerning the subsurface geology, regional mineral potential and correlation of an ash-flow unit in the Bullfrog Hills, Oasis Valley and th. Our recent part of Beatty Wash, with the Spearhead Member of the Stonewall Fla important constraint on the timing of movement on the fault system (stat Tuff, contributes an Weiss et al., 1988). Near the mouth of Beatty Wash, flat-lying Spearhead Member tuff was deposited
within, or was overlain by Tertiary gravel deposits that lap unconformably over tilted basalts
and older units in the hanging wall of the Fluorospar Canyon Fault and older units in the hanging wall of the Fluorospar Canyon Fault. This relation indicates $\mathrm{Ma}$. To the west, at Churrie Well in the western Eullfrog Hills, the Spearhead Me about 6.3
overlies a nearly flat-lying basaltic lava. In the southwestern Bulf considered by Maldonado [pers. communication, southwestern Bullfrog Hills, ash-flow tuff dipping. If his identification of Spearhead in the 1988 ] to be the same unit is moderatelymovement on the Bullfrog Hills segment continued southwestern Bullfrog Hills is correct, younger deformation in the adjacent Death Valley region.
To date we have tilted Spearhead Member south of Currie Well. Nevertheless, the presence of the Spearhead 
Member at Currie Well, and in and near the mouth of Beatty Wash requires that a large valley or depression was present to channel the Spearhead Member nearly $90 \mathrm{~km}$ from the Stonewall Mountain center. This implies that Sarcobatus Flat and Oasis Valley were topographically low and suggests that much of the present-day topography was largely formed by about $6.3 \mathrm{Ma}$.

Although Cornwall and Kleinhampl [1964] and Beck [1984] have proposed the existence of calderas in the Bullfrog Hills, it is clear that much of the hydrothermal activity, ore deposition, and substantial magmatic activity was closely associated with faults accommodating extension in rocks above the Bullfrog Hills segment of the detachment fault system [Ransome, 1910; Maldonado, 1988; Jackson, 1988]. Important Au deposits have been, and are continuing to be mined from these structures in welded silicic tuffs and other rocks of the southwestern Nevada volcanic field (e.g., Original Bullfrog Mine, Goldbar Mine, Rhyolite district, Montgomery-Shoshone Mine, Mayflower Mine, Pioneer Mine). The recent discovery of a blind deposit containing over 3 million ounces Au at Ladd Mountain indicates World-class mineralization is present [Booth, 1988]. Thus, though the existence of a detachment system beneath Yucca Mountain remains equivocal, the relations in the Bullfrog Hills demonstrate the importance of testing major structures in areas of known hydrothermal activity, regardless of the lack of surface chemical or mineralogical expression of mineralization.

\section{EVALUATION OF MAJOR HYDROTHERMAL SYSTEMS OF POSSIBLE QUATERNARY AGE IN SOUTHWESTERN NEVADA}

A very important question at the Yucca Mountain Repository Site involves the age and origin of the previously mentioned vein-filling material composed largely of calcite, cristobalite, opal and quartz that fills high-angle fault structures at Yucca Mountain [Szabo and O'Malley, 1985; Taylor and Huckins, 1986; Vaniman et al., 1988]. These have been interpreted as hypogene, that is, having been deposited from ascending hydrothermal solutions or supergene, that is, having been deposited above the water table from descending solutions. The importance of these vein fillings lies largely in the fact that if they are sufficiently young, and were formed by ascending solutions, they indicate that there heve been very marked changes in the elevation of the water table within the near past, a.1 thus that a similar marked rise in the water table might be expected within the period of time during which the Repository must provide effective containment of high-levt! inclear waste.

\section{Ongoing Studies of Task 3}

Task 3 has recognized that a greater probability would exist that calcite-silica veins at Yucca Mountain are young, and have been deposited from ascending solutions, if it were demonstrated that there has been major fault-related hydrothermal activity elsewhere in southwestern Nevada during the last several million years, that is, during Quaternary and(or) latest Pliocene time. At present we have identified two areas of major fault-related hydrothermal activity that may date within the last several million years. These are: 1) along the major, in part Quaternary (and possibly presently active ??) E-W trending high-angle fault that bounds Stonewall Mountain on the north [Foley, 1978], and 2) at Bailey's Spring in Oasis Valley north of Beatty, Nevada.

Hydrothermal activity along the Stonewall Mountain fault is reflected by multiple veinlets and veins (in places several meters in width) composed largely of quartz and chalcedony; these veins possess many of the structural, textural, and mineralogic features typical of precious-metal bearing epithermal vein systems of the low-base metal type. We have collected, and are presently preparing, materials for radiometric dating (adularized wall rock along the Stonewall Mountain fault, and alunite-bearing acid-leached rock at Bailey's Springs). We plan to sample the Stonewall Mountain vein system for $\mathrm{Au}, \mathrm{Ag}, \mathrm{As}$, $\mathrm{Sb}, \mathrm{Hg}, \mathrm{T}$, and other trace elements. 
Past hydrothermal activity at Bailey's Spring is reflected by a large area of high-level opalization and acid leaching, locally containing alunite, of the type typical of the uppermost parts of geothermal systems [e.g., Schoen et al., 1974]. Plans have not been formulated for study of the Bailey's Spring system. Bailey's is one of several low-temperature hot springs in the Oasis Valley area [Garside and Schilling, 1979; White, 1979; Vaniman et al. 1988], and a geochemical survey for $\mathrm{Hg}$ and perhaps $\mathrm{As}$ and $\mathrm{Sb}$ may be warranted to outline the area of past as well as present geothermal activity.

\section{ANALOGUE STUDIES OF THE STONEWALL MOUNTAIN VOLCANIC CENTER}

As a subsidiary part of our investigations, we have been carrying out an ongoing analogue study of the Stonewall Mountain volcanic center, the youngest (about $6.3 \mathrm{Ma}$ ) center of large-scale pyroclastic volcanism and caldera collapse in the southwestern Nevada volcanic field (Figure 1 of Appendix II). This work is a continuation of earlier work on the center [e.g., Noble et al., 1984; Weiss, et al., 1984; Weiss, 1987]. The importance of the Stonewall Mountain volcanic center lies largely in the fact that it is young, that important aspects of caldera-margin, ring-fracture sysiem, and intracaldera prism geology are very well preserved and exposed, and that the certer possesses areas of metallization and(or) hydrothermal alteration both related to the ring-fracture system and within the cauldron subsidence block.

\section{Ongoing and Completed Studies}

Work during the period of the contract has largely consisted of field studies in the southern part of Stonewall Mountain and adjacent areas to confirm and extend earlier stratigraphic and structural work in these areas. New field work involving reconnaissance mapping in the northern part of Stonewall Mountain was initiated in April 1988, to begin to sort out the location, nature and extent of hydrothermal alteration and stratigraphic and structural relations of intracaldera units within the main resurgent part of the center.

In addition, and as discussed earlier, we have recently recognized the presence of the Spearhead Member of the Stonewall Flat Tuff in the Beatty-Bullfrog Hills-Bare Mountain area. The important structural implications of this contribution, which are discussed in the section on "Detachment and High-Angle Faulting and Possible Associated Magmatism and Mineralization", provide an excellent example of an unexpected pay-off from basic scientific research.

\section{Publications}

Our work on the Stonewall Mountain volcanic center has lead to a number of publications. In addition to the abstract on the presence of Stonewall Flat Tuff near Beatty, during the period of the contract we have also prepared a majcr paper on the eruptive and subsidence history of the Stonewall Mountain volcanic center [Weiss and Noble, in review], and a shorter paper discussing the age and relation of hydrothermal activity at the Cuprite district northwest of Stonewall Mountain to the Stonewall Mountain caldera [Noble et al., 1988].

\section{MINERAL EXPLORATION, MINING AND MINE DEVELOPMENT WITHIN THE SITE REGION}

The Bullfrog Hills and Bare Mountain districts have a long history of exploration and mining [e.g., Cornwall and Kleinhampl, 1961, 1964; Bell and Larson; 1982a; Tingley, 1984; Jackson, 1988]. Although most exploration and mining took place during the first quarter of the 20th century, recent years have seen a major boom in the precious-metals industry. The Sterling mine, located on the eastern flank of Bare Mountain (Figure 1), has been increasing 
gold production under its current ownership since 1980. The Gold Bar Mine in the western Bullfrog Hills is another historic and current gold producer, and is especially notable because ore mineralization is being mined from part of the Paintbrush Tuff.

Moreover, during the last several years, intensive and successful exploration efforts have been carried out throughout the area. Dallhold Resources has recently announced reserves of 3.2 million ounces Au directly south of the old Montgomery-Shoshone Mine at Ladd Mountain [Booth, 1988], and is both actively continuing exploration and proceeding as rapidly as possible to put the World-class property into production. The Dallhold deposit is particularly important, not only due to its size and the near or virtual absence of mineralization above the deposit at the surface trace of the host structure, but also because major ore mineralization is within units of the Paintbrush and Timber Mountain Tuffs.

Closer to Yucca Mountain, Gexa Gold Corp. has recently announced reserves of 4.4 million tons averaging 0.054 ounces per ton Au at a property near the Telluride mine, and is actively continuing exploration [Reno Gazette-Journal, 1988]. Gexa's deposit is mostly within hydrothermally altered tuff, and lava(?) and(or) hypabyssal intrusive(?) rocks that may belong to the Tram Member of the Crater Flat Tuff [P. Orkild, oral communication, 1988], or may be part of a pre-Rainier Mesa Member unit [Jackson, 1988]. The deposit is closely associated with the major normal fault that apparently acted as the easternmost breakaway fault for the proposed Bullfrog - Beatty - Bare Mountain detachment system [Maldonado, 1985, 1988; Carr and Monsen, 1988]. Significantly, no surface geochemical expression of the deposit has been recognized [S. Green, Gexa Gold, oral communication, 1988]. In the wake of the Dallhold and Gexa discoveries, major companies (e.g., Nerco Minerals, Battle Mountain Gold, B. P. Minerals, etc.) are actively negotiating property positions in the Bullfrog Hills and nearby areas. It is likely that industry activity in the region will continue strongly, if not increase, in the coming months.

\section{Activities of Task 3}

Task 3 is currently investigating mineralogic, chemical, chronologic, structural and stratigraphic aspects of alteration and mineralization at the Gold Bar Mine, the Original Bullfrog Mine, the Mayflower - Pioneer area and the Gexa deposit. These investigations will continue during the next funding period, but may be hampered by our reduced level of staffing and operating funds.

Through personal contacts in the minerals industry, field activities in the region and various literature sources, Task 3 has developed an effective, up to date familiarity with mineral exploration, mine development and production in the Beatty region. We believe this type of information is important and we intend to maintain this monitoring activity.

\section{CONCLUSIONS}

\section{Results of Investigations}

In addition to the many observations, interpretations and conclusions discussed and(or) summarized by Jackson [1988], we wish to emphasize the conclusions presented below concerning volcanism and hydrothermal activity of the Yucca Mountain region of the southwestern Nevada volcanic field. They are as follows:

1) Areas of hydrothermal alteration, some with evidence of mineralization, are widespread within, southeast, south, southwest and west of the Timber Mountain caldera complex and are spatially, temporally and probably genetically related to the Timber Mountain magma system (See Figure 1, adapted from Jackson, 1988). One of these areas exists at depth in Yucca Mountain.

2) Field and petrographic observations, stratigraphic relations and radiometric age determinations indicate alteration and mineralization occurred mainly from about 11.5 
Ma to about $9.5 \mathrm{Ma}$, with some hydrothemal activity possibly as old as about 13.3 to 12.2 Ma at Wahmonie, and possibly as yong as about $8.7 \mathrm{Ma}$ at the Original Bullfrog Mine. It is not clear whether the hydrothermal alteration in the vicinity of Bailey's Spring is the result of a fossil hydrothermal system, or if, as we suspect, it is the result of a currently active hot-spring system [c.f., Bish et al., 1988].

3) Economic and potentially economic Au-Ag mineralization in the Bullfrog Hills, Oasis Mountain, the east side of Bare Mountain, Transvaal Hills and Wahmonie are epithermal deposits associaied with quartz-adularia-sericite-calcite-bearing alteration and vein mineral assemblages, in some cases surrounded by areas of argillic alteration. Base-metal concentrations are generally low, except for the western Bullfrog Hills where secondary copper and arsenic minerals have been observed. Fluorite, cinnabar, stibnite are associated with Au mineralization on the east side of Bare Mountain. The alteration mineralogy of economic Au mineralization at the north end of Bare Mountain has not yet been determined, but the low base-metal concentrations, typically low Ag:Au ratios, along with the mercury and arsenic concentrations (Table 2) suggest similarity to the mineralization on the east side of Bare Mountain, and possibly to the mineralization in the Bullfrog Hills.

Extensive areas of opal/cristobalite-chalcedony-quartz-kaolinite-alunite-hematite-, pyrite-bearing assemblages are also present that affect Tertiary volcanic rocks in Oasis Valley, Beatty Wash - Tram Ridge - northernmost Crater Flat, Calico Hills and on the south side of Mine Mountain. It is not clear if these areas of argillic alteration are the upper parts of quartz-adularia-sericite systems, or if they represent the acid-sulfate type of Heald et al. [1987]. In either case, mercury and, locally, arsenic values are slightly elevated, and the alteration affects rocks as young as Timber Mountain Tuff.

Elevated $\mathrm{Au}$ and $\mathrm{Hg}$ values at Calico Hills and Mine Mountain appear to be associated with base metal-bearing silicified fault and hydrothermal breccias hosted by the Eleana Formation. Barite and fluorite are locally present, but adularia, if present, has not been recognized. The relation of this mineralization in the Eleana, to adjacent argillic alteration in the Tertiary volcanic rocks remains to be investigated. The geologic setting and limited chemical data strongly suggest substantial potential for sediment-hosted disseminated Au deposits is present at Mine Mountain, and possibly at Calico Hills.

The distribution and mineralogy of pervasive hydrothermal alteration in Yucca Mountain, as presently known, is similar to that of epithermal metals deposits in volcanic terrains elsewhere and is possibly of similar, or the same age, as productive mineralization in the Bullfrog Hills - Bare Mountain area.

4) Precious-metals deposits and associated alteration in the region are present within a few tens of miles both east and west of Yucca Mountain. These deposits are hosted by prePaintbrush silicic ash-flow units (e.g., Lithic Ridge Tuff and older units at and near the Original Bullfrog Mine), Paintbrush Tuff and coeval units (e.g., Gold Bar Mine and in the subsurface of Ladd Mountain, Bullfrog Hills; Wahmonie-Sayler lavas and tuffs, Horn Silver Mine) and post-Paintbrush silicic ash-flow tuff and intrusive rocks (e.g., Rainier Mesa Member of the Timber Mountain Tuff, southern Bullfrog Hills, subsurface of Ladd Mtn), as well as by Paleozoic sedimentary rocks at Bare Mountain (Sterling Mine).

Productive Au-Ag deposits appear to be closely associated with major faults or areas of numerous, closely spaced faults. Several of these deposits are clearly associated with epithermal quartz-adularia-sericite systems, and in some cases possess little, if any, surface expression of mineralization. 


\section{Significance for Mineral Potential at and Near Yucca Mountain}

Two controlling processes are generally recugnized to be necessary for the formation of economic, or potentially economic, epithermal metallic ore deposits. One is the development of deep-seated zones of high permeability in the upper crust, usually by faulting. The other required process is the operation of a metalliferous hydrothermal system.

It is clear from a variety of evidence that Yucca Mountain and surrounding areas of the southwestern Nevada volcanic field have been subjected to the development of numerous deep-seated faults, and systems of faults, as the result of both regional extension and volcano-tectonic events. It is also clear that numerous large hydrothermal systems have operated in the southwestern Nevada volcanic field, and that one or more of these systems has been found within Yucca Mountain. The multiple episodes of Timber Mountain volcanism increase the likelihood that multiple and(or) lengthy periods of hydrothermal activity occurred within or peripheral to the Timber Mountain caldera cornplex and Yucca Mountain. Furthermore, it is obvious that more than one of these hydrothermal systems have been highly metalliferous, and have generated several ore deposits in the same rock units as are present in and near Yucca Mountain.

All of the above indicate a much greater possibility for economic or potentially econornic mineral resources in Yucca Mountain, than in areas where required processes have not occurred. On the basis of the currently available published information from the subsurface of Yucca Mountain, and the relations noted above, we conclude there is a much stronger possibility that epithermal-type mineralization may be present in Yucca Mountain than has heretofore been recognized.

The fact that economic epithermal Au deposits have recently been discovered in the southwestern Nevada volcanic field by direct drilling programs, where little or no surficial evidence of mineralization is present above the deposit, largely invalidates several of the assumptions in the DOE's past evaluations of low potential for mineralization and(or) future exploratory drilling at Yucca Mountain. Exploration in the region is likely to rely increasingly on the identification and drilling-based testing of potentially mineralized structures. Furthermore, the DOE assumption that only the potential at depths less than 1 $\mathrm{km}$ need to be addressed (SPC chapter 1.7) is tenuous, at best, in light of deep discoveries and current development plans in other mineralized districts (e.g., Carlin Trend, Battle Mountain area)

A systematic investigation should be carried out to test the faults, fracture-zones and breccia-zones at depth in Yucca Mountain for evidence of mineralization. Task 3 intends to begin such an investigation if existing drill core becomes available. In addition, we recommend the continuation of ongoing field and laboratory studies of alteration in the northern Crater Flat, Claim Canyon - Prow Pass, Calico Hills and Mine Mountain areas.

Task 3 also plans to maintain close contact with U.S.G.S. and Los Alamos National Laboratory workers active in the region, such as R. Warren, F.M. Byers, W.J. Carr, M.D. Carr, F. Maldonado and E.H. McKee.

\section{PART 2: HYDROCARBON POTENTIAL RELATED TO MISSISSIPPIAN SEDIMENTARY ROCKS OF THE YUCCA MOUNTAIN AREA OF THE NEVADA TEST SITE REGION}

Literature research and direct field studies of Paleozoic sedimentary rocks in the Nevada Test Site region were carried out by Mr. Alan K. Chamberlain, a Graduare Student Research Assistant with extensive professional recognition and experience in oil exploration and the Paleozoic stratigraphy of the Basin and Range province of Nevada and Utah. Mr. Chamberlain's progress report (Appendix I) contains summaries of his observations, interpretations, and recommendations, and a list of pertinent references concerning the 
potential for undiscovered hydrocarbon resources in the vicinity of Yucca Mountain. A total of twelve stratigraphic sections were measured and selected samples were analyzed for palynomorph assemblage, Total Organic Content, Conodont Alteration Indices and Visual Thermal Alteration Indices. It should be emphasized that Mr. Chamberlain's explorationoriented approach, combining basic field observation with modern paleontological and organic chemical analysis, has probably not been applied to the Nevada Test Site region since the development and recognition of the Railroad Valley oil fields as a significant oil producing area.

In general, Chamberlain's research strongly suggests there is more hydrocarbon resource potential in the pre-Tertiary rocks of the Yucca Mountain - NTS i. ea than has been previously recognized. His observations and interpretations indicate that 1) Paleozoic strata within the hydrocarbon maturation window are present in the Nevada Test Site and may contain appropriate hydrocarbon source rocks, and 2) contrary to existing interpretations of marine depositional environments, important paleontological evidence was found suggesting the Mississippian clastic rocks may be partly or entirely of a nonmarine depositional environment. If this is the case, then much of the presently accepted stratigraphic picture may require re-evaluation. It is also notable that Mississippian siliciclastic rocks have been recognized as a potentially significant hydrocarbon source in other areas of Nevauid. Clearly, in the absence of direct tests by a deep $(10,500 \mathrm{~m})$ drill hole, a much better knowledge of the depositional environments, organic content, thermal histcry and regional structural geometry of the pre-Tertiary section of the NTS region is needed to address the question of hydrocarbon resource potential in the subsurface of Yucca Mountain. 


\section{REFERENCES CITED AND OTHER PEPTINENT LITERATURE}

The following references were selected because of their direct bearing on the Cenozoic volcanic stratigraphy and caldera geology, hydrothermal activity, and mineral potential of the Site Vicinity. Additional pertinent references on mineral potential, and particularly unpublished data in files of the Nevada Bureau of Mines and Geology, are given by Bell and Larson [1982b].

Ahern, R., and Corn, R.M., 1981, Mineralization related to the volcanic center at Beatty, Nevada: Arizona Geological Society Digest, v. XIV, p. 283-286.

Ander, H.D., and Byers, F.M., 1984, Nevada Test Site field trip guidebook; Reno, Nevada, University of Nevada-Reno, Department of Geological Sciences, v. 2, 1984, 35 p.

Anderson, R.E., Ekren, E.B., and Healey, D.L., 1965, Possible buried mineralized areas in Nye and Esmeraldo Counties, Nevada: U.S. Geological Survey Professional Paper 525-D, p. D144-D150.

Anonymous, 1928, One strike of real importance made at Nevada's new camp: Engineering and Mining Journal, v. 125, no. 1, p. 457.

Aronson, J.L., and Bish, D.L., 1987, Distribution, K/Ar dates, and origin of illite/smectite in tuffs from cores USW G-1 and G-2, Yucca Mountain, Nevada, a potential high-level radioactive waste repository: Abstract of presentation at Clay Minerals Society Meeting, Socorro, NM, 1987.

Bailey, E.H., and Phoenix, D.A., 1944, Quicksilver deposits in Nevada: Nevada Bureau of Mines and Geology Bulletin 41.

Barton, C.C., Tectonic significance of fractures in welded tuff, Yucca Mountain, Southwest Nevada: Geological Society of America, Abstracts with Programs, v. 16, 1984, p. 437.

Bath, G.D., and Jahren, C.E., 1984, Interpretations of magnetic anomalies at repository site proposed for Yucca Mountain area, Nevada Test Site: U.S. Geologicai Survey OpenFile Report 84-120, $40 \mathrm{p}$.

Bath, G.D., and Jahren, C.E., 1985, Investigation of an aeromagnetic anomaly on west side of Yucca Mountain, Nye County, Nevada: U.S. Geological Survey Open-File Report $85.459,24 \mathrm{p}$.

Beck, B. A., 1984, Geologic and gravity studies of the structures of the northern Bullfrog Hills, Nye County, Nevada: California State University at Long Beach, unpublished MSc Thesis, $86 \mathrm{p}$.

Bedinger, M.S., Sargent, K.A., and Langer, W.H., 1984, Studies of geology and hydrology in the Basin and Range Province, Southwestern United States, for isolation of high-level radioactive waste; characterization of the Death Valley region, Nevada and California: U.S. Geological Survey Open-File Report 84-743, 173 p. 
Bedinger, M.S., Sargent, K.A., and Langer, W.H., 1984, Studies of geology and hydrology in the Basin and Range Province, Southwestern United States, for isolation of highlevel radioactive waste; evaluation of the regions: U.S. Geological Survey Open-File Report 84.745, $195 \mathrm{p}$.

Bell, E.J., and Larson, L.T., 1982a, Overview of energy and mineral resources of the Nevada Nuclear Waste Storage Investigations, Nevada Test Site, Nye County, Nevada: U.S. Department of Energy Report NVO-250 (DE83001418), 64 p. plus maps.

Bell, E.J., and Larson, L.T., 1982b, Annotated bibliography, Overview of energy and mineral resources for the Nevada Nuclear Waste Storage Investigations, Nevada Test Site, Nye County, Nevada: U.S. Department of Energy Report NVO-251 (DE83001263), $30 \mathrm{p}$.

Benson, L.V. and McKinley, P.W., 1985, Chemical composition of the ground water in the Yucca Mountain area, Nevada: U.S. Geological Survey Open-File Report 85-484, 10 p.

Bentley, C.B., 1984, Geohydrologic data for test well USW G-4, Yucca Mountain area, Nye County, Nevada: U.S. Geological Survey Open-File Report 84-63, 67 p.

Bish, D.L., 1987, Evaluation of past and future alteration in tuff at Yucca Mountain, Nevada based on clay mineralogy of drill cores USW G-1, G-2, and G-3: Los Alamos, New Mexico, Los Alamos National Laboratory Report LA-10667-MS, 42 p.

Booth, M., 1988, Dallhold finalizes plans for huge Nevada mine: The Denver Business Joumal, April 4, 1988, p. 10.

Broxton, D.E., Byers, F.M., Warren, R.G. and Scott, R.B., 1985, Trends in phenocryst chemistry in the Timber Mountain-Oasis Valley volcanic field, SW Nevada; evidence for isotopic injection of primitive magma into an evolving magma system: Geological Society of America, Abstracts with Programs, v. 17, p. 345.

Broxton, D.E., Warren, R.G., Byers, F.M., Jr., Scott, R.B., and Farner, G.L., 1986, Petrochemical trends in the Timber Mountain-Oasis Valley caldera complex, SW Nevada: EOS (American Geophysical Union Transactions), v. 67, p. 1260.

Broxton, D.E., Warren, R.G., Hagan, R.C. and Luedemann, G., 1986, Chemistry of diagenetically altered tuffs at a potential nuclear waste repository, Yucca Mountain, Nye County, Nevada: Los Alamos, New Mexico, Los Alamos National Laboratory Report LA-10802-MS, 160 p.

Byers, F.M., Jr., Carr, W.J., Christiansen, R.L., Lipman, P.W., Orkild, P.P., and Quinlivan, W.D., 1976b, Geologic map of the Timber Mountain Caldera area, Nye County, Nevada: U.S. Geological Survey Miscellaneous Investigations Series, I-891, sections, $1: 48,000$ scale.

Byers, F.M., Jr., Carr, W.J., and Orkild, P.P., 1986, Calderas of southwestern Nevada. Evolution of understanding, 1960-1986: EOS (American Geophysical Union Transactions), v. 67, p. 1260. 
Byers, F.M., Jr., Carr, W.J., Orkild, P.P., Quinlivan, W.D. and Sargent, K.A., 1976a, Volcanic Suites and related cauldrons of Timber Mountain-Oasis Valley caldera complex: U.S. Geological Survey Professional Paper 919,70 p.

Byers, F.M., Jr., Orkild, P.P, Carr, W. J., and Quinlivan, W.D., 1968, Timber Mountain Tuff, southern Nevada, and its relation to cauldron subsidence: Geological Society of America Memoir 110, p. 87.97.

Caporuscio, F., Vaniman, D.T., Bish, D.L., Broxton, D.E., Arney, D., Heiken, G., Byers, F.M., and Gooley, R., 1982, Petrologic studies of drill cores USW-G2 and UE25b1H, Yucca Mountain, Nevada: Los Alamos, New Mexico, Los Alamos National Laboratory Report LA-9255-MS, 114 p.

Carr, M.D., and Monsen, S.E., 1988, A field trip guide to the geology of Bare Mountain: Geological Society of America Field Trip Guidebook, Cordilleran Section Meeting, Las Vegas, Nevada, p. 50-57.

Carr, M.D., Waddell, S.J., Vick, G.S., Stock, J.M., and Monsen, S.A., Harris, A.G., Cork, B.W., and Byers, F.M., Jr., 1986, Geology of drill hole UE25p-1: A test hole into preTertiary rocks near Yucca Mountain, southern Nevada: U.S. Geological Survey Open File Report 86-175.

Carr, W.J., 1964, Structure of part of the Timber Mountain dome and caldera, Nye County, Nevada: U.S. Geological Survey Professional Paper 501-B, p. B16-B20.

Carr, W.J., 1974, Summary of tectonic and structural evidence for stress orientation at the NrS: U.S. Geological Survey Open-File Report 74-176, 53 p.

Carr, W.J., 1982, Volcano-tectonic history of Crater Flat, southwestern Nevada, as suggested by new evidence from drill hole USW-VH-1 and vicinity: U.S. Geological Survey Open-File Report 82-457, 23 p.

Carr, W.J., 1984a, Regional structural setting of Yucca Mountain, southwestern Nevada, and late Cenozoic rates of tectonic activity in part of the southwestern Great Basin, Nevada and California: U.S. Geological Survey Open-File Report 84-0854, 114 p.

Carr, W.J., 1984b. Timing and style of tectonism and localization of yolcanism in the Waiker Lane belt of southwestern Nevada: Geological Society of America, Abstracts with Programs, v. 16, p. 464.

Carr, W.J., 1988, Styles of extension in the Nevada Test Site region, southern Walker Lane Belt: an integration of volcano-tectonic and detachment fault models: Geological Society of America, Abstracts with Programs, v. 20, p. 148.

Carr, W.J., Byers, F.M., and Orkild, P.P., 1984, Stratigraphic and volcano-tectonic relations of Crater Flat Tuff and some older volcanic units, Nye County, Nevada: U.S. Geological Survey Open-File Report 84-114, 97 p.

Cars, W.J., Byers, F.M., and Orkild, P.P., 1986, Stratigraphic and volcano-tectonic relations of Crater Flat Tuff and some older volcanic units, Nye County, Nevada: U.S.

Geological Survey Professional Paper 1323, 28p. 
Carr, W.J., and Quinlivan, W.D., 1966, Geologic map of the Timber Mountain quadrangle, Nye County, Nevada: U.S. Geological Survey Geologic Quadrangle Map GQ-503, $1: 24,000$ scale, sections.

Carr, W.J., and Quinlivan, W.D., 1968, Structure of Timber Mountain resurgent dome, Nevada Test Site: Geological Society of America Memoir 110, p. 99-108.

Carr, W.J. and Parrish, L.D., 1985, Geology of drill hole USW VH-2, and structure of Crater Flat, southwestern Nevada: U.S. Geological Survey Open-File Report 85-475, 41 p.

Christiansen, R.L., and Lipman, P.W., 1965, Geologic map of the Topopah Spring NW quadrangle, Nye County, Nevada: U.S. Geological Survey Geologic Quadrangle Map GQ-444, 1:24,000 scale, sections.

Christiansen, R.L., Lipman, P.W., Carr, W.J., Byers, F.M., Jr., Orkild, P.P., and Sargent, K.A., 1977: Timber Mountain-Oasis Valley caldera complex of southern Nevada: Geological Society of America Bulletin, v. 88, p. 943-959.

Christiansen, R.L., Lipman, P.W., Orkild, P.P., and Byers, F.M., Jr., 1965, Structure of the Timber Mountain caldera, southern Nevada, and its relation to basin-range structure: U.S. Geological Survey Professional Paper 525-B, p. B43-B48.

Cornwall, H.R., 1962, Calderas and associated volcanic rocks near Beatty, Nye County, Nevada: Geological Society of America, Petrologic Studies, A.F. Buddington Volume, p. 357-371.

Cornwall, H.R., 1972, Geology and mineral deposits of southern Nye County, Nevada: Nevada Bureau of Mines and Geology Bulletin 77, p. 49.

Cornwall, H.R., and Kleinhampl, F.J., 1961, Geology of the Bare Mountain quadrangle, Nevada: U.S. Geological Survey Geologic Quadrangle Map GQ-157, 1:62,500 scale.

Cornwall, H.R., and Kleinhampl, F.J., 1964, Geology of the Bullfrog quadrangle and ore deposits related to the Bullfrog Hills caldera, Nye County, Nevada, and Inyo County, California: U.S. Geological Survey Professional Paper 454-J, 25 p.

Cornwall, H.R., and Norberg, J.R., 1978, Mineral Resources of the Nellis Air Force Base and the Nellis Bombing and Gunnery Range, Clark, Lincoln, and Nye Counties, Nevada: U.S. Bureau of Mines Unpublished Administrative Report, 118 p.

Craig, R.W. and Robinson, J.H., 1984, Geohydrology of rocks penetrated by test well UE2.5p\#1, Yucca Mountain area, Nye County, Nevada, U.S. Geological Survey WaterResources Investigations 84-4248, $57 \mathrm{p}$.

Craig, R.W., Reed, R.L., and Spengler, R.W., 1983, Geohydrologic data for test well USW H.6, Yucca Mountain area, Nye County, Nevada: U.S. Geological Survey Open-File Report 83-856, 52 p.

Crowe, B.M., 1980, Disruptive event analysis: Volcanism and igneous intrusion: Batelle Pacific Northwest Laboratory Report PNL-2822, 28 p. 
Crowe, B.M., and Carr, W.J., 1980, Preliminary assessment of the risk of volcanism at a proposed nuclear waste repository in the southern Great Basin: U.S. Geological Survey Open-File Report 80-357, 15 p.

Crowe, B.M., Johnson, M.E., and Beckman, R.J., 1982, Calculation of probability of volcanic disruption of a high-level radioactive waste repository within southern Nevada, USA: Radioactive Waste Management and the Nuclear Fuel Cycle, v. 3, p. 167-190.

Crowe, B.M., Vaniman, D.J., and Carr, W.J., 1983b, status of volcanic hazard studies for the Nevada nuclear waste storage investigations: Los Alamos, New Mexico, Los Alamos National Laboratory Report LA-9325-MS.

Eckel, E.B., ed., 1968, Nevada Test Site: Geological Society of America Memoir 110, 290 p.

Ekren, E.B., and Sargent, K.A., 1965, Geologic map of Skull Mountain quadrangle at the Nevada Test Site, Nye County, Nevada: U.S. Geological Survey Geologic Quadrangle Map GQ-387.

Ekren, E.B., Anderson, R.E., Rodgers, C.L., and Noble, D.C., 1971, Geology of northern Nellis Air Force Base Bombing and Gunnery Range, Nye County, Nevada: U.S. Geological Survey Professional Paper 651, 91 p., $1 \mathrm{pl}$.

Feitler, S., 1940, Welded tuff resembling vitrophyre and pitchstone at Bare Mountain, Nevada: Geological Society of America Bulletin, v. 51, p. 1957.

Flood, T.P., and Schuraytz, B.C., 1986, Evolution of a magmatic system. Part II: Geochemistry and mineralogy of glassy pumices from the Pah Canyon, Yucca Mountain, and Tiva Canyon Members of the Paintbrush Tuff, southern Nevada: EOS (American Geophysical Union Transactions), v. 67, p. 1261.

Foley, D., 1978, The geology of the Stonewall Mountain volcanic center, Nye County, Nevada: Ohio State University, Columbus Ohio, unpublished PhD Dissertation, 139 p.

Fouty, S.C., 1984, Index to published geologic maps in the region around the potential Yucca Mountain Nuclear Waste Repository site, southern Nye County, Nevada: U.S. Geological Survey Open-File Report 84-524, 31 p.

Frischknecht, F.C. and Raab, P.V., 1984, Time-domain electromagnetic soundings at the Nevada Test Site, Nevada, Geophysics, v. 49, p. 981-992.

Frizzell, Virgil, and Shulters, Jacqueline, 1986, Geologic map of the Nevada Test Site: EOS (American Geophysical Union Transactions), v. 67, p. 1260.

Garside L.J. and Schilling, J.H., 1979, Thermal waters of Nevada: Nevada Bureau of Mines and Geology, Bulletin 91, $163 \mathrm{p}$.

Geehan, R.W., 1946, Exploration of the Crowell fluorspar mine, Nye County, Nevada: U.S. Bureau of Mines Report of Investigations 3954, 9 p. 
Hagstrum, J.T., Daniels, J.J., and Scott, J.H., 1980, Interpretation of geophysical well-log measurements in drill hole UE 25a-1, NTS, Radioactive Waste Program: U.S. Geological Survey Open-File Report 80-941, 32 p.

Hall, R.B., 1978, World nonbauxite aluminum resources--Alunite: U.S. Geological Survey Professional Paper 1076-A, 35 p.

Harris, R.N., and Oliver, H.W., 1986, Structural implications of an isostatic residual gravity map of the Nevada Test Site, Nevada: EOS (American Geophysical Union Transactions), v. 67, p. 1262.

Heald, P., Foley, N.K, and Hayba, D.O., 1987, Comparative anatomy of volcanic-hosted epithermal deposits: acid-sulfate and adularia-sericite types: Economic Geology, v. 82 , no. 1, p. 1-26.

Heikes, V.C., 1931, Gold, silver, copper, lead and zinc in Nevada--Mine report, in Mineral Resources of the U.S., 1928: U.S. Department of commerce, Bureau of Mines, pt. 1, p. $441-478$.

Hill, J.M., 1912, The mining districts of the western U.S.: U.S. Geological Survey Bulletin $507,309 \mathrm{p}$.

Holmes, G.H., Jr., 1965, Mercury in Nevada, in Mercury potential of the United States: U.S. Bureau of Mines I.C., 8252, p. 215-300.

Hoover, D.L., Eckel, E.B., and Ohl, J.P., 1978, Potential sites for a spent unreprocessed fuel facility (SUREF), southwest part of the NTS: U.S. Geological Survey Open-File Report 78-269, 18 p.

Hoover, P.B., and others, 1982, Electrical studies at the proposed Wahmonie and Calico Hills Nuclear Waste Sites, Nye County, Nevada: U.S. Geological Survey Open-File Report 82-466.

Jackson, M. J., 1988, The Timber Mountain magmato-thermal event: an intense widespread culmination of magmatic and hydrothermal activity at the southwestern Nevada volcanic field: University of Nevada, Reno - Mackay School of Mines, Reno, Nevada, unpublished MSc Thesis.

Jackson, M.R., Noble, D.C., Weiss, S.I., Larson, L.T., and McKee, E.H., 1988, Timber Mountain magmato-thermal event: an intense widespread culmination of magmatic and hydrothermal activity at the SW Nevada volcanic field, Geol. Soc. Am. Abstr. Programs, v. 20, p. 171.

Kane, M.F., and Bracken, R.E., 1983, Aeromagnetic map of Yucca Mountain and surrounding regions, southwest Nevada: U.S. Geological Survey Open-File Report 83-616, 19 p.

Kane, M.F., Webring, M.W., and Bhattacharyya, B.K., 1981, A preliminary anaiysis of gravity and aeromagnetic surveys of the Timber Mountain areas, southern Nevada: U.S. Geological Survey Open-File Report 81-189, 40 p. 
Kistler, R.W., 1968, Potassium-argon ages of volcanic rocks on Nye and Esmeralda Counties, Nevada: Geological Society of America Memoir 110, P. 251-263.

Knopf, A., 1915, Some cinnabar deposits in western Nevada: U.S. Geological Survey Bulletin 620-D, p. 59-68.

Kral, V.E., 1951, Mineral resources of Nye County, Nevada: University of Nevada Bulletin, v. 45, no. 3, Geological and Mining Series 50, 223 p.

Lahoud, R.G., Lobmeyer, D.H. and Whitfield, M.S., 1984, Geohydrology of volcanic tuff penetrated by test well UE-25b\#1, Yucca Mountain, Nye County, Nevada: U.S. Geological Survey Water-Resources Investigations 84-4253, $49 \mathrm{p}$.

Lincoln, F.C., 1923, Mining districts and mineral resources of Nevada: Reno, Nevada, Nevada Newsletter Publishing Co., Reno, 295 p.

Lipman, P.W., Christiansen, R.L., and O'Connor, J.T., 1966, A compositionally zoned ashflow sheet in southern Nevada: U.S. Geological Survey Professional Paper 524-F, p. F1-F47.

Lipman, P.W., and McKay, E.J., 1965, Geologic map of the Topopah Spring SW quadrangle, Nevada: U.S. Geological Survey Geologic Quadrangle Map GQ-439, 1:24,000 scale.

Lipman, P.W., Quinlivan, W.D., Carr, W.J., and Anderson, R.E., 1966, Geologic map of the Thirsty Canyon SE quadrangle, Nye County, Nevada: U.S. Geological Survey Geologic Quadrangle Map GQ-489, 1:24,000 scale.

Lobmeyer, D.H., Whitfield, M.S., Lahoud, R.G., and Bruckheimer, L., 1983, Geohydrologic data for test well UE-25bH, Nevada Test Site, Nye County, Nevada: U.S. Geological Survey Open-File Report 83-855, 54 p.

Luedke, R.G., and Smith, R.L., 1981, Map showing distribution, composition, and age of late Cenozoic volcanic centers in California and Nevada: U.S. Geological Survey Miscellaneous Investigation Series, 1-1091-C, 2 sheets.

Maldonado, F., 1985, Late Tertiary detachment faults in the Bullfrog Hills, southwestern Nevada: Geol. Soc. Am. Abstr. Programs, 17, p. 651.

Maldonado, F., 1988, Geometry of normal faults in the upper plate of a detachment fault zone, Bullfrog Hills, southern Nevada: Geological Society of America, Abstracts with Programs, v. 20, P. 178.

Maldonado, Florian, and Koether, S.L., 1983, Stratigraphy, structure, and some perrographic features of Tertiary volcanic rocks at the USW G-2 drill hole, Yucca Mountain, Nye County, Nevada: U.S. Geological Survey Open-File Report 83-732, 83 p.

Maldonado, Florian, Muller, D.C., and Morrison, J.N., 1979, Preliminary geologic and geophysical data of the UE25a-3 exploratory drill hole, Nevada Test Site, Nevada: U.S. Geological Survey Report, USGS-1543-6, 47 p.; available only frc m U.S. Department of Commerce, National Technical Information Service, Springfield, VA 22161. 
Maldonado, Florian, Muller, D.C., and Morrison, J.N., 1979, Preliminary geologic and geophysical data of the UE25a-3 exploratory drill hole, Nevada Test Site, Nevada: U.S. Geological Survey Open-File Report 81-522.

Marvin, R.F., Byers, F.M., Mehnert, H.H., Orkild, P.P, and Stern, T.W., 1970, Radiometric ages and stratigraphic sequence of volcanic and plutonic rocks, southern Nye and western Lincoln Counties, Nevada: Geological Society of America, Bulletin, v. 81, p. 2657-2676.

McKague, H.L. and Orkild, P.P., 1984, Geologic Framework of the Nevada Test Site: Geological Society of America, Abstracts with Programs, v. 16, p. 589.

McKay, E.J., 1963, Hydrothermal alteration in the Calico Hills, Jackass Flats quadrangle, Nevada Test Site: U.S. Geological Survey Technical Letter NTS-43, 6 p.

McKay, E.J., and Sargent, K.A., 1970, Geologic map of the Lathrop Wells quadrangle, Nye County, Nevada: U.S. Geological Survey Geologic Quadrangle Map GQ-883, $1: 24,000$ scale.

MaKay, E.J., and Williams, W.P., 1964, Geology of Jackass Flats quadrangle, Nevada Test Site, Nevada: U.S. Geological Survey Geologic Quadrangle Map GQ-368, 1:24,000 scale.

McKee, E.H., 1983, Reset K-Ar ages: evidence for three metamorphic core complexes, western Nevada: Isocron/West, no.38, p 17-20.

Miller, D.C. and Kibler, J.E., 1984, Preliminary analysis of geological logs from drill hole UE-25p\#1, Yucca Mountain, Nye County, Nevada: U.S. Geological Survey OpenFile Report 84-649, 17 p.

Mills, J.G., Jr., and Rose, T.P., 1986, Geochemistry of glassy pumices from the Timber Mountain Tuff, southwestern Nevada: EOS (American Geophysical Union Transactions), v. 67, p. 1262.

Noble, D.C., Mckee, E.H., and Weiss, S.I., 1988, Nature and timing of pyroclastic and hydrothermal activity and mineralization at the Stonewall Mountain volcanic center, southwestern Nevada: Isochron/West, in press.

Noble, D.C., Vogel, T. A., Weiss, S.I., Erwin, J.W., McKee, E.H., and Younker, L.W., 1984, Stratigraphic relations and source areas of ash-flow sheets of the Black Mountain and Stonewall Mountain volcanic centers, Nevada: Journal of Geophysical Research, v. 89 , p. 8593-8602.

Norberg, J.R., 1977, Mineral Resources in the vicinity of the Nellis Air Force Base and the Nellis Bombing and Gunnery Range, Clark, Lincoln, and Nye Counties, Nevada: U.S. Bureau of Mines Unpublished Report, $112 \mathrm{p}$.

Orkild, P.P., 1968, Geologic map of the Mine Mountain quadrangle, Nye County, Nevada: U.S. Geological Survey Geologic Quadrangle Map GQ-746, 1:24,000 scale. 
Orkild, P.P., and O'Connor, J.T., 1970, Geologic map of the Topopah Springs quadrangle, Nye County, Nevada: U.S. Geological Geologic Quadrangle Map GQ-849, 1:24,000 scale.

Papke, K.G., 1979, Fluorspar in Nevada: Nevada Bureau of Mines and Geology, Bulletin 93, $77 \mathrm{p}$.

Ponce, D.A., 1981, Preliminary gravity investigations of the Wahmonie site, Nevada Test Site, Nye County, Nevada: U.S. Geological Survey Open-File Report 81-522, 64 p.

Ponce, D.A., 1984, Gravity and magnetic evidence for a granitic intrusion near Wahmonie site, Nevada Test Site, Nevada, JGR, Journal of Geophysical Research, B, v. 89, p. $9401-9413$

Ponce, D.A., Wu, S.S. and Speilman, J.B., 1985, Comparison of survey and photogrammetry methods to positive gravity data, Yucca Mountain, Nevada: U.S. Geological Survey Open-File Report 85-36, 11 p.

Poole, F.G., 1965, Geologic map of the Frenchman Flat quadrangle, Nye, Lincoln, and Clark Counties, Nevada: U.S. Geological Survey Geological Quadrangle Map GQ-456, $1: 24,000$ scale.

Poole, F.G., Carr, W.J., and Elston, D.P., 1965, Salyer and Wahmonie Formations of southeastern Nye County, Nevada: U.S. Geological Survey Bulletin 1224-A, p. A44A51.

Poole, F.G., Elston, D.P., and Carr, W.J., 1965, Geologic map of the Cane Spring quadrangle, Nye County, Nevada: U.S. Geological Survey Geological Quadrangle Map GQ-455, 1:24,000 scale.

Powers, P.S. and Healey, D.L., 1985, Free-air gradient observations in Yucca Flat, Nye County, Nevada: U.S. Geological Survey Open-File Report 85-530, 18 p.

Quade, J., and Tingley, J.V., 1983, A mineral inventory of the Nevada Test Sitr, and portions of the Nellis Bombing and Gunnery Range, southern Nye County, Nevada: DOE/NV/10295-1, U.S. Department of Energy, Las Vegas.

Quade, J., and Tingley, J.V., 1984, A mineral inventory of the Nevada Test Site, and portions of Nellis Bombing and Gunnery Range southern Nye County, Nevada: Nevada Bureau of Mines and Geology Open File Report 82-2, 40 p. plus sample descriptions and chemical analyses.

Quade, J., and Tingley, J.V., 1986a, Mineral inventory and geochemical survey Groom Mountain Range Lincoln County, Nevada: Nevada Bureau of Mines and Geology Open File Report 86-9, 66 p. plus sample descriptions and chemical analyses.

Quade, J., and Tingley, J.V., 1986b, Mineral inventory and geochemical survey appendices F., G., \& H Groom Mountain Range, Lincoln County, Nevada: Nevada Bureau of Mines and Geology Open File Report 86-10. 
Quinlivan, W.D., and Byers, F.M., Jr., 1977, Chemical data and variation diagrams of igneous rock from the Timber Mountain-Oasis Valley caldera complex, southern Nevada: U.S. Geological Survey Open-File Report 77-724, 9 p.

Ransome, F.L., 1907, Preliminary account of Goldfield, Bullfrog, and other mining districts in southern Nevada: U.S. Geological Survey Bulletin 303, 98 p.

Ransome, F.L., Emmons, W.H., and Garrey, C.H., 1910, Geology and ore deposits of the Bullfrog district, Nevada: U.S. Geological Survey Bulletin 407, 130 p.

Reno Gazette-Journal, June 19, 1988, Gold report is favorable: Business page, Gold, J., Business editor.

Robinson, G.D., 1985, Structure of pre-Cenozoic rocks in the vicinity of Yucca Mountain, Nye County, Nevada; a potential nuclear-waste disposal site: U.S. Geological Survey Bulletin 1647, 22 p.

Rush, F.E., Thordason, William, and Bruckheimer, Laura, 1983, Geohydrologic and drillhole data for test well USW.H1, adjacent to Nevada Test Site, Nye County, Nevada: U.S. Geological Survey Open-File Report 83-141, 38 p.

Schoen, R., White, D.E., and Hemley, J.J., 1974, Argillization by decending acid at Steamboat Springs, Nevada: Clays and Clay Minerals, v. 22, p. 1-22.

Schneider, R. and Trask, N.J., 1984, U.S. Geological Survey research in radioactive waste disposal; fiscal year 1982: U.S. Geological Survey Water-Resource Investigation 844205, $116 \mathrm{p}$.

Schuraytz, B.C., Vogel, T.A., and Younker, L.W., 1986, Evolution of a magmatic system. Part I: Geochemistry and mineralogy of the Topopah Spring Member of the Paintbrush Tuff, southern Nevada: EOS (American Geophysical Union Transactions), v. 67, p. 1261.

Scott, R.B., 1984, Internal deformation of blocks bounded by basin-and-range-style faults: Geological Society of America, Abstracts with Programs, v. 16, p. 649.

Scott, R.B., 1986, Rare-earth element evidence for changes in chemical evolution of silicic magmas, southwest Nevada: EOS (American Geophysical Union Transactions), v. 67, p. 1261.

Scott, R.B., 1988, Tectonic setting of Yucca Mountain, southwest Nevada: Geological Society of America, Abstracts with Programs, v. 20, p. 229.

Scott, R.B., Bath, G.D., Flanigan, V.J., Hoover, D.B., Rosenbaum, J.G., and Spengler, R.W., 1984, Geological and geophysical evidence of structures in northwest-trending washes, Yucca Mountain, southern Nevada, and their possible significance to a nuclear waste repository in the unsaturated zone: U.S. Geological Survey Open-File Report 84-567, 25 p.

Scott, R.B. and Bonk, J., 1984, Preliminary geologic map of Yucca Mountain, Nye County, Nevada, with geologic sections: U.S. Geological Survey Open-File Report 84-494, scale $1: 12,000$, plus $10 \mathrm{p}$. 
Scott, R.B., Byers, F.M. and Warren, R.G., 1984, Evolution of magma below clustered calderas, Southwest Nevada volcanic field [abstr.], EOS (Transactions of the American Geophysical Union) v.65, p. 1126-1127.

Scott, R.B. and Zastellanos, Mayra, 1984, Stratigraphic and structural relations of volcanic rocks in I lrill holes USW GU-3 and USW G3, Yucca Mountain, Nye County, Nevada: U.S. Gec logical Survey Open-File Report 84-491, 121 p.

Scott, R.B., Spengler, R.W., Diehl, S., Lappin, A.R., and Chornack, M.P., 1983, Geologic character of tuffs in the unsaturated zone at Yucca Mountain, southern Nevada: in Mercer, J.M., Rao, P.C. and Marine, W., eds., Role of the unsaturated zone in radioactive and hazardous waste disposal: Ann Arbor press, Ann Arbor, Michigan, p.
289-335.

Scott, R.B., Spengler, R.W., Lappin, A.R., and Chornack, M.P., 1982, Structure and intracooling unit zonation in welded tuffs of the unsaturated zone, Yucca Mountain, Nevada, a potential nuclear waste repository: EOS (American Geophysical Union Transactions), v. 63, no. 18 , p. 330.

Selner, G.I. and Taylor, R.B., 1988, GSDRAW and GSMAP version 5.0: prototype programs, level 5, for the IBM PC and compatible microcomputers, to assist compilation and publication of geologic maps and illustrations: U.S. Geological Survey Open File Report \#88-295A (documentation), 130 p. and \#88-295B (executable program disks).

Selner, G.I., Smith, C.L., and Taylor, R.B., 1988, GSDIG: a program to determine latitude/longitude locations using a microcomputer (IBM PC or compatible) and digitizer: U.S. Geological Survey Open File Report \#88-014A (documentation) 16 p. and \#88-014B (executable program disk).

Smith, C., Ross, H.P., and Edquist, R., 1981, Interpreted resistivity and IP section line. W1 Wahmonie area, Nevada Test Site, Nevada: U.S. Geological Survey Open-Fil.
Report $81-1350,14$ p.

Smith, R.C., and Bailey, R.A., 1968, Resurgent Cauldrons: Geological Society of America Memoir 116, p. 613-662.

Smith, R.M., 1977, Map showing mineral exploration potential in the Death Valley quadrangle, California and Nevada: U.S. Geological Survey Miscellaneous Field Investigation Map MF-873, 1:250,000 scale.

Snyder, D.B., and Carr, W.J., 1982, Preliminary results of gravity investigations at Yucca Mountain and vicinity, southern Nye County, Nevada: U.S. Geological Survey Open-
File Report 82-701, 36 p.

Snyder, D.B. and Carr, W.J., 1984, Interpretation of gravity data in a complex volcanotectonic setting, southwestern Nevada: Journal of Geophysical Research. B, v. 89, p.
10,193-10,206.

Snyder, D.B., and Oliver, H.W., 1981, Preliminary results of gravity investigations of the Calico Hills, Nevada Test Site, Nye County, Nevada: U.S. Geological Survey Open-
File Report 81-101, 42 p. 
Spengler, R.W., Byers, F.M., Jr., and Warner, J.B., 1981, Stratigraphy and structure of volcanic rocks in drill hole USW-G1, Yucca Mountain, Nye County, Nevada: U.S. Geological Survey Open-File Report 82-1338, 264 p.

Spengler, R.W. and Chornack, M.P., 1984, Stratigraphic and structural characteristics of volcanic rocks in core hole USW G-4, Yucca Mountain, Nye County, Nevada: U.S. Geological Survey Open-File Report 84-789, 82 p.

Spengler, R.W., Muller, D.C., and Livermore, R.B., 1979, Preliminary ceport on the geology of drill hole UE25a-1, Yucca Mountain, Nevada Test Site: U.S. Geological Survey Open-File Report 79-1244, 43 p.

Spengler, R.W., and Rosenblaum, J.G., 1980, Preliminary interpretations of geologic results obtained from boreholes UE25a-4, $-5,-6$, and -7, Yucca Mountain, Nevada Test Site: U.S. Geological Survey Open-File Report 80-929, 35 p.

Sutton, V.D., 1984, Data report for the 1983 seismic-refraction experiment at Yucca Mountain, Beatty, and vicinity, southwestern Nevada: U.S. Geological Survey OpenFile Report 84-661, $62 \mathrm{p}$.

Swadley, W.C., Hoover, D.L. and Rosholt, J.N., 1984, Preliminary report on late Cenozoic faulting and stratigraphy in the vicinity of Yucca Mountain, Nye County, Nevada: U.S. Geological Survey Open-File Report 84-788, 44 p.

Swolfs, H.S. and Savage, W.Z., 1985, Topography, stresses and stability at Yucca Mountain, Nevada, Proceedings - Symposium on Rock Mechanics: Research and engineering applications in rock masses, 26, p. 1121-1129.

Szabo, B.J. and Kyser, T.K., 1985, Uranium, thorium isotopic analyses and uranium-series ages of calcite and opal, and stable isotopic compositions of calcite from drill cores UE25a 1, USW G-2 and USW G-3/GU-3, Yucca Mountain, Nevada: U.S. Geological Survey Open-File 85-224, 30 p.

Szabo, B.J. and O'Malley, P.A., 1985, Uranium-series dating of secondary carbonate and silica precipitates relating to fault movements in the Nevada Test Site region and of caliche and travertine samples from the Amargosa Desert: U.S. Geological Survey Open-File Report 85-0047, 17 p.

Taylor, E.M., and Huckins, H.E., 1986, Carbonate and opaline silica fault-filling in the Bow Ridge Fault, Yucca Mountain, Nevada -- deposition from pedogenic processes of upwelling ground water: Geological Society of America, Abstracts with Programs, v. 18 , no. 5, p. 418 .

Thordarson, William, Rush, F.E. , Spengler, R.W. and Waddell, S.J., 1984, Geohydrologic and drill-hole data for test well USW H-3, Yucca Mountain, Nye County, Nevada: U.S. Geological Survey Open-File Report 84-0149, 54 p.

Tingley, J.V., 1984, Trace element associations in mineral deposits, Bare Mountain (Fluorine) mining district, southern Nye County, Nevada: Nevada Bureau of Mines and Geology Report 39, 28 p. 
U.S. Department of Energy, 1986, Environmental Assessment Yucca Mountain Site, Nevada Research and Development Area, Nevada, v. 1: Washington, DC, Office of Civilian Radioactive Waste Management.

U.S. Department of Energy, 1988, Consultation Draft Site Characterization Plan, Yucca Mountain Site, Nevada Research and Development Area, Nevada: Washington, DC, Office of Civilian Radioactive Waste Management, 347 p.

U.S. Geologic Survey, 1984, A summary of geologic studies through January 1, 1983 of a potential high-level radioactive waste repository site at Yucca Mountain, southern Nye County, Nevada: U.S. Geological Survey Open-File Report 84-792, 164 p.

Vaniman, D.T., and Crowe, B.M., 1981, Geology and petrology of the basalts of Crater Flat: Applications to volcanic risk assessment for the Nevada nuclear waste storage investigations: Los Alamos, New Mexico, Los Alamos National Laboratory Report, LA-8845-MS, 67 p.

Vaniman, D.T., Crowe, B.M., and Gladney, E.S., 1982, Petrology and geochemistry of Hawaiite lavas from Crater Flat, Nevada: Contributions to Mineralogy and Petrology, v. 80, p. 341-357.

Vaniman, D.T., Bish, D.L., and Chipera, S., 1988, A preliminary comparison of mineral deposits in faults near Yucca Mountain, Nevada, with possible analogs: Los Alamos, New Mexico, Los Alamos National Laboratory Report LA-11298-MS, UC-70, 54 p.

Vogel, T.A., Ryerson, R.A., Noule, D.C., and Younker, L.W., 1987, Constrains on magma mixing in a silicic magma body: disequilibrium phenocrysts in pumices from a chemically zoned ash-flow sheet: Journal of Geology, v. 95, in press.

Waddell, R.J., 1984, Geohydrologic and drill-hole data for test wells UE-29a\# 1 and UE29a\#2, Fortymile Canyon, Nevada Test Site: U.S. Geological Survey Open-File Report 84-0142, 25 p.

Wang, J.S.Y., and Narasimhan, T.N., 1985, Hydrologic mechanisms governing fluid flow in partially saturated, fractured, porous tuff at Yucca Mountain: University of California Lawrence Berkeley Laboratory Report SAND84-7202 (LBL-18473), 46 p.

Warren, R.G., and Broxton, D.E., 1986, Mixing of silcic and basaitic magmas in the Wahmonie Formation, southwestern Nevada volcanic field, Nevada: EOS (American Geophysical Union Transactions), v. 67, p. 1261.

Warren, R.G., Byers, F.M., and Caporuscio, F.A., 1984, Petrography and mineral chemistry of units of the Topopah Springs, Calico Hills and Crater Flat Tuffs, and some older volcanic units, with emphasis on samples from drill hole USW G.1, Yucca Mountain, Nevada Test site: Los Alamos, New Mexico, Los alamos National Laboratory Report LA-10003-MS.

Warren, R.G., Nealey, L.D., Byers, F.M., Jr., and Freeman, S.H., 1986, Magmatic components of the Rainier Mesa Member of the Timber Mountain Tuff, Timber Mountain-Oasis Valley Caldera Complex: EOS (American Geophysical Union Transactions), v. 67, p. 1260. 
Warren, R.G., McDowell, F.W., Byers, F.M., Broxton, D.E., Carr, W.J., and Orkild, P.P., 1988, Eposodic leaks from Timber Mountain caldera: new evidence from rhyolite lavas of Fortymile Canyon, southwestern Nevada Volcanic Field: Geological Society of America, Abstracts with Programs, v. 20, p. 241.

Weiss, S.I., 1987, Geologic and Paleomagnetic studies of the Stonewall and Black Mountain volcanic centers, southern Nevada: University of Nevada, Reno-Mackay School of Mines, Reno, Nevada, unpublished MSc Thesis, 67 p.

Weiss, S.I., and Noble, D.C., in review, Stonewall Mountain volcanic center, southern Nevada: stratigraphic, structural and facies relations of outflow sheets, near-vent iuffs, and intracaldera units: for special issue, Journal of Geophysical Research.

Weiss, S.I., Noble, D.C., and Mckee, E.H.,1984, Inclusions of basaltic magma in near-vent facies of the Stonewall Flat Tuff: product of explosive magma mixing: Geological society of America, Abstracts with Programs, v. 16, p. 689.

Weiss, S.I., Noble, D.C., and Mckee, E.H., in review, Paleomagnetic constraints on the timing of eruption of the Pahute Mesa and Trail Ridge Members of the Thirsty Canyon Tuff: for special issue, Journal of Geophysical Research.

Weiss, S.I., Noble, D.C., and Mckee, E.H., 1988, Volcanic and tectonic significance of the presence of Late Miocene Stonewall Flat tuff in the vicinity of Beatty, Nevada: Geological Society of America, Abstracts with Programs, submitted for review, 1988 Annual Meeting, Denver Colorado.

White, A.F., 1979, Geochemistry of ground water associated with tuffaceous rocks, Oasis valley, Nevada: U.S. Geological Survey Professional Paper 712-E.

Whitfield, M.S., Eshom, E.P., Thordarson, W., and Schaefer, D.H., 1985, Geohydrology of rocks penetrated in test well USW H-4, Yucca Mountain, Nye County, Nevada: U.S. Geological Survey Water-Resources Investigations Reports, 1985, 33 p.

Whitfield, M.S., Thordarson, W. and Eshom, E.P., 1984, Geohydrologic and drill-hole data for test well USW H-4, Yucca Mountain, Nye County, Nevada: U.S. Geological Survey Open-File Report 84-449, 69 p.

Wu, S.S., 1985, Topographic Maps of Yucca Mountain area, Nye County, Nevada, 6 oversize sheets, scale 1:5,000: U.S. Geological Survey Open-File Report 85-0620. 


\section{FIGURE and TABLES}




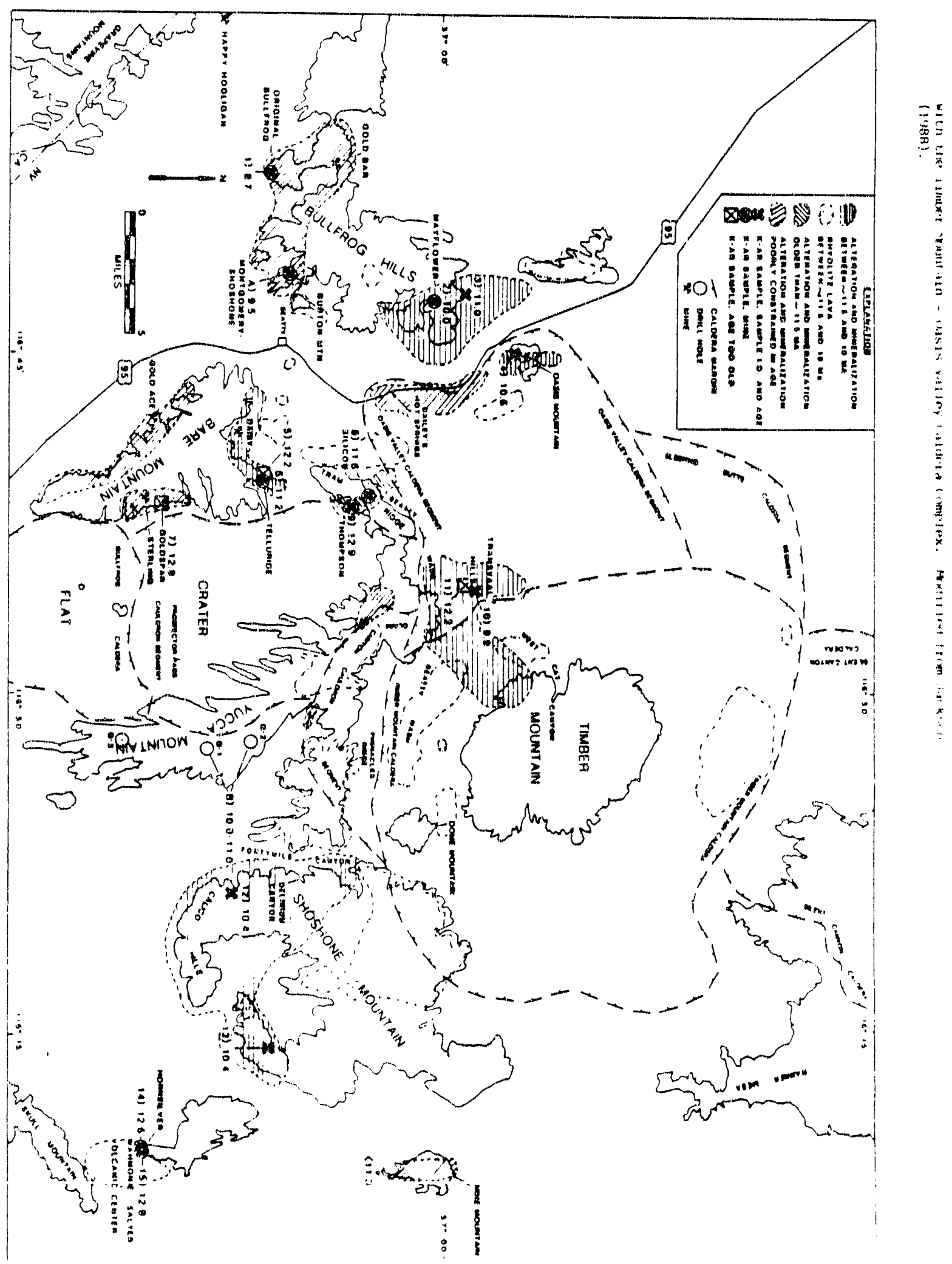


TABLE 1

INDEX TO TASK 3 GEOLOGIC SAMPLE LOCATIONS

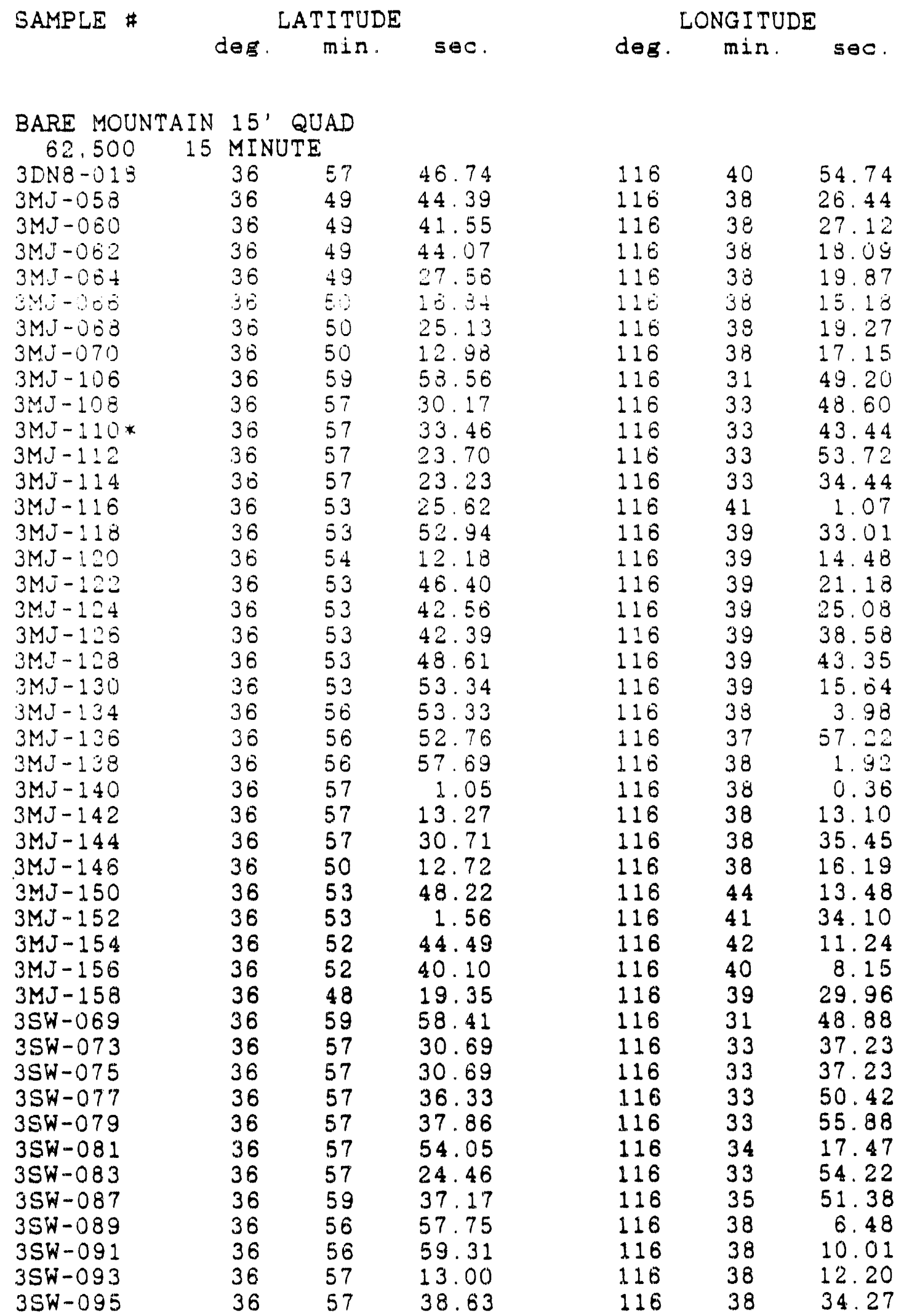


TABLE 1. cont.

\begin{tabular}{|c|c|c|c|c|c|c|}
\hline \multirow[t]{2}{*}{ SAMPLE \# } & \multicolumn{3}{|c|}{ LATITUDE } & \multicolumn{3}{|c|}{ LONGITUDE } \\
\hline & deg. & ain. & sec. & deg. & $\min$. & sec. \\
\hline $\begin{array}{l}87-2-11-1 \\
87-2-11-2 \\
87-2-11-3 \\
87-2-11-4 \\
87-2-11-5 \\
87-2-8-1 \\
87-2-8-2 \\
87-2-8-3 \\
87-2-8-4 \\
87-2-8-5\end{array}$ & $\begin{array}{l}36 \\
36 \\
36 \\
36 \\
36 \\
36 \\
36 \\
36 \\
36 \\
36\end{array}$ & $\begin{array}{l}50 \\
50 \\
50 \\
50 \\
50 \\
53 \\
53 \\
53 \\
53 \\
53\end{array}$ & $\begin{array}{l}19.69 \\
21.50 \\
21.76 \\
24.87 \\
24.62 \\
54.70 \\
54.96 \\
54.96 \\
50.83 \\
47.42\end{array}$ & $\begin{array}{l}116 \\
116 \\
116 \\
116 \\
116 \\
116 \\
116 \\
116 \\
110 \\
116\end{array}$ & $\begin{array}{l}38 \\
38 \\
38 \\
38 \\
38 \\
39 \\
39 \\
39 \\
39 \\
39\end{array}$ & $\begin{array}{l}15.47 \\
16.10 \\
16.10 \\
18.96 \\
19.28 \\
26.88 \\
26.88 \\
26.88 \\
36.83 \\
17.95\end{array}$ \\
\hline
\end{tabular}

Drill cuttings from $N$ end of Bare Mtn. Mother Lode Claims. GEXA gojd Ina. exacz locationa proprietary

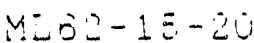

$M L-62-150-160$

MLOD $2-25-30$

ML62-355-300

MLOB-220-225

$M+74-40-50$

ML78-125-130

ML 32-95-105

$M L 87-340-350$

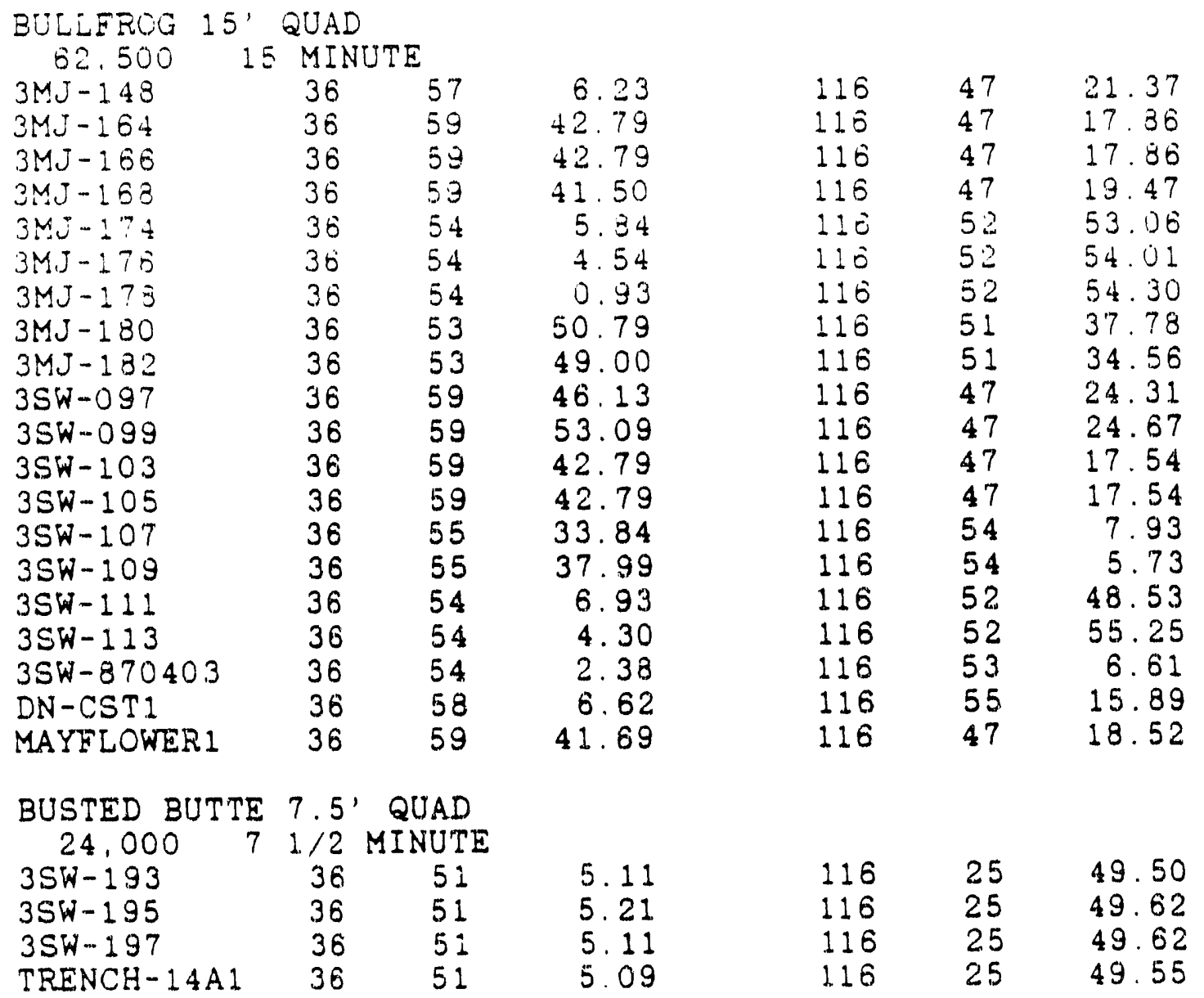


TABLE 1. cont.

\begin{tabular}{|c|c|c|c|c|c|c|c|}
\hline \multirow[t]{2}{*}{ SAMPLE \# } & \multicolumn{4}{|c|}{ LATITUDE } & \multicolumn{3}{|c|}{ LONGITUDE } \\
\hline & & deg. & $\min$. & sec. & deg. & $\min$ & sec. \\
\hline \multicolumn{8}{|c|}{$\begin{array}{l}\text { CACTUS SPRING } 15^{\prime} \text { QUAD } \\
6250015 \text { MINUTE }\end{array}$} \\
\hline $3 S W-227$ & & 37 & 33 & 16.30 & 116 & 57 & 40.63 \\
\hline \multicolumn{8}{|c|}{$\begin{array}{cr}\text { GOLDE IELD } & 15^{\prime} \\
62,500 & 15\end{array}$} \\
\hline $3 D N 8-014$ & & 37 & 36 & 53.31 & 117 & 12 & 47.97 \\
\hline $3 D N 8-015$ & & 37 & 37 & 7.40 & 117 & 12 & 58.23 \\
\hline $3 D N 8-016$ & & 37 & 37 & 0.60 & 117 & 12 & 40.30 \\
\hline $3 D N 8-017$ & & 37 & 36 & 50.94 & 117 & 12 & 25.24 \\
\hline $3 D N 8-019$ & & 37 & 32 & 24.72 & 117 & 3 & 51.95 \\
\hline $3 S W-213$ & & 37 & 32 & 40.57 & 117 & 2 & 5.52 \\
\hline $3 B W-20 \pm$ & & 37 & 32 & 44.04 & 117 & 1 & 55.12 \\
\hline $33 w-223$ & & $3 ?$ & 32 & 34.70 & 117 & 1 & 42.25 \\
\hline $3 S W-225$ & & 37 & 32 & 10.45 & 117 & D & 58.03 \\
\hline \multicolumn{8}{|c|}{ JACKASS FLATS 7.5' QUAD } \\
\hline 24,000 & 7 & $1 / 2$ & MINUTE & & & & \\
\hline $3 M J-190$ & & 36 & 52 & 3.73 & 116 & 18 & 17.50 \\
\hline $3 S W-127$ & & 36 & 52 & 6.05 & 116 & 18 & 15.73 \\
\hline $3 S W-129$ & & 36 & 52 & 29.76 & 116 & 18 & 55.45 \\
\hline $3 S W-175$ & & 36 & 51 & 21.48 & 116 & 17 & 28.61 \\
\hline $3 S W-177$ & & 36 & 51 & 21.48 & 116 & 17 & 28.61 \\
\hline $3 \sin -179$ & & 36 & 51 & 21.48 & 116 & 17 & 28.61 \\
\hline $3 S W-181$ & & 36 & 51 & 42.28 & 116 & 17 & 38.73 \\
\hline $3 S W-183$ & & 36 & 51 & 42.28 & 116 & 17 & 38.73 \\
\hline $3 S N-185$ & & 36 & 51 & 42.28 & 116 & 17 & 38.25 \\
\hline $35 w-187$ & & 36 & 51 & 42.28 & 116 & 17 & 38.73 \\
\hline
\end{tabular}

MINE MOINTAIN 7.5' QUAD

$\begin{array}{rrrrrrr}24.000 & 7 & 1 / 2 & M I N U T E & & & \\ 3 M J-212 & 36 & 53 & 57.53 & 116 & 14 & 5.26 \\ 3 M J-214 & 36 & 53 & 58.97 & 116 & 14 & 8.38 \\ 3 M J-216 & 36 & 54 & 11.64 & 116 & 14 & 16.34 \\ 3 S W-141 & 36 & 54 & 37.68 & 116 & 13 & 53.60 \\ 3 S W-143 & 36 & 54 & 37.34 & 116 & 13 & 55.94 \\ 3 S W-191 & 36 & 58 & 29.18 & 116 & 10 & 0.63 \\ 3 S W-199 & 36 & 58 & 0.97 & 116 & 9 & 17.90 \\ 3 S W-201 & 36 & 58 & 4.02 & 116 & 9 & 12.49 \\ 3 S W-203 & 36 & 57 & 58.62 & 116 & 8 & 55.34 \\ 3 S W-205 & 36 & 59 & 27.24 & 116 & 8 & 51.51 \\ 3 S W-207 & 36 & 59 & 27.82 & 116 & 8 & 54.96 \\ 3 S W-209 & 36 & 59 & 29.13 & 116 & 8 & 59.86 \\ 3 S W-211 & 36 & 59 & 29.01 & 116 & 8 & 59.00 \\ 3 S W-213 & 36 & 59 & 29.36 & 116 & 9 & 0.84 \\ 3 S W-215 & 36 & 59 & 32.81 & 116 & 8 & 56.25 \\ 3 S W-217 & 36 & 59 & 31.18 & 116 & 8 & 19.05\end{array}$

SCOTTY'S JCT. NE 7.5' QUAD

$\begin{array}{crccccc}24.000 & 7 & 1 / 2 & \text { MINUTE } & & & \\ 3870402-1 & 37 & 24 & 26.91 & 117 & 0 & 31.49 \\ 3870402-2 & 37 & 24 & 25.67 & 117 & 0 & 35.22 \\ 3870402-3 & 37 & 24 & 24.34 & 117 & 0 & 40.68\end{array}$


TABLE 1. cont.

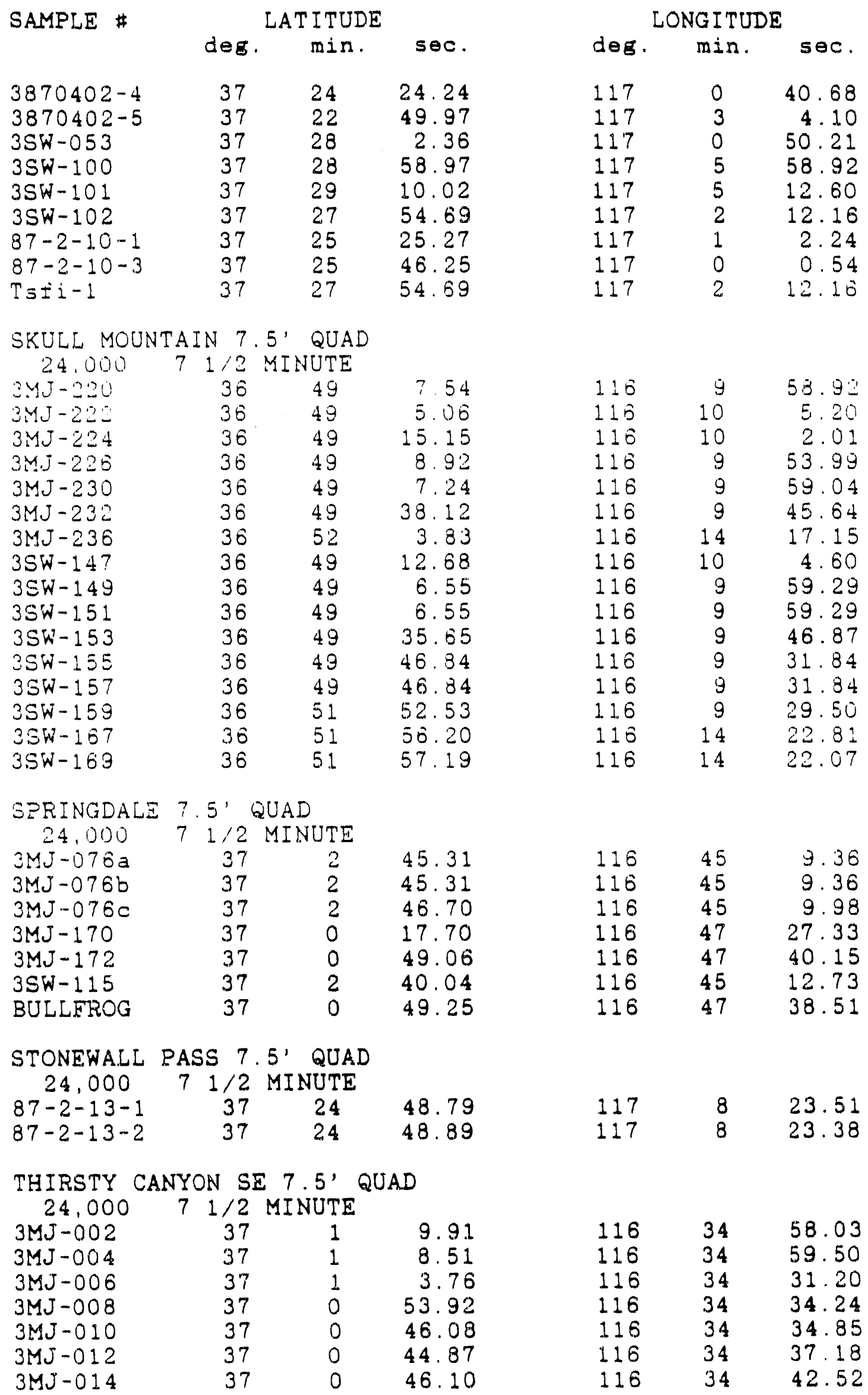


TABLE 1. cont.

\begin{tabular}{|c|c|c|c|c|c|c|}
\hline \multirow[t]{2}{*}{ SAMPLE \# } & \multicolumn{3}{|c|}{ LAT ITUDE } & \multicolumn{3}{|c|}{ LONGITUDE } \\
\hline & deg. & min & sec. & deg. & $\min$. & sec. \\
\hline $3 M J-016$ & 37 & 0 & 52.36 & 116 & 34 & 49.69 \\
\hline $3 M J-018$ & 37 & 0 & 28.19 & 116 & 34 & 30.21 \\
\hline $3 \mathrm{MJ}-020$ & 37 & 0 & 44.57 & 116 & 34 & 9.95 \\
\hline $3 M J-022$ & 37 & 0 & 45.38 & 116 & 34 & 8.23 \\
\hline $3 \mathrm{MJ}-024$ & 37 & 0 & 45.86 & 116 & 34 & 1.31 \\
\hline $3 M J-026$ & 37 & 0 & 43.74 & 116 & 34 & 4.37 \\
\hline $3 \mathrm{MJ}-028$ & 37 & 0 & 45.02 & 116 & 34 & 5.51 \\
\hline $3 \mathrm{MJ}-030$ & 37 & 0 & 52.83 & 116 & 33 & 49.43 \\
\hline $3 M J-0.32$ & 37 & 0 & 55.01 & 116 & 33 & 48.85 \\
\hline $3 M J-034$ & 37 & 0 & 50.59 & 116 & 33 & 44.93 \\
\hline $3 M J-0.36$ & 37 & 0 & 52.61 & 116 & 34 & 4.21 \\
\hline $3 M J-0.38$ & $3 ?$ & 0 & 50.13 & 116 & 34 & 9.68 \\
\hline $3 \mathrm{MJ}-040$ & 37 & 0 & 7.99 & 110 & 32 & 58.06 \\
\hline $3 \mathrm{MJ}-04 \mathrm{Z}$ & 37 & 0 & 5.13 & 110 & 33 & 0.61 \\
\hline $3 M J-044$ & 37 & 1 & 23.22 & 116 & 34 & 55.79 \\
\hline $3 M J-040^{\circ}$ & 37 & 1 & 35.24 & 116 & 35 & 1.94 \\
\hline $3 M J-048$ & 37 & 1 & 55.11 & 116 & 35 & 6.37 \\
\hline $3 \mathrm{MJ}-050$ & 37 & 1 & 54.01 & $1 \pm 6$ & 35 & 8.08 \\
\hline $3 M J-052$ & 37 & 1 & 52.50 & 116 & 35 & 9.29 \\
\hline $3 M J-052$ & 37 & 1 & 52.65 & 116 & 35 & 9.06 \\
\hline $3 \mathrm{MJ}-054$ & 37 & 1 & 36.58 & 116 & 35 & 14.96 \\
\hline $3 M J-050$ & 37 & 1 & 32.11 & 116 & 34 & 58.54 \\
\hline $3 S W-001$ & 37 & 1 & 14.51 & 116 & 34 & 54.57 \\
\hline $3 \mathrm{SW}-003$ & 37 & 1 & 15.68 & 116 & 34 & 45.93 \\
\hline $3 S W-005$ & 37 & 1 & 12.40 & 116 & 34 & 35.49 \\
\hline 3SW-OOEA & 37 & 1 & 10.64 & 116 & 34 & 32.86 \\
\hline $3 S W-009$ & 37 & 1 & 0.52 & 116 & 34 & 34.83 \\
\hline $3 S W-011$ & 37 & 1 & 2.52 & 116 & 34 & 32.87 \\
\hline $3 S W-013$ & 37 & 1 & 3.12 & 116 & 34 & 31.89 \\
\hline $3 S W-115$ & 37 & 1 & 4.72 & 116 & 34 & 31.05 \\
\hline $3 S W-017$ & 37 & 0 & 53.01 & 116 & 34 & 33.36 \\
\hline $3 S W-019$ & 37 & 0 & 46.27 & 110 & 34 & 34.38 \\
\hline $3 S W-021$ & 37 & 0 & 46.12 & 116 & 34 & 39.57 \\
\hline $3 S W-023$ & 37 & 0 & 52.68 & 116 & 34 & 48.57 \\
\hline $3 S W-025$ & 37 & 0 & 33.97 & 116 & 34 & 14.17 \\
\hline 3 SW-027 & 37 & 0 & 35.18 & 116 & 34 & 11.59 \\
\hline $3.5 W-029$ & 37 & 0 & 36.32 & 116 & 34 & 17.05 \\
\hline $3 S W-031$ & 37 & 0 & 42.05 & 116 & 34 & 18.86 \\
\hline $3 S W-033$ & 37 & 0 & 55.78 & 116 & 33 & 49.11 \\
\hline $3 S W-035$ & 37 & 0 & 54.92 & 116 & 33 & 45.14 \\
\hline $3 S W-037$ & 37 & 0 & 56.13 & 116 & 33 & 54.80 \\
\hline $35 W-039$ & 37 & 0 & 10.67 & 116 & 32 & 58.14 \\
\hline $3 S W-041$ & 37 & 0 & 5.88 & 116 & 33 & 2.65 \\
\hline $3 S W-043$ & 37 & 1 & 15.10 & 116 & 35 & 5.96 \\
\hline $3 S W-045$ & 37 & 1 & 33.46 & 11 & 35 & 1.89 \\
\hline $3 S W-047$ & 37 & 1 & 56.58 & 116 & 35 & 7.78 \\
\hline $3 S W-049$ & 37 & 1 & 31.94 & 116 & 35 & 16.59 \\
\hline $3 \mathrm{SW}-051$ & 37 & 1 & 27.80 & 116 & 35 & 13.81 \\
\hline $3 S W-071$ & 37 & 0 & 50.06 & 116 & 31 & 28.63 \\
\hline $3 S W-085$ & 37 & 0 & 52.37 & 116 & 34 & 38.80 \\
\hline $3 S W-085$ & 37 & 0 & 55.26 & 116 & 34 & 41.83 \\
\hline $87-2-12-1$ & 37 & 0 & 26.06 & 11 & 34 & 31.91 \\
\hline $87-2-9$ & 37 & 0 & 50.80 & 116 & 34 & 51.79 \\
\hline
\end{tabular}


TABLE 1. cont.

SAMPLE \#

$87-2-9-2$

$87-2-9-3$

$87-2-9-4$

$87-2-9-5$

$87-2-9-6$

$87-2-9-7$

$87-2-9-P M 1$

$87-2-9-P M 2$
LATITUDE

Leg. min. sec.

$\begin{array}{llr}37 & 0 & 50.80 \\ 37 & 0 & 44.45 \\ 37 & 0 & 44.45 \\ 37 & 1 & 6.44 \\ 37 & 1 & 13.68 \\ 37 & 0 & 52.64 \\ 37 & 0 & 31.89 \\ 37 & 0 & 22.93\end{array}$

THIRSTY CANYON SW 7.5' QUAD

24.000 $71 / 2$ MINUTE

$\begin{array}{lllr}3 M J-072 & 37 & 2 & 18.90 \\ 3 M J-074 & 37 & 2 & 35.53 \\ 3 M J-078 & 37 & 2 & 36.23 \\ 3 M J-080 & 37 & 3 & 1.30 \\ 3 M J-082 & 37 & 3 & 1.40 \\ 3 M J-084 & 37 & 3 & 1.73 \\ 3 M J-086 & 37 & 2 & 59.06\end{array}$

TIPPIPAH SPRING 7.5' QUAD

$\begin{array}{crcr}24,000 & 7 & 1 / 2 & \text { MINUTE } \\ \text { 3SW-171 } & 37 & 6 & 37.93 \\ \text { 3SW-171V } & 37 & 6 & 35.05 \\ \text { TOLIUHA PEAK } & 15, \text { QUAD } \\ \text { - } 500 & 15 & \text { MINUTE } \\ \text { 3SW870404-1 } & 37 & 26 & 58.87 \\ \text { 3SN870404-2 } & 37 & 27 & 1.79 \\ \text { 3SW870404-3 } & 37 & 27 & 15.21 \\ \text { 3SW870404-4 } & 37 & 27 & 12.34 \\ \text { 3SW870404-5 } & 37 & 27 & 14.03 \\ \text { 3SW870405-1 } & 37 & 24 & 57.15 \\ \text { 3SW870405-2 } & 37 & 25 & 16.55 \\ \text { TtP-VIt-1 } & 37 & 24 & 14.65 \\ \text { 87-2-10-2 } & 37 & 25 & 45.22 \\ \text { 87-2-10-4 } & 37 & 25 & 50.31 \\ \text { 87-2-105FM } & 37 & 25 & 50.31\end{array}$

TOPOPAH SPRING 7.5' QUAD

$\begin{array}{lrrr}24,000 & 7 & 1 / 2 & \text { MINUTE } \\ 3 M J-192 & 36 & 52 & 57.01 \\ 3 M J-194 & 36 & 53 & 1.86 \\ 3 M J-196 & 36 & 53 & 1.63 \\ 3 M J-198 & 36 & 52 & 47.52 \\ 3 M J-200 & 36 & 52 & 47.52 \\ 3 M J-202 & 36 & 52 & 47.52 \\ 3 M J-204 & 36 & 52 & 47.52 \\ 3 M J-206 & 36 & 53 & 5.83 \\ 3 M J-208 & 36 & 53 & 42.86 \\ 3 M J-210 & 36 & 54 & 1.74 \\ 3 M J-218 & 36 & 53 & 13.49 \\ 3 M J-234 A & 36 & 55 & 30.89 \\ 3 M J-234 B & 36 & 55 & 32.80\end{array}$

LONGITUDE

deg. min. sec.

$\begin{array}{lll}116 & 34 & 51.79 \\ 116 & 34 & 53.33 \\ 116 & 34 & 53.33 \\ 116 & 34 & 53.68 \\ 116 & 34 & 52.76 \\ 116 & 34 & 50.93 \\ 116 & 34 & 49.62 \\ 116 & 34 & 56.57\end{array}$

$\begin{array}{lll}116 & 44 & 41.86 \\ 116 & 44 & 55.40 \\ 116 & 44 & 51.81 \\ 116 & 44 & 55.60 \\ 116 & 44 & 54.24 \\ 116 & 44 & 37.04 \\ 116 & 44 & 32.58\end{array}$

$\begin{array}{lll}116 & 10 & 29.18\end{array}$

$116 \quad 10 \quad 24.15$

$\begin{array}{llr}116 & 55 & 57.69 \\ 116 & 56 & 49.31 \\ 116 & 57 & 9.38 \\ 116 & 56 & 52.46 \\ 116 & 57 & 20.70 \\ 116 & 55 & 22.72 \\ 116 & 55 & 1.73 \\ 116 & 47 & 6.36 \\ 116 & 59 & 59.19 \\ 116 & 59 & 23.67 \\ 116 & 59 & 23.67\end{array}$

$\begin{array}{lll}116 & 19 & 5.79\end{array}$

$116 \quad 19 \quad 24.24$

$\begin{array}{lll}116 & 19 & 29.67\end{array}$

$\begin{array}{lll}116 & 19 & 38.33\end{array}$

$\begin{array}{lll}116 & 19 & 38.33\end{array}$

$\begin{array}{lll}116 & 19 & 38.33\end{array}$

$\begin{array}{lll}116 & 19 & 38.33\end{array}$

$\begin{array}{lll}116 & 21 & 45.73\end{array}$

$\begin{array}{lll}116 & 20 & 59.23\end{array}$

$\begin{array}{lll}116 & 21 & 25.96\end{array}$

$\begin{array}{lll}116 & 16 & 44.85\end{array}$

$116 \quad 16 \quad 14.40$

$\begin{array}{lll}116 & 16 & 9.10\end{array}$ 
TABLE 1. cont.

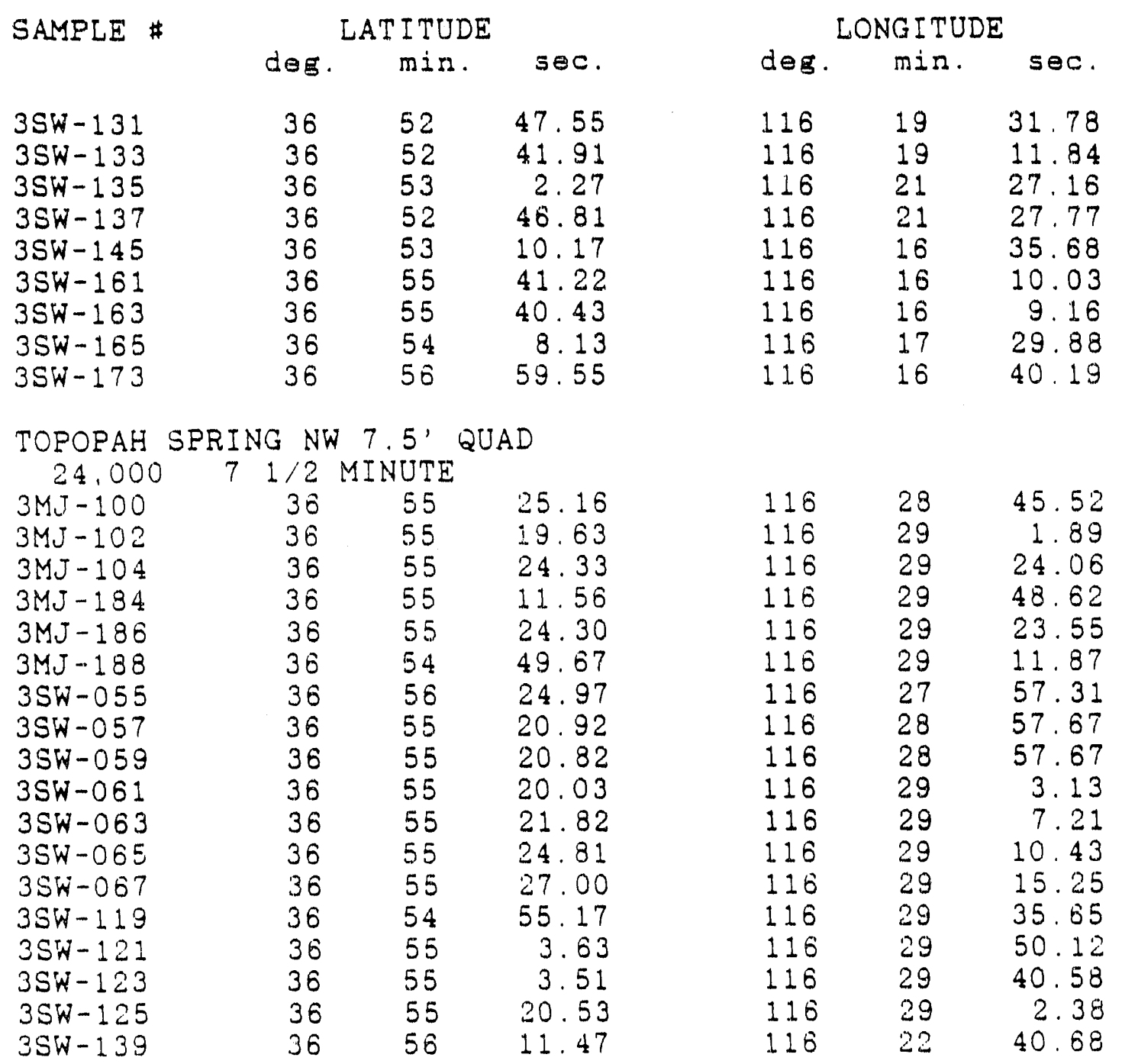




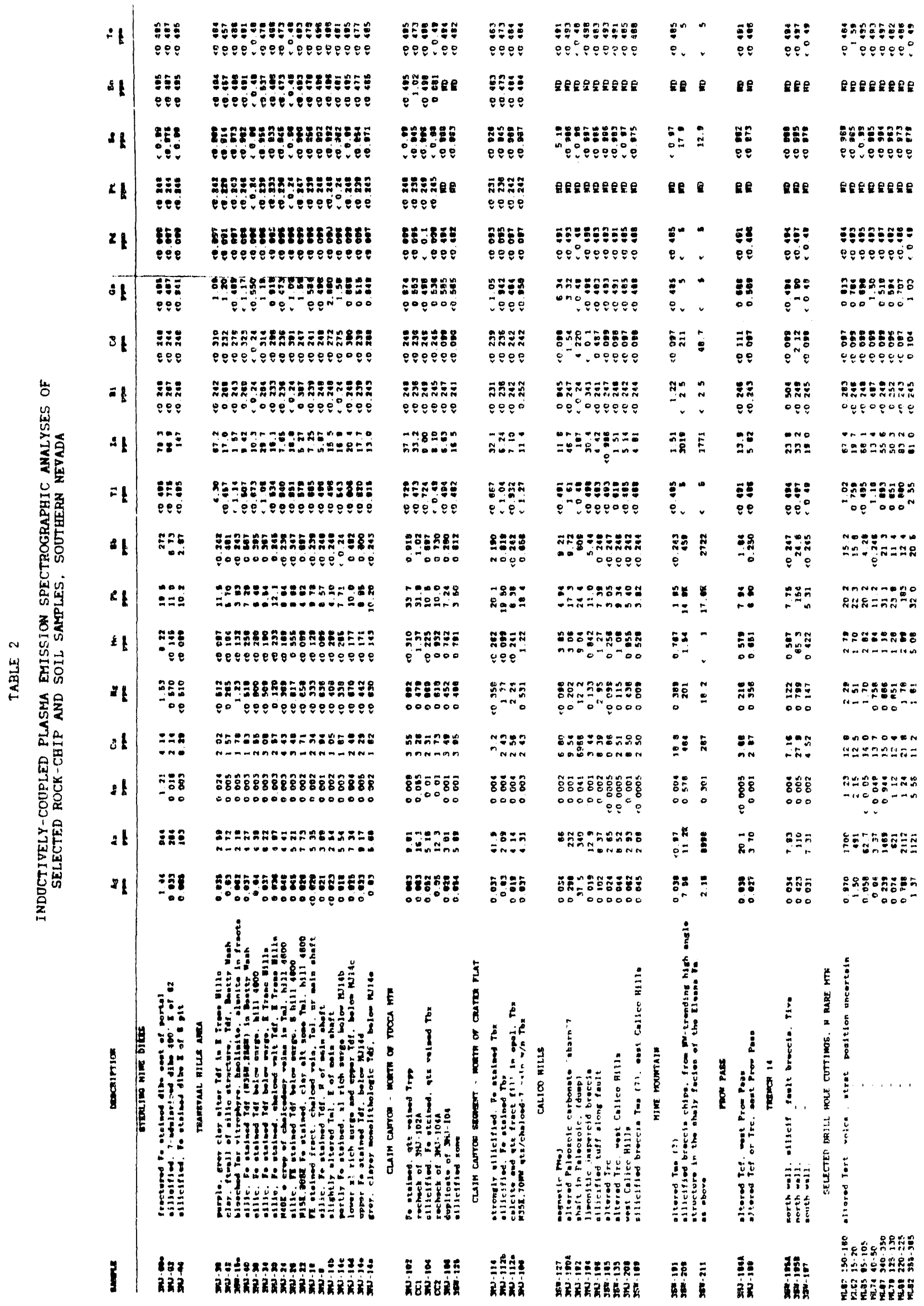


APPENDIX I 


\section{AFEENDIX I}

\section{PROGRESS REPORT}

ZEESPTEESPQ: JAHUARY THROUGH MAY, 1388

$P R=-2: T:$

TASK 2, YUCCA MOUNTAIN PROJECT: OIL AIL GAE POTEVIIAL OE OULCA MCLUTAIN AREA.

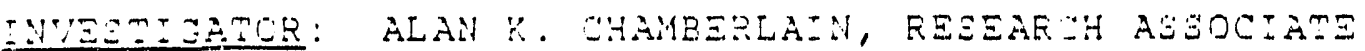

\section{ACCOMPLI SHMENTS}

During this report periad, approximately 2 days were agent condueting library research, 2 days worhing on Eieid wori logis:ics, 39 days conducting Eield work, 2 days preparing jameles, 3 days on basin modeling and 6 days evaluating laboratory resula ヨ几さ

1. Library research: I spent approximately 2 days studying reports of geology pertaining to Missisaippian sedimenta ar. structural complications of Mississippian sediments in the region around Yucca Mountain. During my research, I found several key areaj that I needed to sample, measure and analyze during my next phase of Eield work. After an exhaustive search, I only found two re Eerences that mention fossil flora in the Mississippian sediments. One of the references, poole, et al., 1961, describes some plant stems associated with convolute bedding and flow aasts. The other reference, Exren, et. al, 1971, mentions plant fragments.

2. Logistics for doing field work in the Nevada Test Site: During this quarter, I spent at least 2 days securing permision to inter the Nevada Test aite and getting field gaar, maps, putlications, Eield supplies rrdered and other logistics ready for fieiz work. These days were mogtly conalimed in writing ietsari, makirg phone cails, filling out reports and forms, ete. Most of these two days could have been more productively spent on research had the Center for Neotectonic Studies at University of Nevada, Reno aided me in making arrangements to ente: and work on the Nevada Test aite.

3. Field work: I spent 39 days in the Ejeld and 4 dayj wititiz the juaterly rapart during this report period. Gome at the acoumpidshmentis during the 39 days in the Eieid include:

a. Attending the pre-GSA field trip on a traverse from pioche to 
Alan K. Chamberlaln

Grant Range, Nevada led by Dr. John Bartley (University of Utah) and others ( 3 days). The trip gave an alternative explanation to major thrusting for some of the structural Eeztures in the Giazt Basin. It is my eeeling that Dr. Bartiey and his students who began work in the Great Basin onig five years ago lach tha desalies stzatigiaph: a a structural perspective that I have gained over the last 15 years. This new company of workers has failed to incorporate seismic and well data into their theories. Even thouga [I. Bartiey has had several stucents jpend consideratie time mapping the structure o: the oxant Range, Barley acknowlidges that he does not know huw these thrusts mapped by him and his

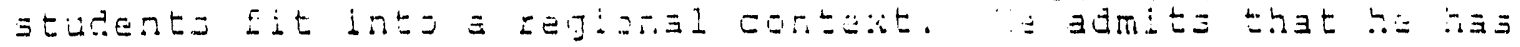

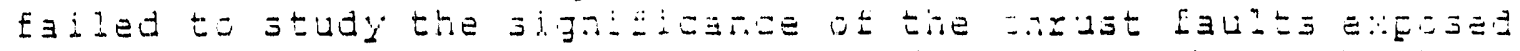
in lhe forest home area where Devorian reservoli rocks have been thruis over Misisaipeian source rocks. This same structural reiationship of Devonian thrust over Misaisaippian rockz exiztz in the Nevada Tast aite. Having overlooked this most important structural reiationship, or. Bartley and team apparentiy are unaware of the magnitude and significance of Mesazjir th:usting in zantzal Vevada as it app:iss to oi and gas aczumulation and antrapment.

b. Attending the GaA Cordilieran secticn Las Vegas ( 2 days). Here I was able to meet several workers with interest in southern Nevada Paleozoic stratigraghy and subsequent structural deformation. After presenting my two talks and conducting the symposium on oil and Gas Exploration of the Great Basin, I had several lively discussions concerning my views of Mississippian depositional environments and their involvement in Mesozoic thrusting and hydrocarbon generation (Chamberlain, 1988a and 1988b). These aiscussions led to arrangements to meet with Dr. Charles Sandberg of the USGS in the field for further discussion on Mississippian depositional envizonments, beginnings of a possible Penrose Conference on Mesozic thrusting in Nevada, and conversations of how my iueds may help develop some of Nevada's hydrocarbon potential.

c. Attending a post-gia field trip led by Brian Wernicie of Harvard University and others to understand their concept of structural style in southern Nevada ( 3 days). Wernicke, like Bartley on the pre-meeting trip, had completely overlooked seismic and well data. Faliure to incorporate hills buried in the alluviated valleys between the ranges during palinjeastic reconstruetions will ioult in erronegus amounts of extensian. Wernicke jugyests, for example, that the ilogai Range broke away from the apring Mountains and that pantump Valiey was a hole caused by the breakaway. His hypothesis ignores the fact that the valley contains buried hilis which are indicated on seismic sections. Most all Nevada Basin and 
Range valleys contain similarly buried hills. His estimate of extension is posiluiy in exzoz by several orders ue magnitude. It ij shouing to reaize that such wideiy arziained madela hive ovelioohed such obvious and important information as buried hilis between ranges.

d. Measuring a series of sections in and around the Nevada Test Site ineluding (13 days):

(1) Quartzite Ridge (4095 Eeet, 27 samples at aec 14 TOBs

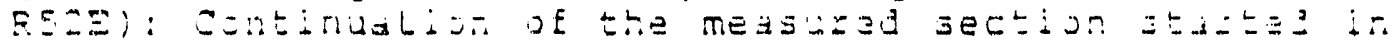

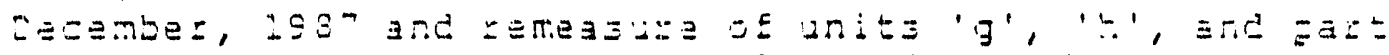

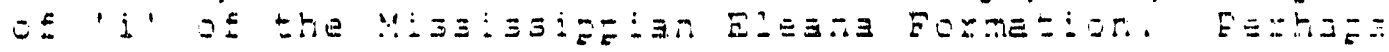
the most signielcant part of the jezticn wis the discovery of Calamites near the top of Cuartaite Ridje which very strongiy suggests a non-marime environment of deposition. stems of reed-like plants were faizly abunjant in unit 'e' but rarejy were found in higher units. Jevers: ap:raled gastropoda were found but ars

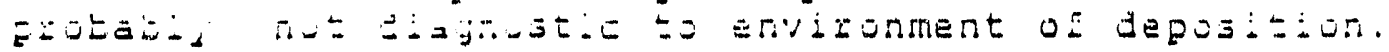
Aradys 3 uE additional Eine-grained unito for palynomorgh aszembiges ray jire additionad alies to depositional environment. Interbedded l.ith the fine-grained units are coarse-grained units. There appear to be three main pulses of these coarser siliciclastic sediments in the stratigraphic column and may represent pulses of Antlez Mountain development.

Falynomorgh analysis of sample number QRA 93 yieldea

rare occurzences of cirratriradites satruni, Densosporites sp., and hycospora sp. This assembiage suggests probable chesterian age and nonmarine deposition. Kerogen type include inertinite 50\%, woody 25\%, and cuticular 25\%. Visual Thermal Alteration Indices (TAI) is 2.5 which is at the beginning of peak hydrocarbon genera:ion.

Geochemical analysij suggest that this sample is incapable of generating significant quantiliti de hydrocarbons since the rotal orjanic content (T:a: is only 0.07\%. Abundant bacteria may have biodegradea the sample and may be responsible for such low Total organio content. Total organic content should increase in the subsurface where the sediments have been shielded from bacterial biodegradation. Recovery of vitrinite was too low Eor reflectance analyais. Analysis of eight ja:tiona: azmpies stat have bean caliected may proyda

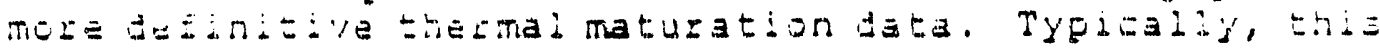
upeer plate of proximai Antiez sidicieiazlicz la overmature. It would be surprising to find it at the peak oil generating window. If it is determined that the upper plate is at the peak oil generating stage, then 
chances of significant hydrocarbon accumulations in the Nevada Test Site area are greatly enhanced.

(2) Captain Jack Spring, Elesna Range (2240 feut, 9 sameies at secs 5 and 6 TOZS KEIE): Aceczing to the geologid mapj of the area, this is ane of the bejt iocationj to measure unit ' $E$ ' of the Eleana Formation. Without biostratigraghic control, it seems impossible to tel: if unit 'E' ij just another Eacies of the other unitz or iE it is a distinctive, mappatle unit. It appears mulh i ise

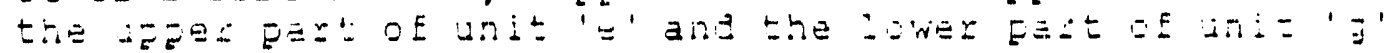

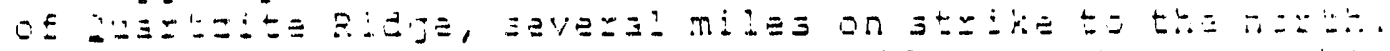

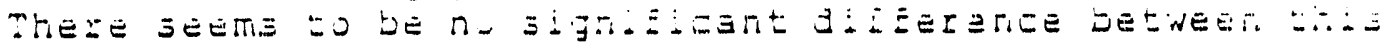
unit ard tie lube ' several jampies of tite finer intervais may previde jumb of the paynobiostratigraphic control to matie better correlations.

(2) Red Canyon Wash, E:eana kange (375 feet, 14 samples it Sec 06 TIOS RSLE): Perhafs the test contact, according to the geajugic maps, between the Misisaippian Eisana

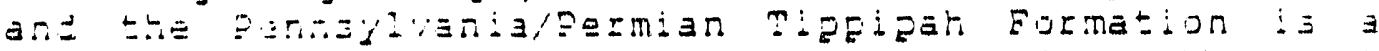
sma:- outzzop adjacent to Red Canyon wash on the east s:je of the Elisia Range, northwest of the shaker jant along the Tippipah Highway. At this outcrop, the contact becomes complex and may be a fault contact instead of a depositional contact. In spite of the possible complications, a section of the uppermost ' $j$ ' unit of the Eleana into the lowermost $T$ ippipah was measured.

The quartzose sandstones interbedded with organicrich, black, Eissile shale of the uppermost Eieana contrast sharply with the rest of the chert-rich, silty Eleana exposed a mile farther west. I found no continuous outcrop between the two ithotypes. There could be structural complications between the two types of lithology.

The most significant feature of this measured section is the presence of Stiamaria with routlets that penetzate bedding pianes in the quartz sandstone outcrops. These depositionad indicatorj leave littie doubt that the sards usnes were deposited in a non-marine depositional environment. This contrasts sharply with published models of depositional environments of these sediments which woula have them deposited in a deep ocean Elyseh trough.

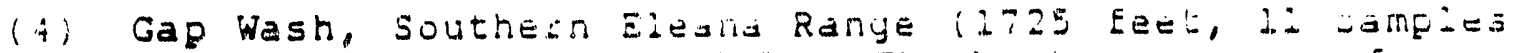
at jecs 1 ? and It TIOS RSIE): The best exposures aE nonmarine flora found in pidce are found in the uppexmost 
Alan K. Chamberlain Progress Report January-May, 1983

exposures of unit 'j' found adjacent to Gap Wash. Here, after measuring several thousand feet of cherty, poorly sorted, silicious siltstones, sandstones, congiomerates and limestone, and atter having measured through about one thousand feet of covered interval without

any sutcrsps, jeveral hundred feet of well-sorted, alean, quartzose sandstones interbedded with black, E:jsible shale were measured. It was in the upger, clean

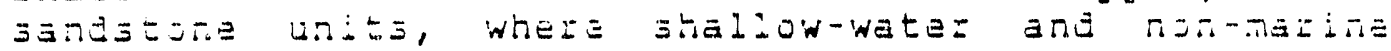
indicatora were found inciuding bimodal ripgle marks and

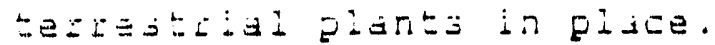

There is a possibility that the covered in:z2\%al represents $a$ thrus: Eault which places proximal, ate:trich facies adjucent to distal, guartz jandstone faこia sinilar to the Newark valley thrust lis m:les to the north. The Newark Vaikey thrust piates proximal, cher:rich facied expozed in the Diamond Range adjacent to

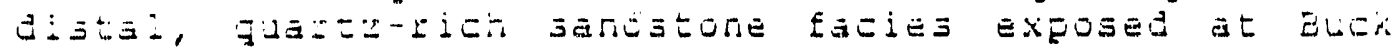
lodrian and the Eancake Rarge.

:t wil: be most useful to have geochemical are palynomorph analysis maue on samples from several dark, organiz-rich black shales. Pajynomorph anaiyis oz sample number STE 42 taken from the tippapah sering, shoshone section which is located several miles ta the south yielded one of the testomorph assembiages yet colieczed in the Nevada Test Site area. The asambiage includes rare occurrences of: Convolutispora spp., Densosporites spp., Discernisporites micromanifestua, LYcospora Spp. Rotaspora disiuncta, Rugosspora Elexuosa. and Waltzispora planiangulata. This assemblage is typicai of Osagian to Meramecian and was probably deposited in a non-marine setting of a swamp or lacustrine environment. Kerogen types inclide: woody 40\%, cuticular 10\%, and amorphous 50\%. Visual thermal alteration indices (TAI) are approaching pear oil generation at 2.6 to 2.7 .

Geochemical aralysis of the same sample yielded 1.05: Total organic Carbon (TOC). Vitrinite reflectance of the sample is 1.29 \% which is beyond the upper peak liguid generating zhase and at a level eguivalent =0 the beginning of condensate generation. Conodont Alteration indices of conodonts from the overlying Tipeagih Limestone places these rocks in or near the peak oil generating window at 1.5 to 2.0 . The conodonts from the imestone form an assemblage that are diagnostic of Early Eennsyivanian, Morkowan time. There's a good likeilnool that the Missisalppiansiliciclastics in this section are in the peak liquid hyorocarbon generation atage. It this is true, then the overburden cause by upper plate thrujt 
Alan K. Chamberlain Progress Report January-May, 1988

loading has not resulted in destructive thermal degradation of the source rock potential of the lower plate. This would mean that the potential of finding significant hydrocarbon resezves in the yucca Mountain arəa is guite high.

(5) Diviue between West sandy wash ard but sandy iash, Spottad Range east ot Mercury (1040 teet, 10 samples at

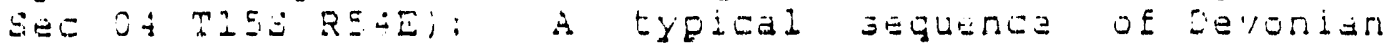
Gudimette, Missisaipeian-Devonian Eilut ghale, Misaisaippian joana -imeszone, and the basa: part ja the Misaissippian antlez ailicielastics was measured in thia section. This sertion is yery similar to a jactior.

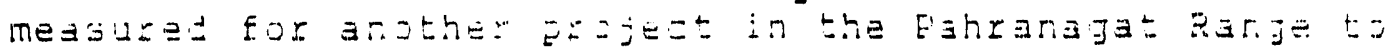

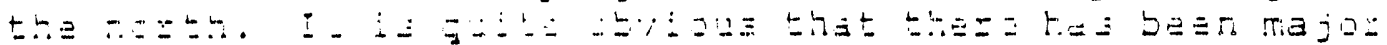

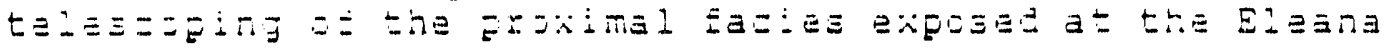
Range with the diztal facies exposed in the gpotsed Range.

iniy a Een tens of feet of the lower Antier silicicisatics are preserved below a major deculienent which tzuneates the rest of the section and places Devonian and pleer Painozoic rocks adjacent to the Mississipeian rocks.

Thi a may be the most aignificant section in the Test site Ara coneerning the potential for major hydrocarbon accumilation of the region. If the Misuissippian sourae rochs in this section are preserved under Mesozoie thrust sheets in the Nevada Test site Area and if they haven't been pushed through the oil and gas window, then there may be strong potential for hydrocarbons to be produced from these subthrusted source rocks.

(6) Carbonate Wash, Nellis Bombing Range (2750 feet, 14 sampies at secs 35 and 36 TO7O R52E): The best section with a contale of the Devonian and overlying proximal

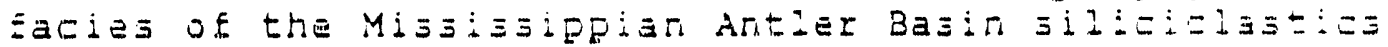
(units 'a', 'b', 'e' of the Eleana Formation) was measured at Carbonare Wash in the Nellis Bombing Range just north of the Nevada Test Site. Here, the upper Devonian Guilmette Eormation contains abundart coral reefs, bioherms and other Eavorable reservoir rocks for hydrocarbon accumulations. The carbonates give off a strong hydrogen suleide odor when freshly broken which suggests that hydracartong couid have migrated through the re rocks sometime in the geologic past. The aundance of coralj, Eenestrate and ramose bryozoans, trachiofods, etc., suggest that the biomass was deposited in or near the photic zone or in very shallow water. Many of the corals, both colonial and rugose varieties are still in 
growth position which indicates that they grew in place at the photic zone and have not been transported into deeper wates.

EErvasive doiomis:aation of the upfermost pazt of the Devonian carbonates left a very porous, coarsely crystailine dolomite most favorable for hydrocarbon reservoir. The doiomite unit is overiain by a fairly thin unit of limestone conglomerate which is in turn

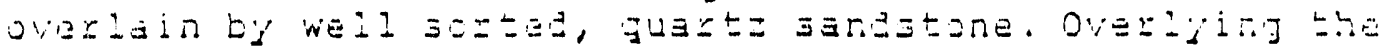

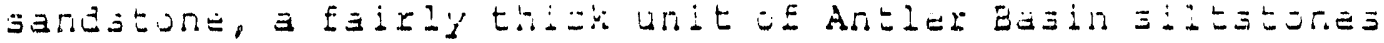

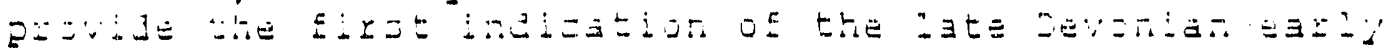

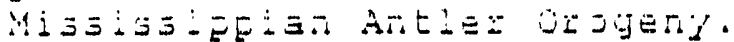

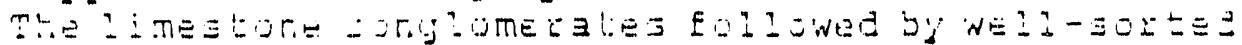
quate jandstone ma $\because$ cepresent a shoaling of the De\%onian jea whes the ilntegtorie conglumerates were depositel within ztozn wave-baje and the uverlying gandatone was deposited at normal wave base. At wave base, the

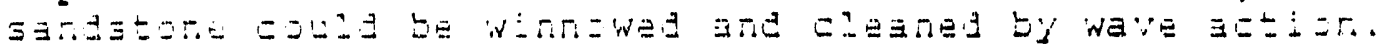

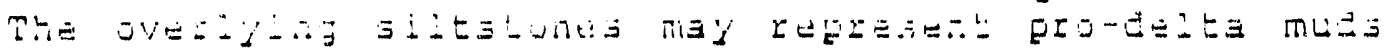

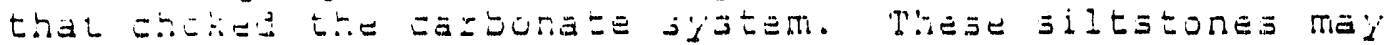
have fusitbiy been depusited $4 \pi$ tidal mudfias oI a least in fairiy shallow water. It is unlikely that they were deposited in deep water since it would require sudden subaldence from deposition at the photic zone to deposition in several hundred seet of water over such a short distance or interval of time.

Units ' $a$ ', ' $b$ ' and ' $c$ ' of the Eleana Formation offer very poor exposures sor study. Basicaizy they are composed of very poorly sorted, chert-rich sandstones, siltstones and some minor amounts of conglomerate beds. As with similar sediments at quartzite Ridge, abundant contorted bedding and cross bedding suggest that fine sediments were poured out onto some slope. No strong depth indicators were found. The sediments could have been deposited in almost any environment from non-marine to jeep marine. I Eavor moderate to shallow maine deposition for most of the sidiciciastics measured.

(i) Tongue Wash, near fianier Mesa ilobs feet, 4 sameies a sec ol, mose RSiEi: It was instructive to messure a section of ruck through a thrust placing ordovician carbonates on Mississippian siliciclastics. Mapped as a norma: Eault on the Rainier Mesa quadrangle, the fault between the underlying Mississippian sediments and the overlying ordovician sediments is probably a thrdst

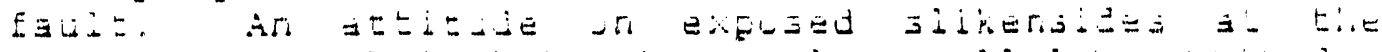

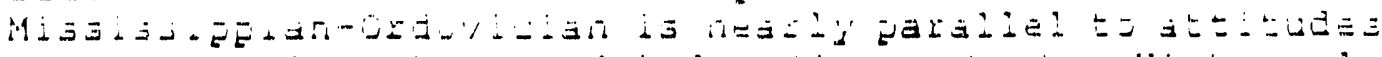

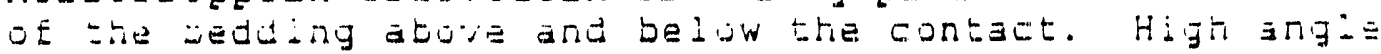
normal faults complicate the relationship at the contact 
Alan $k$. Chamberlain Progress Report January-May, 1988

and may have confused compilers of the geologic map. Furthermore, the thrust contact appears to have been Eairly recentiy exposed from an excavation for a buried catio near the faut contact. Counts per second ices; dropped significantiy from over 200 Ces below the trust

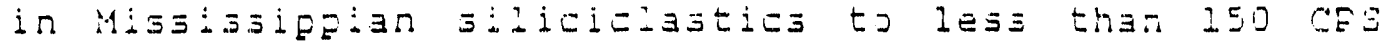
ateve the thisa in ordovician carbonates.

The fact that Tertiary volcanil zocks lie

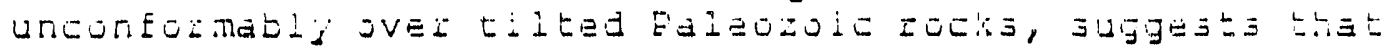
the structura: relationship betwesn Mississipgian and

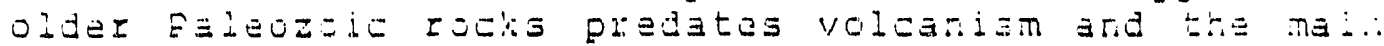
Tertiary extencional events. The folding and thx

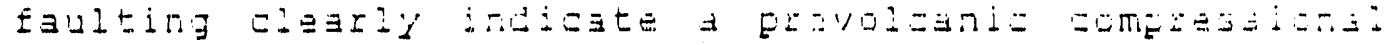

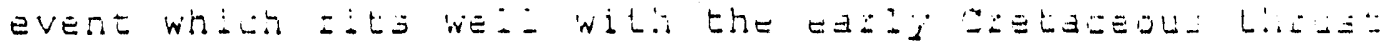
bels that has been decumenzed north or tas iteyda Tez: Site. North of the Nevada Test site, in nuthwestern Railroad Valley, the early Cretaceous syngenetic Newark Canyon Formation toth lies on and is partiy consumed by thrust aheets. At one outcrop, the Newarb Canyon Formation lies discordantly on Misisisippiar. siliciclastics and is partly overridden by Devonian cazbostes. A thin belt of these cretacequa jingeneti. sediments is Eound ail along the thrust belt.

There is a good posibility that the

Tertiary/Cretaceous sediments mapped in the Jumbied Hilis area could be syngenetic sediments related to the Mesozoic thrust belt. In order to properiy evaluate the hydrocarbon potential of Yucca Mountain, these sediments must be studied as well as their relationships with the upper and lower plates.

(8) Cottonwood Wash, Death Valley (465 feet, 5 samples at Sec 23, T15S R43E): During the Wernicke GSA field trip, I heard of a report of fossil flora in Cottonwood wash near Stove Pipe Wells, Death Valley, California. I failed to find the fossil flora but I succeeded in measuring a section very similar to the Mississippian siliciclastic section exposed at Arrow Canyon, north of Las vegas, Vevada. The section forms a reddish strike valiey between a masjive, aliff Eorming limestone unit below and a thick sandy limestone unit above. The siliciclastics are composed of quartz sandstone, claystone, and intertedded limestones. The shale or claystone interyal is rich in anhydrite suggesting a restricted narine envizonment. Should stigmaria rootlets be present as reported, then zome of the sediments would have been deposited in a non-marine environment.

The Cottonwood Wash-Arrow Canyon sections are of similar lithologies and thickness and seem to represent 
Alan $K$. Chamberlaln Progress Report January-May, 1988

the southeastern edge of siliciclastic deposition in the Anteler Basin. The Spotted Range section, north of the Cottonwood Wash aection is very similar to the Meadow Valley and Pahranagat eezion north ok Arrow Canyon and represent a more inland or western facies of the Antler silicieisstic interval. The chert-rich ailiciclastic

sections that apgarentiy have been telescoped eastward by Mesuavil thrugt tauttirg ant exposed at the Eieand and Diamond ranges apzer to be an even more iniand or wegtezn Eacies.

Regionaidy, yude dountain appears to be located slightiy west of the facles responsloie tor generatirg

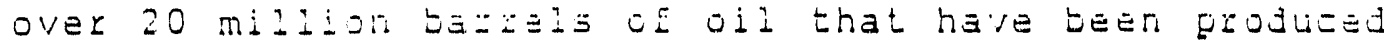
at Railiuad valiey 1:0 miles north and pine valley z40 miles north. Deten, saurce rocks which underlay overmatur Leger plate sedimentz have not been expczed to destautive therma events and may have generated

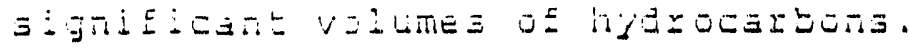

(9) Tarantula Canyon, Bare Mountain (625 feet, 3 samples at Sec 29 TIza $R+3 E$ ): I measured a short interval at the Devonian-Mississippian boundary to compare this aection to others in the Nevada Test Eite area. The Devonian dolomite section below the contact is more cherty, micritic and barren of fossils than other sections in the Nevada rest site. The carbonate conglomerate immediately below the contact is very similar to the limestone conglomerate just below the Mississippianidevonian contact at Carbonate wash 45 miles to the north east. The siltstone unit immediately above the contact is also very similar to the siltstone at Carbonate Wash.

The main difference between the Bare Mountain section and the Carbonate Wash section is the interbedded cazbonates above the Mississippian-Devonian boundary at Bar Mountain. Except for the carbonate interbeds, the Bare Mountain seztion more closely resembles the Carbonate Wash section than any other section in the area. This suggesta that the Bare Mountain and Carbonate Wash sections may have been deposited in a similar environment.

(10) Shoshone Mountain, east side: (1570 feet at secs 35 and 36 TIIS RSIE) The upper Devonian and lowermost 许isiszipgian seglence at Shoshone Mountain is ve:y similar to the same interval exposed in the Eahranaga

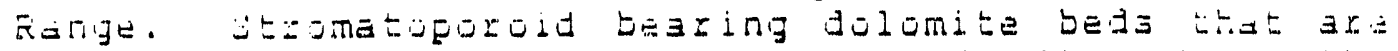
probabiy equivalert to the simonson Dolomite make up the base of the section. Overlying the simonson Dolomite is the Guilmette Formation which is in turn overlain by the 
Pilot shale. Orkild, 1968, referred to these beds as the Nevada Formation and the overlying earbonates as the Devil's iate Limestone. The Guijette Earmation appears vety amilaz to the sandy gectiun at aj-tiririe Muntair and the northern end of the Fahranagat Range. It wouldn't be to surprising to find masive limestones clifes of the Jeana limestone under the volcanic cover of Shoshone Mountain stratigraphically above the section measuzaz.

Five samples from the carbonates below the sil tatane

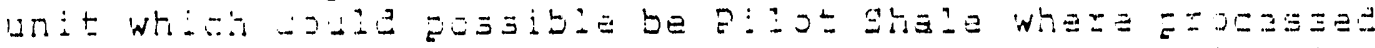

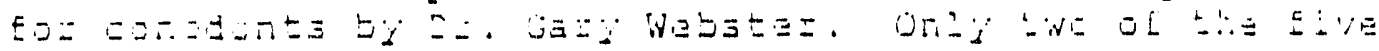

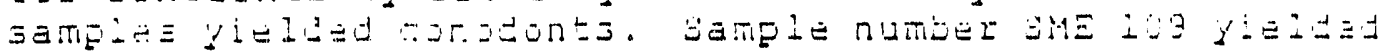

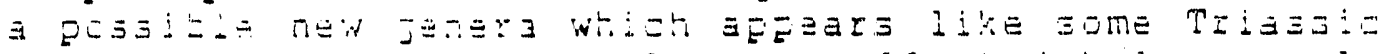
forms. Hodever, the sample was collected beluir sample number sine 147 which yielded a definite kinderhookian assembiage, making SME log somewhat older than kinderhookian ag=. Ferhaps slle 103 is uppermost Devonian. Elements of the Folyanathus inornatus

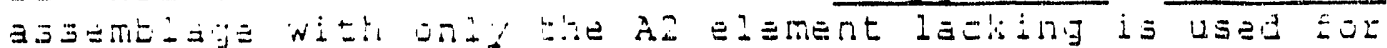

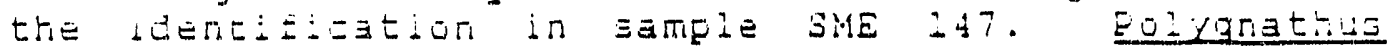
inornatus is a common Kinderhookian form in North America.

Conodont Alternation indices of SME 109 is 3 to 2.3 and of SME 147 is 4 to 4.5 . These values seem a littid high compared to the visual Thermal Alteration Indices (TAI) of the samples taken in the siliciclastie section above the carbonates.

Palynomorph analysis oE sample number SME 287 (which is 287 five-foot measures from the base of the section) reports rare occurrences of Lycospora spp. and Convolutispora sp. This assemblage suggests that the age of the sample is Carboniferous, undifferentiated. The assemblage also suggests that the rock was deposited in nonmarine to lacustrine environment. kerogen typez inciade: woody 5\%, cut:aular 5\%, ard amozghous $30 \%$. Visuai Thermal Alteration Index is 2.3 or very eariy uii generating window. The Amorphous composition is vety Eavorable to hydrucarbon generation. However, geochemical aralysis of the sampie shows only. t4 4 iotal organic Content (TCC) which is quite poor for hydrocarbon production. Conflicting with the palynomorph report, the geochemical laboratory reports that the visual Thermal Alteration Index i: between 3.2 and 4.0 . This would put the jample in the apper liquid hydrocarbon generating window. The gevenemicai laburatory aisu ceported that spores and pollen were absent while the paiyno:og:st reported recovery of the two genera mentioned abuve. 
Alan $K$. Chamberladn Progress Report January-May, 1988

Palynomorph analysis of sample number SKE 300 reports rare occurrence of punctatisporites sp. Which is indicative of larboniferoua, undiEferentiated age ard a nonmaine to marginal mäine depositional envizanent. the herogen type recovered is $100 \%$ amorphous which is the best horogen Eor hydrocarbon generation. Visual Therma? Alteration Index of the kerogen is 2.5 or peak oil generating window. However, the geochemical laboratory reports that there were no recover $z$ of jpores and gulitid and that the visual TAI ranges from 3.0 to 3.5 which wodid be at the las $35 a g e=$ of oiI generation ind the

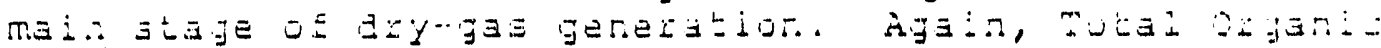

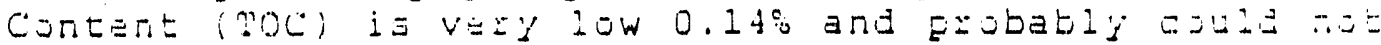
gererdte signisicant guartities of hydrocazbori.

Additional work on the section, especialiy in the siliciclastic interval near the top, may yield aufficient viteinite to get a solid Eix on the thermal maturity of the sediments in thij jection. It it can be determined that the sediments in this structural plate exposed on the east side of shoshone Mountain are stili in the oil generazing window, then is would follow that tine overying Misisalpeian zediments not exposed in the section could still be at peak oil generation presently. since this structural plate probably underides the structural plate exposed at the Eleana fiange, significant quantities of hydrocarbons may have been trapped below. There could be a potential for significant hydrocarbon accumulations at Yucca Mountain should there exist a proper structural trap.

The most definitive approdch of determining the hydrocarbon potential at Yucca Mountain would be driling a test sufficiently deep to penetrate structural plates that may contain significant quantities of hydrocarbons. In the Utah/Wyoming overthrust plate and in the Anadarko Basin, hydrocarbons have been produced from as deep as 25,000 to 30,000 feet. Perhaps a 35,000 feet deep test ought to be made at Yucca Mountain before proceeding with the high level nuclear waste storage. Cost for such a test inciuding seismiL, geochemistry, drili jtem tejts, etc. should te less than $\$ 50,000,000.00$.

(11) Quartzite Ridge, east side, spur north of Quartzite Ridge section described in 1 above: $(1020$ feet at Secs. 23 and 24, TO8S and R52E): This section is not as well exposed as the spur measured to the south but should provide a control point to test the continuity of beds from ridge toridge. It will be interesting to compare surface gamma-ray loga tetieei the two sections as well as the description. 
A geochemical analysis of sample number QRA-93 reports that there was too little kerogen recovery for vitrinite reflection determinations. Palynomorph analysis reports rare occurrences of Circatrizalites satturni, Densosporites sp., Lycospora sp. This aszemblage ia liheli to be Chesterian and aggests tha the depositional environment is nonmazine. Kerogen types include: Inertinite $50 \%$, Woody $25 \%$, and Cuticular $25 \%$, with a visual Thermal Alteration Index (TAI) of 2.5 which is at the beginning of peak oil generation.

(12) Calico Hills: (10s feet at SeE 25 T129 RSOE): It seems that all the rocks in the caliej Hilla area hara undergone hydouthermal alteration. Neverthejesz,

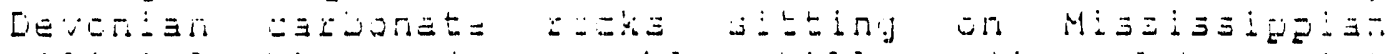
sidiciclastic rochs provide atill another data point along the Mesazole thrust belt. A very short section of Misisisipeian sediments was measured for completenesa sake as the chances of finding any significant source rock preservation or even palynomorph assemblages seemed quite bleak.

Results from palynomorph analysis show that sample number CHA-0 was barren of palynomorphs and only a trace of organic material was recovered with the foliowing kerogen types: inertinite 90\%, woody 5\%, and cuticular 5\%. Visual Thermal Alteration Index is 2.3 to 2.5. There was no kerogen recovery reported in the geochemical analysis and hence no vitrinite reflectance data. Due to the amount of alteration of the rocks of the area, it would seem that the rocks have been exposed to destructive thermal events which would preclude any hydrocarbon generation from the sediments.

e. Photographing Quartzite Ridge and Red Canyon measured sectioni with both video and still photography (2 days). As a step toward guality assurance and as a positive way to document the measured sections, both video with narration and stili photographs were taken. The video provides a unique, three dimensional view of settings, sections and outcrops. The still photographs provide high quality reproductions of outcrops and geologic features and can be used to illustrate reports and papers.

f. Working on the pahranagat shear zone jouth of Alamo with Rebecca Ezwood (5 days). A reconnaisance map of Eolded volcanie units involved in the sheat zone provided more thought on its relationship to features extending southwest toward the Yucca Mountain area. Movement along the northeast trending shear fault must have postdated Tertiary volcanic and Mesozoic thrust fauling. Northeast trending shears like 
the Pahranagat shear may have effected hydrocarbon migration, aこcumulatian, and Frejezvasiun.

Similaz shejis or nothejat-trendiny atrike slip Ealta in rijilroad valiey and pine valley, located 50 and ljo miles to the north respectivoly, enhance porosity and permeability in buried Devonian carbonate reservoirs and bound important oil Eields. In addition, folds associated with the faults form important trags or structures for hydsocirter. accumulations. For example, in the Blackburn field, fine Valley, a large northeast tranding shear seems to baund the

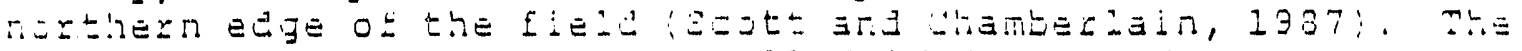
Eleid itsele seems to be a small fold in Devorian carbanatea adjarent to the Eault. Cabbonates adjacent to the fauLL are highly Eractured and serve as excellent reservoirs Es significant hydrocatton accumulations.

g. Reconnoitering cuntral Nevada fold and thrust belt from aliu to Las Vegas (4 days). I'he Aube Range northwest of Elio, Nevada contaira diezmeture Missisaiegian sediments ver: similar to the overnature Eieana Formation in the vevada Tes:

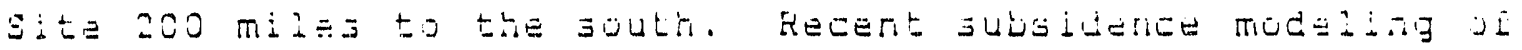
data from the biamond Jhamrock kimbarh kou i-23 suggesta that the entire 12,000 foot section drilied iz probably in an upper plate. Oil in some wells in the area probably has migrated up from a lower plate that is still in the oil generating window to the upper, overmature plate drilled in the KoG well. The modeling was done using a method developed by $D$. Waples (waples, 1985 ).

Pine Mountain, adjacent to Pine Valley, serves $a s$ an excellent model of the Blackburn oil field 15 miles to the southwest. At Pine Mountain, Devonian reservoir rocks have been thrust over Mississippian source rocks by the Mesozoil thrust system. The Blackburn Eield produces Mississippian hydrocarbons from Devonian reservoirs. The oil has probably migrated up from the Mississippian rocks into the overlying Devonian reservoir rocks. Overlying the Devonian sediments is a thin sliver of repeated Mississippian siliciclastics that acL $a s a$ seal for the field.

The Diamond Range lies between the Adobe Range on the north and the Eleana Range on the south and serves as another example of overmature Mississippian sediments being thrust over Mississippian sediments that sit in the peak oil generating window. In other areas along the thrust belt south of the Diamond Range, ordovician rocks are found thrust over Devonian rocks or Devonian thrust over Misisisippian.

one of the test examples of Devonian thrust ous: Missijsippian rocks is found near Duckwater on the norshwes: corner of Railroad valley. There, Devonian rocks have been thrust over early cretaceous syngenetic jadiments that 
Alan K. Chamberlaln

unconformably overly Mississippian rocks. Another excellent example of early Paleozoic rocks thrust cver upper paleozoic rock is found just seven miles east of the grant Canyon sield at Forest Home. Measured sections of upper and lower plates at Furujt Home strongly suggest major displacement along the thrust falt there (Came:on and Chamberlain, 1937 and 1933).

Two other significant exposures of the central Nevada thrust belt occur at the south end of the Golden Gate Range and at the northern end of the Pahranagat Range. In both these exposures, older paleozoil sediments have bean thrust over younger paleozoic sediments. As with exposures to the north, the main flat or decoliement occurs in the

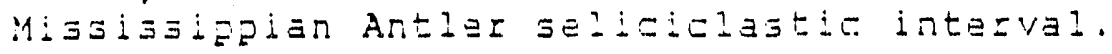

h. Reviewing upper Raieozoi stratigraphy in the Meadow Valieg Mountains and Arzow Canyon (2 dajs). One of the best exposed and relatively undisturbed stratigraphic sections of upper Paleozoic rocks in the general region of the Nevada Test site can be found twelve miles northwest of Rox in the eastern edge of the Meadow Valiey Mountains. Excellent exposures of Stigmazia-bearing Missisaippian Antlar siliciclastics in the section indicate that there were periods of lacustrine deposition between periods of shallow marine deposition.

Foole, 1974, suggested that occurrence of stiomaria in Mississippian sediments in Arrow Canyon indicates estaurine environmental conditions. The occurrence of stigmaria is ubiguitous throughout the Antler Basin (Chamberlain and Waanders, 1984). Many intervals of the Mississippian Antler Basin probably have been deposited in non-marine, lacustrine environments.

In addition to the significant Mississippian beds, the Meadow valley Mountains have one of the most spectacular sections of Pennsylvanian, Rermian and Triassic rocks in the region. An understanding of these upper post Mississippian strata is essential in basin modeling using Lopatin methods. Basin models developed in front of the thrust system could be extrapolated to the Nevada Test site to the west where these sediments are buried below upper plate, older padeo:oic sediments. Access to these exposures may soon become severely restricted in the near future since the Meadow Valiey Mountains may become designated as a wilderness area. Currently, the sections are accessible by an hour crosscountry dirtbike ride as there are no roads into the area.

4. Sample preparation: During this report period, two dais were spent on aumpla preparation and organization. Each geochimiä? sample had to be split, bagged and lateled in preparation to send out for geochemical and palynomorph analysis. Other samples such as sandstone samples, conodont samples, etc. had to be inventoried, labeled and prepared to be sent out for Eurther work. 
Alan K. Chamberlain Progress Report January-May, 1988

5. Basin modeling: During this report period, I had the privilege of being tutored by one of the world's foremost experts in geochemistry and basin modeling, Lr. Douglas waples, ciaraca School of Mines and formerly with Mobil Researeh Company. Dr.

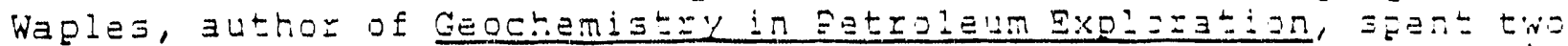
days in Reno giving an intenze presentation of basin modeling uaing stratigraphic and maturation data. The basin models were ca-ibrated with measured maturation data from outcrops and wella.

During the session, I raviewed many of the principles that I

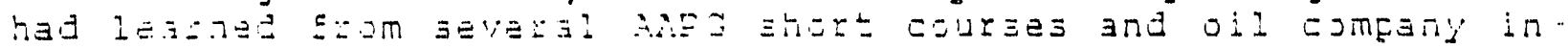

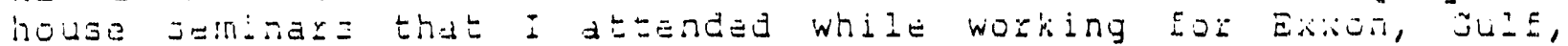

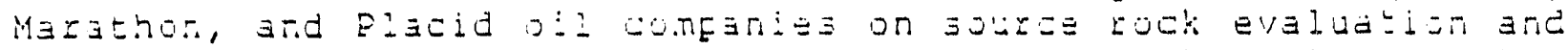
exploration and sourae rock maturity. Jome of the thinga that I reviewed include:

1. Maturity of organic matter in sedimentary rocks controis both the conversion of kerogen to oil, and the cracking of oil to gas. Even excelient-quality source rocks are uninteresting to explorationists unless they are also mature enough to have generated hydrocarbons. Keservoirz, on the other hand, los

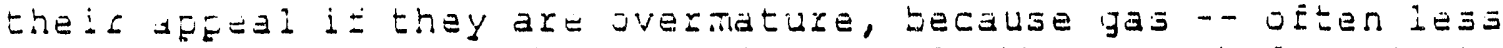
attractive economicaiiy - - is erequentiy the expected prodict. Thus determination of maturity levels of both source ard reservoir rocks is an important aspect of modern exploration.

2. Where measured maturity data are available and of good quality, they are invaluable in establishing the status of both hydrocarbon generation and preservation. Where measured data are lacking. however, or where they are of dubious reliability, maturity modeling plays a vital role in delineating maturity trends. Furthermore, measured maturity data cannot tell us about timing of past events: this is the province of maturity modeling. Timing of generation is critical in chances of oil preservation.

In order to take advantage of the stratigraphic and maturation data that I have recently obtained, I may want to carry out a stuly of the basin evolution and maturation history of the Nevada Tast Sitg area. Jtratigraphie data Erom weils and the measured segtions could form the nucieus of the study. I will calibrate my calculated maturity values with measured maturity data (Tmax, Ro, TAI, and Conodont Alteration Index) from my own data and/or from public sources in order to develop regional consistency.

Uaing the best-fit parameters for erosional and thermal historiej in each area, I will then predict the maturity levels in

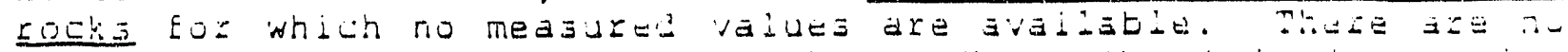
avaliabie outcrops of source rocks at Yucca Mountain co acquire measured maturation values. 
Alari K. Chanteriali

Erogregs Report

January-May, 1988

some of the results of such a study would aid in:

* Determination of Reservoir maturity history to access the experted efEect on hydzucarbonz.

* Determination of source Rock maturation history to understand timing of migration and canjeguentiy target optimum trap style.

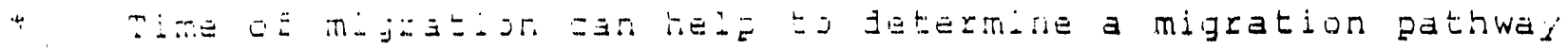
a.t

* Aid in undesztand:ng imeortant thermal and tectonic events in the history of this region of goutherr Nevada.

* Distinguish those areas where Paleozoil source rocks became mature in the Lata Palsozola from areas where source rocks were

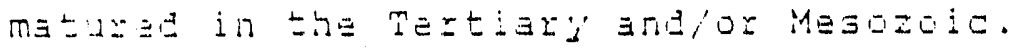

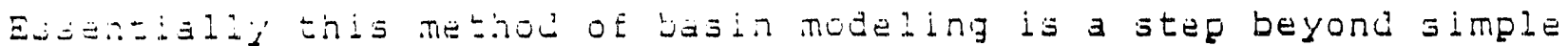

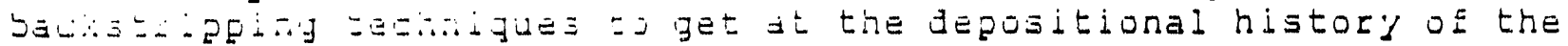

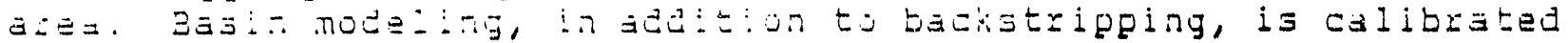
with maturation of the sediments. This greatiy refines the uncertainties and errors that are easily introduced in the Lachstrizping techniques.

In addition to this two day refresher course on geochemistry and basin modeling, I purchased a computer program that will allow me to efficientiy generate and calibrate a variety of models throughout eajtern Nevada. I will be working closely with Dr. Waples in modeling areas like Railroad Valley where there is an abundance of subsurface data to test and calibrate my models.

A proper evaluation of the hydrocarbon potential at Yucca Mountain will not be complete without such modeling because of the paucity of deep subsurface control. It is important to have a stratigraphic and thermal maturity data base to draw from. It is egualiy important that anyone attempting to make such models have зㄷこ: $j$ zania, biostratigraphic, and geochemical experience. Also,

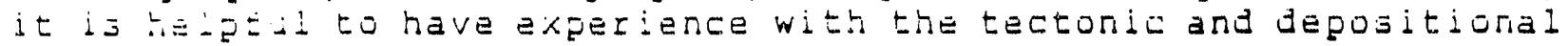
history af the region.

6. Report writing: During thi days were expended compiling field notes and writing this report. Thij repor = couid be the beginning of a more comprehensive report, compiets with photographs, drafted plates illustrating jto and a more comerehensive interpretation of laboratory and fieia data. zhuula i be invited by Yucea Mountain Project leaders to finish my evaiuation of hydrocarbun potential of Yucca Mountain, such a report could be ready by year's end. 


\section{RECOMMENDATIONS}

The best way to properly evaluate the oil and Gas potential. of Yucca Mountain is drill a test hole sufficiently deep, properly engineer su bith suefilient coring, enough Drili stem Tests, and other analysis to exhaust any possible structure that may have trapfed hydrocarbons in it. surface geologic work may help identify some of th models to use in extrapolating to the subsurface but only by testing the area with a well will a definitive answer to the hydrocarbon potential be given.

If the piece of real estate of the Yucca Mountain area is to be forever condemmed to exploration efforts in the practica: future, then I recommend that a deep test be drilled to prove the lack of rydrocarbons there. A test drilled to 35,000 feet shoule penetrate any horizon or major structure that could possibie contain commercial quantities of hydrocarbons. Should shows of hydrocarbon be found in this first test, severab other deep tests in the area may have to be drilied.

In addition to testing for hydrocarbons, a deep test could provide a treasure of data concerning the regional cartonate aquifer and groundwatar below the proposed repository. Deep structural features may be revealed. Shot point tests in the weid couid help tremendously with deep seismic modeling of the area. 
Alan K. Chamberiain

\section{REFERENCES}

Caneron, G. J., and A. K. Chamberlain, 1987, Reevaluation of late

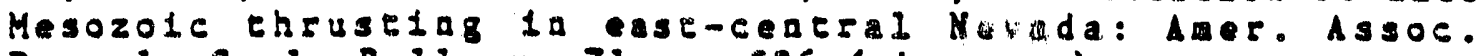
PeE501. Geol. BuIl. P. 71. P. 536 (abseract).

Cameron, G.J., and A. K. Chamberlata, 1988, Delinestion of late Mesozole ehrust bele la ease-centeal Nevada: Geol. Socieey

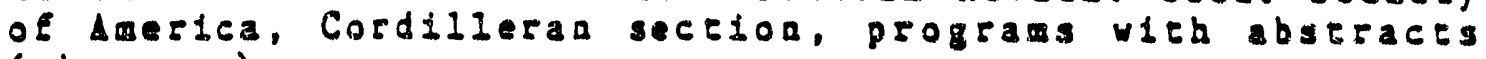
(abserace)

CEDAR STRAT, and Core Laboratorles, Iac, 1986, Anteler Basin Mississippian source rock seudy, unpublished geologie srudy.

CEDAR STRAT, 1984-88, Unpublished measured sections.

Chamberlatn, A. K., 1981, Biostratigaphy of the Great BIue Formation: Brighan Young Oniversitg Geology Scudies, $v$. 23 , PE. 3, P. $9-17$.

Chamberlain, A. R., 1984, Surface gamma-ray logs: A corfelation rool for frontieg areas: Imer. Assoc. Perrol. Geol. Buli. v. 68, P. $1040-1043$.

Chambelais, A. K., 1986, New Paleozole Eropeler play ta eascern Greac Basia: Amer. Assoc. Pecfol. Geol. Bul1. P. 70, p. 572 (absesact).

Chamberlata, A. I. 1987. Depositional eavironaents and hydrocarbon oceurrence of Mississipplan dater Basia, Mevada and Ueah: Aaer. Assoc. Petrol. Geol. Bul1. v. 71, p. 537 (abseract).

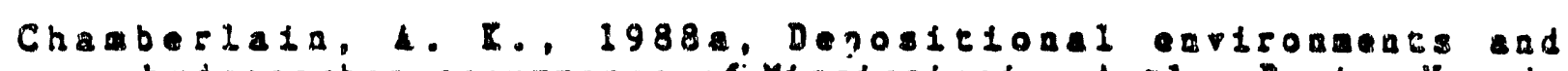
hydrocarbon occurrence of Hissiseippiar Aneler Basin, Mevada and Ueah: Geol. Socterg of dariea. Cordilleran section, programs iteb abseracts (abitract)

Chamberla1a, A. K. 1988b, Petolend exploration 1a Merada, then and nou: Geol. Soclery of darrica. Cordilieran aceior. grograss with bastaces (abacract)

Chamberla10, A. I., ard Gerald L. Handers, 1984, Proliaiary scudy of paljaomorpha and ocher Eoesils frot Hississippian clasele sedineacs, Aacler Basin. Larada and Deab: Maer. Assoc. Petrol. Gaol., . 68, p. 462 (abetrace) 
Chamberlaia. A. R., and C. B. Scote, 1987, Possible Relatioas Between Mississippian Aneler Mounsain Fluvial Systems and Tereiary Disseminated Gold Deposics ta che Eascera Greac Basin: Utah Geological Association Guldebook, in press.

Ekren, E.B., R.E. Aaderson, C.L. Rogers, and D.C. Moble, 1971 , Geology of aortbera Nelils Alr Foree Base Bombiag and Gunnery Range, Nevada: U.S. Geol. Surver Prof. Paper 65.

Fisher, W. L. and J. H. HeGowen, 1969, Depositional syscems ia Wilcox Group (Eocene) of Texas and their relation to occurgence of oil and gas: $\triangle A P G$ Bulletin, r. 53, p. 30-54.

Gueschick, R. C. and C. A. Sandber8, 1983, Mississippian concinental margins of the conterminous United Staces: SEPM Special Publication No. 33, p. 79-96.

Hincze, L. F., 1973, Geologic history of Utah: Brigham Young Universicy Geology Scudies v. 20, pe. 3, 181 p.

Nevada Scour, 1986, Nevada Scout Souree Rock Coupilation, unpublished seudy.

Orkild, P.P., 1963, Geologic ap of the Tipplpah Spriag quadrangle. Nye County. Nevada: U.S. Geol. Surveg Geol. Quad. Map GQ-213.

Orkild, P.P., 1968, Geologic map of the Mibe Mountain quadrangle, Nye County. Nerada: J.S. Geol. Surrey Geol. Quad. map GQ746 .

Poole, F.G., 1974, Flyscb deposits of Antler foreland basia, westera Uated Staies, in Dickenson. W. R., ed. Tectonics and sedineaticion: Soc. Bcon. Paleontologists and Migeralogists Spec. Pub. 22, p. 58-82.

Poole, F.G., F.N. Bouser, and P.F. Ork11d, 1961, Bleana Formacton of Nerada Teac Site ad Vicinity, Nye Coraty. Nerada. in Geological Survey researeh 1961: U.S. Geol. Surver Prof. Papes 424-D, D. D104-D111.

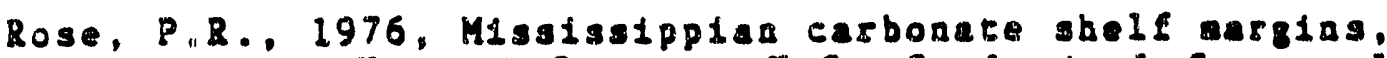
Wescera Oafted Staces: U.S. Geological Susvey Jourad of Resereh, $\nabla .4$, so.4, P. 449-466

Sandbe58, C.A., 1976, Conodont biofacies of lnace Devonian Polygnachus serelacus Zone in wastera Onted Staces, in Baraes, C.R.. ed. Conodone paleoecology: Geological Associacion of Canada Special Paper 15, p. 171-186 
Alan K. Chamberiada Progress Repore Januagy-May, 1988

Saadberg, C. A. and E. C. Guescbiek, 1980, Sediaeneacion and bioseratigraphy of Osagean ad Meramecian searved basia ad Foreslope, Wosera Jaiced Szates, Ia Fouch, T. D., and Magathan, B. R., ads.. Paleozole paleogeography of vestcencral Jaited Scates: Societ of Bcononie Balooncologists and Mineralogists, RockJ Mouneala Section, Wast-Ceacral Uatced Staces Paleogeography Symposium 1, p. 129-147.

Scoet, C., and A. I. Caamberlata, 1987, "Blackbura Eleld, Nevada: a case history," 011 and Gas Journal, August 17, 1987.

Waples, D. W.. 1985, Geochealserg 1n Persoleun Exploracion: International guman Resources Developaent Corporation, Boscon, $232 \mathrm{p}$.

Wilson, B. R. and S. W. Laule, 1979, Tectorics and sedimentation along the Aatler Orogenic Belt of central Mevada, in Newman, G.W. and H. D. Goode, eds., 1979 Basin and Range Sgaposium: Rocky Mountain Association of Geologists and Utab Geological Association, p. 81-92. 
GEULHEH SAMPLES MESA SMHPLES

BUCH 53

DVCH 71

Mat log

MSล 1 เด̉

OSB 303

OSE 311

และ 119

ERis 13!

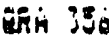

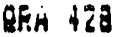

ein 5.59

Qhit 5 it

$\operatorname{lin} 540$

QRH 793

RMCS ISU

TS6i 235

ए5बi \$12

\566 335

isRe is

TSRC II

TSRC 25

TSRE 83
BHTS जos

हMTL Uं।

inte 128

DUCh O

ovci 93

BUtre to

MSR ivis

HSR Uं25

Mấ lús

MSR 127

HSR 163

QRin 190

เกล 224

QRA 279

QRA 30 Q

QRA $40 \%$

QiिA 412

QRi 549

Chi 570

QRA 580

QRA SUO

ORA 624

ORA TIS

20A 757

CRA $T B 0$

ancs coo

ancs 018

PMCs 099

ancs 109

RMCS 203

amcs 236

Rucs 268

anT COS

BMT 103

RHT 161

oxi 217

TSeC OLS

TSeE 135

TSEC 149

TSes 243

TSES 295

T554 نิs

T5E्त IIJ

T564 142

TSRC نेl]

TSAC 028

Tริke 053

ISER 125

TSRC 175

TSRC 450

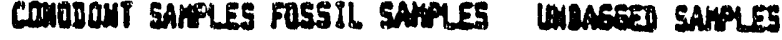

$\operatorname{nsth} 0$

274

125

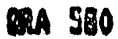

4

ISP 105

ORA 789

apd 728

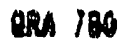

1556165

Tric 053

TSAC 129

$\operatorname{TshC} 175$

resces 84

TSEC 165

TERT 17

101

119

125

128

213

235

279

433

452

495

550 


\section{SOURCE-ROCK EVALUATION}

\section{FIVE OUTCROP SARPLES}

Exlog/Brown \& Ruth Laboratories, Inc. 
Cedar serat

P. $0.80 \times 8909$

24 Mareh 1988

Reno, Nevada 89507

Attention: Mr. Alan Chamberlain

Dear Mr. Chamberlaln:

The attached data were obtalned on live outcrop samples supplied by your company. Total organic carbon (TOC) values range from average $(1.05 \%)$ to very low $(0.04 \%)$. The rocks have no potential to generate hydrocarbons as indlcated by their minimal pyrolysis 52 yields. Furthermore, very low Rock-Eval sl yields indicate that the rocks contain little bitumen.

Vitrinite reflectance and thermal alceration index (TAI) data show that sample STS 42 has passed the maturity levels associated with the main phase of oll generation and is presently at a level equivalent to the beginning of condensate generation. Sample sme 287 lies between the stage of condensate generation and the overmature zone. Siample SME 300 lias between the last stages of oil generation and the main stage of dry-gas generation. Unfortunately, it was not possible to estimate the maturity levels of samples QRA 93 and CHA 0 due to very poor organic preservation.

With the possible exception of sample sTs 42 , it is very unlikely that any of the sarnples has generated signiflcant quantities of hydrocarbons durlng maturation. Sampla STS 42 has a marginal TOC content and could have had some minor source potential at lower maturation levels. It should be polnted out that weachering may have reduced the organle carbon and praservation levels of the samples to some degree as modern bacterla were abundant in QRA 23. 
Extog/Brown and Ruth laboratorles is plessed to have been of servlce to Cedar strat. If you have any questions regurding the results please contact thls offlce.

Yours truly,

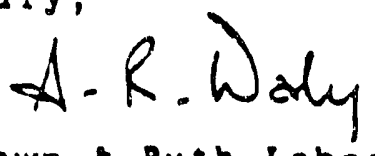

Exlog/Brown \&uth Laboratorles, Inc.

A Ian Da!y 
Results of Total Organic Carbon Aralysts and Rock-Eval Pyrolysis

\begin{tabular}{|c|c|c|c|c|c|c|c|c|c|}
\hline $\begin{array}{l}\text { Sample } \\
\text { Number }\end{array}$ & $\begin{array}{l}\text { Depth } \\
(f t)\end{array}$ & $\begin{array}{c}\text { TOC } \\
(w t . \%)\end{array}$ & $\begin{array}{c}s 1 \\
(m g / g)\end{array}$ & $\begin{array}{c}\mathrm{sz} \\
(\mathrm{mg} / \mathrm{g})\end{array}$ & $\begin{array}{c}\mathrm{s3} \\
(\mathrm{mg} / \mathrm{g})\end{array}$ & $\underset{\left({ }^{\circ} \mathrm{C}\right)}{T \max }$ & $\begin{array}{l}\text { Production } \\
\text { index }\end{array}$ & $\begin{array}{l}\text { Hydrogen } \\
\text { Index }\end{array}$ & $\begin{array}{l}\text { Oxygen } \\
\text { Index }\end{array}$ \\
\hline $6419-001$ & STS 42 & 1.05 & $<0.10$ & $<0.10$ & 2.34 & 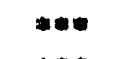 & $\infty$ & $-\infty$ & 223 \\
\hline $6419-002$ & QRA 93 & 0.07 & $<0.10$ & $<0.10$ & 0.15 & $m$ & - & $\cdots$ & 218 \\
\hline $6419-003$ & SME 287 & 0.44 & $<0.10$ & $<0.10$ & 0.36 & $m=$ & $\cdots$ & $\cdots$ & 82 \\
\hline 6419-004 & SME 300 & 0.14 & $<0.10$ & $<0.10$ & 0.22 & 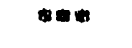 & - & -- & 159 \\
\hline $6419-005$ & СНА 0 & 0.04 & $<0.10$ & $<0.10$ & $<0.10$ & 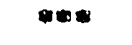 & $-\infty$ & $\cdots$ & 152 \\
\hline
\end{tabular}

- Unable to determine due to insulficient 52 yiald, multiple peaks, etc. 


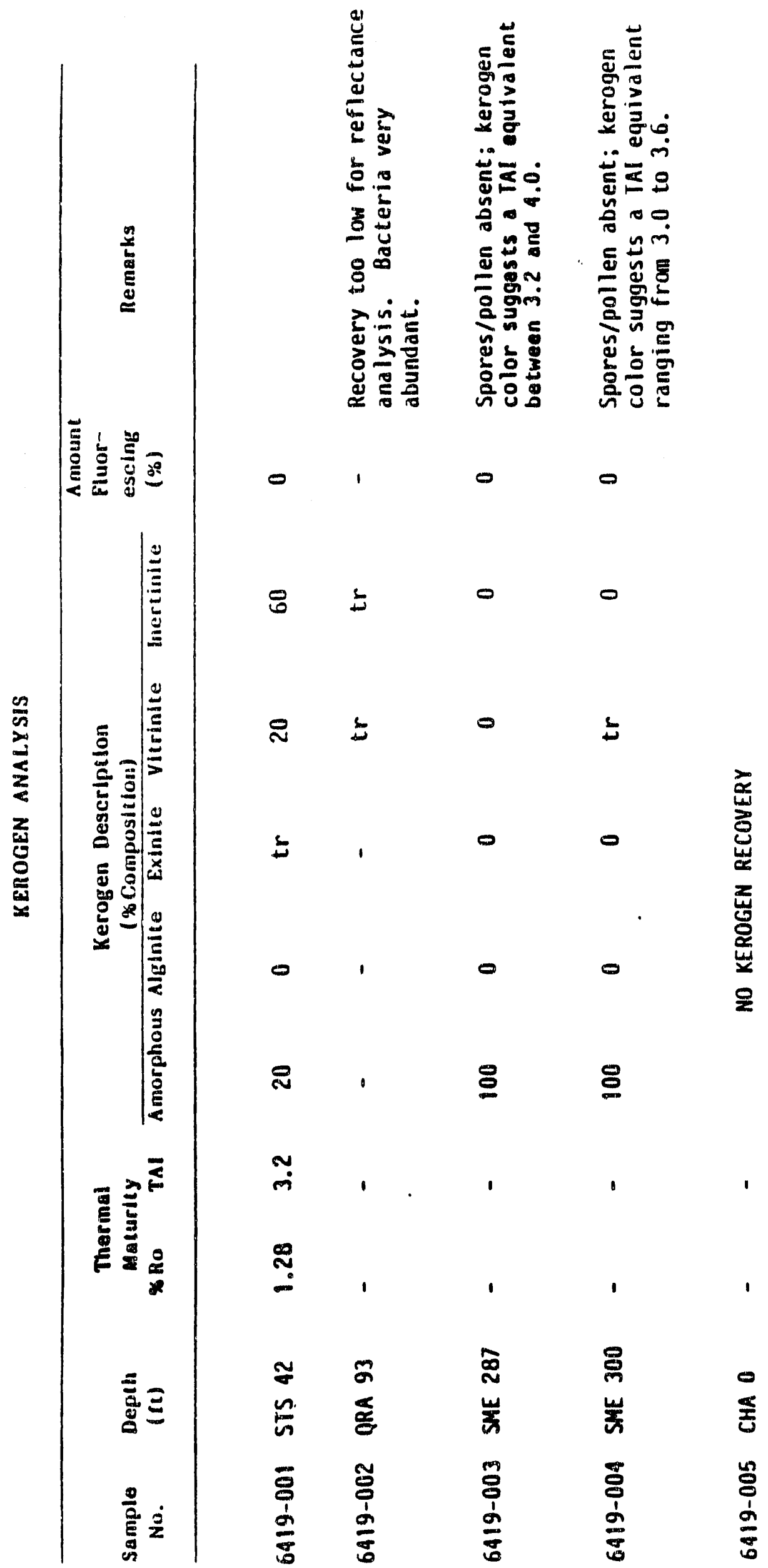


SAMPIE NUMBER. 6419-001

COMMENT....... STS 42

DEPTH.

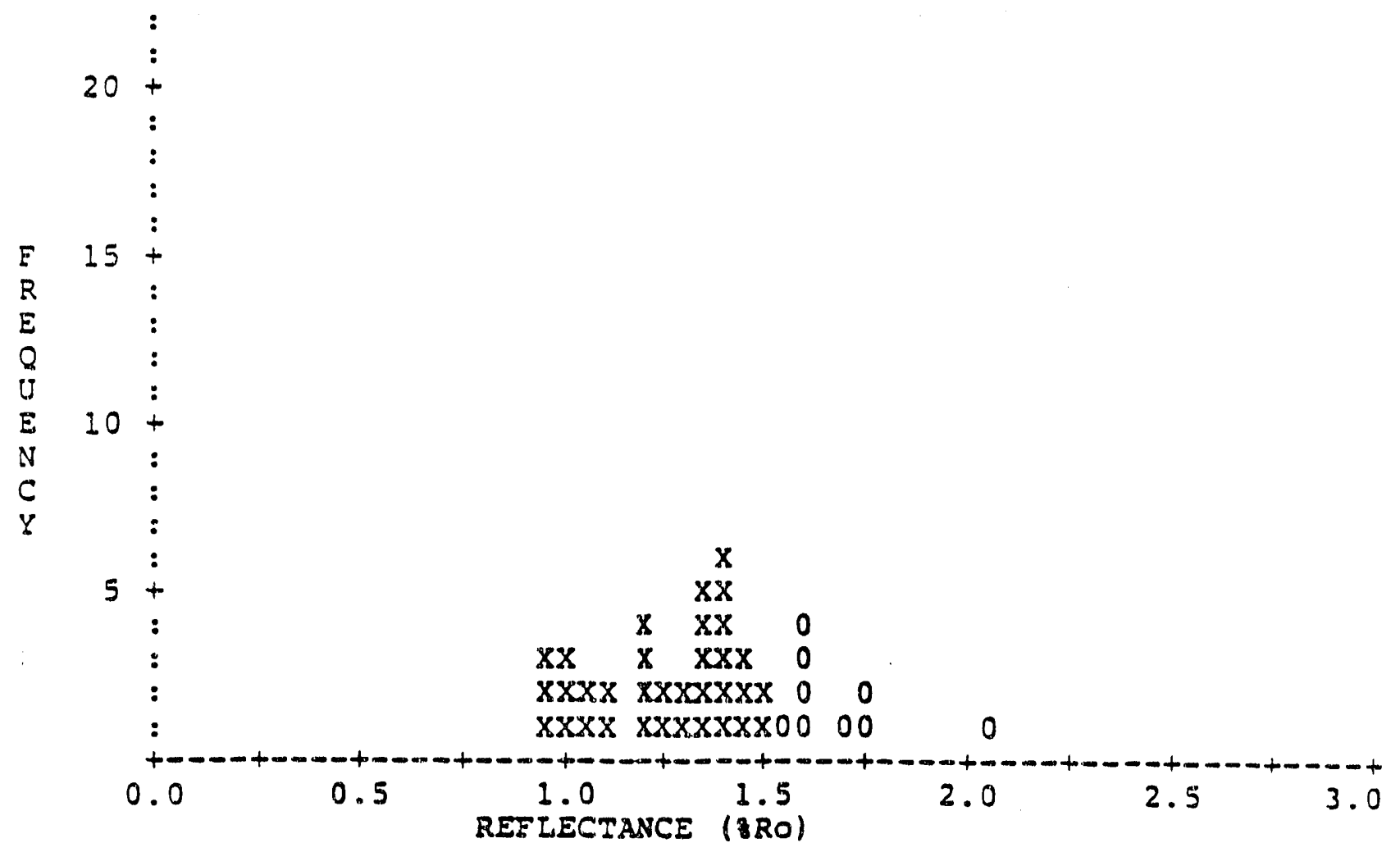

POPULATION GROUPS

\begin{tabular}{|c|c|c|c|c|c|c|}
\hline $\begin{array}{c}\text { EOP. } \\
1 \\
2\end{array}$ & $\begin{array}{c}\text { COUNT } \\
34 \\
9\end{array}$ & $\begin{array}{c}\text { MIN. Ro } \\
0.99 \\
1.56\end{array}$ & $\begin{array}{c}\text { MAX. Ro } \\
1.54 \\
2.06\end{array}$ & $\begin{array}{c}\text { STD. DEV. } \\
0.172 \\
0.139\end{array}$ & $\begin{array}{c}\text { MEAN RO } \\
1.28 \\
1.70\end{array}$ & $\begin{array}{l}\text { COMMENT } \\
\text { INDIGENOUS }\end{array}$ \\
\hline
\end{tabular}

$\mathrm{X}$ denotes readings interpreted as indigenous 


\section{VITRINITE REFIECTANCE EISTOGRAM}

SAMPLE NUMBER. 6419-004

COMMENT...... SME 300

DEPTH.......

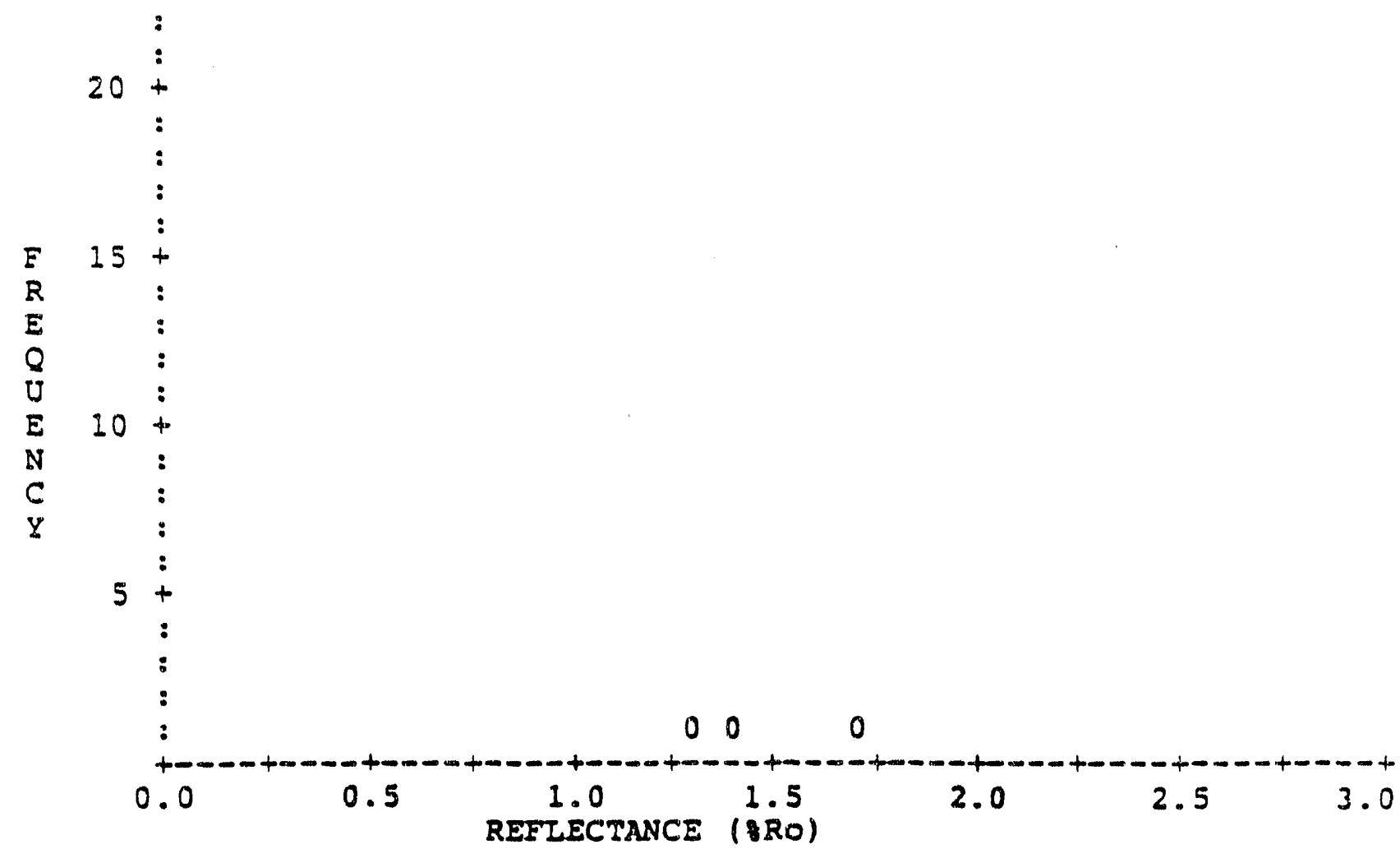

POPOLATION GROUPS

$\begin{array}{ccccccc}\text { POP. } & \text { COUNT } & \text { MIN. RO } & \text { MAX. RO } & \text { STD. DEV. } & \text { MEAN RO } & \text { COMMENT } \\ 1 & 2 & 1.32 & 1.12 & - & 1.37 & \\ 2 & 1 & 1.74 & 1.74 & - & 1.74\end{array}$




\section{ORDERED REELECTANCE VALUES}

SAMPLE NO.: 6419-001

$\begin{array}{lllllllllll}0.99 & 0.99 & 0.99 & 1.00 & 1.03 & 1.04 & 1.07 & 1.09 & 1.11 & 1.115 \\ 1.20 & 1.22 & 1.22 & 1.24 & 1.25 & 1.28 & 1.34 & 1.34 & 1.35 & 1.35 \\ 1.37 & 1.38 & 1.38 & 1.41 & 1.41 & 1.42 & 1.43 & 1.44 & 1.44 & 1.45 \\ 1.47 & 1.48 & 1.52 & 1.54 & 1.56 & 1.62 & 1.63 & 1.63 & 1.64 & 1.70 \\ 1.75 & 1.75 & 2.06 & & & & & & & \end{array}$

SAMPLE NO.: 6419-002

No measurable vitrinite

SAMPLE NO.: 6419-003

No measurable vitrinite

SAMPLE NO.: 6419-004

$1.32 \quad 1.42 \quad 1.74$

SAMPLE NO.: 6419-005

No measurable vitrinite 


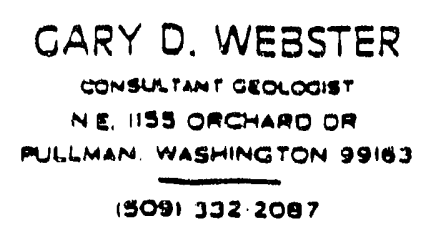

1 April 1988

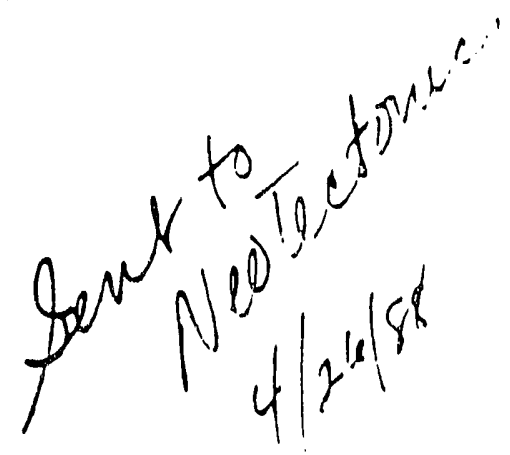

Mr. Alan K. Chamberlain

Cedar Strat

P. O. Box 8909

Renn. Nevada 39507

Dear Alan:

Ihe conodont analyses of the sin samoles that you sell are sumlliar is sis as:

Sile 45 No racovery

Si:E 109 Late Permian? more likely Triassic, see detailed report

Sivie 14i Mississippian, kinderhookian

Sive $200^{\circ}$ in recovery

Sile 221) No recovery

Sis 210 Pennsylvanian, Morrowan

The enclosed report sheets give the color alteration index, conodnnt identitications, and age analysis.

Sorry to be so slow with these but we have besn converting the heavy inimprill recovery itep to sodium metatungstate (a non-toxic) and [ reran all if youm samples when we got such low recoveries. The recoveries were gnod. as ith: rerun added no new specimens.

Charges for the andyses are 6 @ $\$ 90.00=\$ 540.00$.

We con have photos (SEx) of some of the conodonts taken if you desire thrili. Cosc will be apprnximately \$75.00. There are only 3 of the specinens it sufficiently good preservation to be photographed.

I will keep the specimens unless I hear from you that you want them retlipliec.

Sincerely,

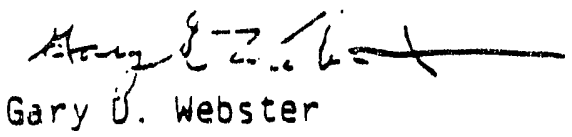




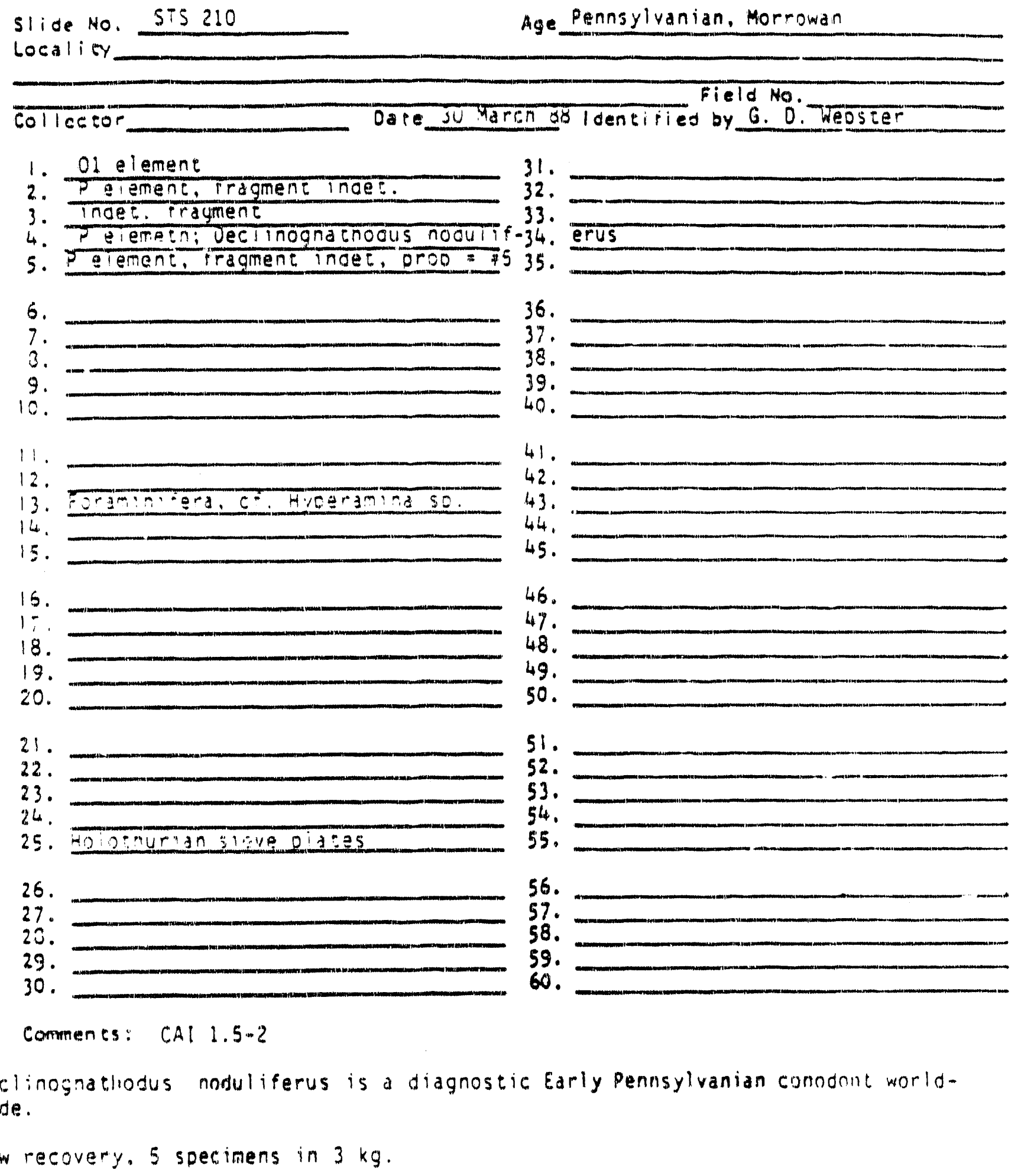



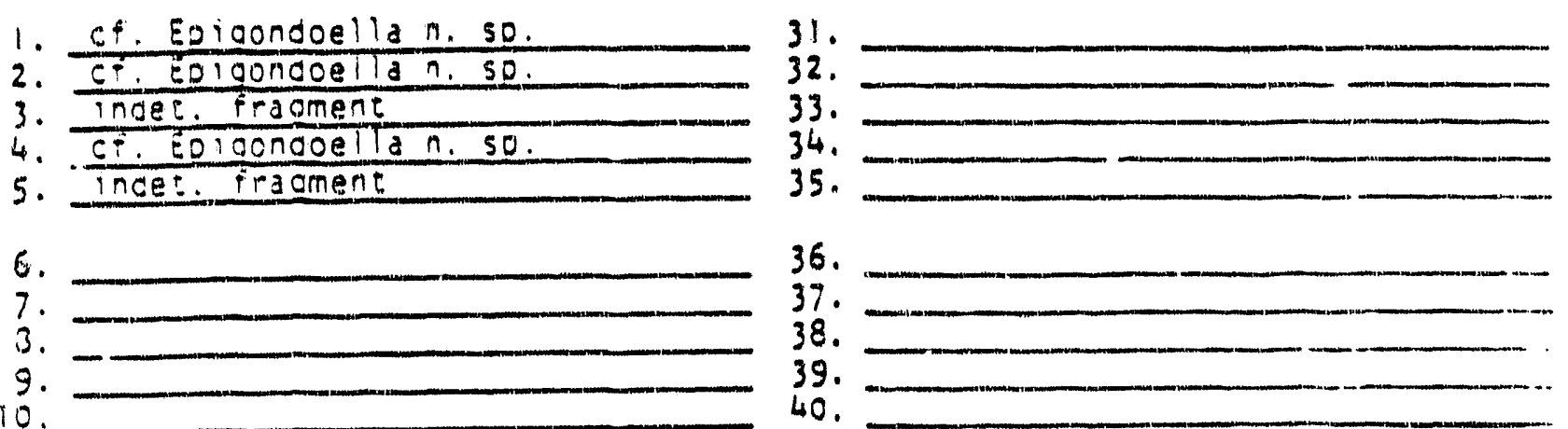

36. 37.

38.

39. 40.

11.

12.

13.

is.

15.

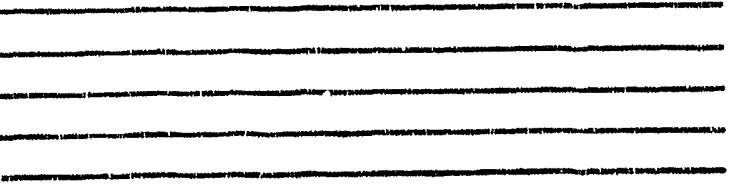

41. 42.

43. 44.

16.

17.

18.

19.

20.

45.

21.

22.

23.

24.

25.

46.

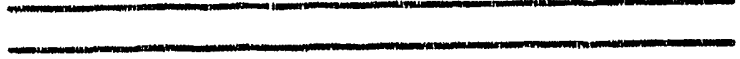

47.

48.

49.

50.

51.

52.

53.

54.

55.

26.

27.

23.

29.

30 .

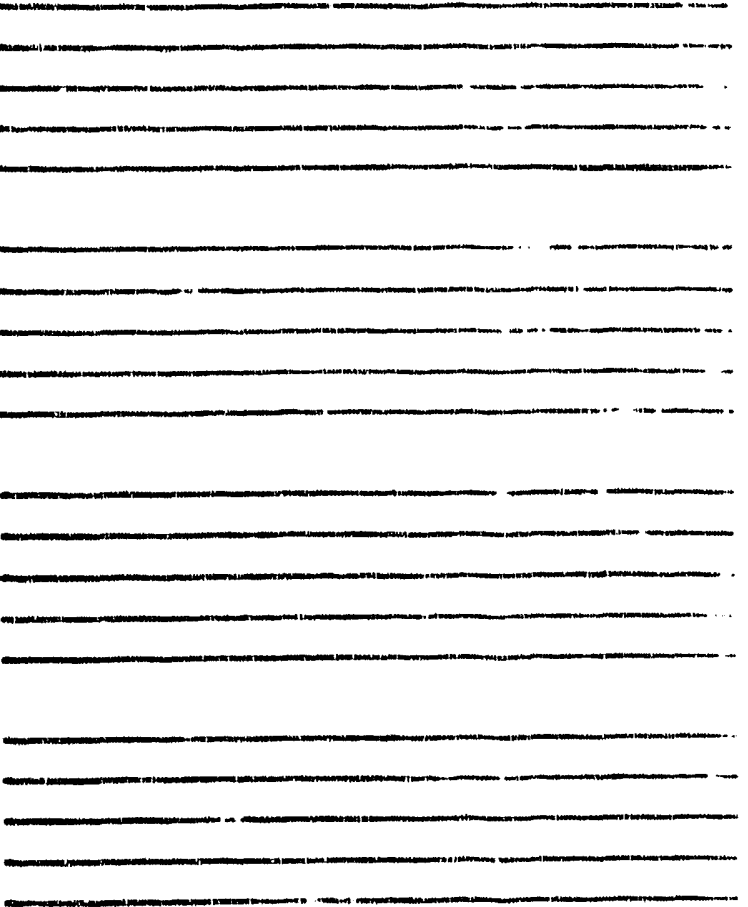

\section{Commenes: CAI $3-3.5$}

These specimens ( $1.2,4)$ represent advanced gondoellids, perhaps a new genus, clearly new species. They could be of Late Permian age but more likely are of Triassic, Middle to Late, as they show some norphologic similarity co Epigandoellids with widely expanded platforms with secondary denticles on the platforms as rported from Middle and Late Triassic rocks by Kovacs and Kozur, 1980.

Low recovery 5 specimens in $3 \mathrm{~kg}$. 
Slide No. $\operatorname{SifF} 147$

Collector

Date 30 yareh 88 ldencitied by G. D. Weoster

1. Q1 element

2. Ol elament

3. Pelement Polvanathus inornatus

4. $Y$ alamant

5. Aialament

31.

32.

33.

34.

35.

6. A3 elametn

7 .

3.

9.

10.

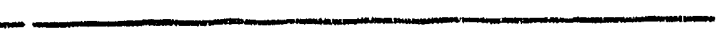

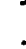

11.

12.

13.

inco- fracriment

14. inget fracmemt

15. Vennriaminalic en

15. Dianoriomindice on

16.

17.

18.

19.

20.

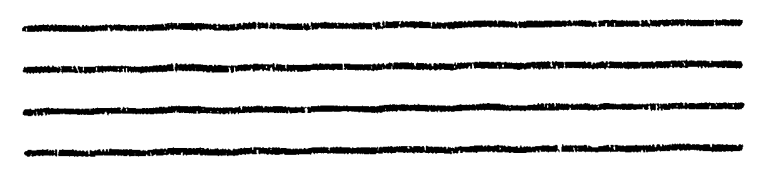

36.

37.

38.

39.

40.

$4 i$.

42.

43.

44.

45.

46.

47.

48.

49.

50.

21.

22.

26.

25 .

51.

52.

53.

54.

55.

26.

56.

27.

23.

29.

30 .

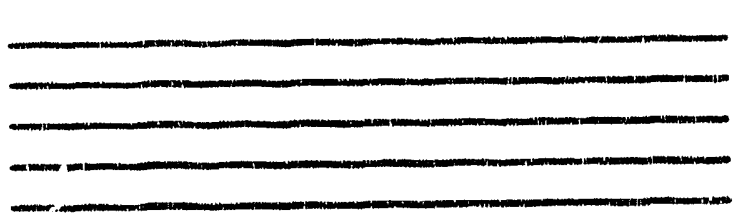

57.
58.
59.
60.

Comments: CA! $4-4.5$

Specimens 1-6 represent elements of the the asseblage pol ygnathus inornatus; only the $\dot{a} 2$ element is lacking. The $p$ element is priarily used for the identification. $P$. inornatus is a comon Kinderhookian form in M.A.

The recovery is low, 12 specimens in? $\mathrm{kg}$. 
Waanders Palynology Consulting, Inc.

16L:- R Rancho Sunia fe Rd.

San fulsecos. Calilornid 92069

(619) $744-7 \leq 71$

Eebruary 1, 1988

ro: cedar stzat

P.O. $30 \times 3909$

Renc, Nevada 89507

RE: OUt: $=0 p$ Samples Received 1-22-38

STS T2, ZRA 93, SME 237, S:IE 300, and CIIA $O$

\section{PALYXOLOGI RE?ORT}

A tota: os $;$ outcrop sampies weze procesied and analyzed for palyomozphs. Each sample is listed individually in the pages that soliow oy sample number along with the taxa fourd and best fossibie age and paleoenvizonment that can be assigned.

\section{ORGANIC MAIUPATION REPORT}

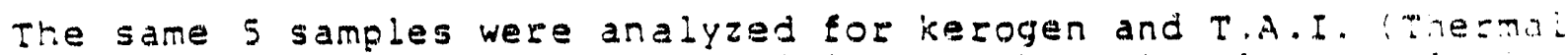
A iteration Index) values in addition to the palynology aralysis in order to assist in the determination of source rock potentinl.

The pages that jollow list the samples by number and they provide the total organics recovered, qualitative visual keroger est imand and T.A.I. valies along with the palynology data. As a genezil rule voody kerogens are primarily gas generating hereas condorsates arid higuids are the products of cuticular and amorphous kerogens. T.A.I. values are considered to be at peak liquid generation a": a value of 2.5 poak gas gelleration begins at a T.A.I. value of 2.8 and continues to 3.7 . All kerogens become gas generating sources at T.A.I. values greater than 3.0

ANALYSIS BY:

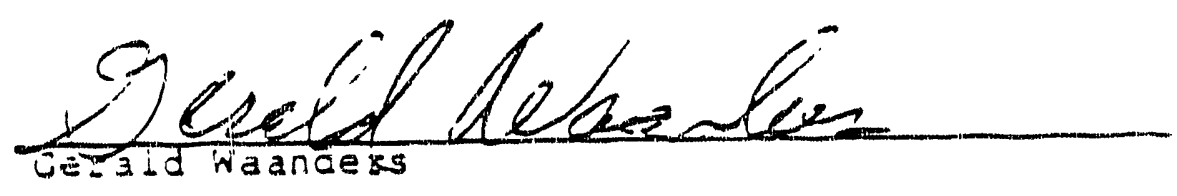


P.E: Cedaz $5=z 36$, Misc. OLEz=00 Spls, Rec'd. 1-22-38

1. Samal.e \$5T5 42

$$
\text { spores and pollen: }
$$

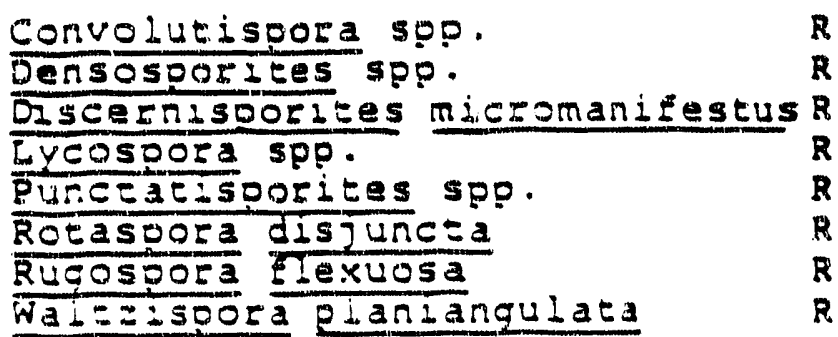

ACE: Mississipoian, Probable osagian to Meramncian

ENYTRONMEVT: Nonmazine, Swamp to Lacusteins

$$
\text { Ozgaric Recovery: } .30 \mathrm{mls} / 20 \mathrm{~g}
$$

Kezogen Tyoe:

$\begin{array}{ll}\text { Woody: } & 403 \\ \text { Cutichla: } & 103 \\ \text { Amorphous: } & 503\end{array}$

$$
\text { T.A.I.: } 2.6-2.7
$$

2. Samole \#nga 93

Spores and polien:

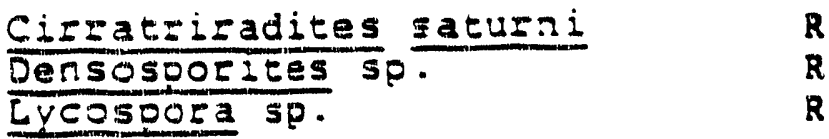

AGE: Mississipoian. Probable Chesterian

ENVIRONMENT: Nonmarine

Organic Recovery: Trace/log.

Keroger: Type:

Inertinite: 508

Woody: 258

Cuticulas: 253

T.A.I.: 2.5

3. SaMPle SME 287

spores and pelien:

Eycosoora spp.

Convolueisoora sp.

$\mathbf{R}$

$\mathbf{R}$ 
Re: Cedaz St:3t, Misc, Outc=op spis. Res'd. $1-22-38$

3. Sanpla SME 287 (con'te.)

AGE: Carboniferous, Undifferentiated

ERIVIRORMENT: NOREsine to Lacustrine

Organis Recovery: Trace/log

kisogen Tyom:

Woody: $\quad 5$ के

Cuticular: 53

rnicrphous: 908

I.A.I.: 2.3

4. $\quad 5.1-12=15 \sin 302$

spcses and palien:

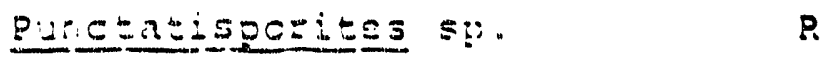

AGE: Cazنo::ifersus, Undiffersn:iated

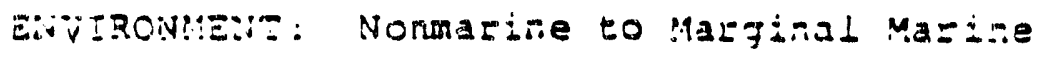

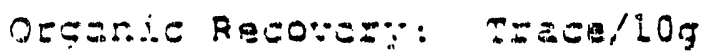

หre=nge: T: T:E:

Amorflicus: L $100 \%$

T.A.I.: : Z.

5. Samp La CHA O

Bazzin of balyromsegl:s

Aris: Indatermunate

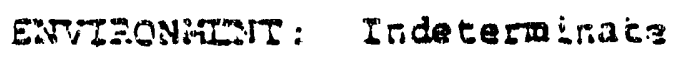

Degari $i=$ Pecoser $;:$ Traca,log

n̈erogen rype:

[ne:tinize: 913

fiocdy: 5 ?

Cuticula: : j;

T.A.I.: 2.3-2.5 


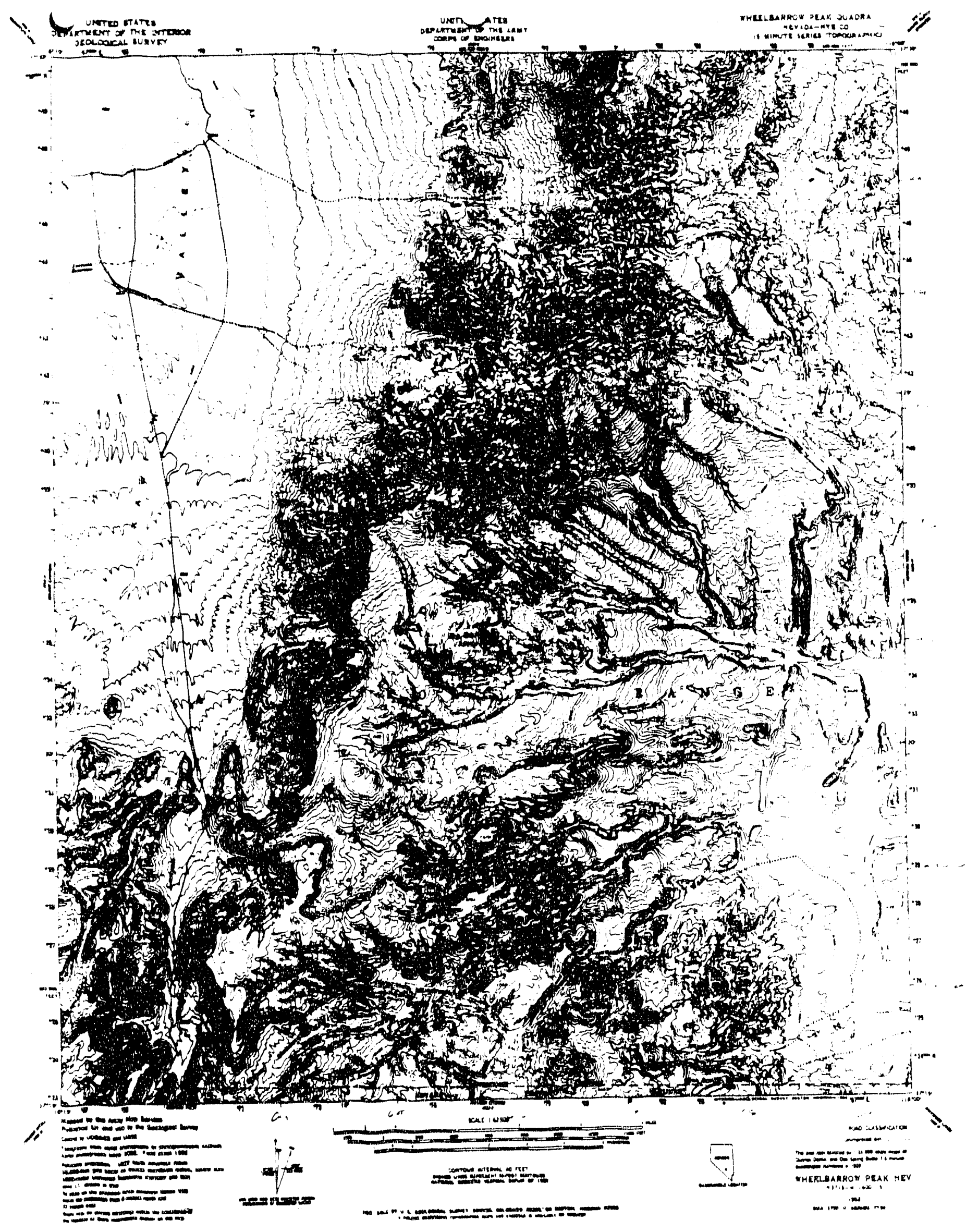




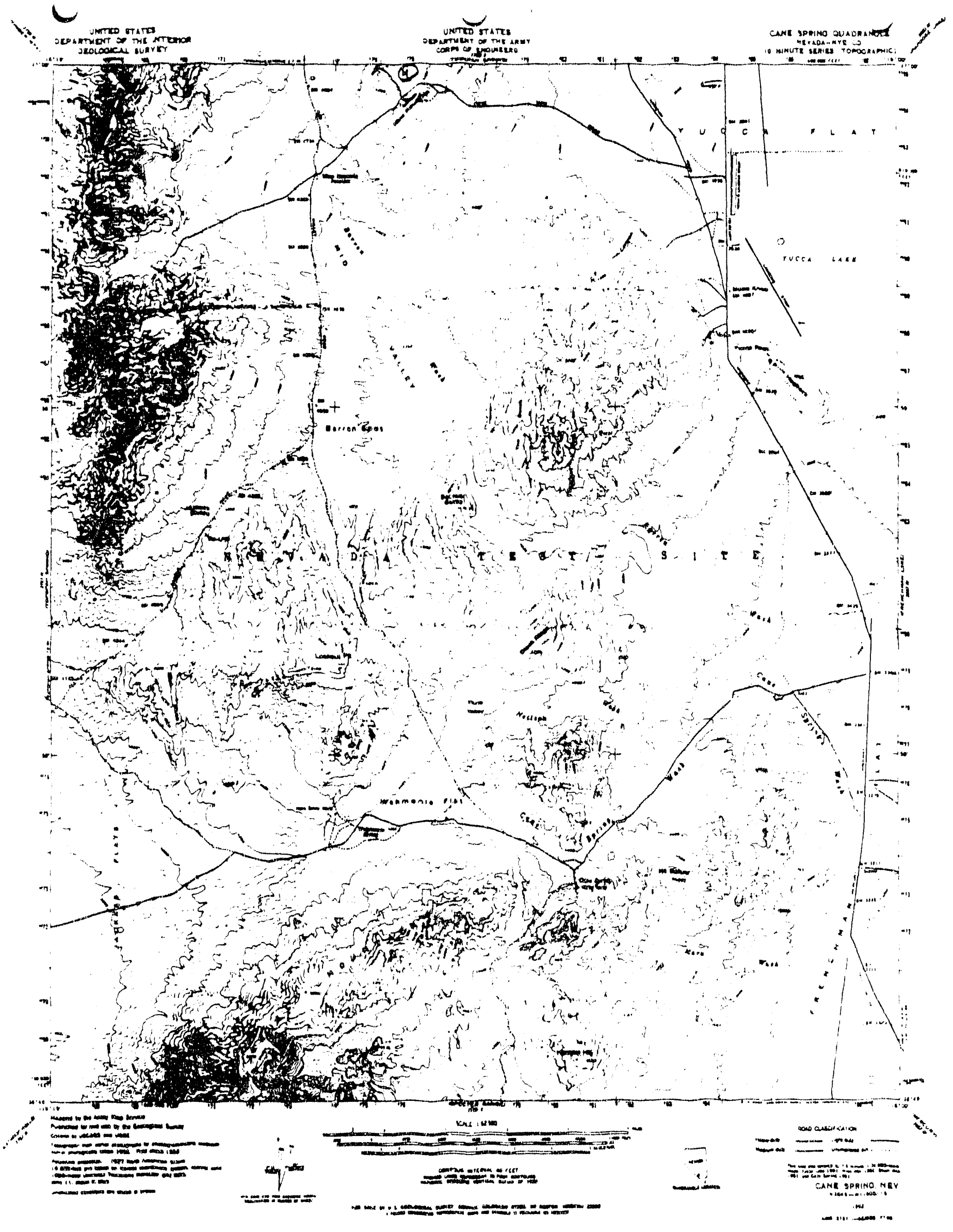




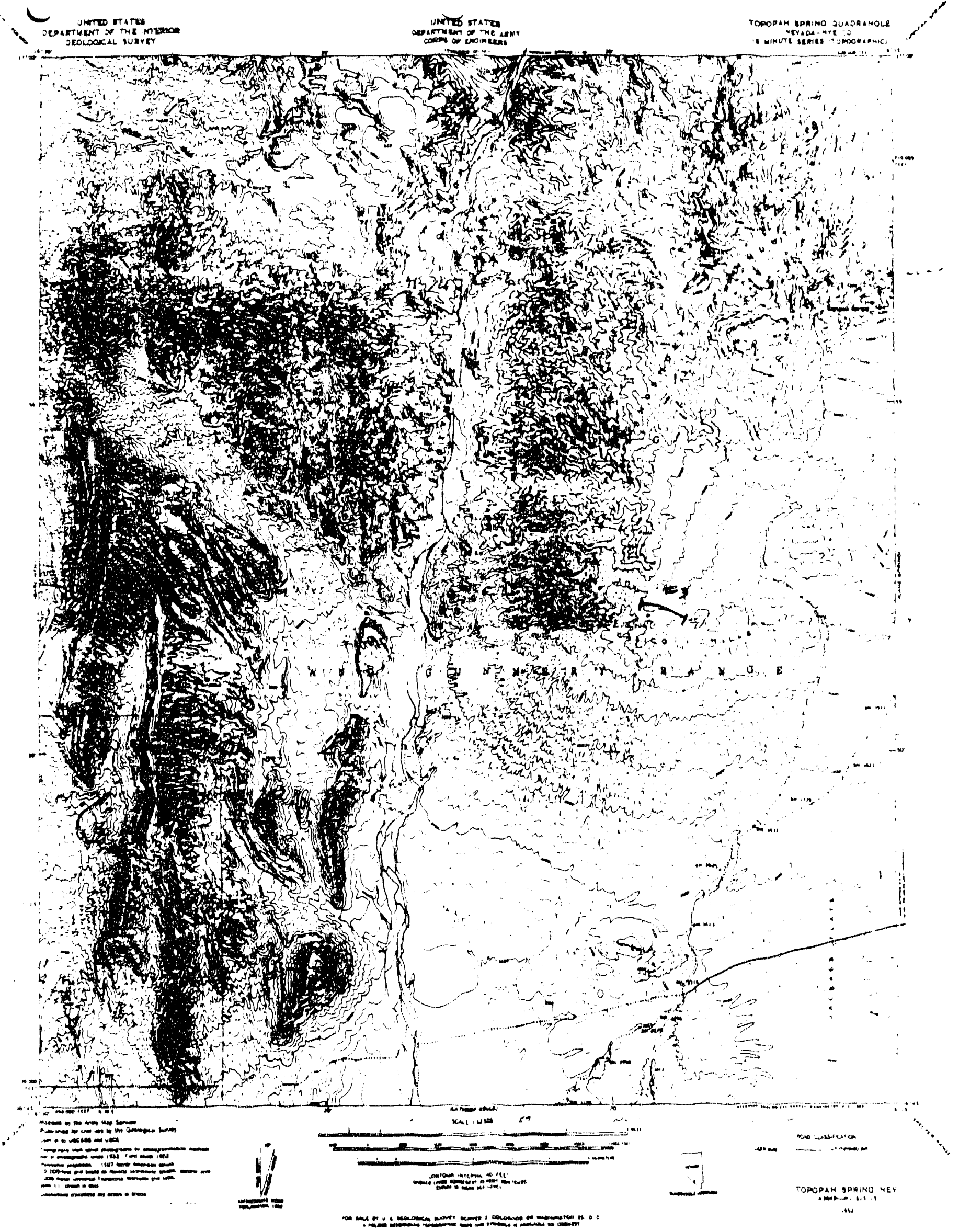




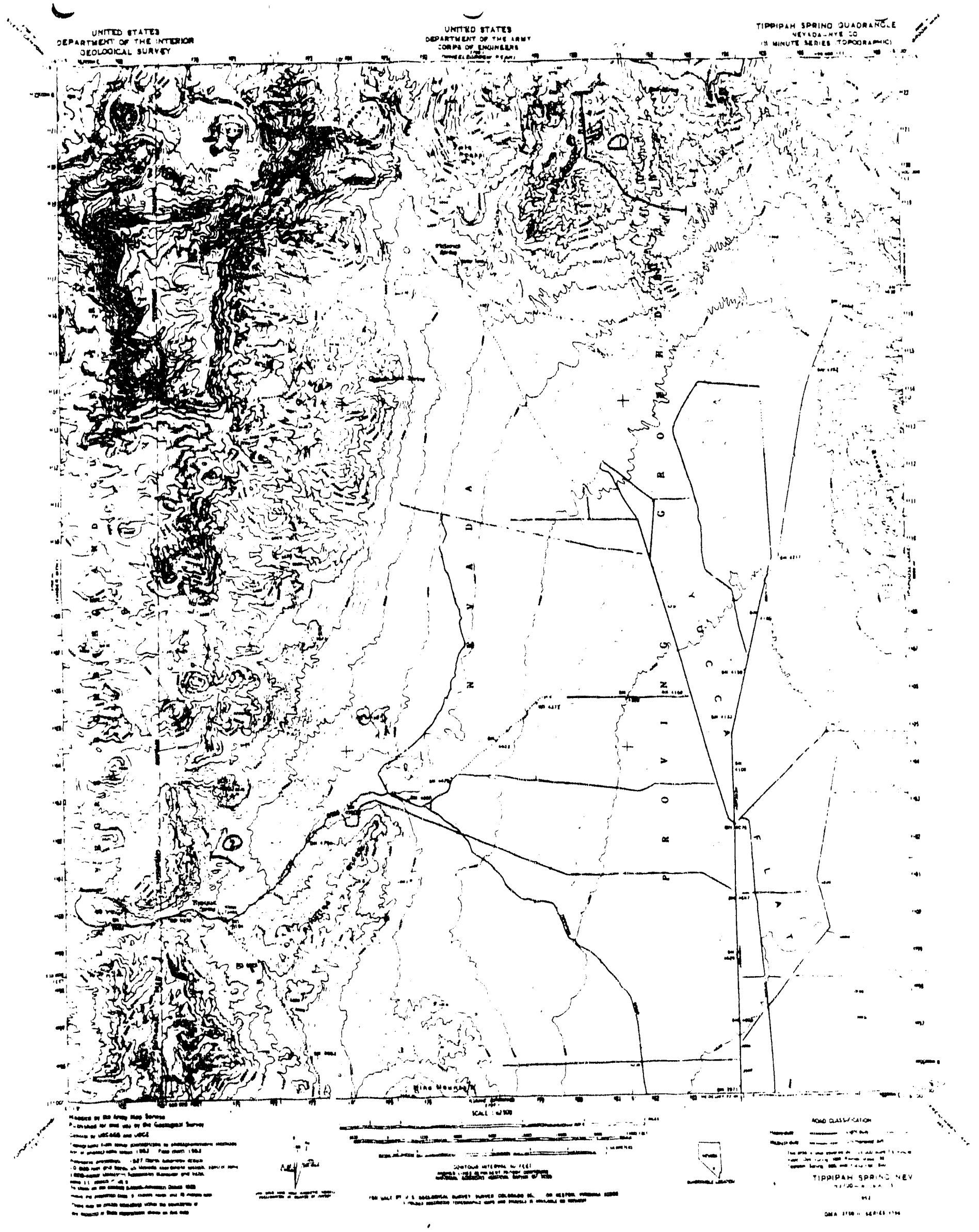




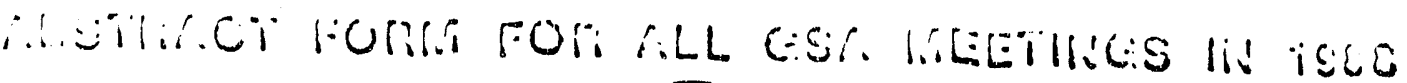 Comptote sections 1 inrough 2 ]}

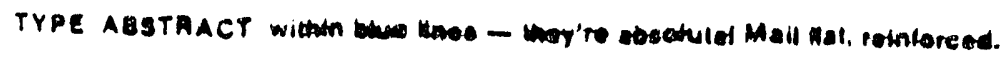

\section{No $\quad 3355$}

\section{DELINEATION OF LATE MESOZOIC THRUST BELT IN EAST-CENTRAL}

CAMERON, Greg, 516 Ward, Martinez, California, 94553.

CHAMBERLAIN, Alan R., CEDAR STRAT, PO Box 8909 , Reno, Nevada, 89507.

The Railroad Valley and Pine Valley oil fields of eastcentral Nevada occur along the frontal eastern margins of a north trending belt of thrust faulis believed to be wholly or partly Cretaceous in age. This structural belt, herein termed the east-central Nevada thrust belt (ECNTB), is recognized as far north as Elko County and as far south as Clark Colinty. Scructures within the belt included lowangle faults which juxtapose older Paleozoic miogeoclinal rocks on top of younger Paleozolc miogeoclinal rocks. In large scale recumbent folds, involving rocks as young as Triassic in age, both fault and fold geometry suggests eastwardiy directed transport.

The ECNTB believed to be Cretaceous in age, based on the depositional relationships of the early Cretaceous Newark Canyon Formation in the northern part of the belt and an unnarad Cretaceous to Tertiary (?) congloderatic unit in the southern portion of the belt. Both of these inits appear to be synorogenic sediments deposited within and in front of the advancing thrust sheets. The thrusting event was completed by Oligocene tine, as indicated by field relationships involving the unconformitg beneath the earliest Tertiarg ignimbrites. Throughout the ECNTB the eastern most exposed thrust juxtaposed Devonian Carbonate reservoir rock on top of Mississippian clastic source rocks and collectively thrust faults have telescoped the western margin of the Mississippian aged Antler Basin.
2

CATEGOAIE ALL ABSTAACT - Check one dioctoune bolow whien reviewers wovid bo quelthed to evaluste this ebuliect.

D 1 archerotogical geotooy

- 2 coel geosony

- 1 aconamie geotogy

a engineering georoar

a 5 environmeniel geology

D genoral geolooy

D geochemisiry

- geologr oducalion

- 9 geomorpnology

Dlo geopnyacs

Dit georcience intormation

012 glacial geology

013 hisiory of geolooy

Di4 nydrogeology

Q15 marine geology

016 microdulaniology

017 minar logy/erysullography

Q18 ocenogreany

Q 10 Delooniology/ouleobouny

Q20 Detroloum goolooy

021 petrology, experimental

Q22 Detrolooy. igneous

Q23 Dulrology. malamorohic

D2A Deliolegy. sedimenury

D25 Dienetury godogy

Q26 Precamorian goology

027 Quaternary goology

Q2s remole sansing

029 sodimentalagy

口30 stralloradny

031 structural geolony

D32 locionics

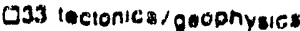

a34 volcanology
TIPES OF EESSIONS AVAILABLE

A. SPECIAL - INVITED ABSTAACT FOA A SYMPOSIUM. $\square$ This abstract was inwled for the symposium dtted

If you choeked nore. skip to item 4

G. VOLUNTEERED ABSTRACTS

(1) SPECIAL-THEME SESSION. ANNUAL MEETING ONLY. I would like inis uggtract conadored for oral presentation the following Theme Sesaion for the Annual Meeting. Denver, 1988.

D 1 Dingenegis of lecustrine rocks

Q 2 Geology \& Public Policy lor the 21 is Century

D 3 Geophysical partern in North America

- Alobal aspects al secimentiry geology

o 5 Orgunic compounde in ground water

O - Pateontologic constranie on accieted hurraner

O 7 Physics and chemistry of myionites

- Secular variation in in ceamentery record

If not eccepted for the Theme Session. do you want it considered for a regular lochnical session?

a Yes D No

(2) D ORAL SESSION D POSTER SESSION D ETHEA TYPE D I'll accept a change of session rypo (ORAL - POSTEF) il necessary.

- Withoraw iny aosiract cather than charige session ivpe is of this papea paEVIOUSLY PRESEITTED

Whare and when

5 CAN YOU OE A SESSION CHAIRISAIA? Y Yes

TODIC

Your nama

Tolephone (late Junu/early Juty)

6 SPEALEN'S IDEIITITY AI:O MLILIIIG ADORESS

Speaker's name

Addrass

Addrese

Ciry Suto

Zip

Couniry

Orile Telepprione:

Home rolephone:

Dates wo can reach you:

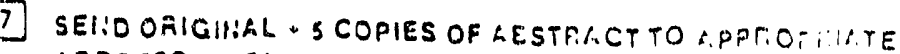
AODAESS SHOLiW OH INSTRUCTIOH SHEET AI:O OI: $1: C:$

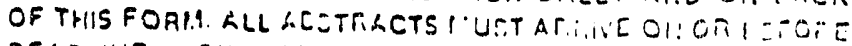
OELOLII:S SHOI:H: FOR C/ CHI'SCTHC 


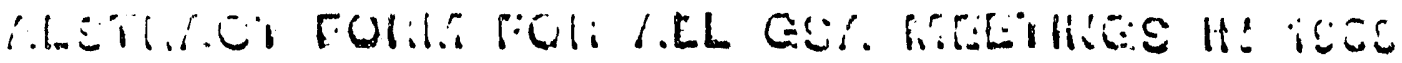

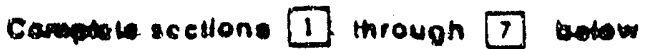

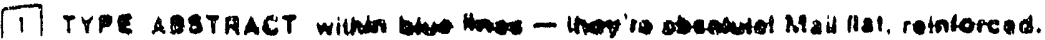

\section{PETROLEUM EXPLORATION IN NEVADA, THEN AND NOW \\ CHAMBERLAIN, Alan R., Cedar Strat, PO Box 8909, Reno, NV, 89507 .}

Serious petroleum exploration in Nevada is nearly forty years old with the mose significant advancements made in the last decade. Early exploration first centered on the Paleozoic sediments that were deposited in the Cordilleran Miogeocline. The focus of exploration seemed to have shifted from a Paleozoic to a Tertiary play after the discovery of Eagle Spring in 1954. Most holes drilled from then until the early 1980's stopped at the Tertiary unconformity. This pariod of exploration resulted in the discovery of the Trap Spring Field in 1976.

Discovery of Mississippian oil in Devonian carbonates at Grant Canyon and at Blackburn in the early 1980's has caused the focus of exploration to shift back to the more promising Paleozoic play. Several new developments that may guide the explorationists to new discoveries in Nevada include a better understanding of depositional environments of the Mississippian Antler basin and their relationship to source rock richness and maturation, depositional environrents of the Devonian carbonates and their

zlationship to reservoir trends, and the Mesozoic thrust oelt trend and its relationship to oil generation, migration and seructural traps.

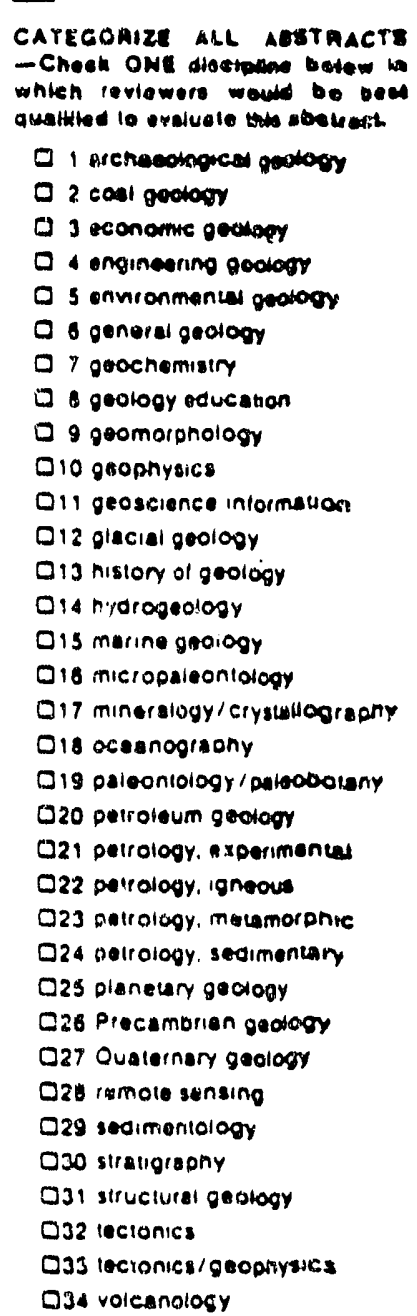

CAYECOAIZE ALL AeETRACTE - Cheeh ON drostane betaw hie which teviewers would bo beat D 1 prenecompoces gablosy a coul goologr

a 3 economic gealep Q o genoral gectooy

Q 7 oochemistry D 9 geomoronology D 12 glacial geolooy Q13 nistony of geology 018 micropaleontology Q 020 petroleum geology 21 petrotooy experimente Q24 nelrology, sedimentany Q25 planelary geclogy Q20 rumote sunsing 229 sedimeritology 032 tecionics 034 volcanology
3 TYPES OF SESSIOH:S RVALLALLE

A SPECIAL - INVITED ABSTRACT FOA A SYMPOSIUM. - This absiract was inwted lor ine symposium velod

If you checkeo nere, exid 10 ikem 4

B. VOLUNTEERED ABSTRACTS

(1) SPECIAL-THEME SESSION. ANNUAL MEETING ONLY I would like this Bbatruct considered for oral presentation at the following Theme Session for the Annual Meelling. Denver. 1988.

D I Diagenesis ol lacustrine racks

Q 2 Goulagy \& Public Pollicy lor the 21 n Comann

a 3 Geophysteal periorns in North amence

O a Globel aspucts of gedimentary geovoy

Q 5 Orgenic compounds in ground waser

- 6 Peleontorogic consuseints on aceretes werranes

a T Physes and chanerising of mylonitos

O a secular varintion in tha sedimaniany recoro

If not acceoled for the Therne Seswon. do you want it considered for a rogular iecnnical session?

D Yes $\square$ No

(2) D ORAL. SESSSON D POSTER SESSON O ETMEATTPE D I'll acced a crange ol session roe (ORAL — POSTER) it necessary.

[) Wilhdraw iny zostracl rainer inan change session iner
I6 OF THIS PAPEA PAEVIOUSLY PRESEIJTED Where and when

5. CAN YOU BE A SESSION GHAIRHIAN? O YOS

TOPIC

Your name

Talephone (late June/early July)

6] SPEAKEA'S IDEI!TITY ARID I.:GILII:G ADOFESS

Speaker's neme

Addraes

Addrass

Ciry Stare Zio

Country

Orlice Tulephone:

Horne Tulephene: 1

Cales we can reach you:

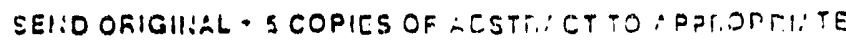

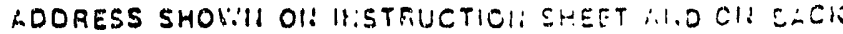

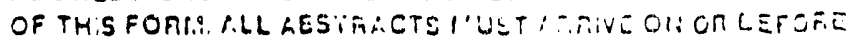
DE/ DLIHE SHOWOHIFON E/ CHIIEETI, S 


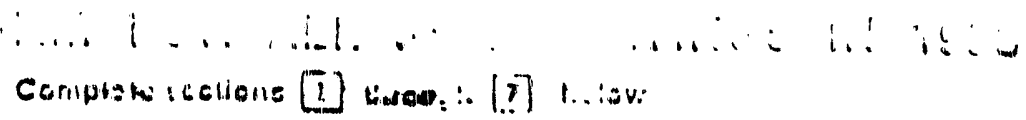

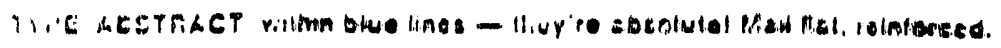

BLACKBURN FIELD, NEVADA: A CASE HISTORI

Scott, Choryl B. ad Chambola1n, Alan K, CEDAR STRAT

P.0. BOX 8909, R०40, NV 89507.

Blackbura Fiold lio ia selonally conglex ara, witb

facios changes, thrusting, taar faults, unconforatiles, ad normal block faltiag. Lat Hesozole thruatiag plays a signiflcant part ia the hydrocarbon gonoration and location of tho fiold. Tho flold itoolf is a rolativaly simplo northwest tronding anticlinal fold of Tortiary ago which is bounded by faulta.

Blackbura 1 dollied into grandto, and Blackburn \#2 is dry. Amoco Blackbura t3, tho discovary woll, bound oli is three separato horlzons--Tertiary Indian Heli Formation, Mississippian Chainan Foration and in the Devonian Nevada Formation. Nine subspquat wolls were drilled of which three produce oil. Blackbura \#10 produces from tho Indian Hell Formation, and \#14 \#16 wolls produce rrom tho Nevada Foration. Total production rot tha field a of June 1987 , is $1,112,664$ bbls o11.

Pay in the Indian Well Foration cones from poorly welded, porous tuffs and tuffacoous sandstonos which are capped by a weldod tuff unit. Calcaroous dolonito is the - "ing unit of the Devonian Nevada Formation. Practure

osity in addition to intergraular porosity are the wost agnificant typos of porosity in this carbonato reservolr. Seal for this Paleozole roservoir is provided by shales of the Mississippian Chatnan Formation whicb was inglaced by an 3 t tanution falt.

Analysis of tho Blackbura Fiold may holp in doveloping an exploration model for petrolaur exploration ta tals frontice area of astera Nevada. Although all the bastc eleants of a play wus be considered, soal and source are particularly ioportant cousderations la tbis provinco.
2

GATECOMIRE ALL ABSTAACTS

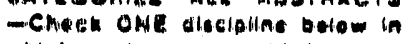
wheh enviciwerle woula be basl

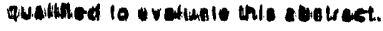

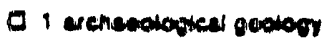

Q $2 \mathrm{cos}$ andicar

Q I economive geotang

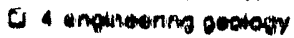

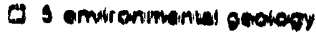

a o omoral gochosy

D 7 gocenemialy

a amoteng roducation

D - somorgnologr

D10 gnophysies

Q11 georeir inlormation

012 glucial geology

Q13 hision of geovioy

Dia myarogonology

015 marino propogy

Q10 miciopaleorilology

Q17 minaraboy/grysceliogrephy

Qis acemerogruishy

010 paleoniolegy/daloneduny

C20 gutroluum grotogy

021 periotogy uxperimenuel

022 pulrabedy, ignuous

O23 poltology, mulamenonic

Q34 oovology cusimmuny

D2S glenelary goology

D26 Pivesamijian poology

O27 Quniornary onology

Q28 rumolo manumo

Qze simdimentology

Caso atratigraphy

Qj) alvetural gatagy

0.32 inciankes

Q33 thesomes/geophyouss

ola volesnology
A. SPECIAL - INVITEO AMSTRACT FOA A SYMPOSIUMA.

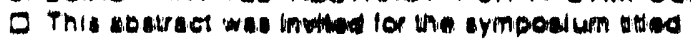

IT you encexida nara. waip no mam 4

B. VOLUNTEEREO ABSTRACTS

(1) SPECIAL-THENE SESSION. ANNUAL MEETINIB ONLY.

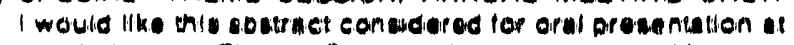

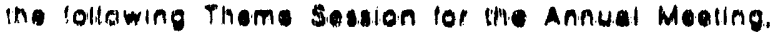
Donver, 1900.

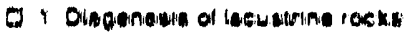

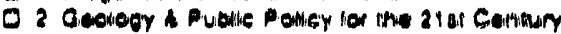

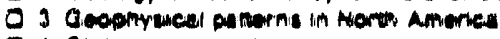

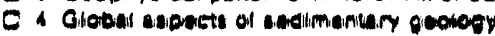

- S Diganur compreunds in prownes waser

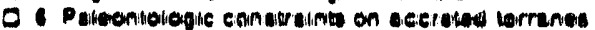

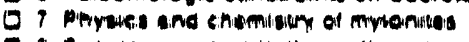

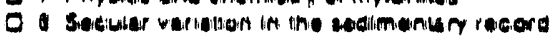

if not eccepted lof the Thern. Sesurom. do you want it consumed tor a rogular lochnical messon?

D Yn: O No

(2) O OAML SESSNON O POSTER SESSWON D ETMER TYPE

O I'll cecoDI y change of sesmon YON (ORAL DPOSTEA) is nocesusery.

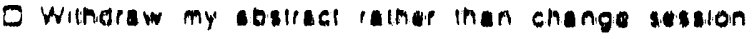
iran

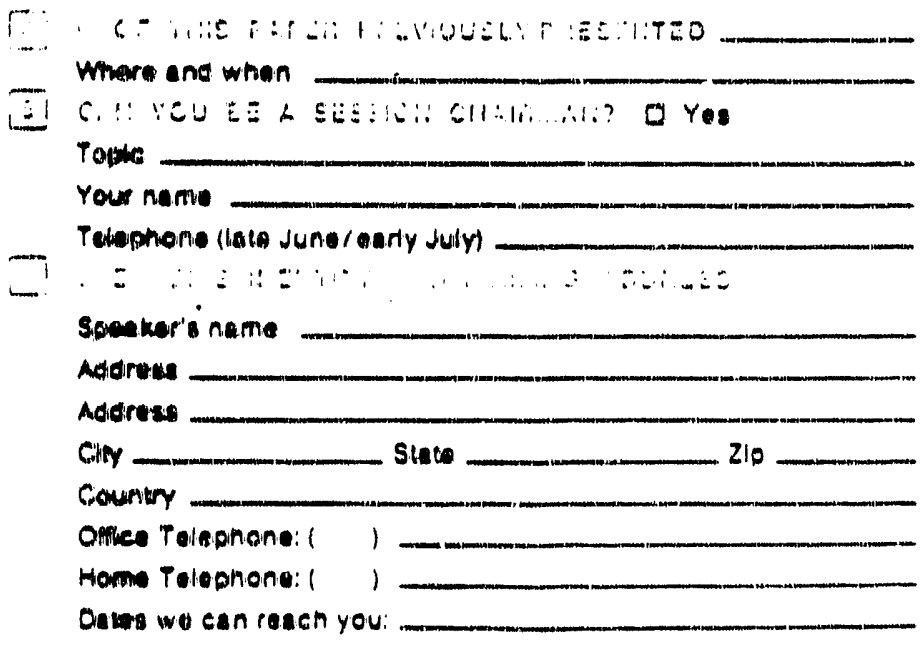


APPENDIX II

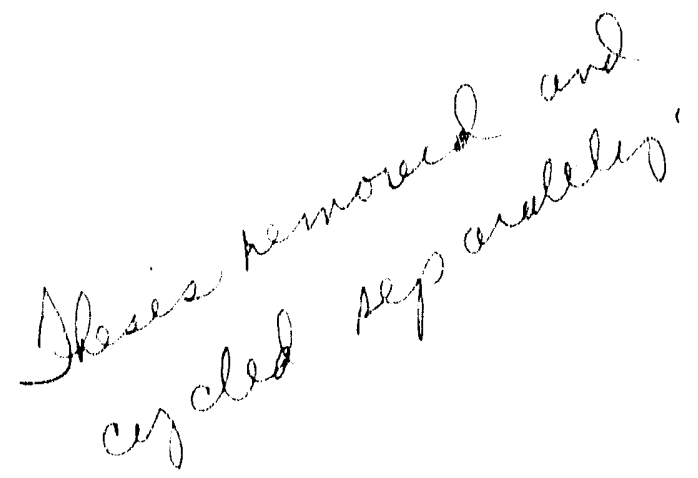


APPENDIX III 
$$
\text { No } \quad 8442
$$

VOLCANTC AND TECTONTC SIGNUTCWNCE OF TFE PRESENCE OF LATE MOOCENE STONEWALI FLAT TUFF IN THE VICANITY OF BEATTY, NEVADA

WEISS, Stever L. NOBLE Dooald C. Mackay School of Mires, Uaiv. Nerada-Rewa, Reco. NV 89557; MCKEE Etwin IL. US. Geol. Survey, 345 Muddlefield Rosd, Mealo Park, CA $94025 ;$

Recesat work bas greacty enlarged the leowa discriburion of the late Miocene (about $63 \mathrm{Ma}$ )

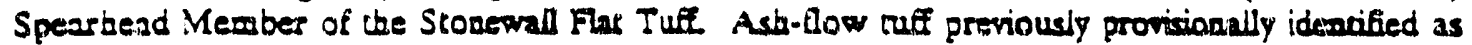
Thirsty Canyon Tuff in the viciniry of Currie Well in the sorthwesters Bullfrog Frlla, in the aorthera part of Oasis Valley, and in the western part of Beacry Wash is now recogrized as part of the Spearbead Member. Correlacion is besed on Eeld appearance, a distinccive phesocryst assemblage including the preseace of sodic amphibole, fayalise, and ison-rich dinopyroxene, and by a $\mathrm{K}$-As age (saridine) of 6 =0 2 . Ma on the Currie Weil exposure. The Speartead Meraber, which was erupted from 3 veat area ceatered on Stonewall Mourtain, is now known to exend for about $115 \mathrm{kom}$ in a NNW.SSE direcrion Erow northwess of Goldfield to the exposures in Bearty Wast and is cherefore a major pyroclastic unit comparable in exreat to the Timber Mountain and $P$ aintbrush Tuffs and older

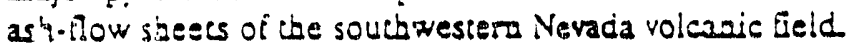

The preseace and distribucion of the Speartead Mexner in the Bearty-Bare Mountain area sets an importass constraint on the timing of uplif and fauleing in that area and on the age of Terciary graveis aorth of Bare Mouncain Sarcobacus Flat and the area soucth of Tolicha Peat suust

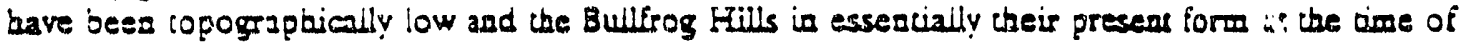
deposicion. The Sarcobarus Flat paleodepression is consisteat with major extensional and(or) transform basin formation after deposicion of the Timber Mouncain Tuf (ca. 113-115 Ma).

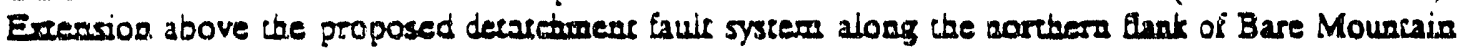
(Maidonado, 1985; Cars and Mousen, 1988) muss bave largely ceased by abour 63 Ma because the flar-iving Speartend and overtying thict gravels in Bearry Wash bury rotaled upper plate rocks to the

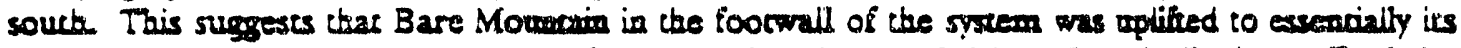
preseas elevacion relative to surrowoding areas by abour $63 \mathrm{Ma}$. Steepty-dipping triff of the

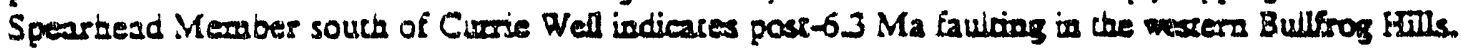
Likewise. sorreal taults formed durion and after eraption of the Stonewall Flat Tuff south and soucherest of Stonewail Mouncain.
\end{abstract}

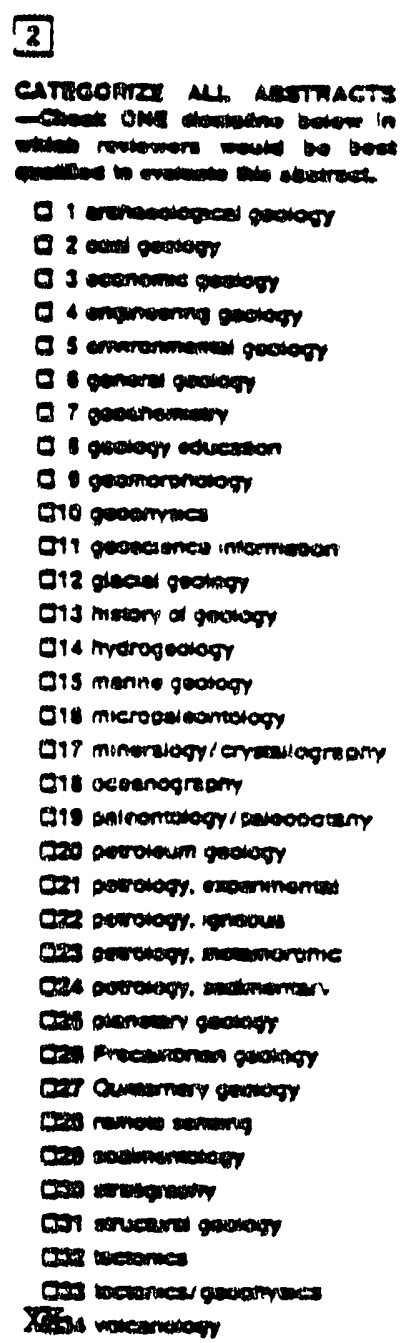

3 Tres of semons avallater

A SPECLAL - IMVTTD ACSTRACT FOA A SMAPOSTUM.

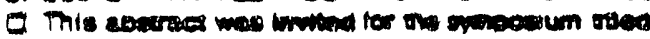

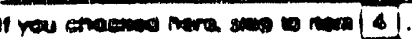

a VOLUNTLARE AQSTRACTS

(1) SPEOULL-THEMC SESWOK NMUAL MEETNG ONLY.

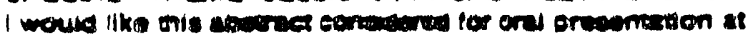

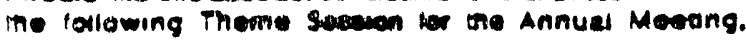
Cemver. 1 ses.

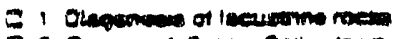

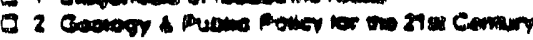

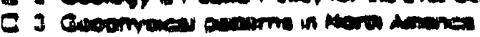

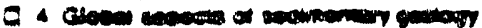

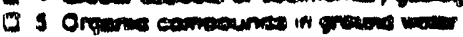

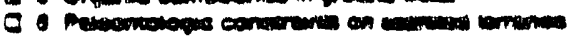

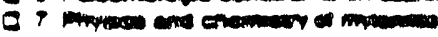

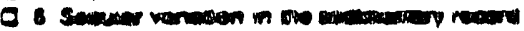

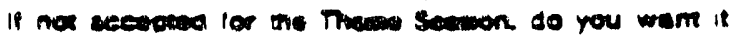

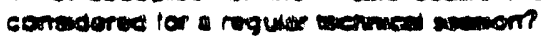

Q Yo Q No

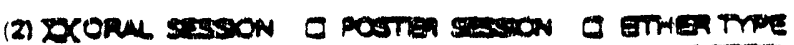

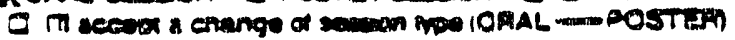
if nuceneary.

- Nimoraw my aogtrnes renter hen Enange yession ve.

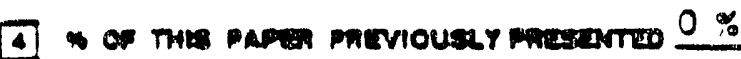
nover and when

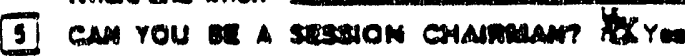
Poue Volinaoloor

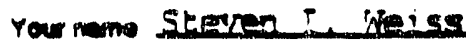

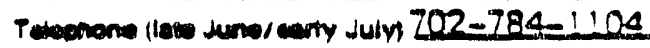

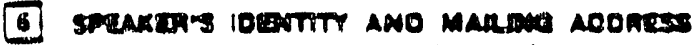

somarom nam Steven [. Weigs

nent Senlacinal sciences

now liniversity of jeyada-2eno

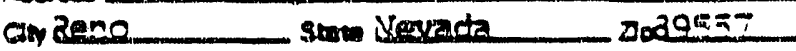

counsy ISTa

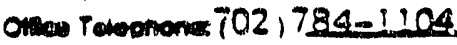

T02,717-5921

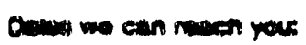

Indas

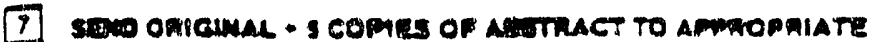
ADORESS SHOWN OM INSTRUCTION SHERT ANO ON BACX

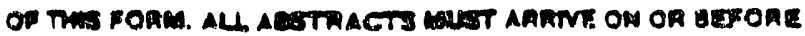
OEAOLINE SHOWN BOR EACH MUTTMG. 
APPENDIX IV 


\author{
SCP Consultation Dratt Review \\ rask 3 \\ I. T. Larson, D. C. Noble and S. I. Weiss \\ MaY, 1988
}

sumang comments

The assigned responsibilities of the Task 3 group bave a focus on volcanic geology and associated mineral/energy resources relative to yucca Mountain and most of our comments which follow, ever if they are on tectorics or geophysics, geochemistry, volcanies, or other topics, are ultimately premised upon and directed toward this rask 3 charge. We have not read the antire SCF draft but those pares which we have reviewad strongly suggest to us that the following general comments are called for:

1. We consider that the activities proposed in the DOE draft SCP iill not provide geologic, volcanological, geochemical, geochronological, tectonic, or geophysical information required to appropiately evaluate the mineral/energy potential of yucca Mountain and the lands about the potential site. If only the pireserely planned activities are carried out we will have only a very marginaliy better idea of the size and value of resources at depth below Yucea Mountain in either the tuffs or the underlying paieozolc strata. Further, the same coment applies to presently known mineralization in or near the site area such as that at Wahmonie, Calico Hilis, etc. Sampling programs, drilling programs, gelophysical studies (with respect to mineralization) and geochemical programs are simply inadequate. For example, has any thought been given to the possibility that mineralization at Yucca might have taken place before deposition of the Tertiary tuffs. or before deposition of the Tiva or Topopah Spring Mambers? If this oc:curred, how will surface or repository horizon geochemistry detect such? It could not! We believe that DOE continues not to take seriously concerns of resource potential.

2. We believe that DOE has an apparently very incomplete and compartmentalized concept as to volcanic/caldera geology and, in particular, to how hydrothermal activity and mineralization may folate to volcanism. Nune of the proposed activities we have raviewed are adequate or intagrated in such a way that major inprovments will result in our knowledge of potential mineralization in and about the rimber uts. caldera, the crater Flat caldara, Yucca Mountain, etc. A serious omission is evident il the ir lack of recognition in sections $1.7,1.8$ and Chapter 8 of the world-wide inportance of structural control on localization of ore mineralization in bydrothormal mineral deposits. Clearly, sulficient evidence currenty exists for bydrotbermal mineralization beneath Yucea Mountain, yet ao mention is made of any plans to directly test the types of structures in Yucea Mountain that elsowbere localize aconomic nineralization. 
The "evaluation" of miseral and bydrocarbon resource potential given in sections 1.7 and 1.8 is built on incomplete, outdated, often inaccurate and/or misleading information and is wholly inadequate. 13 assumptions, interpretration, discussion and analysis given in sactions 1.7 and 1.8 do not constitute data (sacts). All references in Chaptar 8 and lsewhere in the SCP to sections $1.7,1.8$ and much of the rest of chapter 1 as "data" constitute misrepresentation and should be reroved.

3. The proposed borehole drilling program is totally inadeguate to evaluate the resource base in and near Yucca Mtn. and thus completely inadequate to provide data which will keep the likelihood of future human interference at a minimum. Future drilling must include boreholes (several) in the site proper and about it, and these must penetrate completely the Tertiary section and provide samples from a representative section of the underlying paieozoic rocks. Several boreholes must also directly tes = fults, intersections of faults, breccia zones and highly fractured zones for evidence of hydrothermal mineralization. The hydrocarbon potential will also remain untested without deeo drilling (20,000 - 25,000 feet) in the controlled area or the repository blosk. such a deep borehole would yield imporsant geologic, geophysical and regional stxuctural information.

4. This SCP drat has within it technical procedures and methods that make use of of almost every conceivable geologic, geochemical, geophysical tool known to man. One gets the distinct impression that the DOE attitude and thought process is one that given a problem they don't understand, thair answer is to 'throw' technology at the problem and hope the answer will 'fall' out; a classic example of the 'shotgun' approach. Cost or likely time for completion appear to be of very little concern. What further concems us in this regard is that we believe that some of the proposed methods are likely to be ill-used, misapplied or underutilized. For example, proposed surface geophysics is not at all to be focussed on potential resources at depth and geochemistry sampling is only at surface or repository levels- not in holes in rocks which underlie the proposed repository unit and would likely be the target of future axploration efforts.

5. This edition of the SCP wakes frequent and continued use of terms such as near to, proximal to, adjacent to, at, in the vicinity of, and so on. Just what do these terms mean concerning the distance from the proposed site where it is essential to have complete ksowladge of geologic framework, mineral/cuergy

potential, or, for that matter, seiswicity, etc.? Give us some definitions and the rationale behind than!

6. The Draft refers to the nod to ap and interprete 'small scale' structures (atc.) and they propose that the langest scale of mapping to be used is $1: 12,000$ (one inch 1000 feet), or twice that of a of a $71 / 2$ ninute topograpaic quadrangle. Mis scale is 
mach too smali for idatali' unless DOE defines detail diffarentiy than do we. Cortainly rerctura sigailicant to the localization of oro in many mines throughout the porid cannot be depicted on such a scale.

7. The draft SCP sections on minerel/anargy resources and buman intrusion fail to recognize and iddress the fact that water is curtentily being exploited imodiately adfacant to the site. such exploitation of water reources is likely to accelerate dramaticaliy is the near futwre as gold mines in the Bastey-Bare Mountain area, eurrenty in the development and permitting stages, comence production.

8. It is our opinion that this scp draft exudes the feeling of 'Lait aceomoli'. The draft reads as though the DOE has a predetermined opinion that Yucea is clearly an accepcable and desirable location for a repository and the activities proposed are 'going through the motions' to prove they are right. The draft simply does not to us read as a scientific/engineering effort to do a complete assessment and evaluation preceding a decision. We are convinced that in the area of our expertise, such is the case. 


\section{APPENDIX V}

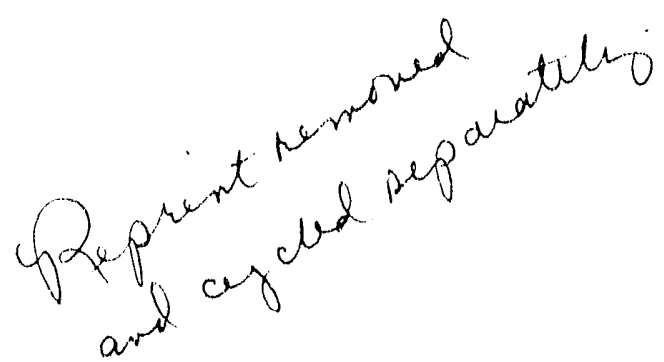


APPENDIX VI

\begin{abstract}
STONEWALL MOUNTAIN VOLCANIC CENTER, SOUTHERN NEVADA: STRATIGRAPHIC, STRUCTURAL, AND FACIES RELATIONS OF OUTFLOW SHEETS, NEAR-VENT TUFFS, AND INTRACALDERA UNITS
\end{abstract}

\author{
Steven I. Weiss and llonald C. Noble \\ The Macka, School of Mines, Universit.v of Nevada-Reno
}

\begin{abstract}
Directly south and southeast of Stonewall Mountain. Nevada, a depression and north-facing caldera scarp were formed during and(or) after eruption of the Spea"head Member of the late Miocene Stonewall Flat Tuff. Abundant large lithic and juvenile blocks are present in the Spearhead Member within $0.5 \mathrm{~km}$ of this topographic margin, but absent elsewhere in the ash-flow sheet, consistent with eruption from vents in the Stonewall Mountain area. Within about 100,000 years, comendite tuff of the overlying Civet Cat, Canyon Member of the Stonewall Flat Tuff buried the depression and associated scarp. The Civet Cat Canyon Member is traceable continuously to the north from an outflow sheet capping northwestern Pahute Mesa, into near-vent tuff on the southeastern flank of Stonewall Mountain. Proximal outflow-sheet tuff locally exhibits strong rheomorphic disruption and is overlain without a cooling break by surge, flow, and fall deposits of trachytic composition. Much of Stonewall Mountain is composed of welded tuff and megabreccia interpreted as intracaldera tuff of the Civet Cat Canyon Member, strongly suggesting that the vent area of the Member was largely within Stonewall Mountain. Welded tuff of trachytic composition comprises an important part of the intracaldera Civet Cat Canyon Member, which was intruded by dikes and plugs of trachyte and rhyolite. Juvenile inclusions of basalt dispersed in near-vent facies trachvte tuff provide direct evidence for the high-level involvement of basaltic magma in the evolution of the highly potassic Stonewall Mountain center. Complex discordant compaction foliations and the widespread presence of megabreccia within the intracaldera tuff suggest, following Foley [1978], caul-dron subsidence by piecemeal collapse during eruption of the Civet Cat Canyon Member. The elevation of intracaldera tuff and intrusions in Stonewall Mountain above the surrounding ash-flow sheet suggests a significant amount of magmatic uplift, perhaps involving the emplacement of plugs, dikes and small stocks within the intracaldera tuff prism.
\end{abstract}


APPENDIX VII

PALEOMAGNETIC EVIDENCE FOR AN EXTREMELY SHORT PERIOD OF TIME BETWEEN ERLIPTION OF THE PAHUTE MESA AND TRAIL RIDGE MEMBERS OF THE THIRSTY CANYON TLFF, SOUTHERN NEVADA

\author{
Steven I. Weiss and Donald C. Noble \\ Mackay School of Mines, University of Nevada-Reno
}

Edwin H. Mckee

\title{
t.s. Geological Survev, Menlo Park, California
}

Hbstract. Two successive ash-flow cooling units of the Black Mountain volcanic center, the Pahute Mesa and Trail Ridge Members of the late Miocene Thirsty Canyon Tuff, possess nearly indistinguishable reverse polarity remanent magnetization directions of about $178^{\circ}$ declination and $-10^{\circ}$ inclination. These are interpreted to reflect thermoremanent magnetization either during a single geomagnetic field excursion or polarity transition, or possibly from a field oriented near the limit of secular variation. This strongly suggests that the Pahute Mesa Member was overlain by the Trail Ridge Member befor appreciable shift of the anomalous geomagnetic field. Estimated rates of directional change when the field is far from its time-averaged mean position range from several tens of degrees per vear during transitions and excursions to secular variation of about $10^{\circ}$ per century. The best estimate of polarity transition interval is about 4000 to 15,000 vears. The inferred interval between eruption of the two ash-flow sheets is thus less than 15.000 year's and probably on the order of 100 years. This conclusion is supported by the local absence of a complete cooling break between the two units.

The interval between eruption of the Pahute Mesa and Trail Ridge lembers was too brief for re-establishment of chemical stratification in the Black Yountain magma system. Nevertheless, a small volume of highly evolved comendite magma developed and was erupted as lava within the Black Mountain caldera and as a component of the Trail Ridge Member. The short repose interval and rapid development of the comendite, together with evidence for mixing of magmas of silicic to near-mafic composition (Vogel et al., this issue), and the presence of air-fall tuff at the base of the Trail Ridge, leads us to conclude that eruption of the Trail Ridge Member was probably triggered by injection of hot, relatively unevolved magma into the Black Mountain magma body. 

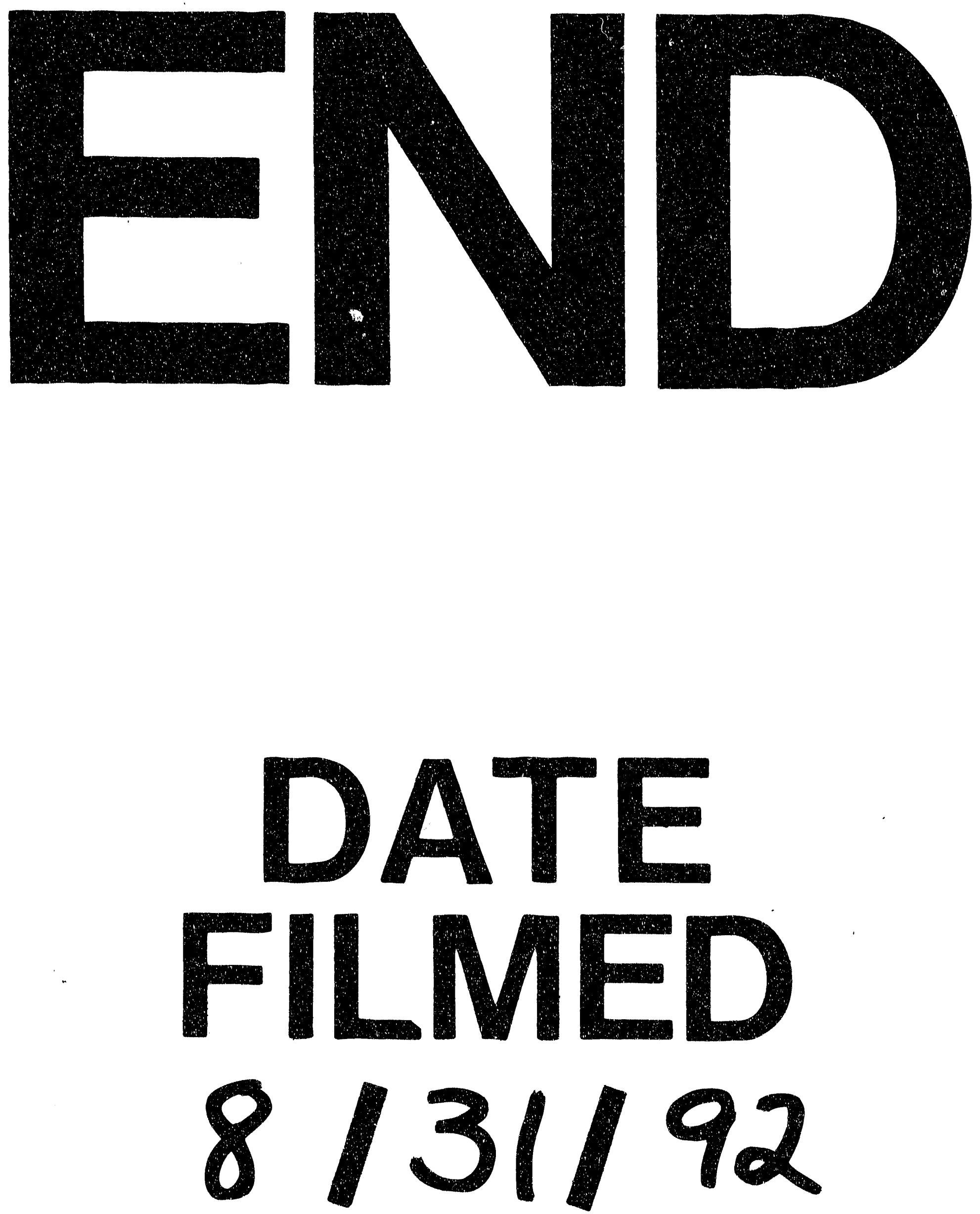
